\title{
Biodiversidad de Cicadellini en las regiones norte y centro de la Argentina (Hemiptera: Cicadellidae)
}

Tesis Doctoral

\section{Lic. Bárbara S. Defea}

Directora: Dra. Susana L. Paradell

Codirector: Dr. Rodney R. Cavichioli

Facultad de Ciencias Naturales y Museo

Universidad Nacional de la Plata 
Esta tesis está dedicada a mis padres, Neki y Robert, y a mis amores, Hilario y Mariano Lucia. 


\section{Agradecimientos}

Después de cinco años de trabajo en esta tesis tengo que agradecer a muchas personas valiosísimas. En primer lugar, a la Dra. Ana Marino y la Dra. Susana Paradell, quienes me dieron la oportunidad de trabajar libremente junto a ellas, por haber confiado en mí, guiarme y brindarme en todo momento su apoyo y conocimientos que definitivamente enriquecieron mi formación sobre los auquenorrincos, pero principalmente gracias por la calidez humana con que lo hicieron. Al Dr. Rodney Cavichioli por aceptar la codirección a distancia, por abrirme las puertas de su laboratorio y por sus enriquecedores consejos durante mi estadía en Curitiba. Del laboratorio, quiero agradecer a mis amigos Álvaro y Eugenia por el aguante, son una excelente compañía desde hace 11 años, gracias por las charlas interminables, consejos y su constante apoyo. A Nano Maciá por sus consejos, muy grata compañía y valiosa ayuda con los programas y cálculos estadísticos. A los chicharrólogos Roxana Mariani, Andrea Toledo y, a las recientes incorporaciones, Santiago Martín y Daniela De Laf, por su ayuda, charlas y por los lindos momentos compartidos. Quiero destacar que este trabajo no se podría haber realizado sino fuera por el grupo del laboratorio de entomología de la EEA INTA Bella Vista; quiero agradecer especialmente a Roxana Almonacid, por su invalorable ayuda con el trabajo de campo y los hermosos momentos compartidos y charlas durante mis estadías en Bella Vista. Al Ing. Máximo Aguirre y a la Ing. Sara Cáceres por abrirme las puertas del laboratorio y brindarme todo lo necesario para llevar adelante los muestreos. A Lucía y Laura por estar siempre dispuestas para brindarme su ayuda y por las lindas charlas y compañía de aquellos días. Al Ing. Beltrán por permitirme realizar los muestreos en su lote, la experiencia y conocimientos brindados y al resto del grupo humano que trabaja en la Estación Experimental por su buena predisposición para acompañarme en el trabajo.

También quiero agradecer a mis colegas, quienes contribuyeron con material e identificaciones. Mariano Lucia, Leopoldo Álvarez, Daniel Aquino y Fernando Zamudio de quienes recibí numerosos e interesantes ejemplares. A Eduardo Virla, quien me recibió con los brazos abiertos durante mi visita a la colección de la Fundación Miguel Lillo en San Miguel de Tucumán, y que junto con Érica Luft Albarracín realizó la identificación de los parasitoides recolectados. A Isabel Barrios, Ana Marino y Matias Rusconi por la identificación del resto de los enemigos naturales. 
A Stuart McKamey (Smithsonian Institution), Michael Engel (Kansas University) y Rodney Cavichioli (Universidade do Paraná) por los préstamos de material. Agradezco al Consejo Nacional de Investigaciones Científicas y Técnicas (CONICET) por el otorgamiento de la beca de estudio durante estos cinco años que me permitió llevar adelante este trabajo de tesis y a la División Entomología del museo de La Plata por brindarme lugar para mi trabajo.

Este trabajo de tesis no sería lo que es sino fuera por mi compañero, Mariano, que estuvo a mi lado en todo momento, gracias por tus valiosos consejos, charlas y por tanto amor; y por mis viejos, Nelly y Roberto, quienes me dieron la oportunidad de estudiar y me apoyaron incondicionalmente en mis decisiones y siempre hicieron todo por mi felicidad. Para lo último el más importante de mi mundo, el sol de mi vida, Hilario, que me acompaña desde hace 16 meses y me hace la persona más feliz del mundo, hijo gracias por la paciencia y perdón por las horas perdidas. Hoy no puedo pedir más... gracias a todos!!. 


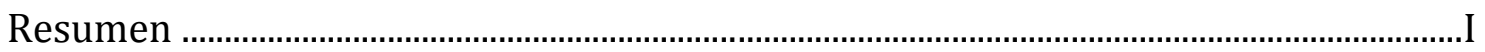

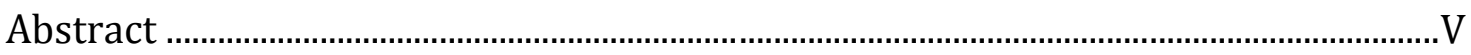

Capítulo I: Introducción ........................................................................................................

Capítulo II: Taxonomía de la tribu Cicadellini (Auchenorrhyncha: Cicadellinae)

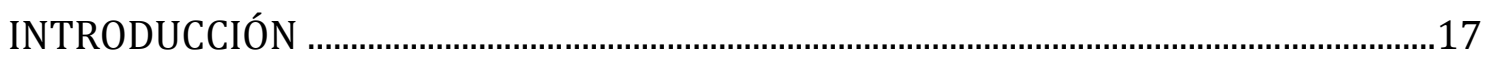

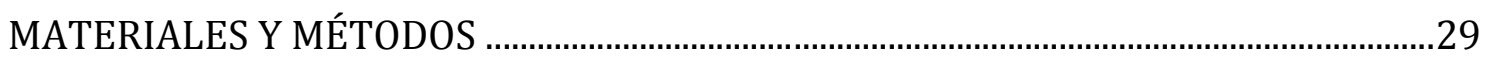

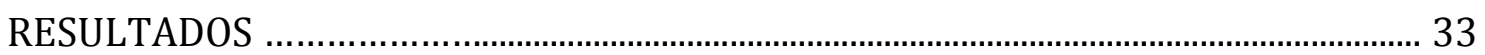

Tribu Cicadellini Van Duzee ...................................................................................................... 33

Género Balacha Melichar......................................................................................................34

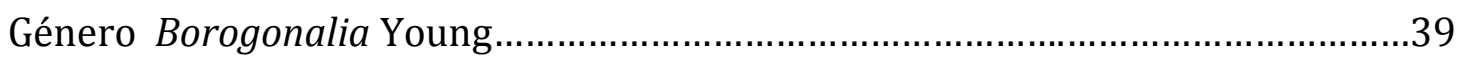

Género Bucephalogonia Melichar....................................................................................42

Género Ciminius Metcalf \& Bruner .......................................................................................51

Género Diedrocephala Spinola ..........................................................................................63

Género Dilobopterus Signoret ..........................................................................................70

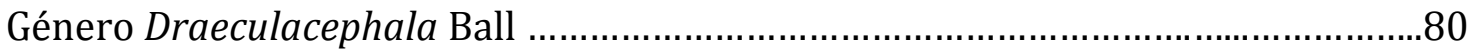

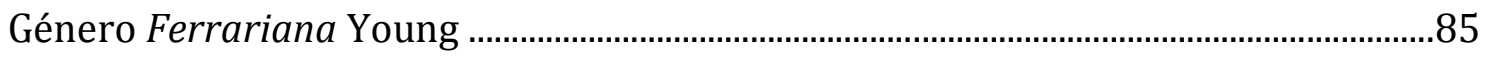

Género Hortensia Metcalf \& Bruner .......................................................................................91

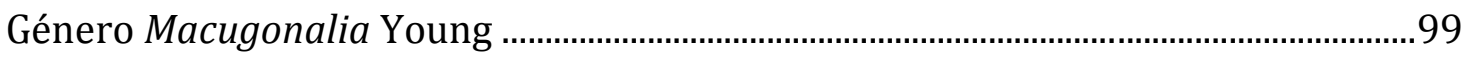

Género Oragua Melichar..........................................................................................................118

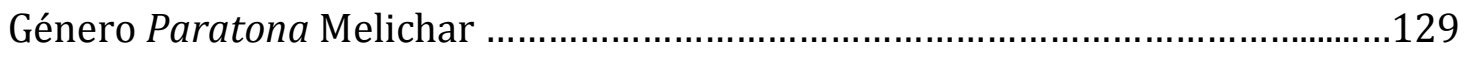

Género Pawiloma Young ...................................................................................................136 
Género Plesiommata Provancher

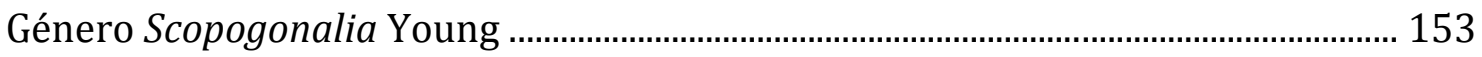

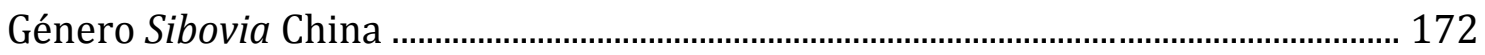

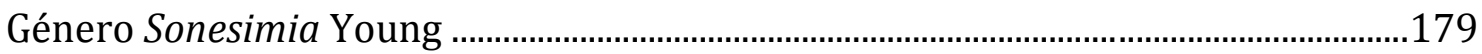

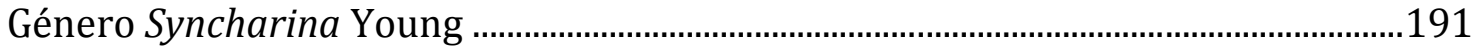

Clave para la identificación de los géneros de Cicadellini presentes en la Argentina .207

CONCLUSIONES 210

Capítulo III: Cicadellinae asociados a agroecosistemas citrícolas del norte de la Argentina

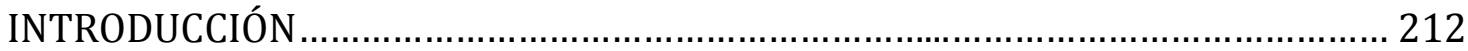

MATERIALES Y MÉTODOS …........................................................................................ 221

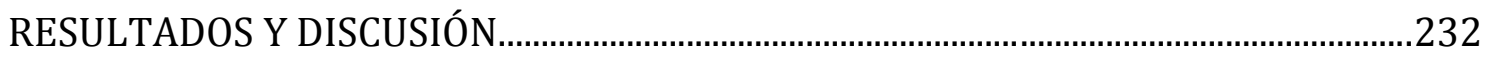

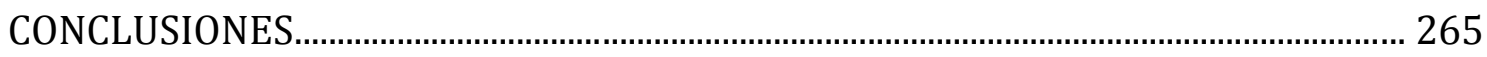

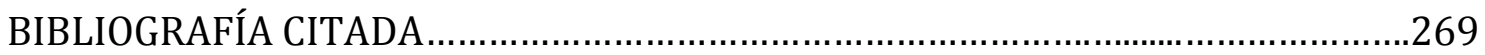




\section{Resumen}

El orden Hemiptera reúne más de 90000 especies de insectos hemimetábolos agrupadas en base a su distintivo aparato bucal de tipo sucto-picador. Actualmente incluye dos subórdenes de los cuales los Auchenorrhyncha se destacan por su capacidad de transmitir diversos fitopatógenos a plantas de importancia comercial. La familia Cicadellidae, la más numerosa, incluye actualmente 22 subfamilias entre las cuales se destaca por su alta diversidad, principalmente en el neotrópico, y su importancia fitosanitaria la subfamilia Cicadellinae; tradicionalmente dividida en dos tribus, Cicadellini y Proconiini, incluye más de 2400 especies distribuídas en todas las regiones zoogeográficas. La tribu Cicadellini, es cuatro veces más diversa (1886 especies en 266 géneros) y de mayor complejidad sistemática que los proconinos debido a que exhibe menor variación morfológica entre sus miembros. Por esto, la genitalia de los machos no siempre es suficiente para definir y relacionar géneros, por lo cual los caracteres de las hembras empezaron a ser considerados; sin embargo, la diversidad morfológica de la genitalia femenina es aún poco conocida ya que su estudio detallado es relativamente reciente.

En Ámerica, los Cicadellinae son los vectores más importantes de la bacteria Xylella fastidiosa $(X f)$ a cítricos y plantas de café. En cultivos citrícolas, esta bacteria causa la enfermedad llamada Clorosis Variegada de los Cítricos (CVC), que afecta a todas las variedades comerciales de naranja dulce y otras especies cítricas. En Argentina, las principales áreas citrícolas productoras se desarrollan en el noreste, severamente afectada por la CVC y el noroeste, en donde representa una amenaza potencial. Para avanzar en el conocimiento de estrategias que permitan abordar de manera eficiente esta enfermedad es necesario conocer diversos aspectos de los insectos potencialmente vectores en cada región.

En la Argentina, la información disponible sobre esta subfamilia, y en particular de la tribu Cicadellini, es realmente escasa y proviene principalmente de estudios faunísticos en cultivos de importancia comercial. Por lo antes expuesto, se propuso estudiar desde el punto de vista taxonómico los géneros de la tribu Cicadellini presentes en agroecosistemas frutícolas, particularmente citrícolas, de la Argentina, y de cada género, estudiar todas las especies presentes en el país; elaborar un registro de las especies presentes en las áreas estudiadas incluyendo datos morfológicos, de 
distribución y biológicos, plantas hospedadoras, enemigos naturales e importancia fitosanitaria, y describir los caracteres de la genitalia de la hembra útiles en la identificación de las especies de esta tribu. Respecto a los estudios bioecológicos, se propuso estudiar la composición y fluctuación estacional de los Cicadellinae presentes en agroecosistemas citrícolas en distintas áreas del norte y centro del país, describir los estados de desarrollo de las especies predominantes y registrar la presencia de sus enemigos naturales potenciales controladores biológicos.

Este trabajo de tesis constituye un gran aporte en el conocimiento de la tribu Cicadellini en la Argentina. Se estudiaron ejemplares tipo y de colección general depositados en las colecciones nacionales más importantes (MLP, IFML, MACN) y en colecciones del exterior (USNM, UK); también se estudió material procedente de diversas localidades de nuestro país recolectados en ecosistemas naturales y agroecosistemas citrícolas durante los años 2013 y 2016.

Como resultado del estudio taxonómico se amplió el conocimiento acerca de la diversidad específica de los Cicadellini en los agroecosistemas citrícolas del noreste y noroeste de la Argentina. Se estudiaron 37 especies de cicadelinos distribuídos en 18 géneros, de las cuales 23 especies se encontraron asociadas a agroecosistemas citrícolas. Se cita por primera vez para la fauna argentina un género y dos especies de Cicadellini, una de las cuales es vector confirmado de la bacteria $X$. fastidiosa en Brasil. Se confeccionó una clave para la identificación de los 18 géneros de cicadelinos. Para cada género se aportó la sinonimia, una diagnosis y para aquellos con más de una especie registrada en la Argentina se confeccionó una clave para la identificación de las mismas. Para cada una de las especies estudiadas, se proporcionó la sinonimia correspondiente y una diagnosis, se aportaron observaciones taxonómicas y se reunió toda la información conocida acerca de la distribución geográfica, plantas hospedadoras, biología, enemigos naturales e importancia fitosanitaria. Se actualizó la distribución geográfica de todas las especies estudiadas, ampliándose el registro de distribución de 30 de ellas; se registraron 12 nuevas asociaciones con plantas hospederas y nuevos registros de enemigos naturales para dos especies. Por primera vez se describieron e ilustraron en detalle los caracteres de la genitalia de la hembra de 28 especies de Cicadellini.

Como resultados de los muestreos en agroecosistemas citrícolas: 1) en el NEA (EEA INTA Bella Vista, Corrientes), se identificaron un total de 50 especies de 
auquenorrincos pertenecientes mayormente a la familia Cicadellidae (33), distribuídas en ocho subfamilias y a Membracidae, con 12 especies reunidas en tres subfamilias. De las 50 especies identificadas, se mencionan una especie nueva del género Webaskola (Iassinae), se cita por primera vez para la Argentina al vector de Xf Plesiommata corniculata; 12 nuevas citas para la provincia de Corrientes, siete especies y cinco géneros; y 15 nuevas asociaciones con agroecosistemas citrícolas. Particularmente de la subfamilia Cicadellinae se recolectaron un total de 5245 especímenes. La tribu Cicadellini presentó el mayor número de especies (12 especies) tanto en los cítricos (9) como en la vegetación espontánea (10). En los muestreos realizados con trampas adhesivas amarillas, dos especies de Cicadellinae fueron predominantes: Dilobopterus costalimai y Molomea lineiceps, mientras que en la vegetación circundante a los cítricos, predominó sólo la especie Hortensia similis. Se estudió mediante un ANOVA sí el riego en los cítricos afectaba la abundancia de las especies predominantes resultando sólo la abundancia de la especie Dilobopterus costalimai significativamente afectada. Se registra por primera vez a las especies $P$. corniculata y Acrogonia virescens en agroecosistemas citrícolas del NEA, lo que eleva a 10 el número de especies vectoras de $X f$ asociadas a este agroecosistema en la Argentina. Se estudió la fluctuación estacional de las especies predominantes sobre los cítricos, $D$. costalimai y $M$. lineiceps, y se registraron los momentos del año con máxima densidad. Por primera vez, se describió e ilustró mediante fotografías, el quinto estadio larval de las especies $H$. similis, Sonesimia grossa y Tapajosa rubromarginata. Se confeccionó una clave para la identificación del estadio larval V de cinco especies de cicadelinos presentes en agroecosistemas citrícolas. Los enemigos naturales registrados en el área estudiada fueron: nematodes de la familia Mermithidae, tres especies de parasitoides oófagos: Comosmocomoidea annulicornis, C. metanotalis (nueva asociación) (Hymenoptera: Mymaridae) y Burksiella sp. (Hymenoptera: Trichogrammatidae) (nueva asociación) y estrepsípteros de la familia Halictophagidae. 2) En el NOA (Lules, Tucumán y Yatasto, Salta), se recolectaron un total de 733 ejemplares de Cicadellinae. Se registraron 16 especies y dos aún no identificadas de los géneros Borogonalia y Oragua. La tribu Cicadellini fue la mejor representada con 12 especies. Se menciona un nuevo género para la Argentina (Borogonalia), y de las especies identificadas, ocho nuevas citas para la provincia de Salta y seis para Tucumán; y cinco nuevas asociaciones con agroecosistemas 
citrícolas. En los agroecosistemas estudiados, las especies más abundantes recolectadas sobre los cítricos fueron Macugonalia cavifrons y Scopogonalia subolivacea y en la vegetación circundante al cultivo, $H$. similis fue la especie más abundante en Tucumán; en el agroecosistema salteño los individuos se distribuyeron de manera equitativa. Se registraron tres especies vectoras de Xf: Bucephalogonia xanthophis, D. costalimai y Oncometopia facialis, y seis de las especies confirmadas como portadoras de la bacteria en Misiones y/o Entre Ríos: B. xanthophis, H. similis, Macugonalia leucomelas, Plesiommata mollicella, M. lineiceps y T. rubromarginata. Se confeccionó una clave taxonómica para la identificación de las especies de Cicadellinae presentes en agroecosistemas citrícolas de la Argentina.

Los resultados obtenidos en esta tesis junto con los datos registrados previamente para las provincias de Misiones y Entre Ríos permitieron establecer la situación actual de los cicadelinos en las principales áreas citrícolas productoras de la región Litoral y del NOA. 


\begin{abstract}
The Order Hemiptera includes more than 90000 species of hemimetabolous insects grouped based on its unique piercing sucking mouthparts. Actually, it comprised two suborders of which Auchenorrhyncha is recognized by its capacity to transmit diverse phytopathogens to important crops. The family Cicadellidae, the most numerous, includes 22 subfamilies among which stands out the Cicadellinae by its high diversity and phytosanitary importance; traditionally divided in two tribes, Cicadellini and Proconiini, includes more than 2400 species distributed in all zoogeographical regions. The tribe Cicadellini, is four times more numerous (1886 species in 266 genera) and of greater taxonomic complexity than proconines owing to it exhibits less morphological variation among its members. For this reason, the male genitalia is not always enough to define and relate genera, so the characters of the females began to be considered; however, the morphological diversity of the female genitalia is still poorly known since its detailed study is relatively recent.

In America, Cicadellinae includes the most important vectors of the xylem bacteria Xylella fastidiosa $(X f)$ to citrus and coffee plants. In citrus orchards, this bacterium causes the disease called Citrus Variegated Chlorosis (CVC), which affects all commercial varieties of sweet orange and other citrus species. In Argentina, the main producing citrus areas are developed in the northeast, severely affected by the CVC and the northwest, where it represents a potential threat. In order to progress in the knowledge of strategies that allow us efficiently approach this disease, it is necessary to know different aspects of the potentially vector insects in each region.

In Argentina, contributions referred to the tribe Cicadellini are really scarce and mostly come from faunistic studies in commercial crops. Thus, it was proposed the taxonomic study of the genera and species of Cicadellini present in fruit crops, particularly citrus, in northern Argentina, considering all species of each genera present in our country; to develop a register of the species present in the study areas including morphological, distributional and biological data, host plants, natural enemies and phytosanitary importance, and to describe the female genitalia characters useful in the identification of species of Cicadellini. About bioecological studies, it was proposed to study the composition and seasonal fluctuation of the Cicadellinae found on citrus orchards in different areas of northern and center of our
\end{abstract}


country, describe the inmature stages of the predominant species and to record the natural enemies, potential biological control agents.

This work represents a great contribution in the knowledge of the tribe Cicadellini in Argentina. Type and general collection specimens deposited in the most important national (MLP, IFML, MACN) and international collections (USNM, UK) were studied; it was also studied material from different localities of our country collected in natural ecosystems and citrus agrosystems during 2013-2016.

As result of the taxonomic study, it was increased the knowledge about specific diversity of the Cicadellini associated with agrosystems in northeast and northwest of Argentina. 37 species distributed in 18 genera were studied, of which 23 species were found in citrus orchards. One genus and two species of Cicadellini are cited for the first time for Argentina, one of those is a confirmed vector of $X f$ in Brasil. A key for the identification of genera is presented. For each genus, the synonymy and a diagnosis were provided along with a key for that ones with more than one species recorded in Argentina. For each species studied, a diagnosis and all known information about geographic distribution, hosts plants, biology, natural enemies and phytosanitary importance were provided. The distribution record for 30 species was expanded, new associations with host plants of 12 species and new records of natural enemies for two species of Cicadellini were registered. The characters of the female genitalia of 28 species of Cicadellini were for the first time described and illustrated in detailed.

As result of three years of sampling in citrus agrosystems: 1) in northeast region (EEA INTA Bella Vista, Corrientes), 50 species of Auchenorrhyncha were identified, the majority belongs to the families Cicadellidae (33), distributed in eight subfamilies, and Membracidae, with 12 species grouped in three subfamilies. Of the 50 identified species, one species of the genus Webaskola (Iassinae) is described, the vector species Plesiommata corniculata is mentioned for the first time for Argentina, 12 species are recorded for the first time for Corrientes province, and 15 new records on citrus crops are reported. Of the subfamily Cicadellinae 5245 specimens were collected. The tribe Cicadellini was the best represented (12 species) in citrus (9) and weeds (10). In the surveys with sticky yellow traps, two species of Cicadellinae were predominant: Dilobopterus costalimai and Molomea lineiceps, while on weeds only the species Hortensia similis was predominant. An ANOVA analysis was carried out to prove if the 
irrigation of the citrus plants affected the abundance of the predominant species proving that only the abundance of $D$. costalimai was significantly affected. The vector species $P$. corniculata and Acrogonia virescens are for the first time associated with citrus crops in northeast regions of Argentina, elevating to 10 the number of vector species of $X f$ in this crop in our country. The seasonal fluctuation of the predominant species, D. costalimai and M. lineiceps, collected on citrus were studied, and the moments of greater density were registered. The fifth larval stage of the species $H$. similis, Sonesimia grossa y Tapajosa rubromarginata were for the first time described and a key to identified the fifth larval stage of five species of Cicadellinae associated with citrus crops was provided. The natural enemies present in the study area were: nematodes of the family Mermithidae, three species of egg parasitoids: Comosmocomoidea annulicornis, C. metanotalis (new association) (Hymenoptera: Mymaridae) and Burksiella sp. (Hymenoptera: Trichogrammatidae) (new association) and specimens of the order Strepsiptera (Halictophagidae). 2) in northwest region (Lules, Tucumán y Yatasto, Salta), 733 specimens of Cicadellinae were collected. 16 species and two species not identified yet of the genera Borogonalia and Oragua were recorded. The tribe Cicadellini was the best represented with 12 species. One genus is for the first time recorded for Argentina (Borogonalia), and of the species identified, eight are recorded for the first time for Salta province and six for Tucumán province; and five new records on citrus crops are reported. In the orchards studied in Tucumán and Salta, the most abundant species on citrus were Macugonalia cavifrons y Scopogonalia subolivacea, and on weeds, $H$. similis was the most collected in Tucumán, while in Salta the specimens were distributed more equally. Three confirmed vector species: Bucephalogonia xanthophis, D. costalimai and Oncometopia facialis, and six species confirmed as positive for $X f$ in Misiones and/or Entre Ríos provinces were recorded: B. xanthophis, H. similis, Macugonalia leucomelas, Plesiommata mollicella, M. lineiceps y T. rubromarginata. A taxonomic key to identify the species of Cicadellinae associated with citrus agrosystems in Argentina were presented.

The results obtained in this work along with the data previously registered for Misiones and Corrientes provinces allowed to establish the current situation of the cicadellines in the main citrus producing areas of the Litoral and the northwest region of Argentina. 


\section{Capítulo I}

\section{Introducción}

El orden HEMIPTERA es el grupo más numeroso de insectos no-holometábolos; actualmente reúne más de 90000 especies descriptas y su alta diversidad probablemente se corresponde con la radiación de las angiospermas. Este grupo monofilético se agrupa en base a su distintivo aparato bucal de tipo sucto-picador, que consiste en dos pares de estiletes, las mandíbulas y las maxilas, contenidos por el labio y, a la pérdida de palpos maxilares y labiales (Figura 1) (Sorensen et al. 1995, Grimaldi \& Engel 2004). Tradicionalmente, fue dividido en dos grupos: Homoptera y Heteroptera (Kristensen 1991). Actualmente en desuso, los "Homoptera" reunían a todos los hemípteros excepto los Heteroptera. Esta primera propuesta acerca de la posición filogenética de este grupo fue realizada por Boudreaux (1979) y Hamilton (1981), quienes justificaban su monofilia por los siguientes rasgos sinapomórficos: cabeza con foramen magno amplio y sutura loral grande demarcando la placa mandibular, alas anteriores más grandes que las posteriores, tarsómeros reducidos en tamaño, y morfología de las células espermáticas. Actualmente, la inclusión de estudios moleculares y reinterpretación de datos morfológicos pusieron de manifiesto la parafilia del grupo (Hennig 1981, Campbell et al. 1995, Sorensen et al. 1995, von Dohlen \& Moran 1995, Gullan 1999), dividiendo sus componentes en dos series o subórdenes: Sternorrhyncha y Auchenorrhyncha (Carver et al. 1991, Wheeler et al. 1993). Respecto a éstos, estudios moleculares realizados por Campbell et al. (1995) y Sorensen et al. (1995) soportan la monofilia de Sternorrhyncha pero cuestionan la de Auchenorrhyncha. Sin embargo, numerosos autores (Carver et al. 1991, Dworakowska 1988, Hennig 1981, Kristensen 1973, Kukalova-Peck 1983, Yoshizawa \& Saigusa 2001) apoyan el clado por las siguientes sinapomorfías 
morfológicas: sistema acústico timbal, antena aristoide y alas anteriores con las venas $\mathrm{ScP}+\mathrm{R}$ fusionadas; asimismo análisis de datos moleculares aportados por Wheeler et al. (1993), von Dohlen \& Moran (1995) y Cryan \& Urban (2012) apoyan la hipótesis de Auchenorrhyncha como grupo natural.

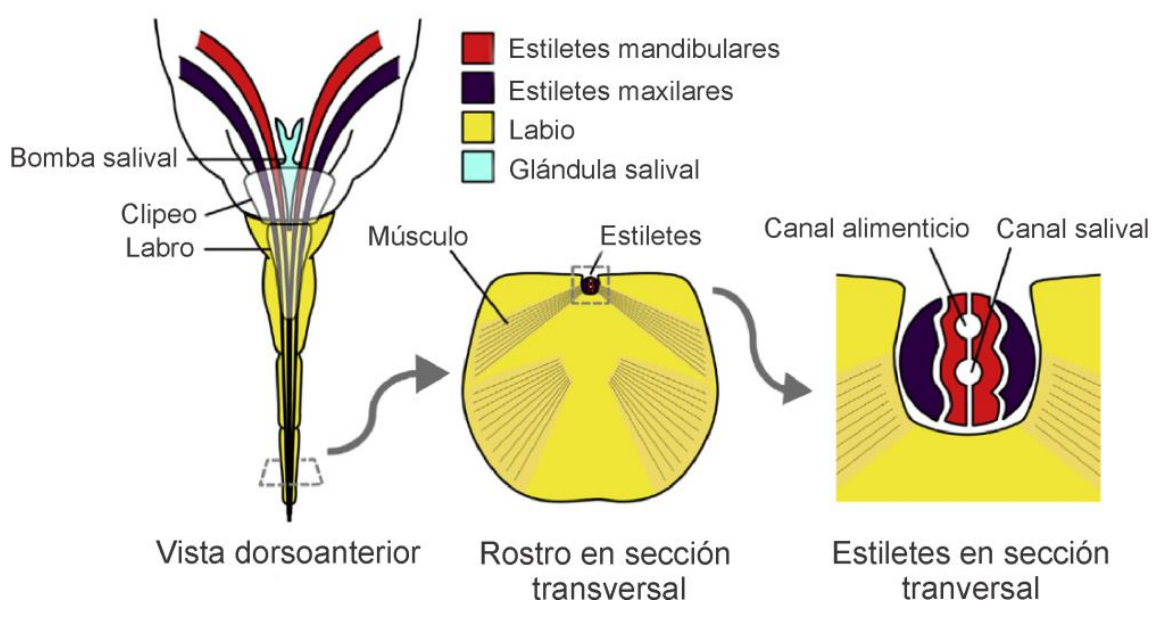

Figura 1. Anatomía del aparato sucto-picador de los Hemiptera (Extraído de Panfilio \& Angelini 2017)

Los Auchenorrhyncha han sido tradicionalmente divididos en dos infraórdenes aparentemente monofiléticos: Fulgoromorpha y Cicadomorpha (Carver et al. 1991, Grimaldi \& Engel 2004, Hennig 1981). El clado Cicadomorpha se distingue de otros Hemiptera por la siguiente combinación de caracteres: 1) clípeo ensanchado; 2) antenas con pedicelo pequeño sin sensilas conspicuas, y flagelo aristiforme; 3) tégula ausente; 4) venas anales del ala anterior usualmente separadas desde la base en toda su longitud; 5) coxas medias pequeñas con sus bases unidas (Figura 2) (Carver et al. 1991, Hamilton 1981, Wilson \& Claridge 1991). Este grupo comprende más de 35000 especies descriptas en el mundo, agrupadas en tres superfamilias monofiléticas en base a criterios morfológicos y moleculares: (Membracoidea "chicharritas" + (Cicadoidea "chicharras" + Cercopoidea "salivazos") (Cryan 2005, Dietrich 2005) (Figura 2).

Los Membracoidea Rafinesque 1815 (= Cicadelloidea Latreille 1825) se caracterizan morfológicamente por presentar: espacio costal angosto en el ala anterior, coxas metatorácicas grandes, transversalmente articuladas, fémures posteriores elongados, tibias posteriores con una hilera longitudinal de setas 
alargadas y apodemas escutelares. Análisis filogenéticos basados en datos morfológicos y moleculares soportan la monofilia de los membracoideos; sin embargo nuevos estudios indican que la familia Cicadellidae es parafilética respecto a las otras tres familias (Melizoderidae, Aetalionidae y Membracidae) que conforman esta superfamilia (Dietrich 2013) (Figura 2). En conjunto comprenden cerca de 25000 especies descriptas agrupadas en más de 50 subfamilias, 150 tribus y 3500 géneros (Dietrich et al. 2001a, b, 2005, Oman et al. 1990, McKamey 1998). Todos los membracoideos se alimentan de la savia vegetal y consecuentemente, están entre los grupos de vectores de fitopatógenos más importantes (Nielson 1968).

La familia Cicadellidae Latreille 1825 es la más grande de esta superfamilia, con aproximadamente 20000 especies descriptas en el mundo (Dietrich 2013), constituyendo la familia más numerosa del orden Hemiptera y una de las 10 familias más diversas de insectos (Takiya 2007). Según Dietrich (2005), los cicadélidos se caracterizan por la presencia de cuatro hileras de setas largas en las tibias posteriores, una articulación de tipo "peg and socket" entre las coxas posteriores y la producción de brocosomas (partículas proteináceas producidas por los túbulos de Malpighi (Rakitov 1996)). Sin embargo, análisis filogenéticos recientes basados en secuencias 28S de ADN ribosómico indican que Cicadellidae es probablemente parafilético respecto a Aetalionidae y Membracidae (Dietrich et al. 2001b). El número de subfamilias incluídas varía según los distintos autores, esto probablemente se deba al poco conocimiento de las relaciones filogenéticas entre las numerosas subfamilias y tribus, así como también al gran número de especies reunidas. Tradicionalmente, la clasificación propuesta por Oman et al. (1990) es la más utilizada y propone 40 subfamilias y 121 tribus, sin embargo con el fin de reflejar mejor las relaciones filogenéticas, reducciones sustanciales en el número de subfamilias han sido propuestas recientemente (Dietrich 2005, 2011) y el número actualmente reconocido es de 25 (Dietrich 2013). 

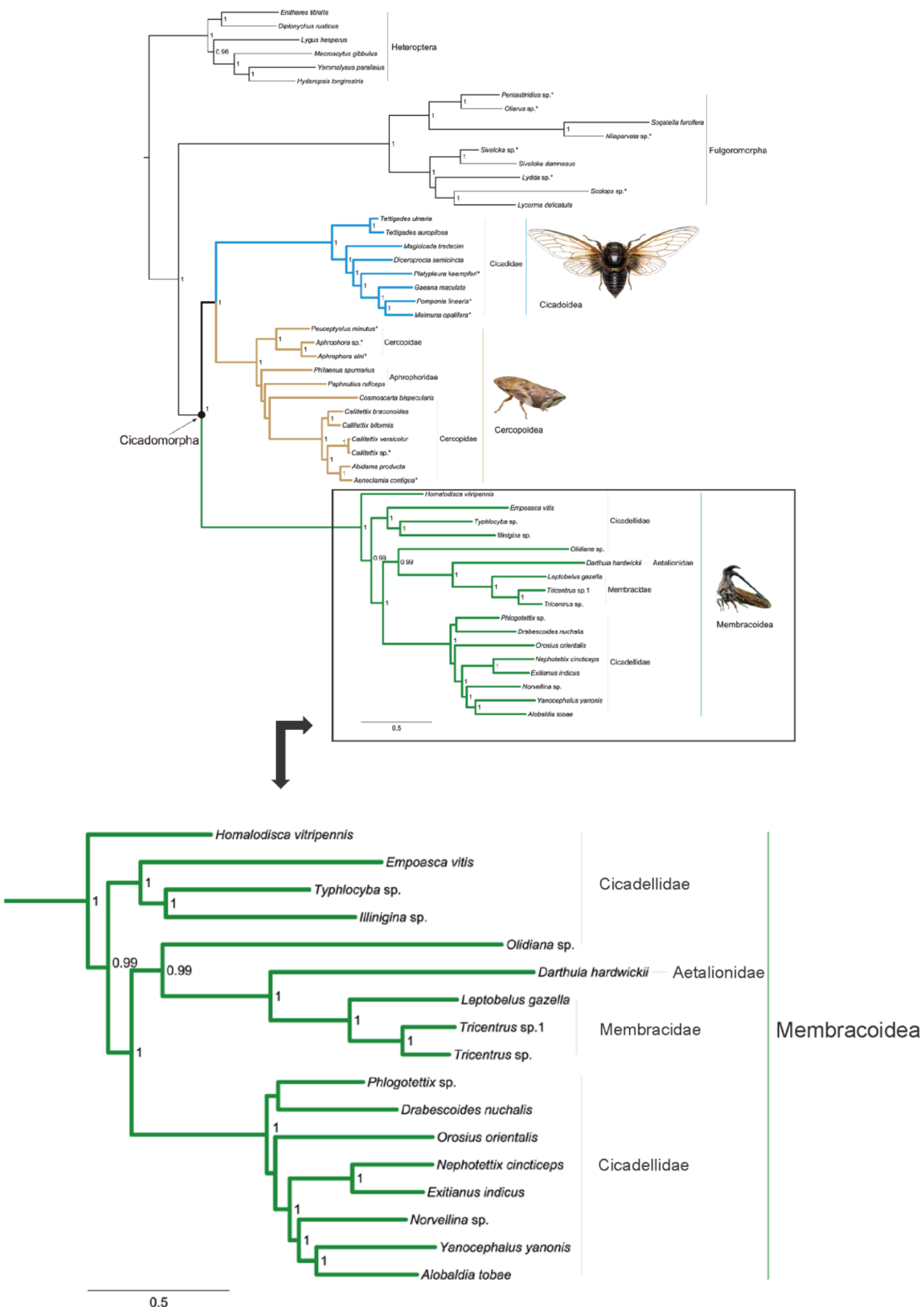

Figura 2. Análisis filogenético, basado en ADN mitocondrial, de las relaciones entre las tres superfamilias de Cicadomorpha (Extraído de Song et al. 2012) 
La subfamilia Cicadellinae incluye aproximadamente 340 géneros y más de 2400 especies distribuídas en el todo el mundo, siendo el grupo más diverso de cicadélidos de la región Neotropical (Wilson et al. 2009). La delimitación de esta subfamilia es controversial y numerosos autores incluyen diferentes combinaciones de las tribus Cicadellini, Proconiini, Mileewini, Errhomenini, Evacanthini y Makilingiini (Evans 1947, Metcalf 1965, Oman 1949). Tradicionalmente, es dividida en dos tribus, Cicadellini y Proconiini, que pueden ser diferenciadas en base a los siguientes caracteres morfológicos: posición de la articulación fémoro-tibial del tercer par de apéndices, microsetas y macrosetas del pigóforo y placas subgenitales del macho, y protuberancia del puente antenal en vista dorsal (Young 1968, 1977). Estudios recientes basados en datos morfológicos y moleculares apoyan la delimitación propuesta por Young $(1968,1977)$ e indican la cercanía filogenética con las subfamilias Evacanthinae, Mileewinae y Typhlocybinae, pero señalan que las tribus Cicadellini y Proconiini no son monofiléticas (Dietrich 2013).

La tribu Cicadellini, cuenta con aproximadamente 1886 especies distribuídas en 266 géneros (Mc Kamey 2007). La identificación taxonómica de sus especies se basa principalmente en los caracteres de la genitalia del macho, mientras que las hembras son identificadas por comparación con el macho predeterminado (Dietrich \& Pooley 1994, Mejdalani 1995). En la Argentina, los aportes referidos a la tribu Cicadellini son realmente escasos.

\section{Breve historia del estudio taxonómico de los Cicadellinae}

Las primeras cuatro especies de Cicadellinae fueron descriptas por Linneo (1758) dentro del género Cicada, el cual reunía a otras especies de Auchenorrhyncha como membrácidos, cercópidos, fulgoromorfos y cicádidos. Posteriormente, este género fue redefinido por Fabricius (1794) quien transfirió algunas de las especies de Linneo a otros géneros. En 1833, Germar propuso el género Tettigonia Geoffroy considerando caracteres que posteriormente definirían a la subfamilia: ocelos en la parte media de la cabeza y frente hinchada. Veinte años más tarde, el francés Victor Signoret (1853ac, 1854a-d, 1855a-d) presentó la primera revisión taxonómica de esta subfamilia tal cual la interpretamos actualmente. En su monografía redescribió y describió un gran número de especies, acompañadas de llamativas ilustraciones a color. Posteriormente, las especies hasta ese momento incluidas en Tettigonia fueron 
tratadas por Stål (1869) quien intentó separar géneros y describió otros nuevos. Siguiendo este formato, el inglés William Fowler escribió los capítulos de HemipteraHomoptera del libro "Biologia Centrali-Americana" que apareció entre 1894 y 1909 en donde describió numerosas especies centroamericanas incluyendo láminas a color (Figura 3) y, al igual que todos los autores de este período, sólo considerando caracteres externos. La segunda revisión más importante de los cicadelinos pertenece a Melichar, la cual fue publicada luego de su muerte en 1924. Este autor es el primero en dividir la subfamilia en dos secciones: los Proconiaria con 54 géneros y los Cicadellaria con 101 géneros, los cuales se corresponden, con algunas excepciones, con las tribus Proconiini y Cicadellini consideradas posteriormente por Young (19681977). Si bien la obra de este autor (Melichar) constituyó un gran avance en el estudio del grupo, no consideró las estructuras de la genitalia interna masculina y no presenta ilustraciones. Aproximadamente cuarenta años después, en 1968 y 1977, el norteamericano David Young publicó la revisión más importante del grupo que no sólo representó un avance en su delimitación sino que sentó las bases para su estudio futuro. Siguiendo a autores como Oman (1949), Young consideró caracteres externos e incorporó caracteres de la genitalia de machos y hembras tales como el séptimo esternito abdominal, el pigóforo $y$, en algunos casos, la valva II del ovipositor de las hembras, para delimitar géneros y diagnosticar algunas especies. A partir del análisis riguroso de la morfología del grupo constituyó grupos genéricos que si bien son subjetivos sirven como punto de partida para estudios filogenéticos que utilicen una metodología objetiva (Mejdalani 1998). La taxonomía de la tribu Cicadellini se basa principalmente en los caracteres de la genitalia masculina (Mejdalani 1998, Young 1968, 1977) y las claves para la identificación de la mayoría de los géneros y especies son exclusivas para los ejemplares machos, mientras que las hembras son identificadas por comparación con el macho predeterminado (Dietrich \& Pooley 1994, Mejdalani 1998). El estudio de la diversidad morfológica de las estructuras de la genitalia femenina es relativamente reciente ya que hasta mitad del siglo XX sólo el esternito abdominal VII, y excepcionalmente el pigóforo, fueron considerados taxonómicamente útiles. Nielson (1965) fue el primer autor en reconocer que el esternito abdominal VIII podía ser una estructura útil para la diagnosis de las especies. 


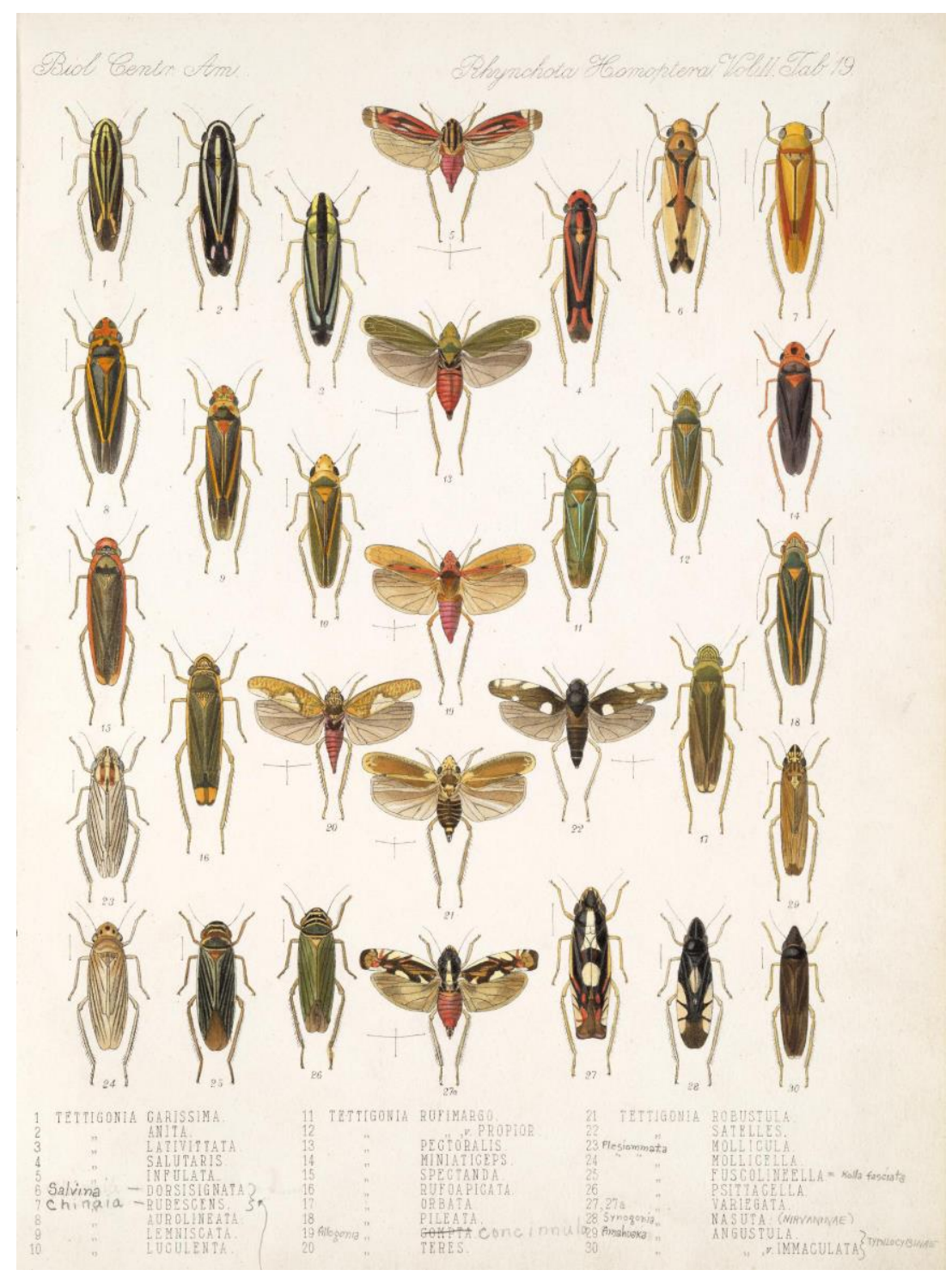

Figura 3. Lámina del libro "Biologia Centrali-Americana" de Fowler (1809-1909) mostrando el hábito dorsal de numerosas especies de Cicadellinae.

Posteriormente, Young (1977) demostró la importancia de la valva II del ovipositor para el establecimiento de relaciones entre los géneros de la tribu Cicadellini. Recientemente, la subfamilia fue abordada por Mejdalani (1998) quien realizó una relevante contribución al conocimiento de su morfología, utilizando entre otros, los caracteres del pigóforo, de los esternitos abdominales VII y VIII, y del ovipositor de las hembras. Reconocidos especialistas como Cavichioli, Dietrich y Takiya, entre otros, realizaron numerosas redescripciones y descripciones de varios géneros y especies utilizando caracteres morfológicos de la genitalia masculina y femenina 
constituyendo un valioso aporte al conocimiento de esta subfamilia en América (Cavichioli 1992, 1996, 1997, 2004, Cavichioli \& Wayler 1992, Dietrich 1994, Takiya et al. 2001, Takiya \& Cavichioli 2004, Takiya \& Mejdalani 2004, Takiya 2007).

En Argentina, el estudio de los Cicadellinae ha estado principalmente enfocado a conocer la composición faunística de esta, y otras subfamilias, en diversos cultivos de importancia comercial entre los que caben destacar los realizados por Remes Lenicov et al. (1999) y Dellapé et al. (2016) en agroecosistemas citrícolas de Misiones y Entre Ríos, respectivamente. En cuanto a los estudios de carácter taxonómico, la tribu Proconiini ha sido ampliamente abordada por Dellapé (2013) mientras que el estudio de los Cicadellini es más reciente y hasta el momento sólo se cuenta con las contribuciones realizadas por Defea \& Paradell (2016) y Defea et al. (2016).

\section{Aspectos biológicos y ciclo de vida}

En lo que se refiere a la biología, los Cicadellinae, al igual que el resto de los Auchenorrhyncha, son insectos hemimetábolos que pasan por tres estados: huevo, larva y adulto o imago. El período de tiempo desde la cópula hasta la eclosión de los huevos es muy variable en las distintas especies, siendo el período de preoviposición variable de 1 a 20 días y el embrionario entre 10 y 12 días. Las larvas recién eclosionadas son muy similares a los adultos, pero se diferencian por el tamaño, desarrollo de las alas y por poseer estructuras reproductivas inmaduras; en general, se mantienen agregadas por algunas horas y luego se dispersan activamente para iniciar la alimentación. Los Cicadellinae pueden pasar por cinco o seis estadios larvales antes de convertirse en adultos; generalmente la duración de los primeros estadios es marcadamente más corta pero va en aumento hasta el quinto estadio que es el de mayor duración. La duración del ciclo de vida es muy variable entre las especies pudiendo durar aproximadamente 10 a 60 días y la longevidad promedio de un adulto oscila entre 5 y 100 días. Estos parámetros pueden variar según la planta hospedadora y las condiciones climáticas, principalmente la temperatura (Mamoudou \& Walker 2005, Marucci et al. 2002, Paiva et al. 2001, Turner \& Pollard 1959). 


\section{Cópula y oviposición}

En zonas templadas, la mayoría de los cicadelinos pasa el invierno en estado adulto en zonas arboladas, donde se refugian y alimentan. Durante esta época entran en diapausa reproductiva $y$, aunque existen observaciones de acoplamiento durante el invierno, la oviposición no comienza hasta principios de la primavera (Lauzière \& Sétamou 2010). Excepcionalmente algunas especies pasan la época desfavorable en forma de huevo, tal es el caso del cicadelino europeo Cicadella viridis (L.) cuyas hembras oviponen durante el otoño y mueren con las primeras heladas; la eclosión de estas posturas se produce a principios de la primavera (Linskii 1980) y las larvas alcanzan la adultez en pleno verano; así las hembras de la segunda generación darán lugar a la tercer generación que emergerá en agosto (Chu \& Teng 1950, Zhixian 1996). Aparentemente las hembras de Cicadellinae copulan sólo una vez durante su vida y luego de un período de preoviposición, la hembra puede realizar un número variable de posturas en el período de oviposición cuya duración también es muy variable entre las especies. Los huevos pueden ser depositados de manera aislada, generalmente a lo largo de la nervadura principal de las hojas o agrupados formando "clusters" que pueden contener 2 a 28 huevos. En ambos casos las posturas son colocadas frecuentemente en el envés de las hojas, excepcionalmente en el haz, o sobre las ramas (Mamoudou \& Walker 2005, Paiva et al. 2001, Turner \& Pollard 1959). Cada huevo, puesto de manera independiente, puede ser dejado sobre la epidermis foliar o de la rama (oviposición exofítica), o ser insertado bajo la misma (oviposición endofítica). En varias especies, principalmente de la tribu Proconiini, la hembra luego de oviponer cubre los huevos con brocosomas, partículas proteicas ultramicroscópicas producidas en los túbulos de Malpighi. Los brocosomas son producidos por la mayoría de los cicadélidos, pero su utilización en la oviposición sería una especialización de un limitado número de especies (Rakitov 2004). Las hembras listas para la oviposición utilizan sus patas posteriores para transferir pequeñas gotas de una suspensión líquida de brocosomas, liberada desde el ano, sobre las alas, en donde se secan como una esfera blanca o "pellets" (Hix 2001, Swain 1937). Una vez depositados los huevos las hembras aplicarán una capa polvorienta de brocosomas sobre los "clusters". La función de esta cubierta no está completamente dilucidada, y varias funciones hipotéticas fueron propuestas (protección contra 
depredadores, parasitoides y patógenos, entre otras) pero muy pocas han sido testeadas experimentalmente (Hix 2001, Rakitov 2004); hasta el momento, sólo Velema et al. (2005) demostraron que los brocosomas reducen la eficiencia del parasitoidismo por parte del mimárido (Hymenoptera) Cosmocomoidea ashmeadi Girault sobre los huevos de Homalodisca coagulata (Say).

Cabe destacar que la mayoría de los trabajos relacionados con el ciclo biológico y la ecología de los cicadelinos toman principalmente como especie de estudio al proconino Homalodisca vitripennis Germar, debido a su importancia como vector de la bacteria Xylella fastidiosa Wells et al. a cultivos de importancia comercial en Estados Unidos (Takiya 2007).

\section{Caracterización de los estados inmaduros de la subfamilia Cicadellinae}

En América, particularmente en la región neotropical, se describieron las larvas de unas pocas especies de cicadelinos, principalmente de los proconinos Cuerna costalis (Fowler) (Turner \& Pollard 1959), Oncometopia facialis (Signoret) y Acrogonia sp. (Marucci et al. 2000); en tanto que de la tribu Cicadellini sólo fueron descriptos los estados inmaduros de una única especie, Dilobopterus costalimai Young, por Marucci et al. (2000). En dicho estudio, los cinco estadios larvales fueron descriptos, caracterizados morfológicamente e ilustrados; se elaboraron claves para el reconocimiento de los diferentes estadios y para la identificación de las larvas del quinto estadio de las especies estudiadas. Una clave similar fue elaborada por Wilson \& Claridge (1991) para las especies encontradas en arrozales de Asia. La descripción de los estados inmaduros es una laguna en el conocimiento de la biología de los Cicadellinae. Estos estudios son relevantes ya que ayudan a comprender problemas asociados a la taxonomía, morfología y a la entomología agrícola. Los estudios poblacionales requieren el reconocimiento y distinción de los especímenes inmaduros ya que permiten comprender cambios en el tamaño de la población, procesos de regulación y construcción de tablas de vida. Con el surgimiento de numerosas enfermedades causadas por la bacteria $X$. fastidiosa, y dado que tanto los adultos como las larvas de Cicadellinae tienen relevancia en su transmisión, su 
reconocimiento es de vital importancia para encarar de manera eficiente programas de control de estos insectos.

\section{Alimentación}

Los Cicadellinae, a diferencia de la mayoría de los cicadélidos que se alimentan del floema o del tejido parenquimático, consumen preferentemente la savia xilemática de las plantas, un recurso mucho más diluído que conlleva a una excreción excesiva y continua de parte del líquido consumido durante la alimentación, por lo cual, se los conoce comúnmente en inglés como "sharpshooters". Este modo de alimentación, que se encuentra en la superfamilia Cicadoidea y Cercopoidea, es una condición plesiomórfica retenida por algunos Membracoidea, entre ellos, los Cicadellinae. El consumo de un recurso tan diluído como el xilema, compuesto en un 95\% por agua, impone limitaciones al crecimiento y desarrollo de estos herbívoros. Una manera de sobrellevar esta deficiencia es a través de simbiosis con bacterias las cuales pueden ser una fuente adicional de algunos aminoácidos esenciales y vitaminas (Morán et al. 1993, Thao et al. 2001, 2002) y la incorporación de numerosas estrategias comportamentales y fisiológicas como la extrema polifagia (utilizando hospederos con perfiles químicos diferentes), sincronización del ritmo de alimentación a las fluctuaciones químicas circadianas del xilema, mostrando mayor consumo cuando la concentración de aminoácidos es mayor en los vasos (Andersen et al. 1992, Brodbeck et al. 1993), excreción primaria de amonio, situación rara en insectos terrestres, altos niveles de consumo, pudiendo ingerir hasta 300 veces su propio peso y una alta eficiencia metabólica de los compuestos orgánicos, entre otros (Andersen et al. 1992, Brodbeck et al. 1993, Mittler 1967). Tanto la larva como el adulto presentan un comportamiento alimenticio similar. Aparentemente, las larvas requieren una dieta baja en amidas y con una concentración mayor de otros aminoácidos (Brodbeck et al. 1996). Para los adultos la alternancia de numerosos hospedadores que permitan un balance nutricional óptimo es crítico para el desarrollo y crecimiento (Brodbeck et al. 1999). Sin embargo está demostrado que los primeros estadios larvales son capaces de sobrevivir y desarrollarse sobre una o pocas plantas (Brodeck et al. 1995, 1996, 1999). 


\section{Importancia económica de los Cicadellinae en América}

Los hemípteros constituyen el orden de insectos con el mayor número de vectores de patógenos (Harris \& Maramorosch 2013). Su aparato bucal especializado les permite penetrar cuidadosamente los tejidos de la planta evadiendo las barreras naturales de la epidermis y favoreciendo la inoculación de patógenos. Asimismo, pueden producir daño directo a los tejidos debido a la alimentación u oviposición. Algunos Cicadellinae fueron reportados causando daño directo como es el caso de Hortensia similis Metcalf \& Bruner, causante de daño mecánico durante la alimentación en arroceras de la Argentina (Remes Lenicov \& Tesón 1985) y plaga de pasturas en Colombia (Bautista et al. 2014). En América, esta subfamilia reúne a los vectores más conocidos a nivel mundial de la bacteria Xylella fastidiosa Wells et al. (Xf) siendo todas sus especies consideradas vectores potenciales de distintas cepas de la misma. Este fitopatógeno es ampliamente conocido en el continente americano desde hace más de un siglo, donde causa enfermedades en numerosas plantas cultivadas, ornamentales y forestales. Puntualmente, la enfermedad de Pierce (PD) de la vid, en California, y la Clorosis Variegada de los Cítricos (CVC) en Brasil, han ocasionado problemas considerables en la agricultura durante el siglo XX (Hernandez Martinez et al. 2006, Hopkins \& Purcell 2002, Redak et al. 2004). También es el agente causal de otras enfermedades como la escaladura de la hoja en ciruelas (PLS), el "Phony Peach" del duraznero (PPD) y la escaladura de la hoja del café (CLS) (Fletcher \& Wayadande 2002). Hasta el presente, plantaciones citrícolas de Costa Rica, Paraguay, Brasil y Argentina se encuentran afectadas por la CVC (Agostini 1993, Aguilar et al. 2005, Contreras 1990, de Coll et al. 2000a, 2000b, de Coll 2006, Fundecitrus 2007, Laranjeira et al. 2005), en donde se la considera una amenaza potencial para la producción si un vector adecuado se halla presente en el área (Damsteegt et al. 2006). Hasta el momento, 40 especies (20 géneros) fueron identificadas como vectores de distintas cepas de $X f$ de las cuales 13 están presentes en Sudamérica (Redak et al. 2004, Yamamoto et al. 2007, Lopes 2017). La adquisición de la bacteria se produce cuando los cicadelinos adultos se alimentan de una planta infectada y una vez adquirida, por tratarse de un patógeno persistente no circulativo, lo transmiten durante toda la vida (Hopkins 1989). Durante el estado de larva también tienen la capacidad de adquirir y transmitir la bacteria, sin embargo después de cada muda 
deben adquirirla nuevamente ya que al estar alojada en el intestino anterior de los insectos se pierde luego de dicho proceso (Alves et al. 2008).

Actualmente, los principales estudios referidos a los Cicadellinae presentes en cultivos citrícolas fueron realizados en Brasil y están enfocados en el conocimiento de la taxocenosis y su fluctuación estacional con la intención de identificar a los vectores potenciales y/o claves de la bacteria $X f$ en las distintas regiones productoras así como también en distintos aspectos ecológicos de los vectores comprobados (Dos Santos et al. 2005, Giustolin et al. 2009, Gravena et al. 1998, Lopes 1996, 1999, 2017, Menegatti et al. 2008, Miranda et al. 2009, Molina et al. 2006, 2010, Nunes et al. 2007, Parra et al. 2003, Yamamoto \& Gravena 2000, Yamamoto et al. 2002, 2007, Lopes \& Krugner 2016).

\section{Cicadellinae en la Argentina y su importancia fitosanitaria en las regiones citrícola productoras del NEA y NOA}

En la Argentina, hasta el presente, el estudio sistemático y biológico más importante de esta subfamilia contempla sólo a la tribu Proconiini (Dellapé 2013), mientras que de los Cicadellini se cuenta con simples diagnosis de algunas especies asociadas a cultivos de arroz, maíz y cítricos (Paradell 1995, Remes Lenicov \& Tesón 1985, Remes Lenicov \& Virla 1993, Remes Lenicov et al. 1997, 1999). La tribu Cicadellini es cuatro veces más diversa y de mayor complejidad sistemática que Proconiini. Como señala Young (1977), uno de los principales revisores de la subfamilia, los cicadelinos exhiben una variación morfológica menor entre sus miembros lo que tal vez se deba a una rápida radiación adaptativa. Por esto, la genitalia de los machos no siempre es suficiente para definir y asociar géneros, por lo cual los caracteres de las hembras deben ser considerados para juzgar sus relaciones filogenéticas. Sin embargo, la diversidad morfológica de la genitalia femenina de la mayoría de las especies es aún desconocida comparada con el conocimiento de los machos. La morfología de las hembras de numerosos cicadelinos ha sido estudiada en Brasil (Camisão et al. 2014, Carvalho \& Mejdalani 2006, 2014, Leal et al. 2009, 2016, Mejdalani 1995, 1998), Estados Unidos (Hummel et al. 2006) y China (Meng \& Yang 2012) pero son escasos los estudios realizados sobre las especies de Argentina, los cuales describen 
principalmente hembras de la tribu Proconiini (Dellapé 2015, Dellapé \& Paradell 2011, Remes Lenicov \& Tesón 1985); sólo dos estudios detallados de las hembras de Cicadellini han sido realizados en nuestro país (Defea \& Paradell 2016, Defea et al. 2016). En vistas de esta situación, nuevos estudios morfológicos y comparativos de la genitalia de las hembras en un gran número de géneros y especies son necesarios para avanzar en el conocimiento de este grupo.

En Sudámerica, los cicadelinos intervienen en la transmisión de la bacteria $X f$ a plantas de gran importancia comercial como los cítricos y el café (Redak et al. 2004). Hasta el presente, fueron identificadas 13 especies vectoras (Redak et al. 2004, Yamamoto et al. 2007, Lopes 2017), de las cuales 10 se encuentran presentes en la región del NEA (6 Cicadellini, 4 Proconiini) (Beltrán et al. 2004, Dellapé et al. 2016, Remes Lenicov et al. 1999). En la Argentina, Xf causa la Clorosis Variegada de los Cítricos (CVC), la cual limita la producción, y la Escaladura de la hoja del almendro (ALS) (De Lima et al. 1998, Haelterman et al. 1996, Nome et al. 1992, Rosato et al. 1998). En el NEA, la CVC está ampliamente distribuída y afecta severamente plantaciones de Citrus sinensis (L.) Osbeck en las provincias de Misiones (Montecarlo, Cerro Azul), Corrientes (Bella Vista, Monte Caseros) y Entre Ríos (Concordia) (Beltrán et al. 2004, Costa 2009, De Coll et al. 2000a y 2000b).

La información disponible acerca de esta subfamilia, y en particular de la tribu Cicadellini, proviene principalmente de estudios faunísticos en cultivos de importancia comercial siendo los más importantes los realizados sobre arroz, maíz, sorgo y cítricos (Paradell 1995, Remes Lenicov \& Tesón 1985, Tesón et al. 1986, Remes Lenicov et al. 1997, 1999, Paradell et al. 2006, Paradell et al. 2014b, Dellapé et al. 2016). Las contribuciones realizada por de Coll (1996), Remes Lenicov et al. (1999), de Coll et al. (2000) y Dellapé et al. (2016) aportaron información detallada acerca de la composición faunística y de especies potencialmente vectoras en los agroecosistemas citrícolas de las provincias de Misiones y Entre Ríos; mientras que en la provincia de Corrientes, donde la CVC también afecta severamente a cultivos de naranja dulce, sólo se cuenta con un listado preliminar de las especies de auquenorrincos presentes en las plantas cítricas (Beltrán et al. 2004). Recientemente $X f$ fue detectada por primera vez afectando olivos (Olea europaea L.) de la variedad Arauco (Haeltermann et al. 2015) en la provincia de La Rioja; previamente, en la región de Cuyo fue detectada afectando almendros en la provincia de Catamarca 
(Haelterman et al. 1996, Nome et al. 1992). Considerando la importancia de las zonas citrícolas productoras de la región del NOA, cabe destacar que se cuenta con escasa información respecto a los cicadelinos presentes en dichas áreas y más aún sí nos limitamos a los agroecosistemas citrícolas.

La alta diversidad de la tribu Cicadellini en ecosistemas naturales y agroecosistemas, su importancia para la agricultura y la complejidad morfológica que exhiben, hacen necesario abordar estudios morfológicos detallados que faciliten la identificación de las especies, y estudios biológicos que permitan conocer en mayor profundidad la composición y el comportamiento de las comunidades de los Cicadellinae, principalmente en las áreas citrícola productoras donde ejercen un gran impacto debido a su capacidad vectora.

En la Argentina, los estudios realizados sobre la taxonomía, abundancia, distribución, registro de plantas hospederas y asociaciones insecto/planta son aún insuficientes y fragmentarios, y la mayoría de los estudios bionómicos existentes no se enfocan de manera específica en el grupo. Merece destacarse que existe una gran demanda de información sobre especies regionales o locales de este grupo de chicharritas por parte de técnicos e investigadores de distintos centros especializados en temas agrícolas del norte de nuestro país (Jujuy, Salta, Tucumán, La Rioja, Córdoba, Misiones y Corrientes). La complejidad y el tamaño de la tribu Cicadellini, la carencia de estudios de los estados inmaduros y su importancia fitosanitaria demandan un mayor conocimiento de las especies con implicancia vectora y de aquellas que por su frecuencia y/o abundancia en los cultivos puedan representar una amenaza a nivel regional y/o local.

Por todo lo antes expuesto, es claro que los Cicadellini constituyen un grupo taxonómicamente poco estudiado, que se encuentra afectando cultivos frutícolas, especialmente plantaciones citrícolas del norte de la Argentina. Estas carencias presuponen un fecundo campo de investigación que aportará y ampliará los conocimientos taxonómicos y bionómicos tanto desde el punto de vista del conocimiento de la biodiversidad como el agronómico.

Es por ello que se plantea la siguiente hipótesis:

- Existe un mayor número de especies de Cicadellini potencialmente vectoras asociados a los sistemas frutícolas del norte y centro de la Argentina, que las que actualmente se conocen. 


\section{OBJETIVOS}

\section{Objetivo general}

Conocer la taxocenosis de la tribu Cicadellini, particularmente el complejo de especies potencialmente vectoras, en agroecosistemas frutícolas del norte y centro de la Argentina.

\section{Objetivos específicos}

1) Estudiar bajo el aspecto taxonómico las especies de la tribu Cicadellini, en particular los géneros fitosanitariamente importantes, así también aquellos que puedan representar una amenaza por su densidad y/o frecuencia en los cultivos.

2) Describir los estados inmaduros de las especies más importantes (por su implicancia vectora, frecuencia y/o abundancia).

3) Generar claves de identificación que reúnan a las especies asociadas a cultivos frutícolas presentes en las principales áreas productoras.

4) Elaborar un registro de las especies allí presentes incluyendo datos morfológicos, fenológicos, distribucionales, plantas hospederas, entre otros, a fin de caracterizar las especies asociadas a cada hospedante y/o cultivo.

5) Conocer la composición faunística y aspectos demográficos poblacionales de las especies de Cicadellini presentes en cultivos frutícolas en el norte argentino.

6) Realizar estudios biológicos para la caracterización morfológica y biométrica de los diferentes estados y estadios de desarrollo de las especies que representan una amenaza por su implicancia vectora, frecuencia y/o abundancia. 


\section{Capítulo II}

\section{Taxonomía de la tribu Cicadellini (Auchenorrhyncha: Cicadellinae)}

\section{INTRODUCCIÓN}

La subfamilia Cicadellinae incluye aproximadamente 350 géneros y 3400 especies descriptas en todo el mundo (Wilson et al. 2009) (Figura 4), siendo una de las subfamilias de cicadélidos más diversa de la región Neotropical. Son conocidos comúnmente como "sharpshooters" debido a la gran cantidad de excretas que liberan durante la alimentación. Son fitófagos generalistas que se alimentan de numerosas familias de plantas (Basset \& Charles 2000, Novotny \& Wilson 1997, Young 1968, 1977). Debido a su hábito de alimentación, muchas especies son importantes vectores de la bacteria Xylella fastidiosa, agente causal de severas enfermedades en diversos cultivos de importancia comercial (Redak et al. 2004).

La subfamilia Cicadellinae se caracteriza por la siguiente combinación de caracteres: ocelos ubicados sobre la corona, generalmente más cerca del margen posterior que del ápice; las suturas clipeales laterales se extienden hasta la corona y usualmente llegan hasta los ocelos o cerca de ellos; cuerpo frecuentemente no aplanado dorsoventralmente; alas anteriores con el margen externo de la celda apical interna paralelo al eje longitudinal del ala; tibias posteriores con cuatro hileras regulares de macrosetas; proepisterno expuesto (Young 1968). 


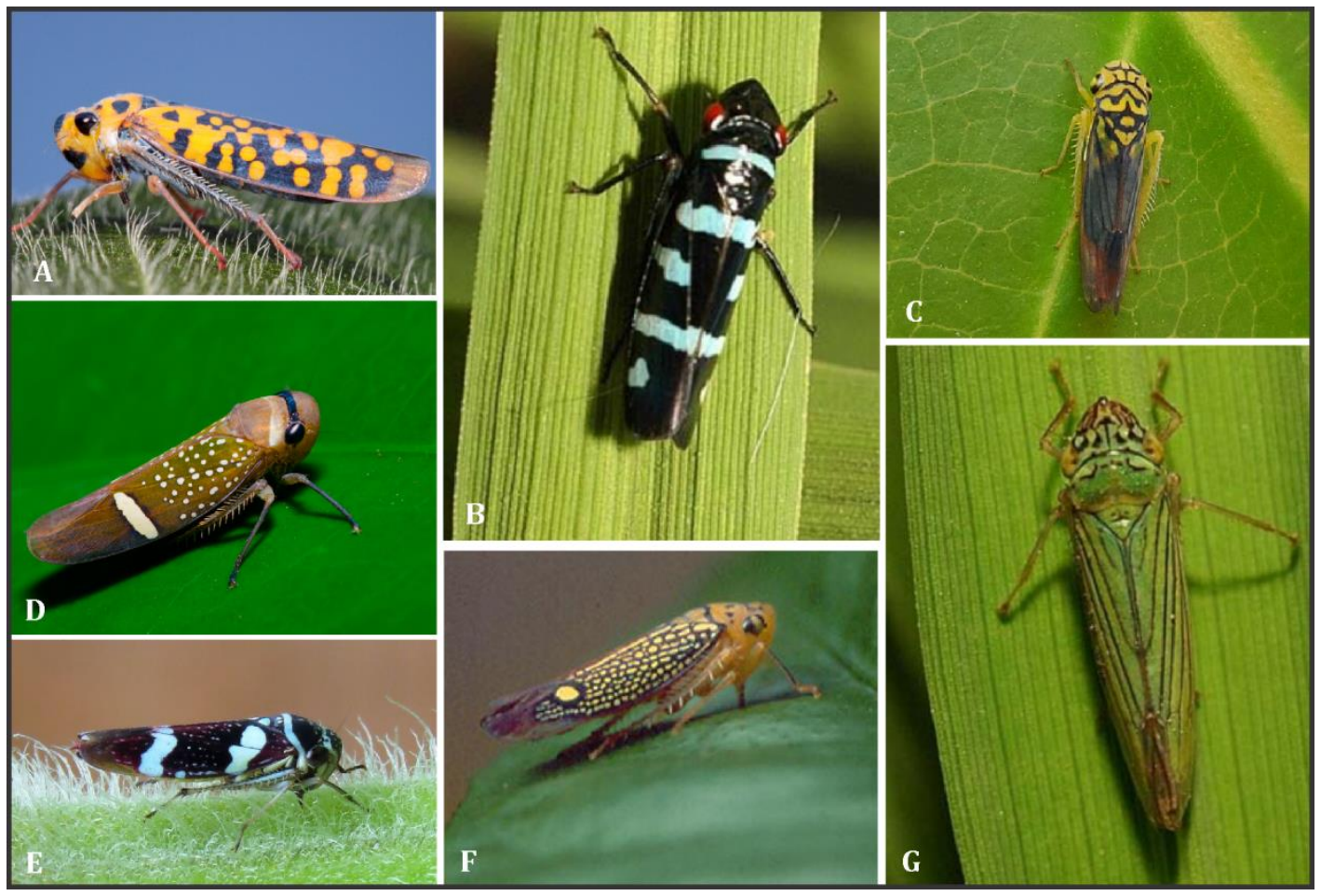

Figura 4. Cicadellinae. Pawiloma victima (Germar) (A), Balacha melanocephala (Signoret) (B), Dilobopterus costalimai Young (C), Scoposcartula limitata (Signoret) (D), Macugonalia leucomelas (Walker) (E), Parathona gratiosa (Blanchard) (F), Syncharina argentina (Berg) (G). (Fotografías: (A) tomada por Mc Rae T.C; (D, E, C) extraídas de las páginas PICSSR, Flickr y Proyect Noah, respectivamente; (B, G) cedidas por Bonott G.; (F) extraída de Fundecitrus (1999).

La delimitación de las tribus dentro de Cicadellinae es controversial. Tradicionalmente, varios autores incluyeron en esta subfamilia diferentes tribus: Cicadellini, Proconiini, Mileewini, Errhomenini, Evacanthini y Makilingiini (Evans 1947, Metcalf 1965, Oman 1949). Sin embargo Young (1968, 1977, 1986) considera sólo a las tribus Cicadellini y Proconiini como pertenecientes a Cicadellinae, y transfiere Mileewini a la subfamilia Typhlocybinae, considerando Errhomenini, Evacanthini y Makilingiini como subfamilias separadas. No obstante, algunos autores, todavía tratan esos grupos como tribus dentro de Cicadellinae (Godoy \& Webb 1994, Hamilton 1983, Linnavuori 1979, Nielson \& Knight 2000, Oman et al. 1990), sobre la base de rasgos morfológicos, como el clípeo hinchado y consecuente desplazamiento de los ocelos a una posición dorsal, lo que probablemente se correlaciona más con su modo de alimentación, en lugar de su proximidad filogenética (Takiya 2007). 
Estudios filogenéticos basados en datos morfológicos y moleculares (Dietrich 1999, 2005, Dietrich et al. 2001b) han demostrado que la subfamilia Cicadellinae sensu lato (en oposición a sensu Young 1968, 1977) no es probablemente un grupo monofilético. En base a estos análisis, los Cicadellinae como los delimita Young (1968, 1977), parecen estar estrechamente relacionados, pero pueden ser parafiléticos sin la inclusión de los representantes de la subfamilia Phereurhininae en este grupo. Además, la tribu cosmopolita Cicadellini, podría ser un taxón parafilético con respecto a la tribu Proconiini, restringida al nuevo mundo (Takiya 2007).

En el presente trabajo se siguió la clasificación de Young $(1968,1977,1986)$, la cual divide a la subfamilia Cicadellinae en dos tribus en base a la combinación de los siguientes caracteres:

- Articulación fémoro-tibial del tercer par de apéndices, en posición de reposo, alcanzando el margen posterior del proepímero (Figura 5A); pigóforo y placas subgenitales del macho con macrosetas o con microsetas no dispersas; puente antenal usualmente no protuberante en vista dorsal ...Cicadellini

- Articulación fémoro-tibial del tercer par de apéndices, en posición de reposo, no alcanzando el margen posterior del proepímero (excepto en el género Splonia Signoret) (Figura 5B); pigóforo y placas subgenitales del macho con numerosas microsetas eventualmente dispersas y ocasionalmente algunas macrosetas; puente antenal protuberante en vista dorsal Proconiini

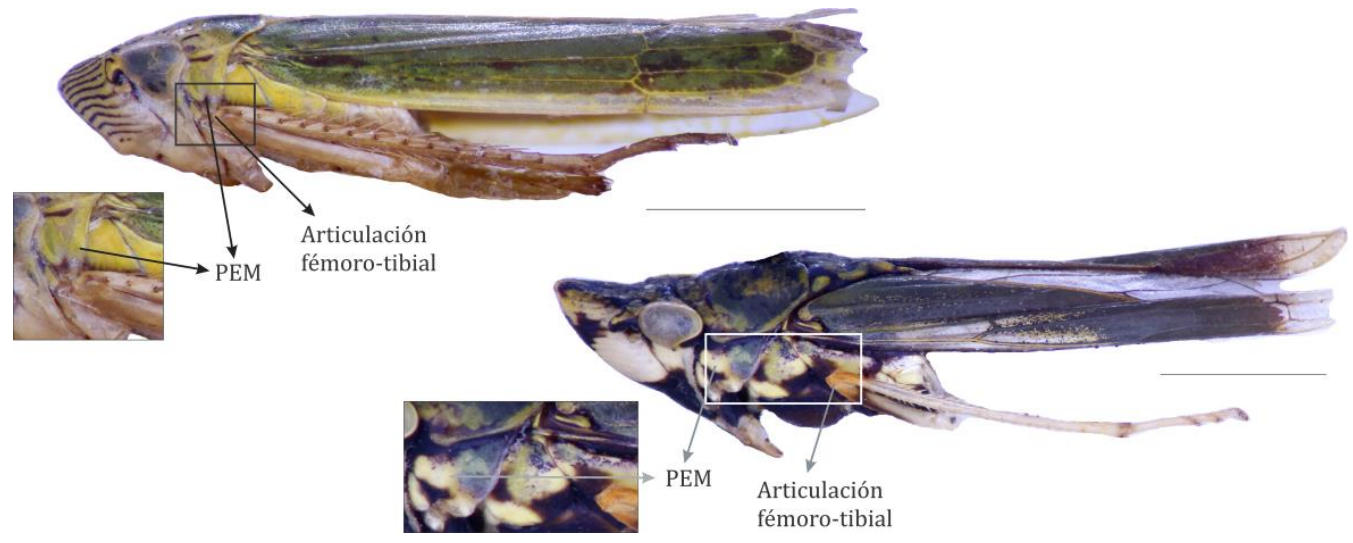

Figura 5. Posición de la articulación fémoro-tibial del tercer par de patas en posición de reposo en Cicadellini (A) y en Proconiini (B). PEM: proepímero. 


\section{Tribu Cicadellini sensu Young}

Cicadellini cuenta con aproximadamente 266 géneros y 1886 especies distribuidas en todas las regiones zoogeográficas (McKamey 2007).

\section{Morfología}

\section{Caracteres diagnósticos}

La tribu Cicadellini incluye cicadélidos de tamaño pequeño a grande, con el tegumento más esclerotizado que los miembros de otras subfamilias, con el fémur posterior achatado en sección transversal y el tegumento del clípeo usualmente glabro. Poseen mayormente patrones de coloración llamativos, aunque también pueden presentar el tegumento casi totalmente oscuro o pálido. También es común que algunas especies presenten variaciones en el patrón de coloración, que en la mayoría de los casos no se corresponden con variaciones morfológicas. En la Argentina pueden citarse como ejemplo a las especies Syncharina argentina (Berg), $S$. punctatissima (Signoret) y Bucephalogonia xanthophis (Berg). Si bien la coloración no es considerada un carácter diagnóstico constante es un rasgo útil y complementario para la identificación de los especímenes.

Cabeza (Figura 6). La longitud, medida a través de la línea media, y el ancho intery transocular son caracteres importantes en la taxonomía del grupo; el ancho interocular se corresponde a la distancia transversal entre los ojos compuestos medida desde sus puntos más cercanos mientras que el ancho transocular es la misma medida tomada desde los puntos más lejanos de los ojos compuestos. La corona (co) representa la superficie dorsal entre los ojos; el contorno de su superficie, generalmente convexa o con una concavidad longitudinal o transversa, es un carácter útil al igual que la pubescencia yla textura que puede ser lisa, granulosa, punteada o rugosa. Los ocelos pueden estar, en vista dorsal, alineados con los ángulos anteriores de los ojos, o por delante o por detrás de una línea imaginaria que pasa entre el ángulo anterior de los ojos. La transición de la corona al clípeo puede ser redondeada, angulosa o carenada. Los lóbulos supra-antenales (lsa), también llamados puentes antenales, son excepcionalmente protuberantes en vista dorsal en algunos Cicadellini, sobresaliendo apenas en la mayoría de las especies. Las suturas clipeales laterales 
(scl) se extienden hasta la corona y usualmente llegan hasta o cerca de los ocelos, excepto en el género Mesogonia en el que no alcanzan a estar sobre la corona. La transición desde la corona al clípeo puede ser gradual o abrupta y marcada por un ángulo o carena. El clípeo (cl) se separa del clipelo (clp) por una sutura transclipeal (stcl), generalmente no distintiva medialmente. Las impresiones arqueadas de los músculos (IM) que dilatan el cibario pueden estar débil-o fuertemente marcadas. El contorno del clipelo es generalmente una continuación del perfil del clípeo, pero frecuentemente la porción inferior es casi paralela al eje longitudinal del cuerpo.
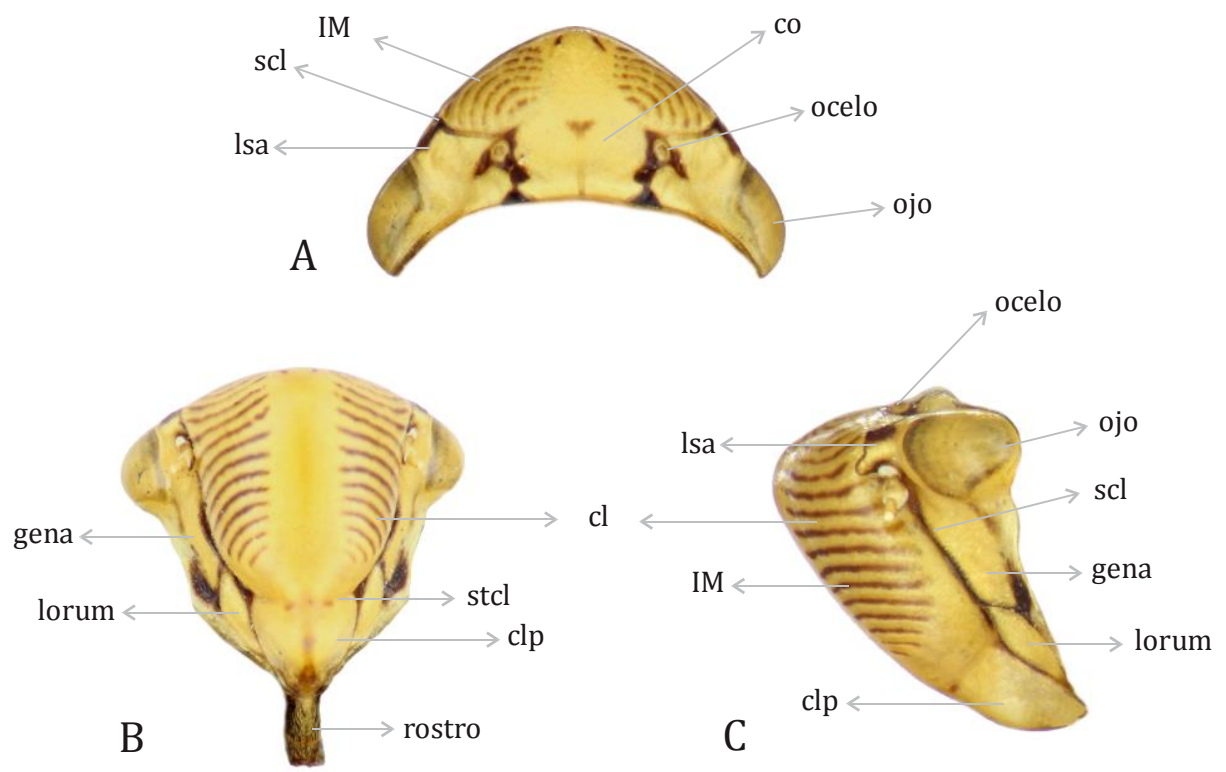

Figura 6. Morfología de la cabeza de Cicadellini en vista dorsal (A), en vista ventral (B) y en vista lateral (C). Referencias: cl, clípeo; clp, clipelo; co, corona; IM, impresiones musculares; lsa, lóbulos suprantenales; scl, sutura clipeal lateral; stcl, sutura transclipeal.

Tórax (Figura 7). El tórax tiene varios caracteres taxonómicamente útiles: el ancho del pronoto comparado con el ancho transocular, la forma de sus márgenes laterales en vista dorsal (paralelos, convergentes, divergentes), la esculturación y la pubescencia del disco, la forma del margen posterior y la textura del escutelo. En vista lateral, la carena dorsopleural del protórax es generalmente completa (alcanzando el margen de los ojos) en los Cicadellini del Hemisferio Oeste, aunque puede estar 
ausente como en el género Draeculacephala Ball, o ser incompleta (no alcanza el margen de los ojos). En algunos Cicadellini el meron (m) queda expuesto cuando las alas anteriores están en reposo (p. ej. Dilobopterus Signoret).

A

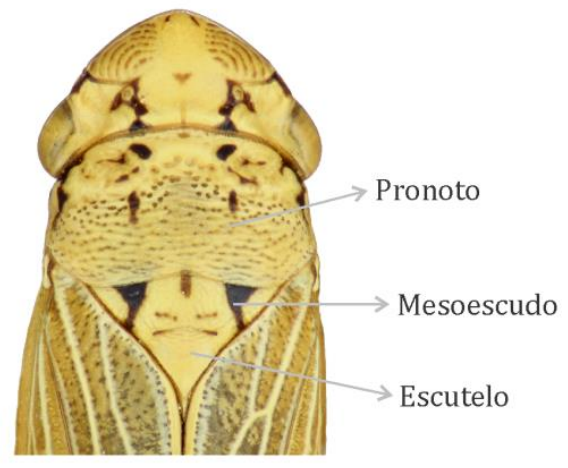

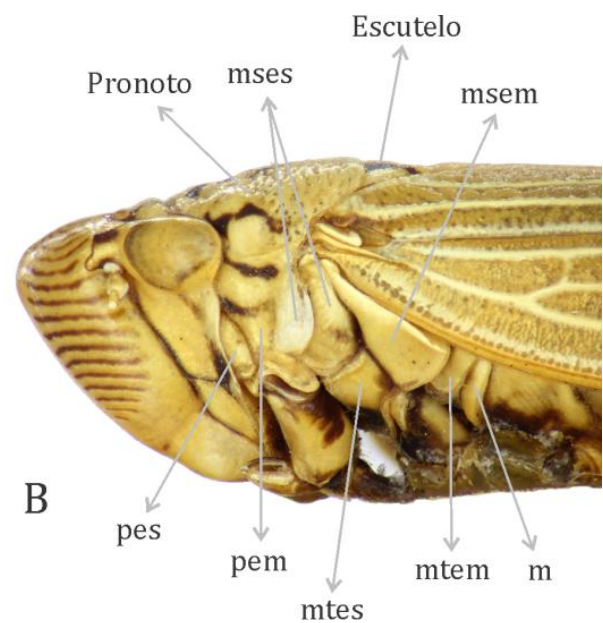

Figura 7. Morfología del tórax de Cicadellini en vista dorsal (A) y en vista lateral (B). Referencias: m, meron; msem, mesoepímero; mses, mesoepisterno; mtem, metaepímero; mtes, metaepisterno; pem, proepímero; pes, proepisterno.

Las patas posteriores tienen varios caracteres taxonómicamente útiles. En la mayoría de los géneros la articulación fémoro-tibial del tercer par de patas se extiende hasta el margen posterior del proepímero en posición de reposo. La setación de los fémures posteriores es un carácter de valor taxonómico. Todas las variantes posibles dentro de la subfamilia están presentes en Cicadellini. La disposición setal se expresa por las siguientes fórmulas: 2:0:0 (un par de setas apicales), 2:1:0 (un par de setas apicales y una seta proximal), 2:1:1 (un par de setas apicales y dos setas proximales en serie), 2:1:1:1 (un par de setas apicales y tres setas proximales dispuestas en serie), 3:1:1 (tres setas apicales y dos setas proximales en serie) (Figura 8). La forma de la tibia posterior, en sección transversal, tiende a ser más aplanada que en la tribu Proconiini. Además, en las patas posteriores, la longitud relativa del primer tarsómero comparada con la longitud combinada del segundo y tercer tarsómero, es un carácter útil en la clasificación. 


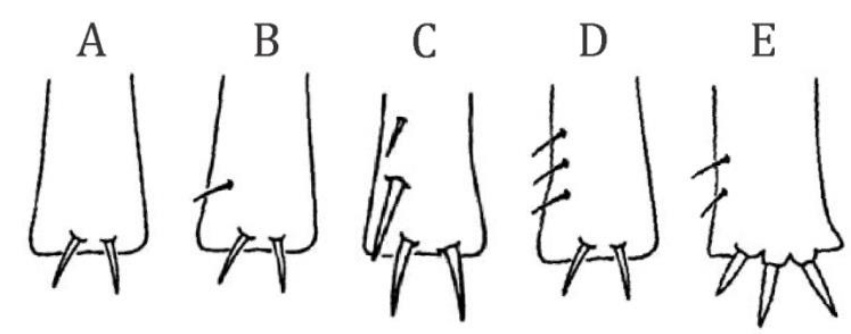

Figura 8. Ápice del fémur posterior, en vista dorsal, mostrando la disposición setal: 2:0:0 (A), 2:1:0 (B), 2:1:1 (C), 2:1:1:1 (D), 3:1:1 (E). Esquema adaptado de Rakitov (1998).

La textura de las alas anteriores puede ser coriácea o membranosa, o presentar una porción membranosa cuya extensión es variable. Las venas pueden distinguirse y estar elevadas o directamente no observarse. Las celdas anteapicales pueden estar presentes en número de dos (p. ej. Ciminius Metcalf \& Bruner) o tres y estar basalmente abiertas o cerradas. Pueden tener cuatro o cinco celdas apicales. En algunos géneros, se observan venas supernumerarias formando plexos apicales. La forma del margen apical puede ser convexa o ser ligeramente cóncava como en el género Diedrocephala Spinola. En las alas posteriores pueden también observarse varios caracteres útiles en la clasificación: la vena submarginal puede coincidir, o no, con el margen apical como en el género Vidanoana Young. Excepcionalmente pueden presentar una emarginación profunda entre el jugum y el resto del ala como en algunas especies del género Dilobopterus. La vena $\mathrm{R}_{2+3}$ puede ser completa, como en el género Stehlikiana Young, o estar excepcionalmente interrumpida, o ausente.

Abdomen. El aspecto del abdomen no presenta modificaciones relevantes para la clasificación, excepto en el género Lissoscarta Stål que se encuentra constreñido basalmente.

Genitalia del macho (Figura 9). Consiste en estructuras que conforman el segmento abdominal IX. La cápsula genital o pigóforo (Py), puede ser fuerte- a ligeramente proyectado posteriormente; varía en su forma y en el contorno de su margen posterior, el cual puede ser agudo, redondeado, truncado, cóncavo o profundamente emarginado. La quetotaxia de la superficie también se utiliza en taxonomía: posee dos tipos de setas: las setas más gruesas o macrosetas y las más delgadas (visualmente lineales a bajos aumentos) o microsetas. El pigóforo con 
frecuencia, puede llevar procesos cuyo punto de origen, forma y la dirección en la cual se extienden es variable entre géneros y especies (p. ej. en el género Scopogonalia Young). El esterno del segmento abdominal IX forma las placas subgenitales (PSG); su longitud, forma y quetotaxia son de valor taxonómico. Respecto a lo que se conoce como genitalia "interna": los estilos son estructuras pares, cuya forma y longitud relativa respecto al ápice del conectivo son caracteres útiles. El conectivo se extiende entre las porciones basales de los estilos y su forma es relativamente constante; generalmente tiene forma de Y con el eje usualmente llevando una quilla; su forma y longitud son caracteres usados en la clasificación. Muchos autores lo consideraron como un esclerito basal del edeago. Las paráfisis (p), son estructuras pares o impares así como también simétricas o asimétricas. La asimetría puede ser por diferencias en la forma, posición en planos asimétricos o una sola estructura no posicionada en el plano medio. Las paráfisis pueden estar articuladas con el conectivo y el edeago, o pueden estar separadas de una o ambas estructuras. La forma del órgano copulador o edeago, es mayormente constante, básicamente, es campaniforme; posee un anillo basal, el atrio, que ocasionalmente puede tener una extensión anterior, el preatrio, el cual cuando está presente articula con el conectivo. El eje del edeago es la porción atravesada por el gonoducto, y también la porción más allá del gonoporo excepto cuando esta parte aparece como un proceso. Puede tener, o no, procesos pares o impares, que pueden originarse en distintas partes del edeago (procesos atriales, del eje, apicales, basales, etc.); articula basalmente con el conectivo, aunque pueden estar completamente separados; en este caso, se establece una conexión más fuerte con el tubo anal.

El tubo anal (segmento abdominal X) raramente posee procesos. 


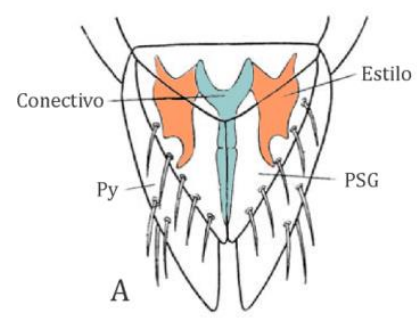

B
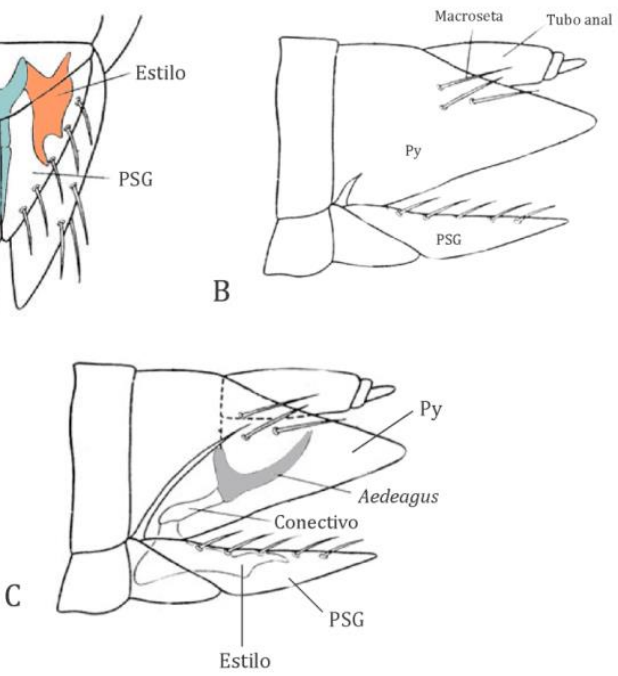

Figura 9. Morfología de la terminalia del macho de Cicadellini. Esquema general en vista ventral (A), esquema general en vista lateral sin edeago, estilos ni conectivo (B), esquema general en vista lateral con edeago, conectivo y estilo (C). Referencias: PSG, placa subgenital; Py, pigóforo. Esquemas adaptados de Anufriev \& Emeljanov (1988).

Genitalia de la hembra (Figura 10). Estructuras accesorias: El esternito abdominal VII (E7) posteriormente puede ser ligera-a fuertemente proyectado; la forma de sus márgenes laterales y margen posterior, la quetotaxia y coloración son características útiles para la clasificación. El esternito abdominal VIII (E8)es generalmente membranoso y en algunos géneros puede presentar esclerotizaciones puntuales de distintas formas (p. ej. Pawiloma Young). El segmento abdominal IX forma el pigóforo (Py), su forma en vista lateral, margen posterior y el patrón de setación son usados en taxonomía. El pigóforo encierra al ovipositor, cuyas funciones son cortar la epidermis de la hoja creando una cavidad para depositar el huevo, y servir de conducto para su desplazamiento desde el gonoporo hasta la cavidad en la hoja durante la oviposición. El ovipositor está formado por dos pares de valvas de origen apendicular: valvas I y valvas II, más las gonoplacas. En este estudio la terminología utilizada para la descripción de estas estructuras sigue a Nielson (1965) y Hill (1970), excepto por la tercer valva que aquí es tratada como gonoplaca siguiendo lo propuesto por Mejdalani (1998). La valva I (VLI) es alargada en vista lateral, estrechándose hacia el ápice; posee áreas esculturadas dorsal y ventral (AED, AEV), formadas por procesos tegumentarios de diferente forma y disposición. En la 
superficie lateral, se puede observar una estructura de acoplamiento (EAV) esclerotizada cuya longitud puede ser menor, igual o mayor que la longitud de la mitad basal del eje. La valva II (VLII) también es alargada en vista lateral, ensanchándose, o no, a partir de la curvatura basal; la forma del ápice y la presencia de una prominencia preapical (PP) puede variar y se utilizan para las descripciones en este estudio. La superficie dorsal de la VL II posee dientes (D), cuya forma varía, pudiendo ser redondeados, sub/triangulares o sub/cuadrangulares; cada diente puede llevar numerosos dentículos (de) pequeños a diminutos en alguno o todos sus márgenes. En la superficie lateral, se pueden observar estructuras esclerotizadas denominadas ramas (r) que pueden llegar hasta el ápice de la valva, y ductos (du) que pueden o no extenderse hasta los dientes y el ápice del eje. La gonoplaca (GP) es alargada y su ápice generalmente redondeado; su forma es constante entre las distintas especies de Cicadellini; puede llevar setas apicales, que pueden extenderse posteriormente hasta la porción basal del eje, acompañanadas por procesos espiniformes (pe), más concentrados en las porciones basal y apical, a veces a lo largo del margen ventral. El valvifer I (VFI) está ligado al margen basal de la VLI, es esclerotizado y su forma varía en las distintas especies. El valvifer II (VF II) generalmente es más esclerotizado que el VFI y se relaciona dorsalmente con la extremo proximal de rama de la VL II y ventralmente con la base de la GP en el punto de articulación (PA); generalmente, su forma no varía en las distintas especies; la superficie puede estar cubierta en mayor o menor extensión por pequeños procesos espiniformes y el área adyacente al punto de articulación con la GP, posee un grupo de microsetas robustas. 
A

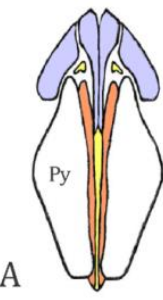

$\mathrm{B}$
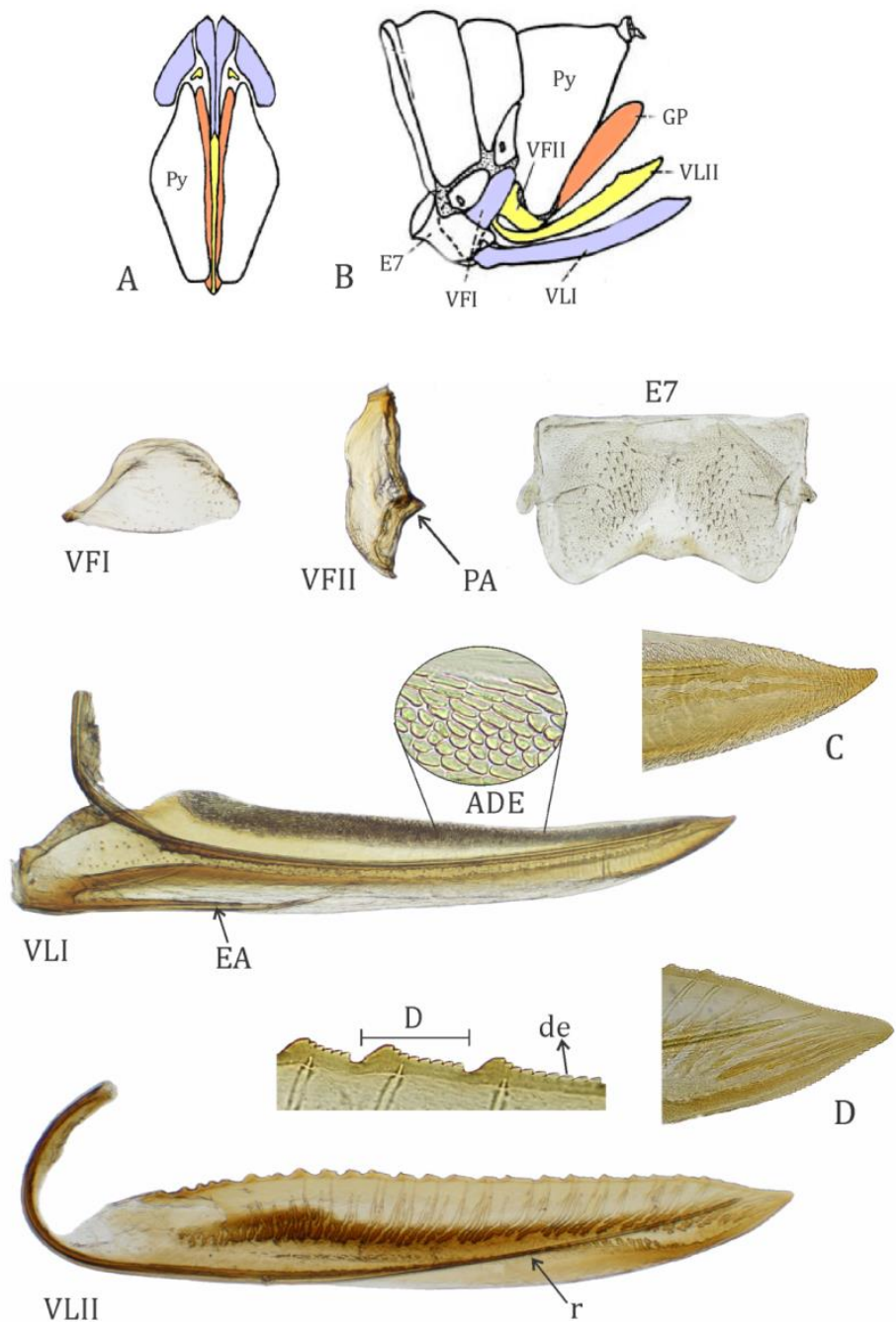

Figura 10. Morfología de la genitalia de la hembra de Cicadellini. Esquema general en vista lateral (A), esquema general en vista ventral sin esternito VII (B), detalle ápice valva I (C), detalle ápice valva II (D). Referencias: ADE, área dorsal esculturada; D, diente; de, dentículo; EA, estructura de acoplamiento; GP, gonoplaca; Py, pigóforo; r, rama; VFI, valvifer uno; VFII, valvifer dos; VLI, valva uno;VLII, valva dos. Esquema (A) adaptado de Hummel et al. (2006) y (B) de Kramer (1950).

\section{Biología}

Los Cicadellini se alimentan exclusivamente a partir de los vasos xilemáticos cuya savia está constituida por más de un $95 \%$ de agua y compuestos orgánicos e inorgánicos en muy bajas concentraciones. Debido al consumo de un recurso tan diluído, estos insectos adoptaron numerosas estrategias para afrontar esta dieta nutritivamente deficiente; por ejemplo, tienen tasas extremadamente altas de 
alimentación, pudiendo consumir hasta 100 veces su peso corporal por hora; establecen simbiosis permanentes con bacterias las cuales son una fuente adicional de algunos aminoácidos esenciales y vitaminas; poseen una adaptación morfológica en su sistema digestivo denominada cámara de filtro, la cuales permite eliminar el exceso de agua mientras se alimentan y de esta manera concentran los nutrientes para su absorción. Además, exhiben una extrema polifagia, es decir, se alimentan de un amplio rango de plantas hospedadoras con diferentes perfiles químicos que les permiten maximizar la obtención de nutrientes óptimos para su crecimiento y desarrollo (Andersen et al. 1989, Brodbeck et al. 1993, Mizell \& Andersen 2001, Morán et al. 1993, Sisterson et al. 2015, 2017, Thao et al. 2001, 2002, Tipping \& Mizell 2004).

A diferencia de los Proconiini, cuyo comportamiento de oviposición es muy variable, las hembras de la tribu Cicadellini insertan sus huevos en los tejidos vegetales ya sea de manera aislada a lo largo de las venas foliares o agrupados formando "clusters" como en el género Graphocephala (Hackman 1922). Excepto las hembras de los géneros Pamplona y Pamplonoidea, el resto luego de oviponer no espolvorea brocosomas sobre las posturas (Rakitov 2004).

En su desarrollo postembrionario, los Cicadellini, al igual que otros cicadélidos, poseen cinco estadios larvales que pueden ser diferenciados por el desarrollo de los esbozos alares en el tórax, la quetotaxia (Wilson \& Claridge 1991), la coloración, la cantidad de artejos en los metatarsos y la presencia o ausencia de ocelos (Marucci et al. 2000). El número de generaciones varía entre las especies, siendo en general de una o dos al año, excepcionalmente tres (Chu \& Teng 1950, Turner \& Pollard 1959). Tanto las posturas como los estadios larvales son más abundantes entre la primavera y el verano, transcurriendo el invierno principalmente en estado adulto. Los cicadelinos adultos se encuentran durante todo el año, siendo sus poblaciones más abundantes en primavera y verano (Almeida \& Lopes 1999, Coelho et al. 2008, Paiva et al. 2001, Tipping \& Mizell 2004, Turner \& Pollard 1959).

El escaso conocimiento de las especies de Cicadellini, un grupo fitosanitariamente importante para el sector citrícola, en áreas productoras de la Argentina, impulsó el objetivo general de éste trabajo de tesis: "Conocer la taxocenosis de la tribu Cicadellini, particularmente el complejo de especies potencialmente vectoras, en agroecosistemas frutícolas del norte y centro de la Argentina". Los objetivos 
específicos planteados en este capítulo fueron: 1) abordar bajo el aspecto taxonómico los géneros y especies, aportando nuevos caracteres cuando fuera posible, 2) describir las estructuras diagnósticas de la genitalia de la hembra, 3) aportar nuevos datos y reunir los ya conocidos sobre la distribución geográfica, plantas hospedadoras, biología, importancia fitosanitaria y enemigos naturales de cada una de las especies estudiadas y 4) generar una clave de identificación que reúna a los géneros asociadas a cultivos frutícolas, particularmente citrícolas, presentes en las principales áreas productoras del NEA Y NOA.

\section{MATERIALES Y MÉTODOS}

\section{Material estudiado}

\section{De colecciones nacionales e internacionales, y cedido por investigadores}

El material estudiado corresponde a los ejemplares de colección general y material tipo de la tribu Cicadellini depositados en las siguientes instituciones:

> Fundación Miguel Lillo, San Miguel de Tucumán, Tucumán, Argentina (IFML).

$>$ Museo Argentino de Ciencias Naturales "Bernardino Rivadavia", Ciudad de Buenos Aires, Argentina (MACN).

$>$ Museo de La Plata, La Plata, Buenos Aires, Argentina (MLP).

$>$ Museo Nacional de Historia Natural del Smithsonian Institution, Washington DC, USA (USNM).

$>$ Colección de la Universidad de Kansas, Lawrence, Kansas (KU).

Asimismo, fueron estudiados ejemplares de distintas especies cedidos por el Dr. Alejandro Sosa (FUEDEI), el Dr. Eduardo Virla (Fundación Miguel Lillo-PROIMI). Diversos especímenes fueron enviados desde Estaciones Experimentales Agropecuarias del INTA de Entre Ríos, Concordia por el Dr. Juan Pedro Bouvet, del INTA Famaillá, Tucumán por la Ing. Noemí Carrizo, del INTA Yuto, Jujuy por la Ing. Silvia Tapia y del INTA Chilecito, La Rioja por la Ing. Andrea Calahorra.

También se utilizaron ejemplares recolectados en la provincia de Misiones por el Dr. Mariano Lucia, Dr. Leopoldo Álvarez, Dr. Daniel Aquino y el Dr. Fernando Zamudio. 


\section{Recolectado}

Se estudiaron ejemplares recolectados por el doctorando durante diferentes viajes de campaña realizados entre los años 2013-2016 en áreas naturales de diferentes provincias del norte de la Argentina: Jujuy, Tucumán, Formosa (Parque Nacional Río Pilcomayo), Misiones (Parque Nacional Iguazú) y Corrientes (Parque Nacional Mburucuyá). También se contó con especímenes aportados por proyectos en los que el doctorando interviene como colaborador (Bases para el manejo racional de la Clorosis Variegada de los Cítricos: relevamiento de potenciales vectores (Hemiptera: Cicadellidae) en agroecosistemas citrícolas del NOA y NEA, y selección de parasitoides oófilos para su control biológico. Cod: PICT 2014-0607-E1; Biodiversidad de auquenorrincos potenciales vectores de patógenos (Hemiptera: Cicadellidae: Cicadellinae) asociados a agroecosistemas citrícolas del NEA. Estudios taxonómicos y bioecológicos. Cod: 11/N723 UNLP). Los muestreos fueron realizados principalmente en primavera-verano ya que en esa época las poblaciones son más numerosas. Estos materiales fueron depositados en la Colección Entomológica del Museo de La Plata.

\section{Preparación de los especímenes}

Los ejemplares fueron observados con microscopio estereoscópico. La longitud del cuerpo fue medida desde el margen anterior de la corona hasta el extremo posterior del abdomen. A cada espécimen se le seccionó el abdomen con agujas entomológicas y se colocó en un vaso de precipitado con hidróxido de potasio 10\%caliente durante 5-7 minutos para aclararlo; los ejemplares hembra fueron aclarados utilizando hidróxido de potasio 10\% frío durante 24 hs. Posteriormente se lavó con agua destilada y se sumergió en una gota de glicerina sobre un portaobjeto excavado para observar las estructuras genitales bajo microscopio binocular.

Los géneros fueron identificados utilizando las claves y descripciones de Young (1977).

En los ejemplares macho, las estructuras genitales fueron utilizadas para la identificación de especies siguiendo las claves y descripciones preexistentes: Signoret (1853, 1854, 1855), Stål (1869), Melichar (1924, 1925, 1926), Schröder (1959) y Young (1977), entre otras. En los ejemplares hembra, se estudiaron y describieron los caracteres de las estructuras genitales, siguiendo los trabajos de Mejdalani (1995, 1998). Estas estructuras fueron montadas entre porta y cubreobjetos y fueron 
fotografiadas bajo microscopio estereoscópico y microscopio triocular. A partir de las fotografías tomadas se confeccionaron las figuras descriptivas de cada especie considerando el esternito abdominal VII en vista ventral, el esternito abdominal VIII en vista caudal, el pigóforo, los valvíferes I y II, las valvas I y II y la gonoplaca en vista lateral. Las estructuras fueron orientadas de la siguiente manera:

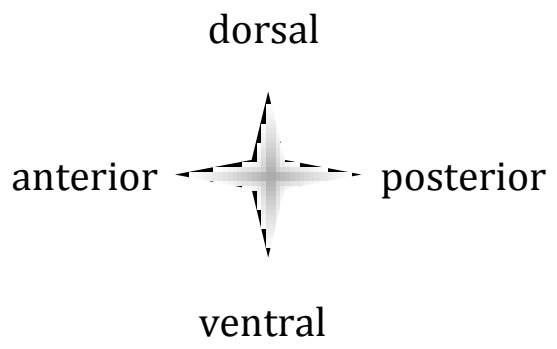

Para cada género se reproducen las redescripciones realizadas por Young (1977) excepto para los géneros Balacha, Draeculacephala y Oragua para los cuales se consideraron las revisiones realizadas por Takiya \& Mejadalani (2004), Dietrich (1994) y Camisao et al. (2008), respectivamente.

La información de las especies estudiadas de cada género se organizó de la siguiente manera: sinonimia, diagnosis, observaciones taxonómicas, distribución geográfica, plantas hospedadoras, datos biológicos, enemigos naturales, importancia fitosanitaria, en todos los casos se reunió la información conocida desde la bibliografía y en otras se aportaron nuevos registros, por último se resaltó el material estudiado. Para las diagnosis se consideraron caracteres diagnósticos ya conocidos, donde se indica el autor entre paréntesis y en muchos otros casos se propusieron nuevos caracteres. Las descripciones de la genitalia de la hembra solo están consideradas cuando corresponden a nuevos aportes para la especie estudiada. Se confeccionó una clave para el reconocimiento de los géneros y de las especies presentes en la Argentina. Para cada especie se incluyen un mapa de distribución, fotografías del hábito dorsal del adulto, como así también las estructuras diagnósticas de la genitalia de la hembra descriptas. El material estudiado está ordenado según la colección entomológica de procedencia (IFML, MACN, MLP, etc.); en el caso del material recolectado aún no ingresado a la colección del MLP, se indica (UNLP). 


\section{Distribución geográfica}

Para confeccionar los mapas de distribución geográfica se utilizó el programa Simple Maps. En cada mapa, los puntos de distinto color corresponden a cada una de las especies estudiadas; los puntos de color negro hacen referencia a la presencia de una o más especies del mismo género en la provincia marcada. 


\section{RESULTADOS}

\section{Tribu CICADELLINI Van Duzee}

Cicadellini Van Duzee 1916: 65 (Género tipo: Cicadella Latreille)

Draeculacephalini Metcalf \& Bruner 193: 916

Graphocephalini Metcalf 1955: 264

Helocharini Metcalf 1965: 356

Neokollini Metcalf 1965: 265

Diagnosis. Tamaño pequeño a grande $(3,4-19 \mathrm{~mm})$. Cabeza con los puentes antenales ligeramente protuberantes en vista dorsal; clípeo usualmente glabro. Articulación fémoro-tibial de las patas posteriores en reposo alcanzando el margen posterior del proepímero; fémures aplanados en sección transversal. Pigóforo y placas subgenitales del macho con macrosetas (Young 1977).

Distribución. Cosmopolita

Observaciones taxonómicas. Los Cicadellini son un grupo intrincado cuya morfología sugiere una rápida radiación por lo cual es más frecuente encontrar discontinuidades morfológicas pequeñas.

En agroecosistemas citrícolas del norte de la Argentina la tribu Cicadellini está representada por 18 géneros (37 especies). 


\section{Género Balacha Melichar}

Especie tipo: Tettigonia melanocephala Signoret 1854: 27 (Por designación subsecuente de China 1938:184).

Longitud 6,1-9,5 mm.

Cabeza. Corona moderada a fuertemente proyectada anteriormente, longitud media de la corona 0,6-0,9x el ancho interocular; margen anterior, en vista dorsal, estrechamente redondeado a subanguloso; ocelos sobre o detrás de la línea que pasa entre los ángulos anteriores de los ojos. Superficie de la corona glabra, sin esculturaciones. Suturas clipeales laterales extendiéndose sobre la corona y alcanzando los ocelos. Puentes antenales,en vista dorsal,no protuberantes; con el margen anterior, en vista lateral, rectilíneo y ligeramente oblicuo. Transición coronaclípeo redondeada. Clípeo, en vista lateral, aplanado, disco finamente granulado; impresiones musculares débilmentemarcadas; sutura transclipeal completa o incompleta. Clipelo no protuberante, contorno de la porción inferior, en vista lateral, formando un ángulo con el resto de la superficie.

Tórax. Ancho del pronoto menor que el ancho transocular, márgenes laterales paralelos y margen posterior fuertemente cóncavo a transverso; carena dorsopleural, en vista lateral, completa o incompleta; superficie de laporción posterior deldisco glabra,con rugosidades o finamente estriada, o también no esculturada. Mesonoto mayormente sin esculturaciones, usualmente con estrías transversales finas luego del surco transversal. Alas anteriores coriáceas, no esculturadas, con o sin porción membranosa; venas usualmente no marcadas; con cinco celdas apicales, base de la tercera más apical que la base de las restantes. En las hembras, las alas en reposo ocultan, o no, el ovipositor. Fórmula setal del fémur posterior 2:1:0 o 2:1:1; longitud del primer tarsómero mayor que la longitud combinada del segundo y tercer tarsómeros; superficie plantar con dos hilerasde setas pequeñas paralelas, la hilera externa puede presentar setas con forma de clavija.

Genitalia del macho. Pigóforo moderadamente proyectado posteriormente, estrechándose posteriormente, con el margen posterior estrecho a ampliamente redondeado, disposición de las macrosetas en el disco variable. Valva transversa, más ancha que larga; márgenes anterior y posterior paralelos, margen anterior con una 
concavidad o ambos márgenes con una constricción de posición media. Placas subgenitales estrechas, triangulares; fusionadas basalmente, a veces unidas por membrana lo que les da la apariencia de estar fusionadas; apicalmente redondeadas;usualmente se extienden posteriormente hasta el ápice del pigóforo; macro- y microsetas distribuidas de manera variable sobre la superficie ventral. Estilos sobrepasando ampliamente el ápice del conectivo,ápice redondeado o truncado;sin lóbulo preapical. Conectivo lineal (barra transversa) o triangular, con o sin una quilla de posición media. Edeago simétrico, eje cilíndrico, estrecho y curvado en su base $180^{\circ}$; dorsalmente, con o sin hileras de procesos tegumentarios dentiformes; con un par de procesos apicales. Paráfisis presentes o ausentes.

Genitalia de la hembra. Esternito abdominal VII, en vista ventral, variable entre especies; margen anterior recto o proyectado anteriormente, con o sin un pliegue longitudinal mediano; margen posterior ampliamente redondeado,con una concavidad superficial o profunda en su porción media y un par de concavidades laterales a la porción media. Esternito abdominal VIII no esclerotizado o, cuando presente, formando una placa dorsal con el margen posterior ampliamente cóncavo. Pigóforo, en vista lateral, corto a fuertemente proyectado posteriormente; margen posterior estrechamente redondeado o angostándose hacia el ápice agudo; con algunas macrosetas distribuidas a lo largo del margen posteroventral. Segunda valva, en vista lateral, eje ensanchadomás allá del tercio basal; eje regularmente ensanchado a ligeramente aguzado hacia el ápice. Con dientes continuos a lo largo de la porción ensanchada, cada diente con la mitad anterior proyectada dorsalmente y la mitad posterior regularmente alta llevando dentículos en toda su longitud; márgenes dorsal y ventral de la porción preapical denticulados, con la prominencia preapical ligeramente marcada. Ápice estrechamente redondeado. Gonoplacas con el ápice agudo a ampliamente redondeado.

Coloración. Coloración general de la cabeza y el tórax negra, a veces con máculas pálidas, anaranjadas o rojizas en la corona y bandas o máculas, rojizas, anaranjadas o blancas, en el pronoto.

Observaciones taxonómicas. El género Balacha fue recientemente estudiado por Takiya \& Mejdalani (2004), quienes lo distinguen del resto de los géneros de Cicadellini por la siguiente combinación de caracteres: corona proyectada 
anteriormente con el margen anterior subanguloso; transición corona-clípeo formando un ángulo agudo; superficie dorsal del pronoto, en vista lateral, aplanada continuando con el contorno de la cabeza y el mesonoto; margen anterior de los dientes de la segunda valva con una proyección anterodorsal. Estos autores lo relacionan al género Cavichia (Takiya, Cavichioli \& Mejdalani) y descartan lo propuesto previamente por Young (1977) quien lo relacionaba con los géneros Pegogonia Young, Sivobia China y Pawiloma Young.

Distribución. Sudamericana, con registros en Argentina, Brasil, Paraguay y Uruguay (Takiya \& Mejdalani 2004).

Datos biológicos. Aparentemente, todas las especies de Balacha viven en el interior de la roseta que forman las hojas del género Eryngium L. (Apiaceae). Es un comportamiento particularmente raro ya que los miembros de Cicadellinae son mayormente generalistas alimentándose de diversos géneros de plantas (Basset \& Charles 2000, Nielson \& Knight 2000, Novotny \& Wilson 1997). Todas la especies previamente descriptas por Cavichioli \& Sakakibara (1988) y Takiya \& Mejdalani (2004) en Brasil, fueron colectadas en diferentes especies de Eryngium.

El género Balacha cuenta con siete especies descriptas de las cuales una está presente en la Argentina.

\section{Balacha melanocephala (Signoret) (Figura 11)}

Tettigonia melanocephala Signoret 1854: 341 [n. sp.]

Diagnosis. Especímenes grandes, longitud: ㅅํ 7ㄱ 7,6-8,0 mm, 우 9,2-9,5 mm. Cabeza con la corona fuertemente proyectada anteriormente, margen anterior subanguloso en vista dorsal. Alas anteriores sin porción membranosa. Coloración general negra; pronoto generalmente con una banda transversal blanquecina en la mitad posterior (completamente negro en algunos especímenes). Tegmen con cuatro bandas transversas blanquecinas: la más basal transcomisural, la siguiente se origina en el margen costal y alcanza la sutura claval, la tercera es transcomisuralatravesando 
el ápice claval y las más apical originándose en el margen costal y alcanzando la mitad de la celda anteapical, o más corta. Pigóforo del macho con macrosetas distribuidas principalmente sobre el margenposterodorsal; placas subgenitales con macrosetas cortas (más cortas que la mitad del ancho basal de la placa). Esternito abdominal VII de la hembra con una proyección posterior ampliamente redondeada en la porción media del margen posterior (Takiya \& Mejadalani 2004).

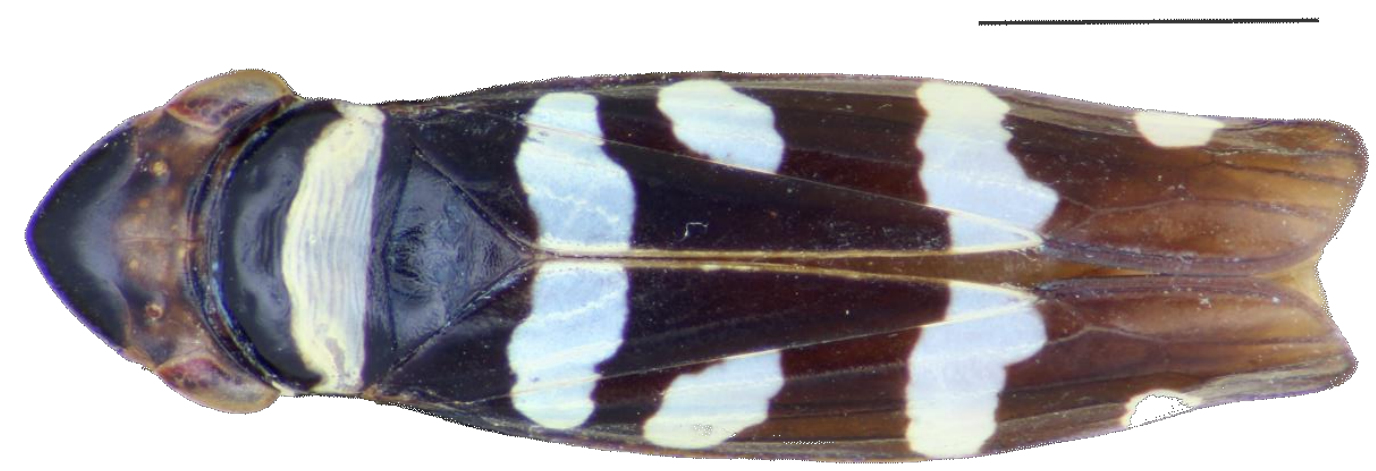

Figura 11. Hábito dorsal de Balacha melanocephala (Signoret). Escala $2 \mathrm{~mm}$.

Observaciones taxonómicas. Balacha melanocephala está cercanamente relacionada a B. Similis Cavichioli \& Sakakibara, de la cual se diferencia por su mayor tamaño, por la distribución de las macrosetas en el pigóforo del macho y por la forma del margen posterior del esternito abdominal VII de las hembras (Takiya \& Mejdalani 2004).

Distribución. Argentina, Brasil, Paraguay yUruguay. Registros de Colombia dudosos (Takiya \& Mejdalani 2004). En la Argentina está registrada para las provincias de Entre Ríos (Dellapé et al. 2016) y Buenos Aires (Takiya \& Mejdalani 2004). Se amplía la distribución para Misiones (Santa Inés), Corrientes (Colonia Pellegrini, Santo Tomé) y Santa Fé (Guadalupe, Silva) (Figura 12).

Plantas hospedadoras. Eryngium L. (Apiaceae) (Takiya \& Mejdalani 2004).

Enemigos naturales. Desconocidos. 
Datos biológicos. Desconocidos

Importancia fitosanitaria. Desconocida.

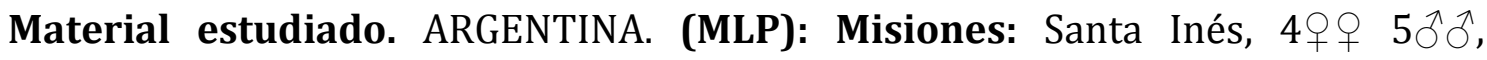
24/XII/1957, M. Birabén col. Corrientes: Colonia Pellegrini, 2 q $+1 \delta$, 12/XI/1962, Birabén-Bezzi cols.; Santo Tomé, $3 q+$, 27/XII/1952, M. Birabén col. Santa Fé:

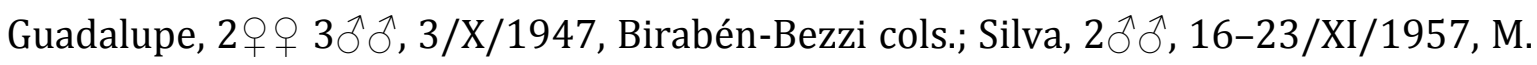
Birabén.

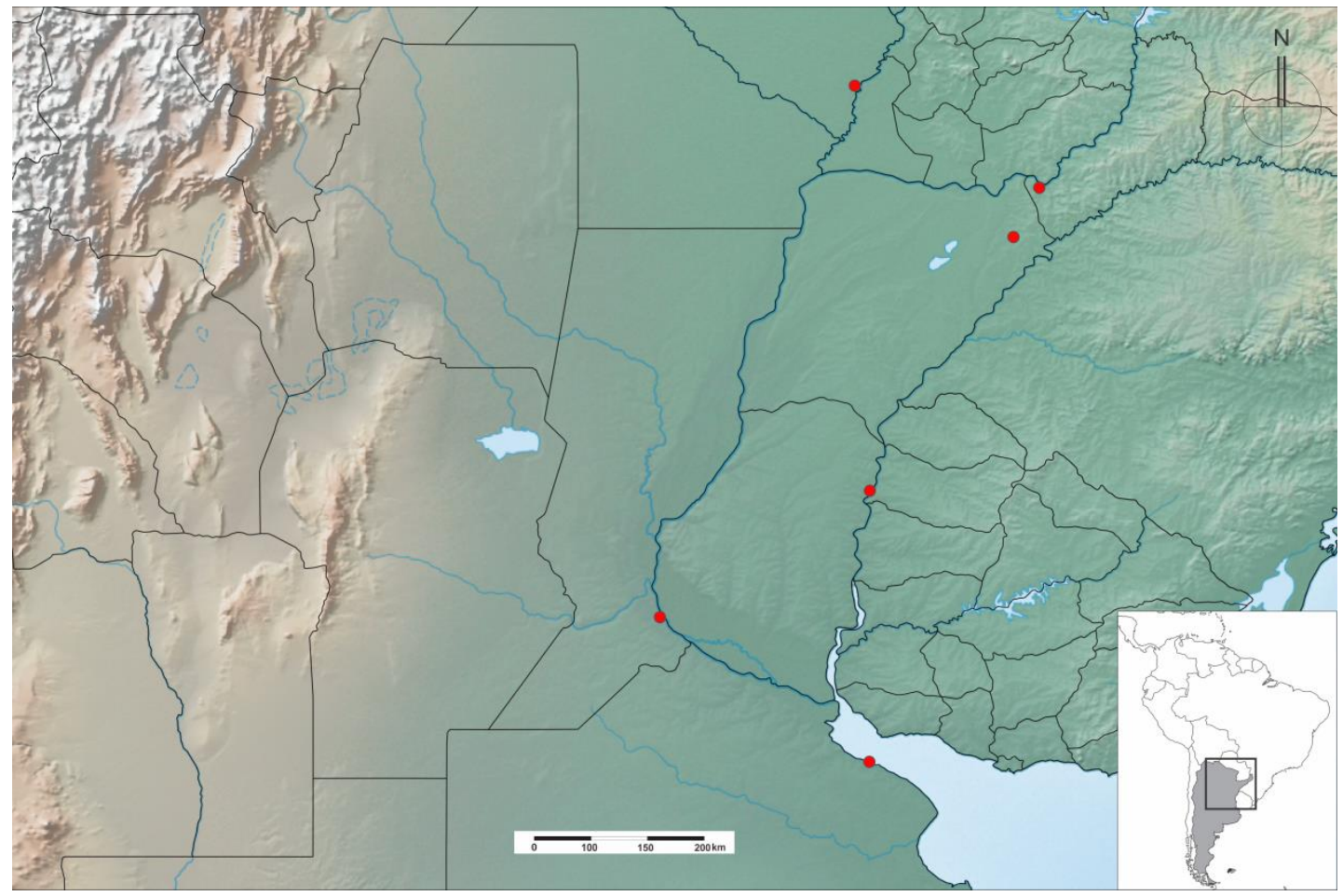

Figura 12. Registros de Balacha melanocephala (Signoret) en Argentina. 


\section{Género Borogonalia Young}

Especie tipo: Tettigonia impressifrons Signoret 1854: 16 (Por designación original).

Longitud total 4,4-6,8 $\mathrm{mm}$.

Cabeza. Corona corta, longitud media aproximadamente $0,5-0,7 \mathrm{x}$ el ancho interocular; margen anterior, en vista dorsal, ampliamente redondeado; ocelos sobre la línea que pasa entre los ángulos anteriores de los ojos o ligeramente por detrás. Superficie de la corona con una concavidad transversal anterior a los ocelos desde donde comienza un área cóncava de posición media que se extiende hasta el margen posterior de la cabeza. Superficie del disco de la corona glabro, no esculturado. Suturas clipeales laterales extendiéndose sobre la corona, sin alcanzar los ocelos. Puentes antenales, en vista dorsal, no protuberantes, con el margen anterior, en vista lateral, oblicuo y frecuentemente convexo. Transición corona-clípeo redondeada. Clípeo ligeramente convexo en su porción media; impresiones musculares débilmente marcadas, usualmente oscuras. Contorno del clipelo en continuidad con el perfil del clípeo.

Tórax. Ancho del pronoto menor que el ancho transocular, márgenes laterales paralelos; carena dorsopleural completa; superficie del disco glabro, débilmente, o no, esculturado. Superficie del escutelo por detrás del surco transversal sin estriaciones transversales. Alas anteriores con la porción membranosa delimitada de forma difusa (algunos especímenes con la porción basal de las celdas apicales 2, 3 y 4 opaca) celda apical interna siempre membranosa; venas débilmente marcadas, no elevadas; con tres celdas anteapicales cerradas, cuyas bases se localizan próximas a una línea imaginaria que atraviesa el ápice claval del ala; con cuatro celdas apicales, la base de la cuarta más proximal que la base de la tercera. En las hembras, las alas en reposo ocultan el ovipositor. Fórmula setal del fémur posterior 2:1:1; longitud del primer tarsómero mayor a la longitud combinada del segundo y tercer tarsómeros; superficie plantar usualmente con dos hileras paralelas de setas.

Genitalia del macho. Pigóforo fuertemente proyectado posteriormente, ápice convexo, con numerosas macrosetas de longitud variable sobre el tercio apical que se sobre los márgenes antero- y postero-ventrales; con microsetas en la superficie anteroventral, sin procesos. Placas subgenitales triangulares, con numerosas 
microsetas largas, macrosetas ausentes, o cuando presentes, dispuestas irregularmente. Estilos alargados, extendiéndose más allá del ápice del conectivo, ligeramente curvados y con el ápice truncado; sin lóbulo preapical. Edeago corto, con cuatro lóbulos apicales, sin procesos. Paráfisis variable entre las especies, formada por una base alargada, furcada en la mitad apical con las ramas de longitud variable, toda la estructura asimétrica tanto en la forma como en la posición.

Genitalia de la hembra. Esternito abdominal VII, en vista ventral, margen posterior moderada- a fuertemente proyectado medialmente, con el ápice anguloso, redondeado o ligeramente emarginado. Esternito abdominal VIII membranoso. Pigóforo moderadamente proyectado, con el ápice redondeado, con macrosetas sobre la mitad posterior. Ovipositor con la porción del margen dorsal dentada de extensión variable entre las especies, cada diente de forma cuadrangular llevando numerosos dentículos; ápice agudo, con los márgenes dorsal y ventral anteapicales denticulados.

Coloración. Corona, pronoto (excepto el disco), escutelo y frente de color verdoso amarillento; disco pronotal y tegmen verde oscuro. La corona, el escutelo y frecuentemente la frente con máculas de color negro.

Observaciones taxonómicas. Este género se asemeja externamente a Tortigonalia Young del cual se diferencia por las microsetas largas y finas de las placas subgenitales del macho.

Distribución. Sudamericana con registros en Brasil, Bolivia, Colombia, Ecuador y Perú (Young 1977). Se cita por primera vez para la Argentina.

Otros datos. Según Young (1977), Borogonalia es un género de importancia económica debido a que numerosos ejemplares de B. impressifrons (Signoret) fueron recolectados sobre alfalfa, poroto, zanahoria, maíz, papa, remolacha y frutilla en Colombia.

El género Borogonalia cuenta con tres especies descriptas. Los especímenes recolectados en la vegetación asociada a agroecosistemas citrícolas de la provincia de Salta (Yatasto) se encuentran actualmente en estudio ya que sus caracteres no se corresponden con los de las especies descriptas hasta el momento. 


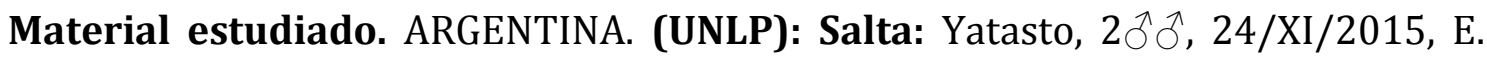
Virla col.; 3웅 1ð, 8/II-17/II/2017, E. Virla col. 


\section{Género Bucephalogonia Melichar}

Especie tipo: Tettigonia xanthophis Berg 1879: 249 (Por monotipia)

Longitud total 4,5-5,8 $\mathrm{mm}$.

Cabeza. Cabeza moderadamente proyectada, longitud media de la corona $0,4-0,5 \mathrm{x}$ el ancho interocular; margen anterior, en vista dorsal, ampliamente redondeado, superficie glabra, no esculpturada; ocelos localizados ligeramente por delante de la línea que pasa entre los ángulos anteriores de los ojos; superficie de la corona convexa con, o sin, una concavidad transversa débilmente marcada. Suturas clipeales laterales extendiéndose sobre la corona y alcanzando los ocelos. Puentes antenales, en vista lateral, con el margen anterior convexo y oblicuo. Clípeo convexo, con impresiones musculares distintivas; sutura transclipeal incompleta; contorno del clipelo, en vista lateral, en continuidad con el perfil del clípeo.

Tórax. Ancho del pronoto menor que el ancho transocular, márgenes laterales paralelos y el margen posterior ligeramente cóncavo; carena dorsopleural, en vista lateral, oblicua y completa; disco con, o sin, rugosidades transversales; superficie del escutelo por detrás del surco transversal usualmente con estrías transversales. Alas anteriores coriáceas en la porción basal con la membrana apical bruscamente delimitada y de extensión variable: incluyendo las celdas apicales y el área costal contigua en algunos especímenes, mitad apical completamente membranosa en otros, o de extensión intermedia; venas marcadas, no elevadas; con cuatro celdas apicales, la base de la cuarta más proximal que la base de la tercera, sin plexo anteapical. En las hembras, las alas en reposo ocultan el ovipositor. La articulación fémoro-tibial de la pata posterior en posición de descanso frecuentemente no alcanzando el margen posterior del proepímero (Fig. 13C); fórmula setal del fémur posterior 2:1:0 (ocasionalmente 2:1:1); longitud del primer tarsómero casi tan largo como la longitud combinada del segundo y el tercer tarsómeros.

Abdomen del macho con un par de apodemas basiventrales robustos.

Genitalia del macho. Pigóforo moderadamente proyectado, con el ápice truncado, con algunas macrosetas sobre el disco y cerca del ápice, con numerosas microsetas 
submarginales a lo largo del margen ventral. Placas subgenitales alargadas de forma subtriangular, que se extienden más allá del ápice del pigóforo, superficie con macrosetas dispuestas en hileras múltiples. Estilos sobrepasando el ápice del conectivo, apicalmente redondeados; sin lóbulo preapical. Conectivo en forma de "T", con el eje más corto que las ramas laterales. Edeago muy corto con la mitad apical curvada dorsalmente, sin procesos. Paráfisis ausentes.

Genitalia de la hembra. Esternito abdominal VII (Fig. 14A), en vista ventral, margen posterior con un lóbulo medio, apicalmente subanguloso (con lóbulos laterales no distintivos en especímenes no macerados). Esternito abdominal VIII membranoso, sin esclerotizaciones puntuales. Pigóforo (Fig. 14B) con numerosas macro- y microsetas sobre el disco, con algunas macrosetas agrupadas cerca al margen posterodorsal. Valva II (Fig. 14I) del ovipositor con numerosos dientes, que llevan dentículos, a lo largo del margen dorsal luego de la curvatura basal hasta el ápice; márgenes preapicales dorsal y ventral con denticulados. Caracteres nuevos: Valvifer I (Fig. 14C), en vista lateral, subtriangular con el margen anterodorsal más esclerotizado; margen dorsal con un pliegue interno; superficie de la mitad apical densamente cubierta por procesos tegumentarios espiniformes. Valva I (Fig. 14E), en vista lateral, lanceolada; porción basal con un lóbulo dorsal y la superficie ventral cubierta por numerosos procesos tegumentarios espiniformes (Fig. 14F); AED (Fig. 14F) cubriendo los tres cuartos apicales del eje, formada por procesos tegumentarios filiformes con el margen anterior dentado, dispuestos en líneas oblicuas; AEV restringido a la superficie preapical del eje formada por procesos escamiformes no imbricados. EVA larga, visible hasta casi la mitad basal del eje. Margen preapical vetral denticulado, ápice agudo (Fig. 14H). Valvifer II (Fig. 14D), en vista lateral, de forma y aspecto típicos de la tribu. Valva II (Fig. 14I), en vista lateral, abruptamente más amplia luego de la curvatura basal, con el margen dorsal del eje ligeramente recto, llevando numerosos dientes continuos; cada diente (Fig. 14J) subtriangular con el margen posterior en declive y más extenso que el margen anterior, ambos con pequeños dentículos subtriangulares. Ductos poco desarrollados, mayormente alcanzan los dientes y el ápice. Porción preapical con los márgenes dorsal y ventral denticulados, ápice agudo (Fig. 14K); ventralmente sin prominencia preapical. Gonoplacas (Fig. 14M), en vista lateral, porción anterior estrecha, 0,5x más extensa 
que la porción posterior, la cual es marcadamente expandida; con macrosetas submarginales a lo largo del eje anteroposterior; ápice redondeado.

Coloración. Especímenes de coloración muy variable (Figura 13). Tegumento de la corona desde fuertemente marcado con negro a amarillento y sin marcas. La porción coriácea del tegmen puede variar en extensión y color, de verde a casi negra, pasando por castaño-rojiza.

Distribución. Sudamericana con registros en la Argentina, Bolivia, Brasil, Paraguay y Perú (Wilson et al. 2009, Young 1977).

El género Bucephalogonia incluye sólo una especie, B. xanthophis, que se encuentra presente en la Argentina.

\section{Bucephalogonia xanthophis (Berg) (Figura 13-14)}

Tettigonia xanthophis Berg 1879: 249 [n. sp.]

Tettigonia guaranitica Berg 1884: 24 [n. syn]

Metascarta guaranitica Metcalf 1965: 197 [n. Comb.]

Bucephalogonia xanthophis Young 1977: 1094 [n. syn.]

Bucephalogonia xanthophis Young 1977: 1094

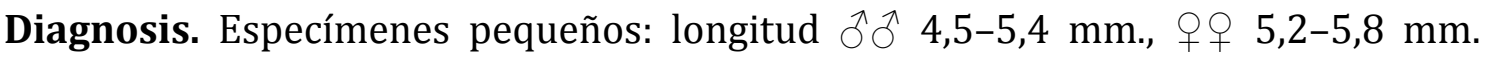
Pigóforo del macho y de la hembra corto, apicalmente truncados; eje aedeagal corto, curvado dorsalmente en su mitad apical, sin procesos. Esternito abdominal VII de la hembra con una proyección subangulosa en su porción media (Young 1977).

Distribución. Sudamericana con registros en Argentina, Bolivia, Brasil, Paraguay y Perú (Young 1977). En la Argentina está presente en las provincias de Jujuy, Córdoba, Misiones (Remes Lenicov et al. 1999), Corrientes (Beltrán et al. 2004), Entre Ríos (Dellapé 2013), Santa Fé y Buenos Aires (Paradell et al. 2014a). Se amplía la distribución para las provincias de Formosa (Laguna Oca), Salta (Los Sauces, Orán, Quebrada Río Las Conchas, Tartagal), Tucumán (Río Punco, Trancas), Santiago del Estero (Loreto), Chaco (Chilecito, Colonia Brandsen, Makallé, 
Presidencia de la Plata, Resistencia, Roque Saenz Peña), Catamarca (Andalgalá, Belén, El Rodeo, San Antonio), La Rioja (Anillaco, Famatina, Sañogasta), San Luis (Concarán, Santa Rosa), San Juan y Mendoza (San Martín) (Figura 15).

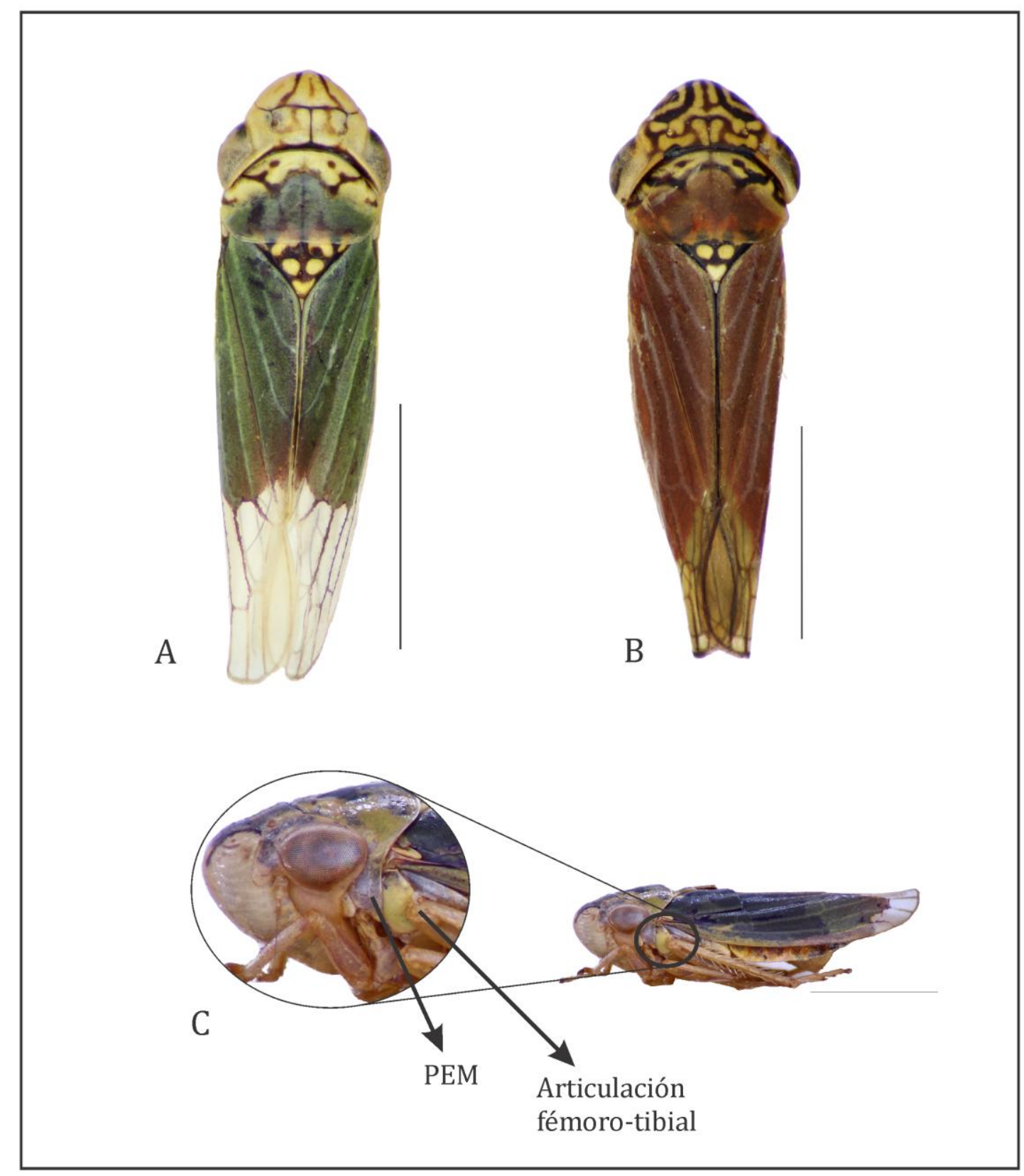

Figura 13. Bucephalogonia xanthophis (Berg): Hábito dorsal, patrones de coloración presentes en Argentina (A, B); posición de la articulación fémorotibial respecto al proepímero (PEM), en vista lateral (C). Escalas A-C: $2 \mathrm{~mm}$. 
Plantas hospedadoras. Citrus sinensis Osb. (Rutaceae) (Remes Lenicov et al. 1999), Vitis vinifera L. (Vitaceae) (Ringenberg 2008), Prunus domestica L. (Rosaceae) (Hickel et al. 2001), Coffea sp. (Rubiaceae) (Garita Cambronero et al. 2008), Vernonia condensata (Baker) (Asteraceae), Duranta repens L. (Verbenaceae) (Marucci et al. 2003), Brassica napus L. var. oleifera (Paris et al. 2012) (Brassicaceae). Se registran por primera vez los siguientes hospedadores: Allium cepa L. "cebolla" (Amaryllidaceae), Olea europaea L. var Arauco "olivo" (Oleaceae), Solanum tuberosum L. “papa” (Solanaceae), Tecoma stans (L.) “guarán” (Bignoniaceae), Gossypium sp. “algodón” (Malvaceae) y Baccharis sp. (Asteraceae). 


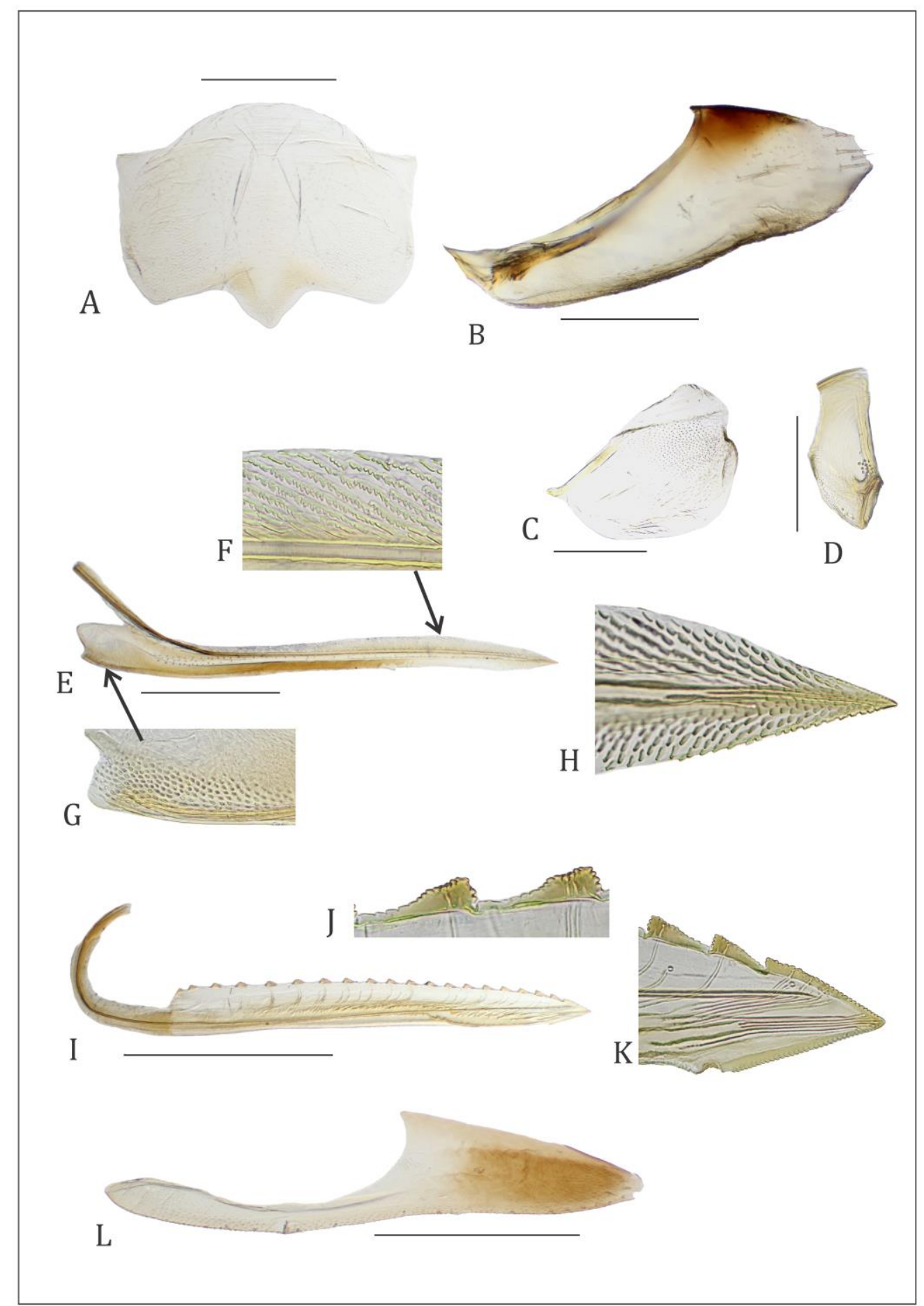

Figura 14. Genitalia de la hembra de Bucephalogonia xanthophis (Berg). Esternito VII (A), Pigóforo (B), valvifer I (C), valvifer II (D), valva I (E), detalle AED de la valva I (F), detalle de la esculturación basal de la valva I (G), ápice de la valva I $(\mathrm{H})$, valva II (I), detalle dientes valva II (J), ápice de la valva II (K), gonoplaca (M). Escalas 0,5 mm: A, B, E, I, L; 0,3 mm: C, D. 
Datos biológicos. En Misiones, B. xanthophis es una especie predominante sobre los cítricos, aunque también está presente en la vegetación espontánea durante todo el año con un pico de máxima densidad a fines del otoño-invierno (Remes Lenicov et al. 1999). En Entre Ríos, es una especie predominante en plantaciones de naranja Valencia, registrándose dos picos de mayor densidad, uno en invierno y otro en verano, coincidentes con los períodos de brotación de la plantas (Dellapé et al. 2016). A diferencia de lo que ocurre con esta especie en Misisiones y Entre Ríos, en Corrientes, B. xanthophis no es predominante aunque es capturada con frecuencia sobre los cítricos y su presencia fue casi nula en la vegetación asociada al cultivo (Capítulo III).

Importancia fitosanitaria. Esta especie es vector confirmado en Brasil de la bacteria Xylella fastidiosa subsp. pauca, agente causal de la CVC, en donde, es una especie muy abundante en plantaciones en formación y en la vegetación asociada al cultivo; es considerada la de mayor importancia en cuanto a su capacidad de transmisión a las plantas (Fundecitrus 1999). También, es referida como especie potencialmente vectora en café (Leite \& Nunes 2003). En la Argentina, estudios de detección de $X$. fastidiosa realizados con ejemplares recolectados en Misiones y Entre Ríos resultaron positivos (de Coll et al. 2000, Dellapé et al. 2016).

Material estudiado. Sintipo de Tettigonia guaranitica Berg, especie sinonimizada con B. xanthophis por Young (1977): 1 s/abdomen, Chaco, Spegazzini col., (MLP). ARGENTINA: (MLP): Salta: km 56, 1 s/abd., 14/III/1939, Birabén-Scott cols. Jujuy: $1{ }^{\lambda}$, s/papa, Bruch; Frayle Pintado, 1 ㅇ $1 \delta^{\Uparrow}$ 1s/abd., 28/VII/1945, s/papa, Torres-De Santis cols. Tucumán: Río Punco, $3 \widehat{\jmath}$, 20/III/1939, Birabén-Scott cols. Santiago del Estero: Loreto, 1§, 19/XII/1939, CMAM col. Catamarca: Andalgalá, 1§̂, 3/III/1939, Birabén-Scott cols.; El Rodeo, 19 1§, 3/III/1962, Torres-Ferreyra cols. La Rioja: Sañogasta, 1ㅇ, 24/II/1939, Birabén-Scott cols.; “Entre Peñas y Pinchas”, 1§ิ, 26/II/1939, Birabén-Scott cols.; Anillaco, 1ðત, 27/II/1939, Birabén-Scott cols.; Famatina, $9 ð 33$ ㅇ 1 s/abd., 22/II/1959, Torres-Gardella cols. Formosa: Laguna Oca,

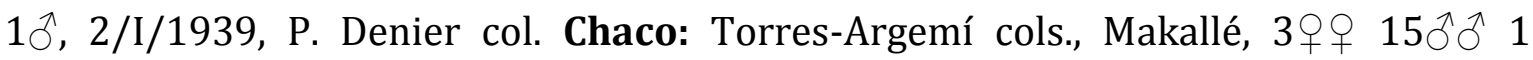


s/abd., 13-14/I/1954, s/algodón, Roque Saenz Peña, 9o+ 7ðð, 14/I/1954 s/algodón, Presidencia de la Plaza, 3우 16/I/1954, Colonia Brandsen, $2 q+$, 17/I/1954, s/algodón. Misiones: Loreto, 19 1 $\widehat{\jmath}, 11 /$ XII/1941, Birabén-Bezzi cols.,

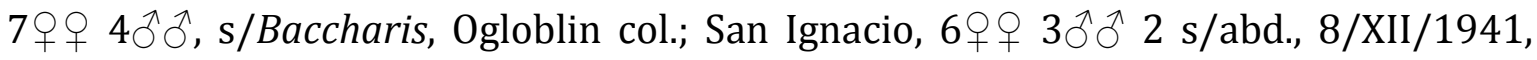

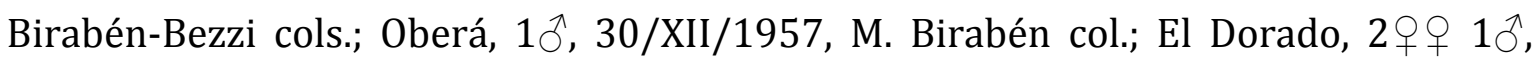
XI/1944, B.A. Torres col.; Puerto Iguazú, XI/1944, 1§̂, M. Birabén col., 1q, Torres col.

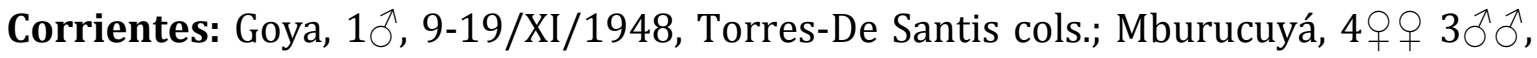
15-23/XI/1957, M. Birabén col.; San Roque, 1ðત, II/1920, Bosq col.; Santo Tomé, $1 \delta^{\lambda}$, 12/XI/1957, M. Birabén col. Entre Ríos: Concordia (INTA), 1ㅇ, 18/IV/1978, 1q, 31/I/1979, 1ㅇ, 5-14/VIII/1979, M. Portillo col., Concordia, 19 1§, VI/1934. Santa Fé: El Rabón, 1 + 1ð, 27/XI/1939, Birabén-Bezzi cols.; Guadalupe, 3ðへ 1 s/abd., 27/XI/1939, Birabén-Bezzi. Buenos Aires: Brazo Largo, 2ðð, XII/1939, S.R. Castillo

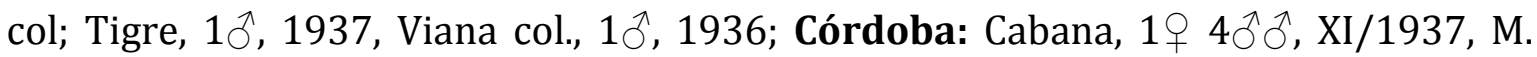
Birabén; Rayo Cortado, 1 s/abd., 15/XII/1939, CMAM; Valle Hermoso, 1 s/abd., 2/II/1956; Yacanto, 10 , Christensen col. San Luis: Concarán, 1, 16/III/1960, Vidal S. Trotta col.; Santa Rosa, 1§̂, 15/III/1960, Vidal S. Trotta col. Mendoza: San Martín, 663 msnm, 1q, 20/III/1945, B.A. Torres col. (IFML): Salta: Quebrada Río Las Conchas, $2 q \propto$ 우 $2 \hat{\jmath}, 20-21 / \mathrm{I} / 1968$, Golbach-Terán-Willink cols.; Los Sauces, 1 , 22/I/1968, Golbach-Terán-Willink cols.; Tartagal, 2우, 11/II/1950, Golbach col.;

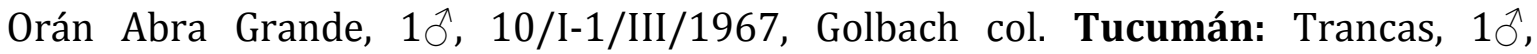
31/X/1980, Willink col. Catamarca: Belén, $4+q$ 1§, 1-15/IX/1968, Willink-Terán

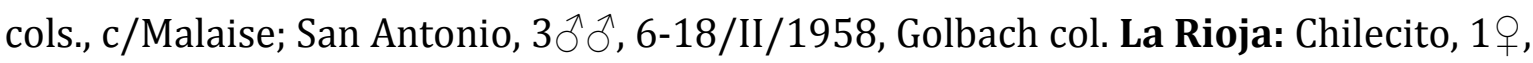
20/I/1960. Chaco: Resistencia, 1, 17/XI/1948, Golbach col. (UNLP): La Rioja: Chilecito, 5 ふぇ 5우, XI-XII/2017, s/olivo, Calahorra col. San Juan: San Juan, 8 우

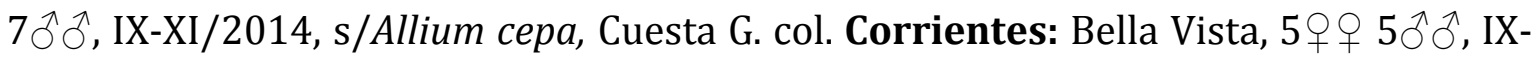
X/2014, B. Defea col. Buenos Aires: Berisso, $3 q q 4 \widehat{\jmath} \widehat{\jmath}$, XII 2015, s/Tecoma stans, Defea col.; Mercedes, $2 \hat{\jmath} \widehat{\partial}$, I/2016, s/T. stans, Defea col. 


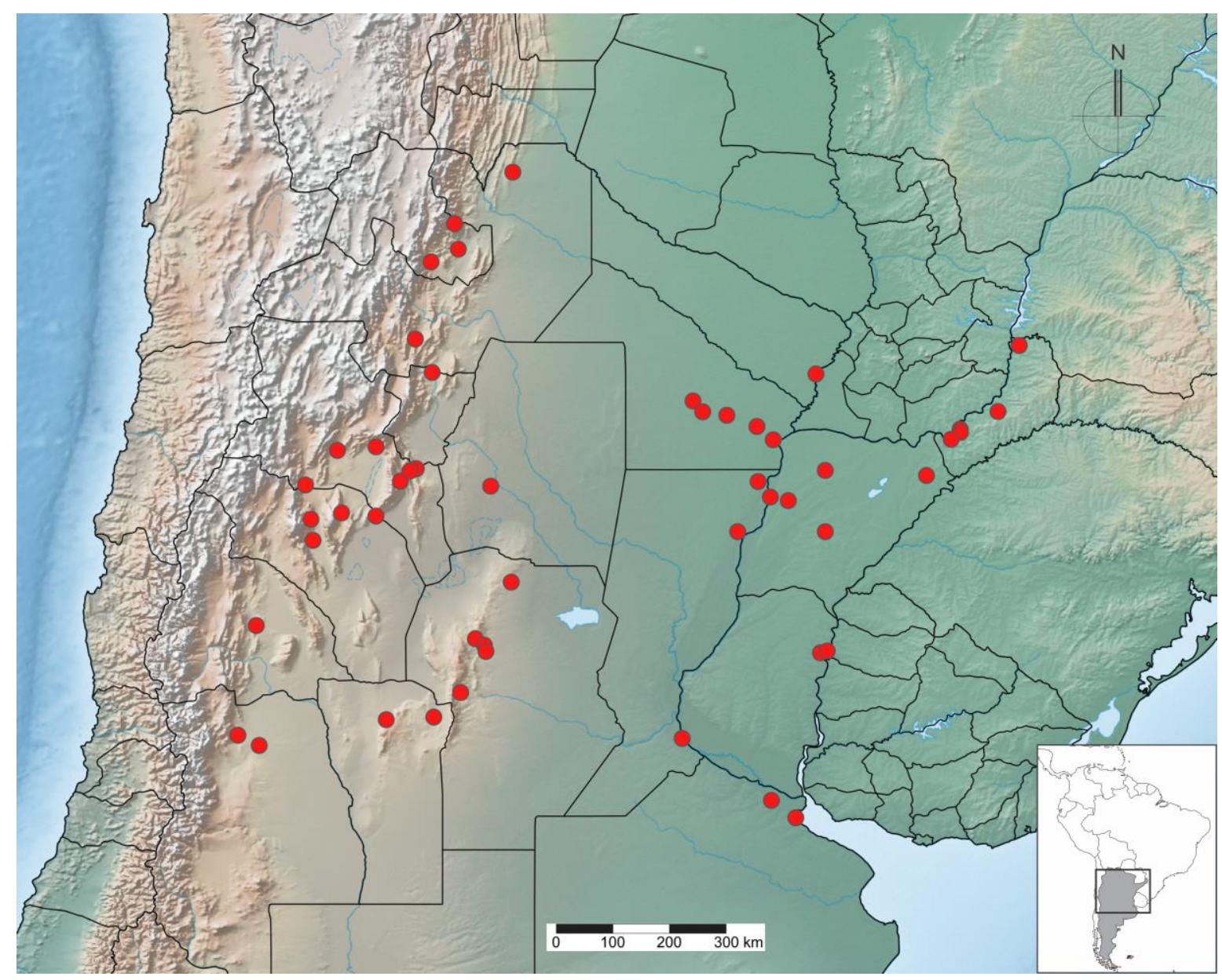

Figura 15. Distribución de Bucephalogonia xanthophis (Berg) en Argentina. 


\section{Género Ciminius Metcalf and Bruner}

Especie tipo: Tettigonia hartii Ball 1901: 61 (Por designación original).

Longitud total 3,6-5,6 mm.

Cabeza. Ligeramente proyectada, longitud media de la corona 04-0,6x el ancho interocular, margen anterior, en vista dorsal, ampliamente redondeado; ocelos localizados sobre la línea que pasa entre los ángulos anteriores de los ojos; superficie de la corona convexa y punteada, ocasionalmente rugosa. Puentes antenales, en vista dorsal, no protuberantes, con el margen anterior, en vista lateral, rectilíneo o cóncavo y vertical o ligeramente oblícuo. Transición corona-clípeo redondeada. Clípeo convexo, no protuberante, granulado o punteado en su porción media; sutura transclipeal usualmente completa; perfil del clipelo, en vista lateral, siguiendo el contorno del clípeo, superficie glabra.

Tórax. Ancho del pronoto respecto del ancho transocular de la cabeza intraespecíficamente variable; márgenes laterales paralelos o ligeramente convergentes anteriormente; carena dorsopleural a veces completa; superficie del disco usualmente rugosa, glabra; superficie del escutelo por detrás del surco transversal usualmente rugosa. Alas anteriores sin área membranosa claramente delimitada, venas marcadas; con dos celdas anteapicales, la celda externa abierta basalmente, y cuatro celdas apicales; textura alar basalmente coriácea, gradualmente translúcida hacia el ápice. En las hembras, las alas en reposo ocultan el ovipositor. Fórmula setal del fémur posterior 2:1:0; longitud del primer tarsómero más corta que la longitud combinada del segundo y tercer tarsómero, con dos hileras de setas paralelas sobre la superficie plantar, algunas paleadas.

Genitalia del macho. Pigóforo corto, margen posterodorsal convexo y margen posteroventral usualmente cóncavo, con numerosas macrosetas de tamaño variable en los dos tercios posteriores del disco, sin procesos. Placas subgenitales triangulares, no alcanzando posteriormente el ápice de pigóforo, con los márgenes internos ligeramente curvados en la porción basal; superficie con macrosetas uniseriadas. Estilos no extendiéndose posteriormente hasta el ápice del conectivo, apicalmente truncados; con o sin lóbulo preapical. Conectivo en forma de Y con las ramas 
ampliamente divergentes articuladas al eje principal que es un esclerito separado que se extiende dorsalmente, con una quilla de posición media en el eje principal. Edeago corto, eje con o sin procesos lobulados. Paráfisis pares en la base, estrechas y apicalmente agudas, porción impar dispuesta en el plano medio sagital.

Genitalia de la hembra. Esternito abdominal VII con el margen posterior usualmente transverso, con una proyección media subangulosa (excepto $C$. albolineatus (Taschenberg)). Esternito abdominal VIII membranoso. Pigóforo con macrosetas pequeñas en la mitad del disco, con macrosetas robustas en la superficie preapical y algunas cerca del margen posteroventral. Ovipositor con la segunda valva expandida luego de la curvatura basal, margen ventral convexo o cóncavo; margen dorsal con grandes dientes que se extienden casi hasta el ápice agudo, cada diente llevando numerosos dentículos, márgenes dorsal y ventral de la porción preapical con o sin dentículos.

Coloración. Las especies presentan una coloración general castaña a negra; alas anteriores castaño-verdosas con las venas usualmente amarillentas.

Observaciones taxonómicas. El género Ciminius se diferencia del resto de los Cicadellini por la presencia de dos celdas anteapicales en el tegmen, de las cuales la más externa es abierta basalmente; y en los machos, el conectivo se compone de dos escleritos articulados.

Distribución. Neártica y Neotropical; en el neotrópico con registros en Argentina, Brasil, Bolivia, Cuba, El Salvador, Guyana Francesa, Panamá, Paraguay, Perú, Venezuela (Young 1977) y Colombia (Freytag \& Sharkey 2002).

El género Ciminius cuenta con siete especies descriptas de las cuales tres están presentes en la Argentina.

albolineatus (Taschenberg) 1884: 446.

platensis (Berg) 1879: 259.

yana Young 1977: 593. 
Ciminius albolineatus (Taschenberg) (Figura 16A, 20)

Tettigonia albolineata Taschenberg 1884: 446 [n. sp.]

Tettigella [incert. sed.] albolineata Metcalf 1965: 174

Ciminius albolineatus Young 1977: 593 [n. comb.]

Diagnosis. Edeago del macho, en vista lateral, con el eje ancho a lo largo de toda su longitud (Young 1977). Cabeza con la longitud media de la corona ligeramente menor a ligeramente mayor a la mitad del ancho interocular.

Observaciones taxonómicas. Ciminius albolineatus puede separarse del resto de las especies del género por la morfología del edeago.

Distribución. Neotropical, con registros en Argentina, Bolivia, Brasil, Cuba, El Salvador, Guayana Francesa, Isla de los Pinos, Panamá, Venezuela (Young 1977) y Colombia (Freytag \& Sharkey 2002). En la Argentina, se registra por primera vez para la provincia de San Juan (Calingasta) (Figura 20).

Plantas huéspedes. Avena sativa L. (Poaceae) (Young 1977).

Datos biológicos. Desconocidos.

Enemigos naturales. Desconocidos.

Importancia fitosanitaria. Desconocida.

Material estudiado. ARGENTINA: (MLP): San Juan: Calingasta, $1 \hat{\jmath}, 11 / \mathrm{III} / 1940$, M. Birabén col. 
Ciminius platensis (Berg) (Figura 16, 18B, 19A)

Acocephalus dubius Berg 1879: 162 [n. sp.]

Tettigonia platensis Berg 1884: 25 [nom. nov. para Acocephalus dubius Berg 1879]

Metascarta platensis (Berg), Metcalf 1965: 198

Ciminius platensis (Berg), Young 1977: 593 [n. comb.]

Diagnosis. Edeago del macho, en vista lateral, con el eje ligeramente convexo cerca de la base y una constricción anteapical, margen ventral usualmente dentado (Young 1977). Cabeza con la longitud media de la corona igual o ligeramente menor que el ancho interocular, en los machos, y la mitad o ligeramente mayor, en las hembras. Pigóforo de la hembra globoso, superficie con macrosetas robustas en la mitad posterior, con microsetas dispersas en la mitad anterior. Valva II, en vista lateral, con los tres cuartos apicales del eje expandidos.

Genitalia de la hembra. Esternito VII (Fig. 16B), en vista ventral, rectangular, longitud media 0,6x el ancho máximo; márgenes laterales ligeramente convergentes posteriormente, márgenes lateroposteriores obtusos y margen posterior convexo; superficie cubierta por procesos tegumentarios, con microsetas agrupadas en la mitad anterior equidistantes de la porción media. Esternito abdominal VIII (Fig. 16C), ligeramente esclerotizado en dos placas subcirculares. Pigóforo (Figura 19A), en vista lateral, proyección posterior corta y margen posterior obtuso; superficie con numerosas macrosetas robustas en la mitad posterior, con microsetas dispersas en la mitad anterior. Valvifer I (Fig. 16A), en vista lateral, subcircular con la superficie lisa. Valva I (Fig.16F), en vista lateral, lanceolada, con el margen ventral cóncavo; AED visible luego de la curvatura basal hasta el ápice, formada por procesos tegumentarios filiformes cortos, que no alcanzan el ramus, dispuestos oblicuamente; AEV restringida a la porción preapical del eje, formada por procesos escamiformes. EVA larga extendiéndose hasta la mitad basal del eje; porción preapical aguda con los márgenes dorsal y ventral débilmente denticulados, ápice redondeado (Fig. 16E). Valvifer II (Fig. 16D), en vista lateral, subovalado, superficie lisa con un grupo de microsetas robustas cerca del punto de articulación. Valva II (Fig. 16G), en vista lateral, estrecha luego de la curvatura basal, ocho novenos apicales expandidos; margen dorsal convexo, en declive hacia el ápice y margen ventral recto. Margen 
dorsal con aproximadamente 15 dientes (Fig. 16H) subtriangulares contiguos con dentículos sobre el margen posterior que disminuyen de tamaño hacia el ápice. Ductos visibles a lo largo de toda la porción expandida, alcanzando los dientes y el márgen apical. Porción preapical aguda, ápice redondeado (Fig. 16I); ventralmente sin prominencia preapical. Gonoplaca (Fig. 16J), en vista lateral, porción anterior estrecha, longitud 0,8x la porción posterior, la cual es marcadamente expandida; superficie preapical y ventral con procesos tegumentarios espiniformes; ápice ampliamente redondeado.

Observaciones taxonómicas. Ciminius platensis se distingue del resto de las especies del género por la morfología del edeago; el eje, en vista lateral, tiene una constricción anteapical y es ligeramente convexo cerca de la base, el margen ventral es usualmente dentado (Young 1977). Nuevos caracteres descriptos de la genitalia de la hembra (forma y quetotaxia del pigóforo, y forma de la valva II) permiten separar esta especie de C. yana.

Distribución. Sudamericana, con registros Argentina, Brasil, Paraguay, Perú y Venezuela (Young 1977). En la Argentina, está presente en las provincias de Tucumán, Misiones (Young 1977), Jujuy, Salta, Corrientes, Chaco, San Juan, Mendoza, Córdoba, Santa Fé (Remes Lenicov \& Tesón 1985), Buenos Aires (Remes Lenicov et al. 2006) y Entre Ríos (Dellapé et al. 2016). Se amplía su distribución para las provincias de Catamarca (Fray Mamerto Squiü, El Rodeo), La Rioja (El Tabacal), Santiago del Estero (Termas de Río Hondo) y Formosa (Herradura) (Figura 20).

Plantas hospedadoras. Gossypium hirsutum L. (Malvaceae), Zea mays L. (Poaceae), Cynodon dactylon L. (Poaceae) (Remes Lenicov \& Tesón 1985), Echinochloa crusgalli L. (Poaceae), Digitaria sanguinalis (L.) (Poaceae), D. decubens Stent (Poaceae), Bracharia decubens (L.) (Poaceae) (Zanol \& Menezes 1982), Citrus sinensis (L.) Osb. (Rutaceae) (Remes Lenicov et al. 1999), Sorghum halepense L. (Poaceae) (Remes Lenicov et al. 2006), Oriza sativa L. (Poaceae) (Paradell et al. 2014a), Vicia villosa Roth (Fabaceae) (Paradell et al. 2014b). 
Datos biológicos. En la provincia de Misiones, Remes Lenicov et al. (1999) registraron a C. platensis sobre cítricos y la vegetación asociada al cultivo.

Enemigos naturales. Strepsiptera de la familia Halictophagidae (Remes Lenicov 1982) y las especies de microhimenópteros Anagrus breviphragma Soyka y Cosmocomoidea virlai Triapitsyn, Logarzo \& de León (Hymenoptera: Mymaridae) (Luft Albarracín et al. 2009).

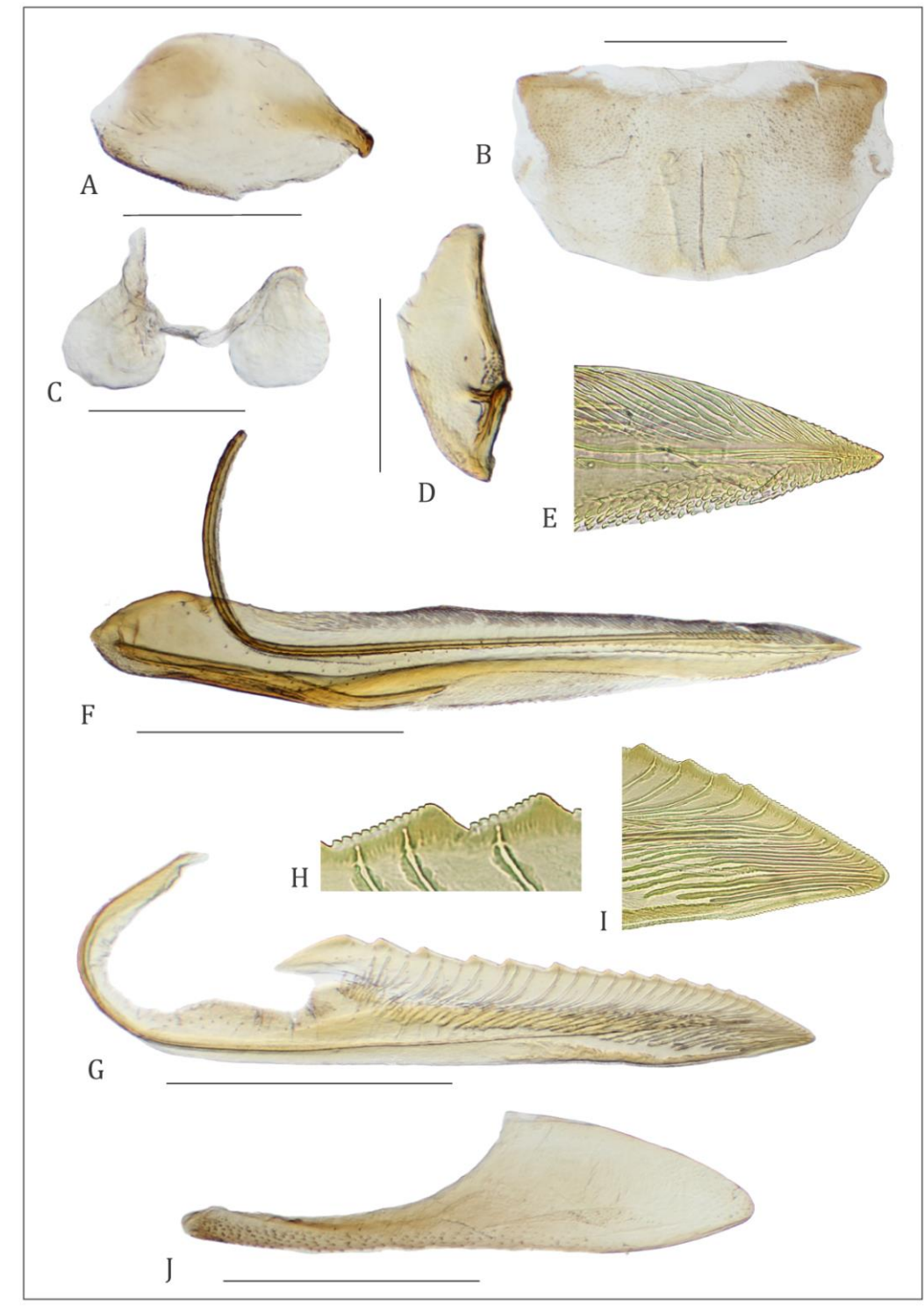

Figura 16. Genitalia de la hembra de Ciminius platensis (Berg): valvifer I (A), esternito abdominal VII (B), esternito abdominal VIII (C), valvifer II (D), valva I (F), ápice valva I (E), valva II (G), dientes valva II (H), ápice valva II (I), gonoplaca (J). Escala 0,5mm: B, F, G, J; 0,3mm: A, C, D. 
Importancia fitosanitaria. Desconocida.

Material estudiado. ARGENTINA: (MLP): Jujuy: Dique La Ciénaga, $1 q 1{ }^{\lambda}$, 30/I/1958, Torres -Ferreyra cols. Salta: $1 \widehat{\jmath}$, s/datos, Kohler col. Tucumán: Trancas, 1ठ, 15/III/1939, Birabén-Scott cols.; Río Cochuna, 1ठ, 2/XII/1957, M. Birabén col. Catamarca: Fray Mamerto Squiü, 1へ, 6/III/1962, Torres-Ferreyra cols.; El Rodeo, $1 \delta$, 3/III/1962, Torres-Ferreyra cols. La Rioja: El Tabacal, 6 우 1ठ 1s/abd., XI/1933.

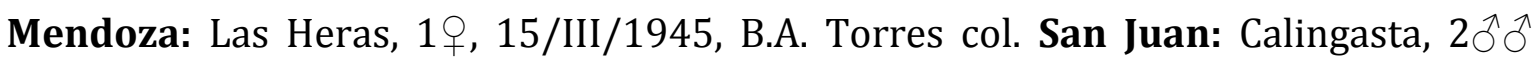

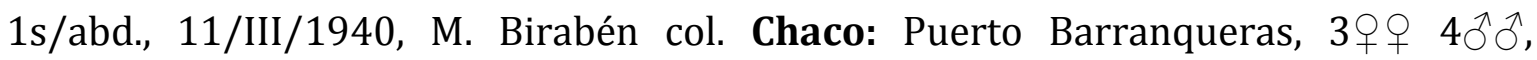
02/XII/1939, Birabén-Bezzi cols.; Tirol, 5へへ, 7/XII/1939, Birabén-Bezzi cols.; Presidencia de la plaza, 1§̂, 16/I/1954, Torres-Argemí cols. Córdoba: San Francisco,

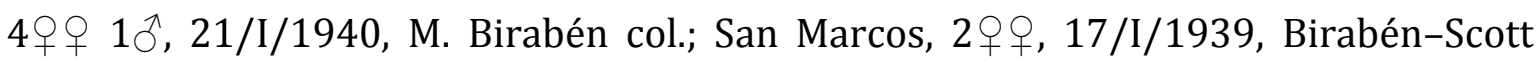
cols. Misiones: Puerto Deseado, $1 \hat{\jmath}, 31 / \mathrm{VII} / 1955$, Zabarce-Donath cols.; Loreto, $1{ }^{\lambda}$ 1ㅇ, s/datos; 2 de Mayo, 1q, 2/XII/1957, M. Birabén col. Corrientes: $3 q 0$ 1 $\widehat{\jmath}$, Trujillo col.; Manantiales, 1, 1-10/III/1959, M. Birabén col.; Santo Tomé, 1q, 12/XI/1957, M. Birabén col. Santa Fé: Reconquista, 3우, 9ふ̋, 20/XI/1939, Birabén-Bezzi cols.

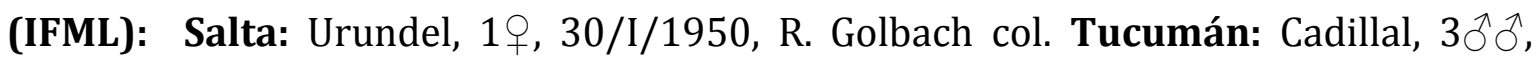
II/1947, De la Sota col. Santiago del Estero: Ojo de Agua, $8+q$ 5ふえへ, I/1947, Fernandez col.; 9ㅇ, 20/XII/1920, T. Acrez col.; Termas de Río Hondo, 191 $^{\Uparrow}, 18-$ 19/IV/1970, L Stange-Porter cols. Chaco: Colonia Benitez, 4qq 5ふえ, 112/XII/1948, R. Golbach col. Córdoba: Punilla, 1ð, II/1947, Reales col. Santa Fé: Villa Guillermina, 25우 3ڤึ, II/1946, Willink-Hayward cols. (MACN): Formosa: Costa

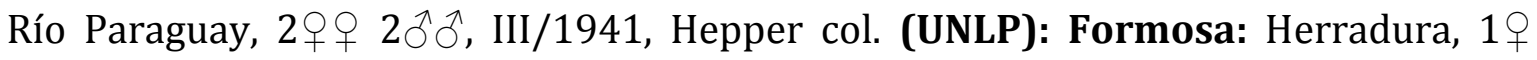

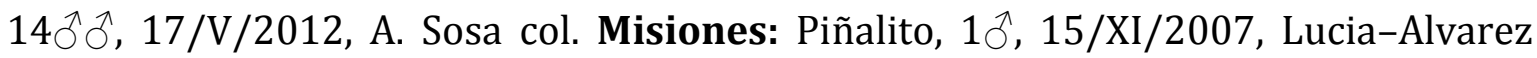
cols. Mendoza: San Rafael, $2 \uparrow+2 \hat{\jmath}, 11 / \mathrm{II} / 2008$, E. Virla col.

Ciminius yana Young (Figura 17, 18C, 19B)

Ciminius yana Young 1977: 593 [n. sp.].

Diagnosis. Cabeza con la longitud media de la corona ligeramente menor (machos) a ligeramente mayor (hembras) que la mitad del ancho interocular. Edeago del macho, en vista lateral, con un proceso posterodorsal lobulado sobre el margen dorsal del eje (Young 1977). Pigóforo de la hembra alargado, superficie con 
macrosetas en la mitad posterior y a lo largo del margen ventral. Valva II, en vista lateral, dos tercios apicales del eje expandido.

Genitalia de la hembra. Esternito VII (Fig. 17A), en vista ventral, rectangular, longitud media $0,5 \mathrm{x}$ el ancho máximo; márgenes laterales convergentes posteriormente, márgenes lateroposteriores subangulosos, margen posterior transverso con un lóbulo medio débilmente marcado; superficie cubierta por procesos tegumentarios, con microsetas agrupadas en la mitad anterior equidistantes de la porción media. Pigóforo (Figura 19B), en vista lateral, alargado, proyectado moderadamente, margen posterior redondeado; superficie con numerosas macrosetas robustas en la proyección posterior y a lo largo del margen ventral, microsetas dispersas sobre la mitad anterior. Valvifer I (Fig. 17B), en vista lateral, subcircular con la superficie lisa. Valva I (Fig. 17D), en vista lateral, lanceolada, tercio basal ligeramente dirigida hacia arriba; AED (Fig. 17E) visible luego de la curvatura basal hasta el ápice, formada por procesos tegumentarios filiformes dispuestos oblicuamente que alcanzan el ramus hacia el ápice; AEV restringida a la porción preapical del eje, formada por procesos escamiformes. EVA larga extendiéndose casi hasta la mitad basal del eje; porción preapical aguda con los márgenes dorsal y ventral no denticulados, ápice redondeado (Fig. 17F). Valvifer II (Fig. 17C), en vista lateral, subovalado, superficie lisa con un grupo de microsetas robustas cerca del punto de articulación con la valva II y la gonoplaca. Valva II (Fig. 17G), en vista lateral, estrecha luego de la curvatura basal, con los tres cuartos apicales expandidos; margen dorsal convexo, en declive hacia el ápice y margen ventral ligeramente cóncavo. Margen dorsal con aproximadamente 16 dientes (Fig. 17H) subtriangulares contiguos con dentículos sobre el margen posterior; dientes del cuarto apical pequeños. Ductos visibles a lo largo de toda la porción expandida, alcanzando los dientes y el márgen apical. Porción preapical aguda, ápice redondeado (Fig. 17I); ventralmente sin prominencia preapical. Gonoplaca (Fig. 17J), en vista lateral, porción anterior estrecha, longitud $0,7 \mathrm{x}$ la porción posterior, la cual es marcadamente expandida; superficie preapical y ventral con procesos tegumentarios espiniformes; ápice ampliamente redondeado. 
Observaciones taxonómicas. Ciminius yana puede separarse del resto de las especies del género por la morfología del edeago en los machos (Young 1977). El forma y quetotaxia del pigóforo y la forma de la valva II de la genitalia de las hembras permiten separar esta especie de $C$. platensis.

Distribución. Sudamericana, citada para Argentina y Brasil (Young 1977). En la Argentina, se registra por primera vez para la provincia de Jujuy (Yuto) (Figura 20).

Plantas hospedadoras. Desconocidas.

Datos biológicos. Se menciona por primera vez asociada a agroecosistemas citrícolas del NOA. Esta especie junto con C. albolineatus (Taschenberg) son frecuentes en la vegetación herbácea asociada a plantaciones citrícolas de Sudamérica (Redak et al. 2004).

Enemigos naturales. Desconocidos.

Importancia fitosanitaria. Desconocida.

Material estudiado. ARGENTINA: (UNLP): Jujuy: Yuto, 5우 $5 \hat{\jmath}, \mathrm{V}-\mathrm{VII} / 2016$, Tapia col. 


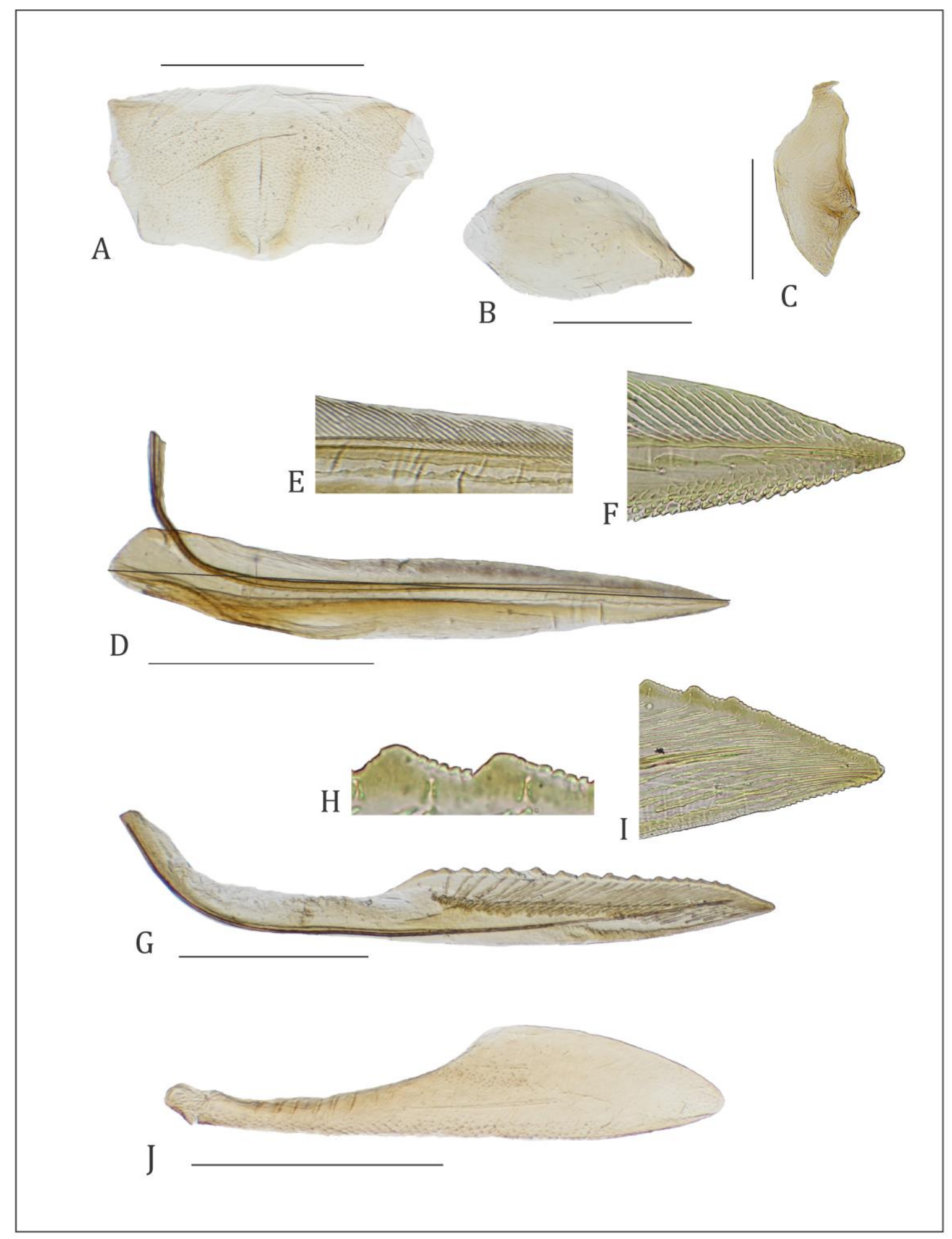

Figura 17. Genitalia de la hembra de Ciminius yana Young: esternito abdominal VII (A), valvifer I (B), valvifer II (C), valva I (D), detalle AED (E), ápice valva I (F), valva II (G), dientes valva II (H), ápice valva II (I), gonoplaca (J). Escala 0,5mm: A, D, G, J; 0,3mm: B, C. 
Clave para el reconocimiento de machos y hembras de las especies del género Ciminius presentes en la Argentina.

1. Machos con el eje aedeagal, en vista lateral, ancho a lo largo de toda su longitud C. albolineatus

-. Machos con el eje aedeagal con una constricción preapical o un proceso dorsal 2

2. Edeago, en vista lateral, eje con un proceso lobado postero-dorsal. Hembras con el pigóforo alargado con macrosetas en la proyección posterior y a lo largo del margen ventral C. yana

-. Edeago, en vista lateral, eje simple, sin un proceso postero-dorsal, con una constricción preapical y margen ventral usualmente dentado. Hembras con el pigóforo ovalado con macrosetas en la mitad posterior C. platensis

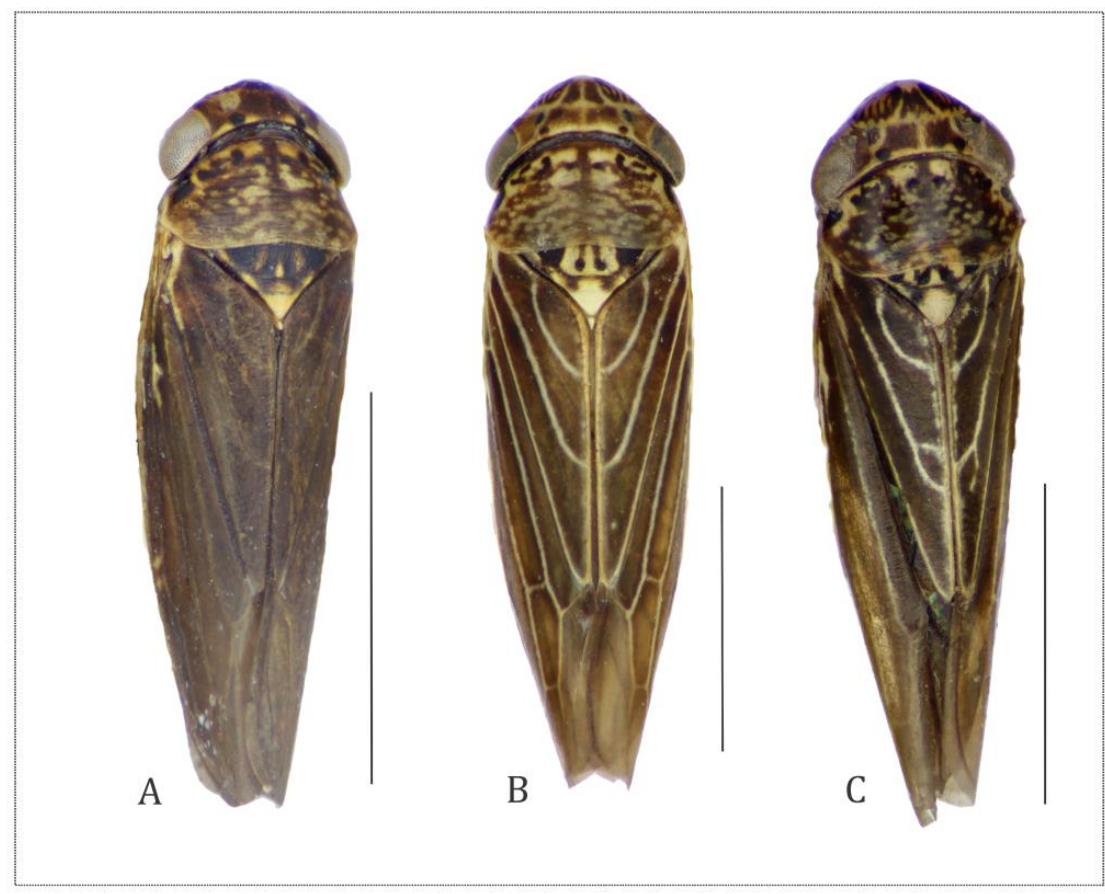

Figura 18. Hábito dorsal de las especies del género Ciminius presentes en Argentina. C. albolineatus (Taschenberg) (A), C. platensis (Berg) (B), C. yana Young (C). Escalas $2 \mathrm{~mm}$ : A-C. 


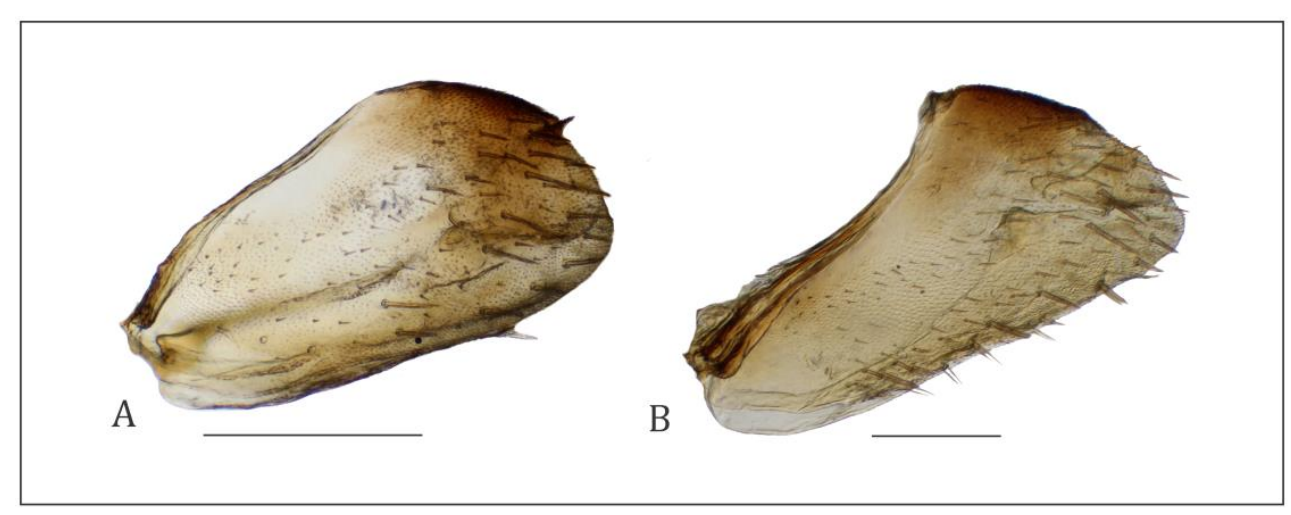

Figura 19. Estructuras diagnósticas de la genitalia de la hembra de las especies del género Ciminius. C. platensis (Berg): pigóforo (A); C. yana Young: pigóforo (B). Escala 0,5 mm: A, B.

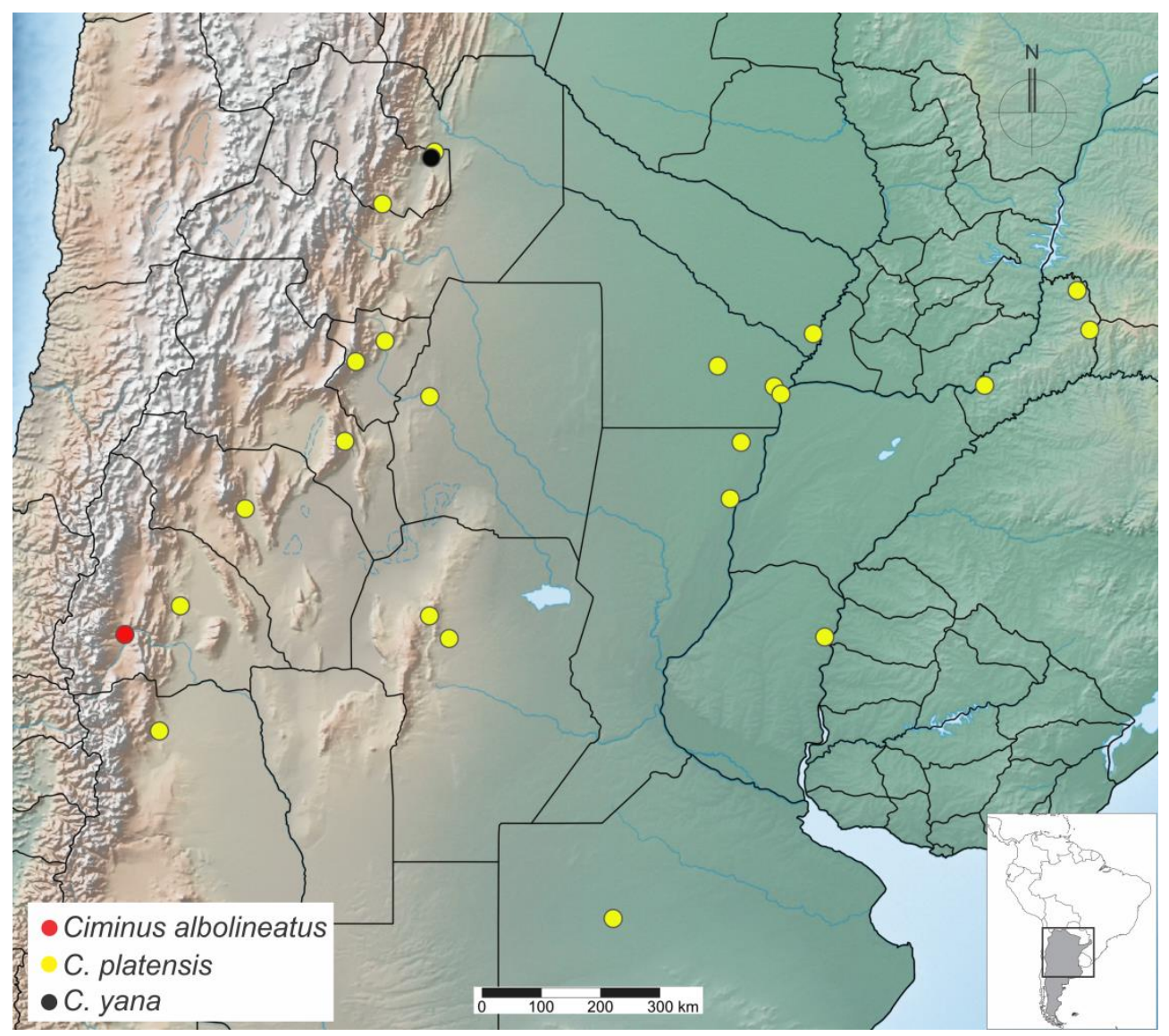

Figura 20. Distribución de las especies del género Ciminius Metcalf \& Bruner en Argentina. 


\section{Género Diedrocephala Spinola}

Especie tipo: Cicada variegata Fabricius (= Diedrocephala bimaculata Gmelin 1789)

Longitud total 6,2-9,5 $\mathrm{mm}$.

Cabeza. Longitud media de la corona 0,25-0,8x mayor que el ancho interocular, margen anterior, en vista dorsal, anguloso, de aspecto triangular, carenado; ocelos localizados detrás de la línea que pasa entre los ángulos anteriores de los ojos; superficie de la corona cóncava en la mayoría de las especies, con una fovea longitudinal de posición media, superficie glabra, al menos el área interocular finamente estriada. Puentes antenales, en vista dorsal, no protuberantes, y en vista lateral con el margen anterior rectilíneo y vertical o levemente oblicuo. Clípeo convexo, no protuberante; sutura transclipeal incompleta; contorno del clipelo, en vista lateral, en continuidad con el perfil del clípeo.

Tórax. Ancho del pronoto mayor que el ancho transocular, márgenes laterales convergentes anteriormente; carena dorsopleural, en vista lateral, completa; tegumento del disco glabro, frecuentemente con rugosidades transversales; superficie del escutelo por detrás del surco transversal no estriado. Alas anteriores con o sin membrana, superficie no esculturada, margen apical levemente cóncavo, con tres celdas anteapicales, la más externa, de forma lenticular, no alcanza las celdas apicales y la mediana abierta basalmente; con tres celdas apicales, la segunda apicalmente estrecha; sin plexo anteapical. En las hembras, las alas en reposo ocultan el ovipositor. Fórmula setal del fémur posterior 2:1:1. Longitud del primer tarsómero mayor que la longitud combinada del segundo y tercer tarsómeros, con dos hileras paralelas de setas en la superficie plantar.

Genitalia del macho. Pigóforo proyectado posteriormente de manera leve a moderado, margen posterior regularmente convexo, con macrosetas de longitud variable sobre la mitad posterior del disco, sin procesos. Placas subgenitales cortas y triangulares, con macrosetas uniseriadas. Estilos extendiéndose más allá del vértice del conectivo, apicalmente truncados; con lóbulo preapical. Ramas laterales del conectivo muy cortas. Edeago simétrico, direccionado ventral- o posteroventralmente, ligeramente expandido en el ápice. Paráfisis asimétricas y de forma variable entre las especies. 
Genitalia de la hembra. Esternito abdominal VII con el margen posterior emarginado. Esternito abdominal VIII con o sin escleritos, cuando presentes, poco definidos. Pigóforo con numerosas macrosetas subamarginales apicales y apicoventrales. Valva II del ovipositor expandida luego de la curvatura basal, con dientes cuadrangulares alargados a lo largo del eje los cuales llevan numerosos dentículos; margen dorsal preapical denticulado, ápice redondeado.

Coloración. Especímenes de color castaño a negro generalmente con marcas blancas longitudinales en la línea media, muy variable a nivel inter- e intraespecífico.

Observaciones taxonómicas. Diedrocephala le da el nombre a uno de los grupos genéricos propuestos por Young (1977) el cual incluye varios géneros descriptos por Melichar: Pachitea, Tipuana, Iragua, Microgoniella, Platygonia, Pamplona y otros: Ladoffa, Soosiulus, Palingonalia, Pamplonoidea, Aurogonalia, Medlerola y Ramosulus descriptos por Young (1977). El género Diedrocephala se diferencia del resto de los géneros del grupo por la nerviación del primer par de alas (Young 1977).

Distribución. Neotropical con registros en Argentina, Bolivia, Brasil, Colombia, Costa Rica, El Salvador, Guyana Francesa, Honduras, Mexico, Panamá, Paraguay, Perú, Surinam y Venezuela (Young 1977), Nicaragua (Maes \& Godoy 1993).

El género Diedrocephala cuenta con once especies descriptas de las cuales una está presente en la Argentina.

Diedrocephala bimaculata (Gmelin) (Figura 21, 22A, B, C)

Cicada variegata Fabricius 1775: 684 [n. sp.]

Cicada virginea Fabricius 1803: 66 [n. sp.].

Diedrocephala bimaculata McKamey 2006: 674 [n. syn.]

Cicada bimaculata Gmelin 1789: 2106 [nom. nov. para Cicada variegata Fabricius 1775]

Diedrocephala bimaculata McKamey 2006: 674 [Considerada nombre válido]

Cicada virginea Young 1965: 18 [Lectotipo designado]

Diedrocephala variegata Young 1977: 325 [n. syn.] 
Diagnosis. Coloración dorsal negra. Cabeza negra, ventralmente amarilla. Tórax negro con una línea blanca longitudinal mediana. Élitros negros, con líneas rojas, con una mácula amarilla pálida cercana al ápice, medialmente con una banda amarillenta; margen externo hialino, interrumpido medialmente. Coloración ventral amarilla (Fabricius 1775). Margen apical de la corona con bandas blancas cortas. Macho con paráfisis asimétricas, con dos ramas curvadas de longitud variable.

Genitalia de la hembra. Esternito VII (Fig. 21A), en vista ventral, subrectangular, longitud media 0,5x el ancho total; márgenes laterales ligeramente convergentes posteriormente y el margen posterior ligeramente emarginado; superficie con un grupo de microsetas a cada lado sobre el margen anteromedial. Esternito VIII (Fig.21B), en vista caudal, moderadamente esclerotizado en una placa, sin esclerotizaciones puntuales. Pigóforo (Fig. 21E), en vista lateral, subtriangular con el margen posterior proyectado moderadamente; superficie con macrosetas subamarginales a lo largo del margen ventral y en el tercio posterior. Valvifer I (Fig. 21C), en vista lateral, subtriangular, con el margen anterodorsal más esclerotizado; superficie con pequeñas microsetas dispersas y con procesos tegumentarios espiniformes en la porción central. Valva I (Fig. 21F), en vista lateral, lanceolada, ligeramente rectilínea en los dos tercios apicales con la porción basal direccionada dorsalmente, márgenes irregulares; AED extendiéndose sobre los dos tercios apicales del eje, formada por procesos tegumentarios subrectangulares dispuesto en hileras oblicuas; AEV restringida a la porción preapical del eje, formada por procesos escamiformes no imbricados. EVA larga, extendiéndose sobre la mitad basal del eje; márgenes preapicales dorsal y ventral denticulados; ápice agudo (Fig. 21G). Valvifer II (Fig. 21D), en vista lateral, de forma y aspecto típicos de la tribu, margen posterior bilobado; superficie de la mitad ventral con numerosas microsetas y procesos espiniformes. Valva II (Fig. 21H), en vista lateral, gradualmente ensanchada luego de la curvatura basal, margen dorsal convexo y ventral casi rectilíneo, con numerosos dientes (Fig. 21I) continuos de forma subrectangular con dentículos romos sobre el margen dorsal. Ductos alcanzando, a veces los dientes, y al ápice. Ápice (Fig. 21 J) ampliamente redondeado y denticulado; ventralmente con prominencia preapical débilmente marcada. Gonoplaca (Fig. 21K), en vista lateral, porción anterior estrecha y ligeramente más larga que la posterior, la cual es marcadamente expandida; 
superficie preapical con algunas macrosetas; ápice (Fig. 21M) ampliamente redondeado.

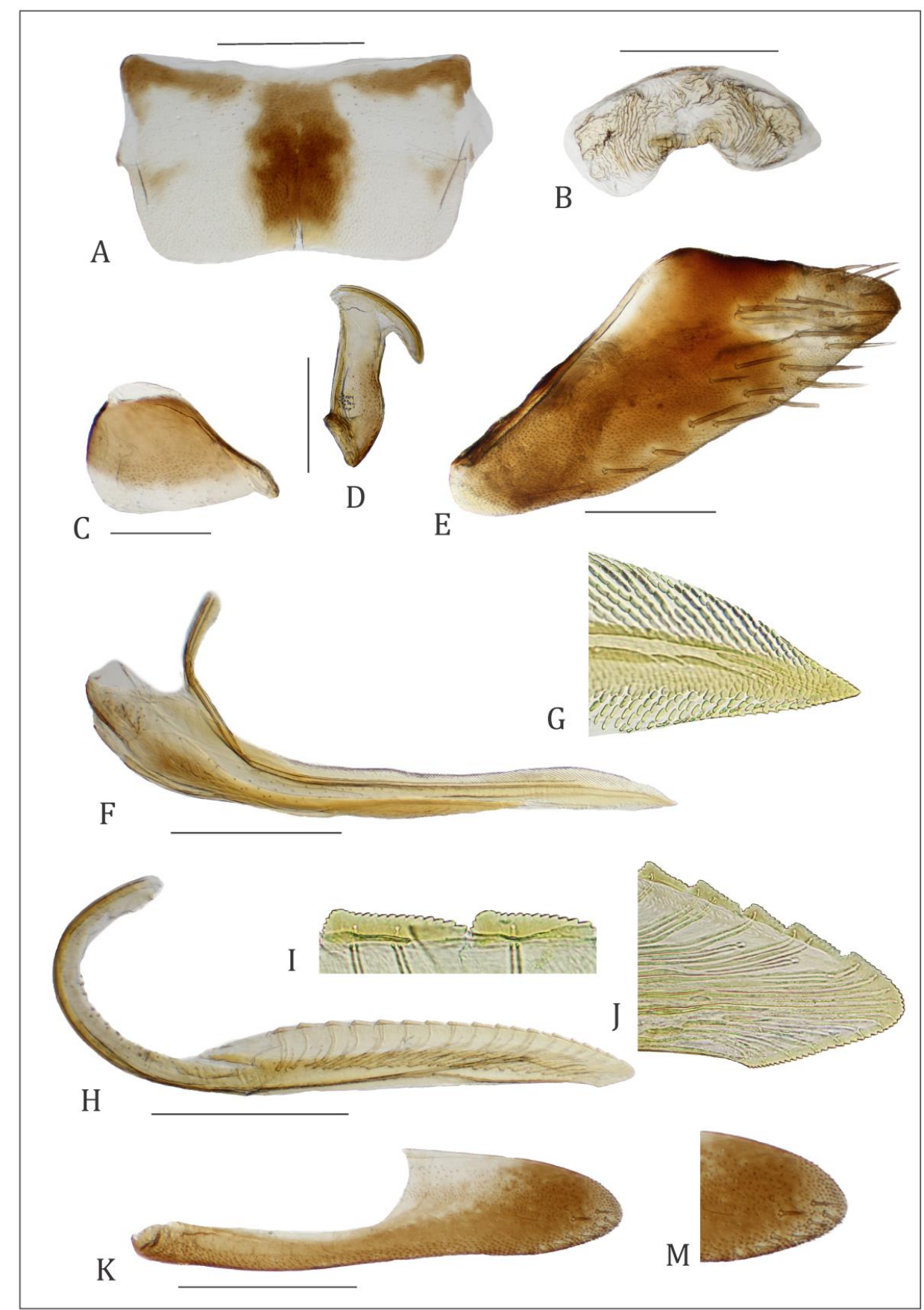

Figura 21. Genitalia de la hembra de Diedrocephala bimaculata (Gmelin). Esternito VII (A), Esternito VIII (B), valvifer I (C), valvifer II (D), pigóforo (E), valva I (F), ápice de la valva I (G), valva II (H), detalle dientes valva II (I), ápice de la valva II (J), gonoplaca (K), ápice de la gonoplaca (M). Escala 0,5 mm: A, B, E, F, H, K; 0,3 mm: C, D 
Observaciones taxonómicas. Los ejemplares de esta especie presentan una gran variación en el patrón de coloración (Figura 22). Los especímenes pueden presentar una coloración negra a castaña clara; la banda longitudinal blanca mediana se proyecta, o no, desde el margen preapical de la corona, pronoto o escutelo, hasta la región subapical del clavus; pudiendo ser contínua, estar interrumpida o estar completamente ausente. Se estudiaron numerosos ejemplares con distinto patrón de la coloración pero no se encontraron diferencias morfológicas asociadas.

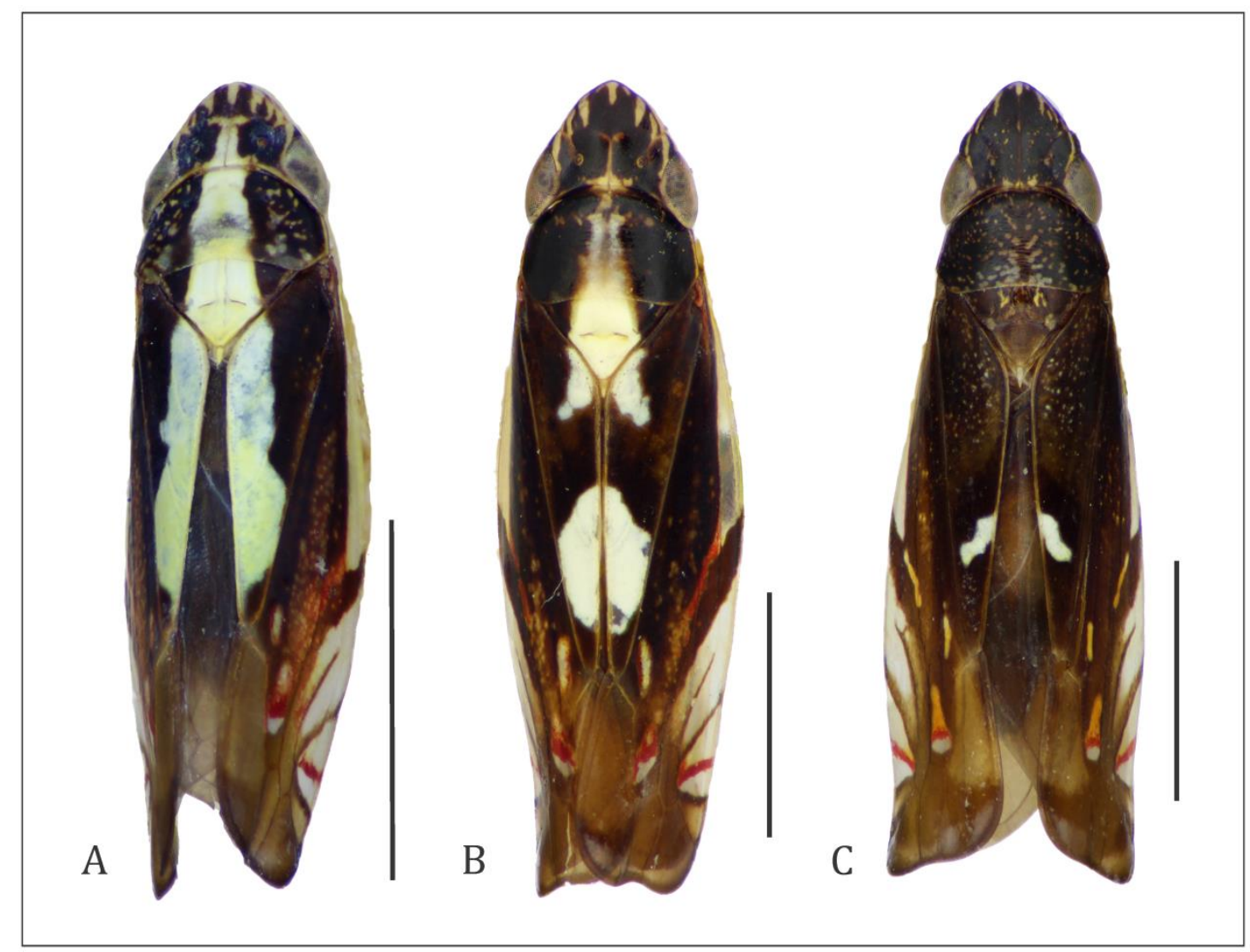

Figura 22. Hábito dorsal de Diedrocephala bimaculata (Gmelin). Patrones de coloración presentes en Argentina (A, B, C). Escala 2 mm.

Distribución. Diedrocephala bimaculata es la especie del género más ampliamente distribuída con registros en Argentina, Bolivia, Brasil, Colombia, Costa Rica, El Salvador, Guyana, Francesa, Honduras, Mexico, Panamá, Paraguay, Perú, Surinam y Venezuela (Young 1977), Nicaragua (Maes \& Godoy 1993). En la Argentina está presente en las provincias de Tucumán, Chaco, Santa Fé, Misiones (Remes Lenicov et al. 1999) y Entre Ríos (Dellapé et al. 2016). Se amplía la distribución para las 
siguientes provincias: Formosa (Misión Lashí), Jujuy (Termas del Rey), Salta (Orán, Tartagal, Yatasto) y Corrientes (Bella Vista, San Roque) (Figura 23).

Plantas hospedadoras. Citrus sinensis Osb. (Rutaceae) y la vegetación espontánea asociada (Remes Lenicov et al. 1999).

Observaciones biológicas. En Misiones, Corrientes y Entre Ríos, D. bimaculata fue colectada tanto sobre los cítricos como en la vegetación asociada. En Misiones, estuvo presente durante todo el año, siendo más abundante en los cítricos desde agosto hasta septiembre (Remes Lenicov et al. 1999).

Importancia fitosanitaria. Desconocida.

Material estudiado. ARGENTINA: (MLP): Jujuy: 1 s/abd., 30/XII/1906, Bruch.

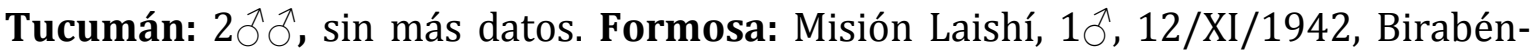
Bezzi cols. Chaco: El Zapallar, 1, 10/XI/1942, Birabén-Bezzi cols., Colonia Cnel.

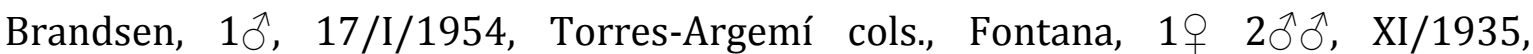
Resistencia, 1ㅇ, sin más datos. Misiones: 2 de Mayo, 1q, 2ðð, 2/XII/1957, M. Birabén, Iguazú, $3 q$ ㅇ 1 $\delta^{\lambda}$ XI/1944, M. Birabén; Loreto, 4 우 1ठ, Ogloblin col.; Oberá, $1 \widehat{\jmath}, 22 / X I / 1944$, B.A. Torres col.; San Ignacio, 1ठ, 8/XII/1941, Birabén-Bezzi cols.

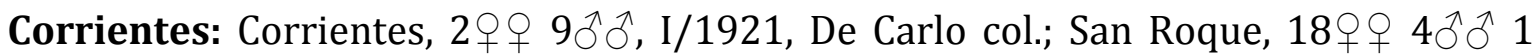
s/abd., II/1920, Bosq col. Santa Fé: Guadalupe, 3우 2ふึત, 27/XI/1939, Birabén-

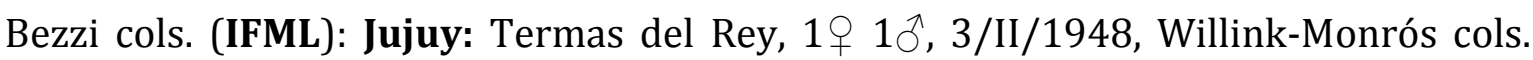

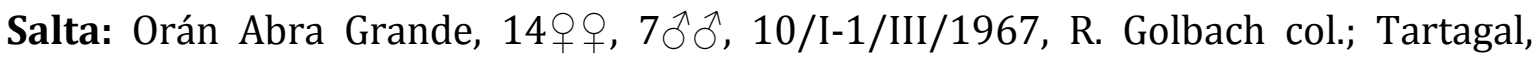
2웅, 3ðึ, 11/II/1950, R. Golbach col. Tucumán: Burruyacu, 1ð, 7-8/II/1961, Willink-Monrós cols. Chaco: El Zapallar, 1, 19/VI/1948, R. Golbach col. Formosa: Misión Laishí, 2 s/abd. 17/XI/1950, Willink-Monrós cols. Misiones: Bernardo de Irigoyen, 1ठ, 12/XI/1973, Tomsic-Willink cols.; Iguazú, 7우, 30/I-13/III/1973, Hayward-Willink-Golbach cols.; Parque Nacional Iguazú, 1へ, 10/XI/1973, WillinkTomsic cols.; Panambí, 1ㅇ, 24/XI/1951, Monrós-Willink cols.; San Javier, $6 q$ ㅇ $4 \widehat{\jmath}$, 20/XI/1973, Willink-Tomsic cols. BOLIVIA: Coroico, 1ð̊, 26/II/1962, F. Monrós col. (MACN). Chaco: Fontana, 1, XI/1935, Daguerre col.; Resistencia, $6 \hat{\jmath}$. (UNLP): Tucumán: La Virginia, 1q, 22/XI/2011, c/red, s/herbáceas, B. Defea col. Misiones: 
Loreto, 1q, 21/X/2008, Virla col.; Piñalito, 1q, 15-16/XI/2007, Lucia-Alvarez cols.; Ruta Pcial 102, 19/I/2014, 1ð, c/red, s/gramíneas, B. Defea col.; San Pedro, 2ふえ, 1922/XI/2007, Lucia-Alvarez cols. Corrientes: Bella Vista, 5우 5ふふえ, IX-XII/2014, B. Defea col.

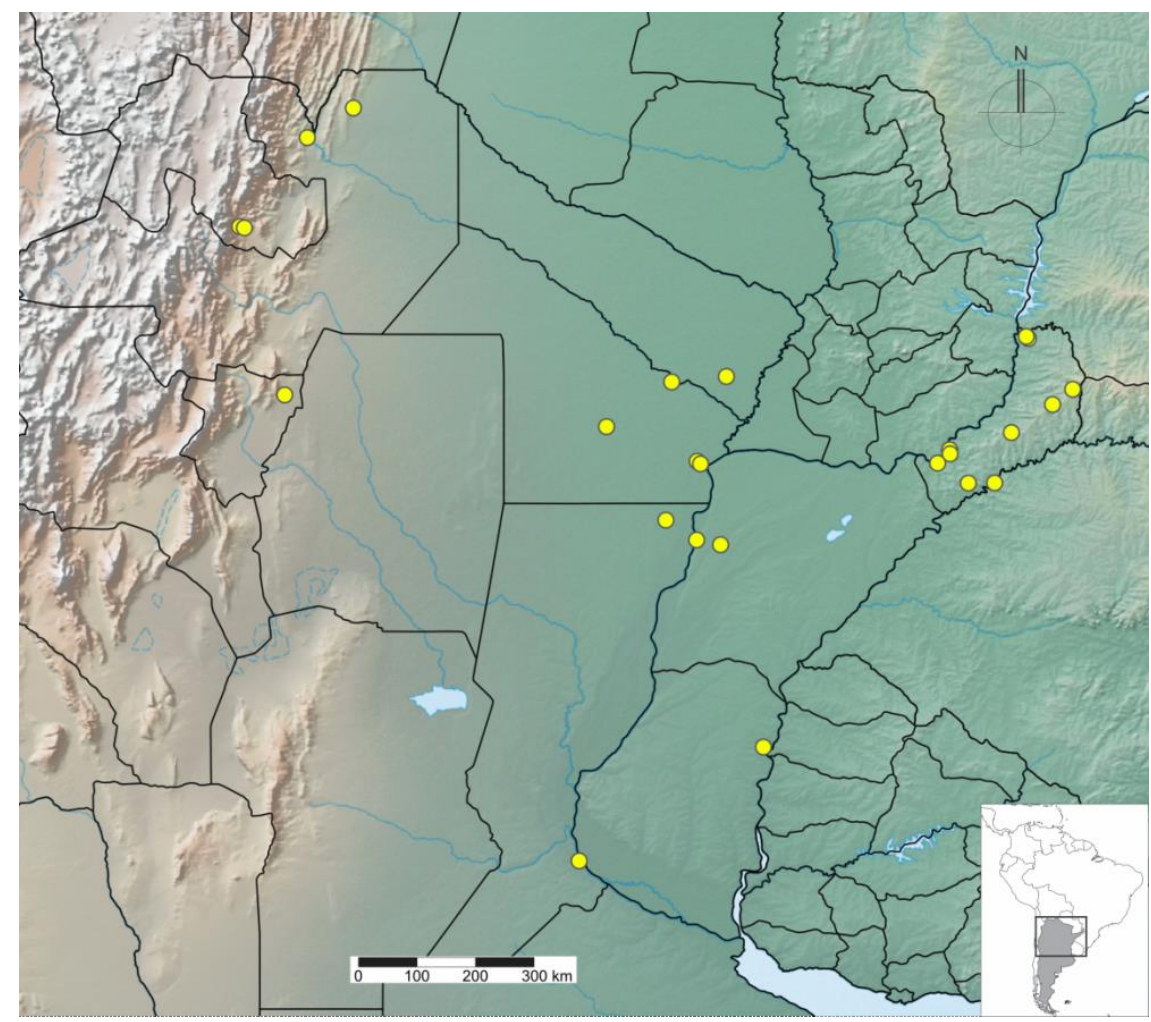

Figura 23. Distribución de Diedrocephala bimaculata (Gmelin) en Argentina. 


\section{Género Dilobopterus Signoret}

Especie tipo: D. decoratus Signoret, 1850:285 (Por designación subsequente de Osborn 1926:172).

Longitud total 6,6-16 $\mathrm{mm}$.

Cabeza. De desarrollo variable desde ligera- a moderadamente proyectada, longitud media de la corona $0,3-0,75 \mathrm{x}$ el ancho interocular; margen anterior, en vista dorsal, ampliamente redondeado, raramente subanguloso; superficie de la corona convexa, o con una ligera concavidad cerca de la longitud media, disco glabro; ocelos, en la mayoría de las especies, localizados detrás de la línea que pasa entre los ángulos anteriores de los ojos. Suturas clipeales laterales generalmente no alcanzando los ocelos. Puentes antenales, en vista lateral, con el margen anterior oblicuo y convexo o rectilíneo. Transición corona-clípeo redondeada. Clípeo, en vista lateral, convexo, finamente pubescente; sutura transclipeal incompleta; clipelo ligeramente protuberante.

Tórax. Ancho del pronoto menor que el ancho transocular, márgenes laterales subparalelos o ligeramente convergentes posteriormente; carena dorsopleural oblicua e incompleta; superficie del disco glabro, liso o con rugosidades transversales; superficie del escutelo por detrás del surco transversal no estriado. Alas anteriores apicalmente membranosas, o con un área membranosa amplia anterior a las celdas apicales; venas marcadas en la porción apical, no elevadas; con cuatro celdas apicales; sin un plexo de venas anteapicales; textura mayormente hialina con áreas coriáceas en la mayoría de las especies. En las hembras, las alas en reposo ocultan el ovipositor. Alas posteriores más cortas que las anteriores, a veces con un lóbulo jugal conspicuo parcialmente separado del resto del ala por una escisión profunda. Al menos en los machos, las alas en reposo, dejan expuesto el meron de la pata posterior. Fórmula setal del fémur posterior 2:1:1 o 2:1:1:1. Longitud del primer tarsómero mayor a la longitud combinada del segundo y tercer tarsómeros, con diminutas macrosetas biseriadas sobre la superficie plantar.

Genitalia del macho. Pigóforo usualmente fuertemente proyectado posteriormente, con numerosas macrosetas a veces regularmente dipersas; procesos usualmente ausentes, cuando presentes, no fuertemente esclerotizados Placas 
subgenitales triangulares, separadas a lo largo de su longitud o raramente fusionadas en la base, superficie con macrosetas longitudinalmente uni o multiseriadas, con algunas microsetas largas en los márgenes laterales. Estilos de longitud variable respecto a la longitud del conectivo, con o sin lóbulo preapical. Conectivo en forma de Y o T, con o sin una quilla de posición media. Edeago simétrico o asimétrico, con o sin procesos, cuando presentes usualmente impares. Paráfisis presentes, a veces pareadas, simétricas o asimétricas.

Genitalia de la hembra. Esternito abdominal VII muy variable entre las especies, con el margen posterior ampliamente cóncavo a fuertemente desarrollado posteriormente. Pigóforo con el margen posterior ampliamente redondeado con macrosetas de tamaño variable sobre la mitad apical. Ovipositor con la segunda valva expandida luego de la curvatura basal, tres cuartos del margen dorsal con dientes subtriangulares llevando numerosos dentículos, margen ventral convexo; con numerosas denticulaciones dorsales y ventrales en la porción preapical; con prominencia preapical ventral.

Observaciones taxonómicas. Según Young (1977), Dilobopterus está cercanamente relacionado con Lissoscarta Stål, con el cual comparte numerosos caracteres pero del cual puede diferenciarse por la ausencia de una constricción en la base del abdomen; también comparte numerosos caracteres de la genitalia del macho y de la hembra con el género Amblyscartidia Young con el cual probablemente también esté relacionado; la presencia de paráfisis simétricas, alas posteriores amplias y el meron oculto por las alas en reposo permiten separar al género Amblyscartidia de Dilobopterus.

Distribución. Neotropical con registros desde México a través de Centroamérica y Sudamérica hasta la Argentina (Young 1977).

El género Dilobopterus cuenta con 50 especies descriptas de las cuales dos están presentes en la Argentina.

costalimai Young 1977: 136.

dispar (Germar) 1821: 71. 
Dilobopterus costalimai Young (Figura 24, 26A)

Dilobopterus costalimai Young 1977 [n. sp.]

Diagnosis. Longitud media de la corona $0,4-0,6 \mathrm{x}$ el ancho interocular. Alas anteriores con un área membranosa discal y venas clavales no distintivas; alas posteriores con el lóbulo jugal muy desarrollado que se extiende más allá del ápice claval de las alas anteriores en posición de descanso. Edeago del macho, en vista lateral, con un lóbulo corto, romo que se extiende posterodorsalmente, redondeado apicalmente y ligeramente separado del eje aedeagal. Valva I del ovipositor de la hembra lanceolada, con un pliegue amplio sobre el margen ventral. Cabeza, pronoto y escutelo de coloración amarilla a anaranjada, sobre el margen anterior de la corona impresiones musculares arqueadas negras, línea media sobre los dos tercios basales que se abre anteriormente a cada lado hasta alcanzar los márgenes arqueados y una mancha corta proyectada desde cada ocelo hacia el margen posterior de la corona, negra; disco del pronoto con una mancha transversal en forma de "W" y una banda marginal posterior, negras; escutelo con una mancha negra en forma de " $\mathrm{H}$ ". Alas anteriores con los márgenes costal, humeral y comisural, sutura claval $\mathrm{y}$ ocasionalmente las venas longitudinales, negras. Frontoclípeo amarillo-anaranjado con una pequeña mancha negra medial; clipelo amarillo. Pleuras torácicas y patas de color amarillo-anaranjado, uñas tarsales negras (Young 1977).

Genitalia de la hembra. Esternito VII (Fig. 24A), en vista ventral, subrectangular, longitud media 0,6x el ancho máximo; márgenes laterales ligeramente convergentes posteriormente y el margen posterior proyectado en su parte media formando un lóbulo ligeramente cóncavo; con microsetas dispersas. Esternito VIII (Fig. 24B), parcialmente membranosos con esclerotizaciones puntuales es su porción media y lateral. Pigóforo (Fig. 24C), en vista lateral, con el margen posterior proyectado moderadamente; superficie con numerosas macrosetas en casi toda la superficie y algunas microsetas dispersas. Valvifer I (Fig. 24D), en vista lateral, romboidal; superficie con numerosas microsetas pequeñas sobre la mitad posterior. Valva I (Fig. 24F), en vista lateral, lanceolada, eje ensanchado hacia el ápice con la porción basal direccionada dorsalmente; con un pliegue (Fig. 24H) amplio sobre el margen ventral cubierto por procesos tegumentarios rectilíneos horizontales; AED extendiéndose sobre los dos tercios apicales del eje, formada por procesos tegumentarios filiformes 
rectilíneos dispuestos oblicuamente; AEV restringida a la porción preapical del eje, formada por procesos escamiformes. EVA restringida a una porción de la mitad basal del eje; porción preapical aguda con los márgenes dorsal y ventral denticulados, ápice (Fig. 24G) redondeado. Valvifer II (Fig. 24E), en vista lateral, superficie lisa con microsetas robustas cerca del punto de articulación. Valva II (Fig. 24I), en vista lateral, fuertemente expandida luego de la curvatura basal, margen dorsal en declive hacia el ápice y margen ventral rectilíneo. Margen dorsal con numerosos dientes (Fig. 24J) subtriangulares continuos, cada diente con dentículos en los márgenes anterior y posterior. Ductos visibles sobre los tres cuartos apicales alcanzando los dientes, los márgenes apical y apicoventral. Porción preapical aguda, ápice (Fig. 24K) redondeado; ventralmente con prominencia preapical. Gonoplaca (Fig. 24M), en vista lateral, porción anterior estrecha, casi tan larga como la porción posterior, la cual es marcadamente expandida; superficie con finas macrosetas submarginales a lo largo del margen ventral; ápice ampliamente redondeado.

Observaciones taxonómicas. Dilopterus costalimai puede ser separada del resto de las especies del género por la morfología aedeagal del macho: con un lóbulo conspicuo, dirigido posteriormente, por encima del ápice del eje, y la coloración del pronoto: con una banda transversal sinuosa de color negra (Young 1977).

Distribución. Dilobopterus costalimai fue registrada en Argentina, Brasil y Paraguay. En la Argentina fue hallada en las provincias de Misiones y Corrientes (Young 1977). Se amplía la distribución para la provincia de Jujuy (Yuto) (Figura 27).

Plantas hospedadoras. Citrus sinensis (Rutaceae) (Remes Lenicov et al. 1999), Coffea arabica L. (Rubiaceae) (Marucci et al. 2001), Vernonia condensata (Asteraceae) (Milanez et al. 2001), Aloysia virgata (Verbenaceae) (Marucci et al. 2003), Hibiscus rosa-sinensis (Malvaceae) (Lopes 2008).

Datos biológicos. Estudios realizados en plantas de Citrus sinensis muestran que D. costalimai se alimenta preferentemente de brotes y hojas nuevas (Marucci et al. 2004). Respecto de la oviposición, deposita sus huevos de manera aislada sobre la 
epidermis foliar y a lo largo de las venas de las hojas nuevas (Fundecitrus 1999). Es una de las especies más frecuente en agroecosistemas de Citrus sinensis en la Argentina; en la provincia de Misiones (Montecarlo) (Remes Lenicov et al. 1999) fue muy abundante en los cítricos con presencia esporádica en la vegetación asociada; en Corrientes (Bella Vista) es una especie predominante sobre las plantas cítricas (Ver capítulo III).

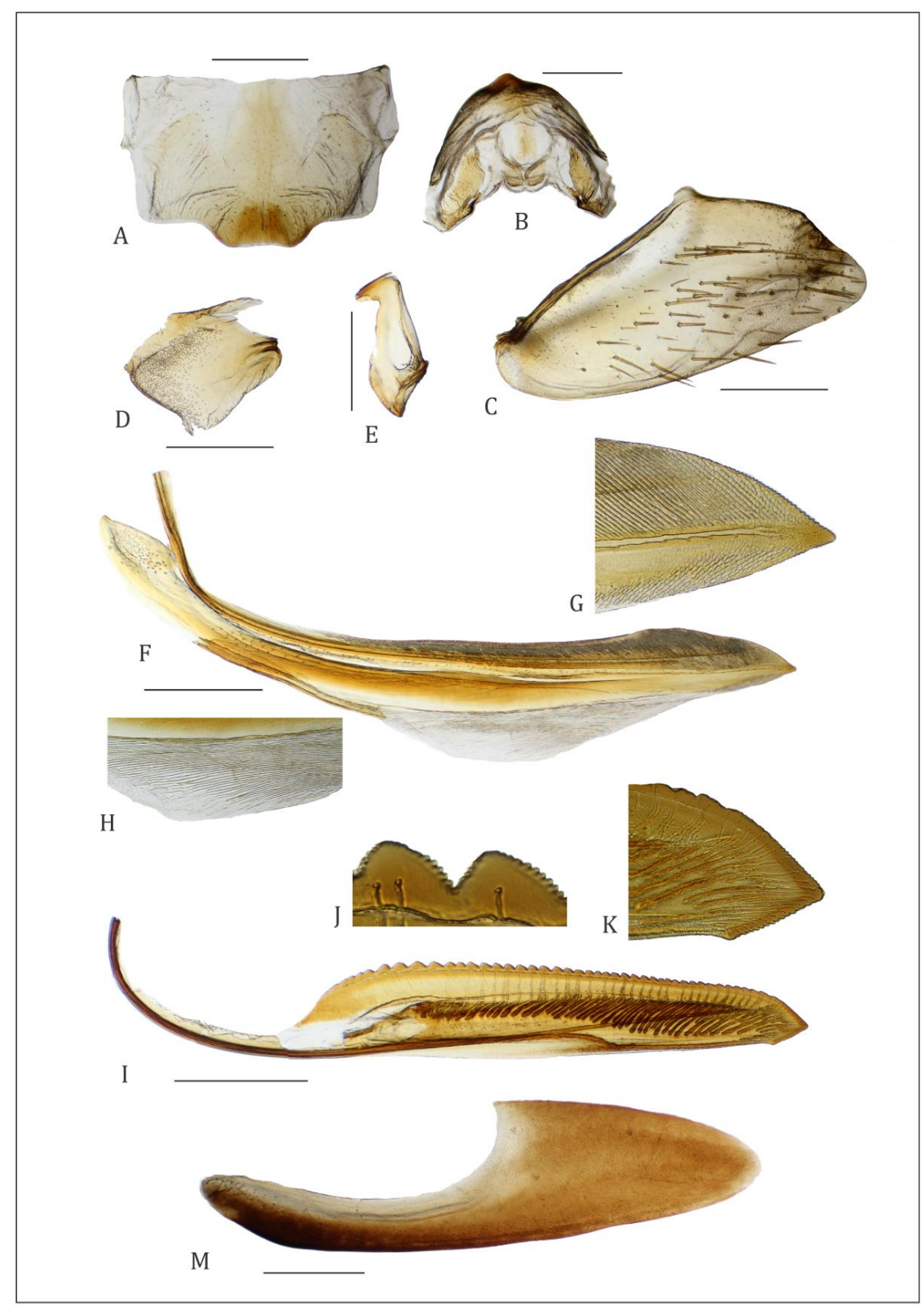

Figura 24. Genitalia de la hembra de Dilobopterus costalimai Young: esternito abdominal VII (A), esternito abdominal VIII (B), pigóforo (C), valvifer I (D), valvifer II (E), valva I (F), ápice valva I (G), detalle esculturación pliegue ventral valva I $(\mathrm{H})$, valva II (I), dientes valva II (J), ápice valva II (K), gonoplaca (M). Escalas 0,5 mm: AF, I, M. 
Enemigos naturales. Desconocidos.

Importancia fitosanitaria. Dilobopterus costalimai es vector comprobado de Xylella fastidiosa subsp. pauca a plantas de Citrus sinensis (L.) Osb. y Coffea arabica L. (Marucci et al. 2008). La eficiencia de transmisión en las plantas de naranja es 5,5\% (Fundecitrus 1999) y en café la tasa de transmisión varía entre 1,2-7,2\% (Marucci et al. 2008).

Material estudiado. ARGENTINA: (MLP): Misiones: San Ignacio, 1ㅇ, 29/X/1929. Corrientes: Mburucuyá, 1q, 16-23/XI/1957, M. Birabén. (IFML): Misiones: San Javier, 1, 22/XI/1973, Escobar-Claps cols. (UNLP): Misiones: Ruta Pcial 102, 1 , 20/I/2014, B. Defea col.; Ruta Pcial 103, 2へへ, 20/I/2015, B. Defea col. Corrientes: Bella Vista, 5우 5ふえ, IX/2014-XII/2014, Defea-Almonacid cols. Jujuy: Yuto, 5우 $5 \hat{\jmath}$ đે, IV/2016, Tapia col.

Dilobopterus dispar (Germar) (Figura 25, 26B)

Tettigonia dispar Germar 1821 [n. sp.]

Tettigonia (Dilobopterus) windmuelleri Berg 1884 [n. sp.]

Dilobopterus dispar Young 1977 [n. syn.]

Diagnosis. Alas anteriores con una mácula anteapical anaranjada. Edeago, en vista lateral, con un lóbulo corto, romo que se extiende posterodorsalmente, redondeado apicalmente con una concavidad profunda que lo separa del eje edeagal (Young 1977). Longitud media de la corona $0,6-0,7 x$ el ancho interocular. Valva I del ovipositor de la hembra lanceolada, sin un pliegue amplio sobre el margen ventral. Corona, pronoto y escutelo de color amarillo-anaranjado, sobre el margen anterior de la corona impresiones musculares arqueadas negras, con una línea media sobre la mitad apical que se proyecta lateralmente hacia las impresiones musculares y posteriormente hasta el margen posterior de la cabeza, con una mácula negra que atraviesa cada ocelo; disco del pronoto con cuatro manchas irregulares grandes y varias más pequeñas sobre el margen anterior, amarillo-anaranjadas; escutelo con 
una mancha negra en forma de T. Alas anteriores con la porción basal hialina, con la venación claval ligeramente distintiva, margen claval, sutura claval y venas longitudinales, negras; alas posteriores con el lóbulo jugal moderadamente desarrollado que se extiende casi hasta la mitad basal del área claval de las alas anteriores en reposo. Clípeo amarillo-anaranjado con una línea media negra que delimita una pequeña área subtriangular anterior que se proyecta posteriormente y forma una barra transversal antes de la sutura transclipeal; clipelo negro. Pleuras torácicas usualmente negras en su mitad interna, el resto y patas de color amarilloanaranjado, tarsos oscuros.

Genitalia de la hembra. Esternito VII (Fig. 25A), en vista ventral, subrectangular, longitud media 0,6x el ancho máximo; márgenes laterales ligeramente paralelos y el margen posterior proyectado en su parte media formando un lóbulo ligeramente cóncavo; con microsetas dispersas. Esternito VIII (Fig. 25B), esclerotizado formando dos grandes placas. Pigóforo, en vista lateral, con el margen posterior proyectado moderadamente, ampliamente redondeado; superficie con numerosas macrosetas en casi toda la superficie. Valvifer I (Fig. 25C), en vista lateral, sin una forma definida; superficie casi completamente cubierta por procesos tegumentarios espiniformes, con algunas microsetas dispersas. Valva I (Fig. 25E), en vista lateral, eje sin el pliegue ventral; el resto de los caracteres como en la descripción de D. costalimai. Valvifer II (Fig. 25D), en vista lateral, superficie lisa con microsetas robustas cerca del punto de articulación. Valva II, en vista lateral, fuertemente ensanchada luego de la curvatura basal, margen dorsal en declive hacia el ápice y margen ventral rectilíneo; margen dorsal con numerosos dientes subtriangulares continuos, cada diente con dentículos sobre los márgenes anterior y posterior. Ductos visibles sobre los tres cuartos apicales alcanzando los dientes y los márgenes apical y apicoventral. Porción preapical aguda, ápice redondeado; ventralmente con prominencia preapical. Gonoplaca (Fig. 25G), en vista lateral, porción anterior estrecha, casi tan larga como la porción posterior, la cual es marcadamente expandida; superficie con finas macrosetas submarginales a lo largo del margen ventral; ápice ampliamente redondeado.

Observaciones taxonómicas. Dilobopterus dispar puede ser separada del resto de las especies del género por la morfología aedeagal del macho y la coloración del 
tegmen: presencia de una mácula redondeada preapical amarillo-anaranjada (Young 1977). La valva I del ovipositor de la hembra permite separarla de D. costalimai por no presentar el pliegue sobre el margen ventral.

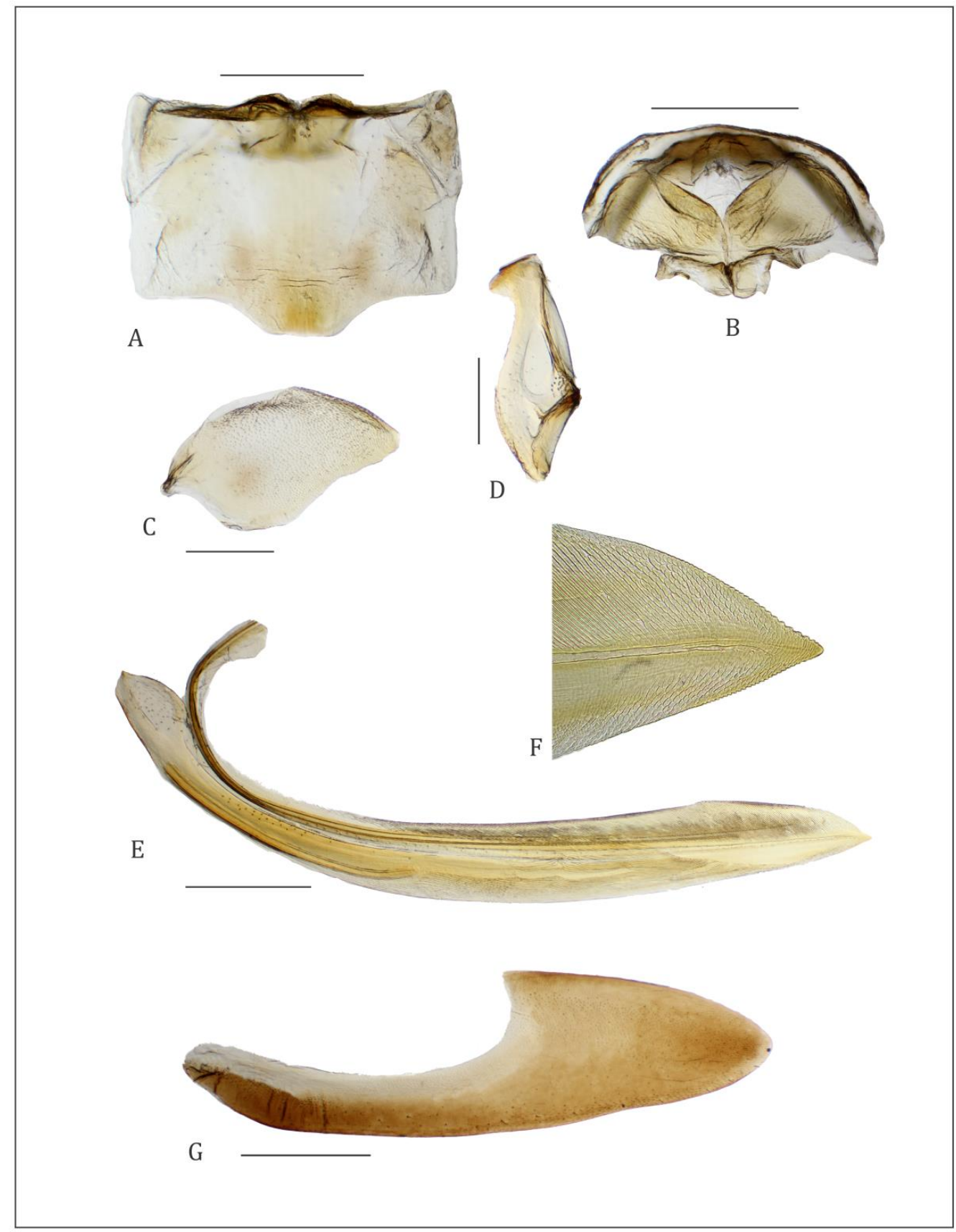

Figura 25. Genitalia de la hembra de Dilobopterus dispar (Germar): esternito abdominal VII (A), esternito abdominal VIII (B), valvifer I (C), valvifer II (D), valva I (E), gonoplaca (G). Escalas 0,5 mm: A, B, E, G; 0,3 mm: C, D. 
Distribución. Dilobopterus dispar fue registrada en Argentina, Bolivia, Brasil, y Uruguay. En la Argentina, fue hallada en la Isla Martín García (Young 1977). Se amplía la distribución para la provincia de Misiones (Loreto) (Figura 27).

Plantas hospedadoras. Prunus domestica L. (Rosaceae) (Hickel et al. 2001), Vitis vinifera L. (Vitaceae) (Ringenberg 2008).

Datos biológicos. Desconocidos.

Enemigos naturales. Desconocidos.

Importancia fitosanitaria. Desconocida.

Material estudiado. Lectotipo Tettigonia windmülleri Berg: 1q, Banda Oriental, Uruguay; paralectotipo, 1 s/abd., mismos datos que el lectotipo (MLP). ARGENTINA: (MLP): Misiones: Loreto, 1ð, Ogloblin col. (UNLP): Misiones: Ruta Provincial 102, 1 , $20 /$ I/2014, B. Defea col.

Clave para el reconocimiento de las especies del género Dilobopterus presentes en la Argentina.

1. Edeago, en vista lateral, con un lóbulo conspicuo dirigido posteriormente por encima del ápice aedeagal, separado del eje por una concavidad profunda; valva I del ovipositor de la hembra, en vista lateral, sin un pliegue sobre el margen ventral D. dispar

-. Edeago, en vista lateral, con un lóbulo conspicuo dirigido posteriormente por encima del ápice aedeagal, no separado del eje por una concavidad profunda; valva I del ovipositor de la hembra, en vista lateral, con un pliegue amplio sobre el margen ventral D. costalimai 


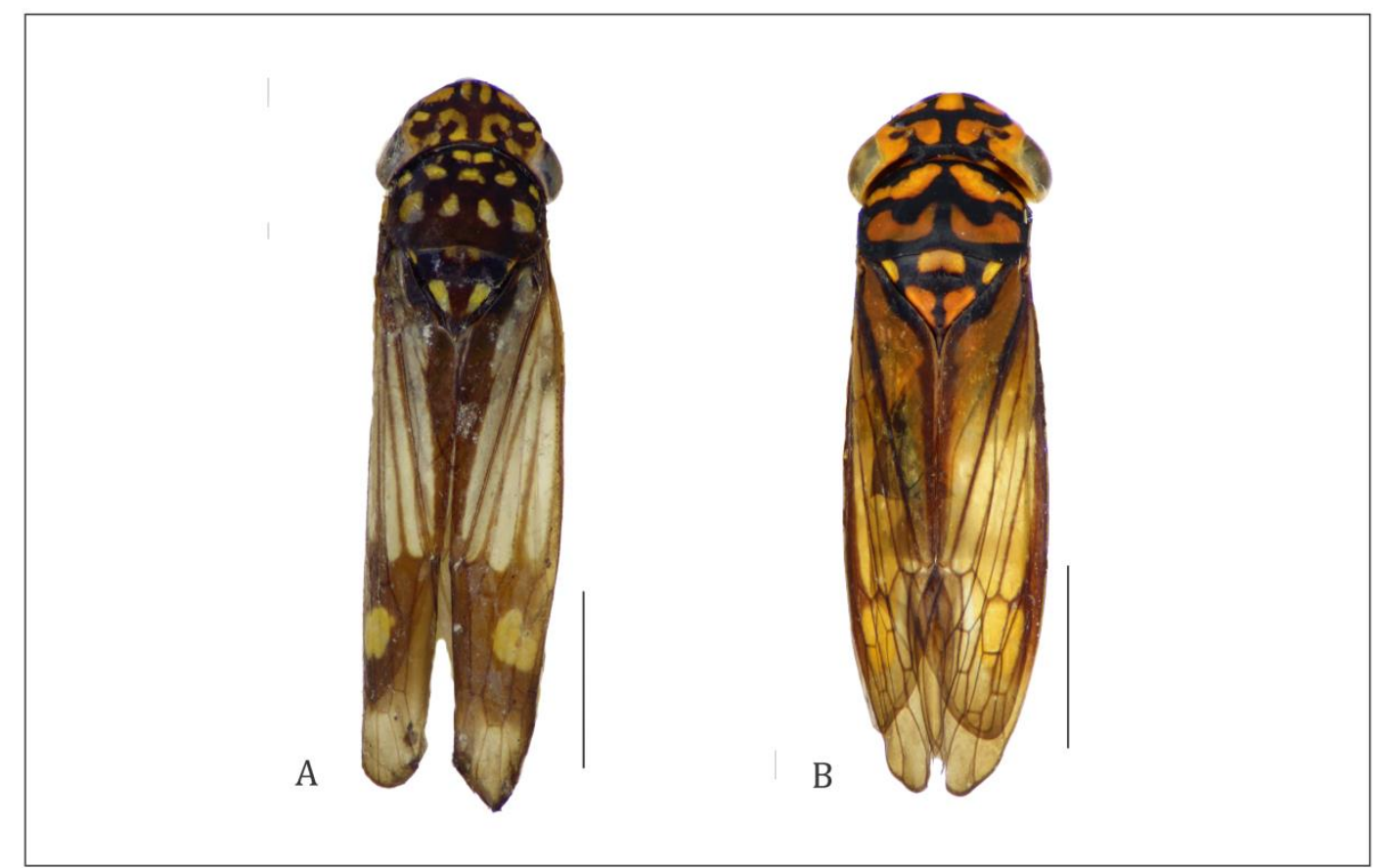

Figura 26. Especies de Dilobopterus presentes en Argentina. D. costalimai Young (A), D. dispar (Germar)(B). Escalas $2 \mathrm{~mm}$.

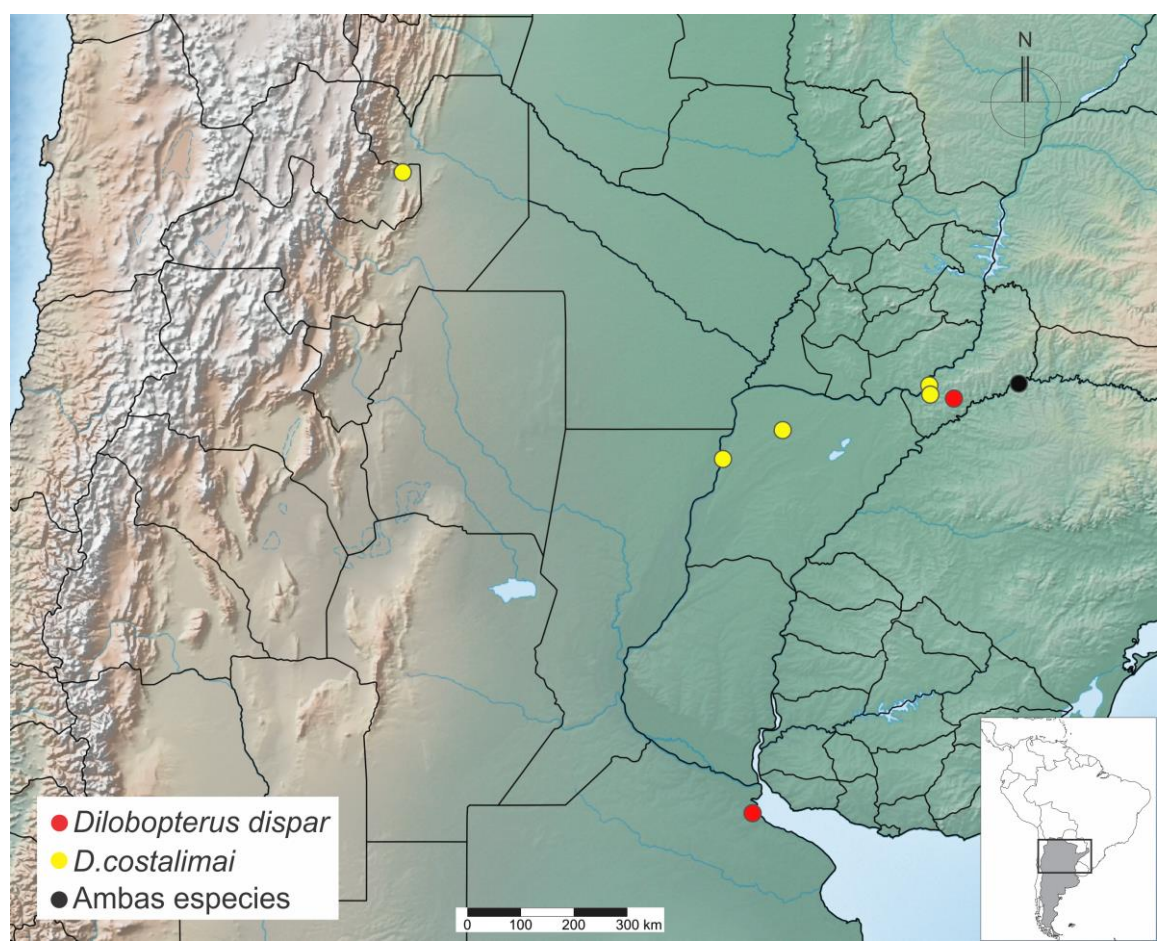

Figura 27. Distribución de las especies del género Dilobopterus Signoret en Argentina. 


\section{Género Draeculacephala Ball}

Especie tipo: Tettigonia mollipes Say 1940: 312

Longitud. 4,8-11,4 mm.

Cabeza. Corona fuertemente proyectada anteriormente, longitud de la corona variable entre especies; margen anterior, en vista dorsal, ampliamente redondeado a anguloso; ocelos sobre la línea que pasa entre los ángulos anteriores de los ojos, cada ocelo aproximadamente equidistante al ángulo anterior del ojo y a la línea media de la corona en los machos, ligeramente más cercano al ojo en las hembras. Superficie de la corona glabra, con una concavidad preapical, no esculturada. Suturas clipeales laterales extendiéndose sobre la corona y alcanzando los ocelos. Puentes antenales, en vista dorsal, no protuberantes, carenados dorsalmente, margen anterior, en vista lateral, ligeramente cóncavo. Transición corona-clípeo angulosa. Clípeo, en vista lateral, ligeramente convexo o aplanado, disco finamente granulado; impresiones musculares marcadas. Contorno del clipelo usualmente en continuidad con el perfil del clípeo o con la porción inferior ligeramente horizontal, superficie glabra.

Tórax. Ancho del pronoto menor que el ancho transocular, márgenes laterales subparalelos y margen posterior ligeramente cóncavo; carena dorsopleural ausente; superficie del disco transversalmente rugoso, glabro. Superficie del escutelo por detrás del surco transversal no esculturado. Alas anteriores con la porción membranosa estrecha incluyendo las celdas apicales y extendiéndose proximalmente a lo largo del margen costal hasta la base alar; nervaduras marcadas; con cuatro celdas apicales, la base de la cuarta más próxima que la base de la tercera; con un plexo de nervaduras apical; tegmen de textura coriácea sin esculturación. En las hembras, las alas en reposo ocultan, o no, el ovipositor. Fórmula setal del fémur posterior 2:1:1; longitud del primer tarsómero aproximadamente igual que la longitud combinada del segundo y tercer tarsómeros; superficie plantar usualmente con dos hileras paralelas de setas, en algunas especies una o las dos hileras poseen setas proximales paleadas.

Genitalia del macho. Pigóforo moderadamente proyectado posteriormente, ápice subagudo, con algunas macrosetas cortas sobre el margen posterodorsal, sin 
procesos. Placas subgenitales triangulares, separadas a lo largo de toda su longitud y con los ápices débilmente esclerotizados; extendiéndose posteriormente hasta el ápice del pigóforo, cada una con una hilera de macrosetas a lo largo del margen lateral. Estilos más cortos que el conectivo, ápice oblicuamente truncado; con lóbulo preapical. Conectivo en forma de Y con el eje mucho más extenso que las ramas. Edeago corto, simétrico, articulado con el conectivo, con o sin procesos. Paráfisis presentes, pares, simétricas, con ramas estrechas y sin base.

Genitalia de la hembra. Esternito abdominal VII, en vista ventral, margen posterior ligeramente proyectado medialmente, redondeado o truncado. Esternito abdominal VIII membranoso. Pigóforo con el ápice estrecho y redondeado, con algunas macrosetas cerca de los márgenes posterodorsal y posteroventral. Ovipositor con la segunda valva expandida luego de la curvatura basal llevando numerosos dientes sobre el margen dorsal; margen ventral convexo. Con dientes basales redondeados y cuadrangulares extendiéndose casi hasta el ápice; cada diente con numerosos dentículos. Márgenes preapicales dorsal y ventral denticulados, sin prominencia preapical.

Coloración. Cabeza y parte del tórax amarillenta, a veces con máculas o bandas castaño oscuras. Tegmen de color verdoso con nervaduras más claras.

Observaciones taxonómicas. Draeculacephala ha sido objeto de estudio de varios autores (Young \& Davidson 1959, Hamilton 1985); posteriormente, Dietrich (1994), presentó un estudio en el que testea la monofilia del género, esclarece sus relaciones filogenéticas y reve caracteres morfológicos, proponiendo que el género puede distinguirse del resto de los Cicadellini por las sinapomorfías: corona fuertemente deprimida en su parte media y proyectada anteriormente con el margen anterior subanguloso; alas anteriores con un plexo de venas apicales; genitalia del macho con paráfisis bien desarrolladas y simétricas, eje edeagal con amplios rebordes laterales. Este género incluye tres linajes principales, de los cuales el grupo neotropical se distingue por presentar una hilera o banda de setas basolaterales en el pigóforo de los machos. 
Distribución. Neártica y Neotropical con registros desde México, hasta el norte de la Argentina (Dietrich 1994, McKamey 2009).

Otros datos. Draeculacephala es un género muy común y ampliamente distribuído en América, e incluye a las especies de cicadellini más abundantes en las zonas templadas de Norteamérica (Dietrich 1994).

El género Draeculacephala cuenta con 25 especies descriptas de las cuales una está presente en la Argentina.

\section{Draeculacephala tucumanensis (Signoret) (Figura 28)}

Draeculacephala tucumanensis Dietrich 1994: 93 [n.sp.]

Diagnosis. Especímenes medianos, longitud: $\widehat{ึ} \overbrace{}^{\lambda}$ 5,7-5,9 mm, 우 7,1-7,8 mm. Márgenes anterolaterales de la cabeza, en vista dorsal, fuertemente convexos. Coloración de la cabeza, borde anterior del pronoto y mesonoto amarillentos, porción preapical de la cabeza con una mácula alargada castaño oscura a negra de posición media; tegmen color verde opaco con nervaduras amarillentas (Dietrich 1994).

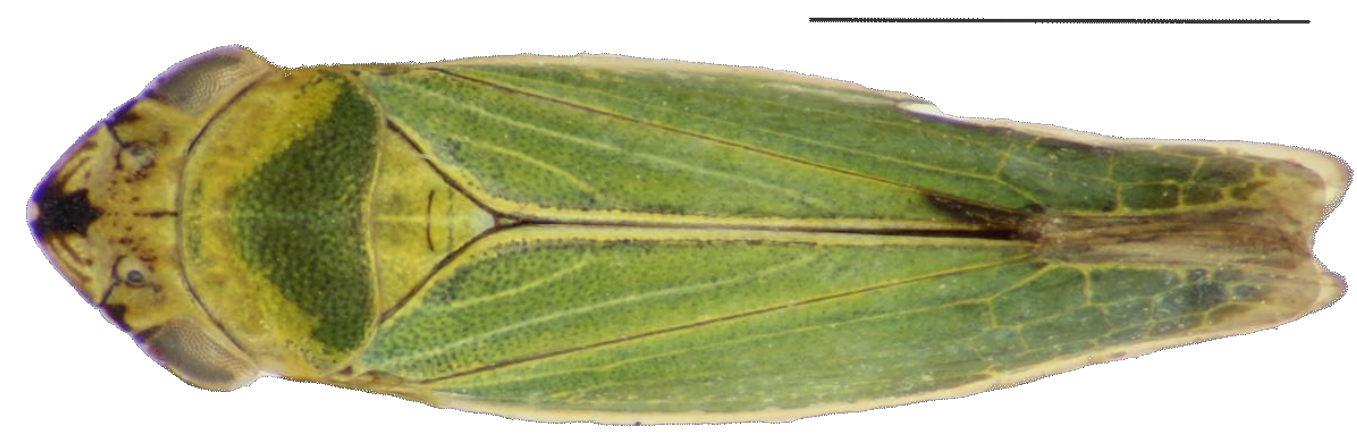

Figura 28. Hábito dorsal de Draeculacephala tucumanensis Dietrich. Escala $2 \mathrm{~mm}$.

Observaciones taxonómicas. Esta especie fue erroneamente identificada como $D$. portola Ball por Remes Lenicov \& Tesón (1985). 
Distribución. Argentina, con registros en la provincia de Tucumán (Dietrich 1994). Se amplía la distribución para Salta (Aguaray, Rosario de Lerma), Jujuy (Manantiales), La Rioja (Chilecito, Famatina) y Buenos Aires (La Plata) (Figura 29).

Plantas hospedadoras. Oriza sativa L. (Poaceae) (Remes Lenicov \& Tesón 1985).

Enemigos naturales. Desconocidos.

Observaciones biológicas. Desconocidas.

Importancia fitosanitaria. Desconocida.

Material estudiado. ARGENTINA: (MLP): Salta: Aguaray, $1 q$ 1 $1 \widehat{\delta}, 5 / \mathrm{IV} / 1954$, Maldonado B. col; Rosario de Lerma, 1 $\widehat{\delta}, 17 /$ V/1994, Virla E. leg. Jujuy: Manantiales, 1 s/abd., 3/II/1958, Torres-Ferreyra leg. La Rioja: Famatina, 1 우 10, 22/II/1959, TorresGardella leg. Buenos Aires: La Plata (Los Hornos), $1 \delta^{\lambda} 2$ s/abd., XII/1974, Remes Lenicov leg. (IFML) La Rioja: Chilecito, $2 \hat{\jmath} \widehat{\partial}, 20 / \mathrm{I} / 1960$, A. Willink col. (UNLP): Salta: Yatasto, $7 ㅇ ㅜ ㅇ ㅜ 1 \hat{\delta}$, 24/XI/2015, Virla E. col. Tucumán: Lules, 4우우 4đ̋ 


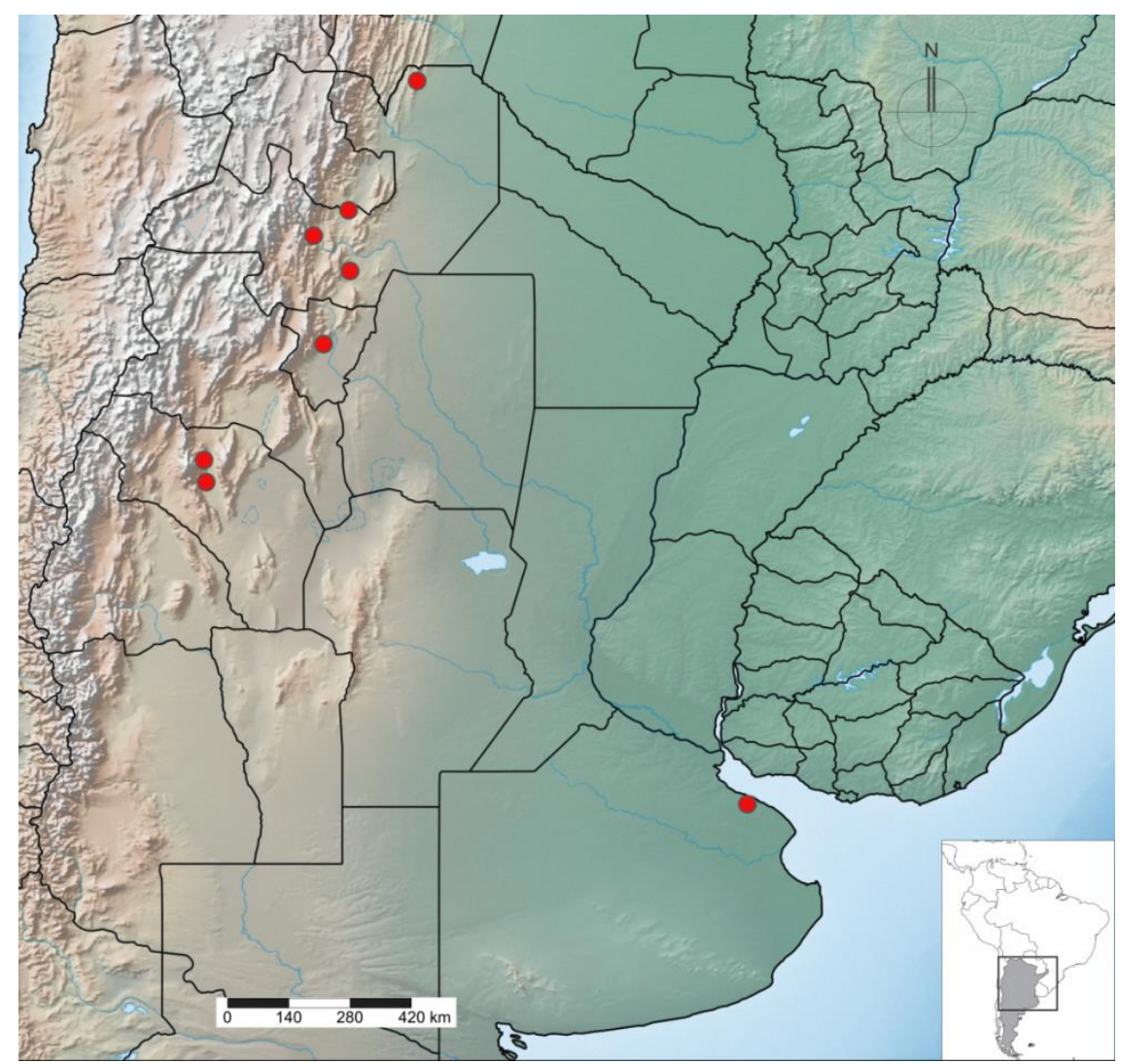

Figura 29. Distribución de Draeculacephala tucumanensis Dietrich en Argentina. 


\section{Género Ferrariana Young}

Especie tipo: Tettigonia trivittata Signoret 1854:349

Longitud total 5,7-7,5 mm.

Cabeza. Moderadamente proyectada, longitud media de la corona $0,6-0,75 x$ el ancho interocular; margen anterior, en vista dorsal, estrechamente redondeado; ocelos localizados sobre o por delante de la línea que pasa entre los ángulos anteriores de los ojos; superficie de la corona glabra, no esculturada, con una concavidad superficial atravesando los ocelos. Puentes antenales, en vista dorsal, no protuberantes, con el margen anterior, en vista lateral, rectilíneo y vertical. Transición corona-clípeo redondeada. Clípeo convexo o ligeramente achatado en su porción media; impresiones musculares débilmente marcadas.

Tórax. Ancho del pronoto igual o menor que el ancho transocular de la cabeza, márgenes laterales paralelos o ligeramente convergentes anteriormente, carena dorsopleural, en vista lateral, completa, disco glabro, no esculturado; superficie del escutelo por detrás del surco transversal débilmente estriado. Alas anteriores con el área membranosa incluyendo las cuatro celdas apicales, venas no marcadas ni elevadas; con tres celdas anteapicales cuyas bases son proximales al ápice claval, celda anteapical mediana ensanchada en el ápice. En las hembras, las alas en reposo ocultan el ovipositor. Fórmula setal del fémur posterior 2:1:1; longitud del primer tarsómero mayor que la longitud combinada del segundo y tercer tarsómero, con dos hileras de setas paralelas sobre la superficie plantar.

Genitalia del macho. Pigóforo fuertemente proyectado posteriormente, margen posterior estrechamente redondeado, con numerosas macrosetas en la mitad apical del disco, sin procesos. Placas subgenitales estrechas, no extendiéndose posteriormente hasta el ápice del pigóforo; superficie con macrosetas uniseriadas. Estilos no extendiéndose posteriormente hasta el ápice del conectivo, truncados apicalmente. Edeago con apodemas basales tan largos como el eje que se extiende posterodorsalmente, sin procesos. Paráfisis birramosas, simétricas.

Genitalia de la hembra. Esternito abdominal VII moderadamente proyectado, ápice ligeramente emarginado. Ovipositor con la segunda valva expandida, margen ventral convexo; margen dorsal con dientes los cuales llevan numerosos dentículos. 
Coloración. Las especies presentan una banda paralela al margen anterior de la corona roja o anaranjada.

Observaciones taxonómicas. Ferrariana Young está relacionado con Graphogonalia Young del cual puede separarse por la nerviación del tegmen y el patrón de coloración de la corona. También es cercano al género Coronigonalia Young del cual se diferencia por la ausencia de procesos en el pigóforo de los machos, y por tener la segunda valva del ovipositor expandida (Young 1977). Las especies del género presentan un característico patrón de coloración bandeado alternando bandas de color verde y anaranjado, que junto con la morfología edeagal de los machos permiten separarlo del resto de los géneros de la tribu.

Distribución. Neotropical con registros en Argentina, Bolivia, Brasil, Colombia, Costa Rica, Panamá, Perú y Paraguay (Wilson et al. 2009).

El género Ferrariana cuenta con dos especies descriptas de las cuales una está presente en la Argentina.

Ferrariana trivittata (Signoret) (Figura 30, 31)

Tettigonia pallipes Walker 1851: 765 [n. sp.].

A Graphocephala trivittata Metcalf 1965: 384

Tettigonia pallipes Young 1965: 186 [designación de lectotipo]

A Ferrariana trivittata Young 1977: 1032

Tettigonia trivittata Signoret 1854: 349 [nom. nov. para Tettigonia pallipes Walker 1851]

Ferrariana trivittata Young 1977: 1032 [n. comb.]

Diagnosis. Cabeza con una banda marginal anterolateral anaranjada que se arquea y aleja ligeramente del margen en cada costado, dejando una pequeña zona marginal anterolateral descubierta. Edeago del macho, en vista lateral, con el eje recto (Young 1977). Pronoto con un par de máculas subtriangulares sobre el disco y una banda paralela al margen anterior interrumpida en su porción media, anaranjadas. 


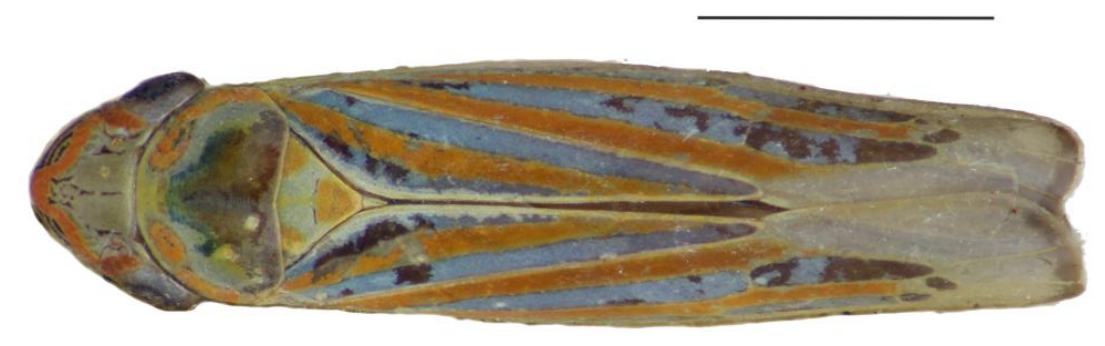

Figura 30. Hábito dorsal de Ferrariana trivitatta (Signoret). Escala $2 \mathrm{~mm}$.

Genitalia femenina. Esternito VII (Fig. 31A), en vista ventral, fuertemente proyectado posteriormente, casi tan largo como ancho; márgenes laterales fuertemente convergentes posteriormente, superficie cubierta por procesos tegumentarios espiniformes, con microsetas agrupadas a cada lado de la línea meddia. Esternito VIII (Fig. 31B) mayormente membranoso, con estrías horizontales débilmente esclerotizadas. Pigóforo (Fig. 31C), en vista lateral, subovalado con el margen posterior moderadamente proyectado; macrosetas robustas sobre la proyección posterior extendiéndose ventralmente hacia la porción anterior. Valvifer I (Fig. 31D), en vista lateral, subovalado con el margen anterodorsal ligeramente más esclerotizado. Valva I (Fig. 31G), en vista lateral, lanceolada, mitad basal del eje fuertemente expandido estrechándose hacia el ápice; márgenes dorsal y ventral casi paralelos, con una escotadura superficial sobre el margen dorsal en la porción basal. AED extendiéndose sobre los tres cuartos apicales del eje, formada por procesos tegumentarios rectangulares en la mitad basal y escamiformes en la mitad apical, no imbricados; AEV restringida al cuarto apical del eje, formada por procesos escamiformes que se extienden cubriendo la superficie preapical. EAV larga, extendida casi hasta la mitad basal del eje. Margen preapical dorsal denticulado, ápice (Fig. 31H) puntiagudo. Valvifer II (Fig. 31F), en vista lateral, subrectangular, estrecho, superficie lisa con microsetas robustas cerca del punto de articulación (PA). Valva II (Fig. 31I), en vista lateral, expandida luego de la curvatura basal con el margen dorsal del eje recto; base de la porción expandida del eje con dientes (Fig. 31J) subtriangulares de cúspide roma los cuales están ampliamente separados del resto de los dientes que disminuyen su tamaño cerca de la porción preapical, cada diente subtriangulares con el margen posterior en declive y más extenso que el anterior, llevando numerosos dentículos sobre ambos márgenes o solamente sobre el margen 
posterior. Ductos débilmente marcados, alcanzando los dientes y el ápice; base de la porción expandida con un grupo de ductos cortos e irregularmente dispuestos. Porción preapical aguda con los márgenes dorsal y ventral denticulados, ápice (Fig. $31 \mathrm{~K}$ ) redondeado; ventralmente sin prominencia preapical. Gonoplaca (Fig. 31L), en vista lateral, porción anterior estrecha, $0,85 \mathrm{x}$ la longitud de la porción posterior, la cual es marcadamente expandida; superficie con numerosos procesos tegumentarios espiniformes en la porción preapical que se extienden anteriormente hasta la porción basal a lo largo del margen ventral, con numerosas microsetas dispersas submarginales; ápice (Fig. 31M) redondeado.

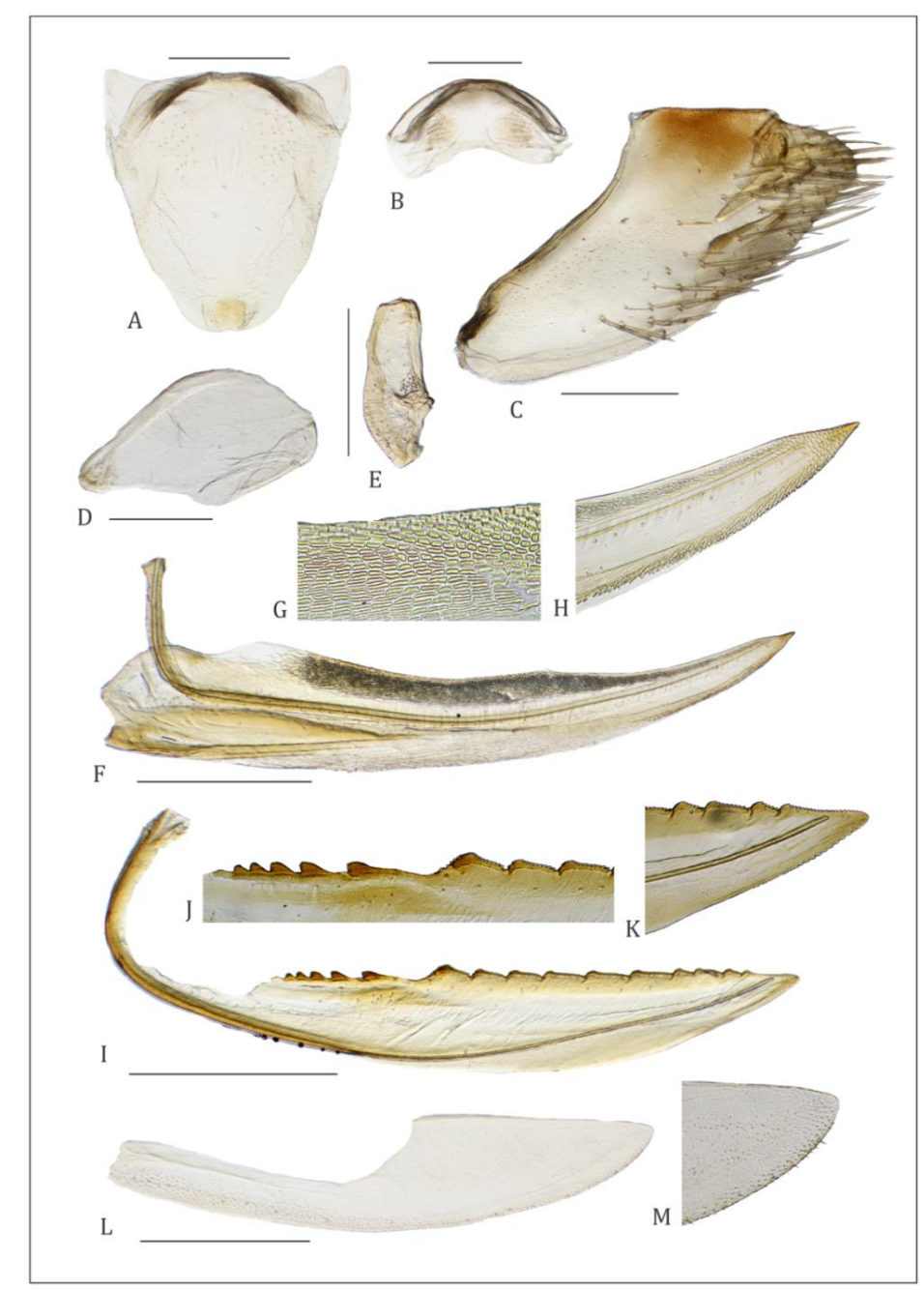

Figura 31. Genitalia de la hembra de Ferrariana trivittata (Signoret): esternito abdominal VII (A), esternito abdominal VIII (B), pigóforo (C), valvifer I (D), valvifer II (F), valva I (G), ápice valva I (H), valva II (I), dientes valva II (J), ápice valva II (K), gonoplaca (L), ápice de la gonoplaca (M). Escala 0,5 mm: A, B, C, I, L; 0,3 mm: D, E. 
Observaciones taxonómicas. Ferrariana trivittata se distingue de la otra especie del género (F. submarginalis (Osborn)) por la morfología del edeago, el cual, en vista lateral, tiene el eje corto y recto, y por el patrón de coloración de la cabeza (Young 1977) y el pronoto. La coloración de esta especie permite claramente diferenciarla del resto de las especies de la tribu.

Distribución. Ferrariana trivittata cuenta con registros en Argentina, Bolivia, Brasil, Colombia, Costa Rica, Panamá, Paraguay y Perú (Young 1977). En la Argentina está presente en la provincia de Misiones (Remes Lenicov et al. 1999) (Figura 32).

Plantas hospedadoras. Citrus sinensis (L.) Osb. (Rutaceae)(Remes Lenicov et al. 1999), Prunus domestica L. (Hickel et al. 2001).

Datos biológicos. En la Argentina, se encuentran poblaciones asociadas a la vegetación circundante a Citrus sinensis (L.) Osb. donde es recolectada de manera abundante durante los meses de primavera y otoño, siendo muy escasa su presencia sobre los cítricos (Remes Lenicov et al. 1999).

Enemigos naturales. Desconocidos.

Importancia fitosanitaria. Es vector comprobado de la bacteria Xylella fastidiosa subsp. pauca en Brasil, bacteria causal de la Clorosis Variegada de los Cítricos (CVC). Presenta un 1,9\% de eficiencia de transmisión (Gravena et al. 1998).

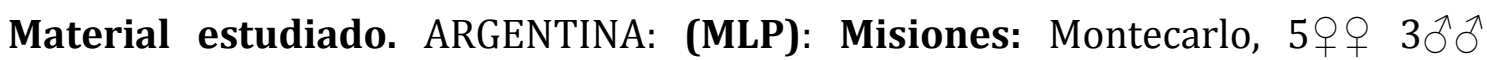
1s/abd., I/1995-16/II/1995, de Coll col.; Loreto, 2 우 1§, s/datos, Ogloblin col. (IFML): Misiones: Apóstoles, 1 s/abd., 4-27/II/1981, R. Golbach col. 


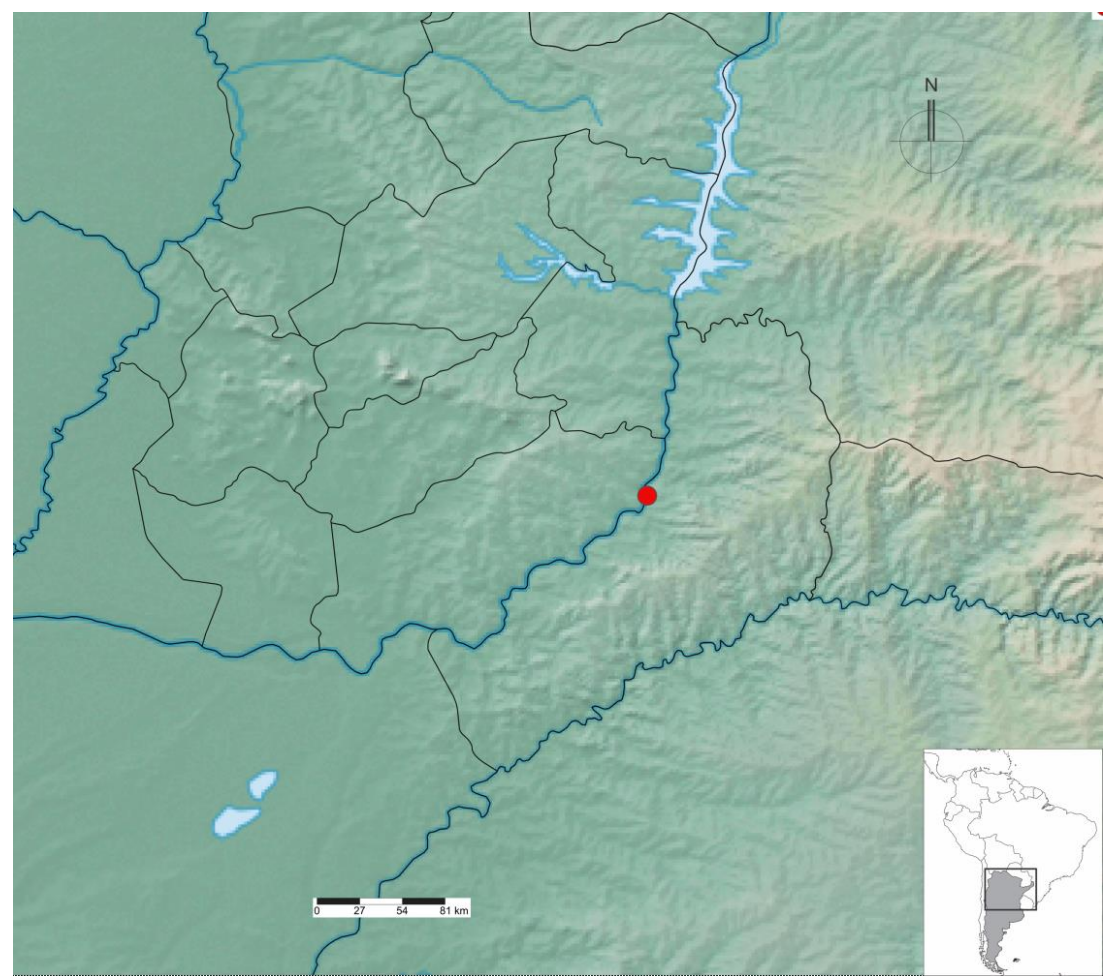

Figura 32. Distribución de Ferrariana trivittata (Signoret) en Argentina. 


\section{Género Hortensia Metcalf \& Bruner}

Especie tipo: Tettigonia similis Walker 1851

Longitud 4,0-7,7mm.

Cabeza. Margen anterior, en vista dorsal, ampliamente redondeado; longitud media de la corona 0,5-0,8x el ancho interocular; superficie del disco de la corona convexa, no esculpturada, glabra; ocelos usualmente alineados con la línea que pasa por los ángulos anteriores de los ojos, excepcionalmente por delante. Suturas clipeales laterales extendiéndose hasta los ocelos. Puentes antenales, en vista dorsal, no protuberantes, margen anterior, en vista lateral, vertical o levemente oblicuo, en ocasiones, ligeramente cóncavo. Transición corona-clípeo redondeada. Clípeo, en vista lateral, convexo con impresiones musculares usualmente marcadas; sutura transclipeal completa o interrumpida medialmente; contorno del clipelo en continuidad con el perfil del clípeo.

Tórax. Ancho del pronoto igual o menor que el ancho transocular, márgenes laterales paralelos o ligeramente convergentes anteriormente, margen posterior cóncavo; superficie del disco glabro, ocasionalmente rugoso; carena dorsopleural, en vista lateral, completa; superficie del escutelo detrás del surco transversal no estriado. Alas anteriores coriáceas, no esculpturadas; área membranosa que incluye todas las celdas apicales; con cuatro celdas apicales, base de la cuarta más proximal que la base de la tercera; con tres celdas anteapicales cerradas; venas no marcadas; sin plexo de venas anteapical. En las hembras, las alas en reposo ocultan el ovipositor. Fórmula setal del fémur posterior 2:1:1. Longitud del primer tarsómero mayor a la longitud combinada del segundo y el tercer tarsómeros; superficie plantar con dos hileras paralelas de setas pequeñas.

Genitalia del macho. Pigóforo, en vista lateral, fuertemente proyectado posteriormente, con la porción apical estrecha y el margen posterior redondeado a anguloso, con un grupo de macrosetas anteapicales. Placas subgenitales triangulares, que alcanzan posteriormente el ápice del pigóforo, superficie con macrosetas longitudinalmente uniseriadas. Estilos extendiéndose hasta el ápice del conectivo, o sobrepasándolo; con lóbulo preapical y ápice oblicuamente truncado. Conectivo en 
forma de $\mathrm{Y}$, con los brazos ampliamente divergentes. Edeago corto y sin procesos. Existen ligeras diferencias intraespecíficas en la forma del edeago. Paráfisis ausentes.

Genitalia de la hembra. Esternito abdominal VII, en vista ventral, con el margen posterior con una corta proyección media, ligeramente emarginada. Esternito abdominal VIII membranoso, sin escleritos. Pigóforo con macrosetas dispersas en la mitad posterior. Ovipositor con la segunda valva expandida luego de la curvatura basal; margen dorsal con dientes cuadrangulares, cada uno con numerosos dentículos; márgenes anteapicales dorsal y ventral con denticulaciones.

Coloración. Las especies de Hortensia presentan un patrón de coloración muy similar; la cabeza, el margen anterior del pronoto y el escutelo de color amarillo pálido; la coloración del disco pronotal y el tegmen varía de verde brillante a verde oliva. Corona, margen anterior del pronoto y escutelo con patrón de líneas negras irregulares.

Observaciones taxonómicas. Hortensia comparte numerosas características con el género neotropical Kapateira Young el cual podría confirmarse como sinónimo de Hortensia a partir del estudio de las hembras (actualmente desconocidas). Asimismo, las especies de Hortensia son de menor tamaño, el pigóforo de los machos está más desarrollado y presenta setas restringidas a la porción posterior, el conectivo es claramente en forma Y y el edeago es más corto (Young 1977).

Distribución. Hortensia es un género ampliamente distribuido en América, presente en las regiones neártica y neotropical (Oman, Knight \& Nielson 1990), con registros en Argentina, Bolivia, Brasil, Colombia, Costa Rica, Cuba, Ecuador, Estados Unidos, Guatemala, Guayana, Guayana Francesa, Haití, Jamaica, México, Panamá, Paraguay, Perú, Puerto Rico, República Dominicana, Surinam, Trinidad y Venezuela (Young 1977).

El género Hortensia posee tres especies descriptas, sólo una presente en la Argentina. 
Hortensia similis (Walker) (Figura 33-34)

Tettigonia similis Walker 1851 [n. sp.]

Tettigonia prolixa Fowler 1900

Cicadella cuneatula Osborn 1926

Hortensia similis Metcalf \& Bruner 1936 [n. comb.]

Diagnosis. Cabeza, margen anterior del pronoto, mesoescudo y escutelo de color amarillo, disco pronotal y tegmen verde intenso. Corona y margen anterior del pronoto con numerosas líneas negras: con una línea mediana bifurcada anteriormente en donde conforma los lados posteriores de un triángulo; con una "C" a cada lado de la línea media y algunas máculas pequeñas cerca de cada ocelo, negras. Clípeo negro; tórax y patas amarillos; abdomen negro (Walker 1851). Edeago, en vista ventral, con el eje simple, ligeramente más angosto hacia el ápice (Young 1977).

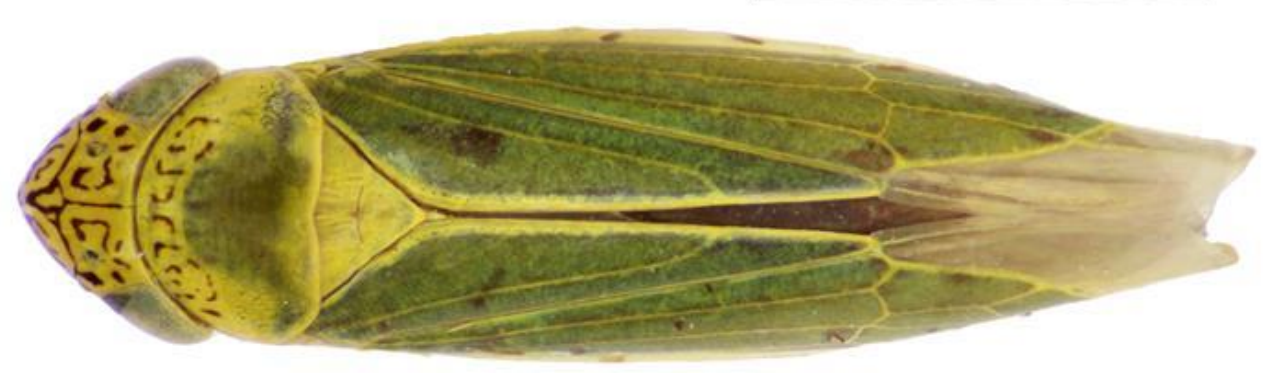

Figura 33. Hábito dorsal de Hortensia similis (Walker). Escala 2 mm.

Genitalia de la hembra. Esternito VII (Fig. 34A), en vista ventral, corto, longitud media 0,6x el ancho máximo; márgenes laterales y posterior subangulosos, los márgenes laterales convergentes posteriormente, superficie cubierta por procesos tegumentarios espiniformes, con microsetas agrupadas en cada lado. Esternito VIII membranoso. Pigóforo (Fig. 34B), en vista lateral, subovalado con el margen posterior proyectado moderadamente; superficie de la mitad apicoventral con numerosas macrosetas robustas, algunas submarginales extendiéndose anteriormente. Valvifer I (Fig. 34C), en vista lateral, subovalado con el margen anterodorsal más esclerotizado. Valva I (Fig. 34E), en vista lateral, lanceolada, eje expandido, ligeramente rectilíneo con el margen basal irregularmente redondeado; AED (Fig. 34F) extendiéndose sobre los seis séptimos apicales del eje, formada por procesos tegumentarios escamiformes 
imbricados, dispuestos en líneas oblicuas; AEV restringida a la porción preapical del eje, formada por procesos escamiformes que se esxtienden cubriendo la superficie apical. EAV larga, extendida sobre la mitad basal del eje. Ápice (Fig. 34G) puntiagudo. Valvifer II (Fig. 34D), en vista lateral, superficie lisa con microsetas robustas cerca del punto de articulación (PA). Valva II (Fig. 34H), en vista lateral, fuertemente expandida luego de la curvatura basal con el margen dorsal del eje regularmente convexo, llevando aproximadamente 24 dientes (Fig. 34I) discontiguos; cada diente subtriangular con el margen posterior en declive, y más extenso que el anterior, llevando numerosos dentículos subtriangulares. Ductos a lo largo de todo el eje, alcanzando los dientes y el ápice. Porción preapical acuminada con los márgenes dorsal y ventral denticulados, ápice (Fig. 34J) redondeado; ventralmente sin prominencia preapical. Gonoplaca (Fig. 34K), en vista lateral, porción anterior estrecha, casi tan larga como la porción posterior, la cual es marcadamente expandida; superficie con numerosos procesos tegumentarios espiniformes en la porción preapical que se extienden anteriormente hasta la porción basal a lo largo del margen ventral, con algunas microsetas dispersas submarginales; ápice redondeado.

Observaciones taxonómicas. Hortensia similis se distingue del resto de las especies del género por la morfología del edeago, el cual, en vista ventral, es simple con el margen apical ligeramente emarginado, y no abruptamente expandido (Young 1977).

Distribución. Hortensia similis es una especie ampliamente distribuida en América, con registros en Argentina, Bolivia, Brasil, Colombia, Costa Rica, Cuba, Dominica, Ecuador, Estados Unidos, Guatemala, Guayana, Guayana Francesa, Haití, Islas Vírgenes de los Estados Unidos, Jamaica, México, Panamá, Paraguay, Perú, Puerto Rico, República Dominicana, San Vicente, Surinam, Trinidad y Venezuela y Nicaragua (Maes \& Godoy 1993). En la Argentina, H. similis está presente en las provincias de Jujuy, Salta, Misiones, Chaco, Corrientes, Entre Ríos, Santa Fe y Buenos Aires (Remes Lenicov et al. 2006). Se amplía su distribución para las provincias de La Rioja (Chilecito), Tucumán y Formosa (Figura 35). 


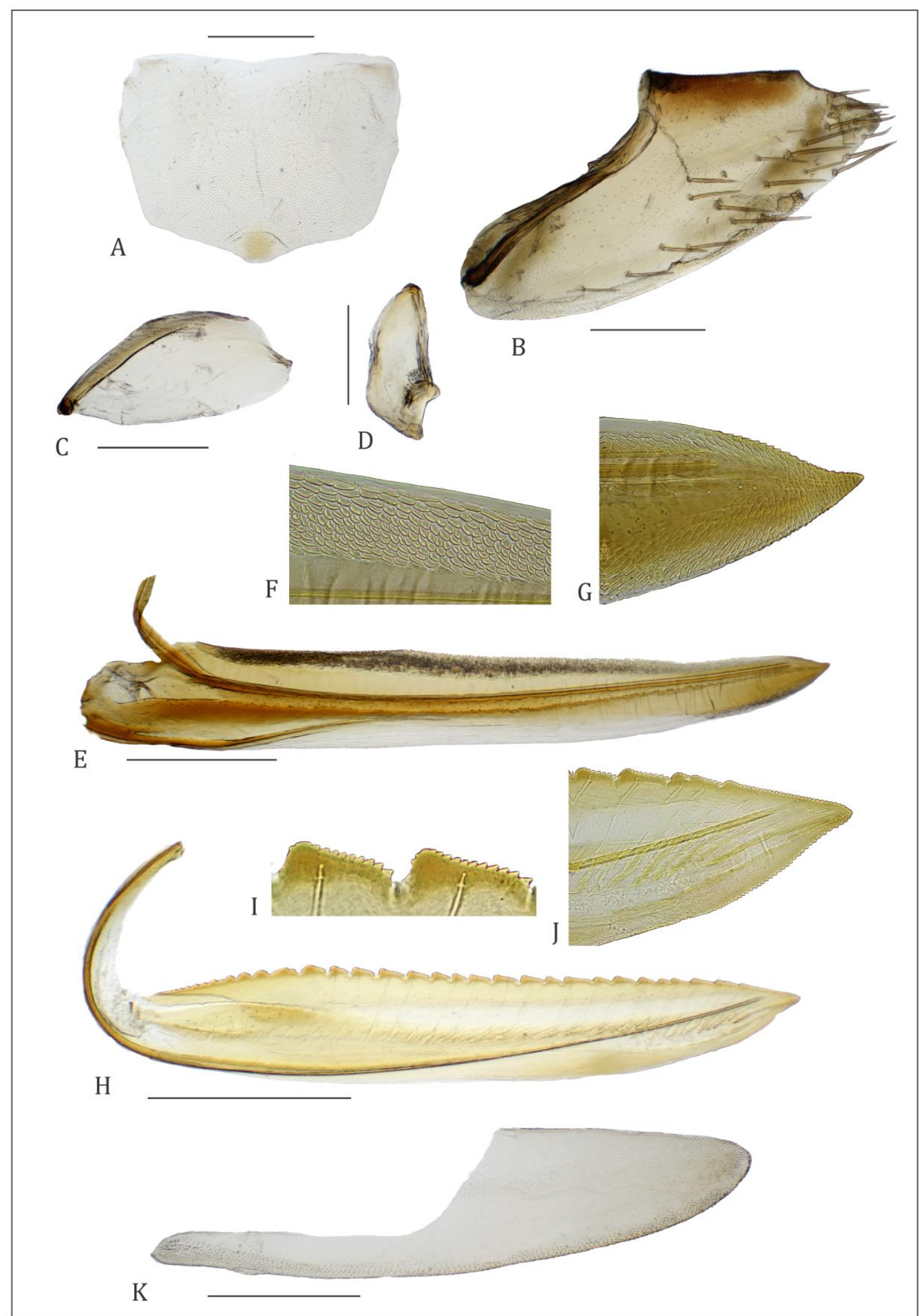

Figura 34. Genitalia de la hembra de Hortensia similis (Walker): esternito VII (A), pigóforo (B), valvifer I (C), valvifer II (D), valva I (E), detalle AED valva I (F), ápice valva I (G), valva II (H), dientes valva II (I), ápice valva II (J), gonoplaca (K). Escalas 0,5 mm A, B, E, H, K; 0,3 mm: C, D. 
Plantas huéspedes. Sorghum halepense L. (Poaceae), Zea mays L. (Poaceae), Medicago sativa L. (Poaceae), Hordeum vulgare L. (Poaceae), Vigna unguiculata L. (Fabaceae), Panicum barbino Trin. (Poaceae), Dolichos sp. (Fabaceae), Bidens sp. (Asteraceae), Fragaria sp. (Rosaceae), Crotalaria sp. (Fabaceae), Phaseolus vulgaris L. (Fabaceae), Cynodon sp. (Poaceae), Paspalum sp. (Poaceae), Pennisetum sp. (Poaceae), "grasses", "pastos indica”, “caña”, "Leguminoseae”, “Canavalia”, Citrus sinensis (L.) Osb. (Rutaceae), Elaeis sp. (Arecaceae), Lactuca sp. (Asteraceae), Brassica sp. (Brassicaceae), Carica sp. (Caricaceae), Ipomeas sp. (Convolvulaceae), Sida sp. (Malvaceae), Hibiscus sp. (Malvaceae), Digitaria sp. (Poaceae), Panicum sp. (Poaceae), Cynodon sp. (Poaceae), Eriochloa sp. (Poaceae), Cenchrus sp. (Poaceae), Coffea sp. (Rubiaceae), Lycopersicon sp. (Solanaceae), Capsicum sp. (Solanaceae) (Maes \& Godoy 1993, Remes Lenicov et al. 1999, Young 1977). Cassia reticulata (Fabaceae)(Gallego \& Velez 1992), Glycine max L. (Fabaceae), Hibiscus esculentum L. (Malvaceae), Oriza sativa L. (Poaceae), Rubus glaucus Benth (Rosaceae) (Posada 1989), Prunus domestica L. (Rosaceae)(Hickel et al. 2001) y Vitis vinífera (Vitaceae)(Ringenberg 2008) y Brassica napus L. var. oleífera (Brassicaceae) (Paris et al. 2012).

Datos biológicos. Es una especie muy abundante en la vegetación asociada a plantaciones citrícolas, en donde cumple su ciclo (Paiva et al. 1996, Yamamoto \& Gravena 2000). En la Argentina, se encuentran poblaciones asociadas a la vegetación asociada a Citrus sinensis (L.) Osbeck (Remes Lenicov et al. 1999). Se registra por primera vez alta densidad de especímenes en la maleza asociada a plantaciones de Citrus paradisi Macfadyen y C. limon (L.) Burm. en la provincia de Formosa.

Enemigos naturales. Strepsiptera de la familia Halictophagidae (Remes Lenicov \& Tesón 1985), Anagrus breviphragma Soyka (Hymenoptera: Mymaridae) (Luft Albarracín et al. 2009), himenópteros de la familia Dryinidae (Remes Lenicov et al. 1999); nematodes de la familia Mermithidae fueron registrados parasitando ejemplares del estadio larval V (Dellapé 2013). Se registran nematodes mermítidos parasitando un adulto hembra y larvas del $\mathrm{V}$ estadio en la localidad de Bella Vista, Corrientes. 
Importancia fitosanitaria. Especie propuesta por Gravena et al. (1998) como posible vector de Xylella fastidiosa subsp. pauca en Brasil, bacteria causal de la Clorosis Variegada de los Cítricos (CVC). Estudios recientes de detección de Xf. en especímenes de esta especie recolectados en Misiones (de Coll et al. 2000a) y Entre Ríos (Dellapé et al. 2016) resultaron positivos; debido a ésto y a su alta abundancia en el agroecosistema citrícola podría considerarse como reservorio y vector potencial de la bacteria. Asimismo, diversos autores mencionan a $H$. similis como causante de daños que se atribuyen, hasta el presente, al efecto mecánico del aparato bucal durante la alimentación (Remes Lenicov \& Tesón 1985). En Colombia es considerada especie plaga de pasturas (Bautista et al. 2014).

Material estudiado. ARGENTINA: (MLP): Salta: Pocitos, $1 q 1 \hat{\jmath}, 24 / \mathrm{XI} / 1954, \mathrm{M}$. Birabén col. Chaco: Estancia Anello, 1q, 10-15/III/1959, M. birabén col.; Puerto Barranqueras, 1ㅇ, 02/XII/1939, Birabén-Bezzi cols.; Resistencia, 1이 20/III/1939, P.

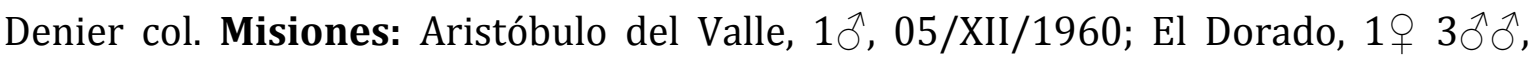
05/XI/1944, M. Birabén, 1 † $1 ð 3$ s/abd., XI/1944, B. A. Torres; Iguazú, 1ð̂, XI/1944,

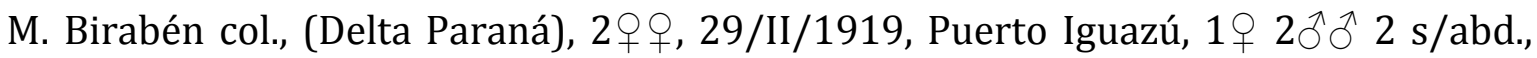
XI/1944, B. A. Torres col.; Loreto, 19, XII/1947, A. R. Bezzi col., 1§^, s/fecha, Colección

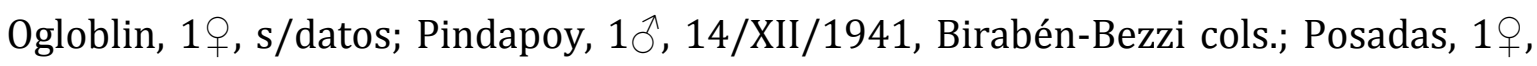
27/XII/1957, M. Birabén col.; San Ignacio, 19 1ठ, 08/XII/1941, Birabén-Bezzi cols.; Santa Inés, $3+q+2 \hat{\jmath}, 13 / X I I / 1941$, Birabén-Bezzi cols. Corrientes: 2 q $q 2 \hat{\jmath} 2$ s/abd., 15-30/II/1959, M. Birabén col., 1 ㅇ 3ð̋ 1 s/abd., I/1982, s/arroz, Trujillo col., det. Remes Lenicov; Mburucuyá, 1q, 16-23/XI/1957, M. Birabén col., Santo Tomé,

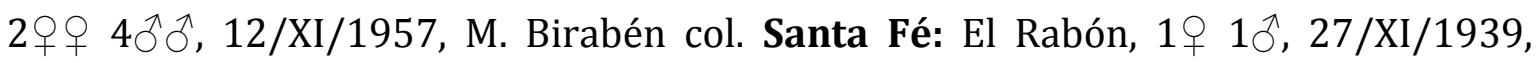
Birabén-Bezzi cols.; Guadalupe, 191 s/abd., 27/XI/1939, Birabén-Bezzi cols.; Reconquista, 1 우 1 đ 2 s/abd., 26/XI/1939, Birabén-Bezzi cols., det. D.A. Young. Entre Ríos: Concordia, $1 \widehat{\jmath}, 19 / X I I / 1941$, Birabén-Bezzi cols.; La Curtiembre, $1 \propto 3 \widehat{\partial}$, V.A. Nuñez R. col.; Paraná, 1q, 10/I/1952. Buenos Aires: Brazo Largo, $191 \delta 3$ s/abd., XII/1939, S.R. Castillo col.; Ibicuycito, $1 \hat{\jmath} 3$ s/abd., 22/II/1939, S.R. Castillo col.;

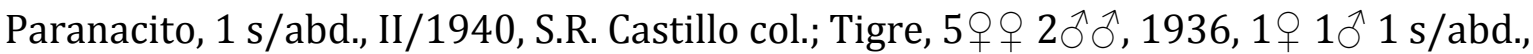
II/1939, $3 \AA \precsim$, I/1938; Castelar, $1 \precsim$. (IFML): Salta: Orán, 1ㅇ, 10/III/1969, R. Golbach col. Tucumán: $3 q q 4 \widehat{\jmath}$, I-II/1941, K.J. Hayward col; Dto. Burruyacu, $2+q 3 \widehat{\jmath}$, 19/XII/1981, R. Golbach col. Misiones: Apóstoles, San José, 1ㅇ, 4-27/II/1981, R. 
Golbach col. La Rioja: Chilecito, 1, 20/I/1960, A. Willink col. (UNLP): Jujuy: Chalican, $1 q 2 \hat{\jmath}, 06 /$ VIII/2002, E. Virla col. Formosa: Herradura, $6 q+1 \hat{\jmath}, 17-$

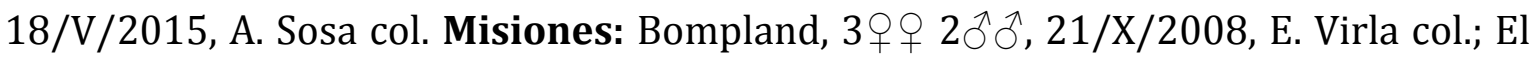
Soberbio, 1ठ, 19/I/2014, B. Defea col.; Iguazú, 2 $q 1$ s/abd., 22/III/2013, M. Lucia col.; San Pedro, 2ふえ, 19-22/XI/2007, Lucia-Alvarez cols. Corrientes: Bella Vista

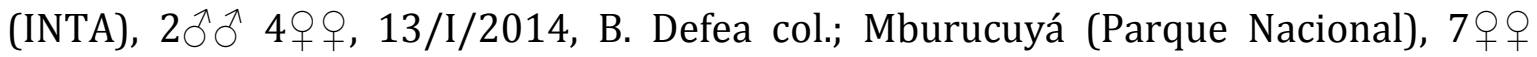
$2 \hat{\jmath}, \mathrm{I} / 2014$, B. Defea col.

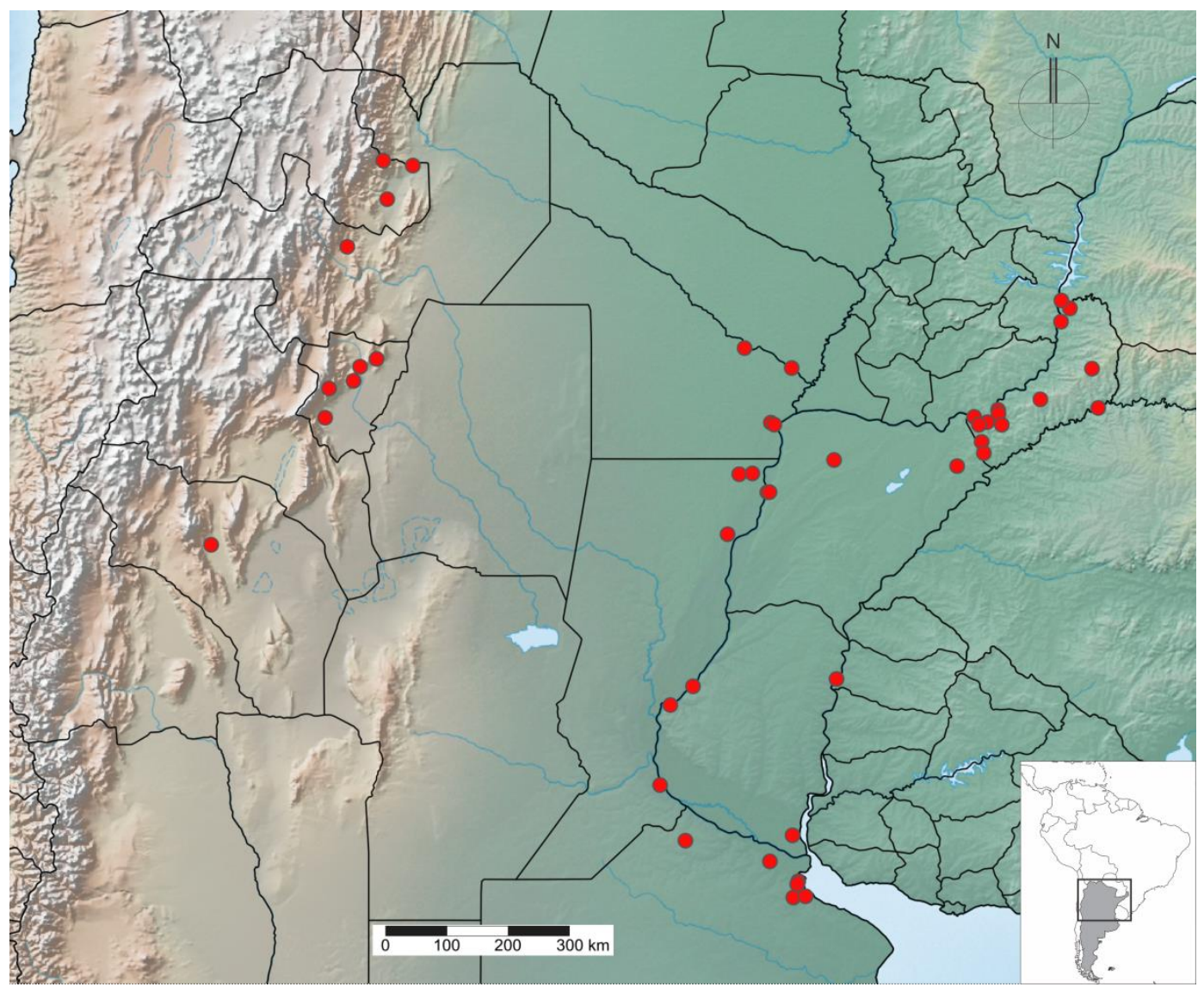

Figura 35. Distribución de Hortensia similis (Walker) en Argentina. 


\section{Género Macugonalia Young}

Especie tipo: Tettigonia sobrina Stål 1862: 41.

Longitud total 5,6-12,7 mm.

Cabeza. Ligeramente proyectada, longitud media de la corona 0,3-0,6x el ancho interocular; margen anterior, en vista dorsal, ampliamente redondeado; ocelos localizados sobre la línea que pasa entre los ángulos anteriores de los ojos, o ligeramente detrás; superficie de la corona convexa. Puentes antenales, en vista dorsal, no protuberantes, con el margen anterior, en vista lateral, rectilíneo y oblícuo. Transición corona-clípeo redondeada. Clípeo fuertemente convexo a aplanado en su porción media; sutura transclipeal interrumpida medialmente; clipelo, en vista lateral, a veces protuberante.

Tórax. Ancho del pronoto menor al ancho transocular de la cabeza, márgenes laterales paralelos, margen posterior ligeramente cóncavo a convexo; carena dorsopleural completa; disco débilmente esculturado, o no esculturado. Superficie del escutelo por detrás del surco transversal usualmente no estriado. Alas anteriores con membrana clara- a difusamente delimitada, variable en extensión; venas a veces distintivas; con tres celdas anteapicales, bases de las dos celdas más internas alineadas transversalmente; con cuatro celdas apicales. En las hembras, las alas en reposo ocultan el ovipositor. Fórmula setal del fémur posterior 2:1:1 o 2:1:1:1; longitud del primer tarsómero mayor que la longitud combinada del segundo y tercer tarsómero, con dos hileras de setas paralelas sobre la superficie plantar.

Genitalia del macho. Pigóforo fuertemente proyectado, margen posterior estrechaa ampliamente redondeado, con numerosas macrosetas agrupadas en la mitad posterior del disco y sobre el margen ventral que se extienden anteriormente, sin procesos; el margen posterodorsal con un pliegue interno liso o dentado. Placas subgenitales triangulares muy cortas, extendiéndose posteriormente hasta el tercio basal del pigóforo, con los márgenes mediales ligeramente curvados en la porción basal; superficie con un hilera regular o irregular de macrosetas. Estilos extendiéndose posteriormente hasta el ápice del conectivo, con un lóbulo lateral en la mitad del eje, ápice truncado en la mayoría de las especies. Conectivo en forma de $\mathrm{Y}$ 
con las ramas ampliamente divergentes. Edeago corto, eje convexo dorsalmente con un par de procesos estrechos que se originan basiventralmente extendiéndose más allá del ápice; con un par de lóbulos apicoventrales. Paráfisis ausentes o vestigiales.

Genitalia de la hembra. Esternito abdominal VII con el margen posterior proyectado, ápice redondeado o agudo, en algunas especies extendiéndose hasta el ápice del ovipositor. Esternito abdominal VIII membranoso, sin escleritos. Pigóforo con numerosas macrosetas en el tercio posterior del disco, algunas basiventrales cercanas al margen ventral. Ovipositor con la segunda valva expandida luego de la curvatura basal, con dientes triangulares cerca de la base y cuadrangulares en los dos tercios apicales, llevando dentículos, excepto en los basales. Ápices variables, nunca agudo, con una ligera concavidad preapical ventral en algunas especies.

Coloración. La mayoría de las especies de Macugonalia presentan una coloración moteada.

Observaciones taxonómicas. Según Young 1977, Macugonalia está cercanamente relacionada con el género Ambigonalia Young del cual se diferencia por la coloración moteada, la forma de la cabeza, presencia de macrosetas en las placas subgenitales y la ausencia de paráfisis en los machos. Especies de los géneros Willeiana Young y Versigonalia Young podrían confundirse con especies de Macugonalia, sin embargo la morfología del edeago, las placas subgenitales muy cortas y la ausencia de paráfisis permiten separarlos. Para la mayoría de las especies del género la genitalia de los machos no ofrece caracteres diagnósticos relevantes, y la genitalia de las hembras está poco estudiada. Es por ello que la identificación de las especies hasta el presente, se realiza a partir de caracteres externos como la coloración lo que representa un problema para algunas especies que son externamente muy similares o también puede confundirse con especies de otros géneros.

El esternito abdominal VII fuertemente proyectado es un carácter que comparten algunas especies del género: $M$. spinolai (Signoret), M. variabilis (Signoret), $M$. testudinaria (Fowler), M. cavifrons (Stål), M. contaminata (Fabricius), M. fritilla Young y M. umbrosa Young y M. geographica (Signoret). Según Carvalho \& Mejdalani (2005) estas especies podrían conformar un subgrupo dentro de Macugonalia. Por otro lado, la forma del eje de la valva II del ovipositor de las especies estudiadas es muy similar 
en aquellas con el esternito fuertemente proyectado ( $M$. cavifrons (Stål) y $M$. geographica (Signoret)); esto contribuye a la idea del subgrupo sin embargo es necesario continuar con el estudio de la genitalia femenina de las especies de todo el género.

Distribución. Neotropical con registros en Argentina, Bolivia, Brasil, Ecuador, El Salvador, Guayana, Guatemala, México, Panamá, Paraguay, Perú, Surinam y Venezuela (Young 1977) y Colombia (Freytag \& Sharkey 2002).

El género Macugonalia cuenta con 28 especies descriptas de las cuales cinco están presentes en la Argentina.

cavifrons (Stål), 1962:41.

geographica (Signoret), 1855: 780.

leucomelas, (Walker), 1851: 764.

moesta (Fabricius), 1803: 704.

sobrina (Stål), 1862: 41.

Macugonalia cavifrons (Stål) (Figura 36, 39A, 40A)

Tettigonia cavifrons Stål 1862: 41 [n. sp.].

Tettigonia cavifrons Young 1963: 224 [Designación lectotipo]

Macugonalia cavifrons Young 1977: 944 [n. comb.]

Diagnosis. Patrón de coloración moteado, corona y pronoto con pequeñas máculas amarillentas, el moteado se extiende sobre el clípeo, excepto en su porción media formando una franja longitudinal lisa. Edeago, en vista lateral, eje convexo, ampliamente redondeado, con dos procesos cortos divergentes sobre el margen anterobasal y dos procesos estrechos basiventrales que se proyectan dorsoapicalmente, con dos lóbulos apicales dirigidos ventralmente (Young 1977). Longitud: Љへ 7,1-8,1 mm, 우 7,9-9,0 mm. Tegmen moteado de color verde oscuro. Margen posterodorsal del pigóforo del macho con un pliegue interno liso. Esternito abdominal VII de la hembra fuertemente proyectado en su parte media, proyección 
posterior espiniforme que se extiende más allá de la mitad basal del pigóforo, ápice redondeado.

Genitalia de la hembra. Esternito VII (Figura 40A), en vista ventral, cuadrangular, fuertemente proyectado posteriormente, longitud media aproximadamente $1,5 \mathrm{x}$ el ancho máximo; márgenes posterolaterales ligeramente lobulados y margen posterior con una proyección media espiniforme que se extiende más allá de la mitad basal del pigóforo, ápice redondeado; superficie con dos pequeños grupos de microsetas en la mitad del disco equidistantes de la porción media. Pigóforo (Fig. 36C), en vista lateral, moderadamente proyectado, margen posterior redondeado; superficie con numerosas macrosetas robustas en la mitad posterior, algunas extendiéndose anteriormente. Valvifer I (Fig. 36A), en vista lateral, subovalado con la superficie lisa. Valva I (Fig. 36D), en vista lateral, margen dorsal convexo luego de la curvatura basal, margen ventral ligeramente recto; porción basal estrecha; AED (Fig. 36E) cubriendo los dos tercios apicales del eje, formada por procesos tegumentarios filiformes dispuestos oblicuamente; AEV restringida a la porción preapical del eje, formada por procesos filiformes. EVA larga extendiéndose más allá de la mitad basal del eje; porción preapical obtusa con los márgenes dorsal y ventral no denticulados, ápice (Fig. 36F) subredondeado. Valvifer II (Fig. 36B), en vista lateral, alargado longitudinalmente, superficie anteroventral con un grupo de procesos tegumentarios robustos. Valva II (Fig. 36G), en vista lateral, eje expandido luego de la curvatura basal estrechándose a partir de la porción preapical; margen dorsal regularmente convexo y margen ventral recto. Margen dorsal con numerosos dientes (Fig. 36H) subtriangulares con el margen posterior más largo y en declive, no protuberantes, basalmente pequeños e irregulares, luego grandes disminuyendo su tamaño hacia el ápice; cada diente con aproximadamente 3 dentículos sobre el margen posterior; cuarto apical del eje con pequeños dientes romos. Ductos visibles a lo largo de toda la porción expandida, en mitad basal cortos y en la mitad apical alcanzando los dientes y el margen apical. Porción preapical y ápice (Fig. 36I), redondeados; ventralmente sin prominencia preapical. Gonoplaca (Fig. 36J), en vista lateral, porción anterior estrecha, 1,3x más larga que la porción posterior, la cual es marcadamente expandida; superficie preapical y ventral con procesos tegumentarios espiniformes y algunas microsetas robustas; ápice (Fig. 36K) ampliamente redondeado. 


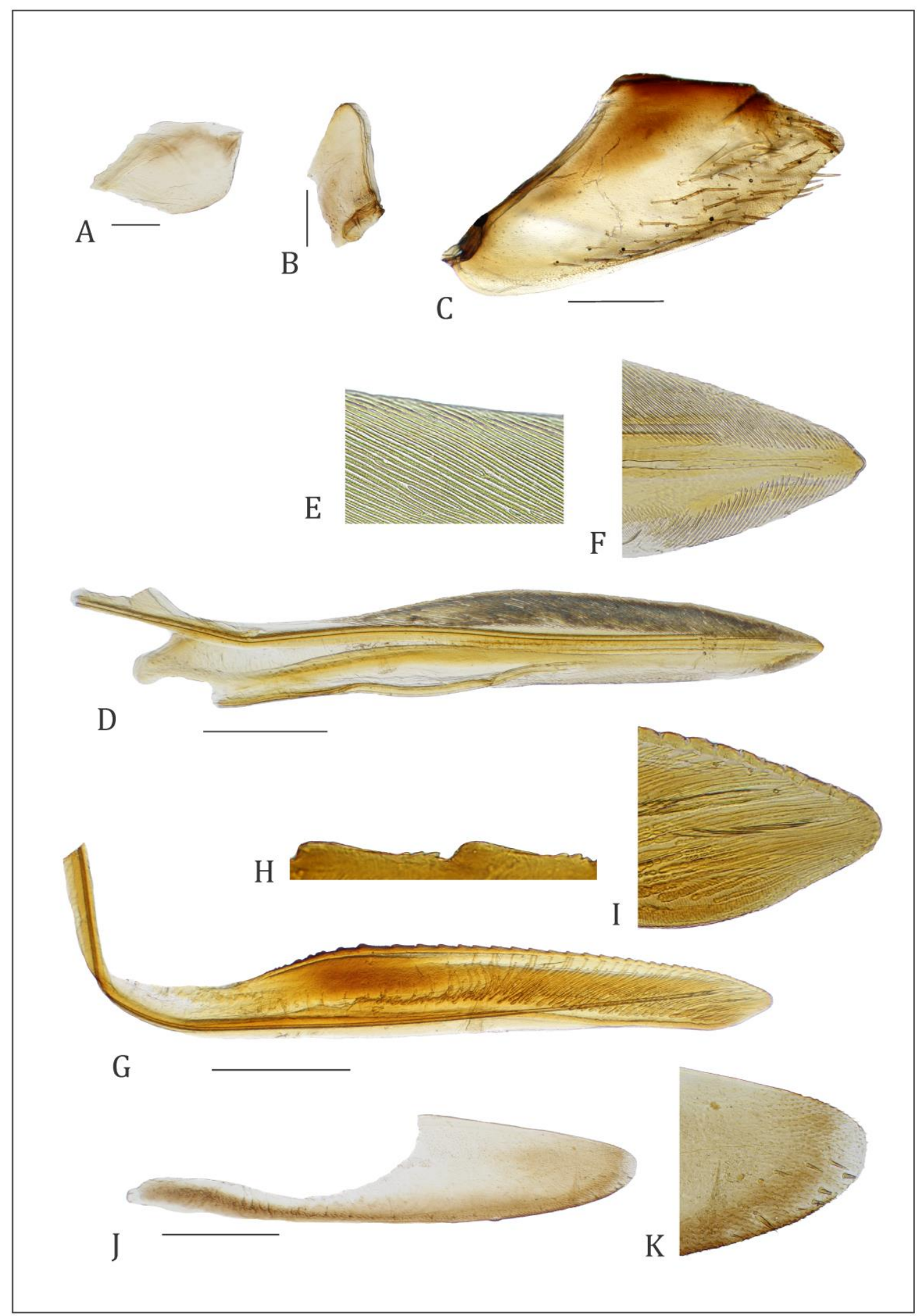

Figura 36. Genitalia de la hembra de Macugonalia cavifrons (Stål): valvifer I (A), valvifer II (B), pigóforo (C), valva I (D), detalle AED valva I (E), ápice valva I (F), valva II (G), dientes valva II (H), ápice valva II (I), gonoplaca (J), ápice gonoplaca (K). Escalas 0,5 mm: C, D, G, J; 0,3 mm: A, B. 
Observaciones taxonómicas. Externamente, $M$. cavifrons es similar a $M$. sobrina (Stål) de la cual puede diferenciarse, en los machos, por poseer un pliegue interno no denticulado en el pigóforo, y en las hembras, por el esternito abdominal VII fuertemente proyectado posteriormente. La presencia de este tipo de esternito VII, es un carácter peculiar compartido con otras siete especies del género: M. spinolai (Signoret), M. variabilis (Signoret), M. testudinaria (Fowler), M. geographica (Signoret), M. contaminata (Fabricius), M. fritilla Young y M. umbrosa Young. Según Carvalho \& Mejdalani (2005), es posible que estas especies formen un subgrupo dentro de Macugonalia.

Distribución. Sudamericana, con registros en Argentina, Bolivia, Brasil, Colombia, Paraguay, Perú y Venezuela (Young 1977). En la Argentina, está registrada para las provincias de Misiones (Remes Lenicov et al. 1999) y Entre Ríos (Dellapé et al. 2016). Se amplía su distribución para las provincias de Jujuy (Manantiales), Salta (Ajuarez, Embarcación, Pocitos, Urundel), La Rioja (Chilecito), Tucumán (Lules), Formosa (Misión Laishí), Chaco (Laguna Blanca), Corrientes (Bella Vista) y Buenos Aires (Figura 41).

Plantas hospedadoras. Citrus sinensis (L.) Osb. (Rutaceae) (Remes Lenicov et al. 1999), Brassica napus L. var. oleifera (Brassicaceae)(Paris et al. 2012), Vitis vinífera L. (Vitaceae) (Ringengerg 2008), Coffea arabica L. (Rubiaceae) (Carvalho et al. 2015). Se cita por primera vez para Citrus x limon (L.) Burm. F. “limón” (Rutaceae) y Olea europaea L. var. arauco “olivo” (Oleaceae).

Datos biológicos. Es una especie frecuentemente recolectada en árboles de $C$. sinensis en el NEA (Remes Lenicov 1999, Ver Capítulo III) y es una de las dos especies predominantes en cítricos del NOA (Ver Capítulo III).

Enemigos naturales. Se observó por primera vez a un juvenil de la familia Salticidae (Chelicerata: Aranae) alimentándose activamente de un ejemplar hembra de esta especie sobre una planta de Citrus sinensis (L.) Osb. en plantaciones ubicadas en Bella Vista, Corrientes.

Importancia fitosanitaria. Desconocida. 
Material estudiado. ARGENTINA: (MLP): Jujuy: Manantiales, 1, 3/II/1958, Torres-Ferreyra cols. Salta: Pocitos, 1ðત, 24-26/XI/1954, M. Birabén col. Tucumán: 1ㅇ, s/datos. Chaco: Puente de la Plaza, 1q, 7/XII/1939, Birabén-Bezzi cols.; Laguna Blanca, 1q, 7/XII/1939, Birabén-Bezzi cols. Misiones: 2 de Mayo, 1 \% 1 s/abd.,

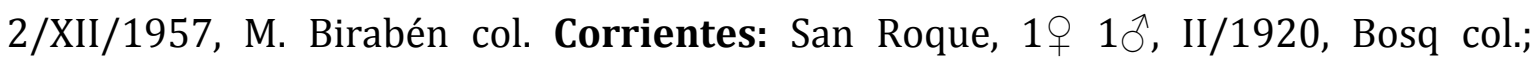

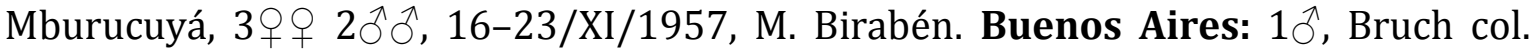

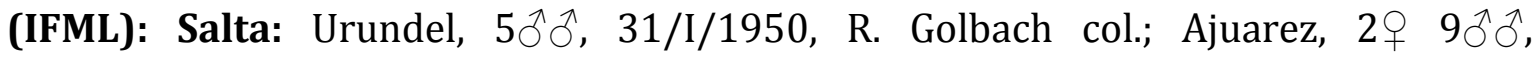
14/II/1950, R. Golbach col.; Embarcación, 2§ðત, 2/II/1950, R. Golbach col. Formosa: Misión Laishí, $2+q$ 1§, 15-18/XII/1950, R. Golbach col. (UNLP): Salta: Yatasto, $2+q$

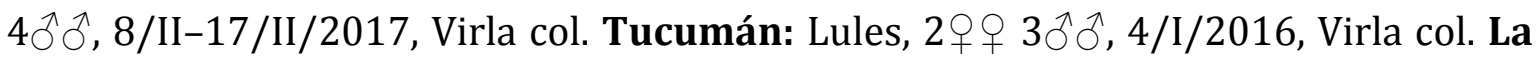
Rioja: Chilecito, $3+$ 우 $5 \hat{\jmath}$, XII/2016, s/ Olea europaea L. var. arauco, Calahorra col. Formosa: Villa Escobar, 2 $+9,2014$, s/Citrus x limón, Bermudez col. Misiones:

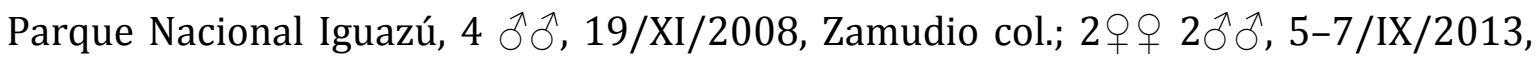
Alvarez col. Corrientes: Bella Vista, $5+q$ 오 $5 \hat{\jmath}$, I/2015, Defea col.

Macugonalia geographica (Signoret) (Figura 39E)

Tettigonia geographica Signoret 1855: 780 [n. sp.].

Apogonalia geographica Metcalf 1965: 289

Tettigonia geographica Young 1964: 11 [Designación Lectotipo]

Macugonalia geographica Young 1977: 944 [n. comb.]

Diagnosis. Corona, pronoto y mesonoto de coloración amarilla con marcas negras,; alas anteriores castaño-rojizas, con el área basal con dos máculas amarillas con un reborde castaño oscuro; placas subgenitales del macho subtriangulares, ápice marcadamente fino; estilos con el ápice truncado; edeago con un par de procesos basiventrales que se extienden más alla del ápice del eje aedeagal (Carvalho \&

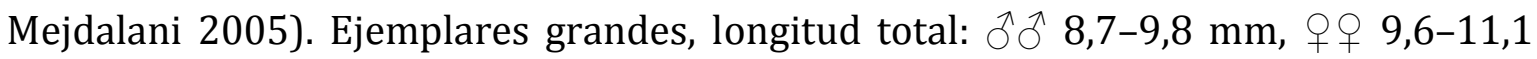
$\mathrm{mm}$. Esternito abdominal VII de la hembra fuertemente proyectado en su parte media, proyección posterior aguda, ápice redondeado; superficie convexa con una concavidad longitudinal mediana que se extiende desde la base hasta el ápice. 
Observaciones taxonómicas. El patrón de coloración de $M$. geographica es muy característico y permite diferenciarla fácilmente del resto de las especies del género.

Distribución. Sudamericana, con registros en Argentina y Brasil. En la Argentina, fue registrada en la provincia de Misiones (Young 1977) (Figura 41).

Plantas hospedadoras. Vitis vinifera L. (Vitaceae) (Sampaio de Azevedo Filho et al. 2011).

Datos biológicos. Desconocidos.

Enemigos naturales. Desconocidos.

Importancia fitosanitaria. Desconocida.

Material estudiado. ARGENTINA: (MLP): Misiones: Loreto, $3 q \circ 1$ s/abd., III/1936, Ogloblin col.

Macugonalia moesta (Fabricius) (Figura 37, 39H, 40D)

Cicada moesta Fabricius 1803: 74 [n. sp.]

Cicada moesta Young 1965: 14 [Designación lectotipo]

Macugonalia moesta Young 1977: 944 [n. comb.]

Diagnosis. Tegmen rojizo, con dos bandas anchas blanquecinas oblicuas cuyos márgenes tienen un borde estrecho de color negro, una en el tercio basal y la otra a la

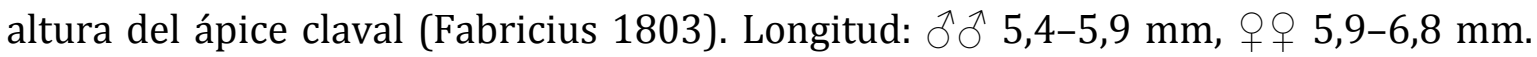
Edeago del macho, en vista lateral, eje convexo, margen anterior proyectado anteriormente formando un lóbulo redondeado apicalmente. Esternito abdominal VII de la hembra proyectado en su parte media, proyección posterior lobulada, extendiéndose hasta el tercio basal del pigóforo, ápice redondeado. 
Genitalia de la hembra. Esternito VII (Figura 40D), en vista ventral, subrectangular, debilmente proyectado posteriormente, longitud media $0,7 \mathrm{x}$ el ancho máximo, márgenes posterolaterales subangulosos, margen posterior con una proyección media lobulada que se extiende hasta el tercio basal del pigóforo, ápice redondeado; superficie con dos pequeños grupos de microsetas en la mitad anterior del disco, equidistantes a la línea media. Pigóforo (Fig. 37C), en vista lateral, moderadamente proyectado, margen posterior ampliamente redondeado; superficie con numerosas macrosetas en la superficie posteroventral, algunas extendiéndose anteriormente por el margen ventral; finas microsetas en la superficie posterodorsal. Valvifer I (Fig. 37A), en vista lateral, romboidal. Valva I (Fig. 37D), en vista lateral, eje ancho con los márgenes dorsal y ventral casi paralelos aguzándose hacia el ápice. AED (Fig. 37E) cubriendo la mitad apical del eje, formada por procesos tegumentarios filiformes dispuestos oblicuamente; AEV extendida en la mitad apical del eje, compuesta por estrías longitudinales, excepto en la porción preapical del eje, formada por procesos filiformes. EVA larga sobrepasando ligeramente los dos cuartos basales del eje, porción preapical aguda con el margen dorsal y ventral no denticulados, ápice (Fig. 37F) puntiagudo. Valvifer II (Fig. 37B), en vista lateral, aguzado, con un grupo de microsetas robustas sobre el punto de articulación. Valva II (Fig. 37G), en vista lateral, fuertemente expandida luego de la curvatura basal, estrechándose hacia el ápice; margen ventral recto. Sobre el margen dorsal numerosos dientes (Fig. 37H) no protuberantes, rectangulares con el margen dorsal más largo llevando numerosos dentículos, porción basal del eje con dientes triangulares pequeños. Ductos ligeramente visibles a lo largo del eje, alternando cortos y largos que alcanzan los dientes y el margen apical. Ápice (Fig. 37I) ampliamente redondeado; ventralmente con prominencia preapical. Gonoplaca (Fig. 37J), en vista lateral, porción anterior estrecha, más larga que la porción posterior, la cual es marcadamente expandida; superficie preapical, basal y margen ventral con procesos tegumentarios espiniformes, con algunas macrosetas preapicales y microsetas dispersas a lo largo del margen ventral; ápice ampliamente redondeado.

Observaciones taxonómicas. Externamente M. moesta es similar a M. leucomelas sin embargo, los estilos del macho tienen el ápice truncado, el esternito abdominal VII 
de la hembra es más proyectado posteriormente y la valva II del ovipositor posee dientes rectangulares no protuberantes.

Distribución. Sudamericana, con registros en Brasil, Bolivia, Ecuador, Guayana, Guayana Francesa, Surinam, Perú (Young 1977) y Colombia (Freytag \& Sharkey 2002). Se registra por primera vez para la Argentina Jujuy (Termas de Reyes) (Figura 41).

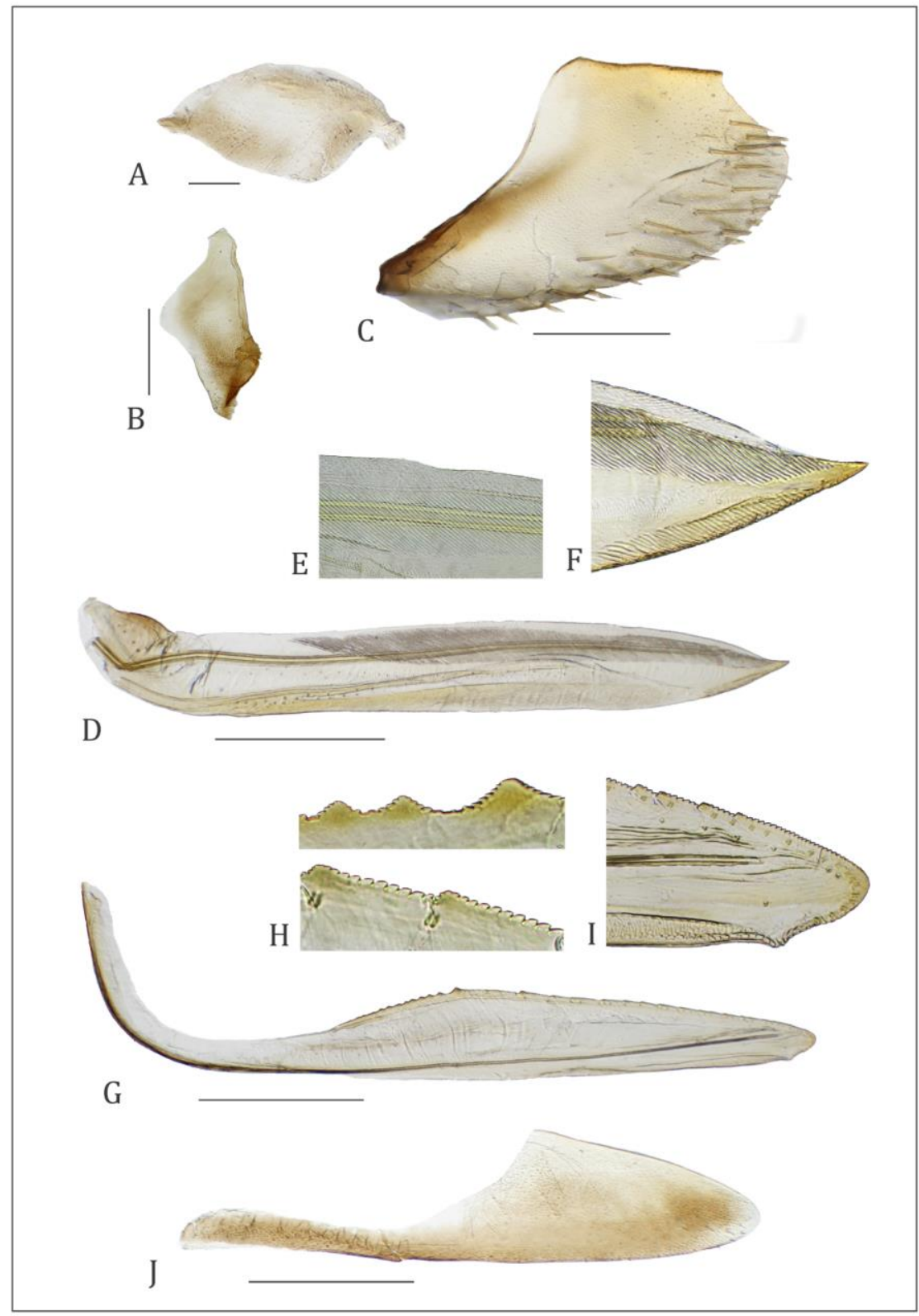

Figura 37. Genitalia de la hembra de Macugonalia moesta (Fabricius): valvifer I (A), valvifer II (B), pigóforo (C), valva I (D), detalle AED valva I (E), ápice valva I $(F)$, valva II (G), dientes valva II (H), ápice valva II (I), gonoplaca (J). Escalas 0,5 mm: C, D, G, J; 0,3 mm: A, B. 
Plantas hospedadoras. Desconocidas.

Datos biológicos. Desconocidos.

Enemigos naturales. Desconocidos.

Importancia fitosanitaria. Desconocida.

Material estudiado. Argentina: (MLP): Jujuy: Termas de Reyes, $3 \circ q 2 \hat{\jmath}$, 3/II/1948, Willink-Monrós cols.

Macugonalia leucomelas (Walker) (Figura 39F, G, 40C)

Tettigonia leucomelas Walker 1851: 764 [n. sp.].

Tettigonia leucomelas Young 1965: 182 [Holotipo esclarecido]

Macugonalia leucomelas Young 1977: 944 [n. comb.]

Tettigonia albopunctulata Taschenberg 1884: 440 [n. sp.]

Macugonalia leucomelas Young 1977: 944 [n. syn.]

Diagnosis. Coloración general oscura, castaño-rojiza; corona con manchas blanquecinas o amarillentas pequeñas, en algunos especímenes, totalmente oscura con una banda transversal blanquecina a la altura de los ocelos y paralela al margen posterior, pronoto con una banda blanquecina paralela a los bordes lateral y posterior, disco pronotal usualmente con pequeñas manchas blanquecinas, porción posterior del escutelo color blanquecino. Tegmen típicamente con dos bandas oblicuas blanquecinas, una en el tercio basal, y la otra en el ápice claval (Walker 1851). Edeago, en vista lateral, eje convexo, margen posterodorsal subanguloso, y margen anterobasal sin procesos, con dos procesos estrechos basiventrales que se proyectan dorsoapicalmente, y dos lóbulos apicales aguzados dirigidos ventralmente

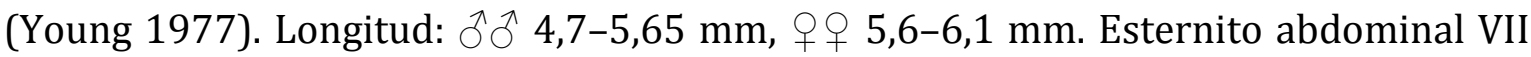
de la hembra moderadamente proyectado, con una proyección media obtusa. 
Genitalia de la hembra. Esternito abdominal VII (Figura 40C) de la hembra moderadamente proyectado, con una proyección media obtusa. Esternito abdominal VIII y ovipositor descriptos por Mejdalani (1998).

Observaciones taxonómicas. Externamente, $M$. leucomelas es muy similar a $M$. moesta, sin embargo las bandas blanquecinas del tegmen no poseen un borde negro, los estilos del macho tienen el ápice redondeado, el esternito VII de la hembra es más proyectado posteriormente. Si bien es una especie que es variable en su patrón de coloración, éste junto con la morfología del esternito VII de la hembra y rasgos de la valva II del ovipositor permiten diferenciarla del resto de las especies del género.

Distribución. Sudamericana, con registros en Venezuela (Metcalf 1965), Argentina, Bolivia, Brasil y Paraguay (Young 1977). En la Argentina, fue registrada en la provincia de Misiones (Remes Lenicov et al. 1999). Se amplía la distribución para las provincias de Jujuy (Manatiales, Yuto), Salta (Orán, Tartagal, Urundel, Yatasto), Tucumán (Lules) y Corrientes (Santo Tomé) (Figura 41).

Plantas hospedadoras. Citrus sinensis (L.) Osb. (Rutaceae) (Remes Lenicov et al. 1999). Se registra por primera vez sobre Citrus x limon (L.) “limón” Burmeister (Rutaceae) y Bauhinia candicans Benth. “pezuña de vaca” (Fabaceae).

Datos biológicos. Se observó en plantaciones citrícolas en Misiones, recolectada tanto sobre las plantas cítricas como en la vegetación asociada al cultivo, aunque en escaso número (Remes Lenicov et al. 1999). También estuvo presente en muy bajo número en plantaciones de Citrus sinensis (L.) Osb. en las provincias de Tucumán y Salta (Ver capítulo III).

Enemigos naturales. Hymenoptera de la familia Dryinidae (Remes Lenicov et al. 1999).

Importancia fitosanitaria. Macugonalia leucomelas es vector comprobado de Xylella fastidiosa subsp. pauca a plantas de Citrus sinensis (L.) Osb. La eficiencia de transmisión es 17,3\% (Fundecitrus 1999). 
Material estudiado. ARGENTINA: (MLP): Jujuy: Manantiales, $7 q \uparrow, 3 / \mathrm{II} / 1958$, Torres-Ferreyra cols.; Salta: Orán, 1s/abd., II/1948, Golbach col.; Pocitos, $2 q q$, 24/XI/1954, M. Birabén col.; Río El Sauzal, 1 † 1§, XI/1933; El Tabacal, 1ठ, XI/1933. Misiones: Puerto Deseado, $4 \uparrow+1 \delta, 21-23 / X I I / 1955$, Zabarce-Donath cols.; Caraguatay, $3 q \propto$ 1 $\delta^{\lambda}, \mathrm{I} / 1960$, Ronderos-Trotta cols. Corrientes: Santo Tomé, $3 q q$, 12/XI/1957, M. Birabén col. (IFML): Jujuy: Termas de Reyes, 2 + + 5へぇ, 3/II/1948,

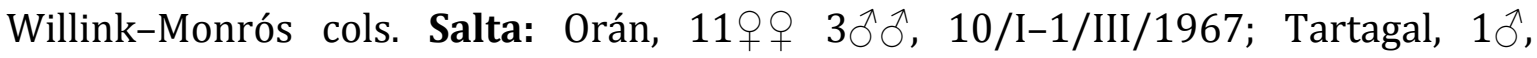
11/II/1950; Urundel, 4우 2えへ, 31/I/1950, Hayward-Willink-Golbach. Misiones: Bernardo de Irigoyen, 1ð, 12/XI/1973, Willink-Tomsic cols.; San Javier, 6우 4ðえ, 20/XI/1973, Willink-Tomsic cols.; Puerto Nacional Iguazú, 2q+, 10/XI/1973, Willink-Tomsic cols. (UNLP): Jujuy: Yuto, Salta: Yatasto, 1ð, 24/XI/2015, Virla col.

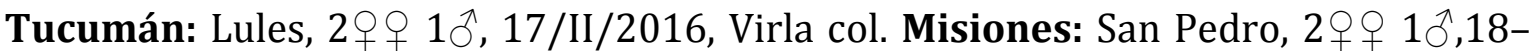
21/XI/2007, Lucia col.; Puerto Nacional Iguazú, 5 우 9ðð

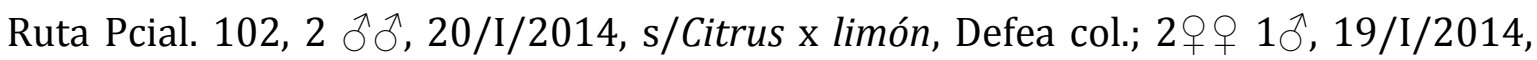
s/Bauhinia candicans, Defea col.

Macugonalia sobrina (Stål) (Figura 38, 39C, D, 40B)

Tettigonia sobrina Stål 1862: 41 [n. sp.].

Amblyscarta sobrina Metcalf 1965: 229

Tettigonia sobrina Young 1963: 226 [designación lectotipo]

Macugonalia sobrina Young 1977: 944 [n. comb.]

Diagnosis. Corona, pronoto y escutelo con pequeñas máculas blanquecinas que se extienden ventralmente sobre todo el clípeo. Tegmen oscuro, castaño-rojizo, con manchas alargadas color verde oscuro discontinuas que permiten observar la coloración de base. Edeago, en vista lateral, eje convexo, ampliamente redondeado, margen anterior con un proceso prominente dirigido dorsalmente, dos procesos estrechos basiventrales que se proyectan apicalmente, y dos lóbulos apicales dirigidos ventralmente. Margen posterodorsal del pigóforo del macho con un pliegue interno denticulado (Young 1977). Longitud: †ิ $\widehat{T}$ 5,2-5,7 mm, 우 6,2-6,5 mm. Esternito abdominal VII de la hembra moderadamente proyectado en su parte media, 
proyección posterior ampliamente aguda, que se extiende hasta la mitad basal del pigóforo, ápice puntiagudo.

Genitalia de la hembra. Esternito VII (Figura 40B), en vista ventral, cuadrangular, moderadamente proyectado posteriormente, casi tan largo como ancho, márgenes laterales marcadamente emarginados y márgenes posterolaterales subangulosos, margen posterior con una proyección media ampliamente aguda que se extiende hasta la mitad basal del pigóforo, ápice puntiagudo; superficie con dos pequeños grupos de microsetas en la mitad del disco equidistantes de la línea media. Esternito abdominal VIII (Fig. 38B) esclerotizado en una placa ampliamente emarginada en su porción media. Pigóforo (Fig. 38D), en vista lateral, moderadamente proyectado, proyección posterior ligeramente cóncava dorsalmente, margen posterior redondeado; superficie con varias macrosetas robustas en la proyección posterior, algunas extendiéndose anteriormente; con microsetas diminutas en la superficie posterodorsal. Valvifer I (Fig. 38A), en vista lateral, en forma de gota. Valva I (Fig. 38E), en vista lateral, eje fuertemente expandido, excepto el cuarto basal; porción expandida con el margen dorsal convexo y el ventral cóncavo; AED cubriendo los tres cuartos apicales del eje, formada por procesos tegumentarios filiformes dispuestos oblicuamente, superficie ventral del cuarto basal con numerosos procesos tegumentarios espiniformes; AEV restringida a la porción preapical del eje, formada por procesos filiformes. EVA larga extendiéndose más allá de la mitad basal del eje; porción preapical aguda con el margen dorsal débilmente denticulado, ápice (Fig. 38F) redondeado. Valvifer II (Fig. 38C), en vista lateral, subrectangular, superficie anteroventral con algunas microsetas robustas. Valva II (Fig. 38G), en vista lateral, eje fuertemente expandido luego de la curvatura basal estrechándose hacia el ápice, margen ventral recto. Margen dorsal con numerosos dientes (Fig. 38H) subtriangulares con el margen posterior más largo y en declive, no protuberantes, porción basal con dientes triangulares pequeños, luego grandes disminuyendo su tamaño hacia el ápice; cada diente con aproximadamente 1-2 dentículos obtusos al final del margen posterior; cuarto apical del eje con dientes más pequeños que casi alcanzan el ápice. Ductos visibles a lo largo de los dos tercios apicales de la porción expandida del eje, alternando cortos y largos que alcanzan los dientes y el margen apical. Ápice (Fig. 38I) redondeado; ventralmente sin prominencia preapical. 
Gonoplaca (Fig. 38J), en vista lateral, porción anterior estrecha y ligeramente más larga $(1,2 x)$ que la porción posterior, la cual es marcadamente expandida; superficie del tercio preapical y basal con procesos tegumentarios espiniformes, con algunas macrosetas sobre el margen preapical ventral y microsetas dispersas a lo largo del margen ventral; ápice ampliamente redondeado.

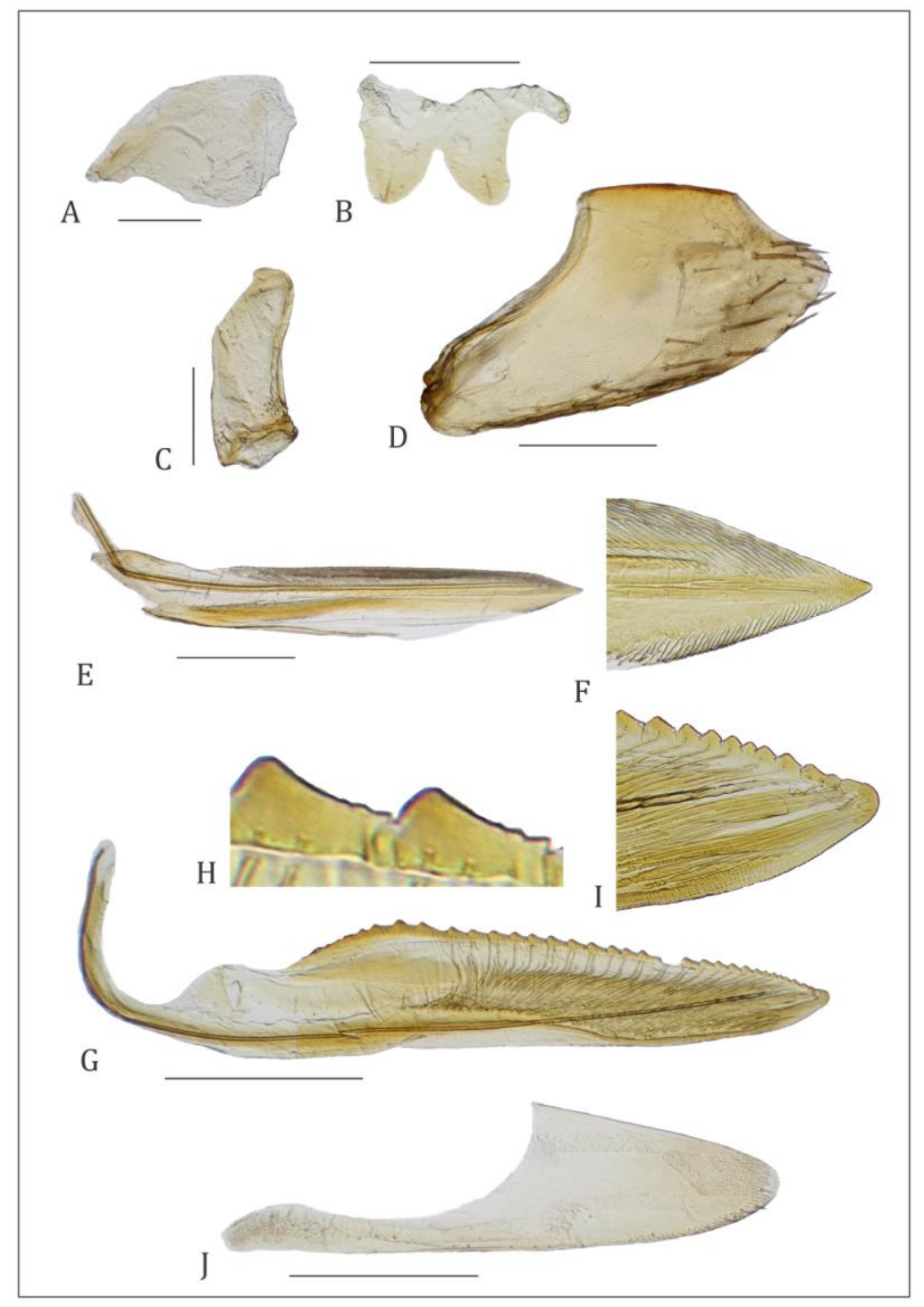

Figura 38. Genitalia de la hembra de Macugonalia sobrina (Stål): valvifer I (A), esternito VIII (B), valvifer II (C), pigóforo (D), valva I (E), ápice valva I (F), valva II (G), dientes valva II (H), ápice valva II (I), gonoplaca (J). Escalas 0,5 mm: C, D, G, J; 0,3 mm: A, B.

Observaciones taxonómicas. Macugonalia sobrina puede ser fácilmente confundida con $M$. cavifrons ya que externamente son muy similares, ambas tienen un patrón de coloración moteado, y se encuentran en el mismo rango de distribución. Sin 
embargo, $M$. sobrina es de menor tamaño y las máculas negras en el clípeo se extienden hasta las suturas clipeales laterales. También, puede ser separada del resto de las especies del género por la morfología del edeago, por el pliegue denticulado en el margen posterodorsal del pigóforo del macho y el esternito abdominal VII de la hembra.

Distribución. Sudamericana, con registros en Argentina y Brasil (Young 1977). En la Argentina, fue registrada en la provincia de Misiones (Remes Lenicov et al. 1999) y Entre Ríos (Dellapé et al. 2016). Se amplía la distribución para las provincias de Jujuy (Ledesma), Salta (Ajuarez, Urundel, Yatasto), Tucumán (Lules), Formosa (Misión Laishí), Corrientes (Mburucuyá), Santa Fé (Guadalupe), La Rioja (Vichigasta) y San Luis (Papagayos) (Figura 41).

Plantas hospedadoras. Citrus sinensis (L.) Osb. (Rutaceae)(Remes Lenicov et al. 1999), Citrus reticulata Hort. Ex Tan x (Citrus Paradise Macf. X Citrus tangerine Hort. Ex Tan.) (Rutaceae) (Dellapé et al. 2016), Coffea arabica L. (Rubiaceae) (Carvalho et al. 2015). Se registra por primera vez sobre Olea europaea L. var. arauco "olivo" (Oleaceae).

Datos biológicos. Está presente en plantaciones de Citrus sinensis (L.) Osb. en la provincia de Entre Ríos (Dellapé et al. 2016) aunque en muy bajo número; en Corrientes, fue recolectada de manera frecuente y durante todo el año sobre las plantas cítricas (Ver Capítulo III).

Enemigos naturales. Desconocidos.

Importancia fitosanitaria. Desconocida.

Material estudiado. ARGENTINA: (MLP): Jujuy: Ledesma, $2 \uparrow q$ 1ठ, 29/I/1958, Torres-Ferreyra cols. Formosa: Misión Laishí, 1§ึ, 12/XI/1942, Birabén-Bezzi cols. Misiones: Loreto, $1 q 2 \hat{\jmath}$, Ogloblin col. Corrientes: Mburucuyá, 1q, 1623/XI/1957, M. Birabén col. Santa Fé: Guadalupe, 2ðð, 27/XI/1939, Birabén-Bezzi cols. San Luis: Papagayos, 21/III/1960, Vidal-Torres cols. (IFML): Salta: Ajuarez,

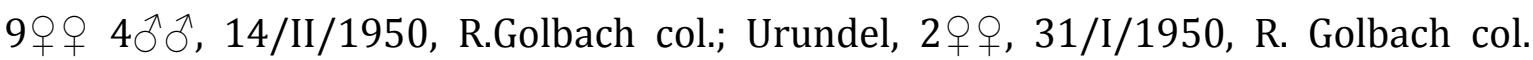


(UNLP): Salta: Yatasto, $3 q q, 8 / \mathrm{III}-13 / \mathrm{IV} / 2016$, Virla Col. Tucumán: Lules, $2 q q$

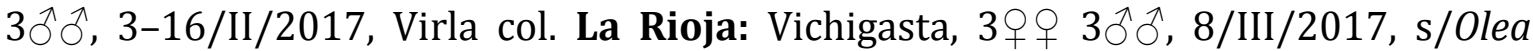
europaea L. var. Arauco, Calahorra col.

\section{Clave para el reconocimiento de las especies del género Macugonalia presentes en la Argentina.}

1. Especímenes grandes 8,7-11,1 mm. Tegmen castaño-rojizo, porción basal con dos máculas grandes de color amarillo con un reborde castaño oscuro, una en el clavus y la otra en el corium; con algunas líneas pálidas sobre las venas M. geographica

-. Especímenes medianos (7,1-9,0 mm) o pequeños (4,7-6,8 mm). Tegmen con otro patrón de coloración 2

2. Coloración del tegmen moteada, clípeo moteado 3

-. Coloración del tegmen bandeada, clípeo liso, castaño oscuro 4

3. Longitud total 7,1-9,0 mm. Margen posterodorsal del pigóforo del macho con un pliegue interno liso, no denticulado. Esternito abdominal VII de la hembra fuertemente proyectado en su parte media, proyección posterior espiniforme que se extiende más allá de la mitad basal del pigóforo, ápice redondeado. Clípeo moteado con una franja media longitudinal lisa M. cavifrons

-. Longitud total 5,2-6,5 mm. Margen posterodorsal del pigóforo del macho con un pliegue interno denticulado. Esternito abdominal VII de la hembra moderadamente proyectado en su parte media, proyección posterior aguda que se extiende hasta la mitad basal del pigóforo, ápice puntiagudo. Clípeo completamente moteado M. sobrina

4. Tegmen con dos bandas blanquecinas transversales, cada una con los márgenes anterior y posterior con un borde estrecho de color negro. Estilos del macho con el ápice truncado. Esternito abdominal VII de la hembra corto, con un lóbulo medio en el margen posterior M. moesta

-. Tegmen con dos bandas blanquecinas transversales, sin borde negro. Estilos del macho con el ápice redondeado. Esternito abdominal VII de la hembra 
moderadamente

proyectado,

proyección

media

posterior

obtusa

M. leucomelas

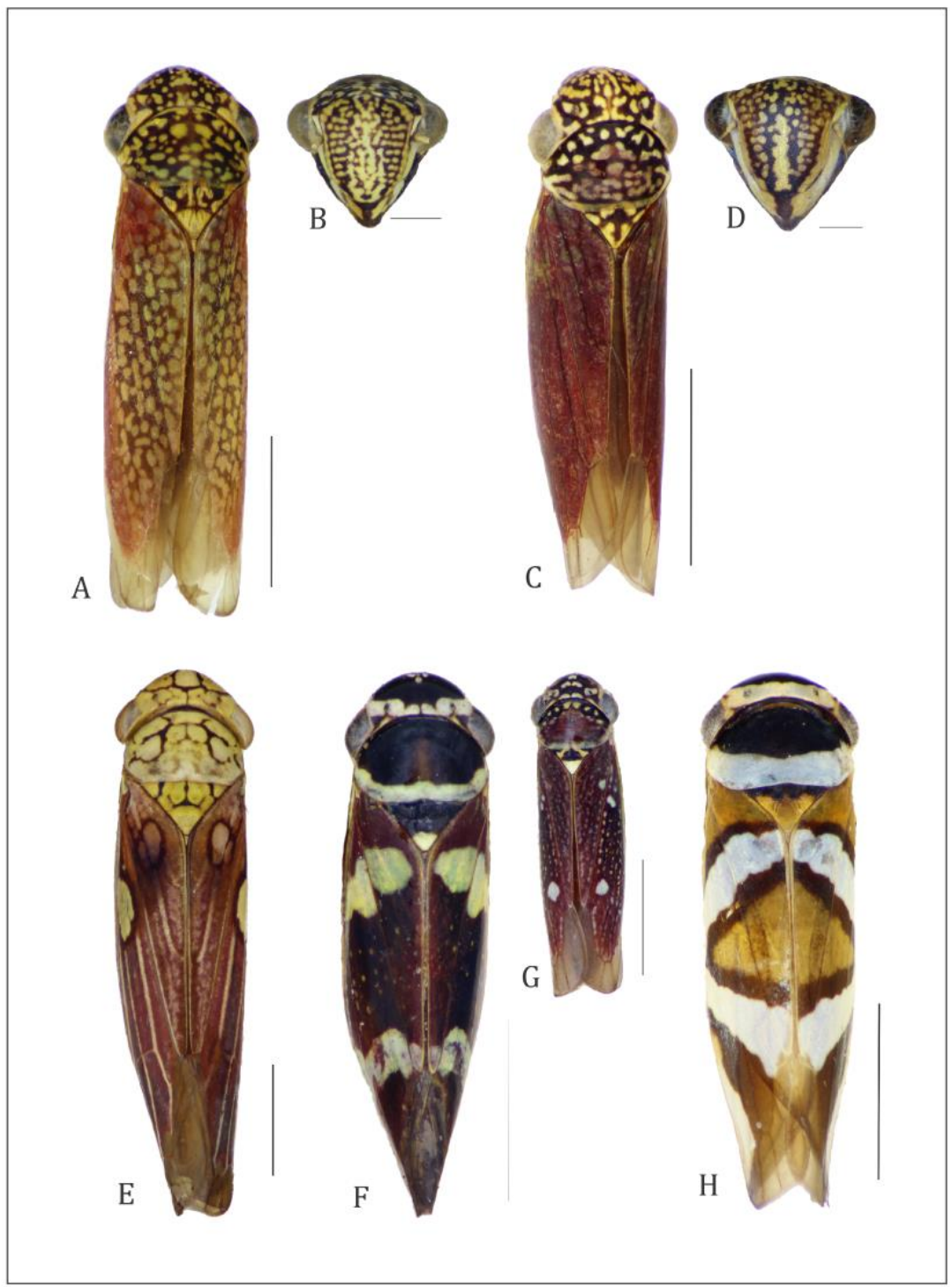

Figura 39. Especies del género Macugonalia Young presentes en Argentina. $M$. cavifrons (Stål) (A), cabeza, en vista ventral, de M. cavifrons (B), M. sobrina (Stål) (C), cabeza, en vista ventral, de M. sobrina (D), M. geographica (Signoret)(E), M. leucomelas (Walker)(F), variante de coloración de M. leucomelas (G), M. moesta (Fabricius)(H). Escalas $2 \mathrm{~mm}$. 


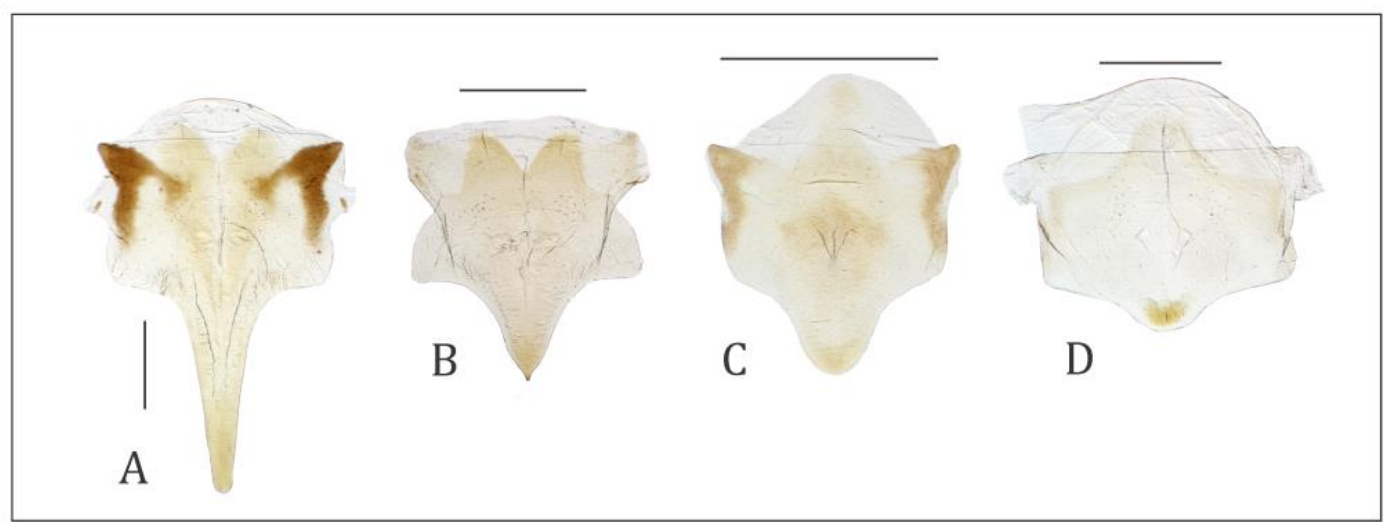

Figura 40. Esternito VII de las especies de Macugonalia Young presentes en Argentina. M. cavifrons (A), M. sobrina (B), M. leucomelas (C), M. moesta (D). Escalas 0,5 mm.

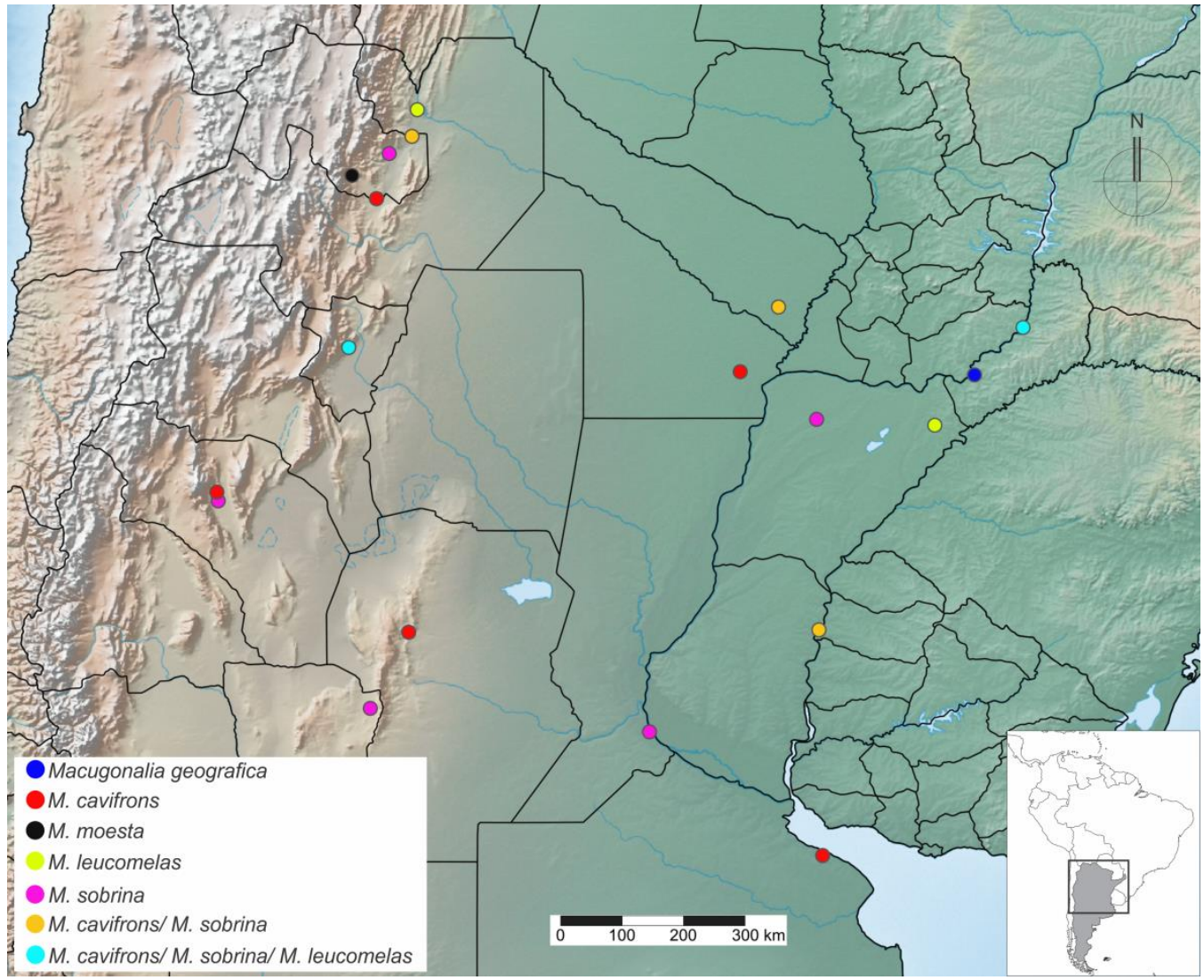

Figura 41. Distribución de las especies del género Macugonalia Young en Argentina. 


\section{Género Oragua Melichar}

Especie tipo: Tettigonia nebulosa Signoret 1854: 343 (Por designación subsequente de China 1938).

Longitud del macho 5,2-10,7 mm.

Cabeza. Ligeramente proyectada, longitud media de la corona $0,3-0,6 \mathrm{x}$ el ancho interocular, margen anterior, en vista dorsal, obtusamente redondeado; superficie de la corona convexa, usualmente fuertemente punteada; ocelos localizados sobre o ligeramente por delante de la línea que pasa entre los ángulos anteriores de los ojos. Puentes antenales, en vista dorsal, no protuberantes ni carenados, con el margen anterior, en vista lateral, vertical u oblicuo, rectilíneo o ligeramente cóncavo a convexo. Transición corona-clípeo redondeada. Clípeo, en vista lateral, ligeramente convexo en algunas especies, o aplanado medialmente, con la porción media fuertemente punteada y usualmente glabro. Sutura transclipeal a veces completa. Porción posterior del clipelo en continuidad con el perfil del clípeo, o fuertemente oblicua.

Tórax. Ancho del pronoto menor o igual que el ancho transocular, márgenes laterales paralelos o ligeramente convergentes anteriormente; carena dorsopleural, en vista lateral, completa; superficie del disco glabra, usualmente punteada, rugosa en algunas especies; escutelo punteado, transversalmente rugoso o no esculturado. Alas anteriores con la membrana incluyendo al menos la celda apical interna, membrana a veces abruptamente delimitada, venas marcadas y elevadas; con cuatro o cinco celdas apicales; textura de la porción anterior a la membrana, coriácea y usualmente punteada. En las hembras, las alas en reposo a veces ocultan el ovipositor. Tibia posterior con una hilera anterodorsal de setas con algunas setas cortas intercaladas (aproximadamente 2-4 entre cada para de macrosetas). Fórmula setal del fémur posterior 2:1:1 o 2:1:1:1; longitud del primer tarsómero igual o mayor que la longitud combinada del segundo y tercer tarsómeros, y con dos grupos longitudinales de setas pequeñas (dos hileras regulares o una hilera irregular) sobre la superficie plantar.

Genitalia del macho. Pigóforo ligeramente proyectado posteriormente, con el margen posterior ampliamente redondeado, con macrosetas distribuídas sobre toda la superficie, excepto dorsobasalmente, o limitadas a la mitad apical; procesos 
ausentes (exc. partitula). Placas subgenitales triangulares, separadas a lo largo de su longitud, extensión posterior respecto del ápice del pigóforo variable, con macrosetas usualmente uniseriadas. Estilos variables en longitud respecto del ápice del conectivo, con o sin lóbulo preapical, ápice variable entre las especies. Conectivo en forma de $\mathrm{Y}, \mathrm{T}$ o $\mathrm{V}$, eje con una quilla mediana dorsal. Edeago variable entre las especies, usualmente con apodemas basidorsales y basiventrales conspicuos. Con o sin paráfisis.

Genitalia de la hembra. Esternito abdominal VII, en vista ventral, margen posterior moderadamente proyectado, usualmente agudo pero también transverso o ligeramente cóncavo. Pigóforo posterodorsalmente redondeado, con numerosas macrosetas dispuestas irregularmente en paralelo al margen posteroventral. Esternito abdominal VIII membranoso o con uno o más escleritos. Valvifer I usualmente redondeado caudalmante. Ovipositor con el AED de la valva I formada por procesos tegumentarios usualmente estrigados que se entrelazan hacia el ápice; esculturación ventral imbricada. Valva II expandida luego de la curvatura basal; con 17-51 dientes sobre el margen dorsal, cada diente con diminutos dentículos; ápice agudo, con dentículos preapicales sobre el margen dorsal, ventralmente, con o sin dentículos preapicales.

Coloración. Las especies son mayormente castaño oscuras con pequeñas máculas de color pálido, o anaranjado en algunas especies.

Observaciones taxonómicas. Según Young (1977), la delimitación del género es dificultosa y no existe un carácter diagnóstico que permita reunir a todas las especies incluídas. Este género se distingue por tener el cuerpo robusto, coloración oscura con máculas pequeñas de color pálido en la mayoría de las especies, corona y clípeo fuertemente punteados, tegmen opaco, pigóforo del macho con numerosas setas y el esternito abdominal VII de la hembra usualmente con una proyección aguda en el margen posterior. Oragua le da el nombre a uno de los grupos génericos propuestos por dicho autor en el cual se incluyen géneros muy diversos (Acrulogonia Young, Tubiga Young, Selvitsa Young, Scoposcartula Young, Schildola Young y Trachygonalia Young) por lo cual, también resulta difícil de caracterizar. Entre estos géneros, Oragua es similar a Acrulogonia y Tubiga, de los cuales se diferencia por la quetotaxia 
y ausencia de procesos en el pigóforo de los machos, corona y clípeo fuertemente punteados, y alas anteriores opacas.

Distribución. Neotropical con registros en Argentina, Bolivia, Brasil, Ecuador, El Salvador, Guatemala, Guayana Francesa, Honduras, México, Panamá, Paraguay, Perú, Surinam, Venezuela (Young 1977) y Colombia (Freytag \& Sharkey 2002).

El género Oragua cuenta con 38 especies descriptas de las cuales tres están presentes en la Argentina.

discoidula (Osborn) 1926:178.

furva Young 1977:635.

triplehorni Young 1977:635.

Oragua discoidula (Osborn) (Figura 42, 44A)

Cicadella discoidula Osborn 1926: 178 [n. sp.]

Tettigella [incert. sed.] discoidula Metcalf 1965: 181 [Catalogado]

Oragua discoidula Young 1977: 614 [n. comb.]

Diagnosis. Placas subgenitales cortas, apenas alcanzando un cuarto del pigóforo (Osborn 1926), con macrosetas uniseriadas. Pigóforo del macho con numerosas macrosetas distribuídas uniformemente sobre toda la superficie; sin procesos. Edeago, en vista lateral, con un par de apodemas cortos dirigidos dorsoanteriormente; eje estrecho, con la mitad apical curvada dorsalmente; ápice puntiagudo, sin procesos. Esternito abdominal VII de la hembra con el margen posterior agudo, ápice emarginado (Young 1977). Esternito abdominal VIII membranoso.

Genitalia de la hembra. Esternito VII (Fig. 42A), en vista ventral, rectangular, poco proyectado posteriormente, longitud media aproximadamente $0,5 \mathrm{x}$ el ancho máximo; márgenes posterolaterales redondeados y margen posterior agudo, con el ápice emarginado; superficie cubierta por procesos tegumentarios espiniformes, excepto en la porción media, con microsetas en la mitad anterior. Pigóforo (Fig. 42B), en vista 
lateral, moderadamente proyectado, margen posterior subredondeado; superficie con numerosas macrosetas, excepto en la porción posterodorsal. Valvifer I (Fig. 42C), en vista lateral, ovalado con la superficie lisa. Valva I (Fig. 42E), en vista lateral, lanceolada; porción basal unida por membrana con esclerito medial redondeado; AED cubriendo los dos tercios apicales del eje, formada por procesos tegumentarios dispuestos de manera estrigada; AEV restringida a la porción preapical del eje, formada por procesos escamiformes. EVA larga extendiéndose casi hasta la mitad basal del eje; porción preapical aguda con los márgenes dorsal y ventral no denticulados, ápice (Fig. 42F) redondeado. Valvifer II (Fig. 42D), en vista lateral, con numerosas microsetas agrupadas cerca del punto de articulación. Valva II (Fig. 42G), en vista lateral, fuertemente expandida luego de la curvatura basal; margen dorsal con numerosos dientes (Fig. 42H) subtriangulares, cada diente con el margen posterior ligeramente más largo y en declive, llevando diminutos dentículos, cúspide roma. Ductos visibles a lo largo de toda la porción expandida, extendiéndose hasta la base de los dientes y el margen apical. Porción preapical aguda, márgenes dorsal y ventral denticulados, ápice (Fig 42I) redondeado; ventralmente sin prominencia preapical. Gonoplaca (Fig. 42J), en vista lateral, porción anterior estrecha, ligeramente más larga que la porción posterior, la cual es marcadamente expandida; superficie con procesos tegumentarios espiniformes sobre el margen ventral y la porción preapical, con algunas microsetas dispersas a lo largo del margen ventral; ápice (Fig. 42K) ampliamente redondeado.

Observaciones taxonómicas. Oragua discoidula es similar a O. furva Young en la morfología de la genitalia del macho, sin embargo es una especie más robusta, de mayor tamaño, la porción curvada del eje aedeagal es más corta que en discoidula y el pigóforo no posee procesos (Young 1977).

Distribución. Sudamericana, con registros en Argentina, Brasil, Paraguay (Young 1977) y Colombia (Freytag \& Sharkey 2002). En la Argentina, se cita por primera vez para la provincia de Tucumán (Rinconada) y Misiones (Parque Nacional Iguazú) (Figura 45).

Plantas hospedadoras. Desconocidas. 
Datos biológicos. Desconocidos.

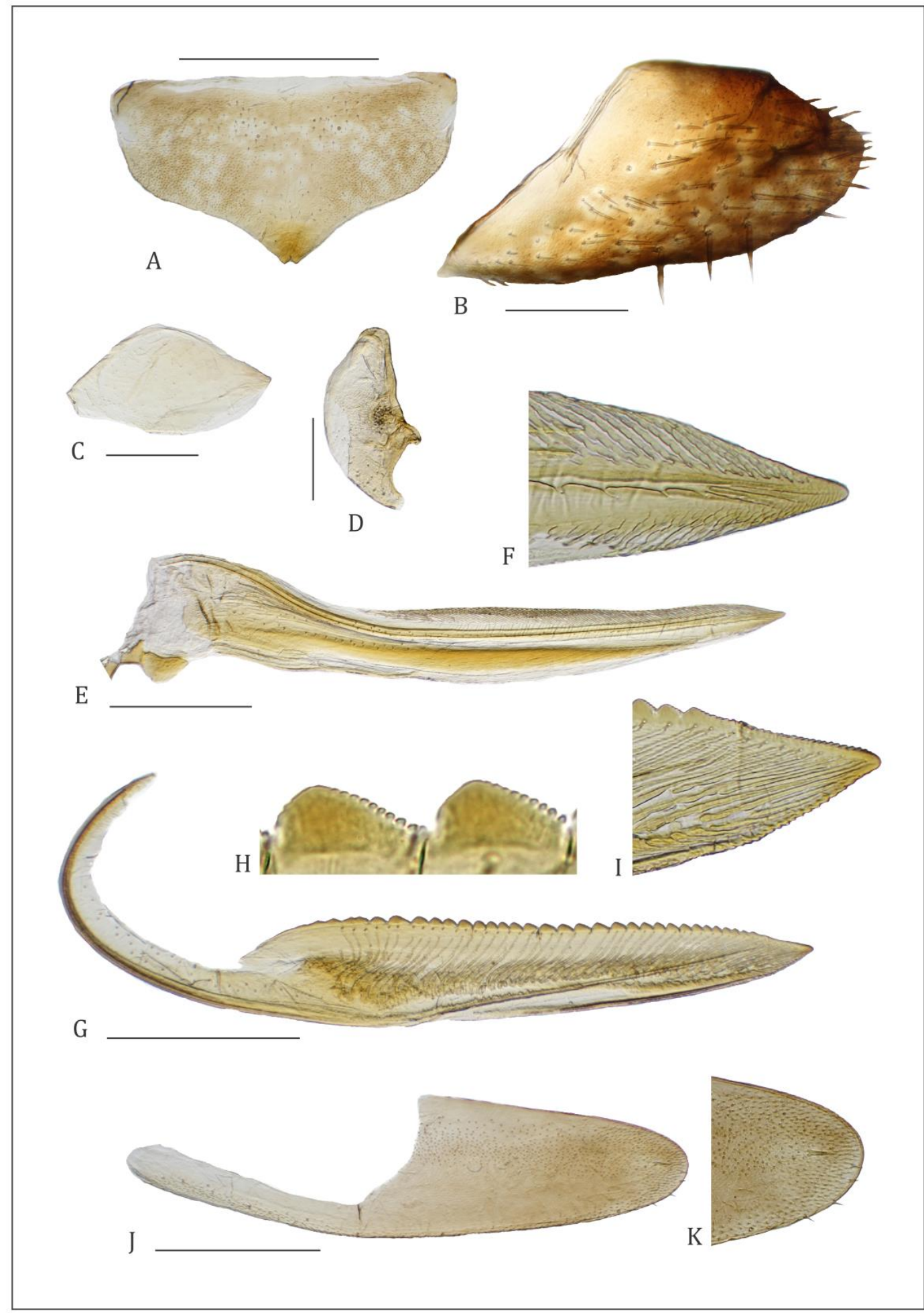

Figura 42. Genitalia de la hembra de Oragua discoidula (Osborn): esternito abdominal VII (A), pigóforo (B), valvifer I (C), valvifer II (D), valva I (E), ápice valva I (F), valva II (G), dientes valva II (H), ápice valva II (I), gonoplaca (J), ápice gonoplaca (K). Escalas 0,5 mm: A, B, E, G, J; 0,3 mm: C, D. 
Enemigos naturales. Desconocidos.

Importancia fitosanitaria. Vector comprobado de la bacteria Xylella fastidiosa subsp. pauca en Brasil (Lopes 2017).

Material estudiado. ARGENTINA: (IFML): Tucumán: Rinconada, 1ðึ, IV/1947, Ares col. (UNLP): Misiones: Parque Nacional Iguazú, 3§ึ̋, 20-21/III/2013, Lucia

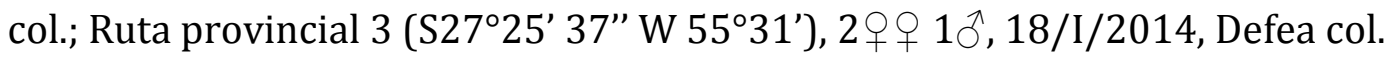

Oragua furva Young

Oragua furva Young 1977: 635 [n. sp.]

Diagnosis. Longitud 5,6 $\mathrm{mm}$. Pigóforo del macho con numerosas macrosetas distribuídas regularmente sobre toda la superficie; con procesos dorsoapicales en forma de placa que se extienden anteromedialmente. Placas subgenitales cortas, alcanzando ligeramente la mitad basal del pigóforo, con macrosetas multiseriadas. Edeago, en vista lateral, con un par de procesos anterodorsales; eje estrecho, con el tercio apical curvado dorsalmente, ápice agudo sin procesos. Hembra desconocida (Young 1977).

Observaciones taxonómicas. Oragua furva es similar a O. discoidula Young en la morfología del edeago, sin embargo los individuos son de menor tamaño y presenta procesos en el pigóforo (Young 1977).

Distribución. Argentina (Tucumán) (Young 1977) (Figura 45).

Plantas hospedadoras. Desconocidas.

Datos biológicos. Desconocidos.

Enemigos naturales. Desconocidos. 
Importancia fitosanitaria. Desconocida.

Material estudiado. No se contó con material disponible para su estudio.

Oragua triplehorni Young (Figura 43, 44B)

Oragua triplehorni Young 1977: 635 [n. sp.]

Diagnosis. Longitud 5,6-6,4 mm. Pigóforo del macho con numerosas macrosetas distribuídas irregularmente sobre toda la superficie; sin procesos. Placas subgenitales largas, extendiéndose más allá del ápice del pigóforo, con macrosetas multiseriadas. Edeago, en vista lateral, con un par de apodemas largos (2x la longitud del eje aedeagal) dirigidos anteriormente; eje estrecho, curvado dorsalmente, con un par de procesos cortos anteapicales. Esternito abdominal VII con el margen posterior transverso (Young 1977). Esternito abdominal VIII formado por dos escleritos débilmente esclerotizados.

Genitalia de la hembra. Esternito VII (Fig. 43A), en vista ventral, subrectangular; longitud media ligeramente menor a un tercio del ancho máximo; márgenes posterolaterales subangulosos y margen posterior transverso con un lóbulo amplio en su porción media; superficie cubierta por procesos tegumentarios espiniformes, excepto en la porción media, con microsetas robustas, en la mitad anterior del disco, y microsetas finas dispersas por toda la superficie. Esternito abdominal VIII (Fig. 43D). Pigóforo (Fig. 43B), en vista lateral, moderadamente proyectado, margen posterior ampliamente redondeado; superficie con numerosas macrosetas, excepto en la porción posterodorsal. Valvifer I (Fig. 43C), en vista lateral, alargado con los márgenes anterior y posterior redondeados, superficie con procesos tegumentarios dispersos. Valva I (Fig. 43E), en vista lateral, lanceolada; AED (Fig. 43F) extendida sobre los dos tercios apicales del eje, formada por procesos tegumentarios dispuestos de manera estrigada; AEV restringida a la porción preapical del eje. EVA larga y débilmente esclerotizada, extendiéndose casi hasta la mitad basal del eje; porción preapical aguda con los márgenes dorsal y ventral no denticulados, ápice (Fig. 43G) redondeado. Valvifer II, en vista lateral, igual que 0 . discoidula. Valva II (Fig. 43H), en 
vista lateral, fuertemente expandida luego de la curvatura basal; margen dorsal con numerosos dientes (Fig. 43I) redondeados; cada diente con aproximadamente tres dentículos romos sobre el margen posterior. Ductos visibles a lo largo de toda la porción expandida, que se extienden hasta la base de los dientes y el margen apical. Porción preapical aguda con los márgenes dorsal y ventral denticulados, ápice (Fig. 43J) redondeado; ventralmente sin prominencia preapical. Gonoplaca (Fig. 43K), en vista lateral, porción anterior estrecha, casi tan larga como la porción posterior, la cual es marcadamente expandida; superficie preapical y basal con procesos tegumentarios espiniformes, con microsetas dispersas a lo largo del margen ventral; ápice ampliamente redondeado.

Observaciones taxonómicas. Oragua triplehorni es similar a O. obscura (Schröder) en la morfología del edeago, sin embargo el ápice aedeagal y la quetotaxia de las placas subgenitales permiten diferenciarlas (Young 1977).

Distribución. Sudamericana, con registros en Argentina (Dellapé 2013), Bolivia y Brasil (Young 1977). En la Argentina, fue registrada para la provincia de Entre Ríos (Dellapé 2013). Se amplía su distribución a las provincias de Tucumán (El Manantial), Corrientes (Bella Vista) y Córdoba (Barranca Yaco) (Figura 45).

Plantas hospedadoras. Citrus sinensis (L.) Osb. (Dellapé 2013).

Datos biológicos. Desconocidos.

Enemigos naturales. Se registra por primera vez un ejemplar hembra de la localidad de Barranca Yaco, Córdoba parasitado por un individuo del Orden Strepsiptera.

Importancia fitosanitaria. Desconocida.

Material estudiado. ARGENTINA: (UNLP): Tucumán: El Manantial, $1 q 1{ }^{\lambda}$, 16/VIII/2011, Virla col. Corrientes: Bella Vista, 5q 5ڤึ, I/2015, Defea col. Córdoba: Barranca Yaco, $3 \uparrow q 2 \widehat{\jmath}$, 9/III/2012, Virla col.; 1§, 24/I/2012, Virla col. 


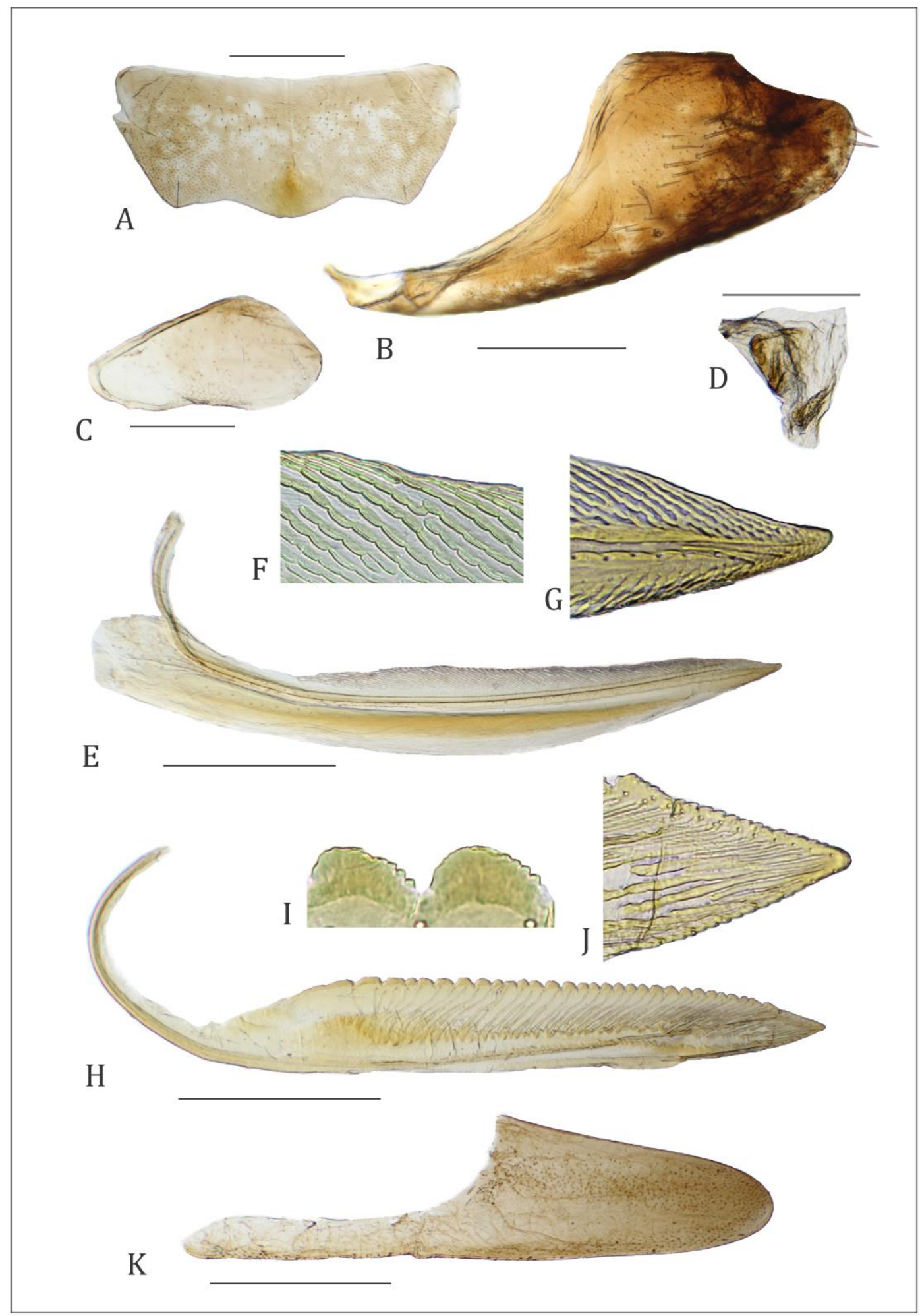

Figura 43. Genitalia de la hembra de Oragua triplehorni Young: esternito abdominal VII (A), pigóforo (B), valvifer I (C), esternito abdominal VIII (D), valva I (E), AED de la valva I (F), ápice valva I (G), valva II (H), dientes valva II (I), ápice valva II (J), gonoplaca (K). Escalas 0,5 mm: A, B, D, E, H, K; 0,3 mm: C. 
Clave para el reconocimiento de las especies del género Oragua presentes en

\section{la Argentina.}

1. Pigóforo del macho con un par de procesos dorsoapicales aplanados, que se extienden anteromedialmente. Hembra desconocida. O. furva

-. Pigóforo del macho sin procesos. Hembra conocida 2

2. Esternito abdominal VII de la hembra con el margen posterior transverso. Edeago con un par de procesos apicales cortos; placas subgenitales del macho con macrosetas multiseriadas. O. triplehorni

-. Esternito abdominal VII de la hembra con el margen posterior agudo. Edeago sin procesos apicales; placas subgenitales del macho con macrosetas uniseriadas O. discoidula

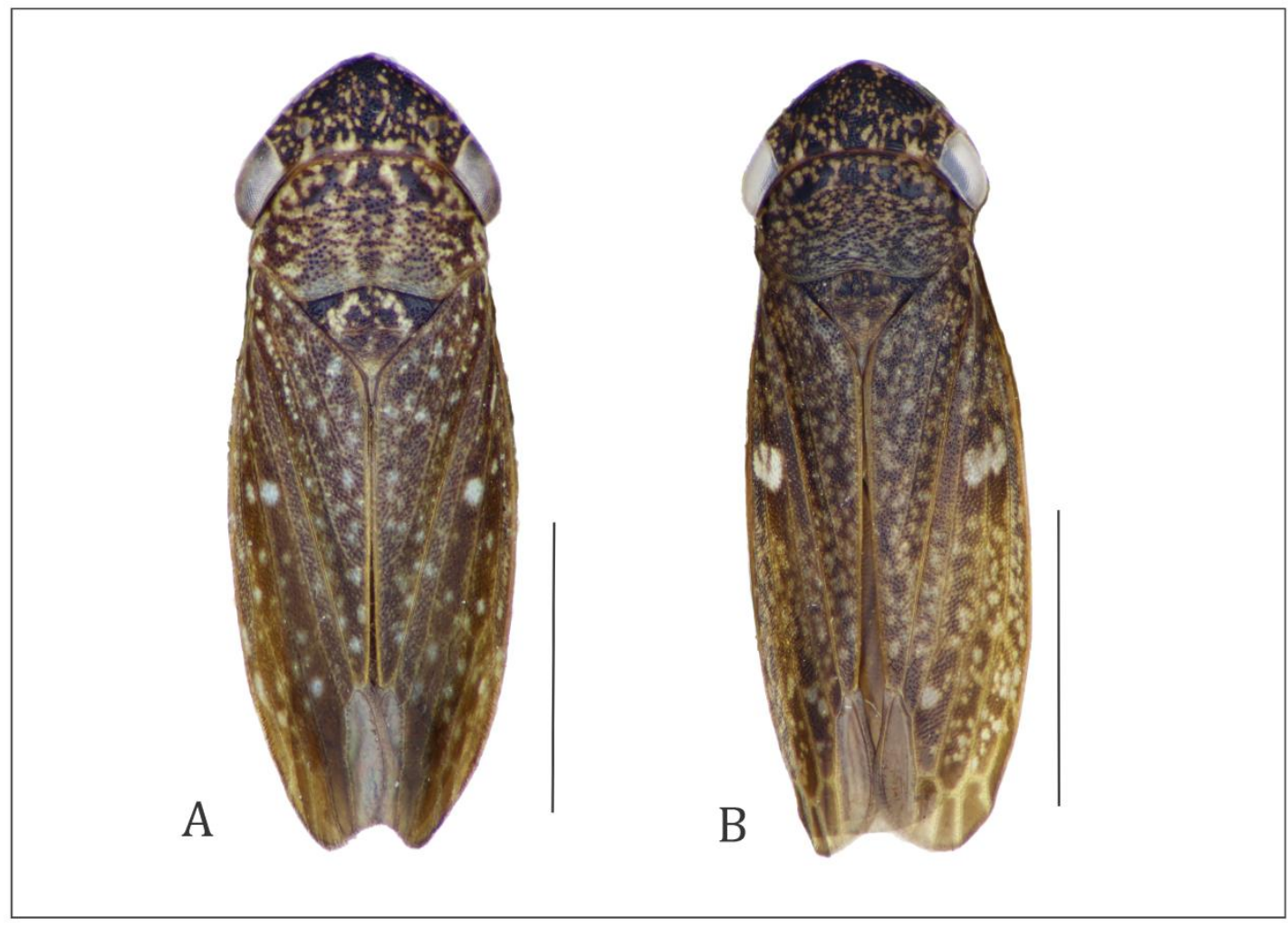

Figura 44. Especies del género Oragua Melichar presentes en Argentina. $O$. discoidula (Osborn) (A), O. triplehorni Young (B). Escalas 2 mm. 


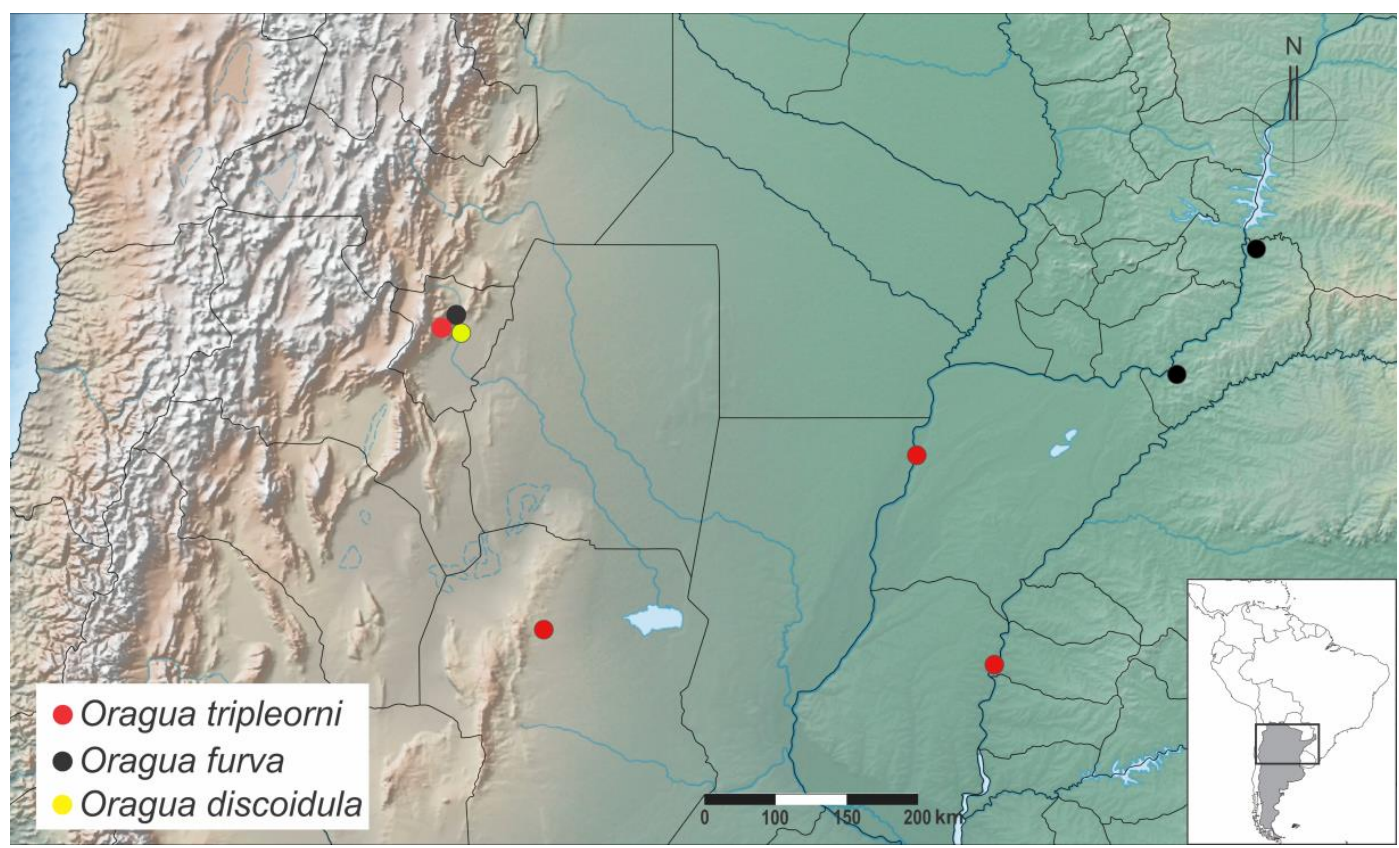

Figura 45. Distribución de las especies del género Oragua Melichar en Argentina. 


\section{Género Parathona Melichar}

Especie tipo: Cicada lyncea Fabricius 1787: 269 (= Cicada cayennensis Gmelin 1798:

Longitud total 8,3-10, $0 \mathrm{~mm}$.

Cabeza. Ligera a moderadamente proyectada, longitud media de la corona $0,4-0,6 \mathrm{x}$ el ancho interocular, margen anterior, en vista dorsal, ampliamente redondeado; superficie de la corona glabra, finamente punteada en su porción anterior, con una concavidad a la altura de los ocelos; ocelos localizados marcadamente por detrás de la línea que pasa entre los ángulos anteriores de los ojos, usualmente cercanos al margen posterior de la cabeza. Puentes antenales, en vista dorsal, no protuberantes, con el margen anterior, en vista lateral, oblicuo, convexo o rectilíneo. Transición corona-clípeo redondeada. Clípeo con impresiones musculares a veces marcadas; sutura transclipeal interrumpida medialmente; clipelo, en vista lateral, no protuberante, con el margen apical cóncavo.

Tórax. Ancho del pronoto variable entre la especies respecto del ancho transocular de la cabeza, márgenes laterales ligeramente convergentes anteriormente; carena dorsopleural a veces completa; superficie del disco usualmente transversalmente rugoso; superficie del escutelo por detrás del surco transversal rugosa, glabra. Alas anteriores con textura variable, completamente membranosas a coriáceas excepto la membrana apical que incluye las cuatro celdas apicales; venas usualmente marcadas; con tres celdas anteapicales cerradas cuyas bases son opuestas al ápice claval o más basales a éste. En las hembras, las alas en reposo ocultan el ovipositor. Fórmula setal del fémur posterior 2:1:1; longitud del primer tarsómero igual o mayor que la longitud combinada del segundo y tercer tarsómeros.

Genitalia del macho. Pigóforo moderadamente proyectado posteriormente, margen posterior convexo, quetotaxia variable entre las especies. Placas subgenitales triangulares, muy cortas, no alcanzando la mitad del pigóforo; superficie con macrosetas uniseriadas o numerosas microsetas multiseriadas. Estilos variables en longitud, nunca extendiéndose más allá del ápice del conectivo. Conectivo en forma de Y, eje con una quilla medial. Edeago simétrico, con un proceso ventral agudo de 
origen basal que se proyecta apicalmente, curvado dorsalmente; eje, en vista lateral, ancho. Paráfisis ausentes.

Genitalia de la hembra. Esternito abdominal VII, en vista ventral, margen posterior transverso a anguloso en el ápice. Pigóforo con macrosetas, variable entre las especies. Ovipositor con la segunda valva expandida luego de la curvatura basal o los tres cuartos apicales; margen dorsal con dientes cuadrangulares.

Observaciones taxonómicas. Las relaciones de Parathona con otros géneros es problemática. Según Young (1977) sería cercano a Baleja Melichar por presentar ambos el clipelo cóncavo, por similitudes en la estructura de la segunda valva del oviporsitor y forma del edeago. Sin embargo, las especies de Parathona son más robustas, tienen la cabeza menos proyectada anteriormente y la porción membranosa del tegmen es más extensa. Externamente, las especies de Parathona son similares a Scoposcartula Young.

Distribución. Neotropical con registros en Argentina, Bolivia, Brasil, Colombia, Panamá, Paraguay, Trinidad y Venezuela (Young 1977).

El género Parathona cuenta con cuatro especies descriptas de las cuales una está presente en la Argentina.

Parathona gratiosa (Blanchard) (Figuras 46, 47)

Tettigonia gratiosa Blanchard 1840: 191 [n. sp.]

Apogonalia gratiosa Metcalf 1965: 290

Parathona gratiosa Young 1977: 307 [n. comb.]

Tettigonia drewseni Stål 1855: 192 [n. sp.]

Apogonalia drewseni Metcalf 1965: 289

Parathona gratiosa Young 1977: 307 [n. syn.]

Diagnosis. Coloración anaranjada; cabeza, en vista dorsal, con una mácula preapical mediana, pronoto con cuatro mácula simétricas sobre el disco y una banda estrecha paralela al margen posterior, negras. Tegmen castaño con bandas longitudinales irregulares de color amarillo, usualmente con dos máculas redondeadas amarillentas preapicales (Blanchard 1840). Pigóforo del macho con 
macrosetas submarginales posteroventrales. Estilos ligeramente más cortos que el conectivo. Edeago, en vista lateral, eje perpendicular a los apodemas aedeagales (Young 1977). Ancho del pronoto ligeramente menor o igual que el ancho transocular. Porción posterior del escutelo débilmente rugoso. Dientes de la valva II tricupidados.

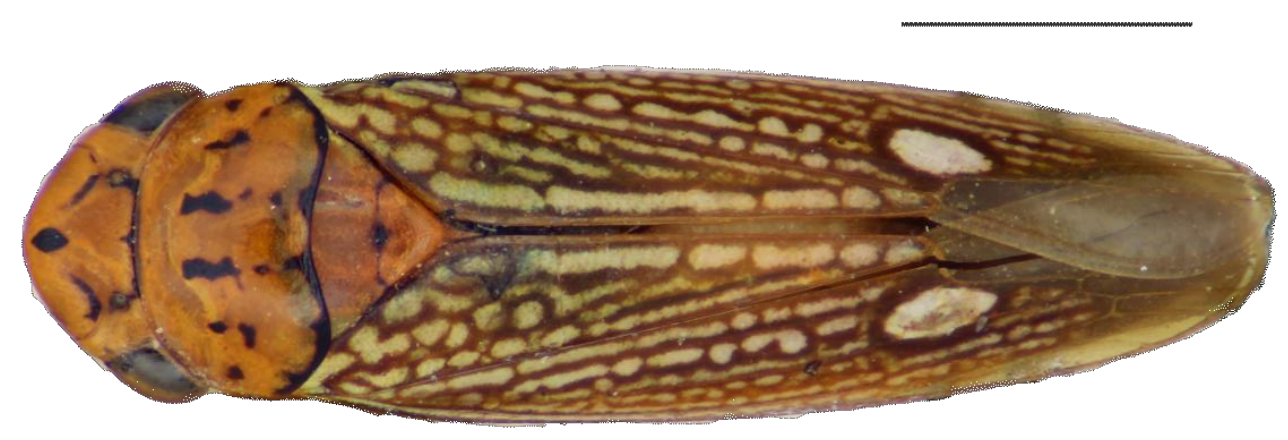

Figura 46. Hábito dorsal de Parathona gratiosa (Blanchard). Escala $2 \mathrm{~mm}$.

Genitalia de la hembra. Esternito VII (Fig. 47A), en vista ventral, tan largo como ancho; márgenes laterales ligeramente convexos y el posterior agudo medialmente con el ápice redondeado, superficie latero posterior cubierta por procesos tegumentarios espiniformes, con algunas microsetas agrupadas en cada lado equidistantes a la porción media. Esternito VIII membranoso. Pigóforo (Fig. 47B), en vista lateral, subovalado con el margen posterior proyectado moderadamente; superficie con algunas macrosetas dispersas y microsetas sobre la superficie anterodorsal. Valvifer I (Fig. 47C), en vista lateral, subcuadrangular, margen anterior plegado internamente, margen posterior cóncavo, dorsalmente convexo y margen ventral sinuoso; con procesos tegumentarios espiniformes sobre el tercio anterior. Valva I (Fig. 47E), en vista lateral, lanceolada, estrecha en toda su longitud con los márgenes dorsal y ventral paralelos; AED extendiéndose sobre los dos tercios apicales del eje, formada por procesosos tegumentarios filiformes, dispuestos en líneas oblicuas; AEV restringida a la porción preapical del eje, formada por procesos escamiformes que se extienden anteriormente cubriendo ligeramente la superficie apical. EAV larga, extendida sobre la mitad basal del eje. Ápice obtuso (Fig. 47F). Valvifer II (Fig. 47D), en vista lateral, margen anterior con una concavidad anterodorsal; superficie de la mitad ventral con procesos tegumentarios 
espiniformes. Valva II (Fig. 47G), en vista lateral, expandida luego de la curvatura basal con los márgenes dorsal y ventral del eje rectos; margen dorsal llevando numerosos dientes (Fig. 47H); cada diente con tres cúspides, la anterior de mayor tamaño, la de posición intermedia, ubicada a continuación de la mayor, más pequeña, la distal, de menor tamaño, se pierde hacia la porción preapical; cada diente llevando numerosos dentículos. Ductos visibles a lo largo de toda la porción expandida del eje, alcanzando los dientes y el ápice. Ápice (Fig. 47I) ampliamente redondeado, margen ventral preapical denticulado; ventralmente con prominencia preapical. Gonoplaca (Fig. 47J), en vista lateral, porción anterior estrecha, 0,35x más larga que la porción posterior, la cual es marcadamente expandida; superficie con numerosos procesos tegumentarios espiniformes en la porción preapical que se extienden anteriormente hasta la porción basal a lo largo del margen ventral, con microsetas dispersas submarginales; ápice ampliamente redondeado. 


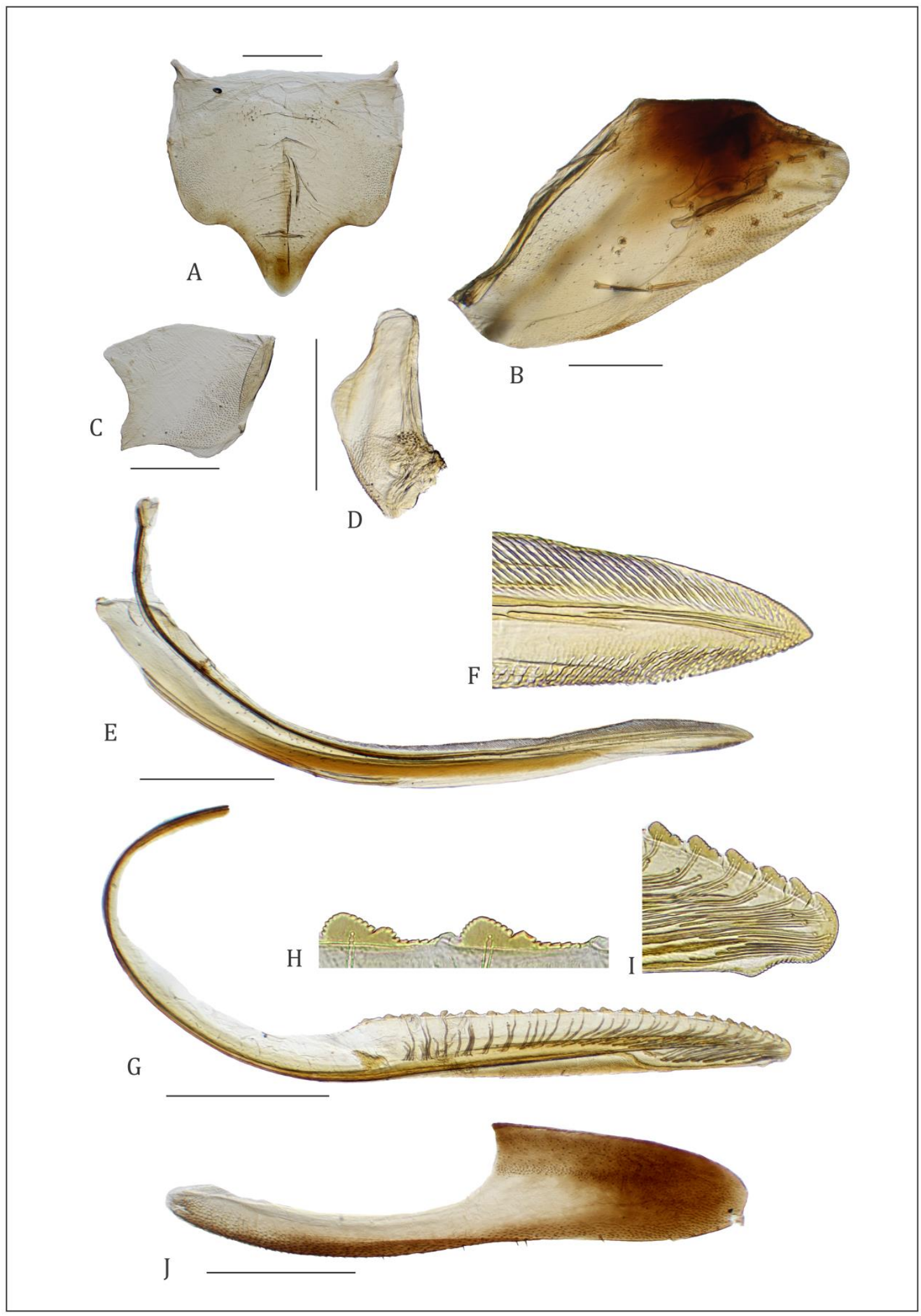

Figura 47. Genitalia de la hembra de Parathona gratiosa (Blanchard): esternito abdominal VII (A), pigóforo (B), valvifer I (C), valvifer II (D), valva I (E), ápice valva I (F), valva II (G), dientes valva II (H), ápice valva II (I), gonoplaca (J). Escalas 0,5 mm: A-D, E, G, J. 
Observaciones taxonómicas. Parathona gratiosa se distingue del resto de las especies del género por la morfología del edeago y quetotaxia del pigóforo del macho (Young 1977), forma de los dientes de la valva II del ovipositor de la hembra y la coloración general.

Distribución: Sudamericana con registros en Argentina, Bolivia, Brasil y Paraguay (Young 1977). En la Argentina, P. gratiosa está presente en las provincia de Misiones (Remes Lenicov et al. 1999). Se amplía su distribución para la provincia de Salta (Agua Blanca), Jujuy (Yuto) y Corrientes (Figura 48).

Plantas hospedadoras. Citrus sinensis (L.) Osb. (Rutaceae) (Remes Lenicov et al. 1999), Vitis vinífera L. (Vitaceae)(Ringenberg 2008).

Datos biológicos. Desconocidos.

Enemigos naturales. Desconocidos.

Importancia fitosanitaria. Desconocida.

Material estudiado. ARGENTINA: (MLP): Salta: Agua Blanca, 1q, I/1961. Corrientes: $1 \precsim$, IV/1947, R.G. Maleq. Misiones: Loreto, 1q, s/datos, Ogloblin col.; Puerto Iguazú, $2 q q$ 1§, XI/1944, B.A. Torres col.; San Ignacio, 1q, 8/XII/1941, Birabén-Bezzi cols.; Aristóbulo del Valle, $1 q 1 \hat{\jmath}, 2 / X I I / 1960$. (IFML): Misiones: Puerto Bemberg, 1, 12-29/I/1945, Hayward-Willink-Golbach cols.; 1어, III/1945, Golbach-Willink-Hayward cols.; $1 \hat{\jmath}$, II/1954, Hayward-Willink-Golbach cols.; Salto Encantado, 1へ̂, 27/XI/1951, Monrós-Willink cols. (UNLP): Jujuy: Yuto, 1へ̂, IV/2016, Tapia col. 


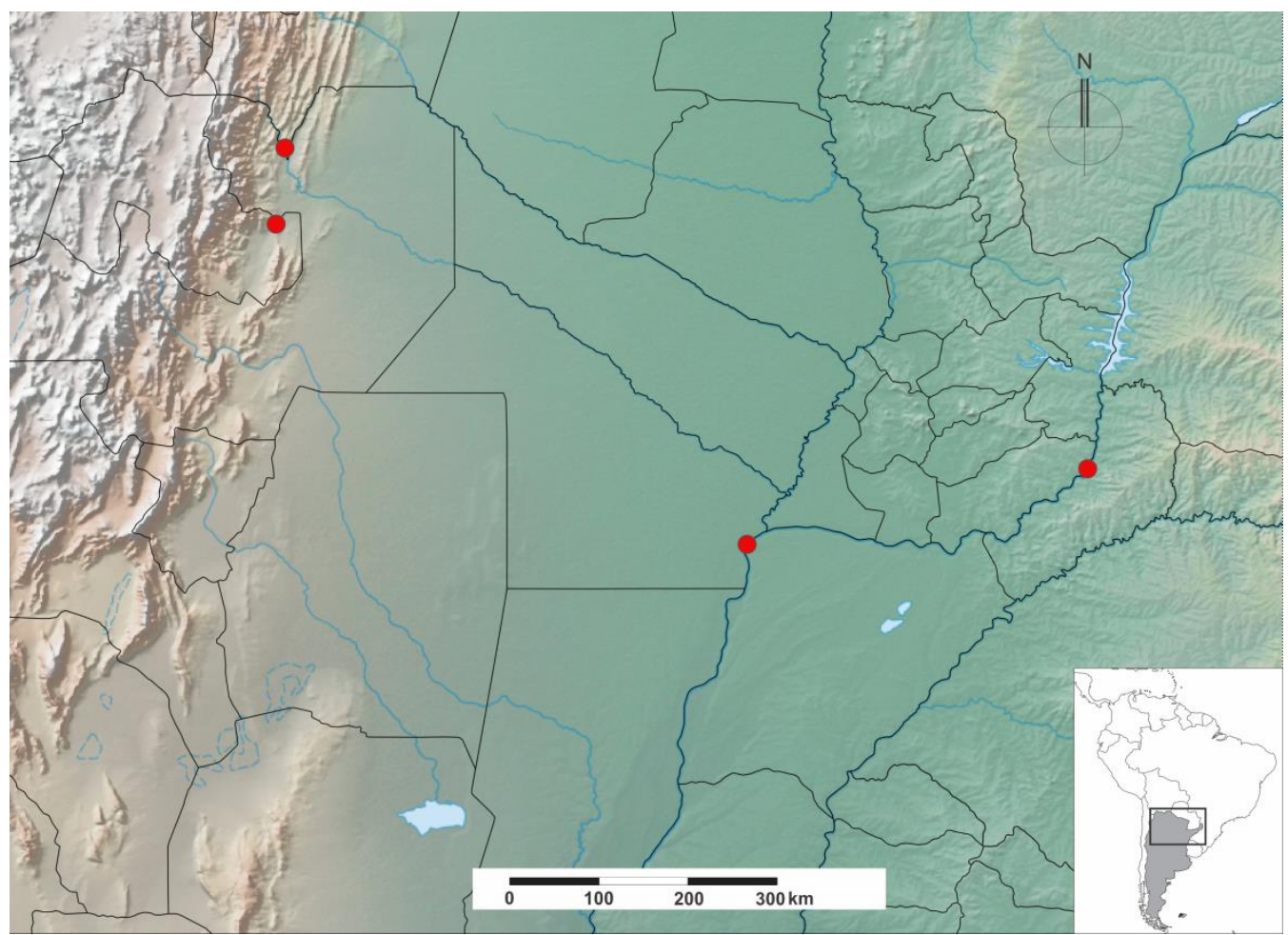

Figura 48. Distribución de Parathona gratiosa (Blanchard) en Argentina. 


\section{Género Pawiloma Young}

Especie tipo: Tettigonia amoena Walker 1851: 759.

Longitud total 7,2-10,4 mm.

Cabeza. Moderadamente proyectada, longitud media de la corona $0,4-0,7 \mathrm{x}$ el ancho interocular; ocelos localizados sobre la línea que pasa entre los ángulos anteriores de los ojos; superficie de la corona con una concavidad transversal a la altura de los ocelos, sin fóvea longitudinal media ni esculturación, disco glabro. Suturas clipeales laterales extendiéndose sobre la corona, alcanzando los ocelos. Puentes antenales, en vista dorsal, no protuberantes, con el margen anterior, en vista lateral, oblicuo y usualmente convexo. Transición corona-clípeo redondeada. Clípeo, en vista lateral, convexo o ligeramente achatado en su porción media, impresiones musculares marcadas o no evidentes; sutura transclipeal completa o interrumpida en su parte media.

Tórax. Ancho del pronoto menor o mayor que el ancho transocular, márgenes laterales paralelos o ligeramente convergentes anteriormente, carena dorsopleural completa o no, disco con débiles rugosidades transversales o no esculturado; superficie del escutelo por detrás del surco transversal con o sin rugosidades. Alas anteriores con porción membranosa y venas no siempre evidentes; con tres celdas anteapicales cerradas, al menos la base de las dos externas próximas al ápice claval, y cuatro celdas apicales; sin plexo anteapical de venas; textura alar variable entre las especies, translúcida a opaca. En las hembras, las alas anteriores en reposo ocultan el ovipositor. Fórmula setal del fémur posterior 2:1:1 o 2:1:1:1. Longitud del primer tarsómero igual o mayor que la longitud combinada del segundo y tercer tarsómero, con dos hileras de microsetas sobre la superficie plantar.

Genitalia del macho. Pigóforo corto a moderadamente proyectado posteriormente; procesos, cuando presentes, de forma variable entre las especies; con macrosetas en la mitad posterior. Placas subgenitales de forma variable entre las especies, sin alcanzar el ápice del pigóforo, con macrosetas uniseriadas dispuestas longitudinalmente. Estilos variables en longitud y forma del ápice, al igual que el conectivo. Edeago simétrico o asimétrico, con o sin procesos, cuando presentes 
usualmente impares. Paráfisis, cuando presentes, con las ramas ampliamente separadas desde la base o consistiendo en una placa ancha transversa.

Genitalia de la hembra. Esternito abdominal VII muy variable entre las especies, con el margen posterior transverso o emarginado a cónico. Ovipositor con la segunda valva expandida luego de la curvatura basal, margen dorsal con dientes, cada uno llevando numerosos dentículos; márgenes preapicales dorsal y ventral denticulados.

Observaciones taxonómicas. El género Pawiloma es similar en varios caracteres al género Erythrogonia Melichar, principalmente en lo que respecta a la forma de las paráfisis en los machos y la forma de la segunda valva del ovipositor en las hembras. Ambos géneros son morfológicamente muy variables, sin embargo ninguna de las especies de Pawiloma (exc. P. paramoena Young) posee las manchas pálidas dorsoanteriores y/o sobre las alas anteriores que caracterizan a Erythrogonia.

Distribución. Neotropical con registros en Argentina, Brasil, Panamá, Paraguay, Perú y Venezuela (Young 1977).

El género Pawiloma cuenta con 13 especies descriptas de las cuales una está presente en la Argentina.

\section{Pawiloma victima (Germar) (Figuras 49, 50)}

Tettigonia victima Germar 1821: 68 [n. sp.]

Poeciloscarta victima Metcalf 1965: 84

Pawiloma victima Young 1977: 732 [n. comb.]

Diagnosis. Cabeza, pronoto y escutelo de color anaranjado intenso, margen anterior de la corona con dos máculas arqueadas de color negro, pronoto con una banda ancha sobre los dos tercios anteriores y una mancha de forma irregular a cada lado, negras. Escutelo con tres máculas negras, la mediana ensanchándose desde el margen anterior hacia el posterior. Tegmen opaco con numerosas máculas anaranjadas, varias circulares. Clípeo anaranjado, impresiones musculares no evidentes, con una mácula negra trirradiada en su porción posterior que se proyecta débilmente sobre el clipelo también de color anaranjado. Pleuras torácicas y 
abdomen de color castaño oscuro a negro (Germar 1821). Longitud total mayor a 9 $\mathrm{mm}$. Edeago simétrico, con un par de procesos estrechos que se originan en la mitad del eje y se proyectan posterodorsalmente. Paráfisis con las ramas ampliamente separadas desde la base. Esternito abdominal VII de la hembra con el margen posterior emarginado (Young 1977). Ancho del pronoto menor que el ancho transocular de la cabeza; márgenes laterales del pronoto ligeramente convergentes anteriormente; disco pronotal con débiles rugosidades transversales; porción posterior del escutelo no esculturado. Alas anteriores con porción membranosa apical y venas no evidentes. Esternito abdominal VIII esclerotizado, en vista lateral, globoso; eje de la valva I del ovipositor con una proyección posteroventral fuertemente esclerotizada.

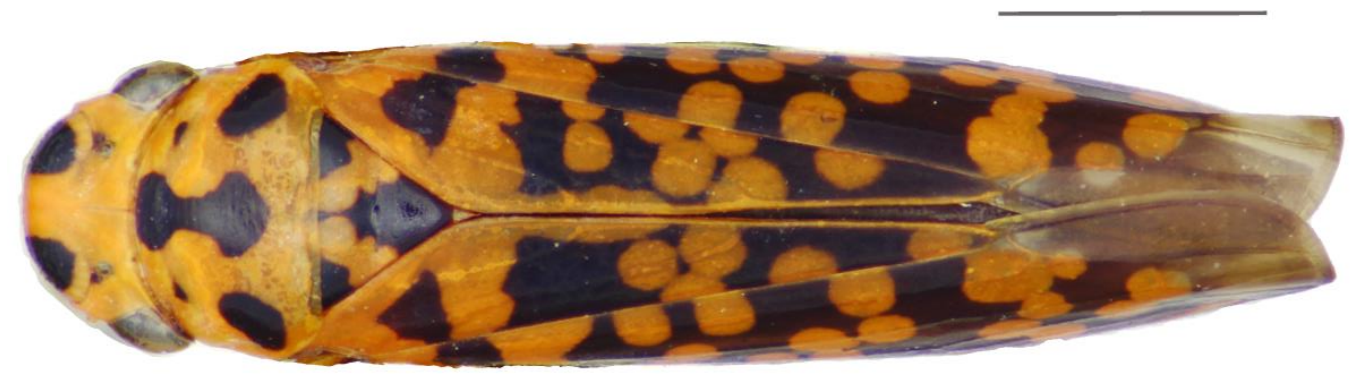

Figura 49. Hábito dorsal de Pawiloma victima (Germar). Escala 2 mm.

Genitalia de la hembra. Esternito VII (Fig. 50A), en vista ventral, triangular; márgenes laterales fuertemente convergentes posteriormente; margen posterior emarginado; superficie finamente punteada. Esternito VIII esclerotizado, en vista lateral (Fig. 50B), globoso; en ventral (Fig. 50C), proyectado posteriormente formando dos ramas fuertemente esclerotizadas. Pigóforo, en vista lateral, proyectado moderadamente con el margen posterior obtuso; superficie con macrosetas dispersas en la mitad posterior, algunas extendiéndose anteriormente a lo largo del margen ventral. Valvifer I (Fig. 50D), en vista lateral, subrectangular con una proyección media sobre el margen dorsal; superficie con numerosos procesos tegumentarios espiniformes, con pequeñas microsetas. Valva I (Fig. 50F), en vista lateral, lanceolada, márgenes dorsal y ventral del eje casi paralelos; eje con una proyección postero-ventral fuertemente esclerotizada. AED visible luego de la curvatura basal formada por procesos tegumentarios filiformes dispuestos oblicuamente, margen anterior con escotaduras; AEV restringida a la porción 
preapical del eje, formada por procesos escamiformes. EVA larga extendiéndose hasta la mitad basal del eje; porción preapical aguda con los márgenes dorsal y ventral no denticulados, ápice (Fig. 50G) agudo. Valvifer II (Fig. 50E), en vista lateral, superficie con numerosas microsetas sobre la mitad anterior. Valva II (Fig. 50H), en vista lateral, fuertemente expandida luego de la curvatura basal, margen dorsal regularmente convexo, margen ventral rectilíneo. Margen dorsal con numerosos dientes (Fig. 50I) subtriangulares no protuberantes y continuos, con dentículos sobre los márgenes anterior y posterior. Sistema de ductos alcanzando los dientes y el margen apical. Porción preapical aguda, ápice (Fig. 50J) ampliamente redondeado con el margen denticulado; ventralmente con una ligera prominencia preapical. Gonoplaca (Fig. $50 \mathrm{~K}$ ), en vista lateral, porción anterior estrecha, 0,2x más corta que la porción posterior, la cual es marcadamente expandida; superficie con procesos espiniformes en la porción basal que se extienden sobre el margen ventral un poco más allá de la mitad basal del eje; con numerosas microsetas principalmente sobre la mitad apical y una hilera de 5-6 macrosetas en la porción preapical; ápice ampliamente redondeado.

Observaciones taxonómicas. Pawiloma victima se diferencia del resto de las especies del género por la morfología aedeagal del macho y la coloración de las alas anteriores con numerosas máculas de color anaranjado, algunas circulares (Young 1977). A los caracteres de los machos pueden sumarse la forma del esternito abdominal VIII de la hembra y rasgos de la valva I del ovipositor.

Distribución. Sudamericana con registros en Argentina, Brasil y Paraguay (Young 1977). Se cita por primera vez para Uruguay (Montevideo). En la Argentina, fue registrada en las provincias de Entre Ríos (Dellapé et al. 2016) y Buenos Aires (Paradell et al. 2014a). Se amplía la distribución para las provincias de Salta (Los Baños), Misiones (Oberá, San Javier) y Córdoba (Yacanto de San Javier) (Figura 51).

Plantas hospedadores. Brassica napus L. var. oleifera (Brassicaceae)(Paris et al. 2012), Persea indica (L.) Sprengel. (Lauraceae), Oriza sativa L. (Poaceae) (Paradell et al. 2014a), Citrus sinensis (L.) Osbeck (Rutaceae) y la vegetación espontanea asociada (Dellapé et al. 2016). Se registra por primera vez sobre Beta vulgaris subsp. cicla 


\section{(L.) “acelga” (K. Koch) (Chenopodiaceae), Eryngium sp. (Apiaceae) y Populus} alba L. "álamo" (Salicaceae).

Datos biológicos. Desconocidos.

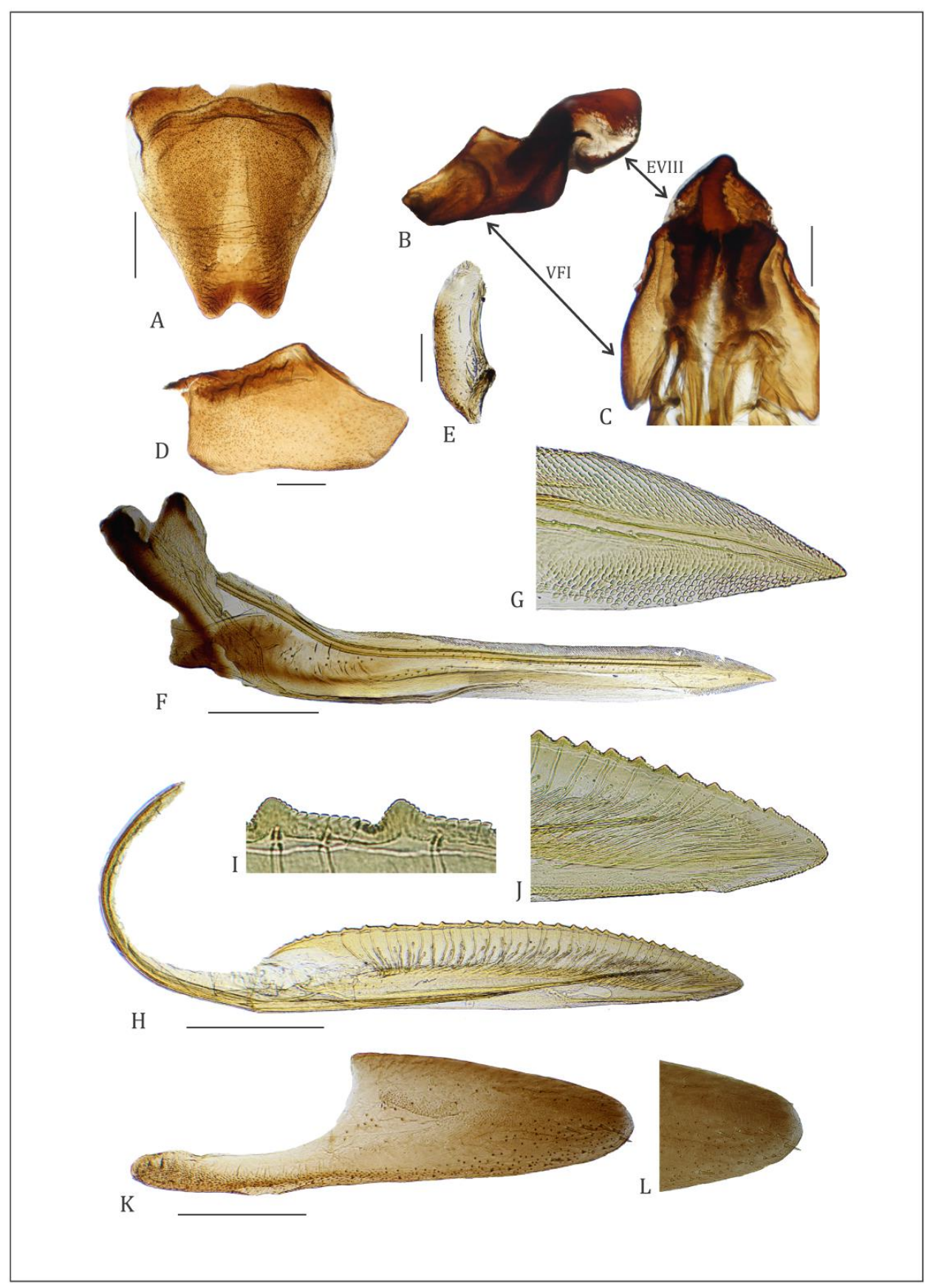

Figura 50. Genitalia de la hembra de Pawiloma victima (Germar). Esternito abdominal VII (A), esternito abdominal VIII, en vista lateral (B) y en vista ventral (C), valvifer I (D), valvifer II (E), valva I (F), ápice valva I (G), valva II (H), dientes valva II (I), ápice valva II (J), gonoplaca (K). Escala 0,5 mm: A-E, F, H, K. 
Enemigos naturales. El hongo entomopatógeno Beauveria bassiana (Toledo et al. 2008).

Importancia fitosanitaria. Desconocida.

Material estudiado. ARGENTINA: (MLP): Salta: Los Baños, 19 1 $\hat{\jmath}, 24 / \mathrm{I} / 2004$, Logarzo col. Misiones: San Javier, $2 \hat{\jmath} \widehat{\jmath}, 16-18 / X I I / 1957, M$. Birabén col. Corrientes:

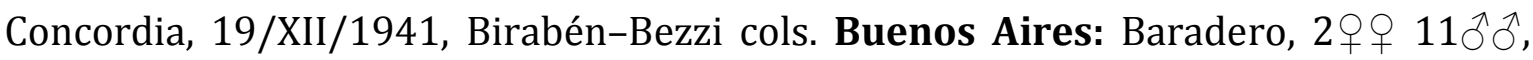

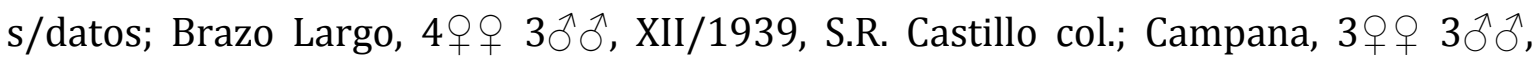
IX/1960, s/Beta vulgaris; Ibicuycito, 4 우 2へへ, 13/IV/1938, S.R. Castillo col.; Isla Martín García, 1ð, 15/VII/1966, Coscaron col.; San Pedro, 4우 5ðð, VI/1947, s/álamo. URUGUAY: Montevideo, $4 \uparrow+6 \hat{\jmath}, \mathrm{s} /$ datos, Tremoleras col. (IFML): Misiones: Oberá, $1 q 1 \widehat{\jmath}, 10 / \mathrm{XI} / 1949, \mathrm{M}$. Aczel col. Córdoba: Yacanto de San Javier,

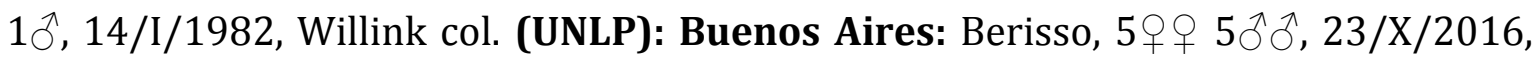
s/Populus alba, Defea col.; 5 우 5ふえ, 10/VI/2015, s/Eryngium sp., Defea col. 


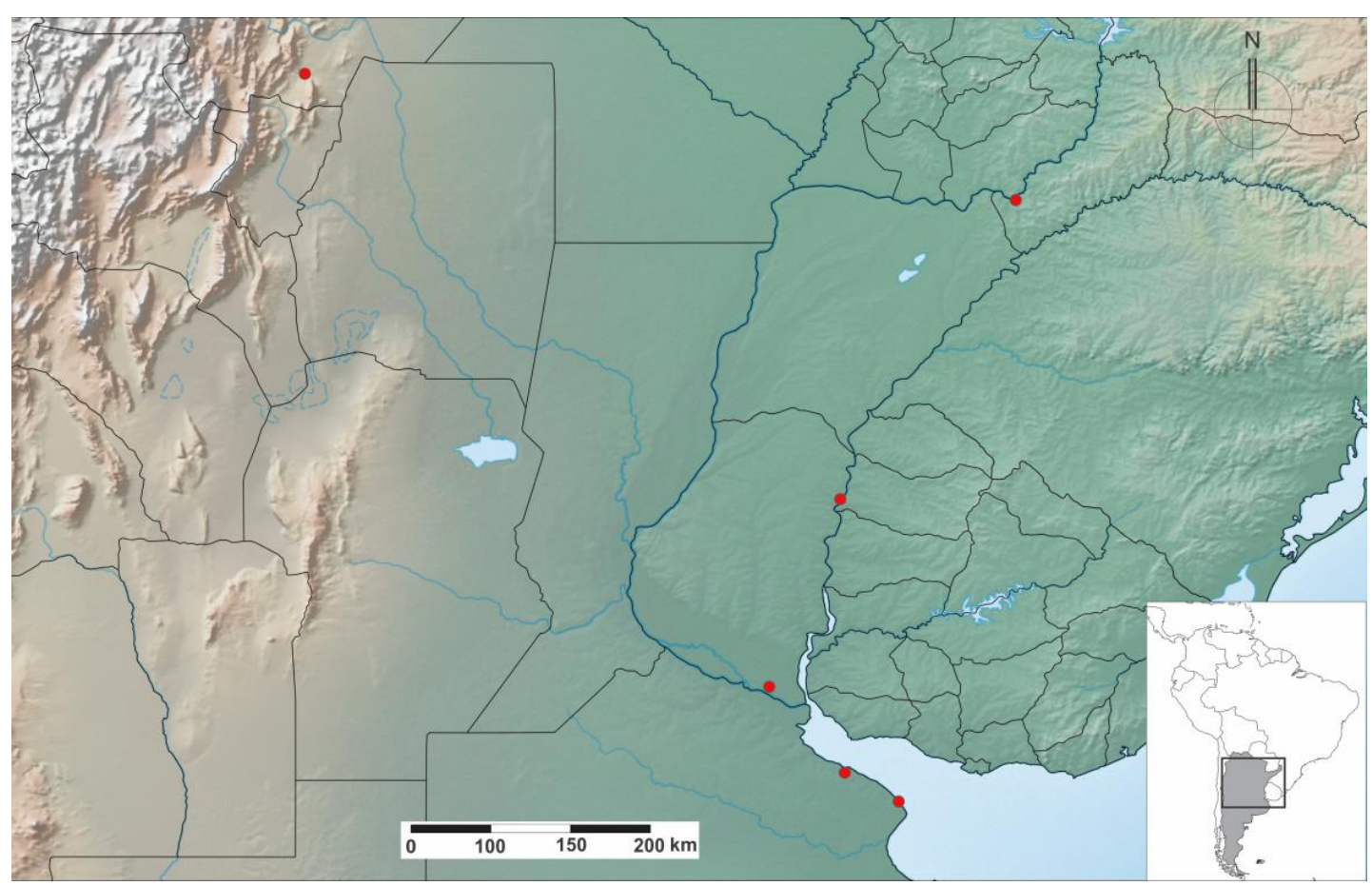

Figura 51. Distribución de Pawiloma victima (Germar) en Argentina. 


\section{Género Plesiommata Provancher}

Especie tipo: P. biundulata Provancher = Tettigonia tripunctata Fitch 1851:55

Longitud total 3,6-5,6 mm.

Cabeza. Margen anterior, en vista dorsal, variable entre especies, amplia- a obtusamente redondeado; longitud media de la corona $0,5-0,8 x$ mayor que el ancho interocular; superficie glabra, no esculturada; ocelos localizados sobre o por delante de la línea que pasa entre los ángulos anteriores de los ojos. Puentes antenales, en vista lateral, con el margen anterior mayormente rectilíneo y vertical o ligeramente oblicuo. Clípeo, en vista lateral, usualmente convexo, finamente granulado en la porción media; impresiones musculares usualmente marcadas; sutura transclipeal completa o interrumpida en su porción media.

Tórax. Ancho del pronoto menor que el ancho transocular, márgenes laterales convergentes anteriormente, y margen posterior cóncavo; carena dorsopleural, en vista lateral, incompleta; disco con, o sin, estriaciones transversales; superficie del escutelo por detrás del surco transversal no estriado. Alas anteriores hialinas o translúcidas, con tres celdas anteapicales, las dos internas basalmente abiertas, y cuatro celdas apicales, sin plexo anteapical. En las hembras, las alas anteriores en reposo ocultan el ovipositor. Fórmula setal del fémur posterior 2:1:1 o 2:1:1:1. Longitud del primer tarsómero casi tan largo como la longitud combinada del segundo y el tercero.

Abdomen del macho con apodemas basales conspicuos.

Genitalia del macho. Pigóforo, en vista lateral, moderadamente proyectado posteriormente, con el margen posterior convexo, con numerosas macrosetas de tamaño variable sobre los dos tercios posteriores del disco. Placas subgenitales gradual a abruptamente cónicas, no alcanzan el ápice del pigóforo; con macrosetas longitudinalmente uniseriadas, con algunas microsetas. Estilos extendiéndose casi hasta el ápice del conectivo, apicalmente en "forma de pie". Conectivo en forma de Y. Edeago corto, con una par de procesos alargados que se originan basiventralmente y se extienden dorsalmente sobre el eje. Paráfisis ausentes. 
Genitalia de la hembra. Esternito abdominal VII, en vista ventral, con el margen posterior transverso y rectilíneo, o ligeramente convexo. Esternito abdominal VIII membranoso, sin escleritos. Pigóforo con macrosetas en el tercio apical. Valva II del ovipositor expandida luego de la curvatura basal, margen dorsal convexo con dientes cuadrangulares; dientes y márgenes posterodorsal y -ventral con dentículos.

Coloración. Las especies del género Plesiommata presentan un patrón de coloración muy similar; el tegumento en general es blanco-amarillento con máculas o bandas en la corona de la cabeza, el pronoto, escutelo y venas del tegmen, castaño claro a oscuro. Alas anteriores hialinas o translúcidas.

Observaciones taxonómicas. De acuerdo con Young (1977), el género Plesiommata pertenece al grupo genérico Cicadella (Young 1977), y estaría relacionado con el género Ciminius Metcalf \& Bruner, del cual se diferencia por la presencia de tres celdas anteapicales en la alas posteriores, la presencia de apodemas abdominales y la ausencia de paráfisis en los machos.

Distribución. El género Plesiommata está ampliamente distribuído en América con especies presentes en las regiones Neotropical, Neártica, o en ambas. Actualmente, se registran tres especies para el neotrópico: P. corniculata Young, $P$. mollicella (Fowler) y P. zanolae Cavichioli, con registros en Argentina, Bolivia, Brasil, Belize, Colombia, Costa Rica, Ecuador, Granada, Guatemala, Guayana, Guayana Francesa, Mexico, Panamá, Paraguay, Surinam, Trinidad y Venezuela (Wilson et al. 2009).

El género Plesiommata cuenta con seis especies descriptas de las cuales dos están presentes en la Argentina.

corniculata Young 1977: 601.

mollicella (Fowler) 1900: 289. 


\section{Plesiommata corniculata Young (Figura 52)}

Plesiommata corniculata Young 1977

Diagnosis. Longitud: $\widehat{\jmath}$ 3,6-4,1 mm., + + 4-4,9 mm. Eje aedeagal del macho, en vista lateral, abruptamente expandido en el ápice, con forma de embudo en vista ventral (Young 1977). En las hembras, la estructura de acoplamiento ventral de la valva I del ovipositor es corta y se extiende a lo largo del tercio basal del eje, y los dientes de la valva II son contiguos, no protuberantes.

Genitalia de la hembra. Esternito VII (Fig. 52B), en vista ventral, corto, longitud media 0,5x el ancho máximo; margen posterior transverso, a veces interrumpido por una pequeña proyección mediana, y márgenes laterales convergentes posteriormente. Esternito abdominal VIII membranoso. Pigóforo (Fig. 52D), en vista lateral, subovalado, proyección posterior corta, margen posterior agudo; superficie de la mitad apical con numerosas macrosetas robustas, algunas extendiéndose anteriormente por el margen ventral, con numerosas macrosetas más pequeñas en la porción dorsal. Valvifer I (Fig. 52C), en vista lateral, subrectangular con el margen anterodorsal más esclerotizado. Valva I (Fig. 51F), en vista lateral, lanceolada con la porción basal dirigida dorsalmente; AED extendiéndose sobre los cuatro quintos apicales del eje, formada por procesos tegumentarios escamiformes no imbricados dispuestos en líneas oblicuas; AEV restringida al tercio medio del eje, formada mayormente por procesos tegumentarios horizontales espaciados, y a la porción preapical formada por procesos escamiformes. EVA corta, visible hasta el tercio basal del eje. Ápice (Fig. 52G) puntiagudo. Valvifer II (Fig. 52E), en vista lateral, subrectangular con una gran área suboval menos esclerotizada cercana al PA. Valva II (Fig. 52H), en vista lateral, expandida luego de la curvatura basal, con el margen dorsal del eje ligeramente recto, llevando aproximadamente 16 dientes (Figs. 52I, J) contiguos, cada diente subtriangular con el margen posterior cóncavo y más extenso que el anterior, llevando pequeños dentículos subtriangulares. Ductos visibles a partir de los dos tercios apicales del eje, alcanzando los dientes y el ápice. Porción preapical aguda con los márgenes dorsal y ventral denticulados, ápice (Fig. 52K) redondeado; ventralmente sin prominencia preapical. Gonoplaca (Fig. 52L), en vista lateral, porción anterior estrecha, 0,6x más larga que la porción posterior, la cual es marcadamente expandida; superficie con numerosos procesos tegumentarios 
espiniformes en la porción preapical que se extienden anteriormente a lo largo del margen ventral; ápice redondeado.

Observaciones taxonómicas. Externamente $P$. corniculata es muy similar a $P$. mollicella (Fowler). Estas especies pueden coexistir en el mismo ambiente y pueden diferenciarse por la morfología del ovipositor y del edeago.

Distribución. En el neotrópico, P. corniculata está presente en Bolivia, Brasil, Colombia, Costa Rica, Grenada, Guyana, Suriname, Mexico, Panamá, Paraguay, Trinidad y Venezuela (Young 1977). Se cita por primera vez para la Argentina con registros para las provincias de Corrientes (Bella Vista, Mercedes, Montecaseros), Entre Ríos (Concordia, Federación), Misiones (Santa Inés) y Santa Fé (El Rabón) (Figura 54).

Plantas hospedadoras. "batata", "palta”, "pastos" (Young 1977), Citrus sinensis Osb. (Rutaceae) (Coelho et al. 2008, Marucci et al. 2002, Molina et al. 2010, Ott et al. 2006, Yamamoto et al. 2002), Coffea arabica L. (Rubiaceae) (Garita-Cambronero et al. 2008), Prunus salicina Lindl. (Hickel et al. 2001) (Rosaceae).

Datos biológicos. Es una especie que vive en la vegetación asociada, principalmente grámineas, a plantaciones citrícolas, sin embargo es raramente observada en los cítricos.

Enemigos naturales. Desconocidos.

Importancia fitosanitaria. $P$. corniculata es vector confirmado de la bacteria Xylella fastidiosa subsp. pauca, agente causal de las enfermedades Clorosis Variegada de los Cítricos (CVC) y Quemadura de la hoja del café (CLS) en Sudamérica (Krügner et al. 2000). Su eficiencia de transmisión (2,9\%) es baja respecto de otras especies vectoras (Fundecitrus 1999).

Material estudiado. Holotipo: $1 \widehat{\jmath}$, Rio 'Caraguata', Mato Grosso, Brazil, III/1953, F. Plaumann col. (NCS). ARGENTINA: (MLP): Corrientes: Montecaseros, $5 q q 3 \hat{\jmath} \widehat{\jmath}$, 
11/II/1987, Paniagua col.; Mercedes, 1ठ, 16/XII/1941, Birabén-Bezzi cols. Entre Ríos: Concordia, 1q 1ठ, 19/XII/1941, Birabén-Bezzi cols.; Federación, 1ठ, 03/XII/1941, Birabén-Bezzi cols. Misiones: Santa Inés, 1 + 4ठึ, 13/XII/1941,

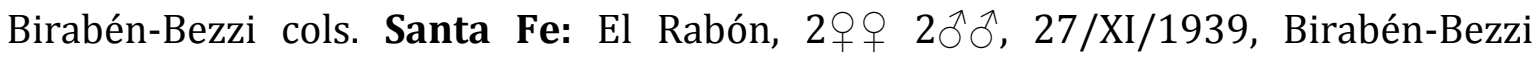
(UNLP): Corrientes: Bella Vista, $1 q 1 \delta, 10 / \mathrm{III} / 2015,1 q 1 \hat{\sigma}, 12 / \mathrm{V} / 2015$, Defea col.

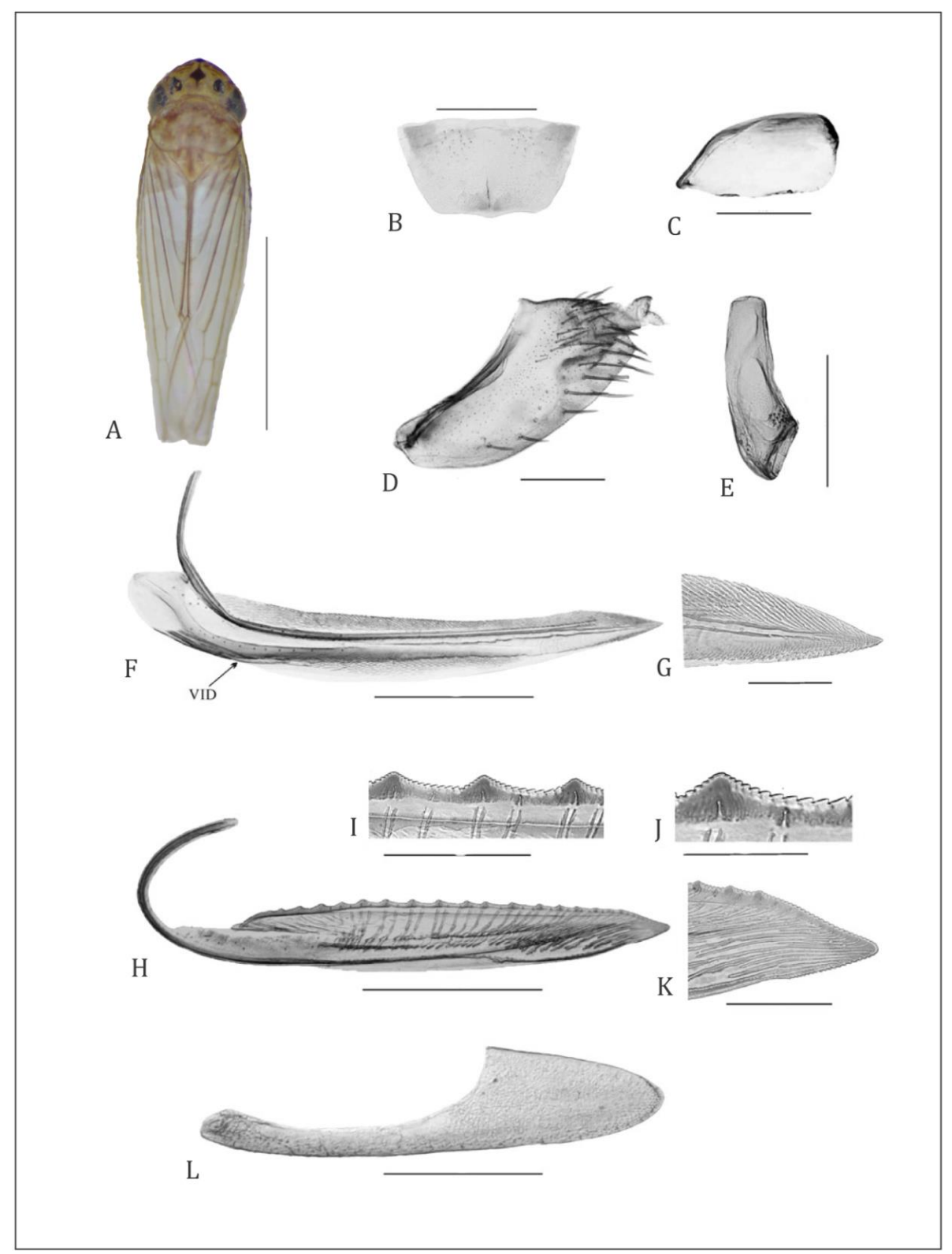

Figura 52. Plesiommmata corniculata Young. Hábito dorsal (A); genitalia de la hembra (B-L): esternito VII (B), valvifer I (C), pigóforo (D), valvifer II (E), valva I $(F)$, ápice valva I (G), valva II (H), dientes valva II (I, J), ápice valva II (K), gonoplaca (L). Escalas 1mm: A; 0,5 mm: B, C, F, H; 0,3mm: D, E, L; 0,1mm: G, I, K; 0,05mm: J. 


\section{Plesiommata mollicella (Fowler) (Figura 53)}

Tettigonia mollicella Fowler 1900: 289 [n. sp.]

Pagaronia mollicella Osborn 1926

Plesiommata mollicella Young 1977: 600 [Implic. n. comb.]

Diagnosis. Eje aedeagal del macho, en vista lateral, con dos expansiones dorsales medianas a cada lado; en vista ventral, eje simple con el ápice ligeramente emarginado (Young 1977). En las hembras, la estructura de acoplamiento ventral de la valva I del ovipositor es larga, visible en la mitad basal del eje, y los dientes de la valva II son discontiguos y protuberantes.

Genitalia de la hembra. Esternito VII (Fig. 53B), en vista ventral, corto, longitud media 0,5x el ancho máximo; margen posterior transverso y márgenes laterales redondeados, convergentes posteriormente. Esternito abdominal VIII membranoso. Pigóforo (Fig. 53D), en vista lateral, subovalado, proyección posterior corta, margen posterior agudo; mitad apical con numerosas macrosetas robustas, algunas extendiéndose anteriormente por el margen ventral, área dorsal con algunas macrosetas dispersas. Valvifer I (Fig. 53C), en vista lateral, subrectangular, margen anterodorsal más esclerotizado, en declive. Valva I (Fig. 53F), en vista lateral, lanceolada con la porción basal recta y truncada; AED extendiéndose sobre los cuatro quintos apicales del eje, formada por procesos tegumentarios escamiformes no imbricados, dispuestos en líneas oblicuas; AEV restringida al tercio medio del eje, formada mayormente por procesos tegumentarios horizontales espaciados, y a la porción preapical formada por procesos escamiformes. EVA larga, visible casi hasta la mitad basal del eje., ápice (Fig. 53G) agudo. Valvifer II (Fig. 53E), en vista lateral, subrectangular con una pequeña área subcircular menos esclerotizada cercana al PA. La valva II (Fig. 53H), en vista lateral, amplia luego de la curvatura basal, margen dorsal del eje regularmente convexo, llevando aproximadamente 24 dientes (Fig. 53I, J) sobresalientes y discontiguos, cada diente subtriangular con el margen posterior en declive y más extenso que el anterior, llevando minúsculos dentículos subtriangulares. Ductos visibles a partir de los dos tercios apicales del eje, alcanzando los dientes y el ápice. Porción preapical aguda con los márgenes dorsal y ventral denticulados, ápice (Fig. 53K) redondeado; ventralmente sin prominencia preapical. Gonoplaca, en vista lateral, porción anterior estrecha, 0,6x más larga que la porción 
posterior, la cual es marcadamente expandida; superficie con numerosos procesos tegumentarios espiniformes en la porción preapical que se extienden anteriormente a lo largo del margen ventral; ápice redondeado.

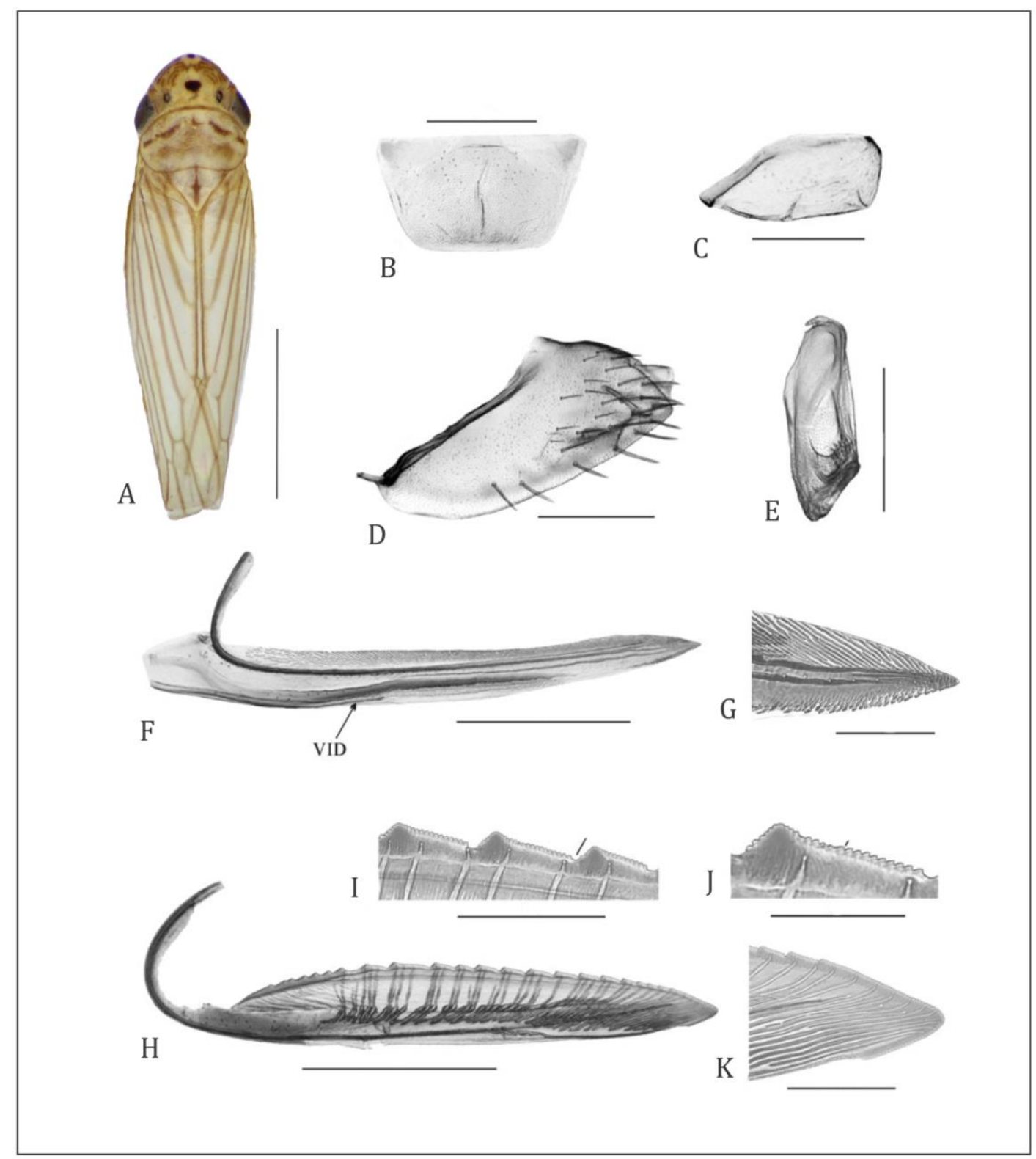

Figura 53. Plesiommmata mollicella (Fowler). Hábito dorsal (A); genitalia de la hembra (B-K): esternito VII (B), valvifer I (C), pigóforo (D), valvifer II (E), valva I (F), ápice valva I (G), valva II (H), dientes valva II (I, J), ápice valva II (K). Escalas 1mm: A; 0,5 mm: B, C, F, H; 0,3mm: D, E; 0,1mm: G, I, K; 0,05mm: J.

Observaciones taxonómicas. Características de la genitalia de machos y hembras permiten diferenciar P. mollicella de la otra especie presente en la Argentina: en los machos, el edeago presenta dos expansiones dorsales laterales en la mitad del eje 
(Young 1977). En las hembras, la valva I, posee la porción basal del eje recta y truncada, y la estructura ventral de acoplamiento es larga, extendiéndose hasta la mitad basal del eje. La valva II posee aproximadamente 24 dientes sobresalientes y discontinuos, cada uno con minúsculos dentículos en el margen posterior.

Distribución. En el neotrópico, esta especie está presente en Argentina, Belize, Bolivia, Brasil, Colombia, Costa Rica, Ecuador, Guatemala, Guyana Francesa, México, Panamá, Paraguay y Venezuela (Young 1977) y Nicaragua (Maes \& Godoy 1993). En la Argentina, P. mollicella está presente en las provincias de Buenos Aires, Córdoba, Salta, Tucumán (Paradell 1995), Misiones (Remes Lenicov et al. 1999) y Entre Ríos (Paradell et al. 2001). Se amplía la distribución para las provincias de Chaco (Pinedo, Resistencia, Tirol) y Santa Fe (Reconquista, Vera, Villa Guillermina) (Figura 54).

Plantas hospedadoras. Zea mays L. (Poaceae), Triticum aestivum L. (Poaceae), Avena sativa L. (Poaceae) y malezas asociadas, Sorghum vulgare (Pers.) (Poaceae), Oriza sativa L. (Poaceae), Brassica sp. (Brassicaceae), Lycopersicon sp. (Solanaceae), Solanum sp. (Solanaceae), Citrus sinensis Osb. (Rutaceae) y malezas asociadas, $C$. reticulata (Rutaceae), Andropogon gayanus Kunth (Poaceae), malezas asociadas a Carica papaya L. (Caricaceae) (Dellapé 2013, Lozada Robles \& Arellano Cruz 2008, Maes \& Godoy 1993, Paradell 1995, Paradell et al. 2014a, Remes Lenicov et al. 1999, 2006, Toledo et al. 1989). Se registra como nuevo hospedero a Vaccinium corymbosum L. “arándano” (Ericaceae).

Datos biológicos. Es una especie ampliamente distribuida en la Argentina que se encuentra frecuentemente en gramíneas.

Enemigos naturales. Anagrus lineolus Triapitsyn, Cosmocomoidea abbreviatus (Ogloblin), C. metanotalis (Ogloblin), C. virlai Triapitsyn (Hymenoptera: Mymaridae) (Luft Albarracín et al. 2009), Gonatopus desantisi Olmi \& Virla y G. silvestrii Kieffer (Hymenoptera: Dryinidae) (Olmi \& Virla 2014). 
Importancia fitosanitaria. Especie portadora de la bacteria Xylella fastidiosa subsp. pauca, agente causal de la enfermedad Clorosis Variegada de los Cítricos (CVC) (Dellapé 2013).

Material estudiado. ARGENTINA: (MLP): Chaco: Pinedo, 1q, 08/XII/1939, Birabén-Bezzi cols. Resistencia, 19, 20/III/1939, P. Denier col.; Tirol, 19, 7/XII/1939, Birabén-Bezzi cols. Misiones: Iguazú, 1어 XI/1944, M. Birabén col. Corrientes: 1 , 15-30/II/1959, M. Birabén col.; Colonia Pellegrini, 05/XII/1941, Birabén-Bezzi cols.; Montecaseros, 1ㅇ, 11/II/1987, Paniagua col. Entre Ríos: Concordia, 1ð, 15/XI/2011, s/Vaccinium corymbosum, J.P. Bouvet col. Paraná, 19, 10/I/1952. Santa Fé: Reconquista, 1, 24/XI/1939, Birabén-Bezzi cols.; Vera, 1ð̊, 26/XI/1939, BirabénBezzi cols. Buenos Aires: 1q, 26/I/1935; La Plata, 1의 otros datos ausentes; Ibicuycito, 1, 13/IX/1938, S. R, Castillo col. (IFML): Santa Fé: Villa Guillermina,

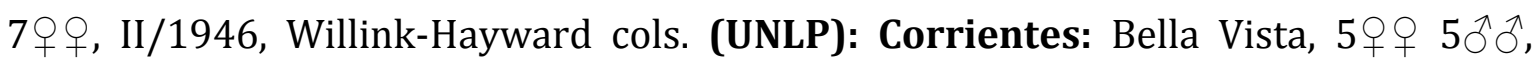
VI/2014, B. Defea col.

Clave para el reconocimiento de las especies neotropicales del género Plesiommata.

1. Corona cefálica con una mancha negra mediana detrás del ápice 2

-. Corona cefálica con una mancha negra apical, mancha mediana negra ausente 3

2. Eje del edeago, en vista lateral, con una expansión dorsal mediana; valva I del ovipositor con la EVA larga, visible en la mitad basal del eje; margen dorsal de la valva II con dientes protuberantes y discontiguos, cada diente con el margen posterior declivo diminutos dentículos ..P. mollicella

-. Eje del edeago, en vista lateral, abruptamente expandido en el ápice, sin la expansión dorsal mediana; valva I del ovipositor con la EVA corta, visible en el tercio basal del eje; margen dorsal de la valva II con dientes contiguos, no protuberantes, 
cada diente con el margen posterior cóncavo llevando pequeños dentículos P. corniculata

3. Especímenes con una banda estrecha castaña oscura a lo largo del pronoto, escutelo y márgenes anales de las alas anteriores P. zanolae

-. Pronoto, escutelo y márgenes anales de las alas anteriores sin la banda

Especies neárticas

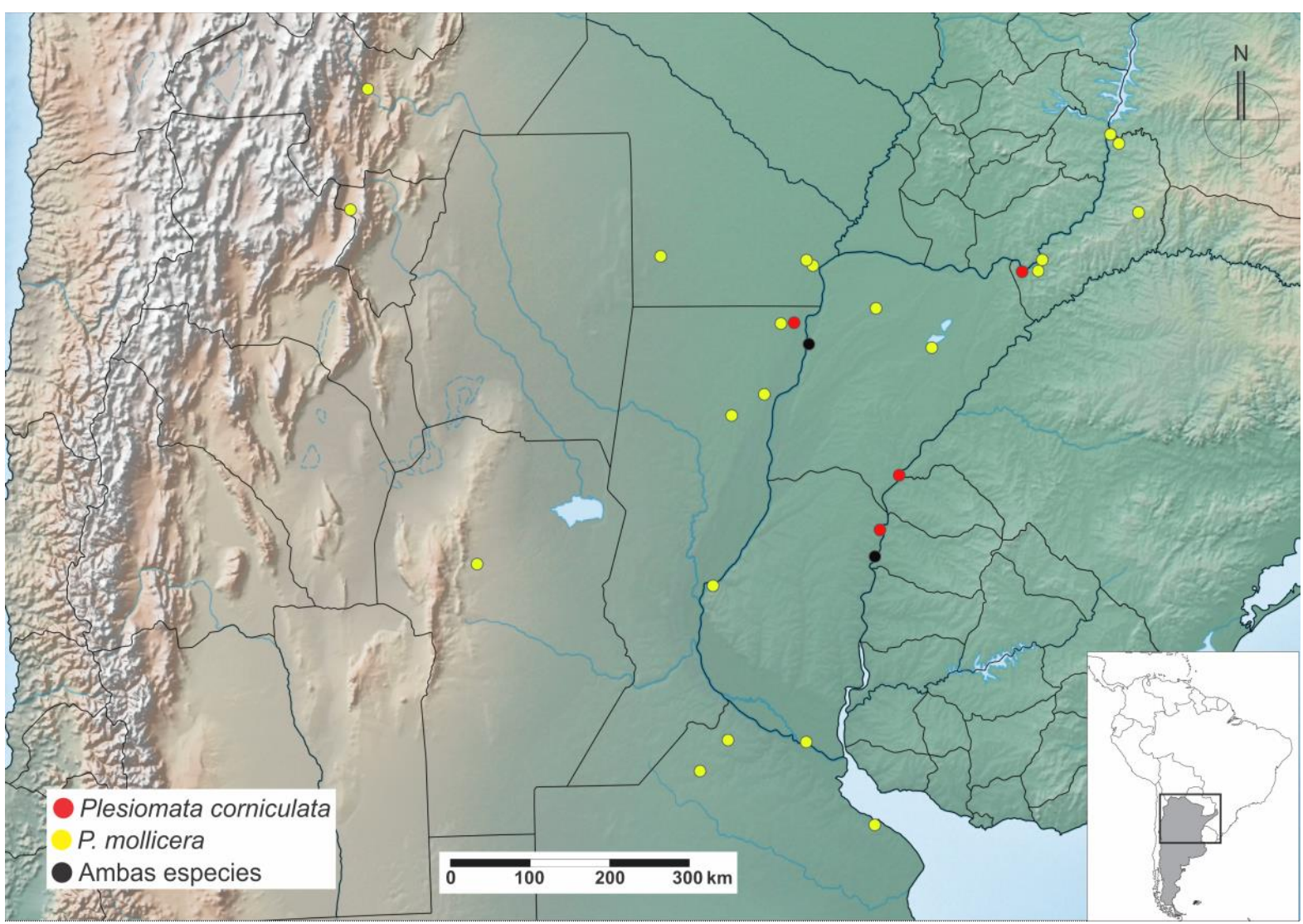

Figura 54. Distribución de las especies del género Plesiommata Provancher en la Argentina. 


\section{Género Scopogonalia Young}

Especie tipo: Tettigonia subolivacea Stål 1862: 42.

Longitud total 4,6-7,7 mm.

Cabeza. Moderadamente proyectada, longitud media de la corona 0,4-0,7x el ancho interocular; margen anterior, en vista dorsal, ampliamente o estrechamente redondeado; corona convexa, usualmente con una concavidad transversal superficial a la altura de los ocelos, sin fóvea longitudinal; superficie glabra, no esculturada; ocelos localizados detrás o sobre la línea que pasa entre los ángulos anteriores de los ojos. Puentes antenales, en vista dorsal, no protuberantes, con el margen anterior, en vista lateral, convexo. Transición corona-clípeo redondeada. Clípeo, en vista lateral, convexo, glabro; impresiones musculares no evidentes; sutura transclipeal completa. Clipelo no protuberante, perfil, en vista lateral, siguiendo el contorno del clípeo.

Tórax. Ancho del pronoto ligeramente igual que el ancho transocular; márgenes laterales ligeramente convergentes anteriormente, o paralelos; carena dorsopleural generalmente completa; superficie del disco glabra, no punteado, frecuentemente sin rugosidades; superficie del escutelo por detrás del surco transversal punteado, transversalmente rugoso o no esculturado. Alas anteriores hialinas o coriáceas con la membrana incluyendo todas las celdas apicales, extendiéndose anteriormente a lo largo del margen costal hasta la mitad basal del ala, ocasionalmente incluyendo la porción apical de las celdas anteapicales; venas marcadas o no; con cuatro celdas apicales; las celdas anteapicales interna y central abiertas basalmente; superficie no esculturada. En las hembras, las alas en reposo ocultan el ovipositor. Fórmula setal del fémur posterior 2:1:1; longitud del primer tarsómero igual o usualmente mayor que la longitud combinada del segundo y tercer tarsómeros, con dos grupos longitudinales de setas pequeñas sobre la superficie plantar.

Genitalia del macho. Pigóforo moderadamente proyectado posteriormente (excepción S. dolixoura Leal), porción posterior estrechamente convexa, con el margen posteroventral ampliamente convexo, con numerosas macrosetas sobre los dos tercios posteriores del disco; con un par de procesos largos y estrechos que se originan en el margen ventral y se proyectan posteriormente o posterodorsalmente, 
con el ápice en "cepillo" (excepción: S. golbachi Young). Placas subgenitales triangulares, basalmente anchas, estrechándose hacia el ápice; posteriormente no extendidas hasta el ápice del pigóforo, basalmente con macrosetas dispuestas en múltiples hileras, luego uniseriadas hasta el ápice. Estilos con o sin lóbulo preapical, no extendidos posteriormente hasta el ápice del conectivo. Conectivo estrecho, en forma de Y. Edeago curvado dorsal- o ventralmente, con uno o más procesos. Paráfisis ramificadas dorsoventralmente en su porción basal; articuladas con la base del edeago y el ápice del conectivo por las ramas dorsal y ventral, respectivamente.

Genitalia de la hembra. Esternito abdominal VII, en vista ventral, margen posterior fuertemente proyectado, estrechándose gradualmente hacia el ápice; margen posterior amplia- y superficialmente emarginado (excepción: S. echinura Young y $S$. golbachi Young). Esternito abdominal VIII a veces con escleritos. Pigóforo apicalmente estrecho, subagudo, con numerosas macrosetas en la mitad posterior. Ovipositor con la valva I ligeramente curvada, con los márgenes dorsal y ventral aproximadamente paralelos; ápice agudo. AED y AEV formadas por procesos tegumentarios escamiformes o filiformes dispuestos en líneas oblicuas; AED cubriendo la superficie posterior a la curvatura basal hasta el ápice, AVE restringida al ápice. Valva II a veces con prominencia preapical; ápice agudo; con dientes triangulares o trapezoidales inclinados sobre las porciones basal y media, triangulares hacia el ápice; los primeros con el área posterior aplanada, que se achica gradualmente hacia el ápice, en donde está ausente; cada diente con dentículos que se continúan en los espacios interdentarios y se extienden sobre el margen dorsal de la porción preapical; longitud de la porción preapical ventral mayor, igual o menor que la dorsal, denticulada.

Coloración. Los especímenes de Scopogonalia pueden presentar una coloración verde brillante a oscura, o amarilla-olivácea a oscura con máculas verde pálido o amarillentas. Con una mácula oscura en el ápice de la cabeza.

Observaciones taxonómicas. Las especies de Scopogonalia son difíciles de identificar; varias especies son externamente muy similares y sólo se diferencian por caracteres de la genitalia, particularmente la de los machos dado que la de las hembras está descripta en detalle sólo para unas pocas especies. El estudio detallado 
de las estructuras de la genitalia femenina de algunas especies demostró que, al igual que en los machos, son estructuras conservativas.

El género Scopogonalia cuenta con 17 especies descriptas, siete presentes en la Argentina.

altmanni Cavichioli 1986: 152.

golbachi Young 1977: 538.

nargena Young 1977: 532.

oglobini Young 1977: 537.

osteiphera Leal \& Creão-Duarte 2016:16.

penicula Young 1977: 536.

subolivacea (Stål) 1862: 42.

Scopogonalia altmanni Cavichioli (Figuras 55, 58A)

Scopogonalia altmanni Cavichioli 1986: 152 [n.sp.]

Diagnosis. Coloración general pálida con una franja lateral de color castaña que se extiende posteriormente desde el margen posterior de los ojos y a lo largo del tegmen Edeago, en vista lateral, corto; en vista caudal, ampliamente expandido, de forma circular (Young 1977). Longitud: $\widehat{\jmath}$ 5,8-6,4, $+\uparrow$ 6,8-6,9 mm. Paráfisis del macho, en vista lateral, con las ramas extendidas por debajo del eje aedeagal, ápices ligeramente curvados dorsalmente. Esternito abdominal VII de la hembra con el margen posterior ampliamente convexo, ápice regularmente redondeado. Valvifer I del ovipositor de forma subtriangular, superficie cubierta por numerosos procesos tegumentarios espiniformes.

Genitalia de la hembra. Esternito VII (Fig. 55A), en vista ventral, moderadamente proyectado posteriormente, longitud media aproximadamente igual al ancho máximo; margen posterior ampliamente convexo, ápice regularmente redondeado; superficie de la mitad apical con numerosos procesos tegumentarios espiniformes; con una quilla longitudinal. Pigóforo (Fig. 55B), en vista lateral, corto, porción posterior estrecha y subaguda, con numerosas macrosetas en la mitad posterior. Valvifer I (Fig. 55C), en vista lateral, subtriangular, centralmente cubierto 
por numerosos procesos tegumentarios espiniformes. Valva I (Fig. 55E), en vista lateral, con los márgenes dorsal y ventral aproximadamente paralelos; margen ventral con un pliegue triangular en el tercio medio; AED (Fig. 55F) cubriendo los dos tercios apicales del eje, formada por procesos tegumentarios filiformes dispuestos oblicuamente; AEV restringida a la porción preapical del eje, formada por procesos escamiformes; superficie del pliegue ventral con estriaciones transversales. EVA larga visible en la mitad basal del eje; porción preapical aguda con los márgenes dorsal y ventral no denticulados, ápice (Fig. 55G) puntiagudo. Valvifer II (Fig. 55D), en vista lateral, fusiforme, superficie de la mitad ventral con numerosos procesos tegumentarios espiniformes. Valva II (Fig. 55H), en vista lateral, porción posterior a la curvatura basal no expandida; margen dorsal regularmente convexo y margen ventral ligeramente recto. Tercio basal de la porción expandida con numerosos dientes (Fig. 55I) subtriangulares grandes con el margen anterior aplanado y en declive; los dos tercios restantes con dientes subtriangulares más pequeños y simétricos. Cada diente con dentículos en los márgenes anterior y posterior. Ductos visibles a lo largo de toda la porción expandida, alcanzando los dientes, en grupos de a tres basalmente y de a pares posteriormente, y el margen apical. Porción preapical aguda con los márgenes dorsal y ventral denticulados y de igual longitud; ápice (Fig. 55J) redondeado; ventralmente sin prominencia preapical. Gonoplaca (Fig. 55K), en vista lateral, porción anterior estrecha, aproximadamente tan larga como la porción posterior, la cual es marcadamente expandida; superficie preapical, ventral y basal con procesos tegumentarios espiniformes, con microsetas sobre el margen ventral de la mitad apical de la porción posterior; ápice (Fig. 55L) obtuso.

Observaciones taxonómicas. Externamente, $S$. altmanni es similar a $S$. oglobini Young de la cual puede diferenciarse por la morfología del eje aedeagal, que en vista lateral, es más estrecho, posee un proceso dentiforme apical y la porción apical está expandida formando una estructura dorsal con forma de "capucha". La morfología del edeago y de las paráfisis es similar a $S$. paula Young pero el edeago posee la estructura dorsoapical. 
Distribución. Sudamericana, con registros Argentina y Brasil (Young 1977). En la Argentina, está registrada para la provincia de Tucumán (Leal \& Creão-Duarte 2016). Se amplía su distribución para la provincia de Córdoba (Nono) (Figura 59).

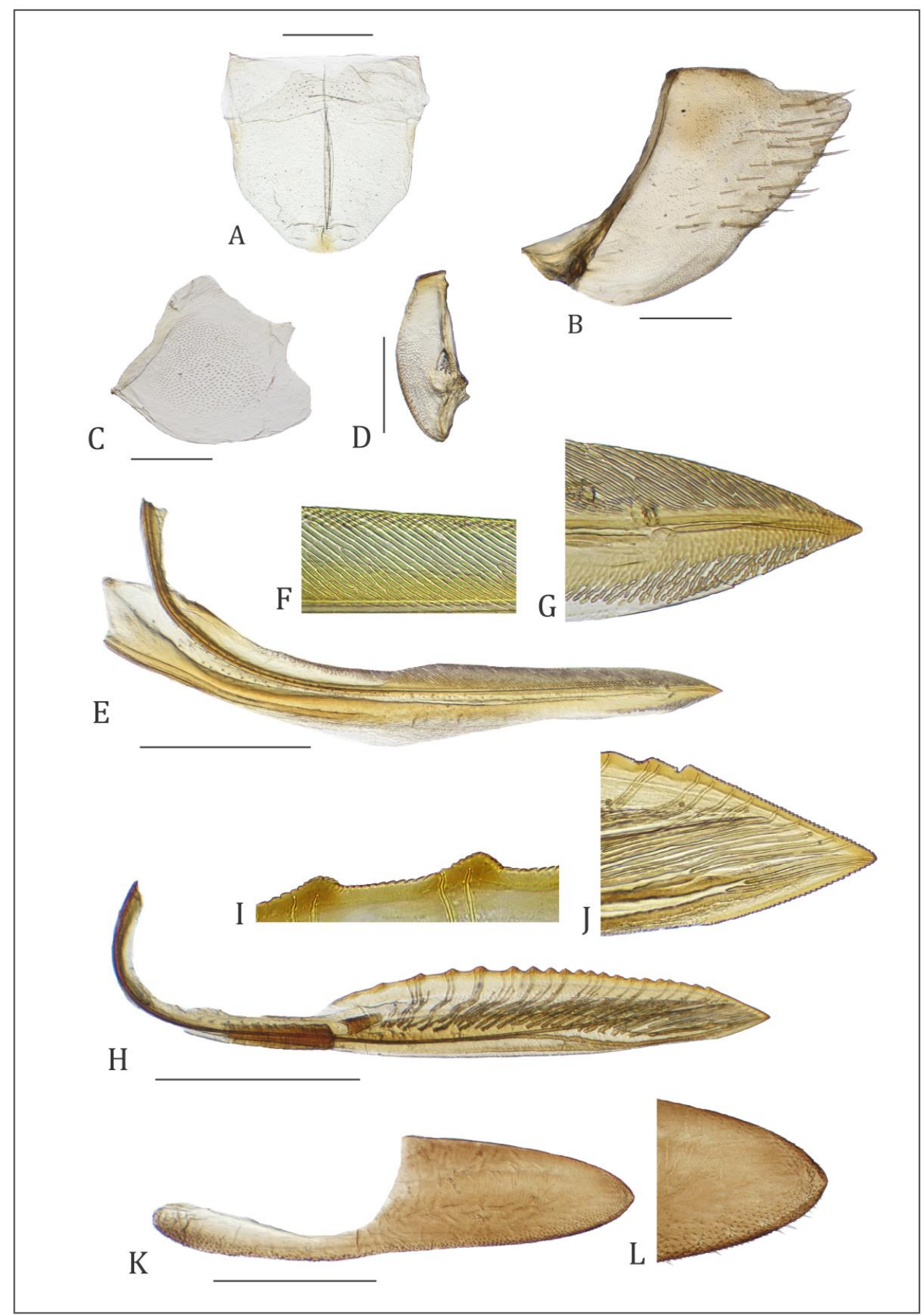

Figura 55. Genitalia de la hembra de Scopogonalia altmanni Cavichioli: esternito abdominal VII (A), pigóforo (B), valvifer I (C), valvifer II (D), valva I (E), detalle AED valva I (F), ápice valva I (G), valva II (H), dientes valva II (I), ápice valva II (J), gonoplaca (K), ápice gonoplaca (L). Escalas 0,5 mm: B, F, G, J; 0,3 mm: A, C, D. 
Plantas hospedadoras. Desconocidas.

Datos biológicos. Desconocidos.

Enemigos naturales. Desconocidos.

Importancia fitosanitaria. Desconocida.

Material estudiado. ARGENTINA: (UNLP): Tucumán: San Miguel, $2 \hat{\delta}$, 18/III/2014, Foieri col.; El Manantial, $2 \uparrow q$ 1§, 14/III/2012, Virla col. Córdoba: Nono, 1 ㅇ 1ð, 28/II-1-2/III/2011.

Scopogonalia golbachi Young (Figuras 56, 58B)

Scopogonalia golbachi Young 1977: 538 [n. sp.]

Diagnosis. Longitud: $\widehat{\jmath} \widehat{o}$ 54,8-5,3 mm, $q \propto$ 5,2-5,3 mm. Pigóforo del macho con procesos apicalmente agudos. Esternito abdominal VII de la hembra con el margen posterior no emarginado (Young 1977). Eje aedeagal largo, mitad apical, en vista ventral, amplio con tres puntas apicales y dos procesos laterales espiniformes más cortos. Paráfisis, en vista ventral, en forma de U, cerrada apicalmente. Esternito abdominal VII de la hembra con el margen posterior estrechamente convexo, con una proyección digitiforme corta de posición media.

Genitalia de la hembra. Esternito VII (Fig. 56A), en vista ventral, moderadamente proyectado posteriormente, longitud media aproximadamente igual al ancho máximo; margen posterior ampliamente convexo, con una proyección digitiforme de posición media color castaño claro; superficie de la mitad apical con numerosos procesos tegumentarios espiniformes; área preapical más oscura que el resto de la superficie. Pigóforo (Fig. 56B), en vista lateral, moderadamente proyectado, porción posterior estrecha y subaguda, con numerosas macrosetas en la mitad posterior. Valvifer I (Fig. 56C), en vista lateral, con un proceso ventral subagudo, dirigido anteriormente. Valva I (Fig. 56E), en vista lateral, con el margen 
dorsal ligeramente convexo, margen ventral del tercio medial marcadamente cóncavo; AED (Fig. 56F) extendiéndose sobre los dos tercios apicales, formada por procesos tegumentarios filiformes con el borde anterior irregular, no rectilíneos, dispuestos oblicuamente; AEV restringida a la porción preapical del eje, formada por procesos escamiformes; con estrías débilmente marcadas a lo largo de la superficie ventral del eje. EVA larga, extendiéndose ligeramente más allá de la mitad basal del eje; porción preapical aguda con los márgenes dorsal y ventral no denticulados, ápice (Fig. 56G) puntiagudo. Valvifer II (Fig. 56D), en vista lateral, fusiforme, superficie de la mitad ventral con numerosos procesos tegumentarios espiniformes. Valva II (Fig. $56 \mathrm{H}$ ), en vista lateral, eje expandido luego de la curvatura basal estrechándose a partir de la porción preapical; márgenes dorsal y ventral casi paralelos, rectos. Margen dorsal con numerosos dientes (Fig. 56I) trapezoidales, discontinuos, inclinados posteriormente con el margen posterior aplanado; cada diente con numerosos dentículos sobre todos los márgenes (anterior, dorsal y posterior). Ductos visibles a lo largo de toda la porción expandida, distribuidos de a pares alcanzan la cúspide de los dientes. Porción preapical aguda con los márgenes dorsal y ventral denticulados, margen dorsal más largo que el ventral, ápice (Fig. 56J) agudo; ventralmente con prominencia preapical. Gonoplaca (Fig. 56K), en vista lateral, porción anterior estrecha, aproximadamente tan larga como la porción posterior, la cual es marcadamente expandida; superficie preapical, ventral y basal con procesos tegumentarios espiniformes, con algunas microsetas dispersas sobre la superficie preapical y a lo largo del margen ventral; ápice (Fig. 56L) ampliamente redondeado.

Observaciones taxonómicas. S. golbachi se diferencia fácilmente del resto de las especies del género por los procesos apicalmente agudos del pigóforo del macho (Young 1977) y por el ápice digitiforme del esternito abdominal VII de la hembra.

Distribución. Con registros sólo en la Argentina en la provincia de Salta (Young 1977). Se amplía la distribución para la provincia de Formosa (Ingeniero Juarez) (Figura 59).

Plantas hospedadoras. Desconocidas. 
Datos biológicos. Desconocidos.

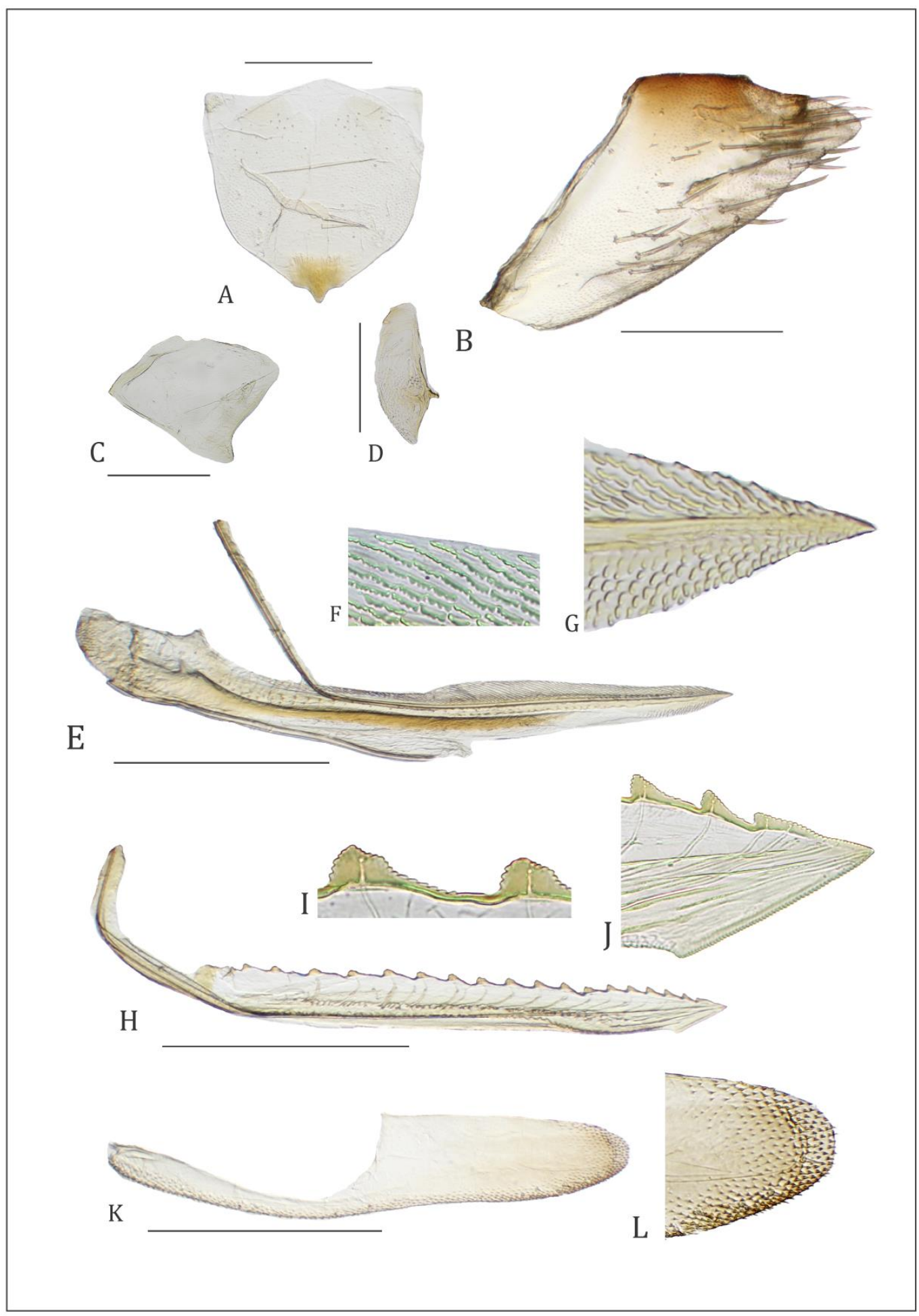

Figura 56. Genitalia de la hembra de Scopogonalia golbachi Young: esternito abdominal VII (A), pigóforo (B), valvifer I (C), valvifer II (D), valva I (E), detalle AED valva I (F), ápice valva I (G), valva II (H), dientes valva II (I), ápice valva II (J), gonoplaca (K), ápice gonoplaca (L). Escalas 0,5 mm: A, B, E, H, K; 0,3 mm: C, D. 
Enemigos naturales. Desconocidos.

Importancia fitosanitaria. Desconocida.

Material estudiado. Holotipo, $\widehat{\jmath}$, Urundel, Salta, Argentina, 31/I/1950, R. Golbach (USNM). ARGENTINA: (IFML): Formosa: Ingeniero Juarez, $2 q q 2 \hat{\partial}, 14 / \mathrm{II} / 1950$, Golbach col.; Embarcación, 1q, 2/II/1950, Golbach col.; Urundel, 2 $q$ 1ภ, 31/I/1950, Golbach col.

Scopogonalia nargena Young (Figura 58C)

Scopogonalia nargena Young 1977: 532 [n. sp.]

Diagnosis. Paráfisis con las ramas basalmente paralelas al eje aedeagal, curvadas dorsalmente a partir de la mitad del eje (Young 1977). Edeago, en vista lateral, expandido apicalmente en un proceso anguloso antero-posterior. Esternito abdominal VII de la hembra, margen posterior con una emarginación media de color negra en la base.

Observaciones taxonómicas. $S$. nargena se diferencia del resto de las especies del género por las paráfisis del macho que, en vista lateral, corren paralelas al eje aedeagal, en el resto de las especies se extienden por debajo del edeago.

Distribución. Sudamericana, con registros en Argentina, Bolivia, Brasil y Colombia. En la Argentina está registrada para la provincia de Misiones (Loreto) (Young 1977) (Figura 59).

Plantas hospedadoras. Desconocidas.

Datos biológicos. Desconocidos.

Enemigos naturales. Desconocidos. 
Importancia fitosanitaria. Desconocida.

Material estudiado. Holotipo, $\widehat{\jmath}$, Santos, San Paulo, Brasil, X/1961, Krauss (USNM).

Scopogonalia oglobini Young (Figura 58D)

Scopogonalia oglobini Young 1977: 537 [n. sp.]

Diagnosis. Edeago, en vista lateral, eje ampliamente expandido en su mitad apical, con un proceso ventral agudo. Paráfisis extendidas por debajo del eje aedeagal, conformada por una porción basal corta y un par de ramas con el ápice curvado dorsalmente. Hembra desconocida. Corona y disco del pronoto castaño pálido, escutelo de mismo color o amarillo pálido, laterales del pronoto y margen costal del tegmen castaño oscuro. Alas anteriores hialinas con las venas del mismo color o algunas más oscuras (Young 1977).

Observaciones taxonómicas. Externamente S. oglobini es similar a S. altmanni, de la cual se diferencia por tener el edeago marcadamente más ancho en su mitad apical, con un proceso ventral agudo.

Distribución. Registrada sólo en la Argentina en la provincia de Misiones (Young 1977) (Figura 59).

Plantas hospedadoras. Desconocidas.

Datos biológicos. Desconocidos.

Enemigos naturales. Desconocidos.

Importancia fitosanitaria. Desconocida. 
Material estudiado. Holotipo, $\widehat{\partial}$, Misiones, Loreto, VIII/1931, A. A. Ogloblin (USNM).

Scopogonalia osteiphera Leal \& Creão-Duarte (Figura 58E)

Scopogonalia osteiphera Leal et al. 2016: 26 [n. sp.]

Diagnosis. Especímenes predominantemente verde brillante, con una mácula negra transversal en forma de "hueso" sobre el tercio anterior del pronoto; alas anteriores con algunas celdas y venas, castaño oscuras a negras. Edeago con un proceso dentiforme apical y otro subapical sobre el margen ventral, porción dorsoapical expandida formando una estructura en forma de "capucha". Paráfisis con las ramas fuertemente curvadas dorsalmente, apicalmente agudos, "abrazando" el edeago

(Leal

$\&$

Creão-Duarte

2016).

Observaciones taxonómicas. Externamente $S$. osteiphera se asemeja a $S$. interruptula (Osborn), de la que se diferencia por poseer paráfisis pares, por el pigóforo del macho con el ápice agudo, el edeago con dos procesos dentiformes, como en S. subolivacea (Stål), y por la "capucha" dorsoapical del edeago, también presente en S. penicula Young y S. altmanni Cavichioli (Leal \& Creão-Duarte 2016).

Distribución. Especie presente sólo en la Argentina con registros en las provincias de Tucumán, Salta y Misiones (Leal \& Creão-Duarte 2016). Se amplía la distribución para las provincias de Jujuy (Potrero de Yala), Catamarca (El Rodeo), La Rioja (Chilecito), Formosa (Ingeniero Juarez, Mojón de Fierro) y Córdoba (Alta Gracia, Cabana, Valle Hermoso, Yacanto) (Figura 59).

Plantas hospedadoras. Se registra por primera vez sobre Citrus sinensis (L) Osb. "naranja dulce" (Rutaceae) y Olea europaea L. var. arauco "olivo" (Oleaceae).

Datos biológicos. Es una de las especies más abundantes en agroecosistemas citrícolas y olivícolas de la región noroeste (NOA); es recolectada sobre las plantas 
cítricas y olivos así como también en la vegetación espontánea circundante a ambos cultivos.

Enemigos naturales. Desconocidos.

Importancia fitosanitaria. Desconocida.

Material estudiado. ARGENTINA: (MLP): Córdoba: Alta Gracia, $1 \uparrow$ 1§, I/1938, C. Bruch col.; Cabana, 7우, XI/1937, Birabén col.; Valle Hermoso, 1, 2/II/1956, Limousin col.; Yacanto, $1 \uparrow 1 \hat{\jmath}$, Christensen col. (IFML): Formosa: Aquarez, $1 q$, 14/II/1950, Golbach col. Catamarca: El Rodeo, 1§, 8-28/I/1959, R. Golbach col.;

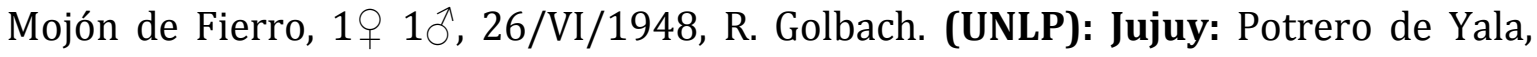

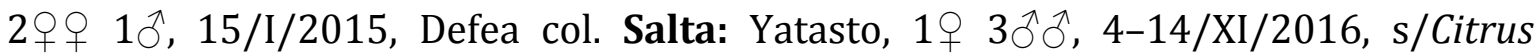
sinensis, Virla col. Tucumán: Lules, $3 \propto q+3 \widehat{\jmath}, 3-16 /$ II/2017, Virla col. La Rioja: Chilecito, $3 ㅇ+3 \hat{\jmath}$, X/2016, s/Olea europaea L. var. arauco, Calahorra col.

Scopogonalia penicula Young (Figura 57, 58F)

Scopogonalia penicula Young 1977: 536 [n. sp.]

Diagnosis. Eje aedeagal con un proceso conspícuo que se origina en el margen ventral de la porción media y se extiende posteriormente (Young 1977); ápice con un proceso triangular extendido posteriormente, en vista ventral con forma de punta de flecha, con un proceso apical anterodorsal en forma de "capucha". Valvifer I del ovipositor, en vista lateral, subpentagonal.

Genitalia de la hembra. Esternito VII (Figura 57A), en vista ventral, moderadamente proyectado posteriormente, longitud media 0,8x el ancho máximo; margen posterior ampliamente convexo, ápice con una emarginación media castaño clara en su base. Pigóforo (Fig. 57B), en vista lateral, moderadamente proyectado, porción posterior aguda, con numerosas macrosetas en los tres cuartos apicales. Valvifer I (Fig. 57C), en vista lateral, subpentagonal, los dos tercios dorsales cubiertos por procesos tegumentarios espiniformes simples o agrupados. Valva I (Fig. 57E), en vista lateral, margen dorsal ligeramente convexo y el ventral fuertemente cóncavo en 
el tercio medio; AED (Fig. 57F) visible luego de la curvatura basal hasta el ápice, formada por procesos tegumentarios filiformes con el borde anterior irregular, no rectilíneos, dispuestos oblicuamente; AEV restringida a la porción preapical del eje, formada por procesos escamiformes, el resto de la superficie ventral con estriaciones débilmente marcadas. EVA larga extendida hasta la mitad basal del eje; porción preapical aguda con el márgen ventral denticulado, ápice (Fig. 57G) puntiagudo. Valvifer II (Fig. 57D), en vista lateral, margen anterior con una proyección anterior aguda; superficie de los dos tercios ventrales con numerosos procesos tegumentarios espiniformes. Valva II (Fig. 57H), en vista lateral, eje expandido luego de la curvatura basal, márgenes dorsal y ventral casi paralelos, rectos. Margen dorsal con numerosos dientes (Fig. 57I) trapezoidales inclinados posteriormente con el margen posterior aplanado, discontinuos; cada diente con numerosos dentículos sobre todos los márgenes (anterior, dorsal y posterior). Ductos visibles a lo largo de toda la porción expandida alcanzando la cúspide dental. Porción preapical aguda con los márgenes dorsal y ventral denticulados, margen ventral más largo que el dorsal, ápice (Fig. 57J) puntiagudo; ventralmente con prominencia preapical. Gonoplaca (Fig. 57K), en vista lateral, porción anterior estrecha, aproximadamente tan larga como la porción posterior, la cual es marcadamente expandida; superficie preapical, basal y margen ventral de la porción expandida con procesos tegumentarios espiniformes, con algunas microsetas dispersas a lo largo del margen ventral; ápice (Fig. 57L) ampliamente redondeado.

Observaciones taxonómicas. Scopogonalia penicula puede ser fácilmente separada de las otras especies del género por la forma del proceso medio del eje aedeagal de los machos y la forma subpentagonal del valvifer I del ovipositor.

Distribución. Argentina, Brasil y Paraguay. En la Argentina está registrada para la provincia de Misiones (Young 1977). Se amplía la distribución para las provincias de Salta (Embarcación), Tucumán (Monte Bello y Villa Padre Monti) y Formosa (Ingeniero Juarez) (Figura 59).

Plantas hospedadoras. Desconocidas. 


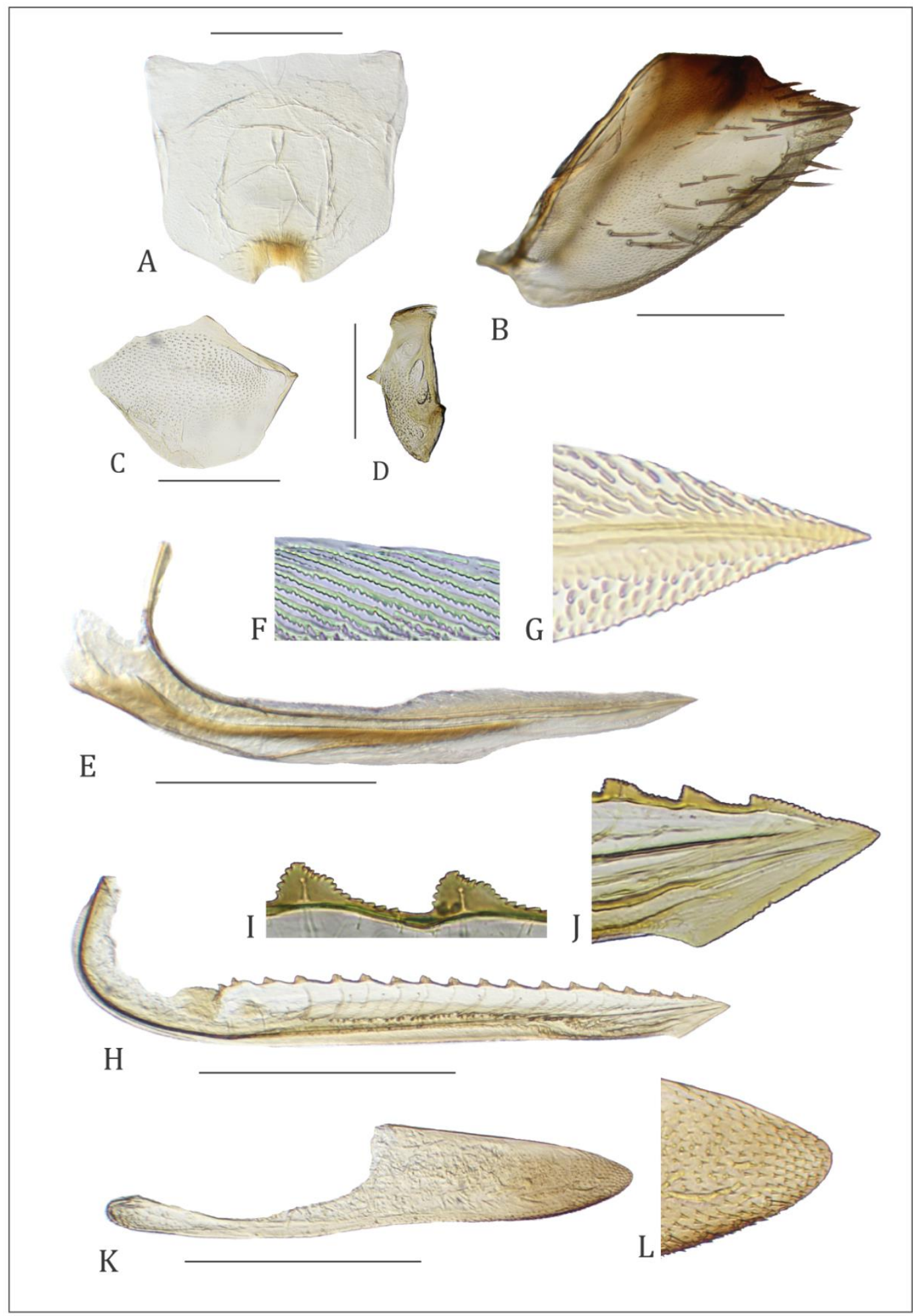

Figura 57. Genitalia de la hembra de Scopogonalia penicula Young: esternito abdominal VII (A), pigóforo (B), valvifer I (C), valvifer II (D), valva I (E), detalle AED valva I (F), ápice valva I (G), valva II (H), dientes valva II (I), ápice valva II (J), gonoplaca (K), ápice gonoplaca (L). Escalas 0,5 mm: A, B, E, H, K; 0,3 mm: C, D. 
Datos biológicos. Desconocidos.

Enemigos naturales. Desconocidos.

Importancia fitosanitaria. Desconocida.

Material estudiado. ARGENTINA: (MLP): Misiones: Iguazú, 1§, XI/1944, Birabén col. (IFML): Salta: Embarcación, 1q, 11/II/1950, Golbach col. Tucumán: Monte Bello, 1ð, III/1947, Willink-Golbach; Villa Padre Monti, 1q, 25/IV/1948, R. Golbach col. Formosa: Aquarez, $5 q 0$ 1 1 s/abd., 14/II/1950, Golbach col. Misiones: Puerto Bemberg, 5우 $2 \hat{\jmath} \widehat{\jmath}, 23 / \mathrm{I} / 1954$, Willink-Golbach (UNLP): Misiones: Iguazú, 1 우 2へ̂̉, 19/XI/2008, Zamudio col.

Scopogonalia subolivacea (Stål 1862) (Figura 58G)

Tettigonia subolivacea Stål 1862

Scopogonalia subolivacea Young 1977

Diagnosis. Pigóforo del macho con el ápice agudo. Edeago con un par de procesos dentiformes (apical y subapical) y dos procesos aliformes dorsolaterales en la porción preapical del eje. Paráfisis con dos ramas cortas extendidas por debajo del edeago (Leal \& Creão-Duarte 2016).

Distribución. Sudamericana con registros en Argentina, Bolivia, Brasil, Paraguay y Perú (Young 1977). En la Argentina está citada para la provincia de Misiones (Remes Lenicov et al. 1999). Se amplía la distribución para las provincias de Tucumán (El Manantial), Salta (Mollar, Yatasto), Jujuy (Potrero de Yala), Corrientes (Santo Tomé) y Santa Fé (Guadalupe) (Figura 59).

Plantas hospedadoras. Citrus sinensis (L.) Osb. (Rutaceae)(Remes Lenicov et al. 1999). 
Datos biológicos. Remes Lenicov et al. (1999) la reportan como una especie muy abundante y constante durante todo el año en agroecosistemas citrícolas en Misiones, siendo recolectada tanto sobre los cítricos (C. sinensis (L.) Osb.) como en la vegetación circundante asociada; con tres picos poblacionales: a principios de la primavera, en otoño y a fines del invierno.

Enemigos naturales. Strepsiptera de la familia Halictophagidae (Remes Lenicov et al. 1999).

Importancia fitosanitaria. Estudios de detección de Xylella fastidiosa en especímenes de S. subolivacea recolectados en Misiones (de Coll et al. 2000a) resultaron positivos; debido a esto y a su alta abundancia en las plantas cítricas es considerada vector potencial de la bacteria en Misiones.

Material estudiado. ARGENTINA: (MLP): Misiones: 2 de Mayo, 1ㅇ, 2/XII/1967, M. Birabén col.; Loreto, 1 ㅇ, Ogloblin col; Puerto Iguazú, $2 \widehat{\jmath} 1$ s/abd., XI/1944, B.A. Torres col.; San Ignacio, 1 q 1ð, 1944, B.A. Torres col.; Uruguaí, 1ð, 13/XII/1957, M. Birabén col. Corrientes: Santo Tomé, $2 q+1 \widehat{\jmath}, 12 / X I / 1957$, M. Birabén col. Santa Fé: Guadalupe, $191 \delta$ 1s/abd., 27/XI/1939, Birabén-Bezzi cols. (UNLP): Jujuy: Potrero de Yala, $2 q q 1 \hat{\jmath}, 15 / \mathrm{I} / 2015$, Defea col. Salta: Mollar, 1, 8/VII/2015, Lucia col.;

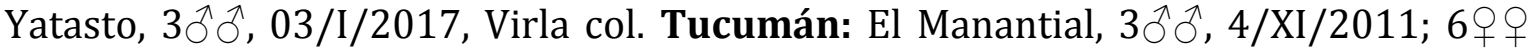
$6 \hat{\jmath}$ đิ 2 s/abd., 28/II/2012, Virla col.

\section{Clave para el reconocimiento de las especies del género Scopogonalia presentes en la Argentina.}

1. Edeago, en vista lateral, con un proceso apical anguloso anteroposterior; paráfisis de los machos, en vista lateral, con las ramas paralelas al eje aedeagal S. nargena

-. Edeago, en vista lateral, sin el proceso apical. Paráfisis de los machos, en vista lateral, con las ramas por debajo del eje aedeagal

2. Edeago, en vista lateral, eje ampliamente expandido en su mitad apical, con un proceso ventral agudo S. oglobini 
-. Edeago, en vista lateral, eje nunca ampliamente expandido en su mitad apical. .3

3. Procesos del pigóforo de los machos, apicalmente agudos. Esternito abdominal VII de las hembras con el margen posterior convexo con una proyección corta, digitiforme de posición media S. golbachi

-. Procesos del pigóforo de los machos, apicalmente en "cepillo". Margen posterior $\begin{array}{lllll}\text { del } & \text { esternito } & \text { abdominal } & \text { de }\end{array}$ forma

4. Edeago, en vista lateral, con un proceso apicoventral 5

-. Edeago, en vista lateral, con un proceso apicoventral y otro subapical 6

5. Ápice aedeagal, en vista caudal, circular. Esternito abdominal VII de la hembra con el margen posterior regularmente convexo, valvifer I del ovipositor subtriangular S. altmanni

-. Ápice aedeagal, en vista caudal, triangular. Esternito abdominal VII de la hembra con el margen posterior emarginado en su porción media, valvifer I del ovipositor subpentagonal S. penicula

6. Edeago con una estructura dorsoapical a modo de "capucha". Margen posterior del esternito abdominal VII de la hembra estrechamente emarginado. Especímenes mayormente verde brillante, con algunas celdas y venas del tegmen, negras S. osteiphera

-. Edeago sin la estructura dorsoapical a modo de "capucha". Margen posterior del esternito abdominal VII de la hembra ampliamente emarginado. Especímenes mayormente verde oliváceo, tegmen completamente verde. S. subolivacea 


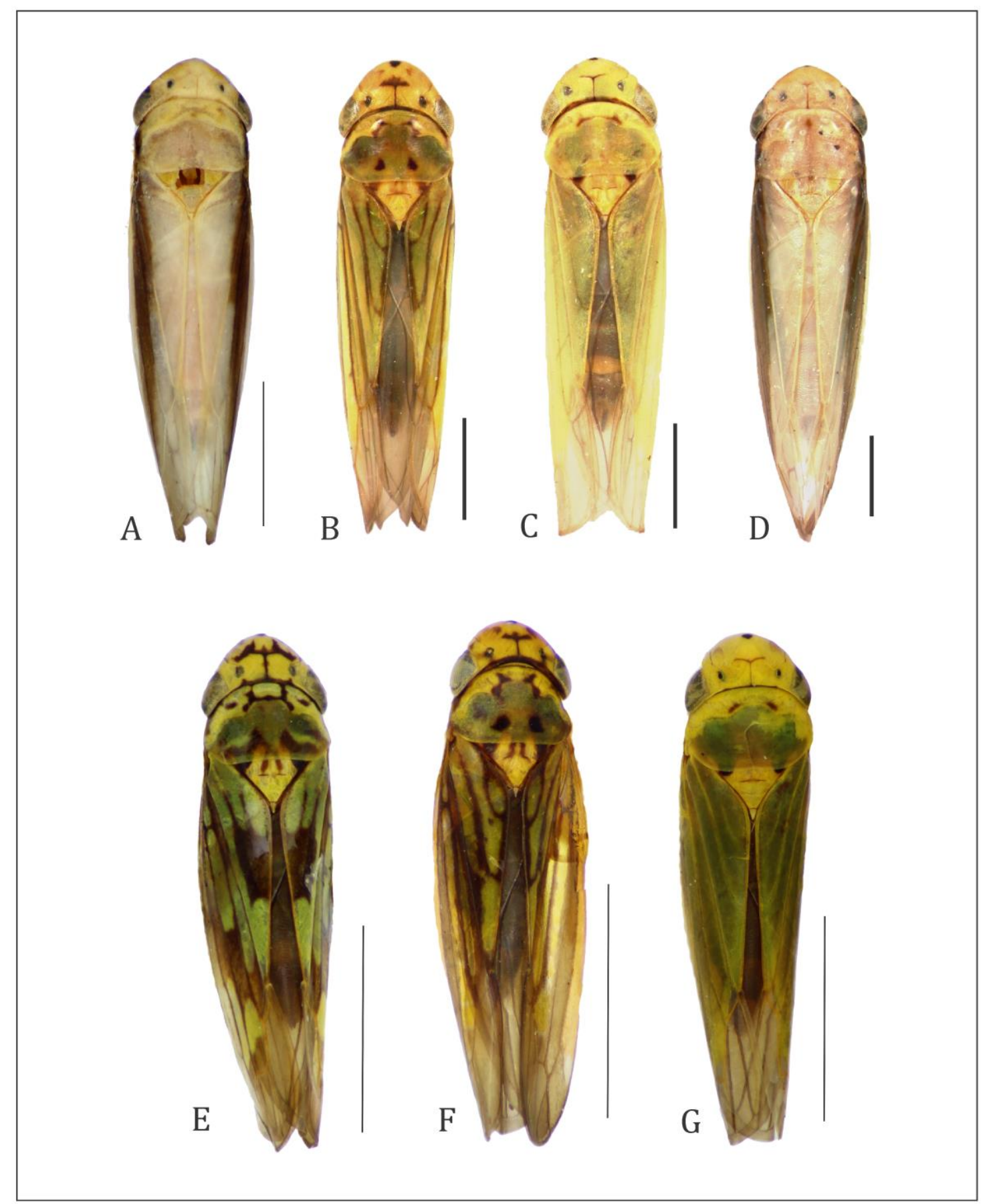

Figura 58. Especies del género Scopogonalia Young en Argentina. S. altmanni Cavichioli (A), S. golbachi Young (B), S. nargena Young (C), S. oglobini Young (D), S. osteiphera Leal \& Creão-Duarte (E), S. penicula Young (F), S. subolivacea (Stål) (G). Escalas $2 \mathrm{~mm}$. 


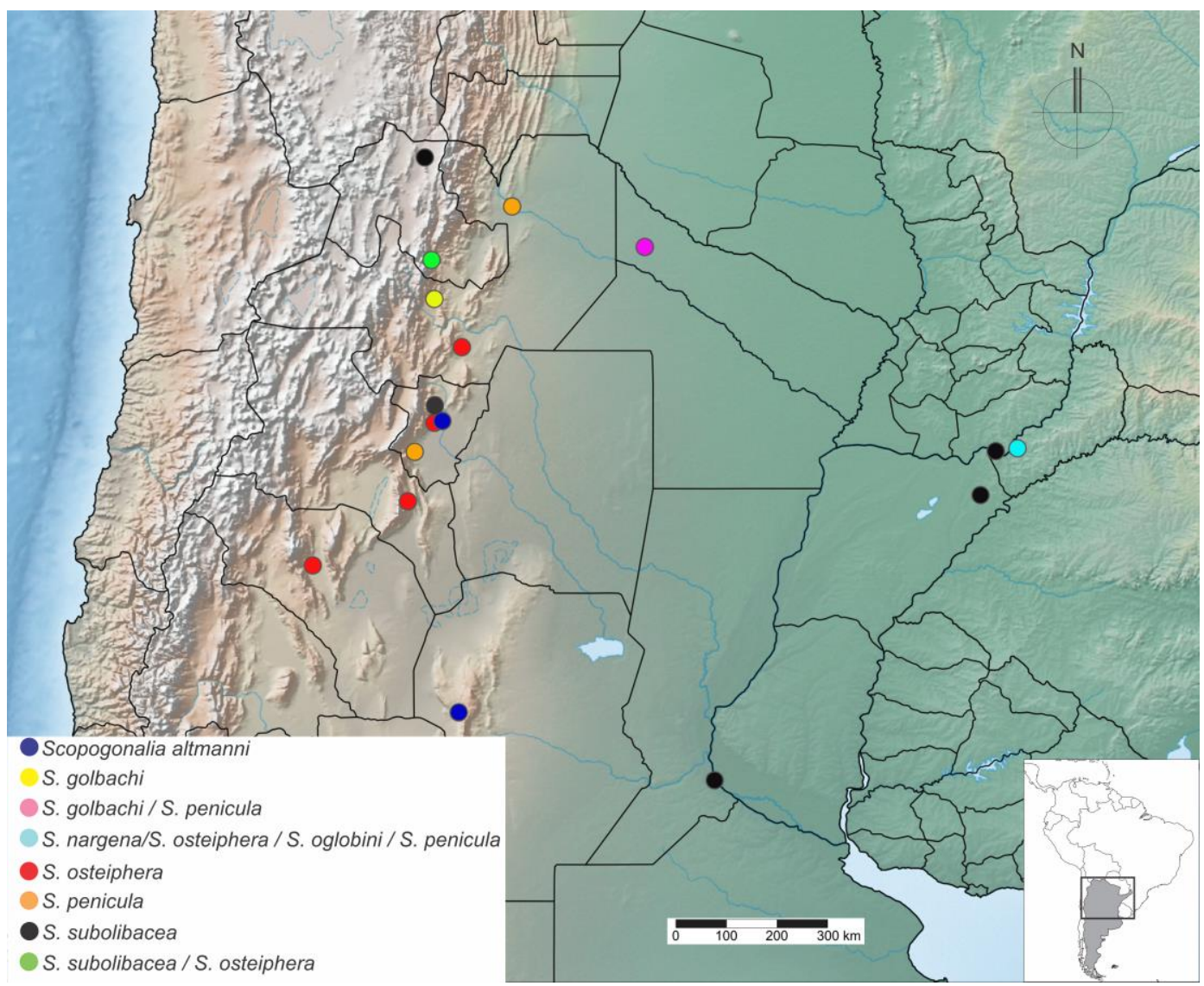

Figura 59. Distribución de las especies del género Scopogonalia Young en Argentina. 


\section{Género Sibovia China}

Especie-tipo: Tettigonia sagata Signoret 1854:27

Longitud total 4,5-7,2 $\mathrm{mm}$.

Cabeza. Moderada a fuertemente proyectada, longitud media de la corona muy variable, 0,5-1x el ancho interocular; margen anterior, en vista dorsal, ampliamente redondeado; ocelos sobre la línea imaginaria que pasa por el ángulo anterior de los ojos, excepcionalmente por detrás (S. chanchama Young); disco de la corona convexo, a veces una concavidad transversal por delante de los ocelos, superficie glabra, usualmente no esculturada (exc: punteada en S. mesolinea (DeLong \& Currie)); suturas clipeales laterales extiendiéndose sobre la corona, a veces alcanzando los ocelos. Puentes antenales, en vista dorsal, no protuberantes, con el margen anterior, en vista lateral, oblicuo y vertical. La longitud de las antenas es inusualmente larga para la tribu. Transición corona-clípeo redondeada. Clípeo convexo o apenas aplanado en la porción media, impresiones musculares débilmente marcadas; sutura transclipeal completa o medialmente interrumpida; clipelo, en vista lateral, no protuberante, acompañando el perfil del clípeo.

Tórax. Ancho del pronoto variable, igual, mayor o menor que el ancho transocular, márgenes laterales ligeramente convergentes anteriormente, margen posterior ligeramente cóncavo; carena dorsopleural, en vista lateral, completa; disco glabro, no esculturado (exc. S. mesolinea); superficie del escutelo por detrás del surco transversal no estriada. Alas anteriores con tres celdas anteapicales cerradas y cuatro apicales, la base de la cuarta más proximal que la base de la tercera, sin plexo anteapical de nervaduras; extensión del área membranosa variable entre especies. En las hembras, las alas anteriores en reposo ocultan el ovipositor. Fórmula setal del fémur posterior 2:1:1; longitud del primer tarsómero mayor a la longitud combinada del segundo y el tercero; superficie plantar con dos hileras paralelas de setas pequeñas.

Genitalia del macho. Pygofer, en vista lateral, moderadamente proyectado posteriormente, margen posterior variable, desde estrecha- a ampliamente redondeado (truncado en $S$. praevia (Melichar)); superficie con numerosas macrosetas en la mitad posterior, extendiéndose anteroventralmente en algunas especies; con un proceso poco esclerotizado, cuando presente. Placas subgenitales 
triangulares estrechas y cortas, usualmente no alcanzan el ápice del pygofer, con algunas macrosetas uniseriadas dispuestas longitudinalmente. Estilos usualmente más cortos que el ápice del conectivo, apicalmente truncados (exc. S. infula); con lóbulo preapical protuberante. Conectivo usualmente con el eje principal más largo que las ramas laterales. Aedeagus corto, sin procesos o con un par de procesos lobulados en la mitad del eje. Paráfisis presentes, forma variable entre especies.

Genitalia de la hembra. Esternito abdominal VII, en vista ventral, margen posterior usualmente truncado o con un lóbulo corto y redondeado de posición media. Esternito abdominal VIII membranoso, sin escleritos. Pygofer con numerosas macrosetas cerca del margen dorsal, paralelas al margen posteroventral. Valva II, en vista lateral, estrecha y sin dientes en su porción basal (generalmente la mitad o más) luego de la curvatura basal (exc. S. recta (Fowler)), margen dorsal de la porción expandida del eje con dientes cuadrangulares cerca de la base, progresivamente más pequeños hacia el ápice (excepciones S. praevia (Melichar) y S. pileata (Fowler)), cada diente con dentículos; ápice agudo con dentículos preapicales sobre el margen dorsal.

Coloración. La mayoría de las especies de Sibovia son de color amarillento a verde con bandas negras simétricas que usualmente alcanzan el ápice de la corona.

Observaciones taxonómicas. El género Sibovia comparte caracteres de la genitalia femenina con algunos géneros incluidos en el grupo genérico Erythrogonia, sin embargo no ha podido ser relacionado directamente con ninguno de ellos. Considerando la genitalia del macho, Sibovia podría acercarse al género Cyclogonia Melichar, incluido en el grupo genérico Juliaca Melichar, del cual se diferencia por tener el margen anterior de la corona más estrecho y la celda anteapical del ala anterior cerrada basalmente (Young 1977).

Distribución. Sibovia es un género ampliamente distribuido en América, con registros desde el sur de Estados Unidos hasta la Argentina (Young 1977).

El género Sibovia incluye 30 especies descriptas, sólo una presente en la Argentina (McKamey 2007, Nielson \& Godoy 1995, Young 1977). 
Sibovia sagata (Signoret) (Figuras 60, 61)

Tettigonia sagata Signoret 1854: 27 [n. sp.]

Diagnosis Cabeza dorsalmente con un par de bandas negras que convergen, anteriormente, en el ápice de la corona y posteriormente, en el ápice claval del

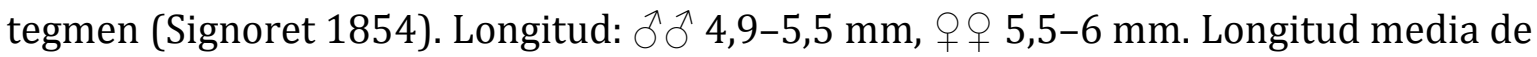
la corona $0,8 \mathrm{x}$ el ancho interocular; superficie de la corona, en vista lateral, con una concavidad transversal. Suturas clipeales laterales extendiéndose sobre la corona, sin alcanzar los ocelos. Ancho del pronoto ligeramente mayor que el ancho transocular. Alas anteriores con el área membranosa apical. Aedeagus del macho, en vista lateral, con el eje levemente ensanchado en el ápice, sin procesos de posición media. Valva II del ovipositor de la hembra, en vista lateral, con el eje estrecho y sin dientes en su porción basal luego de la curvatura basal.

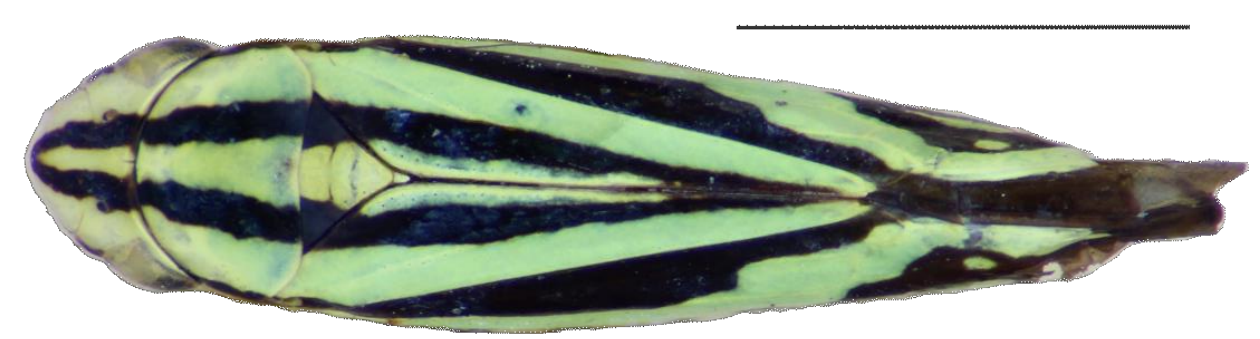

Figura 60. Hábito dorsal de Sibovia sagata (Signoret). Escala 2 mm.

Genitalia de la hembra. Esternito VII (Fig. 61A), en vista ventral, corto, longitud media 0,7x el ancho máximo; márgenes laterales ligeramente paralelos, margen posterior con una proyección corta y aguda de posición media; márgenes lateroposteriores ligeramente lobulados. Esternito abdominal VIII (Fig. 61B) membranoso, excepto por dos áreas circulares ligeramente esclerotizadas. Pigóforo (Fig. 61C), en vista lateral, con el margen posterior moderadamente proyectado, ampliamente redondeado; superficie con numerosas macrosetas sobre la proyección posterior que se extienden anteriormente a lo largo de la mitad ventral. Valvifer I (Fig. 61D), en vista lateral, subovalado con el margen anterodorsal más esclerotizado. Valva I (Fig. 61F), en vista lateral, lanceolada con la mitad basal dirigida dorsalmente; AED extendiéndose mayormente sobre la mitad apical del eje, formada por procesos 
tegumentarios rectangulares no imbricados, dispuestos en líneas oblicuas; AEV restringida a la porción preapical, formada por procesos tegumentarios escamiformes. EVA larga, visible más allá de la mitad basal del eje. Ápice (Fig. 61G) puntiagudo. Valvifer II (Fig. 61D), en vista lateral, fusiforme, superficie de la mitad ventral con numerosos procesos tegumentarios espiniformes. Valva II (Fig. 61H), en vista lateral, estrecha luego de la curvatura basal hasta casi la mitad basal del eje, margen dorsal de la porción expandida convexo, mitad anterior con dientes (Fig. 61I) subtriangulares grandes y mitad posterior con dientes subtriangulares pequeños; cada diente lleva pequeños dentículos en sus caras anterior y posterior. Sistema de ductos compuesto por ductos cortos y largos que alcanzan los dientes y el ápice. Porción preapical aguda con los márgenes dorsal y ventral denticulados, ápice (Fig. 61J) ampliamente redondeado; ventralmente con una prominencia preapical pronunciada. Gonoplaca (Fig. 61K), en vista lateral, porción anterior estrecha, ligeramente más larga que la porción posterior, la cual es marcadamente expandida; superficie preapical con numerosos procesos tegumentarios espiniformes y macrosetas que se extienden anteriormente a lo largo del margen ventral; ápice (Fig. $61 \mathrm{M}$ ) ampliamente redondeado.

Distribución. Sudamericana con registros en Argentina, Bolivia y Brasil (Young 1977). Se cita por primera vez para Paraguay (Villarica). En la Argentina, está presente en las provincias de Jujuy, Misiones, Corrientes, Buenos Aires (Remes Lenicov et al. 1999) y Entre Ríos (Dellapé 2016). Se amplía su distribución a las provincias de Salta (Urundel), Formosa (Misión Laishí) y Neuquén (Figura 62).

Plantas hospedadoras. Zea mays L. (Poaceae), Citrus sinensis Osb. (Rutaceae) y la vegetación herbácea asociada, Pelargonium hortum L. (Geraniaceae) "malvón", Phaseolus vulgaris L. (Fabaceae), Malva parviflora L. (Malvaceae) (Costa Lima 1942, Ott et al. 2006, Remes Lenicov et al. 1999, Young 1977), Vitis vinífera L. (Vitaceae) (Ringenberg 2008). Se registra por primera vez asociada a Mentha sp. L. (Lamiaceae).

Datos biológicos. Sus poblaciones fueron estudiadas en agroecosistemas citrícolas de Misiones en donde se registró su presencia sobre las plantas cítricas y la 
vegetación asociada. En ambos huéspedes el momento de mayor densidad poblacional se observó en primavera (Remes Lenicov et al. 1999).

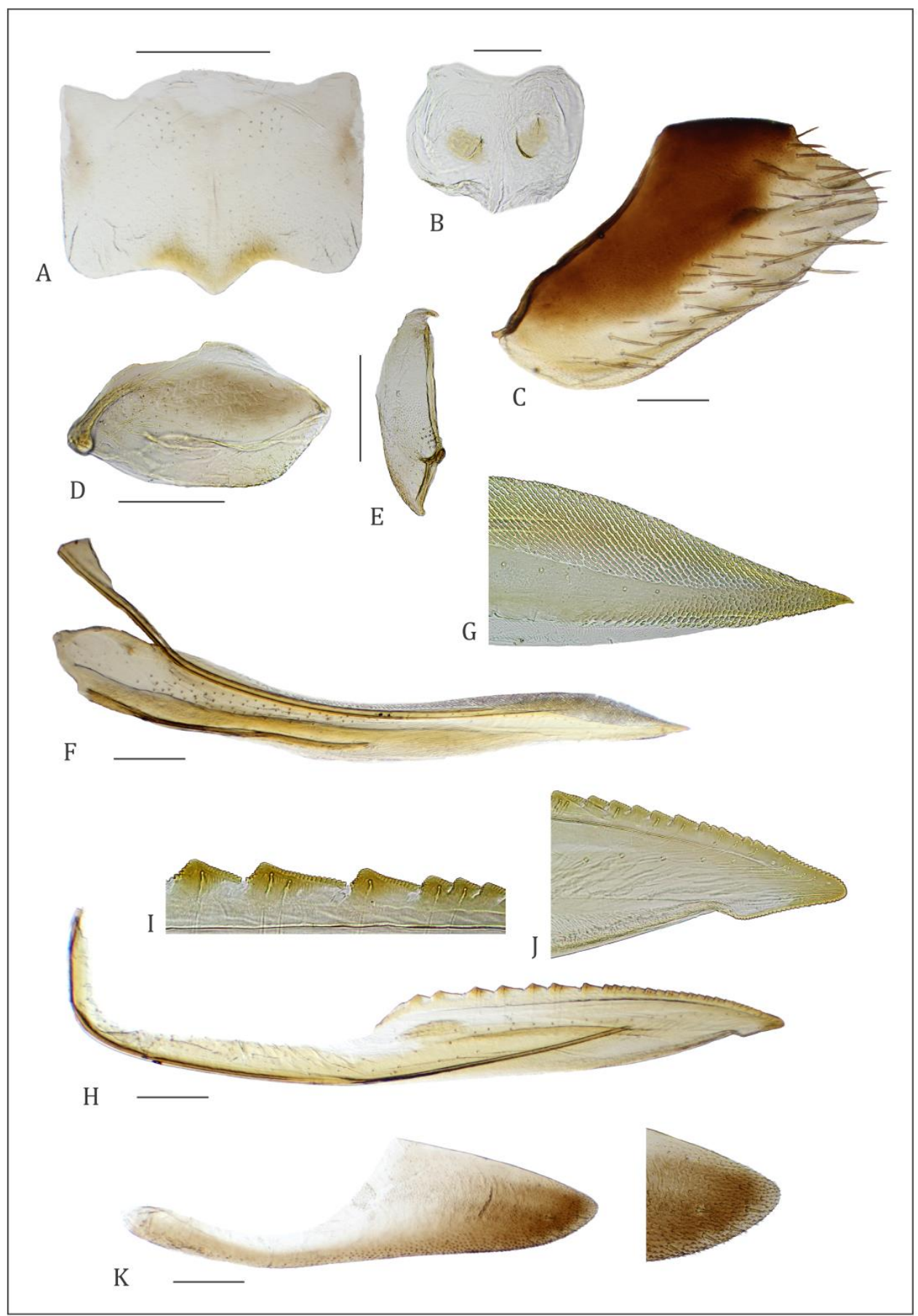

Figura 61. Genitalia de la hembra de Sibovia sagata (Signoret): esternito abdominal VII (A), esternito abdominal VIII (B), pygofer (C), valvifer I (D), valvifer II (E), valva I (F), ápice valva I (G), valva II (H), dientes valva II (I), ápice valva II (J), gonoplaca (K), ápice de la gonoplaca (M). Escala 0,5 mm: A-E, F, H, K. 
Enemigos naturales. Strepsiptera de la familia Halictophagidae (Remes Lenicov \& Tesón 1985), Anagrus breviphragma Soyka (Hymenoptera: Mymaridae) (Luft Albarracín et al. 2009), himenópteros de la familia Dryinidae (Remes Lenicov et al. 1999).

Importancia fitosanitaria. Desconocida.

Material estudiado. ARGENTINA: (MLP): Misiones: Oberá, 1ð̋, 30/XII/1957, M.

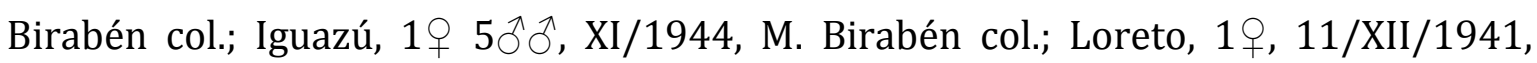

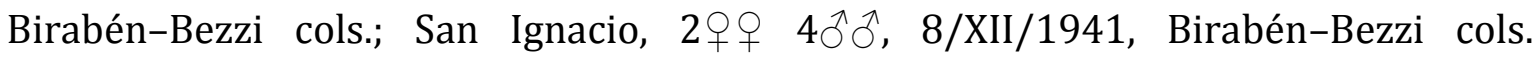
Formosa: Misión Laishí, $1+2 \hat{\jmath}, 12 / X I I / 1942$, Birabén-Bezzi cols. Buenos Aires: $5 ㅇ ㅜ$ 1ठ, III/1894, Bruch col., 1, VI/1952, Rappoport col.; Brazo Largo, 1,

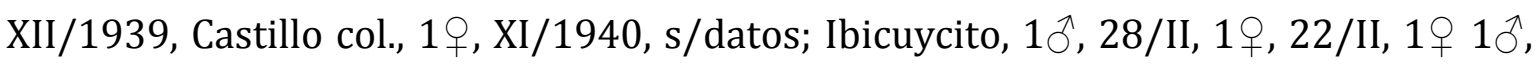
30/IX/1939, 1q, 4 s/abd., Castillo col.; Saavedra, $1 q 2 \hat{\jmath}$, VII/1936, Castillo col.,

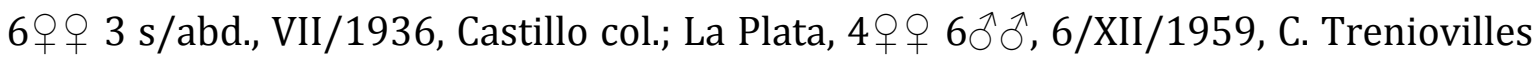
col. Neuquén: $1 \uparrow$, Ferrariis col. (IFML): Salta: Urundel, $2 q q$ 1 $\lambda, 31 / \mathrm{I} / 1950, \mathrm{R}$. Golbach col. Misiones: San Javier, 1 ㅇ 1ð, 20/XI/1973, R. Golgach col.; Puerto Bember, $3 ㅇ ㅜ 1 \delta$, III/1945, Golbach-Willink-Hayward cols. PARAGUAY: Villarica,

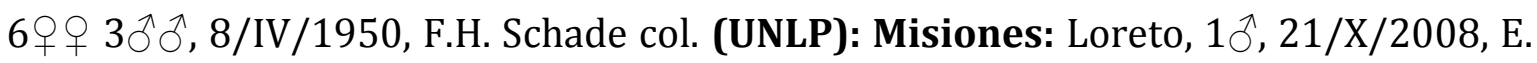
Virla col.; Puerto Iguazú, $2 \widehat{\jmath}, 22 / I X / 2008$, Zamudio col.; Puerto Iguazú (Rta 101),

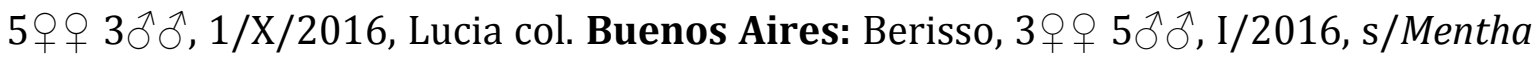
sp., Defea col. 


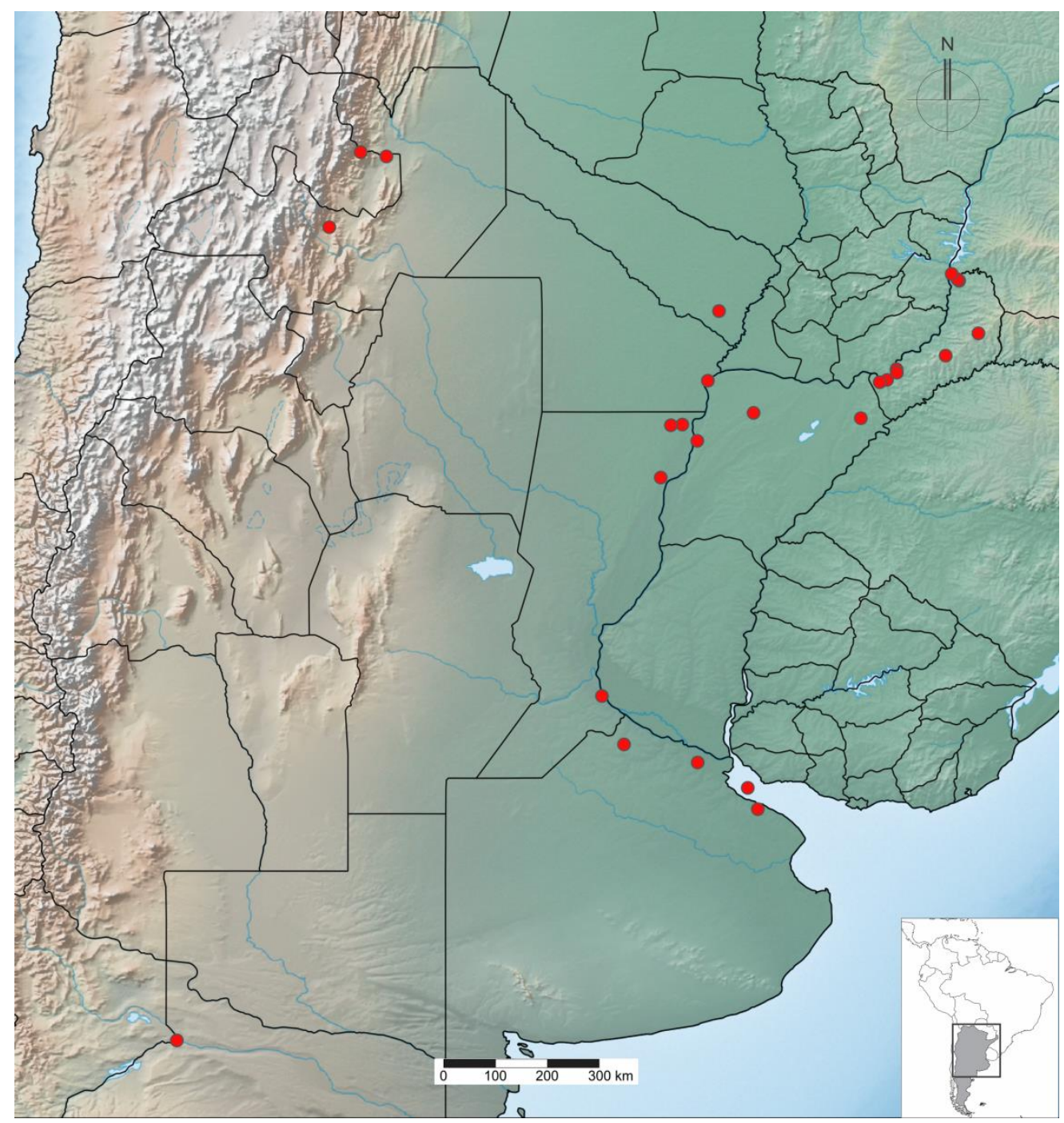

Figura 62. Distribución de Sibovia sagata (Signoret) en Argentina. 


\section{Género Sonesimia Young}

Especie tipo: Tettigonia grossa Signoret 1854:25

Longitud total 9,9-13,7 $\mathrm{mm}$.

Cabeza. Longitud media de la corona 0,5-0,8x el ancho interocular, margen anterior, en vista dorsal, obtuso; ocelos frecuentemente localizados sobre la línea que pasa entre los ángulos anteriores de los ojos; superficie de la corona convexa a cóncava medialmente, con una concavidad en la porción interocular, glabra, no esculturada. Puentes antenales, en vista lateral, con el margen anterior cóncavo. Transición corona-clípeo redondeada. Clípeo convexo; sutura transclipeal interrumpida en su porción media; clipelo fuertemente convexo, con el ápice finamente pubescente.

Tórax. Ancho del pronoto variable respecto del ancho transocular de la cabeza, márgenes laterales paralelos o divergentes posteriormente, carena dorsopleural, en vista lateral, incompleta; disco con rugosidades transversales, glabro; superficie del escutelo por detrás del surco transversal no estriado. Alas anteriores con la membrana incluyendo la celda apical interna y, usualmente, la porción apical de las apicales restantes; venas marcadas y usualmente elevadas; celdas anteapicales central e interna abiertas basalmente, con cuatro celdas apicales, sin plexo anteapical de venas. En las hembras, las alas en reposo ocultan el ovipositor. Fórmula setal del fémur posterior 2:0:0, 2:1:0 o 2:1:1; tibia posterior ligeramente achatada, hileras setales 1 y 2, con setas irregularmente espaciadas con microsetas intercaladas. Longitud del primer tarsómero subigual a la longitud combinada del segundo y tercer tarsómero, con numerosas setas irregularmente dispuestas.

Genitalia del macho. Pigóforo moderadamente proyectado posteriormente o posterodorsalmente, margen posterior redondeado, con numerosas macrosetas pequeñas de disposición variable, ubicadas sobre la mitad basal del disco, submarginales en la porción apical o agrupadas en la porción ventral del disco; con o sin procesos (apicales, anteapicales o dorsales). Placas subgenitales cortas, anchas y fusionadas basalmente, extendiéndose lateralmente más allá del pigóforo y con los márgenes laterales fuertemente convexos; superficie con numerosas microsetas 
regularmente distribuídas. Estilos de longitud variable respecto a la longitud del conectivo, con o sin lóbulo preapical, gradual- o abruptamente curvados lateralmente en la porción apical. Conectivo en forma de Y con las ramas ampliamente divergentes y más cortas que el eje el cual está carenado en su porción apical. Edeago simétrico, con procesos pares o impares originándose ventralmente cerca de la base. Paráfisis usualmente ausentes.

Genitalia de la hembra. Esternito abdominal VII con el margen posterior emarginado medialmente. Esternito abdominal VIII con o sin escleritos. Pigóforo corto, cubierto por microsetas dispersas, con algunas macrosetas cerca del margen posterior. Ovipositor con la segunda valva lanceolada, sin dientes.

Coloración. Presentan una coloración opaca con el tegmen ferruginoso de intensidad variable, con las venas usualmente amarillentas. Sobre la cabeza, pronoto y escutelo se extienden dos bandas longitudinales negras (excepto $S$. dimidiata) extendiéndose desde el ápice de la corona hasta el escutelo.

Observaciones taxonómicas. Varias especies del género Sonesimia presentan numerosas microsetas en la porción apical del fémur posterior las cuales se alargan hacia el ápice asemejándose a las utilizadas para la fórmula setal (Young 1977).

Distribución. Sudamericana con registros en Argentina, Bolivia, Brasil y Paraguay (Young 1977).

El género Sonesimia cuenta con seis especies descriptas de las cuales dos están presentes en la Argentina.

dimidiata Young 1977: 1086.

grossa (Signoret) 1854: 25. 
Sonesimia dimidiata Young (Figuras 63, 65B, 66A, C)

Sonesimia dimidiata Young 1977 [n. sp.].

Diagnosis. Ancho del pronoto mayor que el ancho transocular de la cabeza. Macho con el margen posterior del pigóforo redondeado posteriormente con numerosas macrosetas dispersas y procesos cortos que se originan dorsalmente en la porción anteapical que se extienden posteriormente. Estilos sobrepasando ligeramente el eje del conectivo, sin lóbulo preapical, porción apical estrecha, gradualmente curvada. Edeago, con un par de procesos que se originan ventralmente cerca de la base, curvados dorsal y posteriormente, eje con los márgenes anterior y posterior cóncavos. Esternito abdominal VII de la hembra con el margen posterior cóncavo. Valvifer I, en vista lateral, cuadrangular, con el margen posterior ligeramente cóncavo. Cabeza, pronoto y escutelo amarillentos con una banda arqueada en el ápice de la corona, área irregular bordeando cada ocelo, pequeño punto detrás de cada ocelo sobre el margen posterior de la cabeza, márgenes laterales del pronoto, un par de puntos en la porción anterior del disco pronotal, tres manchas angulares en la base y dos bandas laterales en el escutelo, negras (Young 1977).

Genitalia de la hembra. Esternito VII (Figura 66A), en vista ventral, subrcuadrangular, casi tan largo como ancho; márgenes laterales ligeramente convergentes posteriormente y el margen posterior ligeramente cóncavo en su parte media; con varias microsetas en la superficie lateroposterior. Esternito VIII (Fig. 63A), esclerotizado es su porción media. Pigóforo, en vista lateral, con el margen posterior proyectado moderadamente; superficie con macrosetas subamarginales a lo largo del margen ventral y dorsal de la proyección posterior, y numerosas microsetas sobre la mitad apical. Valvifer I (Figura 66C), en vista lateral, cuadrangular, con el margen posterior ligeramente cóncavo; superficie con pequeñas microsetas dispersas, mayormente concentradas hacia los márgenes dorsal y posterior. Valva I (Fig. 63C), en vista lateral, lanceolada, casi rectilínea con la porción basal direccionada dorsalmente; AED extendiéndose sobre tercio apical del eje, formada por procesos tegumentarios filiformes dispuestos oblicuamente; AEV restringida a la porción preapical del eje, formada por procesos filiformes oblicuos. EVA larga, extendiéndose sobre los tres cuartos basales del eje; ápice agudo, con los márgenes preapicales 
dorsal y ventral lisos, ápice redondeado. Valvifer II (Fig. 63B), en vista lateral, de forma alargada, superficie con procesos espiniformes dispersos sobre la mitad ventral. Valva II (Fig. E), en vista lateral, ligeramente rectilínea con los márgenes dorsal y ventral casi paralelos, sin dientes. Ductos visibles en la mitad apical alcanzando los márgenes dorsal, apical y ventral en la porción preapical. Porción preapical aguda, ápice (Fig. 63F) redondeado; ventralmente sin prominencia preapical. Gonoplaca (Fig. 63G), en vista lateral, porción anterior estrecha basalmente expandida, 0,4x más corta que la porción posterior, la cual es marcadamente expandida; superficie con macrosetas submarginales a lo largo del margen ventral; ápice ampliamente redondeado.

Distribución. Sonesimia dimidiata fue registrada en Argentina y Brasil (Young 1977). En la Argentina, está presente en la provincia de Misiones (Remes Lenicov et al. 1999). Se amplía la distribución para la provincia de Corrientes (Santo Tomé) (Figura 67).

Plantas hospedadoras. Desconocidas.

Datos biológicos. Desconocidos.

Enemigos naturales. Desconocidos.

Importancia fitosanitaria. Desconocida.

Material estudiado. ARGENTINA: (MLP): Misiones: 28$\propto+9 \hat{\jmath}$, sin más datos,

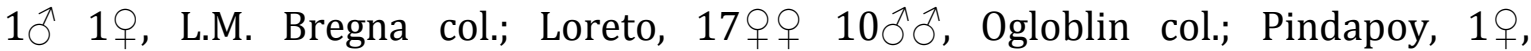
14/XII/1941, Birabén-Bezzi cols.; San Javier, 15/XII/1957, M. Birabén col.; Santa Inés, 1ठ઼, 13/XII/1941, Birabén-Bezzi cols. Corrientes: Santo Tomé, 2ðð, 12/XI/1957, M. Birabén col. 


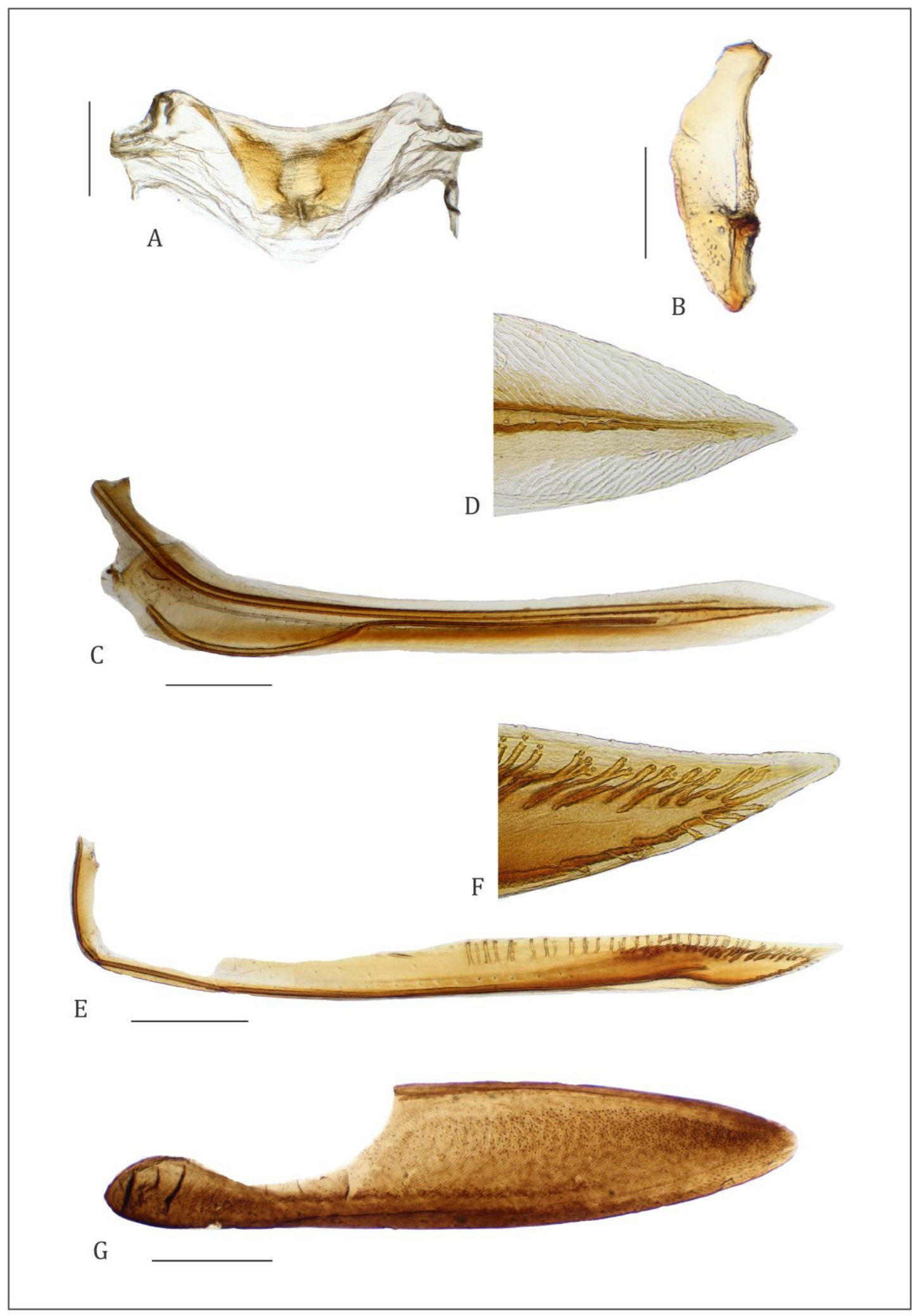

Figura 63. Genitalia de la hembra de Sonesimia dimidiata Young: esternito abdominal VIII (A), valvifer II (B), valva I (C), ápice valva I (D), valva II (E), ápice valva II (F), gonoplaca (G). Escala 0,5 mm: A, C-F; 0,3 mm: B. 
Sonesimia grossa (Signoret) (Figuras 64, 65A, 66B, D)

Tettigonia grossa Signoret 1854 [n. sp.]

Tettigonia grossa; Young \& Beier 1963: 569 [designación Lectotipo]

Sonesimia grossa Young 1977 [n. comb.]

Diagnosis. Cabeza, pronoto y escutelo de color amarillo con dos bandas longitudinales proyectadas desde el ápice de la corona hasta el margen posterior del mesonoto, márgenes laterales del pronoto y una banda más corta central en el mesonoto, negras (Signoret 1854). Ancho del pronoto menor que el ancho transocular de la cabeza (Young 1977). Macho con el margen posterior del pigóforo ampliamente redondeado con algunas macrosetas submarginales apicodorsales y un grupo sobre la porción ventral del disco; procesos cortos que se originan dorsalmente en la porción anteapical y se extienden posteriormente. Estilos sobrepasando ampliamente el eje del conectivo, con lóbulo preapical y porción apical abruptamente curvada. Edeago, con un proceso que se origina ventralmente cerca de la base, curvado ventral y posteriormente, eje simple, más corto que el proceso. Esternito abdominal VII de la hembra con el margen posterior formando un lóbulo medio con una concavidad angulosa central, superficie lisa. Valvifer I, en vista lateral, cuadrangular, con el margen posterior rectilíneo.

Genitalia de la hembra. Esternito VII (Figura 66B), en vista ventral, subcuadrangular, ancho máximo $1,3 \mathrm{x}$ la longitud media; márgenes laterales ligeramente convergentes posteriormente, con el margen posterior formando un lóbulo medio con una concavidad de posición media; superficie lisa. Esternito VIII (Fig. 64A), mayormente membranoso con algunas esclerotizaciones. Pigóforo (Fig. 64C), en vista lateral, con el margen posterior proyectado moderadamente; superficie con macrosetas subamarginales a lo largo del margen ventral y posterior, con numerosas microsetas dispersas en toda la superficie. Valvifer I (Figura 66D), en vista lateral, cuadrangular; superficie con pequeñas microsetas dispersas, mayormente concentradas sobre el margen dorsal. Valva I (fig. 64D), en vista lateral, lanceolada, casi rectilínea con la porción basal direccionada dorsalmente; ADE extendiéndose sobre tercio apical del eje, formada por procesos tegumentarios filiformes dispuestos 
oblicuamente; AVE restringida a la porción preapical del eje, formada por procesos filiformes oblicuos. EVA larga, extendiéndose sobre los tres cuartos basales del eje; ápice agudo, con los márgenes preapicales dorsal y ventral lisos y el ápice (Fig. 64E) redondeado. Valvifer II (Fig. 64B), en vista lateral, subtriangular, margen superficie con procesos espiniformes dispersos sobre la mitad dorsal, margen anteroventral fuertemente esclerotizado. Valva II (Fig. 64F), en vista lateral, ligeramente rectilínea con los márgenes dorsal y ventral casi paralelos, sin dientes. Ductos visibles en la mitad apical alcanzando los márgenes dorsal, apical y ventral en la porción preapical. Porción preapical aguda, ápice (Fig. 64G) redondeado; sin prominencia preapical. Gonoplaca (Fig. 64H), en vista lateral, porción anterior estrecha y basalmente expandida, 0,3x más corta que la porción posterior, la cual es marcadamente expandida; superficie con algunas macrosetas largas submarginales a lo largo del margen ventral; ápice ampliamente redondeado.

Distribución. Sonesimia grossa está registrada en Argentina, Brasil, Bolivia, y Paraguay (Young 1977). En la Argentina, está presente en la provincia de Misiones (Remes Lenicov et al. 1999), Corrientes (Beltrán et al. 2004) y Entre Ríos (Dellapé et al. 2016). Se amplía la distribución para las provincias de Tucumán (El Siambón) y Chaco (Resistencia) (Figura 67).

Plantas hospedadoras. Citrus sinensis (L.) Osbeck Rutaceae) variedades Valencia y Criolla (Remes Lenicov et al. 1999, Dellapé et al. 2016), Coffea sp. (Rubiaceae) (Silva et al. 2007). Se citan por primera vez los siguientes hospedadores Eryngium sp. (Aliaceae), Eucalyptus sp. (Myrtaceae), Hyptis mutabilis (Rich.) Briquet (Lamiaceae), Nicotiana tabacum L. (Solanaceae).

Datos biológicos. En Misiones, es una especie frecuente sobre la vegetación espontánea asociada a plantaciones de cítricos durante todo el año con tres picos de máxima densidad durante noviembre-diciembre, marzo y junio-julio (Remes Lenicov et al 1999). En Entre Ríos, también fue recolectada esporádicamente en la vegetación asociada a plantaciones de naranja de las variedades Valencia y Criolla (Dellapé et al. 2016). En ambos estudios se corroboró su escasa frecuencia sobre los cítricos. En agroecosistemas citrícolas de Corrientes, fue recolectada tanto en los cítricos, aunque 
de manera esporádica, y en la vegetación espontánea, donde su presencia es constante y frecuente durante todo el año (Ver Capítulo III).

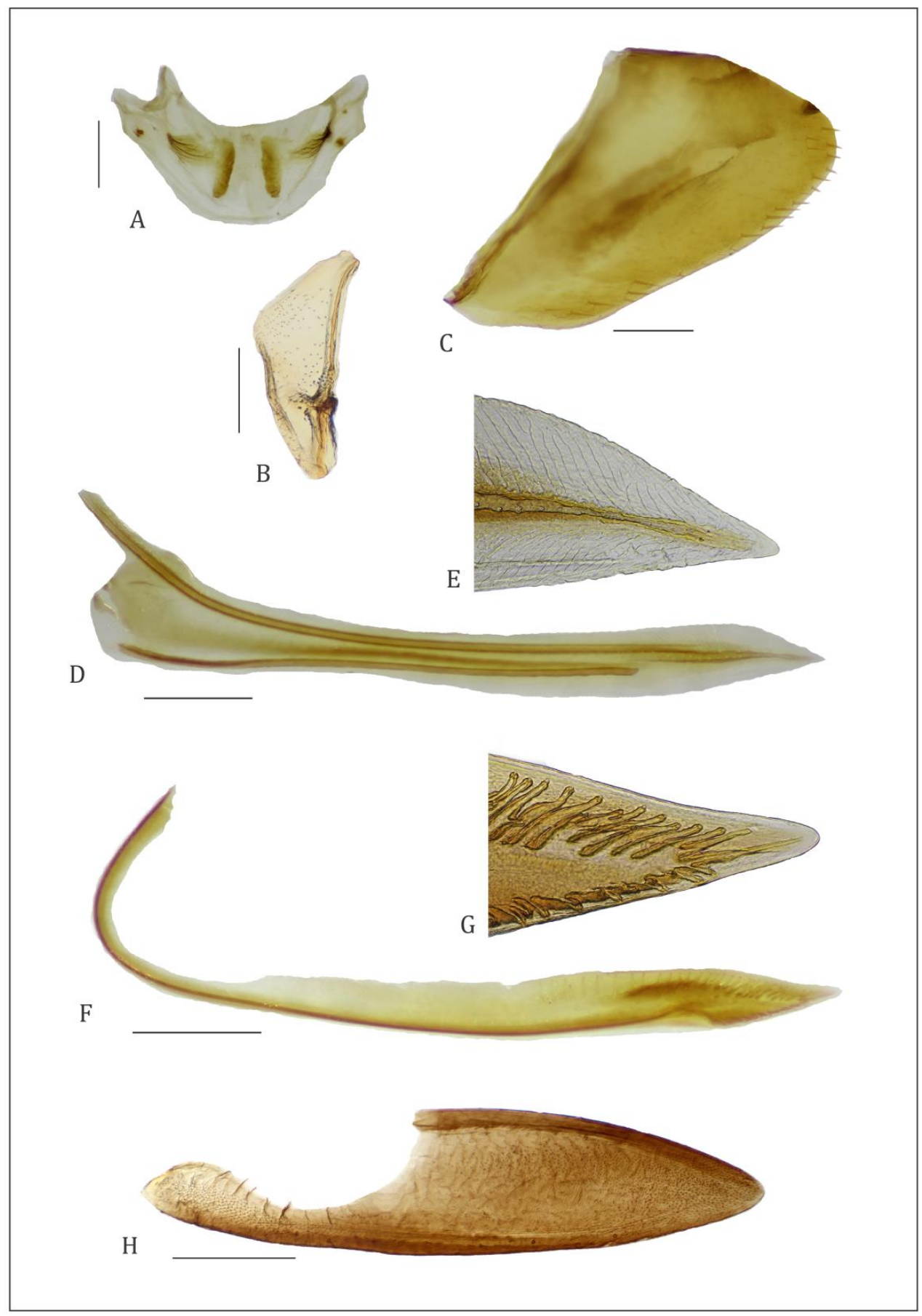

Figura 64. Genitalia de la hembra de Sonesimia grossa (Signoret): esternito abdominal VIII (A), valvifer II (B), pigóforo (C), valva I (D), ápice valva I (E), valva II (F), ápice valva II (G), gonoplaca (H). Escala 0,5 mm: A, C, E-H; 0,3 mm: B. 
Enemigos naturales. Stresiptera de la familia Halictophagidae (Remes Lenicov et al. 1999) y el entomopatógeno Clonostachys rosea (Link: Fries) Schroers, Samuels, Seifert, and Gams (Toledo et al. 2006).

Importancia fitosanitaria. Esta especie es vector confirmado de la bacteria Xylella fastidiosa subsp. pauca, agente causal de la Clorosis Variegada de los Cítricos (Fundecitrus 1999). También, es considerada especie potencialmente vectora en café (Leite \& Nunes 2003). En Argentina, estudios realizados con ejemplares recolectados en Misiones resultaron positivos para Xylella fastidiosa (de Coll et al. 2000a).

Material estudiado. ARGENTINA: (MLP): Misiones: $1+1 \hat{\jmath}, 25 / I X / 1910$, P. Jorgensen col.; 1 ㅇ $2 \widehat{\jmath}, 1 / \mathrm{XI} / 1910$, P. Jorgensen col.; 1ㅇ, 1/I/1911, P. Jorgensen col.;

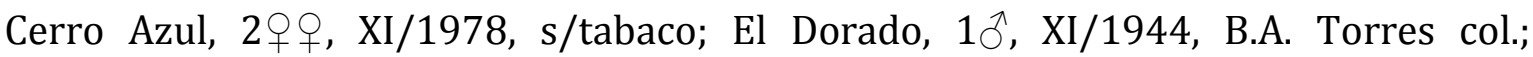
Garuhapé, $1 q$ 1§̂, I/1962; Leandro N. Alem, $2+q, 1939$, s/Eucalyptus sp., P.F. Schnabel; Loreto, $1 q$ 1ठ, XII/1947, A.O. Ubagli col; Oberá, 2qo, 30/XII/1957, M. Birabén; Pindapoy, 1§, X/1895, Berg; Puerto Iguazú, 1§, XI/1944, B.A. Torres; San

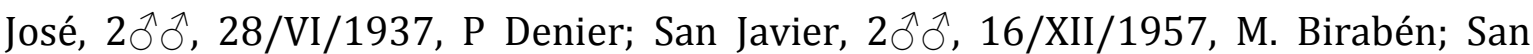
Ignacio, $1 \hat{\jmath}, 8 / I I I / 1941$, M. Birabén; Santa Inés, 19 1 $\widehat{O}, 13 / X I I / 1941$, Birabén-Bezzi

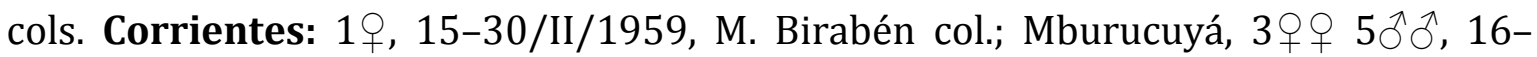
23/XI/1957, M. Birabén. Tucumán: Siambón, 19, II/1933, Bosq col. (IFML): Misiones: Dto. Verde, 1ㅇ, 17/XI/1951, A. Willink col.; Panambi, 1ठ, 24/XI/1961,

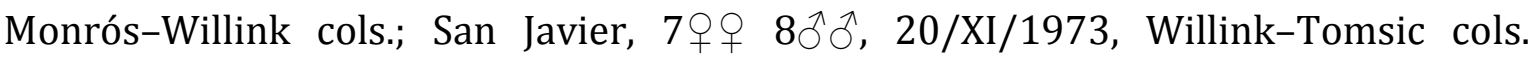
Corrientes: Gobernador Virasoro, Las Marías, $19+2 \widehat{\jmath}, 5 / \mathrm{V} / 1971$, Porter-Stange cols. Chaco: Resistencia, 1, 17/XI/1948, R. Golbach col. (UNLP): Corrientes: Bella

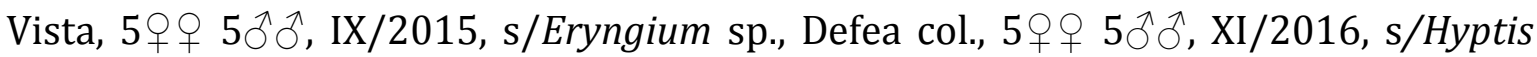
mutabilis, Defea col.; Parque Nac. Mburucuyá, $4 q$ ㅇ 1ठ, I/2014, B. Defea col. 
Clave para el reconocimiento de las especies del género Sonesimia presentes en Argentina.

1. Ancho del pronoto mayor que el ancho transocular de la cabeza. Eje aedeagal con un par de procesos que se originan ventralmente cerca de la base, curvados dorsal y posteriormente. Esternito abdominal VII de la hembra con el margen posterior cóncavo. Valvifer I, en vista lateral, cuadrangular, con el margen posterior con una concavidad S. dimidiata

-. Ancho del pronoto menor que el ancho transocular de la cabeza. Eje aedeagal simple con un proceso que se origina ventralmente cerca de la base, curvado ventral y posteriormente. Esternito abdominal VII de la hembra con el margen posterior formando un lóbulo medio con una concavidad angulosa central; valvifer I, en vista lateral, cuadrangular con el margen posterior regularmente convexo S. grossa

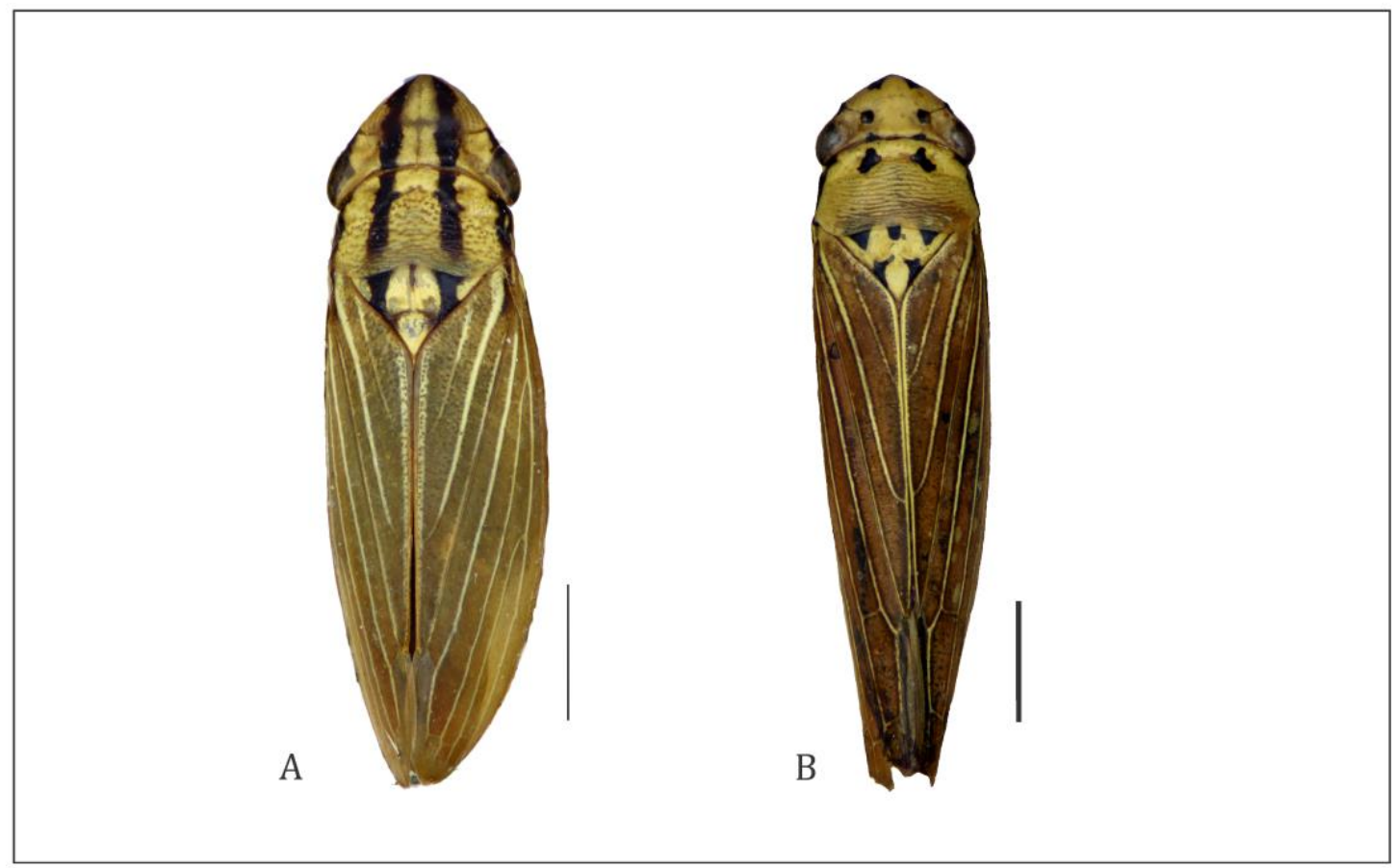

Figura 65. Especies de Sonesimia Young presentes en Argentina: S. grossa (Signoret) (A), S. dimidiata Young (B). Escala 2 mm: A, B. 


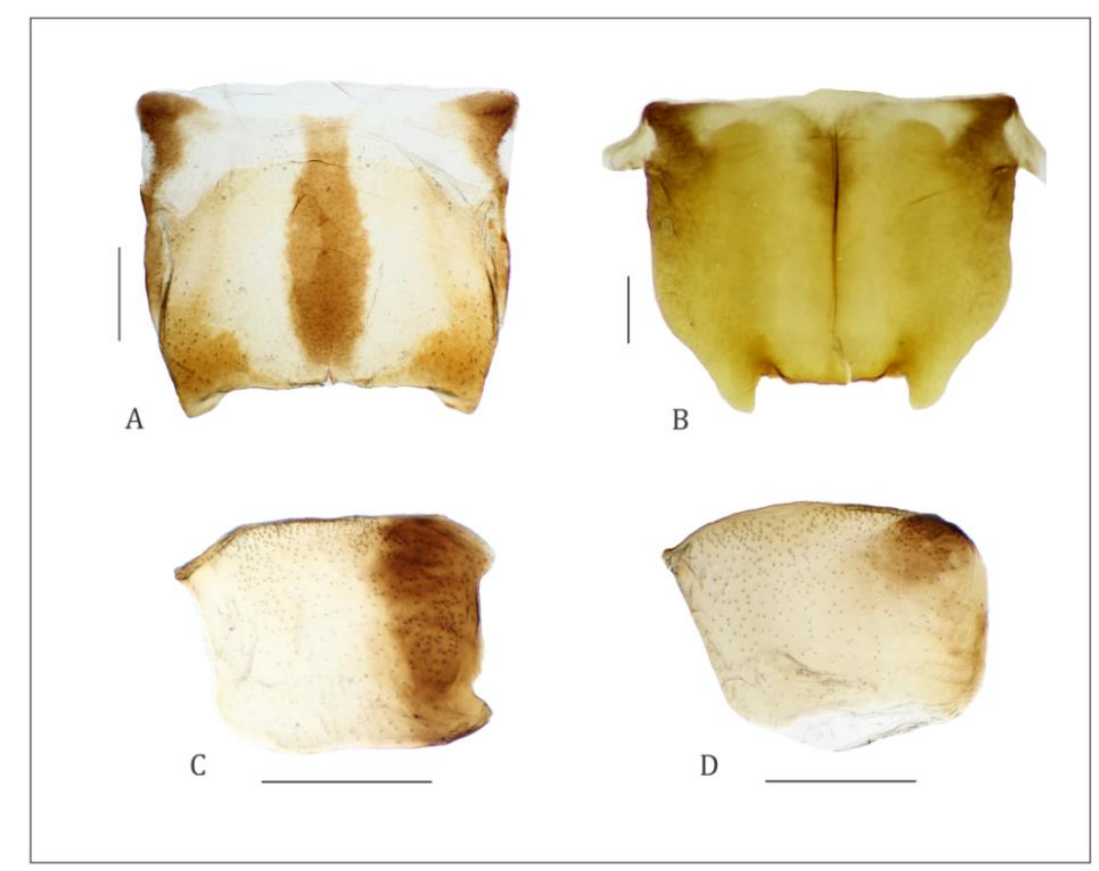

Figura 66. Estructuras diagnósticas de la genitalia de la hembra de las especies del género Sonesimia Young. S. dimidiata Young: esternito abdominal VII (A), valvifer I (C); S. grossa (Signoret): esternito abdominal VII (B), valvifer I (D). Escalas 0,5 mm.: A-D. 


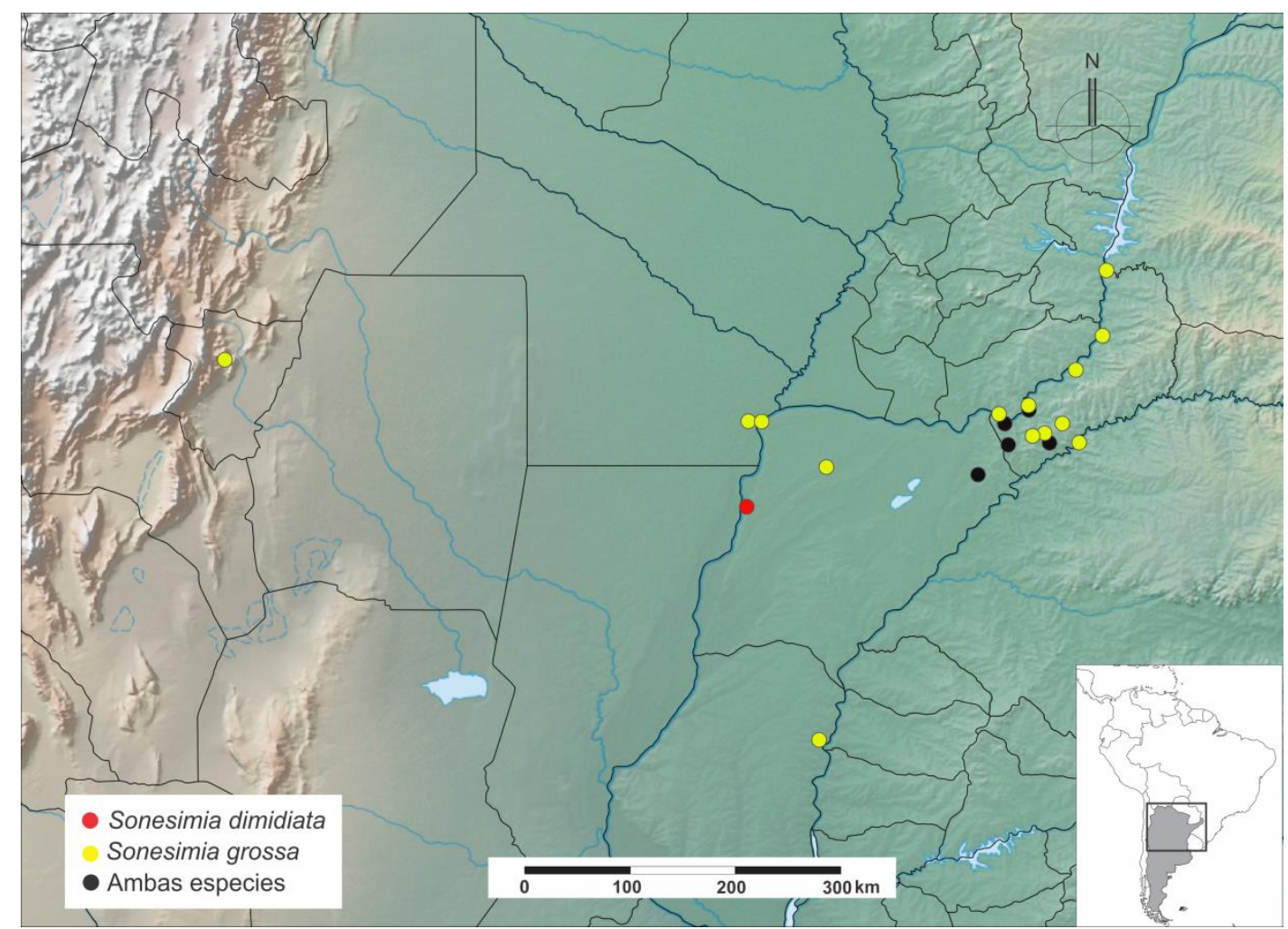

Figura 67. Distribución de las especies del género Sonesimia Young en Argentina. 


\section{Género Syncharina Young}

Syncharina Young 1977. Especie tipo: Tettigonia punctatissima Signoret 1854 (Por designación original).

Longitud total 4,5-8,5 mm.

Cabeza. Margen anterior de forma variable, aguda a obtusamente angulosa; longitud media de la corona desde ligeramente menor a $0,7 \mathrm{x}$ el ancho interocular a ligeramente mayor; ocelos localizados sobre o por delante de la línea que pasa entre los ángulos anteriores de los ojos; superficie de la corona con una fóvea estrecha o ancha de posición media, o ligeramente cóncava entre los ocelos, superficie fuertemente punteada; transición corona-clípeo redondeada. Suturas clipeales laterales extendiéndose sobre la corona y alcanzando los ocelos. Puentes antenales, en vista dorsal, no protuberantes, con el margen anterior, en vista lateral, rectilíneo o cóncavo, y vertical u oblicuo. Clípeo, en vista lateral, ligeramente convexo, raramente el clipelo, y aplanado en su porción media, superficie glabra, con la parte media fuertemente punteada; sutura transclipeal generalmente incompleta. Contorno del clipelo aproximadamente paralelo al eje longitudinal del cuerpo.

Tórax. Ancho del pronoto menor que el ancho transocular, márgenes laterales paralelos o ligeramente convergentes anteriormente, margen posterior cóncavo; carena dorsopleural, en vista lateral, incompleta; superficie completamente punteada, glabra; escutelo fuertemente punteado. Alas anteriores con membrana que incluye todas, o parte de las cuatro celdas apicales, base de la cuarta celda apical más proximal que la base de la tercera, celda anteapical media abierta basalmente, sin plexo de venas anteapical; textura alar anterior a la membrana, coriácea, con el área basal fuertemente punteada. En las hembras, las alas anteriores en reposo ocultan el ovipositor. Fórmula setal del fémur posterior frecuentemente 2:1:0, también 2:0:0, 2:1:1 o 2:2:1. Longitud del primer tarsómero menor a la longitud combinada del segundo y tercer tarsómero.

Genitalia del macho. Pigóforo corto, poco proyectado posteriormente, con la porción apical estrecha y el margen redondeado, con un número bajo de macrosetas pequeñas cerca del margen posterodorsal y algunas microsetas en la porción basal. 
Placas subgenitales triangulares, separadas a lo largo de toda su longitud, tan largas como el

pigóforo. Estilos cortos, con lóbulo preapical y ápice oblicuamente truncado. Conectivo en forma de Y, con el eje principal más largo que los ramas laterales. Edeago corto, simétrico y sin procesos. Paráfisis pares y simétricas.

Genitalia de la hembra. Esternito abdominal VII con el margen posterior ligeramente proyectado y convexo, o ligera- y regularmente cóncavo ( $S$. línea). Pigóforo (Fig. 69B) con numerosas macrosetas pequeñas anteapicales y algunas cercanas al margen posteroventral. Ovipositor con la segunda valva (Fig. 69G) fuertemente expandida luego de la curvatura basal con el margen ventral cóncavo en la porción expandida; margen dorsal con dientes (Fig. 69H) redondeados cerca de la base y cuadrangulares que se extienden hasta el ápice (Fig. 69I), cada diente con numerosos dentículos; márgenes dorsal y ventral preapicales denticulados, sin prominencia preapical ventral.

Caracteres adicionales de la genitalia de la hembra. Superficie del esternito VII (Fig. 69A), en vista dorsal, cubierta casi completamente por pequeños procesos tegumentarios espiniformes, y microsetas agrupadas a cada lado de la línea media. Valvifer I (Fig. 69C), en vista lateral, suboval, con el margen dorsal marcadamente convexo y más esclerotizado formando un borde anterodorsal, vértice anterior agudo, margen posterior subredondeado. Valva I (Fig. 69E), en vista lateral, porción basal del eje ligeramente rectilínea con el tercio apical curvado dorsalmente; margen basal truncado o anguloso; margen dorsal de la porción basal formando un borde fuertemente esclerotizado con una ligera concavidad luego de la curvatura basal. AED extendiéndose desde la curvatura basal hasta el ápice, formada por estructuras tegumentarias escamiformes dispuestas en líneas oblicuas que se imbrican en la porción preapical, margen dorsal del tercio preapical liso, sin procesos tegumentarios; AEV restringida a la porción preapical formada por estructuras tegumentarias escamiformes dispuestas irregularmente; ápice (Fig. 69F) agudo curvado hacia arriba. Valvifer II (Fig. 69D), en vista lateral, ligeramente fusiforme con el margen anterior biconvexo y menos esclerotizado que el posterior, margen anterior rectilíneo interrumpido en la mitad inferior por el PA; con un grupo de 
microsetas cortas y robustas cerca al PA. Gonoplaca (Fig. 69J), en vista lateral, con la porción basal estrecha casi tan larga como la porción posterior, la cual es marcadamente expandida; superficie con procesos tegumentarios en la porción preapical que se extienden ventralmente hacia la porción basal, con finas macrosetas submarginales a lo largo del margen ventral; ápice ampliamente redondeado.

Coloración. Cabeza, pronoto y tegmen verde-amarillento a negro. Corona y pronoto con patrón de marcas de color castaño oscuro a negro variable entre las especies; tegmen con venas (Exc: S. línea) negras.

Observaciones taxonómicas. De acuerdo con Young (1977), Syncharina estaría relacionado a los géneros Helochara Fitch y Helocharina Melichar en base a caracteres tegumentarios, alares y morfología del edeago. En el marco de esta tesis se realizó un estudio comparativo detallado de la genitalia femenina de estos tres géneros. Los resultados preliminares permiten confirmar la relación cercana entre Syncharina y Helochara a partir de caracteres de las hembras, poniendo en duda la cercanía con Helocharina.

Distribución. El género Syncharina se encuentra restringido a Sudamérica con registros en Argentina, Bolivia, Brasil, Chile y Uruguay (Young 1977, Osborn 1926). Se cita como nuevo registro para Paraguay.

Observaciones. El género Syncharina es uno de los géneros de Cicadellini más ampliamente distribuido en la Argentina y la especie $S$. lineiceps representa el límite de distribución más austral para la tribu en nuestro país (Defea et al. 2016).

El género Syncharina incluye cuatro especies, todas presentes en la Argentina.

argentina (Berg) 1879: 251.

linea (Taschenberg) 1884: 451.

lineiceps (Spinola) 1852: 283.

punctatissima (Signoret) 1854: 16. 
Syncharina argentina (Berg) (Figuras 68B, 70A, D, G, J)

Tettigonia argentina Berg 1879

Syncharina argentina Young 1977 [n. comb.]

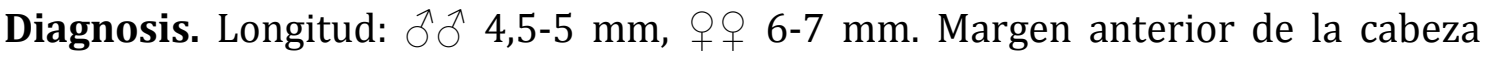
moderadamente aguda en vista dorsal; longitud media de la corona 1,2-1,6x el ancho interocular, con la superficie ligeramente cóncava entre los ocelos; ocelos localizados sobre la línea que pasa entre los ángulos anteriores de los ojos; puentes antenales, en vista lateral con el margen anterior cóncavo y vertical. Pigóforo del macho, en vista lateral, con el margen dorsal levemente escotado, superficie apical con algunas macrosetas robustas, mayormente cubierta por microsetas que se afinan y acortan hacia el margen ventral. Placas subgenitales con una hilera de macrosetas cortas. Paráfisis lanceoladas, en vista ventral solapadas, con el ápice agudo. Coloración variable, castaño oscuro a verde-amarillento, tegmen con venas castañas. Corona con una banda castaña longitudinal mediana, angosta y corta cuando está presente.

Genitalia de la hembra. Esternito VII (Fig. 70A), en vista ventral, con el margen posterior irregularmente convexo, con un ligero lóbulo medio; márgenes lateroposteriores redondeados. Pigóforo (Fig. 70D), en vista lateral, proyectado moderadamente con el margen dorsal de la proyección posterior casi recto y el margen apical ampliamente subredondeado con microsetas y macrosetas robustas algunas de las cuales se extienden anteriormente a lo largo del margen ventral. Valva II, en vista lateral, con 19-24 dientes sobre el margen dorsal. Gonoplacas (Fig. 70J), con la superficie ventral, preapical y basal cubiertas por procesos tegumentarios espiniformes; con pequeñas microsetas dispersas a lo largo del margen ventral. El resto de los caracteres responde a lo descripto para el género.

Observaciones taxonómicas. Syncharina argentina puede ser separada del resto de las especies del género por las paráfisis lanceoladas del macho, en vista ventral, solapadas y, por el margen posterior del esternito VII de la hembra, con un lóbulo medio ligeramente desarrollado.

Distribución. En Sudamérica, S. argentina está presente en Argentina, Brazil, y Uruguay (Osborn 1926, Young 1977). Se cita por primera vez para Paraguay 
(Asunción y Departamento San Pedro, Carumbé). En la Argentina esta especie está presente en las provincias de Buenos Aires, Córdoba, Corrientes, Chaco, Formosa, Santa Fé, Entre Ríos (Paradell et al. 2006, Remes Lenicov \& Tesón 1985). Se amplía su distribución para las provincias de Jujuy (Potrero de Yala), Misiones (Loreto) y Tucumán (El Siambón y Rinconada) (Figura 71).

Plantas hospedadoras. Oryza sativa L. (Poaceae), Sorghum halepense L. (Poaceae), Zea mays L. (Poaceae), Citrus sinensis Osb. (Rutaceae), Hordeum vulgare L. (Poaceae), Medicago sativa L. (Poaceae), Gossypium hirsutum L. (Malvaceae), Cynodon sp.(Poaceae), Triticum aestivum L. (Poaceae) y maleza asociada a los cultivos de arroz y cítricos (Remes Lenicov \& Tesón 1985, Tesón et al. 1986, Remes Lenicov \& Virla 1993, Remes Lenicov et al. 2006, Dellapé 2013). Se registra por primera vez en cultivos Fragaria sp. (Rosaceae).

Datos biológicos. Remes Lenicov \& Tesón (1985) señalan la ocurrencia de picos poblacionales de esta especie durante el período inicial del cultivo de arroz, antes de la "aguación", y bajo determinadas condiciones climáticas (temperaturas elevadas, insolación y baja humedad ambiental). Asimismo, atribuyen daño foliar (clorosis) a la acción mecánica de su aparato bucal y del ovipositor. Su alta abundancia en cultivos de arroz fue corroborada posteriormente por Paradell et al. (2006) en Entre Ríos y Paradell et al. (2014a) en Buenos Aires. Es una especie de ocurrencia accidental en la vegetación asociada a plantaciones citrícolas de Entre Ríos (Dellapé et al. 2016) y Corrientes (Ver Capítulo III).

Enemigos naturales. Desconocidos.

Importancia fitosanitaria. Posible daño directo debido a la alimentación a plantas de arroz (Remes Lenicov \& Tesón 1985).

Material estudiado. ARGENTINA: (MLP): Chaco: Resistencia, $2 \circ q, 17 / \mathrm{VI} / 1948$, Golbach R. col. Tucumán: Siambón, 1 + $1 \overbrace{}^{\Uparrow} 1$ s/abd., II/1946, Olea col.; Rinconada, 1

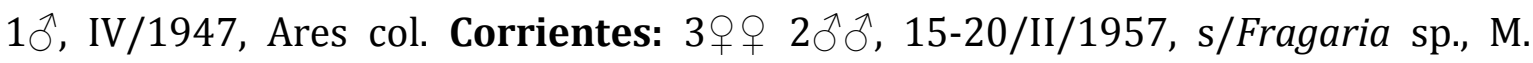
Birabén. Santa Fé: Villa Guillermina, 40 우 $10 \lesssim \widehat{\jmath} 1$ s/abd., II/1946, Willink- 
Hayward cols. Entre Ríos: Villaguay, $3 \circ q 1$ s/abd., 3-9/XI/1959, Ajmat-Benassar cols. (IFML): Formosa: Isla de Oro, Margen del Río Oro, 1ठ, III/1939, P. Denier col. Misiones: Loreto: 1q, IV/1981; 39 , A.A. Ogloblin col. Chaco: Resistencia, 1 s/abd., 20/III/1939, P. Denier col, 1 ㅇ 1 s/abd., 20/I/1953, M. A. Morinigo col.; Roque Saenz Peña, 1 s/abd., 14/I/1954, Torres-Argemí cols.; Tirol, 1 ㅇ 1 s/abd., 7/VII/1939, Birabén-Bezzi cols. Santa Fé: Arocena, 1, 20/XI/1939, Birabén-Bezzi cols.; San Justo, 1q, 21/XI/1939, Birabén-Bezzi cols.; Venado Tuerto, 10̄, II/1942, M. Birabén

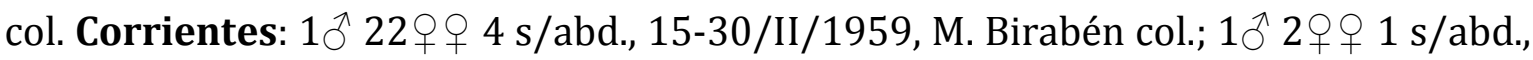
I/1982, Trujillo col.; Manantiales, $39+1$ s/abd., 1-10/II/1959, M. Birabén col. Córdoba: Marull, 1 s/abd., 22/I/1940, M. Birabén col. Buenos Aires: $7 q q$, 26/I/1935; Brazo Largo, 2우, XII/1939, S. R. Castillo col.; Castelar, $1 \hat{\bigcirc} 3$, 28/X/1980, s/maíz, Dalbo col.; Ciudad, 11우, 10/II/1912, 4우, 6/XII/1919, 3 우, 5,17/II/1919; Ibicuycito, 4 q 92 s/abd., 21-30/IX/1938, S. R. Castillo col.; La Plata, 15우우 1 s/abd., sin datos, 1 s/abd., 20/II/1981, Lagrange col., 2우, XI/1977, Tesón col., Los Hornos, 8 우 6へð 12 s/abd., XII/1974; Saavedra, 2 우 1 s/abd., VII/1935, S.

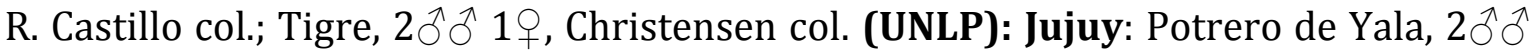
$3 ㅇ$, 14/I/2015, Defea-Lucia cols. Corrientes: Bella Vista, $2 \widehat{\jmath} 5$ 5우 13/I/2014, Defea col. Entre Ríos: Islas de Ibicuy, 2 +,$+ 7 /$ II/2014, Lucia col.; Colón, $3 ð \widehat{\jmath} 3 q+$, 2006, Bonnot col. PARAGUAY: (IFML): Asunción, $1 ð 2$ 2 $q$, 20-22/I/1965, R. Golbach col.; Departamento San Pedro, Carumbé, $2 \hat{\jmath}$ ô 6 우, 28/I-10/III/1965, R. Golbach. URUGUAY: (IFML): Montevideo, 1 s/abd., colección J. Tremoleras.

\section{Syncharina linea (Taschenberg) (Figuras 68A, 69, 70G, I)}

Tettigonia linea Taschenberg 1884: 451

Syncharina linea Young 1977: 607 [n. comb.]

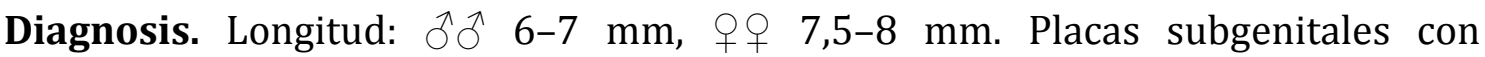
numerosas microsetas multiseriadas (Young 1977). Margen anterior de la cabeza, en vista dorsal, anguloso; longitud media de la corona igual o ligeramente mayor que el ancho interocular, con una fóvea longitudinal angosta sobre la superficie; ocelos localizados sobre la línea que pasa entre los ángulos anteriores de los ojos; puentes antenales, en vista lateral, con el margen anterior rectilíneo y vertical. Pigóforo del 
macho, en vista lateral, con el margen posterodorsal profundamente escotado, superficie apical cubierta por microsetas, con tres macrosetas sobre el margen dorsal. Paráfisis lanceoladas con la mitad apical curvada dorsalmente, en vista ventral, entrecruzadas, con el ápice agudo. Cabeza, pronoto, escutelo y tegmen de color verde-amarillento, con venas castañas. Corona con una banda negra longitudinal mediana, angosta proyectada desde el ápice que puede extenderse a través del pronoto.

Genitalia de la hembra (Figuras 69, 70G, I). Esternito VII (Figura 68G), en vista ventral, con el margen posterior regularmente cóncavo o con un pequeño lóbulo medio emarginado lateralmente; márgenes lateroposteriores redondeados. Pigóforo (Figura 68B), en vista lateral, bien desarrollado posteriormente con el margen dorsal de la proyección posterior recto y el margen apical ampliamente redondeado con microsetas y macrosetas robustas, algunas de las cuales se extienden anteriormente a lo largo del margen ventral. Valva II, en vista lateral, con 21-23 dientes sobre el margen dorsal. Gonoplacas, con la superficie ventral, preapical y basal cubiertas por procesos tegumentarios espiniformes; con pequeñas microsetas dispersas a lo largo del margen ventral; ápice estrecho, redondeado. El resto de los caracteres responde a lo descripto para el género.

Observaciones taxonómicas. Syncharina linea puede ser diferenciada de las otras especies del género a partir de caracteres de los machos: presencia de microsetas largas, multiseriadas en las placas subgenitales, pigóforo marcadamente escotado en el margen dorsal, con la superficie apical cubierta por microsetas y la presencia de tres macrosetas sobre el margen dorsal, y de las hembras: margen posterior del esternito VII cóncavo.

Distribución. Esta especie está presente sólo en la Argentina con registros en la provincia de Mendoza (Young 1977) (Figura 71).

Plantas hospedadoras. Desconocidas.

Datos biológicos. Desconocidos. 
Enemigos naturales. Desconocidos.

Importancia fitosanitaria. Desconocida.

Material estudiado. ARGENTINA: (USNM): Mendoza: Potrerillos, $2 \Uparrow \lesssim 2 q \propto, 16-$ 20/III/1920, Altitud 4000 snm, Cornel University Expedition; 1ð 1, 16-20/III/1920, Altitud 4000 snm, Cornel University Expedition

Syncharina lineiceps (Spinola) (Figuras 68C, 70B, F, G)

Tettigonia lineiceps Spinola 1852: 283

Draeculacephala chilensis DeLong 1967: 184 [syn.]

Syncharina lineiceps Young 1977: 607 [n. comb.]

Diagnosis. Alas anteriores de color verde intenso con venas del mismo color (Young 1977). Longitud: Љ̂ 4-5 mm, 우 5,5-6 mm. Margen anterior de la cabeza, en vista dorsal, ampliamente anguloso; longitud media de la corona excediendo 1,2-1,4x el ancho interocular, superficie con una fóvea longitudinal amplia; ocelos localizados sobre la línea que pasa entre los ángulos anteriores de los ojos o ligeramente por delante; puentes antenales, en vista lateral, con el margen anterior rectilíneo y oblicuo. Pigóforo del macho, en vista lateral, con el margen dorsal levemente escotado, superficie apical cubierta por macrosetas, el resto glabra. Placas subgenitales con una hilera de macrosetas cortas. Paráfisis con la mitad apical curvada dorsalmente, en vista ventral, entrecruzadas, con el ápice agudo. Cabeza, pronoto, escutelo verde-amarillento. Corona con una banda longitudinal negra mediana ancha.

Genitalia de la hembra. Esternito VII (Fig. 70B), en vista ventral, con el margen posterior irregularmente convexo con tres lóbulos, uno central de mayor desarrollo y uno más pequeño en cada márgen lateroposterior. Pigóforo (Figura 70F), en vista lateral, moderadamente desarrollado con el margen dorsal de la proyección posterior casi recto y el margen apical estrechamente redondeado con microsetas y macrosetas pequeñas, algunas de las cuales se extienden anteriormente a lo largo del margen ventral. Valva II, en vista lateral, con 21-26 dientes sobre el margen dorsal. 
Gonoplacas, con la superficie ventral, preapical y basal cubiertas por procesos tegumentarios espiniformes, sin macro- ni microsetas; ápice ampliamente redondeado. El resto de los caracteres responde a lo descripto para el género.

Observaciones taxonómicas. Varios caracteres permiten separar a S. lineiceps de las otras especies del género: presencia de una banda negra longitudinal ancha sobre la corona, pigóforo del macho con macrosetas, sin microsetas, sobre la superficie apical, y margen del esternito VII de la hembra con tres lóbulos, el mediano de mayor desarrollo.

Distribución. En Sudamérica, S. lineiceps está presente en Chile y Argentina (Young 1977). En la Argentina sólo fue registrada para la provincia de Río Negro: El Bolsón (Paradell et al. 2011) (Figura 71).

Plantas hospedadoras. Beta vulgaris L. var. saccharifera (Amaranthaceae)(Casals Bustos et al. 1999), Vaccinium corymbosum L. (Ericaceae) (Paradell et al. 2011).

Datos biológicos. Desconocidos.

Enemigos naturales. Desconocidos.

Importancia fitosanitaria. Desconocida.

Material estudiado. ARGENTINA: (MLP): Río Negro: El Bolsón, 2ðð, 8/XII/2005, 3 우, 1/IV/2006, 1ð, Rocca col. CHILE: (USNM): Cautin: Prov. Rio Cautin Cajon, $1 \overbrace{}^{\lambda}$ 1ㅇ, 3/I/1966, Flint-Cekalovic cols.; Malleco: Rio Malleco Lolenco, 1ㅇ, 3/I/1966, Flint- Cekalovic cols.; Maule: Nirivilo, 1§, 15/XII/1976, Gurney col., Reloca, 1§, 16/XII/1976, A. B. Gurney col.; West San Javier: 2qo, 15/XII/1976, Gurney-Barria cols. 
Syncharina punctatissima (Signoret) (Figuras 68D, 70C, E, H, J)

Tettigonia punctatissima Signoret 1854: 16

Syncharina punctatissima Young 1977: 607 [n. comb.]

Diagnosis. Paráfisis, en vista ventral, en forma de fórceps, con el ápice redondeado (Young 1977). Longitud: đ̂̊ 4,5-5,5 mm, 우 5,5-6,5 mm. Margen anterior de la cabeza, en vista dorsal, obtusamente anguloso; longitud media de la corona excede 1,2-1,4x el ancho interocular, superficie ligeramente cóncava entre los ocelos; ocelos localizados sobre la línea que pasa entre los ángulos anteriores de los ojos; puentes antenales, en vista lateral, con el margen anterior rectilíneo y oblicuo. Pigóforo del macho, en vista lateral, con el margen dorsal levemente escotado, superficie apical cubierta por macro- y microsetas, margen ventral con microsetas finas y cortas. Placas subgenitales con una hilera de macrosetas cortas. Cabeza, pronoto, escutelo y tegmen de color castaño oscuro a verde-amarillento, tegmen con venas negras. Corona con una banda negra longitudinal mediana angosta que se proyecta desde la corona hasta el escutelo. Pronoto usualmente con dos bandas negras oblicuas a los costados de la banda mediana.

Genitalia de la hembra. Esternito VII (Fig. 70C), en vista ventral, con el margen posterior convexo, con un lóbulo central bien desarrollado y los márgenes lateroposteriores redondeados. Pigóforo (Figura 70E), en vista lateral, poco desarrollado posteriormente, con el margen dorsal de la proyección posterior cóncavo proximalmente y el margen apical ampliamente subredondeado con microsetas y macrosetas robustas, algunas de las cuales se extienden anteriormente a lo largo del margen ventral. Porción basal de la valva I, en vista lateral, angulosa con el margen basal redondeado (Figura 70H). Valva II, en vista lateral, con 21-26 dientes sobre el margen dorsal. Gonoplacas (Figura 70J), como en S. argentina. El resto de los caracteres responde a lo descripto para el género.

Observaciones taxonómicas. Syncharina punctatissima se distingue de las otras especies del género por las paráfisis del macho en forma de fórceps, la porción basal de la valva I del ovipositor de forma angulosa, con el margen redondeado y el esternito VII de la hembra con el margen posterior medialmente más desarrollado formando un lóbulo medio claramente distintivo. 
Distribución: En Sudamérica, S. punctatissima está presente en Argentina, Bolivia y Brasil (Young 1977). Se cita por primera vez para Uruguay (Montevideo). En la Argentina esta especie está presente en las provincias de Salta, Jujuy, Corrientes, Entre Ríos, Santa Fé, Buenos Aires, Mendoza y Córdoba (Paradell 1995, Remes Lenicov \& Tesón 1985, Remes Lenicov et al. 1997, Tesón et al. 1986). Se amplía su distribución para las provincias de Catamarca, Tucumán (El Siambón) y San Juan (Departamento Pocito) (Figura 71).

Plantas hospedadoras. Digitaria eriantha S. (Poaceae), Zea mays L. (Poaceae), Triticum aestivum L. (Poaceae), Avena sativa L. (Poaceae), Hordeum vulgare L. (Poaceae), Trifolium spp. (Fabaceae) y malezas, Medicago sativa L. (Poaceae), Oryza sativa L. (Poaceae), Secale cereale L. (Poaceae), Sorghum vulgare (Pers.) (Poaceae) y Vicia villosa Roth (Fabaceae)(Young 1977, Remes Lenicov \& Tesón, 1985, Remes Lenicov et al. 2006, Paradell et al. 2014a, b). Se registra por primera vez la presencia de esta especie en Citrus sp. (Rutaceae), Petroselinum crispum (Mill.) “perejil” (Apiaceae) y Raphanus sativus L. “rabanito” (Brassicaceae).

Datos biológicos. Remes Lenicov \& Tesón (1985) mencionan a esta especie como abundante en cultivos de maíz, trigo, avena, cebada y centeno. Asimismo, señalan la ocurrencia de picos poblacionales en el período inicial del cultivo de arroz, antes de la "aguación", y bajo determinadas condiciones climáticas (temperaturas elevadas, insolación y baja humedad ambiental).

Enemigos naturales. Desconocidos.

Importancia fitosanitaria. Desconocida.

Material estudiado. ARGENTINA: (IFML): Catamarca: Entre ríos, 1ㅇ, 6/IV/1968, Willink-Terán cols. Tucumán: Siambón, 2へ, XI/1945, 2 $q$, II/1946, Olea col. (MLP): Salta: Rosario de Lerma, $2 \hat{\jmath} 1$ s/abd., V/1933. Corrientes: $2 \hat{\jmath}, 15-30 / \mathrm{II} / 1959$, Birabén col.; Solari, $1 \sigma^{\Uparrow} 19$, 8/XII/1941, Birabén-Bezzi cols. San Juan: Villa Aberastain, Departamento Pocito, $1 \widehat{\delta} 2$ 우, 20-25/I/1964, Torres-Ferreyra cols.

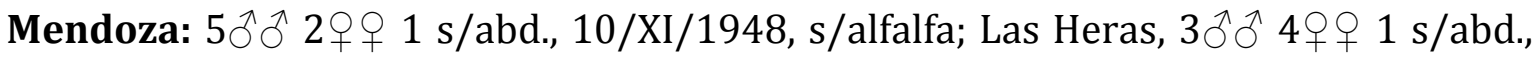




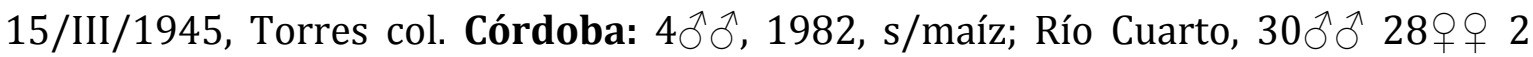
s/abd., 13-17/III/1983, s/maíz. Entre Ríos: Puerto Constanza, 1q, 21/XII/1941,

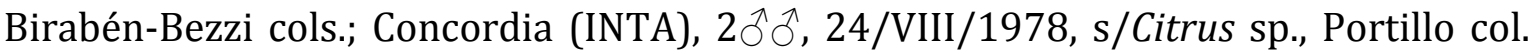
Buenos Aires: 1ㅇ, Bruch col; 1q, 26/I/1935; Castelar, $1 \widehat{\jmath}, 10 q$, 12/X/1980, Dalbo col.; Ciudad, 3우, 17/II/1919; La Plata, 3우, 6/XII/1959, Tremovilles col., $1 \overbrace{}^{\Uparrow} 1$, 21/X/1977; Gorina, 1, 15/XI/1973, s/perejil, Dagoberto-Tesón cols., 1+, 10/XII/1973, Tesón-Dagoberto cols., 1ㅇ, 11/XII/1973, s/rabanito, Dagoberto-Tesón cols., Los Hornos, 1q, XII/1976, 5 q 3 s/abd., 15/X/1976, 2 qq, XII/1974, Remes

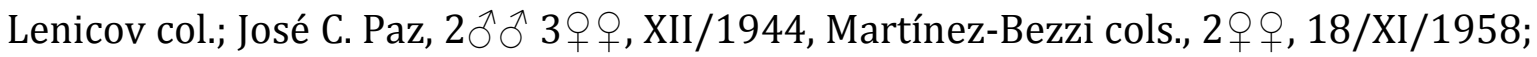
Hurlingham, $2 \hat{\jmath}, 30 /$ VIII/1958; Villa del Parque, $1 \hat{\jmath} 1+$, 20/VII/1937; Punta Indio, 1ㅇ, 4/XII/1938, Birabén-Scott cols.; Pergamino, 1ð̂, 3/V/1974, Remes Lenicov col.,

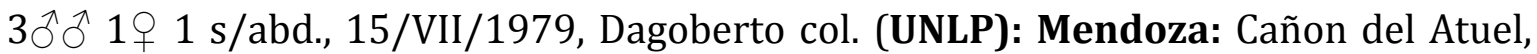
$2 ㅇ, 11 / \mathrm{II} / 2008$, Virla col. Entre Ríos: $3 \hat{\jmath} \widehat{\jmath}, 3 q+$, 2006, Bonnot col. URUGUAY: Montevideo, 2 우, colección J. Tremoleras.

\section{Clave para el reconocimiento de las especies del género Syncharina.}

1. Especímenes medianos, longitud total 6-8,5 mm.; placas subgenitales del macho con microsetas largas multiseriadas; margen posterior del esternito VII de la hembra, en vista ventral, irregularmente cóncavo con un pequeño lóbulo medio S. linea

-. Especímenes pequeños, longitud total 3,5-7 mm.; placas subgenitales del macho con una hilera de macrosetas cortas; margen posterior del esternito VII de la hembra, en vista ventral, convexo

2. Corona con una banda negra longitudinal ancha; paráfisis del macho, en vista ventral, entrecruzadas; margen posterior del esternito VII de la hembra, en vista ventral, con tres lóbulos, uno medio bien desarrollado y uno más pequeño en cada margen láteroposterior S. lineiceps

-. Corona con una banda negra longitudinal angosta, cuando presente; paráfisis del macho, en vista ventral, no entrecruzadas; margen posterior del esternito VII, en vista ventral, con un lóbulo medio 3

3. Corona, pronoto y escutelo con una línea negra longitudinal proyectada desde el ápice de la corona; margen anterior de la corona, en vista dorsal, obtusamente 
anguloso; paráfisis del macho, en vista ventral, en forma de fórceps con el ápice redondeado; esternito VII de la hembra, en vista ventral, más desarrollado medialmente formando un lóbulo claramente distintivo S. punctatissima

-. Corona con una banda negra longitudinal, no proyectada sobre el pronoto y escutelo; margen anterior de la corona, en vista dorsal, agudamente anguloso; paráfisis del macho, en vista ventral, lanceoladas y solapadas con el ápice puntiagudo; margen posterior del esternito VII, en vista ventral, con lóbulo medio ligeramente distintivo

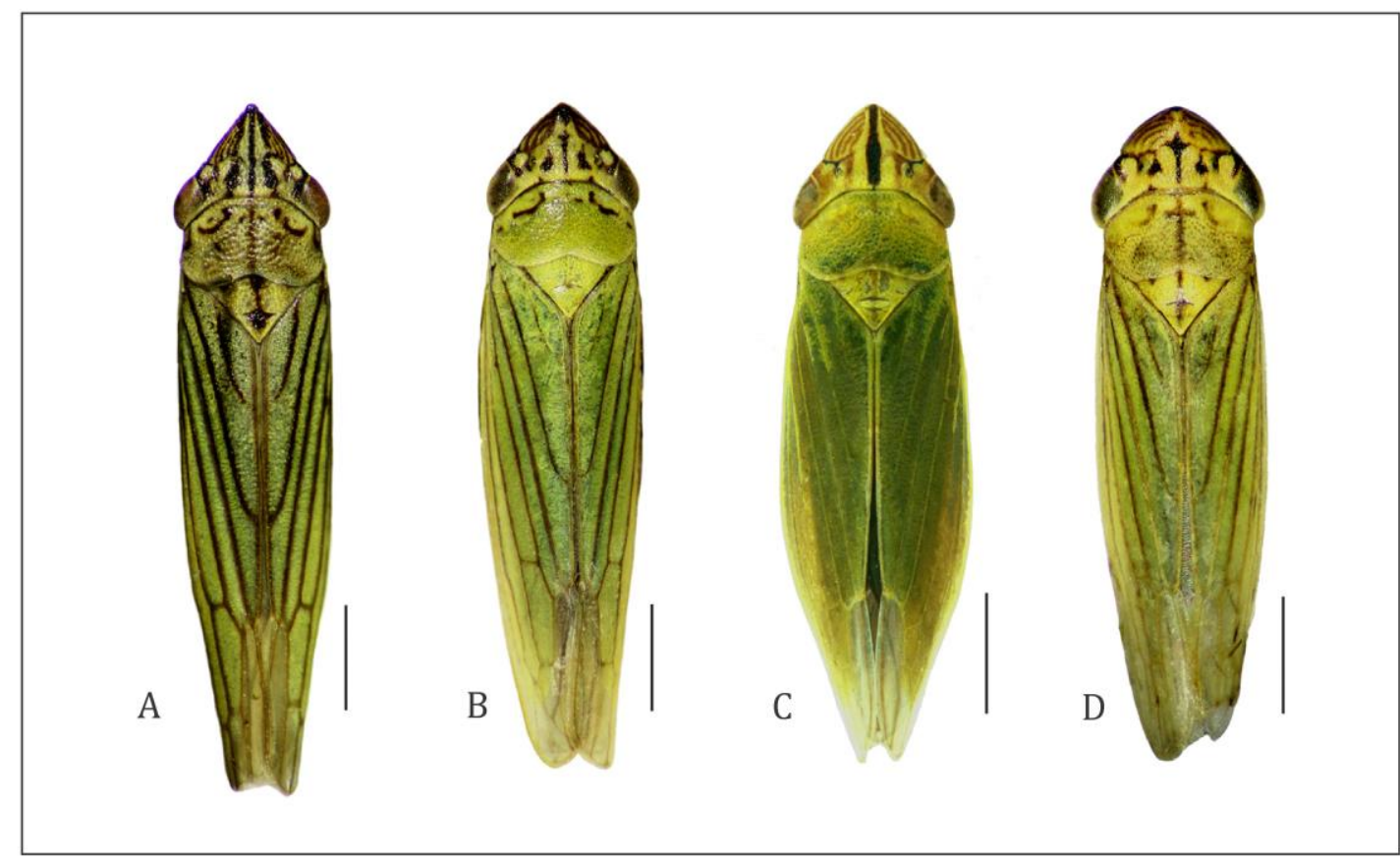

Figura 68. Especies del género Syncharina Young: S. linea (Taschenberg) (A), S. argentina (Berg) (B), S. lineiceps (Spinola) (C), S. punctatissima (Signoret) (D). Escala $2 \mathrm{~mm}$ : A-D. 


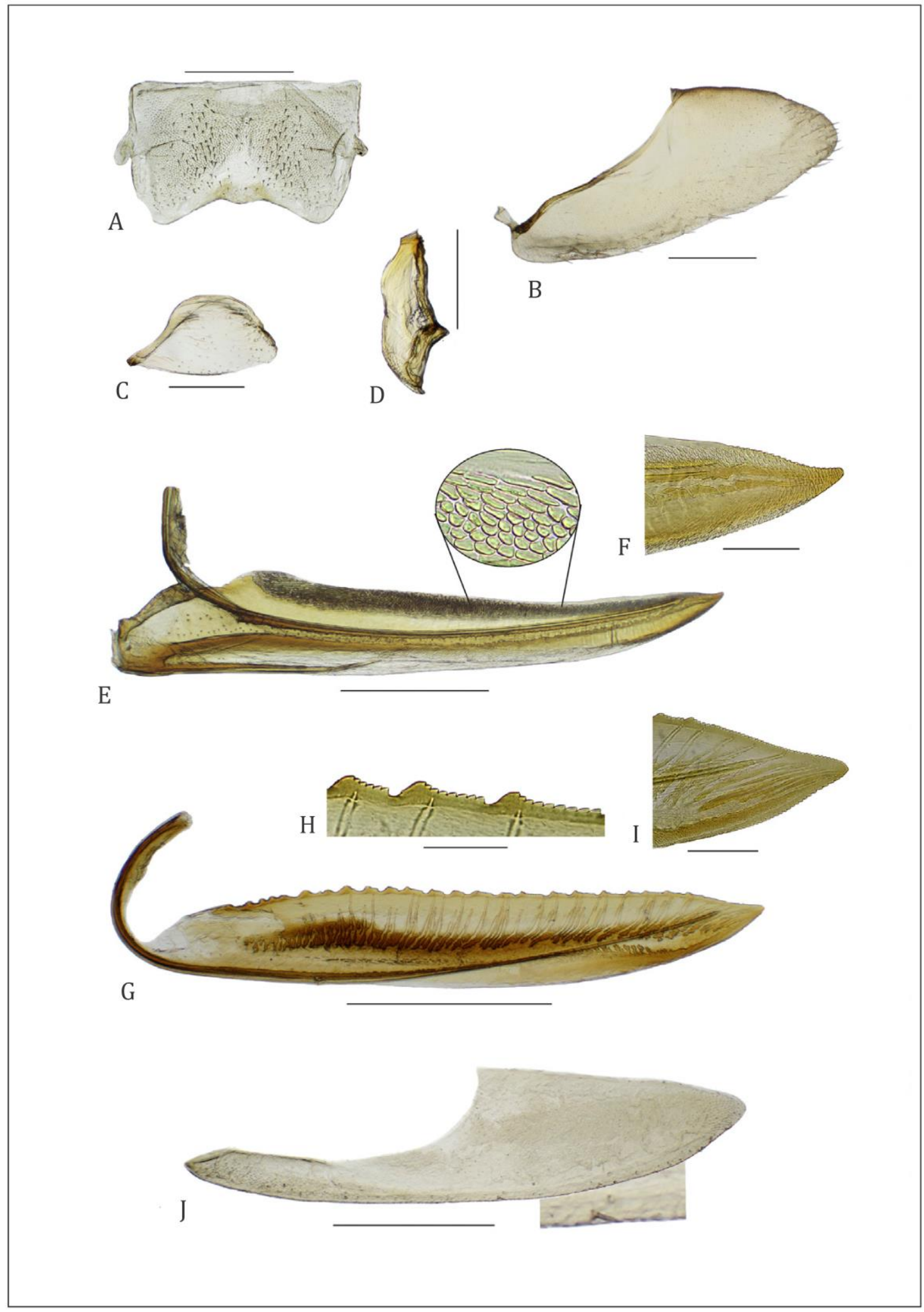

Figura 69. Genitalia de la hembra del género Syncharina (S. linea): Esternito VII (A), Pigóforo (B), valvifer I (C), valvifer II (D), valva I (E), ápice valva I (F), valva II $(G)$, detalle dientes valva II (H), ápice valva II (I), gonoplaca con detalle del margen ventral (J). Escala 0,5mm: A-E, G, J; 0,1mm: F, I; 0,05mm: H. 


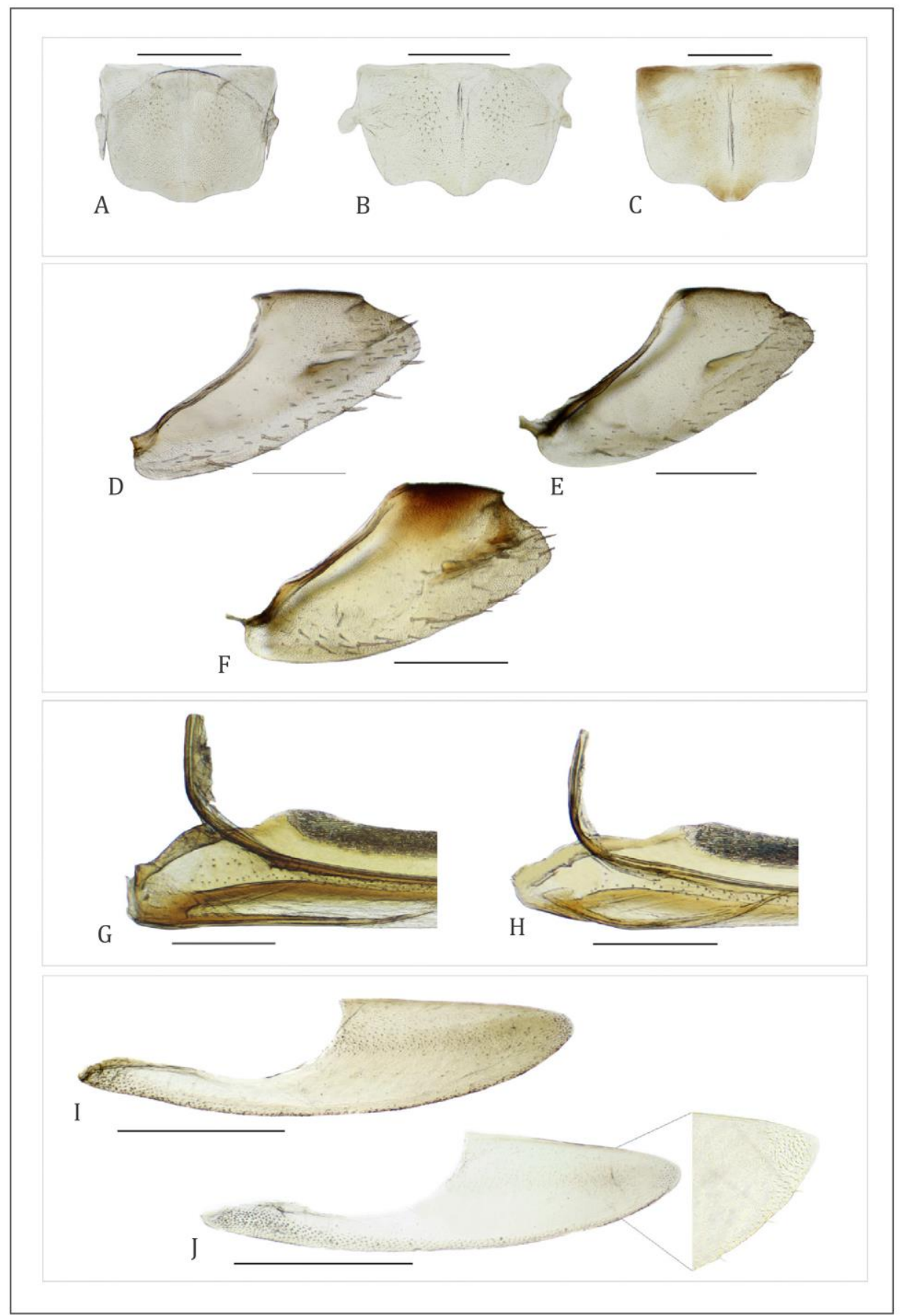

Figura 70. Estructuras diagnósticas de la genitalia de la hembra de las especies de Syncharina Young. S. argentina (Berg): Esternito VII (A), Pigóforo (D), porción basal de la valva I (G), gonoplaca con detalle del ápice (J); S. lineiceps (Spinola): Esternito VII (B), Pigóforo (F), porción basal de la valva I (G); $S$. punctatissima (Signoret): Esternito VII (C), Pigóforo (E), porción basal de la valva I $(\mathrm{H})$, gonoplaca con detalle del ápice (J); S. linea: porción basal de la valva I (G), gonoplaca (I). Escala 0,5 mm: A-F, J, I; 0,3 mm: H, G. 


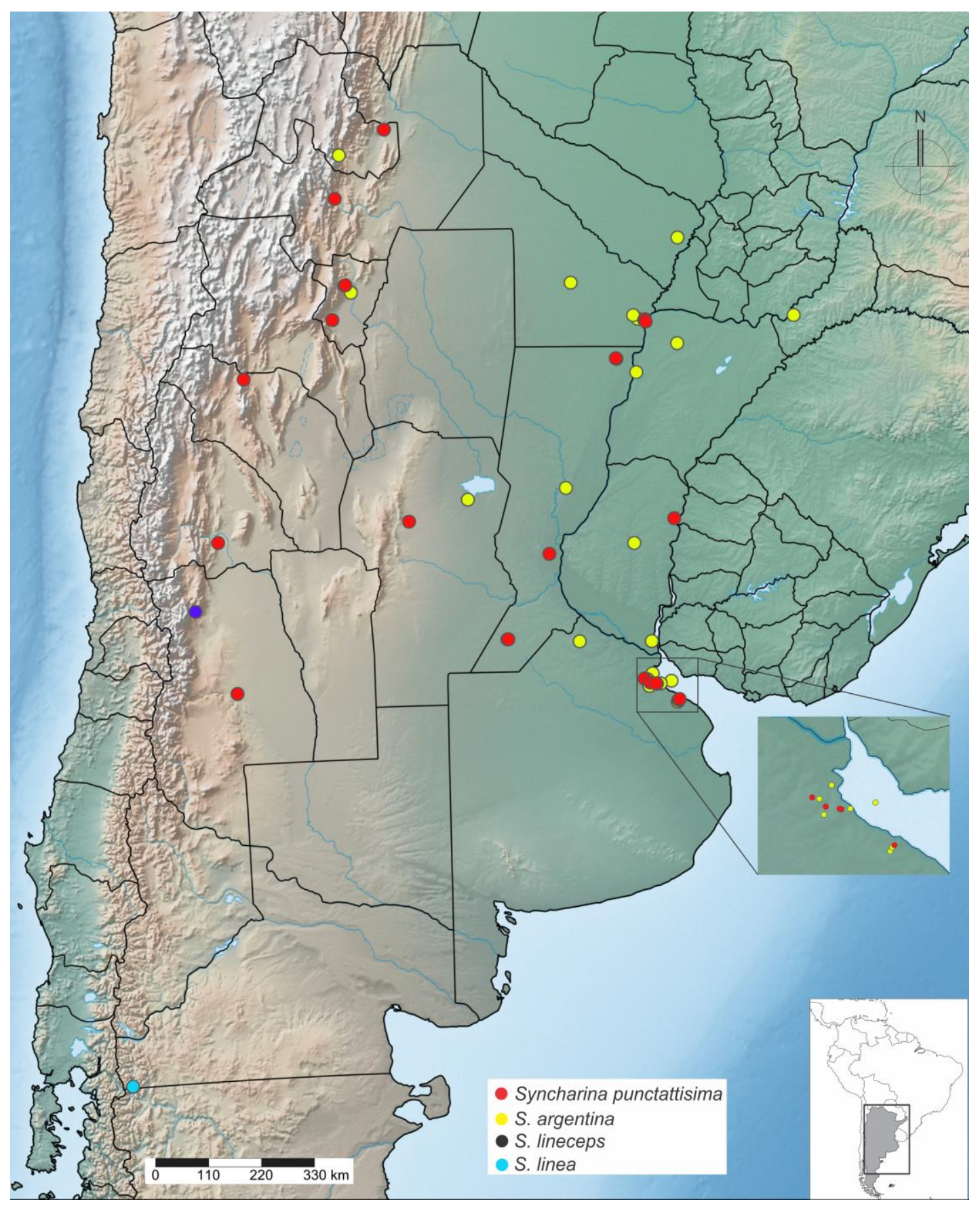

Figura 71. Distribución de las especies del género Syncharina Young en Argentina. 


\section{Clave para la identificación de los géneros de la tribu Cicadellini asociados a agroecosistemas citrícolas del norte de Argentina.}

1. Articulación fémoro-tibial de la pata posterior alcanzando el margen posterior del proepímero en posición de descanso (Figura 5A). Alas posteriores con la celda apical externa angosta, no alcanzando el margen costal. 2

-. Articulación fémoro-tibial de la pata posterior no alcanzando el margen posterior del proepímero en posición de descanso (Figura 13C). Alas posteriores con la celda apical externa ancha, casi alcanzando el margen costal. Bucephalogonia (Pág. 40)

2. Ocelos localizados marcadamente por detrás de la línea que pasa entre los ángulos anteriores de los ojos, separados del margen posterior de la cabeza por una distancia igual o ligeramente mayor que el diámetro ocelar Parathona (Pág. 129)

-. Ocelos localizados por delante, sobre o ligeramente por detrás de la línea que pasa entre los ángulos anteriores de los ojos, separados del margen posterior de la cabeza por una distancia mucho mayor que el diámetro ocelar..... 3

3. Alas anteriores parcial o totalmente hialinas 4

-. Alas anteriores mayormente coriáceas 5

4. Alas anteriores total o parcialmente hialinas, en los machos, las alas en reposo exponiendo el meron; alas posteriores con un lóbulo jugal conspicuo parcialmente separado del resto del ala por una escisión profunda Dilobopterus (Pág. 67)

-. Alas anteriores totalmente hialinas a translúcidas, nunca exponiendo el meron; alas posteriores con el lóbulo jugal poco desarrollado. Plesiommata (Pág. 143)

5. Alas anteriores con la celda anteapical mediana basalmente abierta Syncharina (Pág. 192) 
-. Alas anteriores con la celda anteapical mediana basalmente cerrada .6

6. Corona fuertemente deprimida en su parte media con el margen anterior subanguloso; carena dorsopleural ausente; alas anteriores con un plexo apical de venas Draeculacephala (Pág. 78)

-. Corona no deprimida en su parte media, margen anterior variable; carena dorsopleural completa o incompleta; alas anteriores sin un plexo apical de venas .7

7. Margen apical de las alas anteriores cóncavo, celda anteapical externa corta, de forma lenticular Diedrocephala (Pág. 60)

-. Margen apical de las alas anteriores convexo, celda anteapical larga, nunca lenticular. . .8

8. Coloración general castaña oscura 9

-. Coloración variable, nunca castaña oscura

9. Alas anteriores con pequeñas máculas pálidas; con tres celdas anteapicales Oragua (Pág. 118)

-. Alas anteriores sin máculas; con dos celdas anteapicales

Ciminius (Pág. 48)

10. Coloración general negra; transición corona-clípeo formando un ángulo agudo; superficie dorsal del pronoto, en vista lateral, aplanada continuando con el contorno de la cabeza y el mesonoto Balacha (Pág. 32)

-. Coloración general variable, nunca negra; transición corona-clípeo redondeada; superficie dorsal del pronoto, en vista lateral, sobresaliendo del contorno de la cabeza y el mesonoto .11

11. Patrón de coloración de las alas anteriores con bandas longitudinales paralelas 
-. Patrón de coloración de las alas anteriores variable, nunca con bandas longitudinales 13

12. Alas anteriores con bandas longitudinales negras, el par de bandas interno proyectado desde el ápice claval hasta ápice de la cabeza. Estilos del macho con lóbulo preapical Sibovia (Pág. 174)

-. Alas anteriores con bandas longitudinales color anaranjado y verde, no proyectadas sobre la cabeza. Estilos del macho sin lóbulo preapical Ferrariana (Pág. 82)

13. Coloración de las alas anteriores uniforme 14

-. Coloración de las alas anteriores variable, con máculas o bandas transversas, nunca uniforme 17

14. Alas anteriores de color ferruginoso; hileras setales 1 y 2 de la tibia posterior con setas irregularmente espaciadas con microsetas intercaladas Sonesimia (Pág. 181) -. Alas anteriores verdosas, de intensidad variable; hileras setales 1 y 2 de la tibia posterior dispuestas regularmente sin microsetas intercaladas .15

15. Placas subgenitales del macho con numerosas microsetas largas, similares a "pelos", macrosetas ausentes, o cuando presentes, dispuestas irregularmente Borogonalia (Pág. 37) -. Placas subgenitales del macho sin microsetas, con macrosetas uniseriadas 16

16. Pigóforo del macho con un par de procesos largos y estrechos que se originan en el margen ventral y se proyectan posteriormente o posterodorsalmente, con el ápice en "cepillo" (excepción: S. golbachi Young) Scopogonalia (Pág. 155) 
-. Pigóforo del macho sin procesos

Hortensia (Pág. 89)

17. Edeago corto, con el eje dorsal convexo

Macugonalia (Pág. 97)

-. Edeago de longitud variable, mayormente largo, con el eje dorsal cóncavo Pawiloma (Pág. 136)

\section{CONCLUSIONES}

En el presente capítulo se estudió desde el punto de vista taxonómico a los géneros de la tribu Cicadellini asociados a agroecosistemas citrícolas en la Argentina. De cada género se estudiaron todas las especies presentes en el país y se realizaron las siguientes contribuciones:

- Se estudiaron 37 especies de cicadelinos distribuídos en 18 géneros.

-Se amplió el conocimiento sobre la composición específica de los Cicadellini en agroecosistemas citrícolas del norte de Argentina, incrementando el número de especies asociadas de 30 a 35.

-Se registró por primera vez para la fauna argentina al género Borogonalia y a las especies Macugonalia moesta y Plesiommata corniculata.

-Se registró por primera vez a las especies Pawiloma victima y Syncharina punctatissima en Uruguay; y a Sibovia sagata y Syncharina argentina en Paraguay.

-Se aportaron nuevos caracteres para los géneros Bucephalogonia y Syncharina. Se describieron e ilustraron por primera vez de manera detallada caracteres diagnósticos de la genitalia de la hembra.

-Se confeccionó una clave para la identificación de los 18 géneros de Cicadellini estudiados. Para aquellos con más de una especie registrada en la Argentina se confeccionó una clave para la identificación de las mismas.

-Se aportaron nuevos caracteres morfológicos (de la genitalia del macho y/o de la hembra) y/o del patrón de coloración a las diagnosis de 26 especies.

-Por primera vez se describieron e ilustraron en detalle los caracteres de la genitalia de la hembra de 28 especies: Bucephalogonia xanthophis, Ciminius platensis, C. yana, Diedrocephala bimaculata, Dilobopterus costalimai, D. dispar, Ferrariana 
trivittata, Hortensia similis, Macugonalia cavifrons, M. leucomelas, M. moesta, M. sobrina, Oragua discoidula, O. triplehorni, Parathona gratiosa, Pawiloma victima, Plesiommata corniculata, P. mollicella, Scopogonalia altmanni, S. golbachi, S. penicula, Sibovia sagata, Sonesimia dimidiata, S. grossa, Syncharina argentina, S. linea, S. lineiceps, S. punctatissima.

-Se amplió el registro de distribución para 30 especies.

-Se registraron 12 nuevas asociaciones de plantas hospedadoras.

-Se registraron nuevos enemigos naturales para dos especies: Oragua triplehorni y Macugonalia cavifrons.

-Para cada una de las especies estudiadas se adicionó información complementaria acerca de aspectos taxonómicos, se confeccionaron mapas de distribución geográfica y se reunió toda la información conocida sobre su biología, enemigos naturales e importancia fitosanitaria. 


\section{Capítulo III}

\section{Cicadellinae}

asociados

a

\section{agroecosistemas citrícolas del}

\section{norte de la Argentina}

\section{INTRODUCCIÓN}

\section{Caracterización de los cítricos y la citricultura en la Argentina}

El cultivo de los cítricos se remonta a más de 4000 años, y actualmente, constituye el cultivo frutal de mayor importancia económica en el mundo. En términos botánicos pertenecen al orden de las geraniales, familia de las rutáceas, y a los géneros Citrus, Fortunella y Poncirus. El género Citrus, el más importante de los tres, está compuesto por plantas de mediano a gran desarrollo, con hojas perennes y generalmente glabras; las numerosas especies de este género provienen de las zonas tropicales y subtropicales de Asia y del archipiélago Malayo; una vez en América y desde el Caribe y Brasil (adonde llegaron primero), se extendieron por todo el continente. Actualmente, se desarrollan en casi todas las regiones del mundo dentro de las zonas subtropicales y tropicales delimitadas por la línea de $40^{\circ}$ de latitud $\mathrm{N}$ y $\mathrm{S}$ (Fabiani et al. 1996). 
Los principales productores de cítricos son Brasil, China y Estados Unidos. En la Argentina, que ocupa el octavo lugar, la producción de cítricos abarca casi todo el año y representa una de las actividades frutícolas más importantes para el país. En la actualidad hay más de 140.000 hectáreas plantadas de las cuales 133.000 están en las principales provincias productoras (Informe del sector citrícola en la Argentina 2014/2015-CFI). Su posición geográfica le permitiría convertirse en un proveedor destacado de fruta cítrica fresca durante el verano boreal; sin embargo, enfermedades y plagas cuarentenarias limitan el acceso de los cítricos argentinos a los mercados externos. En los últimos años hubo una apertura del mercado de EE.UU. a cítricos provenientes del NOA por el reconocimiento de que esta región estaba libre de enfermedades y cuenta con bajos niveles de residuos de plaguicidas en la fruta. Por el contrario, la situación en el NEA es más comprometida por sus problemas fitosanitarios donde presenta enfermedades cuarentenarias como la CVC, planteando una marcada dificultad para cumplir con los protocolos de exportación. Geográficamente, en la Argentina la producción citrícola se halla localizada en distintas áreas con diferentes condiciones ecológicas y económicas que pueden ser agrupadas en dos grandes regiones: Litoral y Noroeste, en donde posee un gran impacto socioeconómico. En la región Litoral hay cuatro subregiones: la de Buenos Aires, con la producción concentrada en San Pedro, b) la del Río Uruguay: Concordia y Federación en la provincia de Entre Ríos y Monte Caseros en la provincia de Corrientes, c) la de Bella Vista en la provincia de Corrientes y d) la de la provincia de Misiones. Las principales especies cultivadas en la región del NEA son naranja dulce (C. sinensis (L.) Osb.) y mandarina (C. reticulata Blanco) utilizadas para consumo fresco, industria y exportación. En el NOA, se concentra gran parte de la producción de limón (Citrus limon (L.) Burm.) en la provincia de Tucumán, y de variedades tempranas de naranja, mandarina y pomelo cuyas plantaciones se concentran en Salta, Jujuy y parte de Tucumán. Fuera de las regiones consideradas, la importancia de la producción cítrica es reducida. Sin embargo, existen áreas donde la actividad tiene importancia local y en el futuro podría alcanzar un desarrollo que les permita adquirir significación nacional. En ese sentido se destacan: las provincias de Catamarca, Chaco y Formosa (Fabiani et al. 1996). 


\section{Aspectos fitosanitarios en la citricultura argentina y la Clorosis Variegada de los Cítricos (CVC)}

Las enfermedades que afectan a los cítricos en la Argentina representan uno de los factores más limitantes de la producción y comercialización. Una de ellas, es la "Clorosis Variegada de los Cítricos" (CVC), que desde su descubrimiento en la década del 80' en Brasil, se convirtió en uno de los problemas más graves para la citricultura. Actualmente, está presente en Costa Rica, Brasil, Paraguay y Argentina (Aguilar et al. 2005, Brlansky et al. 1991, Coletta \& Machado 2003, Hartung et al. 1994,), en donde tiene una alta incidencia en el NEA y representa un problema potencial para el NOA. El agente causal de esta enfermedad es la bacteria Xylella fastidiosa subsp. pauca (Xf) (Xanthomonadaceae) (Lee et al. 1993) la cual es transmitida por hemípteros auquenorrincos principalmente por cicadélidos de la subfamilia Cicadellinae (Redak 2004). Esta bacteria se aloja en los vasos xilemáticos de un amplio número de hospedadores (359 especies de plantas) tanto cultivados como silvestres (MarcoNoales et al. 2017). Los árboles afectados muestran síntomas como manchas cloróticas amarillas en la superficie adaxial de las hojas que se corresponden con lesiones gomosas amarronadas de la superficie abaxial; los frutos son mucho más pequeños de lo normal y extremadamente ácidos; una vez que la planta es afectada, su ritmo de crecimiento disminuye, las ramas tiernas y maduras mueren y el dosel se empobrece, sin embargo los árboles enfermos no mueren. Esta enfermedad afecta mayormente a las variedades de naranja, pero también fue detectada propagándose en portainjertos de lima Rangpur, mandarina Cleopatra y limón Volkamer en Brasil (https://nature.berkeley.edu/xylella/biology/pathogen/xylella-fastidiosa-biology/).

En la Argentina, la CVC fue registrada sólo en áreas citrícolas productoras del litoral: en las provincias de Misiones (Agostini 1993, de Coll 1996, de Coll et al. 2000a, 2000b), Corrientes (Beltrán et al. 2004) y Entre Ríos, afectando plantas de naranja dulce y mandarina (Costa et al. 2009). En Misiones y Entre Ríos, fueron realizadas investigaciones sobre la diversidad de auquenorrincos y sus enemigos naturales en agroecosistemas citrícolas (de Coll et al. 2000a, Dellapé 2013, Paradell et al. 2000, Remes Lenicov et al. 1999) y se realizó la detección de la bacteria en varias especies de cicadelinos (de Coll et al. 2000a, Dellapé et al. 2016). En la provincia de Corrientes, sólo se cuenta con un relevamiento preliminar que permitió conocer la 
diversidad de auquenorrincos sólo sobre las plantas citrícas (Beltrán et al. 2004). En el NOA, existen pocos estudios sobre la diversidad de Cicadellinae presente en esta región, y sólo se cuenta con trabajos que dan cuenta de la presencia de algunas especies sobre cultivos de maíz (Paradell et al. 2001, 2005) siendo totalmente nula la información disponible si nos limitamos a agroecosistemas citrícolas.

La gravedad de los daños causados por $X f$ debe ser evaluada, no solo en función de las plantas afectadas o las mermas de producción, sino también por las pérdidas a la industria que utiliza como materia prima los frutos afectados. También se deben tener en cuenta las pérdidas medioambientales en especies forestales, en plantas ornamentales, en puestos de trabajo directos e indirectos, y otros factores sociales difíciles de evaluar. Además, la enfermedad causa también un daño indirecto en las áreas que producen material de plantación, ya que se prohíbe la exportación desde lugares donde está presente la bacteria (Marco-Noales et al. 2017).

\section{Xylella fastidiosa y sus vectores. Situación en Argentina.}

Tal como su nombre específico lo denota esta bacteria habita en el xilema de las plantas hospedadoras (Xylella) y tiene un crecimiento muy lento en los medios de cultivo microbiológicos (fastidiosa). Es transmitida de forma persistente por distintas especies de insectos suctopicadores que se alimentan del xilema de los hospedadores a los que afecta. De hecho, $X f$ coloniza dos hábitats muy distintos: el xilema de las plantas y el intestino anterior (precibario, cibario y esófago) de los insectos alimentadores de savia xilemática que son vectores de la bacteria y necesarios para su diseminación (Figura 70) (Almeida \& Nunney 2015). Hasta el presente, se describieron cuatro grupos genéticos que actualmente se clasifican como subespecies: fastidiosa, pauca, multiplex y sandyi (Schaad et al. 2004, Schuenzel et al. 2005). 


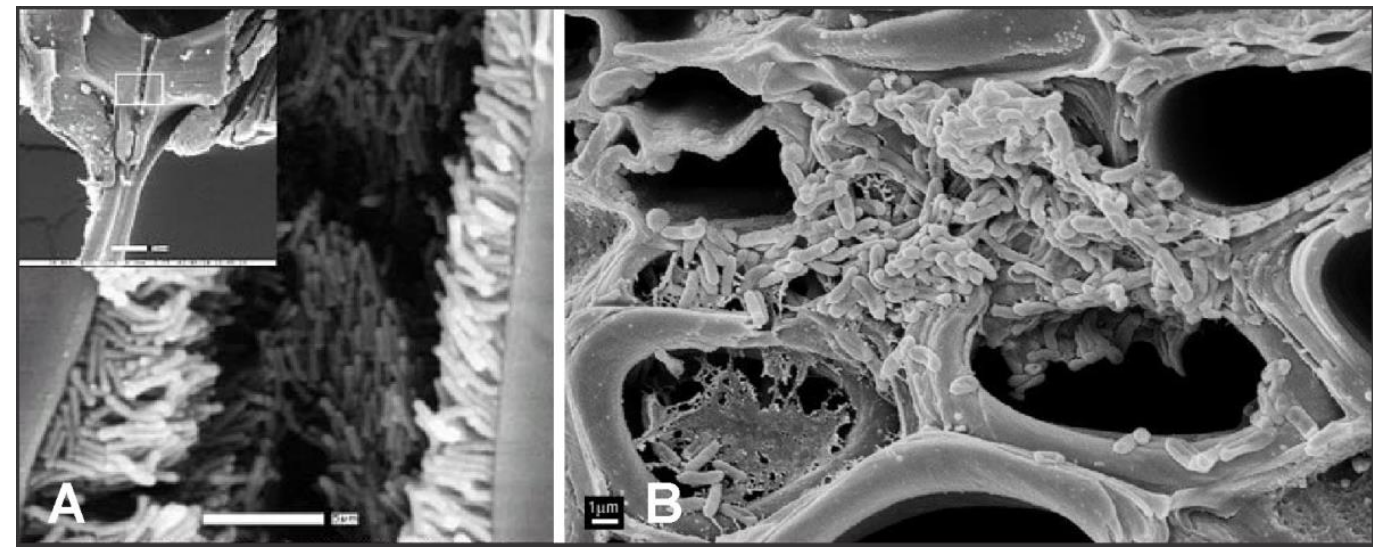

Figura 70. Detalle de Xylella fastidosa en el precibario de un Cicadellinae (A) y en los vasos xilemáticos (B) (tomado de Alves et al. 2008)

Los síntomas que origina la bacteriosis dependen de la combinación específica de la planta hospedadora y la cepa de la bacteria. A medida que ésta invade los vasos del xilema, bloquea el transporte de nutrientes minerales y agua. Generalmente, los síntomas incluyen el denominado quemado, escaldado, chamuscado foliar o necrosis marginal, marchitamiento del follaje, defoliación, clorosis o bronceado en el margen de la hoja y enanismo de la planta (Janse \& Obradovic 2010). Además, al ser muchos de estos síntomas poco específicos, pueden confundirse con los causados por otros factores bióticos o abióticos (otros patógenos, estreses ambientales, deficiencias de agua, salinidad, contaminantes del aire, problemas nutricionales, quemaduras de sol, etc.) (Marco-Noales et al. 2017).

La mayoría de los artrópodos vectores de patógenos a las plantas son insectos y, dentro de este grupo, los hemípteros constituyen el orden con el mayor número de vectores de patógenos (Harris \& Maramorosch 2013). Todos los vectores de $X f$ son hemípteros pertenecientes al suborden Cicadomorpha. En concreto, especies pertenecientes a las superfamilias Cercopoidea, Cicadoidea y Membracoidea han sido identificadas como vectores de $X f$. Dentro de este último grupo, los vectores pertenecientes a la subfamilia Cicadellinae (Cicadellidae), llamados en inglés «sharpshooters», son los más conocidos a nivel mundial. Estos insectos, son organismos que se caracterizan por poseer una potente musculatura en la cabeza que les permite succionar el xilema a niveles altos de tensión negativa (Redak et al. 2004), de manera que la bacteria puede ser transportada desde los vasos del xilema hasta su 
aparato bucal, donde esta se instala y multiplica. Actualmente, 40 especies de Cicadellinae son vectores confirmados (Redak et al. 2004, Yamamoto et al. 2007, Lopes 2017) de los cuales 13 están presentes en Sudamérica y 10 fueron registrados en el litoral argentino asociados a plantaciones de naranja afectados por la CVC (Beltrán et al. 2004, Dellapé et al. 2016, Redak et al. 2004, Remes Lenicov et al. 1999, Lopes 2017). En referencia a esta enfermedad, se conocen 13 especies vectoras en Brasil pertenecientes a la subfamilia Cicadellinae (Fundecitrus 2007, Lopes 2017), de las cuales Acrogonia citrina (Marucci y Cavichioli), Bucephalogonia xanthophis (Berg), Dilobopterus costalimai (Young), Macugonalia leucomelas (Walker) y Oncometopia facialis (Signoret) son considerados, hasta el momento, los cinco vectores clave en la propagación de la enfermedad (Paiva Branco et al. 1996).

Considerando que la CVC es una amenaza potencial cuando el vector adecuado está presente (Damsteegt et al. 2006) y la importancia de los Cicadellinae en la transmisión de $X f$, resulta indispensable conocer la identidad de las especies potencialmente vectoras en cada región, su distribución espacial y temporal en los cultivos afectados, así como el conocimiento de los enemigos naturales asociados que en su conjunto permitirán determinar las estrategias de manejo adecuadas.

\section{Enemigos naturales de Cicadellinae y su importancia para el MIP de estos insectos.}

Tradicionalmente, el control de chicharritas es encarado desde dos frentes: control químico del vector y uso de variedades resistentes. Actualmente, los tratamientos químicos están siendo sustituídos al menos de manera incipiente por técnicas de control biológico (Nielson 1985, Triapitsyn et al. 1998) en los que los enemigos naturales son un factor clave (Denno \& Roderick 1990, Döbel \& Denno 1993).

En general, las chicharritas no son atacadas por patógenos virales, bacterias y/o protozoos, debido a sus hábitos suctopicadores, y existen pocos reportes de hongos patógenos que los afectan (McCaber \& Soper 1985, Toledo et al. 2006); asimismo, existen algunas menciones de nematodes parásitos de la familia Mermithidae (Benrey \& Lamp 1993). A escala mundial, se conoce una gran diversidad de invertebrados que actúan como depredadores y parasitoides de chicharritas, sin embargo, estudios 
realizados hasta el presente, determinan que solo algunos taxa juegan un papel importante en la dinámica de sus poblaciones (Döbel \& Denno 1993). Sin lugar a dudas, entre todos los antagonistas, los parasitoides (oófilos, y de larvas y adultos) son los más estudiados a nivel mundial por su potencial como agentes de biocontrol (Cronin \& Strong 1993). En la Argentina las referencias a parasitoides de larvas y adultos son escasas, muchas de índole taxonómica y otras hacen aportes sobre su biología, mencionándose especies de Dryinidae (Hymenoptera), Pipunculidae (Diptera) y Strepsiptera (Virla \& Luft Albarracín 2012). Los parasitoides de huevos han sido los más investigados como agentes de control biológico comprendiendo especies de Hymenoptera de las familias Trichogrammatidae, Mymaridae, Eulophidae y Aphelinidae; Waloff \& Thompson (1980) y Denno \& Roderick (1990) demostraron que la mortalidad ocasionada por los parasitoides de huevos constituye el "factor clave" en la dinámica poblacional de algunas especies de chicharritas.

En la Argentina, los aportes al conocimiento de los parasitoides de huevos se focalizan mayormente en los parasitoides oófilos de Dalbulus maidis DeLong [in Wolcott], vector del espiroplasma causal del achaparramiento del maíz (CSS), y de chicharritas de la tribu Proconiini (de Coll et al. 2000b, Logarzo et al. 2004, Triapitsyn et al. 2007, Virla et al. 2005, 2008, 2009,), siendo los aportes sobre parasitoides de Cicadellini prácticamente nulos.

\section{Caracterización de los estados inmaduros de la subfamilia Cicadellinae y su implicancia en el manejo de estos insectos.}

La descripción de los estados inmaduros es una laguna en el conocimiento de la biología de los Cicadellinae. En América, particularmente en la región neotropical, se describieron las larvas de unas pocas especies de cicadelinos y principalmente de proconinos: Cuerna costalis (Fowler) (Turner \& Pollard 1959), Oncometopia facialis (Signoret) y Acrogonia sp. (Marucci et al. 2000); en tanto que de la tribu Cicadellini sólo fueron descriptas las larvas de Dilobopterus costalimai Young (Marucci et al. 2000). En dicho estudio, los cinco estadios larvales fueron descriptos, caracterizados morfológicamente e ilustrados y se incluye una clave para el reconocimiento de los diferentes estadios, otra para la diferenciación de machos y hembras a partir del 
tercer estadio y una tercera para la identificación de las larvas del quinto estadio de las tres especies estudiadas. Sin duda, las contribuciones referidas a los estados preimaginales son importantes a la hora de comprender problemas asociados a la taxonomía, morfología y a la entomología agrícola (Decoursey \& Esselbaugh 1962). En los estudios poblacionales el reconocimiento y distinción de los especímenes inmaduros es también de gran importancia ya que permiten prever cambios en el tamaño de la población, procesos de regulación y construcción de tablas de vida (Marucci et al. 2000).

Las larvas de los cicadélidos son morfológicamente similares al adulto; en la cabeza los mismos escleritos están presentes y se localizan de la misma manera (Figura 71A), lo que es más evidente en grupos primitivos como en los Cicadellinae (Dmitriev 2010). El tórax ofrece pocos caracteres diagnósticos, pero el desarrollo relativo de los esbozos alares permite diferenciar fácilmente los estadios larvales (Figura 71B) (Vilbaste 1982), sin embargo puede presentarse alguna dificultad para la separación del primero y segundo estadios debido al tamaño y desarrollo limitado de los esbozos alares (Wilson \& Claridge 1991). En el abdomen el carácter diagnóstico más útil es la quetotaxia. Los grupos primitivos tienden a tener abdómenes glabros considerándose el desarrollo de la quetotaxia un proceso adaptativo, tal vez de formas más arborícolas. Sin embargo en algunas subfamilias como en los Cicadellinae, es posible encontrar la transición desde larvas prácticamente glabras (Hortensia similis (Walker)) a aquellas con una cubierta densa de setas (Tapajosa rubromarginata (Signoret)). Finalmente, los sexos son fácilmente reconocibles en los últimos estadios. En las hembras, la sutura entre los lóbulos del pigóforo se extiende hasta el segmento pregenital; en los machos es más corta (Figura 71C). 


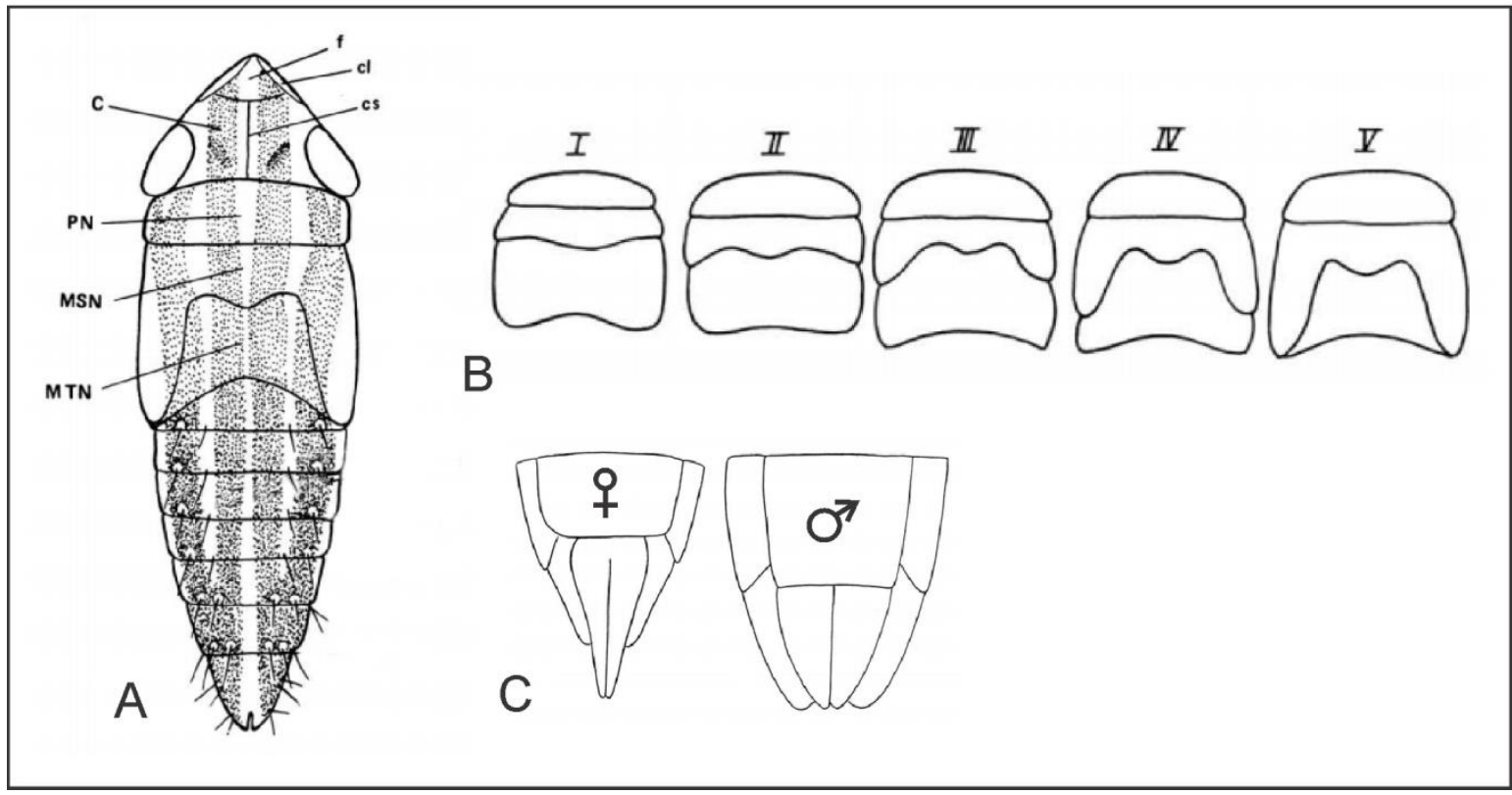

Figura 71. Caracteres externos de una larva de Cicadellidae (A), desarrollo de los esbozos alares: $\mathrm{I}-\mathrm{V}=$ =estadios larvales (B), extremo posterior, en vista ventral, del último estadio larval (C) Referencias: C, corona; Cl, clípeo; CS, sutura coronal; f, frente; MSN, mesonoto; MTN, metanoto; PN, pronoto. Figura (A) y (B) tomada de Vilbaste (1971); figura (C) adaptada de Vilbaste (1982).

La identificación del último estadio larval a campo, junto con el conocimiento del ciclo de vida de las distintas especies son herramientas que podrían ser utilizadas para prever futuros cambios en las poblaciones. Es una ventaja para los programas de control de plagas la capacidad de identificar los estadios inmaduros de muchas especies (Wilson \& Claridge 1991), principalmente en el caso de insectos vectores cuyos estados larval y adulto son capaces de transmitir el fitopatógeno (Marucci et al. 2000, Purcell \& Finlay 1979).

El objetivo de éste capítulo, fue estudiar la taxocenosis y fluctuación estacional de los Cicadellinae presentes en agroecosistemas citrícolas del NEA y NOA. Para ello se plantearon los siguientes objetivos específicos: en el NEA: 1) estudiar la composición específica de cicadelinos presentes en agroecosisemas citrícolas de la provincia de Corrientes, 2) analizar la fluctuación estacional de las especies de cicadelinos predominantes en plantas cítricas, con y sin riego, y en la vegetación espontanea asociada al cultivo, 3) describir los estados inmaduros de las especies predominantes, y 5) registrar la presencia de sus enemigos naturales; en el NOA: 1) estudiar la 
composición específica de cicadelinos presentes en agroecosistemas citrícolas de las provincias de Salta (Yatasto) y Tucumán (Lules), 2) generar claves de identificación que reúnan a las especies asociadas a los agroecosistemas de las principales áreas productoras estudiadas.

\section{MATERIALES Y MÉTODOS}

\section{I. Área experimental}

Los muestreos se realizaron en una plantación de Citrus sinensis (L.) Osb. variedad Valencia Late, injertada sobre Rangpur, afectada por la CVC (Figura 72) y la vegetación espontánea (Figura 73), ubicada en la Estación Experimental Agropecuaria del INTA Bella Vista, en la provincia de Corrientes (28.45오, 58.98으, 60m.snm). La plantación constaba de 784 plantas distribuidas en $20244 \mathrm{~m}^{2}$ y estaba dividida en dos tratamientos: con riego (riego por goteo, con fertirriego) y sin riego (fertilización tradicional). Cada tratamiento constaba de dos réplicas. El manejo del suelo era mínimo, con cubierta vegetal natural abundante y heterogénea.

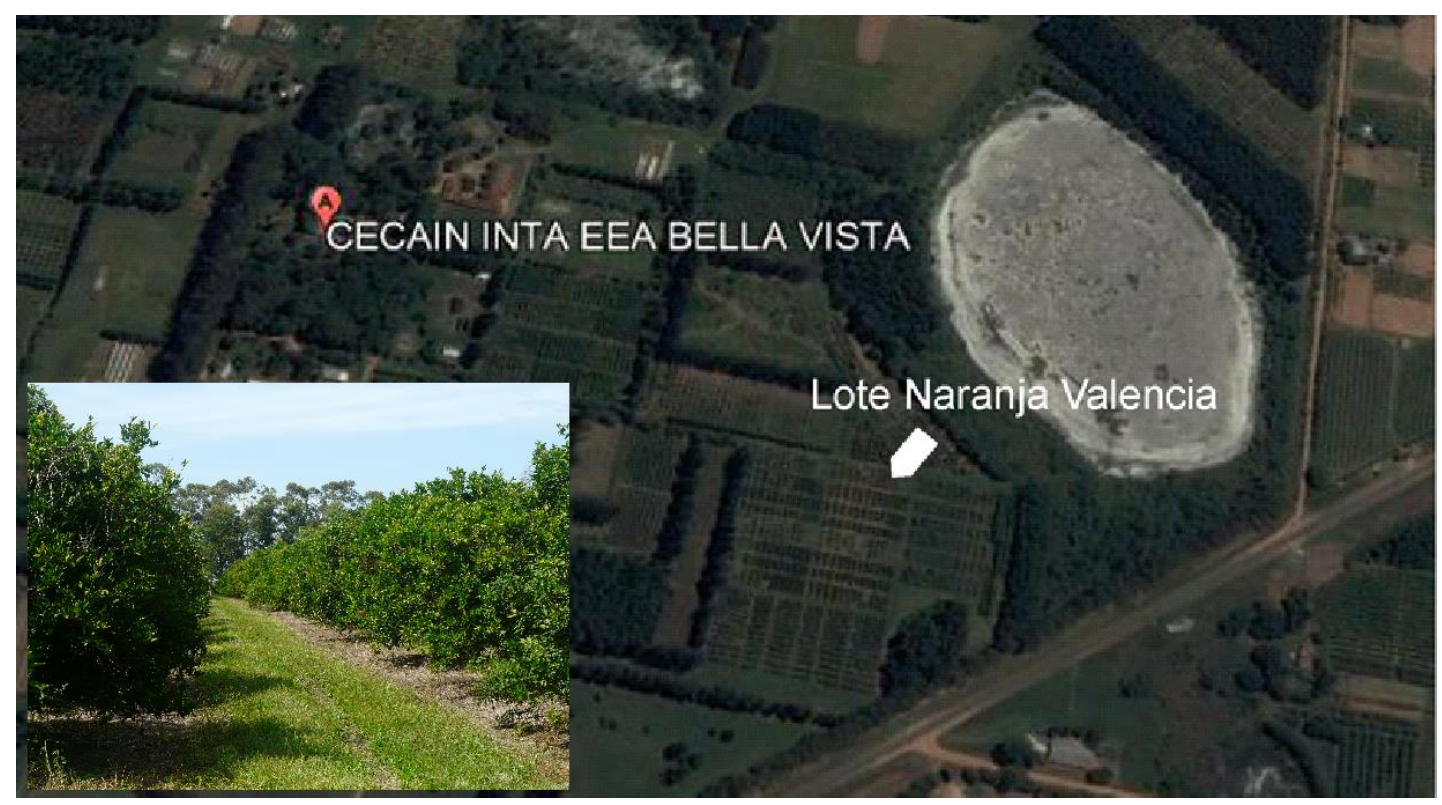

Figura 72. Sitio de muestreo en la EEA INTA, Bella Vista, Corrientes. 
Se realizó un herbario estacional durante los dos años de muestreo para conocer las plantas espontáneamente asociadas al cultivo. Cada planta se colectó manualmente conteniendo raíces, tallos, hojas y la flor (cuando estaba presente). La identificación del material vegetal recolectado se realizó en el herbario del Museo de La Plata a cargo de la Dra. Laura Iharlegui y la Lic. María Eugenia Cano.

En la plantación estudiada la vegetación espontánea fue muy diversa y estuvo compuesta principalmente por poáceas (Eustachys distichophylla (Lag.) Nees, Chascolytrum erectum (Lam.) Desv., Digitaria sanguinalis (L.) Scop., Cynodon dactylon (L.) Pers. Syn. Pl, Melinisrepens (Willd.) Zizka, Bromus unioloides Humb., Bonpl et Kunth, Cenchrusechinatus L., Chascolytrum erectum (Lam.) Desv., Setaria parviflora (Poir.) Kerguélen, Deyeuxia alba subesp. alba J. Presl. Reliq. Haenk, Steinchisma spathellosa (Doll) Renvoize, Cenchrus echinatusL., Melinis repens(Willd.) Zizka, Paspalum notatum Flüggé) y las compuestas (Galinsoga parviflora Cav., Praxelis clematidea R.M. King \& H. Rob., Senecio grisebachii var. grisebachii Baker, Facelis retusa (Lam.) Sch. Bip., Bidens pilosa var. minor (L.). También se identificaron ejemplares de Eryngium L. (Apiaceae), Acicarpha tribuloides Juss. (Caliceraceae), Silene antirrhina L. (Cariophyllaceae), Commelina erecta var. angustifolia (Michx.) Fernald (Commelinaceae), Hyptis mutabilis (Rich.) Briquet (Labiaceae), Stachys arvensis L. (Lamiaceae), Desmodium incanum De Candolle (Leguminosa), Oxalis debilis var. corymbosa (DC.) Lourteig (Oxalidaceae), Portulaca cryptopetala Speg (Portulacacea), Richardia brasiliensis Gomes (Rubiaceae), Parietaria judaica L. (Urticaceae) (Figura 73). 


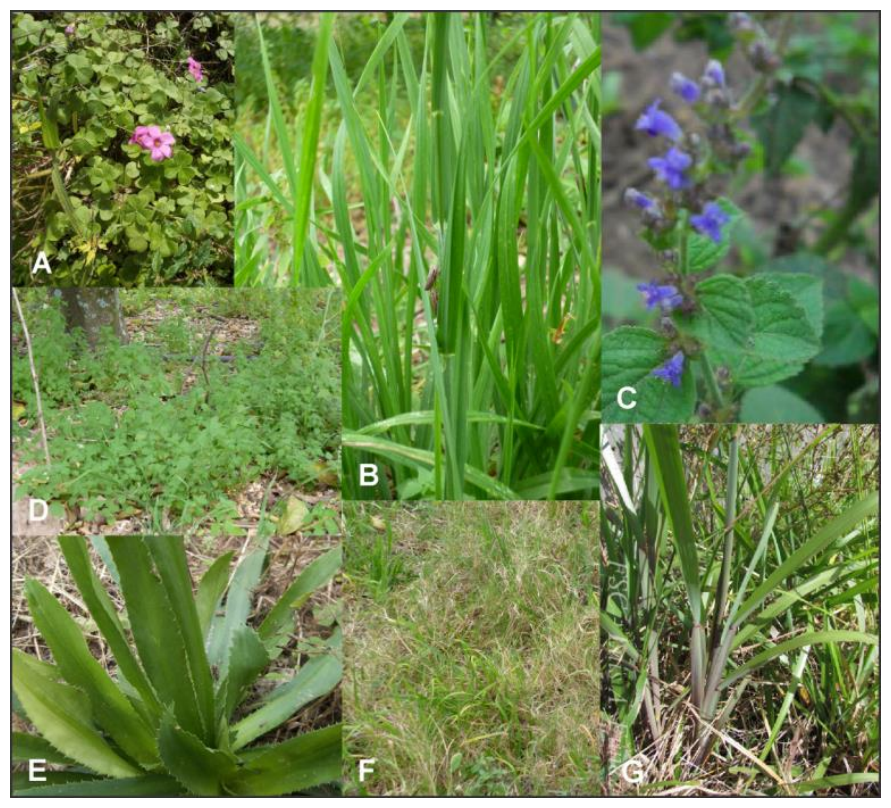

Figura 73. Vegetación espontánea circundante a la plantación de naranja Valencia en la EEA INTA Bella Vista, Corrientes. Oxalis debilis var. corymbosa (A), Digitaria sanguinalis (L.) (B), Hyptis mutabilis (C), Parietaria judaica (D), Eryngium (E), Cynodon dactylon (F), Cenchrus echinatus (G).

\section{Metodología de captura de los insectos}

Los muestreos se realizaron durante tres años consecutivos: desde IX/2013 a IX/2016. Los dos primeros años se realizó un monitoreo de manera continua a través de trampas adhesivas amarillas en los árboles cítricos, y se muestreó una vez por mes la vegetación espontanea asociada al cultivo con red entomológica de arrastre. Durante el último año (IX/2015-IX/2016) se realizó un muestreo por estación.

Para colectar los insectos se utilizaron tres métodos diferentes según la vegetación a muestrear:

-Los muestreos sobre los árboles cítricos se realizaron con trampas adhesivas amarillas de $25 \mathrm{~cm} \times 12,5 \mathrm{~cm}$ (Figura 74B) ubicadas en el sector nordeste de los árboles a 1,6 $\mathrm{m}$ de altura. Se colocaron un total de 32 trampas habiendo aproximadamente 1 trampa cada 9 plantas (8 trampas por cada tratamiento, 4 por réplica). Se consideró cada trampa adhesiva como una unidad de muestreo. Las trampas fueron reemplazadas mensualmente durante los dos años de muestreo (colectándose un total de 384 muestras). En el momento del reemplazo, las trampas fueron envueltas individualmente en papel film para evitar que se adhieran entre sí. 
-Los muestreos sobre la vegetación espontánea se realizaron con red entomológica de arrastre (Figura 74A). Se extrajeron 16 muestras al azar por fecha de muestreo: 8 por tratamiento (4 por réplica). También se extrajo una muestra por cada borde (N, S, E, O). Para las capturas se utilizó un copo de $30 \mathrm{~cm}$ de diámetro; cada muestra estuvo compuesta por 30 golpes sucesivos de red, excepto en los bordes en los que se realizaron 100 golpes. Dichas unidades fueron estimadas en muestreos preliminares siguiendo el método de frecuencias acumuladas. Todo el material recolectado se preservó en etanol 70\% en frascos de plástico debidamente rotulados hasta su recuento e identificación en el laboratorio.

Con el método de muestreo utilizando trampas adhesivas amarillas no se puede afirmar que las chicharritas capturadas estuviesen establecidas en las plantas cítricas ya que el color amarillo es muy atractivo para estos insectos y las trampas podrían atrapar en vuelo a cicadelinos que estuvieran en otras plantas; para descartar este sesgo y complementar el muestreo con las trampas cromáticas y la red entomológica, se realizaron muestreos con la metodología de golpeo sobre las plantas cítricas y observación visual directa en los árboles y la vegetación asociada. En cuatro plantas cítricas de cada réplica ( 8 muestras por tratamiento), elegidas al azar, se realizaron 10 golpes en el dosel para que los insectos presentes en el mismo cayeran sobre un "paraguas" de tela blanca desde donde fueron recolectados con aspirador manual y colocados en frascos de vidrio con etanol 70\%. La unidad de muestra para la observación visual directa tanto en los cítricos como en la vegetación espontánea fue de 10 minutos de observación en cuatro plantas de naranja y en 4 puntos de la vegetación asociada, tomadas al azar, en cada réplica. Los insectos observados fueron recolectados con aspirador manual (Figura 74C) y conservados en etanol $70 \%$. Ambas metodologías se realizaron en 4 oportunidades durante el primer año de muestreo (una vez por período estacional).

\section{Conservación y preparación de los insectos capturados. Identificación de los} especímenes.

Todo el material recolectado fue acondicionado en el laboratorio de Entomología de la EEA INTA Bella Vista (Figura 74D) y posteriormente transportado a la División Entomología de la Facultad de Ciencias Naturales y Museo (UNLP) para su identificación. Allí, los ejemplares fueron retirados de las trampas amarillas con 
bencina, identificados y posteriormente conservados en etanol $70 \%$ en frascos debidamente rotulados. La observación e identificación de los especímenes se realizó con microscopio estereoscópico. Para la identificación específica se les seccionó el abdomen con agujas entomológicas y cada uno por separado, fue colocado en un vaso de precipitado con hidróxido de potasio $10 \%$ caliente durante 5-7minutos (ejemplares macho) y en frío durante 24 hs (ejemplares hembra) para aclararlo. Posteriormente se lavó con agua destilada y sumergió en una gota de glicerina sobre un portaobjetos excavado para disectar y observar las estructuras genitales. La metodología realizada y la identificación taxonómica de los cicadelinos fue realizada siguiendo las claves y descripciones preexistentes de Young $(1968,1977)$, Takiya \& Mejdalani (2004), Dietrich (1994) y Leal et al. (2016).

Representantes de cada una de las especies recolectadas fueron depositados en la Colección Entomológica del Museo de La Plata (MLP).

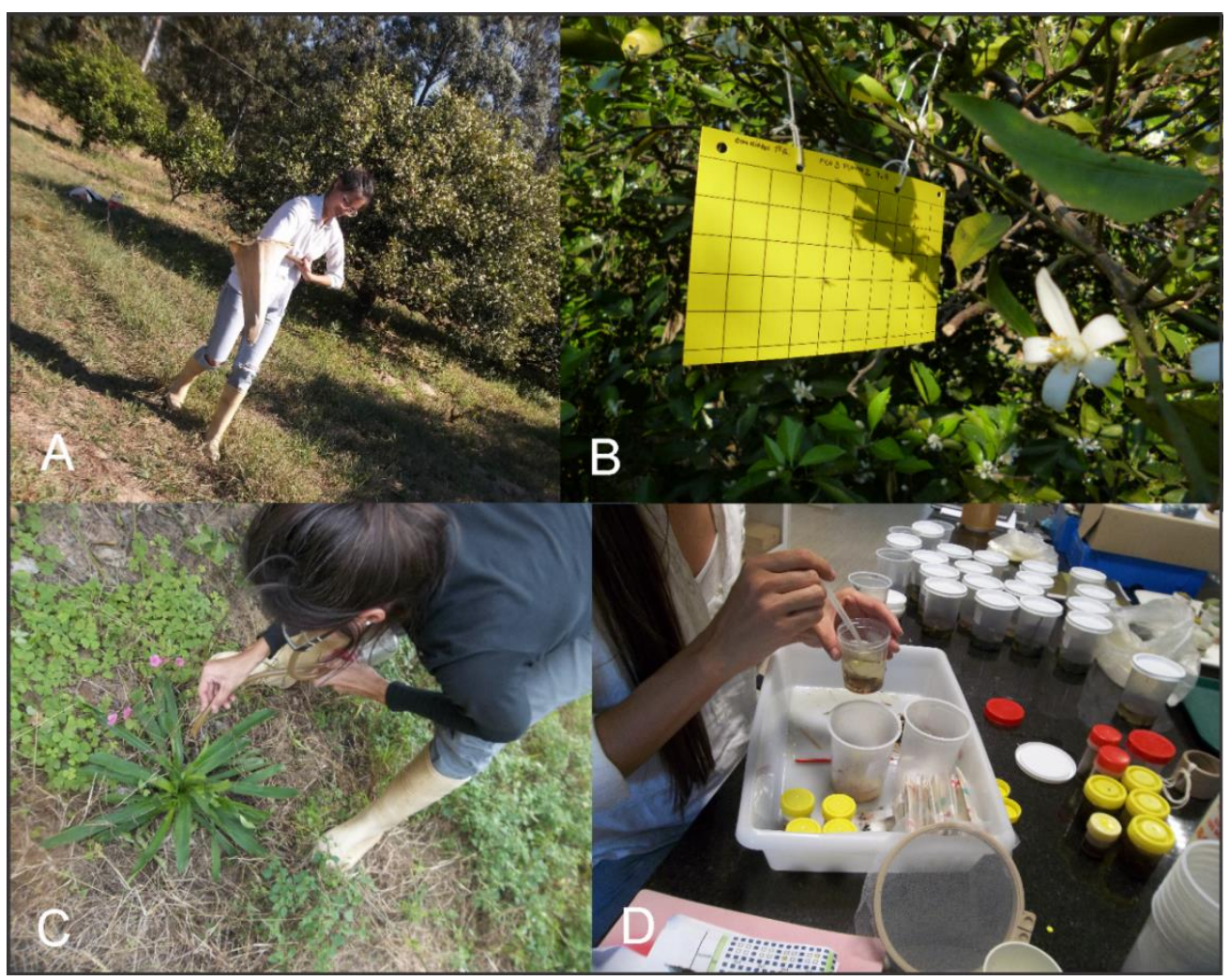

Figura 74. Técnicas de captura de los insectos. Red entomológica de arrastre (A), trampas adhesivas amarilla (B), aspirador manual (C), acondicionamiento en el laboratorio del material recolectado (D). 


\section{Análisis de los datos}

Los insectos recolectados se separaron por técnica de muestreo y por especie, registrándose los valores mensuales y totales de cada una. Debido a que cada técnica tuvo diferente intensidad de muestreo, los datos se analizaron por separado en dos categorías: por un lado, los datos obtenidos a partir de las trampas adhesivas amarillas, y por el otro, los datos recabados de la vegetación espontánea utilizando red entomológica de arrastre.

Análisis faunístico. Para cada categoría se calcularon los índices faunísticos de Abundancia, Constancia, Frecuencia y Dominancia utilizando el software INFOSTAT (Di Rienzo et al. 2012) (Silveira Neto et al. 1976). Los valores de abundancia y frecuencia de cada especie se testearon mediante la prueba de Shapiro-Wilks la cual evalúa si una muestra de la población está distribuida normalmente (Zar 1984). La hipótesis de normalidad fue rechazada y los Intervalos de confianza (IC) se calcularon mediante métodos no paramétricos (Bootstrap) utilizando 1000 réplicas.

Las especies que presentaron los mayores índices faunísticos de abundancia, constancia, frecuencia y dominancia fueron seleccionadas como predominantes (Silveira Neto et al. 1995).

La Abundancia es el número de especímenes por unidad de superficie que varía en espacio y tiempo (Silveira Neto et al. 1976); es determinada por la suma total de individuos recolectados de cada especie. Se calculó el intervalo de confianza de la media aritmética al 1\% y 5 \%de probabilidad, a través de la fórmula:

$$
I C=m \pm t \times S(m)
$$

IC = Intervalo de confianza

$\mathrm{t}=$ Valor de $\mathrm{t}$ al nivel de $5 \%$ y $1 \%$ con $\mathrm{n}-1 \mathrm{G} . \mathrm{L}$.

$\mathrm{m}=$ media de los especímenes capturados en el área

Se establecieron las siguientes clases de abundancia:

- Muy abundante (ma): cuando el número de individuos fue mayor al límite superior del IC1\%. 
- Abundante (a): cuando el número de individuos se encontró entre los límites superiores del IC5\% e IC1\%.

- Común (c): número de individuos situado dentro de los límites del IC5\%.

- Dispersa (d): número de individuos entre los límites inferiores del IC5\% e IC1\%.

- $\quad$ Rara (r): cuando el número de individuos fue menor al límite inferior del IC1\%

Constancia. Se refiere a la distribución de la especie en las capturas, o sea, la proporción de veces que una especie determinada está presente en relación al total de las capturas realizadas. Se calcula a partir de la fórmula:

$$
\mathrm{C}=\frac{P_{x} \times 100}{N} \quad \text { donde }
$$

$\mathrm{C}=$ constancia

$\mathrm{P}=$ Número de capturas conteniendo a la especie $\mathrm{X}$

$\mathrm{N}=$ Número total de capturas realizadas

De acuerdo con el resultado, se reconocen las siguientes categorías según Bodenheimer (1955):

- Constante (x): cuando la especie está presente en más de las 50\% de las capturas;

- Accesoria (y): cuando la especie está presente en un intervalo del 25-50\% de las capturas;

- Accidental (z): cuando la especie está presente en menos del 25\% de las capturas.

Frecuencia. Representa el porcentaje de especímenes de una especie, en relación al total de los especímenes recolectados. Este índice se calculó con la siguiente fórmula:

$$
\mathrm{F}=\frac{I}{T} \times 100 \quad \text { donde }
$$

$\mathrm{F}=$ Frecuencia $(\%)$

I= Número de especímenes de la especie $\mathrm{X}$ en el área

T= Número de especímenes recolectados en el área 
De acuerdo con los resultados obtenidos, se estableció una clase de frecuencia para cada especie, basándose en el intervalo de confianza (IC) a 5\% de probabilidad (Fazolin 1991). Las especies fueron distribuidas en las siguientes clases:

- Poco frecuentes (pf): cuando el porcentaje de individuos capturados fue menor que el límite inferior del IC a 5\% de probabilidad;

- Frecuente (f): cuando el porcentaje de individuos capturados se situó dentro del IC a $5 \%$ de probabilidad;

- Muy frecuente (mf): cuando el porcentaje de individuos capturados fue mayor que el límite superior del IC a 5\% de probabilidad.

Dominancia. Es la acción ejercida por los organismos dominantes de una comunidad. Dominante es un organismo que recibe el impacto del medio ambiente y lo modifica de una forma que puede producir la aparición o desaparición de otras especies (Silveira Neto et al. 1976). Para determinar la dominancia, se utilizó el método de Sakagami y Matsumura (1967), siguiendo lo descripto por Fazolin (1991). Este método considera como especies dominantes aquellas en las que la frecuencia excede el límite de dominancia calculados por la siguiente fórmula:

$$
\mathrm{LD}=\frac{1}{\mathrm{~S}} \times 100 \quad \text { donde }
$$

LD= límite de dominancia

$\mathrm{S}=$ número total de especies

Para las especies predominantes en las plantas cítricas se analizó y comparó su abundancia en los tratamientos con y sin riego con el fin de conocer sí el manejo del cultivo puede aumentar, disminuir o no afectar el número de insectos de cada población. Los datos se analizaron con ANOVA de dos factores con RÉPLICA anidado en TRATAMIENTO. Primariamente se corroboró la homogeneidad de varianzas (Test de Shapiro-Wilks).

La hipótesis de nulidad es que no hay diferencia entre las medias de abundancia de la especie $e_{i}$ entre tratamientos con y sin riego.

El modelo es:

ABUNDANCIA DE SPi $=\mu+($ ABUNDANCIA en cada tratamiento $)+$ (RÉPLICA anidada en TRATAMIENTO) + error experimental. 
También se analizó la abundancia por sexo, la estacionalidad y la abundancia de hembras con brocosomas a lo largo del período de muestreo, se utilizaron los valores de abundancia de las especies predominantes obtenidos a partir de las trampas adhesivas amarillas. En estos análisis se utilizaron tablas de contingencia y se aplicaron test de $X^{2}$. En todos los análisis las hipótesis de nulidad eran que los factores en las tablas de contingencia eran independientes entre sí.

El análisis de la fluctuación de las poblaciones de las especies predominantes se realizó a través de la construcción de histogramas en los que se analizó el número de individuos por mes durante el período IX/2013-IX/2015 y los tratamientos dos considerados.

Los datos obtenidos se compararon con la fenología de los cítricos. La evolución fenológica de las plantas cítricas fue aportada por el Ingeniero Beltrán (EEA INTA Bella Vista) quien realizó el seguimiento detallado de la fenología del lote estudiado durante años sucesivos.

\section{Fluctuación estacional de las especies predominantes en la vegetación espontánea.}

Se analizó el comportamiento poblacional de las especies predominantes recolectadas en la vegetación espontánea basándose en el análisis faunístico. Para esto se realizó un histograma en el que se analizó el número de individuos por fecha de muestreo durante el período IX/2013-IX/2015.

\section{Monitoreo de enemigos naturales}

Para el estudio de los enemigos naturales de larvas y adultos de los cicadelinos, los ejemplares recolectados fueron examinados cuidadosamente bajo microscopio estereoscópico. Los cicadelinos con parasitoides fueron separados y enviados para su identificación a los respectivos especialistas: Dra. Ana María Marino de Remes Lenicov, UNLP (Orden Strepsiptera), Dr. Matias Rusconi y Dra. Fernanda Achinely, CEPAVE (Filo Nematoda). El araneido observado alimentándose activamente de un cicadelino fue recolectado y posteriormente enviado para su identificación a la Lic. Isabel Barrios, UNLP.

Para monitorear la presencia de parasitoides de huevos, se colectaron hojas de cítricos con posturas que fueron colocadas en cápsulas de Petri con una base de 
algodón humedecido y cubiertas con papel film adherente hasta la emergencia de las larvas de cicadelinos y/o de los parasitoides oófilos (Figura 75A-G)). Los parasitoides que emergieron fueron enviados para su identificación a la especialista Dra. Erica Luft Albarracín, PROIMI-CONICET. Las larvas emergidas se mantuvieron hasta el estado adulto en ramas de una planta de $C$. sinensis (L.) aisladas con una capucha de voile. Una vez alcanzado el estado adulto fueron retirados y conservados en etanol $70 \%$ y posteriormente identificados. Los brocosomas de huevos de las posturas recolectadas fueron analizados con microscopio electrónico de barrido en la FCNyM (UNLP). Para la identificación taxonómica se utilizó la clave de brocosomas propuesta por AzevedoFilho \& Carvalho (2005).

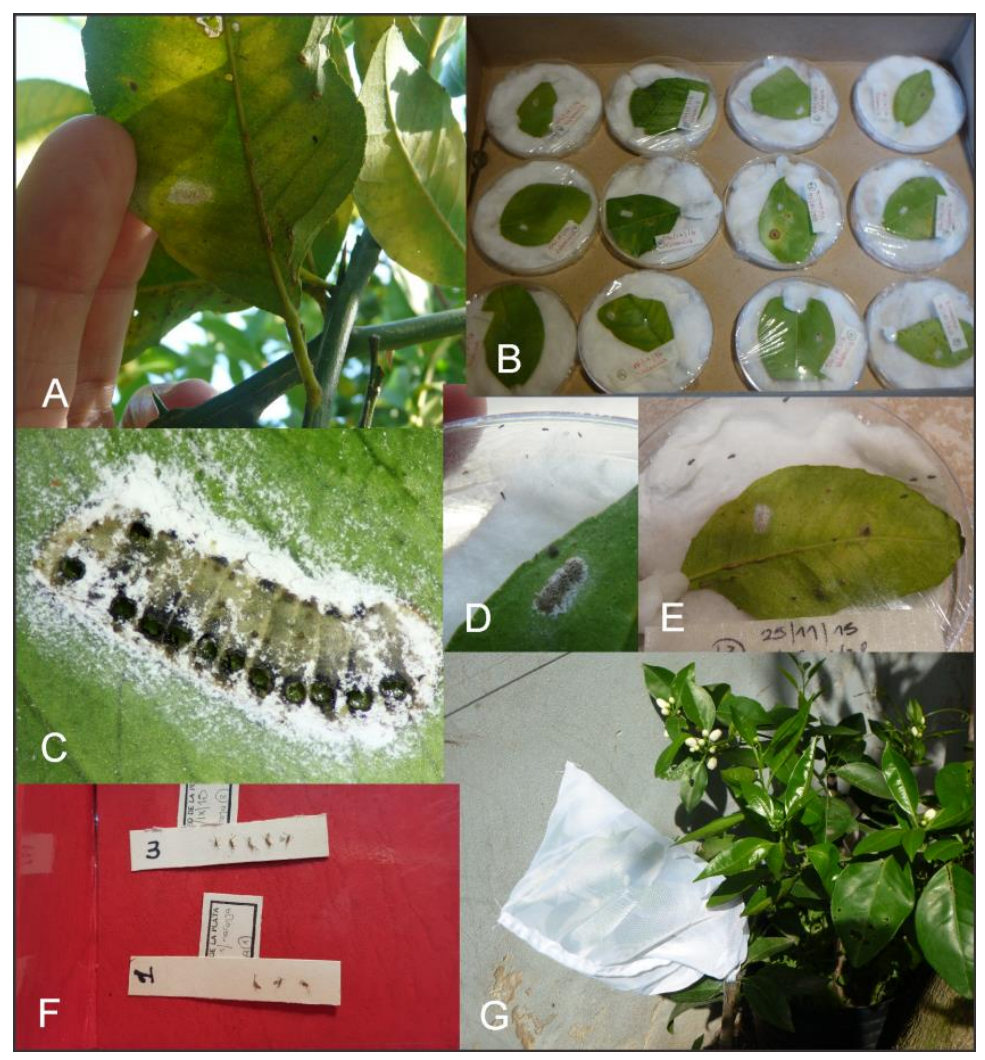

Figura 75. Metodología para la obtención de parasitoides oófilos. Reconocimiento de posturas a campo sobre las plantas cítricas (A), Cápsulas de Petri con las hojas con posturas recolectadas (B), huevos luego de la emergencia de los parasitoides (C), parasitoides y larvas recién eclosionadas de los huevos recolectados (D, E), conservación en seco de los parasitoides obtenidos (F), mantenimiento de las ninfas eclosionadas en plantines de naranja Valencia (G). 


\section{Metodología para el estudio de los estadios larvales}

Se describió morfológicamente el quinto estadio larval de tres especies (Hortensia similis (Walker), Sonesimia grossa (Signoret) y Tapajosa rubromarginata (Signoret) de Cicadellinae. Para la elección de las mismas se tuvieron en cuenta los análisis faunísticos de la vegetación asociada siendo las especies seleccionadas por su abundancia, frecuencia y también teniendo en cuenta su implicancia como vector. Para obtener los 10 ejemplares utilizados para realizar la descripción morfológica se colectaron durante sucesivos muestreos larvas del quinto estadio desde plantas de Eryngium sp. y matas de Hyptis mutabilis (Rich.) Briquet presentes en la vegetación espontánea en la plantación estudiada. La colecta se realizó de manera directa con aspirador manual (Figura 76A) o con red entomológica de arrastre. Una vez capturadas a las larvas se las anestesió con frío para su manipulación y separación en morfoespecies. Numerosos ejemplares de cada morfo fueron colocados por separado en jaulas de cría. Cada jaula consistió en una maceta con la planta hospedadora y un armazón de tela plástica con una ventana lateral de malla de tela tipo voile para proporcionar la ventilación correcta (Figura 76D, E). Los ensayos de realizaron durante la primavera y el verano de 2014 y 2015. Una vez obtenidos los adultos fueron retirados de la jaula con aspirador manual y se conservaron en etanol $70 \%$ hasta su posterior identificación. De esta manera se corroboró la identidad específica de cada morfo. El resto de las larvas recolectadas se conservaron en etanol 70\% para el estudio morfológico. Para su examinación y descripción bajo microscopio estereoscópico, cada espécimen fue aclarado en una solución de $\mathrm{KOH}$ al 10\% en frío. Para la descripción morfológica se siguió la terminología adoptada por Marucci et al. (2000). La forma de conservación de los ejemplares generalmente modifica su coloración natural, siendo la descripción basada en la coloración de los ejemplares conservados en etanol. Las fotografías se tomaron utilizando un microscopio estereoscópico Leica con una cámara réflex acoplada. 


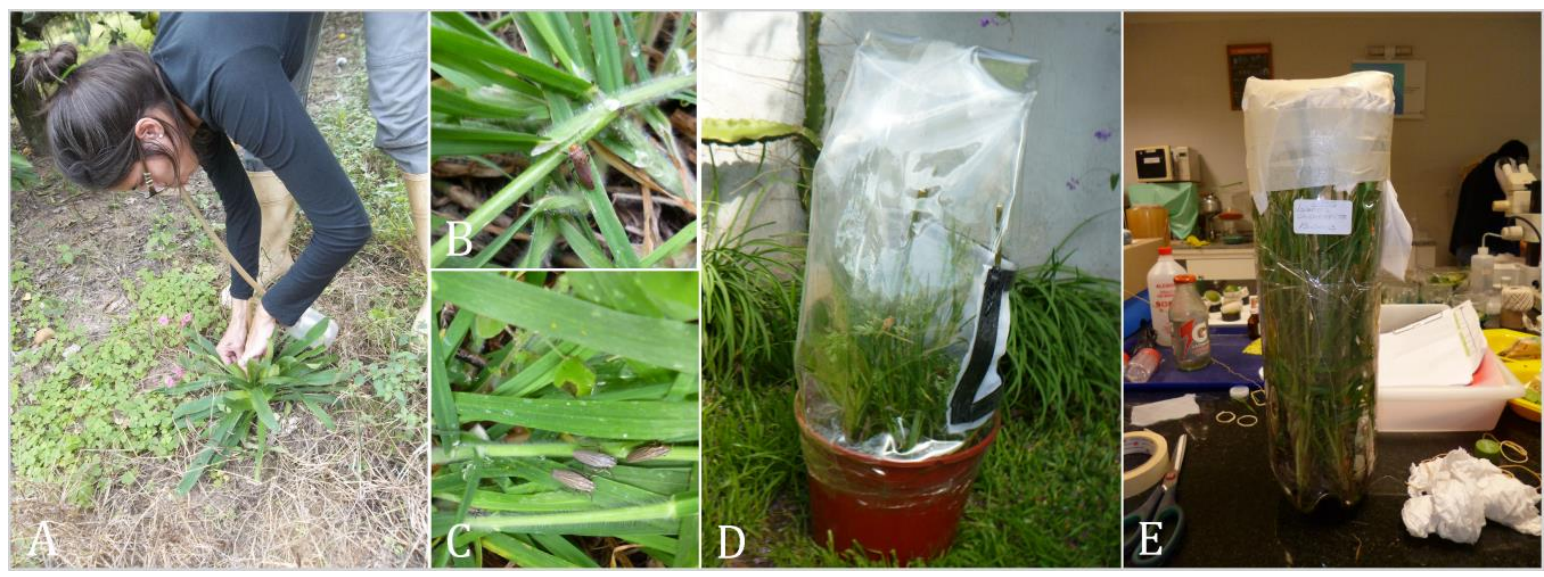

Figura 76. Metodología de colecta de larvas. Ejemplares adultos de Tapajosa rubromarginata (Signoret) (A) y Sonesimia grossa (Signoret) (B) sobre H. mutabilis, colecta directa de las larvas (C), jaulas de mantenimiento de las larvas recolectadas $(\mathrm{D}, \mathrm{E})$.

\section{RESULTADOS Y DISCUSIÓN}

Del total de los individuos recolectados, se identificaron 50 especies de auquenorrincos (47 Cicadomorpha, 3 Fulgoromorpha), distribuídas en 6 familias de las cuales Cicadellidae y Membracidae fueron las mejores representadas por 33 y 12 especies, respectivamente. La familia Cicadellidae estuvo conformada por 16 especies de Cicadellinae, 7 de Deltocephalinae, cuatro de Iassinae y dos de Megophtalminae; las subfamilias Coelidinae, Ledrinae, Typhlocybinae y Xestocephalinae estuvieron representadas por una especie (subfamilias según Dietrich 2005) (Tabla 1). Numerosos ejemplares no identificados se encuentran actualmente en estudio por los especialistas de cada grupo.

De las especies identificadas, se mencionan una especie nueva (actualmente en estudio), una nueva cita para la Argentina, 12 nuevas citas para la provincia de Corrientes (siete especies y cinco géneros) y 15 nuevas asociaciones con agroecosistemas citrícolas (Tabla 1).

De la subfamilia Cicadellinae, se colectaron un total de 5245 especímenes durante el período de muestreo pertenecientes a las tribus Cicadellini (4199) y Proconiini (1046). A partir de las trampas adhesivas colocadas en los cítricos se colectaron un 
total de 1996 individuos mientras que en la vegetación espontánea fueron recolectadas 3249 especímenes. En el agroecosistema se identificaron un total de 16 especies de Cicadellinae (Tabla 2); Hortensia similis (Walker) $(46,9 \%)$ fue la más representativa dentro de las especies recolectadas, seguida por Molomea lineiceps Young (18\%) y Dilobopterus costalimai Young (16,2\%); las 13 restantes representaron el 18,9\% del total de cicadelinos recolectadas. La tribu Cicadellini presentó el mayor número de especies $(\mathrm{S}=12)$ tanto en los cítricos (9 especies) como en la vegetación espontanea (10 especies) mientras que los Proconiini estuvieron representados por cuatro especies de las cuales sólo una fue recolectada en la vegetación espontánea. Resultados similares se obtuvieron en las provincias de Misiones (Remes Lenicov et al. 1999) y Entre Ríos (Dellapé 2013) respecto a la distribución de las especies y la abundancia de las tribus. Varios estudios realizados en Brasil (Giustolin et al. 2009, Marucci et al. 2002, Nunes et al. 2007, Yamamoto \& Gravena 2000) coinciden en una mayor ocurrencia de especies y una mayor abundancia de cicadelinos respecto a los proconinos, corroborando una vez más los resultados obtenidos en este estudio.

Tabla 1. Auchenorrhyncha recolectadas en el agroecosistema de $C$. sinensis en la EEA INTA Bella Vista, Corrientes.

\section{CICADOMORPHA}

\section{Superfamilia Cercopoidea}

Familia Cercopidae

Subfamilia Ischnorhininae

Deois (Deois) knoblauchii (Berg) ${ }^{\bullet}$

D. (D.) mourei Cavichioli \& Sakakibara

Notozulia entreriana (Berg) ${ }^{\bullet}$

Familia Clastopteridae

Clastoptera sp.

\section{Superfamilia Membracoidea}

Familia Cicadellidae

Subfamilia Coeliidinae

Coelidia sp.

Subfamilia Deltocephalinae

Amplicephalus marginellanus (Metcalf)

Chlorotettix oglobini Linnavuori ${ }^{\bullet}$

Copididonus hyalipennis (Stål)

C. vittulatus (Berg) $\mathrm{x}$ 
Frequenamia spiniventris (Linnavuori) $\mathrm{x}$

Graminella puncticeps (Stål) ${ }^{\bullet}$

Scaphytopius bolivianus Oman $\mathrm{x}$

Subfamilia Iassinae

Curtara compacta DeLong ${ }^{\bullet}$

C. mellella DeLong \& Freytag •

C. samera DeLong \& Freytag

Webaskola sp. ${ }^{*}$

Subfamilia Ledrinae

Xerophloea sp.

Subfamilia Megophtalminae

Agalliana ensigera Oman

Bergallia sp.

Subfamilia Typhlocybinae

Empoasca sp.

Subfamilia Xestocephalinae

Portanus sp. ${ }^{\mathrm{X}}$

Familia Membracidae

Subfamilia Darninae

Stictopelta sp. $\mathrm{x}^{\bullet}$

Subfamilia Membracinae

Aconophora sp. $\mathrm{x}$

Notocera sp. $\mathrm{x}^{\bullet}$

Subfamilia Smilinae

Adippe alliacea (Germar) ${ }^{\bullet}$

Ceresa maculipennis Remes Lenicov

C. ustulata Fairmaire

C. vitulus Fabricius $\mathrm{x}^{\bullet}$

Cyphonia braccata Germar $x^{\bullet}$

Entylia carinata Forster

Micrutalus sp. ${ }^{\bullet}$

Paraceresa bifasciata (Fairmaire)

FULGOROMORPHA

Familia Dyctiopharidae

Familia Flatidae

Familia Isiidae

Referencias: ${ }^{*}$ nueva especie para la fauna, ${ }^{\mathrm{x}}$ nuevo registro para Corrientes,

• nueva asociación con agroecosistemas citrícolas.

\section{Índices faunísticos y comportamiento estacional}

Los índices faunísticos calculados se muestran en la Tabla 2. 
De los especímenes recolectadas a partir de las trampas adhesivas amarillas, las especies Molomea lineiceps y Dilobopterus costalimai fueron predominantes ya que obtuvieron los mayores índices faunísticos (Figura 77A, B). En la vegetación asociada a los cítricos, sólo la especie Hortensia similis resultó predominante (Figura 77C).

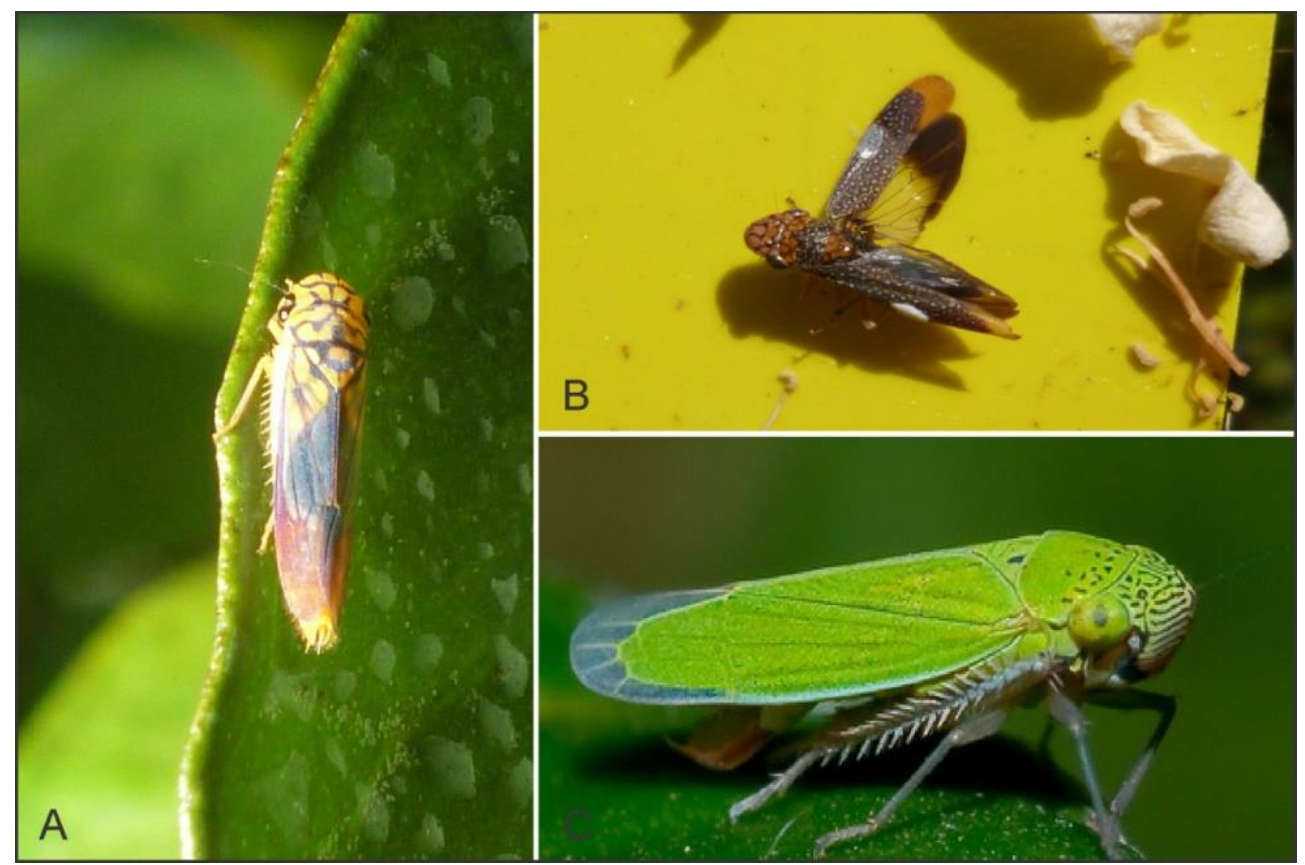

Figura 77. Especies predominantes en plantaciones de naranja Valencia en Bella Vista, Corrientes. Dilobopterus costalimai (A); Molomea lineiceps (B); Hortensia similis (C).

En estudios previos realizados en otras áreas citrícolas productoras del NEA, la especie $M$. lineiceps sólo se encontró en plantaciones de la localidad de Concordia, Entre Ríos; en donde fue hallada sobre variedades de naranja dulce (Citrus sinensis (L.) Osb.) Valencia Late y Criolla y sobre mandarina (Citrus reticulata Hort. Ex. Tan. X (Citrus Paradise Macf. X Citrus tangerine Hort. Ex. Tan.) variedad Nova, pero sólo en esta última fue predominante. En la vegetación asociada a estas plantaciones su presencia fue excepcional (Dellapé 2013). En la contribución realizada por Beltrán et al. (2004) en la provincia de Corrientes esta especie fue la segunda en abundancia en plantaciones de naranja Valencia aunque fue recolectada en bajo número. En los estudios realizados por de Coll et al. (1996) en Misiones M. lineiceps no fue hallada pero otra especie de este género, $M$. consolida, fue encontrada tanto en los cítricos 
como en la vegetación circundante al cultivo, siendo más abundante sobre los árboles aunque su abundancia no superó los 20 ejemplares por muestra en los momentos de máxima densidad. Respecto a su importancia fitosanitaria cabe destacar que en estudios de detección de la bacteria $X f$ realizados en Entre Ríos $M$. lineiceps resultó positiva. En este estudio estuvo presente, y de manera muy abundante, durante todo el periodo de muestreo, siendo una de las dos especies predominantes en los cítricos. Los resultados del ANOVA de las abundancias (sobre datos transformados con log (abundancia) luego de comprobarse falta de normalidad) entre las parcelas con y sin riego demostró que el riego no influyó sobre la abundancia de esta especie $(\mathrm{F}=0,77 ; 1$, 31 g. l.; p=0,69) (Figura 78). Asimismo, sí bien la proporción de sexos resultó la misma en parcelas con y sin riego $\left(X^{2}=3,16 ; 1\right.$ g. l.; $\left.p=0,075\right)$, las hembras $(60 \%)$ fueron significativamente más abundantes que los machos $(40 \%)\left(X^{2}=39,42\right.$, g. l. 1 , p<0,0001). La abundancia de las hembras con brocosomas también resultó independiente del riego ( $\mathrm{F}=0,73$; g. l. 1 ; $\mathrm{p}=0.4)$. En Brasil, M. lineiceps fue asociada a cultivos de naranja Valencia (Azevedo-Filho \& Carvalho 2004, 2006) y otra especie del mismo género, $M$. cincta (Signoret), es considerada vector potencial de la CVC (Fundecitrus 1999).

En Brasil, D. costalimai es uno de los vectores clave de $X f$. subsp. pauca debido a su alta abundancia en los cultivos (Molina et al. 2006, 2010) y a que es una de las especies más eficientes en la transmisión de esta bacteria (Krugner et al. 2000). En este estudio resultó muy abundante y muy frecuente en los muestreos con trampas adhesivas en las plantas cítricas siendo nula su presencia en la vegetación asociada al cultivo. Resultados similares fueron obtenidos en estudios realizados en Misiones por Remes Lenicov et al. (1999) con ocurrencia en la vegetación asociada al cultivo pero con valores insignificantes. En la provincia de Corrientes, D. costalimai fue hallada de manera abundante en cítricos de la localidad de Bella Vista siendo recolectada en bajo número en las localidades de Monte Caseros y Ambrosio (Beltrán et al. 2004). Los resultados del ANOVA de las abundancias entre las parcelas con y sin riego demostró que el riego afecta la abundancia de esta especie siendo significativamente más abundante en la parcela regada $(F=2,16 ; 1,31$ g. l.; $p=0,07)$ (Figura 79). Al igual que con $M$. lineiceps, la abundancia por sexos se mantuvo independiente del factor riego $\left(X^{2}=1,30 ; 1\right.$ g. l.; $\left.\mathrm{p}=0,25\right)$ y las hembras fueron significativamente más abundantes $(66 \%)$ que los machos (34\%) $\left(X^{2}=84,83\right.$, g. l. 1 1; $\left.p=<0.0001\right)$. Estudios respecto de 
la brotación en cítricos implantados en lotes con riego y sin riego afirman que los brotes de los cítricos regados tienen mayor crecimiento en longitud y crecen durante más tiempo que los brotes de plantas sin riego (Beltrán com. pers); ésto sumado a que D. costalimai tiene una preferencia por los brotes jóvenes en crecimiento de las plantas cítricas (Marucci et al. 2004) podría explicar su mayor abundancia en los lotes con riego. Estos resultados no coinciden con las observaciones previas de Beltrán et al. (2004) realizadas en Corrientes ya que en dicho estudio la abundancia de esta especie fue similar en lotes con y sin riego.

Hortensia similis es probablemente uno de los cicadelinos más ampliamente distribuido en América (Wilson \& Claridge 1991, Young 1977). Es muy común encontrarlo en malezas herbáceas asociadas a plantaciones de cítricos en Sudamérica junto a otras especies como Ferrariana trivittata (Signoret), Scopogonalia subolivacea (Stål), y Sonesimia grossa (Signoret) (Paiva et al. 1996, Remes Lenicov et al. 1999, Yamamoto \& Gravena 2000). En este estudio, resultó predominante en la vegetación espontánea siendo nula su presencia en los cítricos. Durante el primer año (IX/13IX/14) tanto adultos $(n=744)$ como larvas $(n=231)$ se registraron en menor número que al siguiente año en el cual se registró un total de 1677 adultos y 412 larvas siendo mayormente recolectadas las del quinto estadio. Esto permite afirmar que allí cumple su ciclo biológico corroborando lo observado previamente por Remes Lenicov et al. (1999) en Misiones. En la provincia de Entre Ríos ocurrió accidentalmente en los cítricos, sin embargo, fue una especie predominante sobre la vegetación asociada a plantaciones de naranja Valencia. Diversos estudios brasileros (Molina et al. 2006, 2010, Nunes et al. 2007, Yamamoto \& Gravena 2000, Yamamoto et al. 2002) coinciden en que es una especie de ocurrencia constante aunque también puede ser accesoria como en plantaciones de Montenegro en Rio Grande do Sul.

Durante el período de muestreo y considerando las dos categorías de captura se puede agrupar a las especies más estrechamente asociadas a los cítricos, aquellas que eligen a la vegetación espontánea asociada al cultivo como hospedador preferencial y otras que comparten ambos hospedadores. Del total de las especies recolectadas en este estudio, sólo cuatro fueron recolectadas con trampas adhesivas amarillas: Acrogonia virescens (Metcalf), D. costalimai, M. lineiceps y Tretogonia notatifrons Melichar (Tabla 2); mientras que sólo tres fueron únicamente asociadas a la vegetación espontánea: $H$. similis, Plesiommata corniculata Young y P. mollicella 
(Fowler) (Tabla 2). El resto de las especies fueron recolectadas tanto en los cítricos como en la vegetación asociada. Sin embargo el análisis del comportamiento de todas las especies a lo largo del período de muestreo señala que varias especies son de ocurrencia accidental tanto en los cítricos como en la vegetación asociada.

De los estudios previos realizados en Misiones (Remes Lenicov et al. 1999) y Entre Ríos (Dellapé 2013), la única especie predominante en común con este estudio fue $H$. similis que en las tres zonas se encontró asociada a la vegetación espontánea. Bucephalogonia xanthophis (Berg) fue predominante en los cítricos de Misiones y Entre Ríos y en este estudio se encontró en ambos hospedadores pero en muy bajo número siendo más frecuente su presencia en los cítricos (Tablas 3 y 4). En Brasil es uno de los principales vectores de la CVC (Marucci et al. 2008), donde es hallada frecuentemente sobre cítricos en formación y la vegetación asociada al cultivo (Coelho et al. 2008, Yamamoto et al. 2002). Algunas investigaciones la mencionan como una especie accidental y poco abundante, siendo en estos casos Dilobopterus costalimai la especie predominante (Giustolin et al. 2009, Molina et al. 2006, 2010, Nunes et al. 2007), lo que concuerda con los resultados obtenidos en este estudio.

La subfamilia Cicadellinae incluye el mayor número de vectores confirmados de $X f$ en América (Redak et al. 2004). De las 13 especies confirmadas como vectores de la subsp. pauca en Brasil, 8 fueron registradas en agroecosistemas citrícolas del NEA (Dellapé 2013, Remes Lenicov et al. 1999). En el capítulo II se dió a conocer la presencia de Plesiommata corniculata en la Argentina, que es vector de $X f$ en Brasil. Esta especie fue registrada para las provincias de Santa Fé, Entre Ríos y Corrientes; en esta última fue hallada en plantaciones citrícolas afectadas por la CVC. Acrogonia virescens es también vector comprobado en Brasil y fue hallada en el área estudiada aunque en muy bajo número; se la registra por primera vez asociada a cítricos en la Argentina. Así el número de especies vectoras asociadas a plantaciones citrícolas en nuestro país se eleva a 10 (Tabla 4). Siete de las especies positivas para $X f$ en Misiones (de Coll et al. 2000a) y/o Entre Ríos (Dellapé et al. 2016) fueron encontradas en el área estudiada, entre las que se destacan por su frecuencia y abundancia Hortensia similis y M. lineiceps (Tabla 2). Teniendo en cuenta esto, estas especies junto con D. costalimai podrían considerarse vectores potenciales de la CVC en la zona estudiada. 
Tabla 2. Índices faunísticos de los Cicadellinae recolectadas en plantaciones de naranja Valencia de la EEA INTA Bella Vista, Corrientes. Las especies predominantes se indican sombreadas.

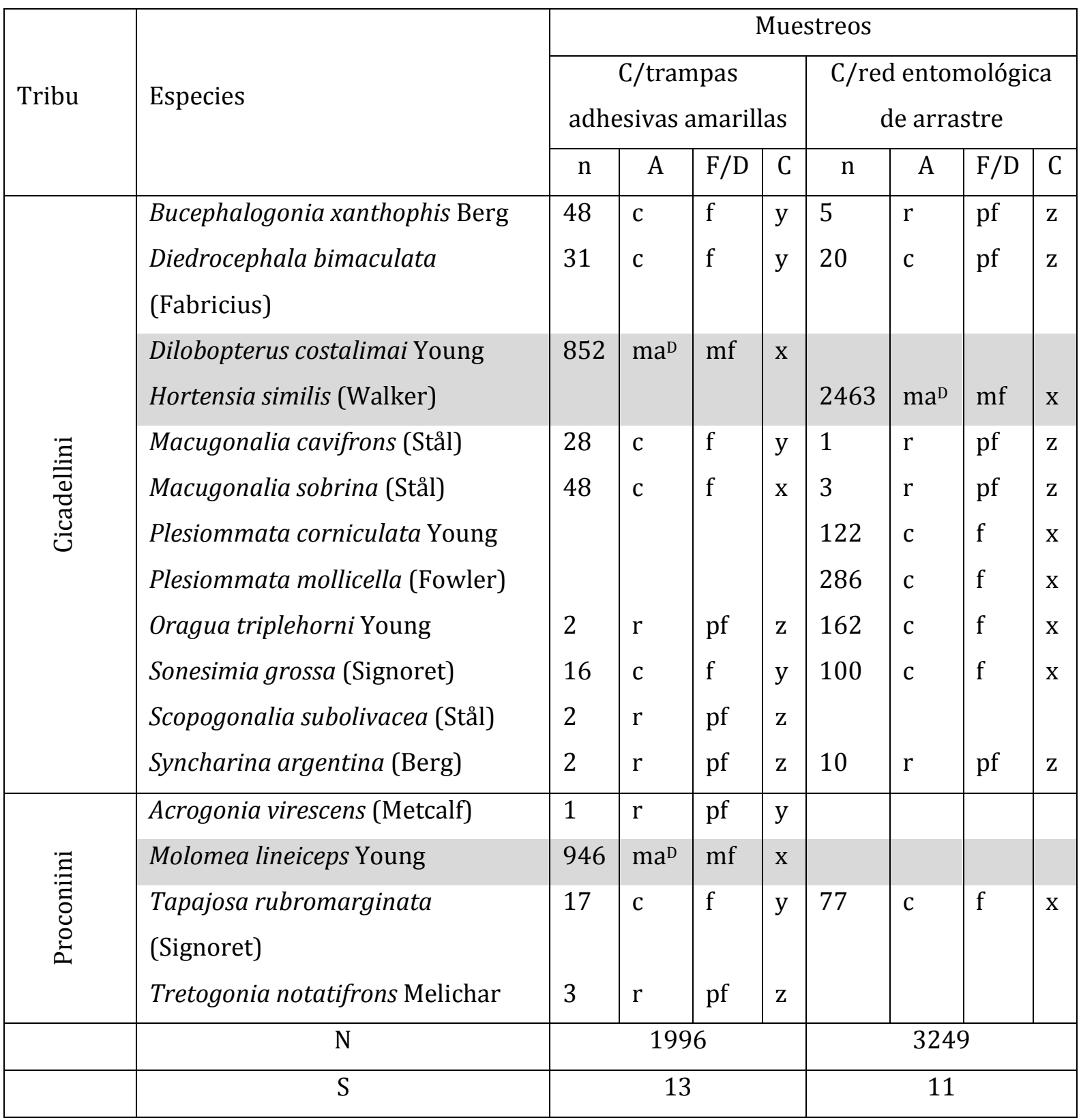

Referencias: n: número total de individuos recolectados; A, abundancia; F, frecuencia; $\mathrm{D}$, dominancia; C, constancia; ma, muy abundante; c, común; r, rara; pf, poco frecuente; f, frecuente; mf, muy frecuente; $\mathrm{x}$, constante; $\mathrm{y}$, accesoria; $\mathrm{z}$, accidental; $\mathrm{N}$, número total de individuos; $\mathrm{S}$, riqueza específica. Los valores de frecuencia con ${ }^{\mathrm{D}}$ son Dominantes, el resto son No Dominantes. 
Tabla III-3. Especies predominantes asociadas a naranja Valencia y la vegetación asociada al cultivo en la región Litoral. En negrita se remarcan las especies predominantes en este estudio.

\begin{tabular}{|c|c|c|}
\hline \multirow{2}{*}{ Provincia } & \multicolumn{2}{|c|}{ Especies } \\
\hline & Naranja Valencia & Vegetación espontánea \\
\hline Misiones (Remes & Acrogonia flaveoloides & H. similis (Walker), \\
\hline Lenicov et al. 1999) & $\begin{array}{l}\text { Young, B. xanthophis } \\
\text { (Berg), } \\
\text { S. subolivacea (Stål) }\end{array}$ & S. grossa (Signoret) \\
\hline Corrientes & $\begin{array}{l}\text { M. lineiceps, } \\
\text { D. costalimai }\end{array}$ & H. similis \\
\hline $\begin{array}{l}\text { Entre Ríos (Dellapé } \\
\text { 2013) }\end{array}$ & $\begin{array}{l}\text { B. xanthophis, } \\
\text { T. rubromarginata }\end{array}$ & $\begin{array}{c}\text { H. similis, } \\
\text { T. rubromarginata }\end{array}$ \\
\hline
\end{tabular}

El comportamiento estacional de las especies que resultaron predominantes tanto en los cítricos como en la vegetación asociada al cultivo fue analizado de manera particular. La especie D. costalimai estuvo siempre presente durante los dos años de muestreo y presentó dos aumentos poblacionales desde diciembre hasta abril (verano, otoño) coincidentes con épocas de elevadas precipitaciones y promedios de temperatura de 23 a $28^{\circ} \mathrm{C}$ (Figura 78). En la zona de Bella Vista, los cítricos en general, presentan tres a cuatro brotaciones principales por año que ocurren en primavera, verano y otoño: Primera brotación (mar-abr), segunda brotación (agosep), tercera brotación (nov-dic) y cuarta brotación (dic-ene) (Diamante et al. 1999), cada una de ellas con diferente intensidad de crecimiento siendo la de primavera la de mayor intensidad (Taiariol com. Pers.). Teniendo en cuenta la evolución fenológica de los cítricos en el área de estudio, los picos poblacionales de $D$. costalimai fueron coincidentes con la primera, tercera y cuarta brotación del cultivo; el mayor incremento se registró en diciembre cuando la brotación es más prolongada en el tiempo (24-31 días) y se da el mayor crecimiento en cm de los brotes jóvenes, por los cuales esta especie tiene mayor preferencia alimenticia. Resultados similares de la estacionalidad de esta especie fueron observados por Beltrán et al (2004) aunque el comportamiento no se repitió en el segundo año de estudio. En Misiones, $D$. costalimai registró dos picos de máxima densidad en otoño y primavera (de Coll et al. 1996). 
Tabla III-4. Especies de Cicadellinae asociadas a agroecosistemas citrícolas del NEA. Las especies sombreadas son vectores de $X f$ en Brasil. En negrita se indica la nueva especie vectora registrada para el país.

\begin{tabular}{|c|c|c|c|c|}
\hline Tribu & Especies & Misiones & Corrientes & Entre Ríos \\
\hline \multirow{20}{*}{ 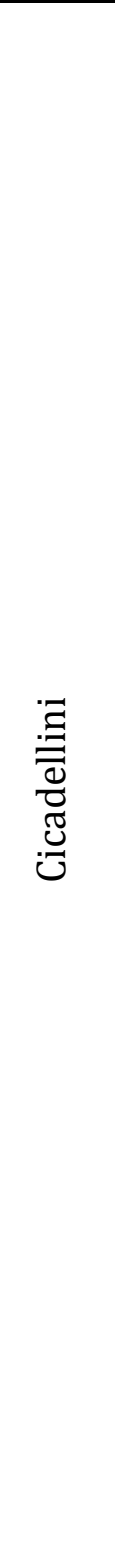 } & Balacha melanocephala (Signoret) & & & $\mathrm{X}$ \\
\hline & Bucephalogonia xanthophis (Berg) & $\mathrm{X}^{+}$ & $\mathrm{X}$ & $\mathrm{X}^{+}$ \\
\hline & Ciminius platensis (Berg) & $\mathrm{X}$ & & \\
\hline & Diedrocephala bimaculata (Fabricius) & $\mathrm{X}$ & $\mathrm{X}$ & $\mathrm{X}$ \\
\hline & Dilobopterus costalimai Young & $\mathrm{X}$ & $\mathrm{X}$ & \\
\hline & Ferrariana trivittata (Signoret) & $\mathrm{X}^{+}$ & & \\
\hline & Hortensia similis (Walker) & $\mathrm{X}^{+}$ & $\mathrm{X}$ & $\mathrm{X}^{+}$ \\
\hline & Macugonalia cavifrons (Stål) & $\mathrm{X}$ & $\mathrm{X}$ & \\
\hline & M. leucomelas (Walker) & $\mathrm{X}^{+}$ & & \\
\hline & M. sobrina Young & & $\mathrm{X}$ & $\mathrm{X}$ \\
\hline & Oragua triplehorni Young & & $\mathrm{X}$ & $\mathrm{X}$ \\
\hline & Parathona gratiosa (Blanchard) & $\mathrm{X}$ & & \\
\hline & Pawiloma victima (Germar) & & & $\mathrm{X}$ \\
\hline & Plesiommata corniculata Young & $\mathrm{X}$ & $\mathrm{X}$ & \\
\hline & P. mollicella (Fowler) & $\mathrm{X}$ & $\mathrm{X}$ & $\mathrm{X}^{+}$ \\
\hline & Scopogonalia subolivacea (Stål) & $\mathrm{X}^{+}$ & $\mathrm{X}$ & \\
\hline & Scoposcartula oculata (Signoret) & $\mathrm{X}$ & & \\
\hline & Sibovia sagata (Signoret) & $\mathrm{X}$ & & $\mathrm{X}$ \\
\hline & Sonesimia grossa (Signoret) & $X^{+}$ & $\mathrm{X}$ & $\mathrm{X}$ \\
\hline & Syncharina argentina (Berg) & & $\mathrm{X}$ & $\mathrm{X}$ \\
\hline \multirow{6}{*}{ 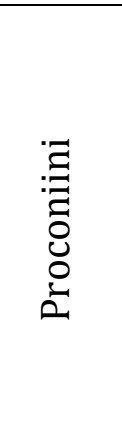 } & A. flaveoloides Young & $\mathrm{X}$ & & \\
\hline & A. virescens (Metcalf) & & $\mathrm{X}$ & \\
\hline & Dechacona missionum (Berg) & $\mathrm{X}$ & & $\mathrm{X}^{+}$ \\
\hline & Homalodisca ignorata Melichar & $\mathrm{X}$ & & \\
\hline & Molomea consolida Schröder & $\mathrm{X}$ & & \\
\hline & M. lineiceps Young & & $\mathrm{X}$ & $\mathrm{X}^{+}$ \\
\hline
\end{tabular}




\begin{tabular}{|llll|} 
Oncometopia facialis (Signoret) & $\mathrm{X}$ & & \\
Phera centrolineata (Signoret) & $\mathrm{X}$ & & \\
Tapajosa rubromarginata (Signoret) & & $\mathrm{X}$ & $\mathrm{X}^{+}$ \\
Tretogonia notatifrons Melichar & $\mathrm{X}$ & $\mathrm{X}$ \\
\hline
\end{tabular}

$\left({ }^{+}\right.$especies positivas para $\left.X f\right)$

Molomea lineiceps no presentó un comportamiento estacional tan marcado como D. costalimai sin embargo se observaron dos incrementos de su población, uno en el invierno (junio a agosto) y otro en primavera (octubre a diciembre) en los dos años de colecta y en concordancia con la segunda y primera brotación, respectivamente (Figura 79). Durante el período de muestreo, de julio a agosto se observó la mayor cantidad de hembras con brocosomas de huevos sobre las alas en relación al número total de hembras recolectadas (2014: 22/104), este comportamiento indica que están próximas a la oviposición que posteriormente conlleva al aumento poblacional registrado a fines de la primavera. El conocimiento de este peculiar comportamiento no sólo tiene significancia teórica sino que también es de interés aplicado ya que podría mejorar las estrategias de manejo de aquellas especies que transmiten enfermedades a cultivos de importancia comercial así como también para establecer colonias de cría para ensayos (Almeida \& Lopes 1999, Gravena et al. 1998, Hix 2001, Paiva et al. 2001, Turner \& Pollard 1959).

En los estudios realizados en Misiones por Remes Lenicov et al. (1999) y de Coll et al. (1996) la especie $H$. similis registró tres picos poblacionales en el año, el primero en marzo, el segundo en septiembre y el último en diciembre. A diferencia de lo observado en Misiones, en el área estudiada el número de individuos recolectadas, tanto adultos como larvas, se incrementó fuertemente en el invierno; en el último invierno el pico fue de mayor intensidad con un $\mathrm{n}_{\text {adultos }}=283$. Las larvas siguieron aproximadamente la misma tendencia de los adultos (Figura 80). 


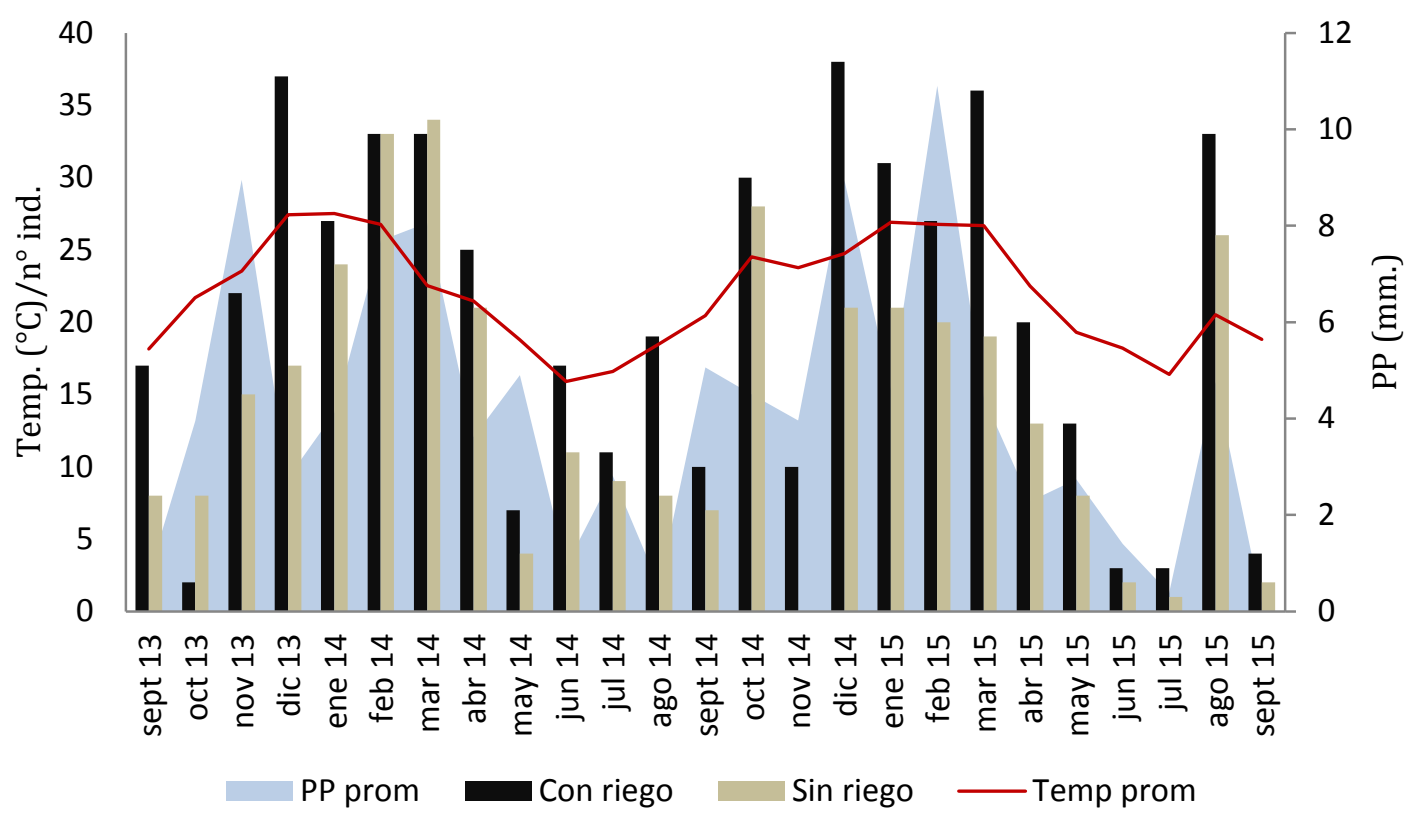

Figura 78. Comportamiento estacional de la especie predominante Dilobopterus costalimai Young, recolectada con trampas adhesivas en plantaciones citrícolas con y sin riego de Bella Vista, Corrientes. Referencias: PP prom., precipitación promedio; Temp. prom., temperatura promedio.

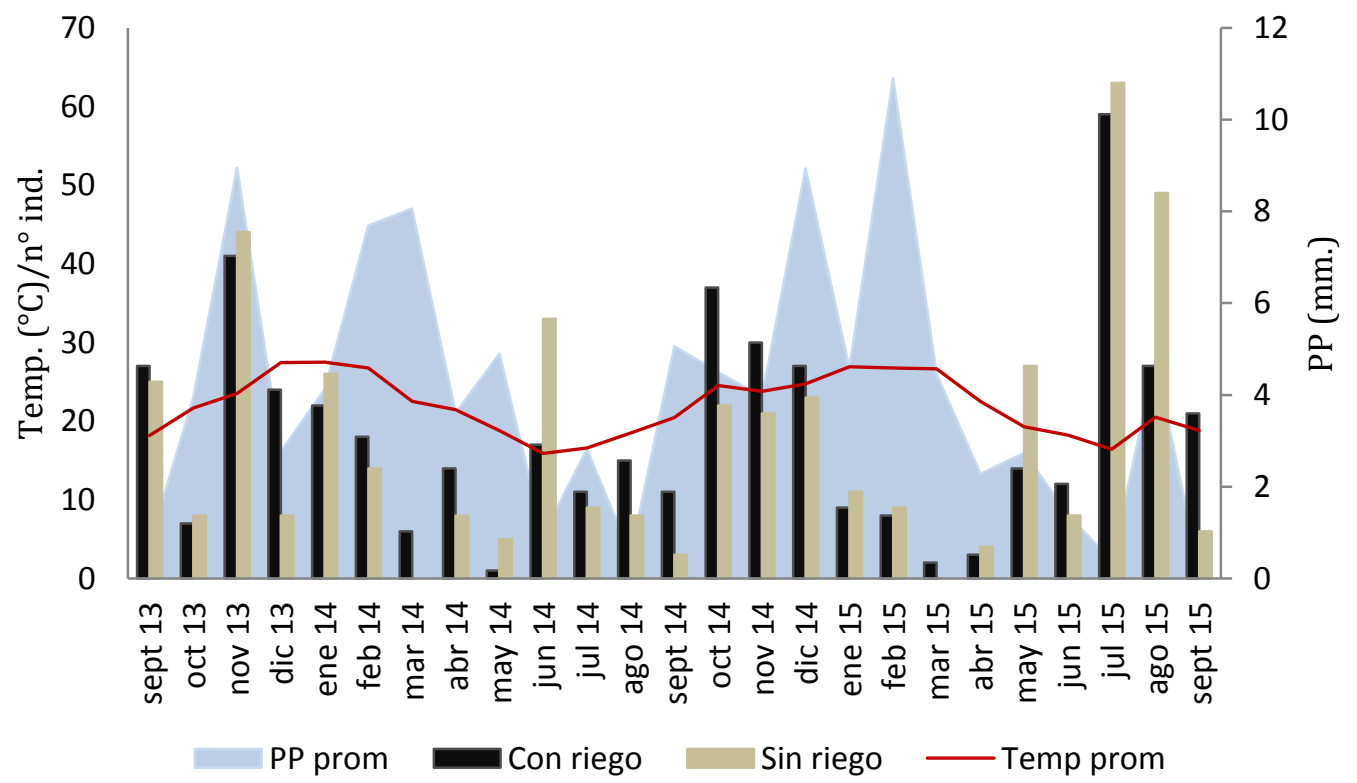

Figura 79. Comportamiento estacional de la especie predominante Molomea lineiceps Young, recolectada con trampas adhesivas en plantaciones citrícolas con y sin riego de Bella Vista, Corrientes. Referencias: PP prom., precipitación promedio; Temp. prom., temperatura promedio. 


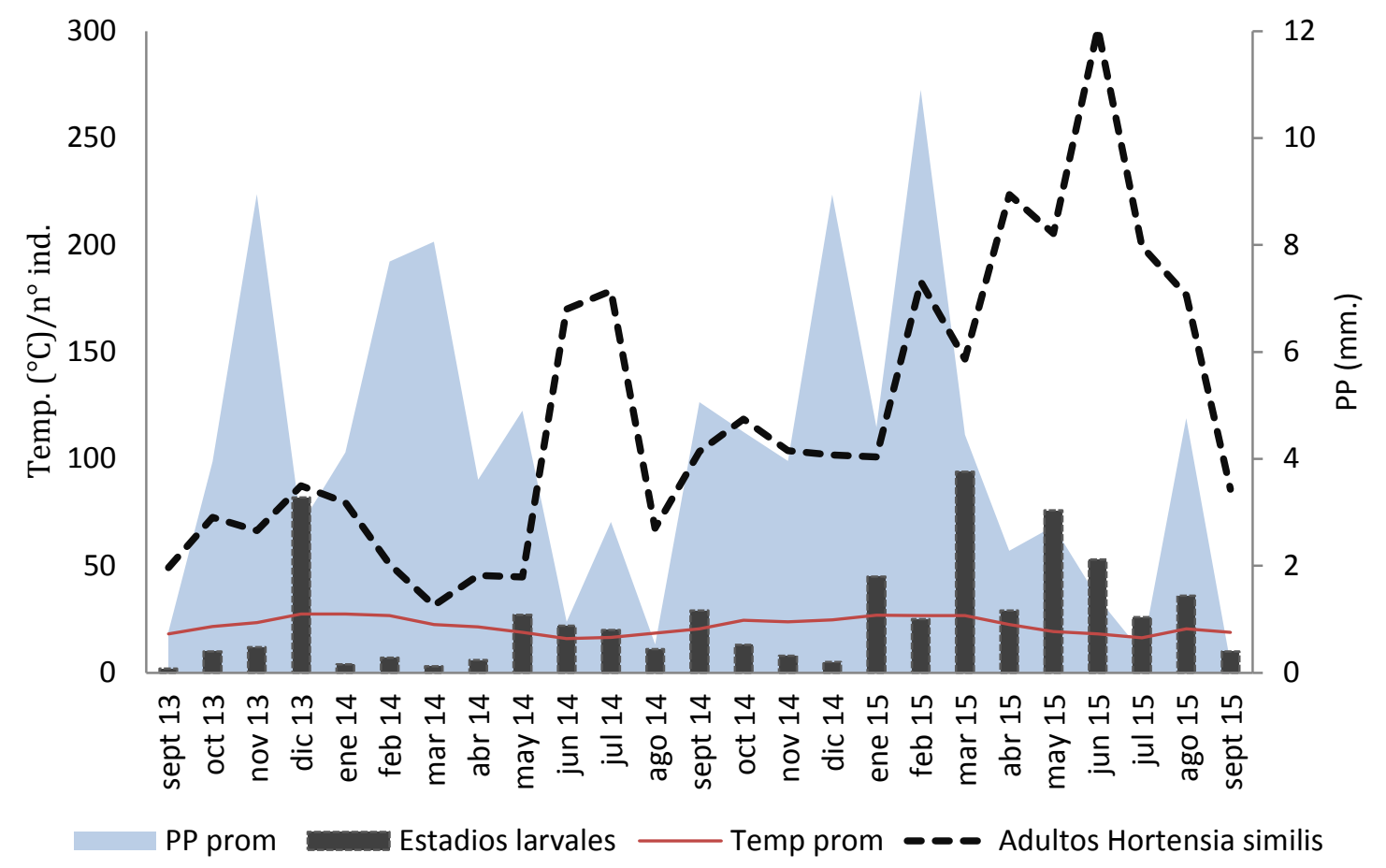

Figura 80. Comportamiento estacional de la especie predominante Hortensia similis (Walker), recolectada con red entomológica de arrastre en la vegetación espontánea de agroecosistemas citrícolas de Bella Vista, Corrientes. Referencias: PP prom., precipitación promedio; Temp. prom., temperatura promedio.

\section{Descripción del quinto estadio larval de especies de Cicadellinae asociadas al agroecosistema citrícola de Bella Vista, Corrientes.}

La elección de las especies para la descripción del $V$ estadio larval se realizó en base a su abundancia en el agroecosistema estudiado e importancia como portadoras y/o vectoras de $X f$.

\section{Hortensia similis (Walker) (Figura 81A-D)}

Longitud aproximada del cuerpo 4,4-5 mm. Coloración general pálida, amarillentaverdosa; en vista dorsal, con dos bandas longitudinales estrechas submedianas proyectadas desde el margen anterior de la corona hasta el extremo posterior del abdomen, con dos manchas triangulares en la frente, con manchas irregulares en la 
mitad anterior del pronoto y dos bandas irregulares sublaterales a lo largo del abdomen, de color castaño. Cabeza con dos máculas negras redondeadas ubicadas por detrás de la línea que pasa entre los ángulos anteriores de los ojos (Figura 81A). Ventralmente de coloración uniforme. Pubescencia. Tegumento glabro. Estructura. Cabeza, en vista dorsal, más ancha que larga (proporción 1,91-2,3:1), con el margen anterior obtuso. Clípeo pálido con impresiones musculares débilmente marcadas en la porción superior. Rostro trisegmentado extendido hasta las coxas del primer par de patas. Tórax. Pronoto rectangular, casi tan ancho como el ancho transocular, o ligeramente menor $(1: 1-1,08)$, con el margen anterior arqueado y el posterior ligeramente recto; tegumento de la mitad posterior débilmente estriado. Longitud del pro- más el mesonoto $2 \mathrm{X}$ la longitud del metanoto. Esbozos mesonotales cubriendo totalmente los esbozos metanotales y sobrepasando la mitad del quinto tergo abdominal. Esbozos meso- y metanotal con el margen posterior oscurecido. Tegumento de las patas liso, de color pálido con las uñas oscurecidas. Pro-, meso- y metatarsos trímeros (segmentación ligeramente evidente) (Figura 81B-D). Abdomen con ochos segmentos visibles dorsalmente.

\section{Sonesimia grossa (Signoret) (Figura $81 \mathrm{E}-\mathrm{H}$ )}

Longitud aproximada del cuerpo 6,6-7,0 mm. Coloración general pálida, en vista dorsal, cabeza con los márgenes laterales y áreas ocelares, de color castaño claro; con dos máculas redondeadas negras sobre el margen posterior de la cabeza. Tórax con una banda longitudinal irregular mediana de color castaño claro; márgenes del pronoto, margen posterior del meso- y metanoto, y márgenes anterior y posterior de los esbozos alares, castaño oscuros. Tegumento de las patas liso, de color castaño. Abdomen, en vista dorsal, margen anterior y posterior de los tergos, castaño oscuro (Figura 81E). Ventralmente, clípeo con una mancha en forma de Y invertida, impresiones musculares y abdomen, de color castaño. Pubescencia. Tegumento con microsetas dispersas. Cabeza, en vista dorsal, más ancha que larga (proporción 1,72,2:1), con el margen anterior obtuso. Rostro trisegmentado extendido hasta el margen posterior de las coxas del segundo par de apéndices. Tórax. Pronoto rectangular, ligeramente más angosto que el ancho transocular (1:1,04-1,09), con el margen anterior arqueado y el posterior ligeramente recto. Longitud del pro- más el mesonoto 2,5X la longitud del metanoto. Esbozos mesonotales cubriendo totalmente 
los esbozos metanotales y alcanzando el margen anterior del quinto segmento abdominal. Pro- y mesotarsos dímeros, metatarsos trímeros (segmentación ligeramente evidente) (Figura $81 \mathrm{~F}-\mathrm{H}$ ). Abdomen con siete segmentos visibles dorsalmente.

\section{Tapajosa rubromarginata (Signoret) (Figura $81 \mathrm{I}-\mathrm{L}$ )}

Longitud aproximada del cuerpo 6,3-7,0 mm. Coloración general castaño oscura, excepto la cabeza, de color amarillo-anaranjada; en vista dorsal, cabeza con dos manchas subtriangulares sobre el margen anterior de la corona, áreas preocelares y una banda irregular extendida entre los ojos, de color castaño oscuro; con dos máculas subredondeadas negras sobre el margen posterior de la cabeza. Mitad posterior del pronoto y porción visible de los esbozos metanotales blanquecinos. Tegumento de las patas liso, mayormente castaño oscuro. Abdomen, en vista dorsal, con tres bandas estrechas longitudinales, una mediana y dos sublaterales, blanquecinas (Figura 81 I). Ventralmente, clípeo con cinco bandas longitudinales estrechas, una mediana, dos sublaterales y dos laterales, que delimitan cuatro bandas claras; impresiones musculares no distintivas; abdomen con tres bandas estrechas longitudinales, una mediana y dos marginales. Pubescencia. Tegumento con numerosas microsetas. Cabeza, en vista dorsal, más ancha que larga (1,8-2,5:1), con el margen anterior obtuso. Rostro trisegmentado extendiéndose hasta el margen posterior de las coxas del segundo par de patas. Tórax. Pronoto rectangular, más angosto que el ancho transocular (1:1,15-1,2), con el margen anterior arqueado y el posterior ligeramente cóncavo; tegumento de la mitad anterior rugoso y el de la mitad posterior débilmente estriado. Longitud del pro- más el mesonoto $3 \mathrm{X}$ la longitud del metanoto. Esbozos mesonotales cubriendo totalmente los esbozos metanotales y alcanzando la mitad anterior del quinto segmento abdominal. Pro- y mesotarsos trímeros (segmentación ligeramente evidente), metatarsos trímeros (segmentación evidente) (Figura $81 \mathrm{~J}-\mathrm{L}$ ). Abdomen con ocho segmentos visibles dorsalmente. 


\section{Clave para la identificación del estadio larval $\mathbf{V}$ de cicadelinos presentes en} agroecosistemas citrícolas (Adaptada de Marucci et al. 2000).

1. Tegumento claro, de color amarillento

- Tegumento oscuro, de color castaño a negro 5

2. Ápice de la cabeza, en vista lateral, dorsalmente curvado. Tegumento uniformemente coloreado sin manchas o bandas de otro color Acrogonia citrina Cavichioli \& Marucci

- Ápice de la cabeza recto. Tegumento con manchas o bandas castañas en la cabeza, tórax y abdomen 3

3. Patrón de coloración con un par de bandas longitudinales submedianas proyectadas desde el margen anterior de la corona hasta el extremo posterior del abdomen Hortensia similis

- Patrón de coloración diferente al descripto anteriormente. 4

4. Margen anterior de la cabeza obtuso. Esbozos alares extendiéndose hasta la base del quinto segmento abdominal. Tórax con una banda castaña de posición media, abdomen con patrón de coloración tranversal Sonesimia grossa

- Margen anterior de la cabeza redondeado. Esbozos alares extendiéndose hasta la base del cuarto segmento abdominal. Tórax sin banda mediana; abdomen con patrón de coloración longitudinal Dilobopterus costalimai

5. Cabeza de color anaranjada con manchas oscuras, resto del cuerpo mayormente castaño oscuro con áreas y líneas longitudinales blanquecinas Tapajosa rubromarginata

- Cabeza del mismo color que el resto del cuerpo sin manchas oscuras, resto del cuerpo de coloración uniforme . Oncometopia facialis 

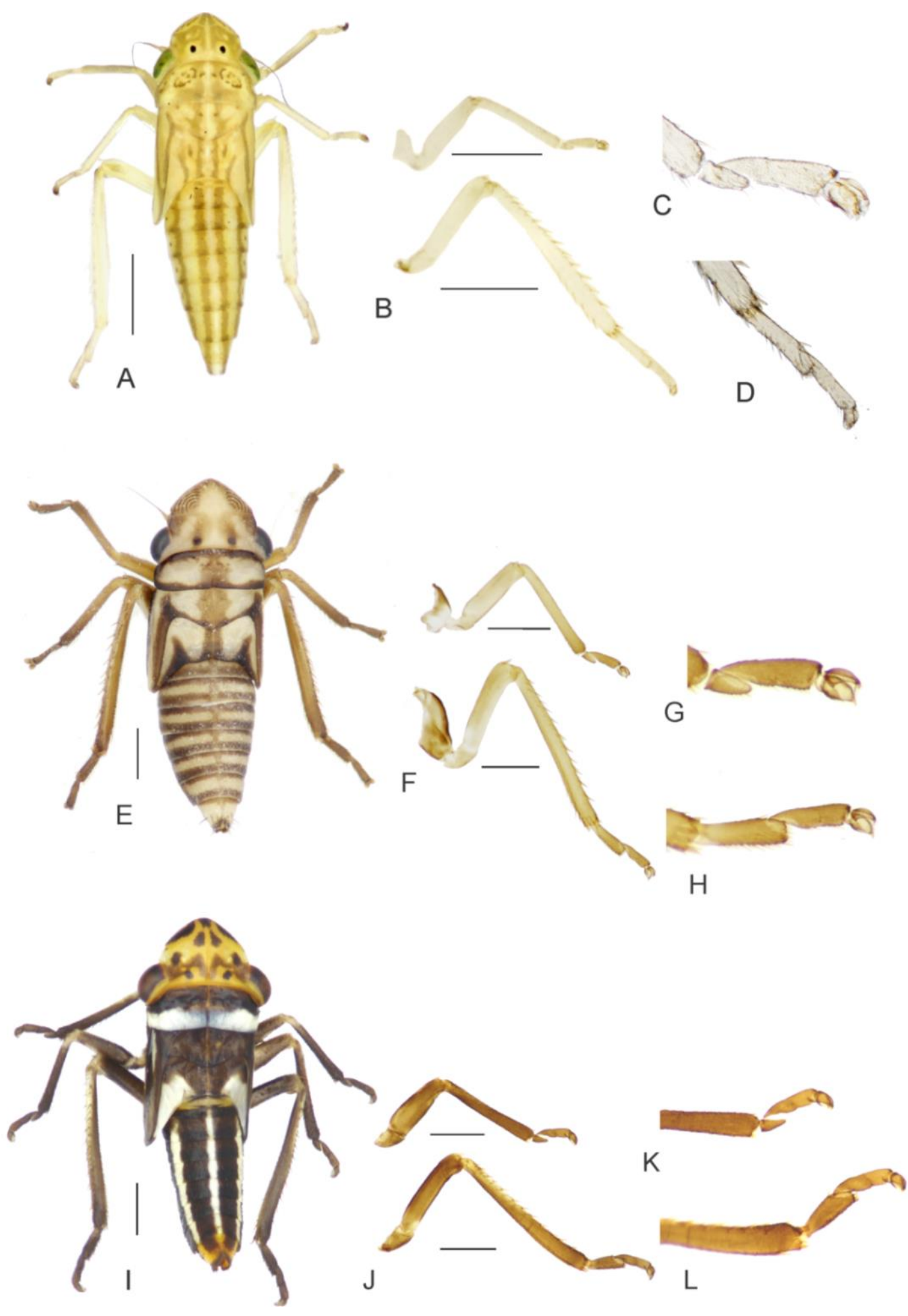

Figura 81. Estadio larval V de las especies: Hortensia similis (A-D), Sonesimia grossa (E-H) y Tapajosa rubromarginata (I-L). Hábito dorsal (A, E, I), patas meso- y metatorácicas (B, F, J), detalle tarso patas pro- y mesotorácicas (C, G, K), detalle tarso patas metatorácicas $(\mathrm{D}, \mathrm{H}, \mathrm{L})$. 


\section{Registro de enemigos naturales}

Durante los dos años de muestreo se registraron los enemigos naturales de los cicadelinos recolectadas en agroecosistemas citrícolas de Bella Vista Corrientes: parásitos nematodes, parasitoides oófilos y de insectos adultos y depredadores.

Nematodes de la familia Mermithidae fueron registrados parasitando seis larvas del quinto estadio y un adulto (hembra) de la especie H. similis (Figura 82). Los ejemplares parasitados fueron recolectados en la vegetación espontánea asociada al cultivo con red entomológica de arrastre. Los nematodos de este género emergen del huésped como una larva post-parasítica; durante dicho proceso de emergencia el huésped muere y por lo tanto el grado de infección por estos parásitos se corresponde con un grado de mortalidad de su hospedador, similar a lo que sucede con los parasitoides. Cuando los insectos hospedadores son preservados en etanol $70 \%$ los mermítidos se conservan en el estado juvenil a partir del cual la identificación morfológica a nivel específico no es posible (Poinar 1975).

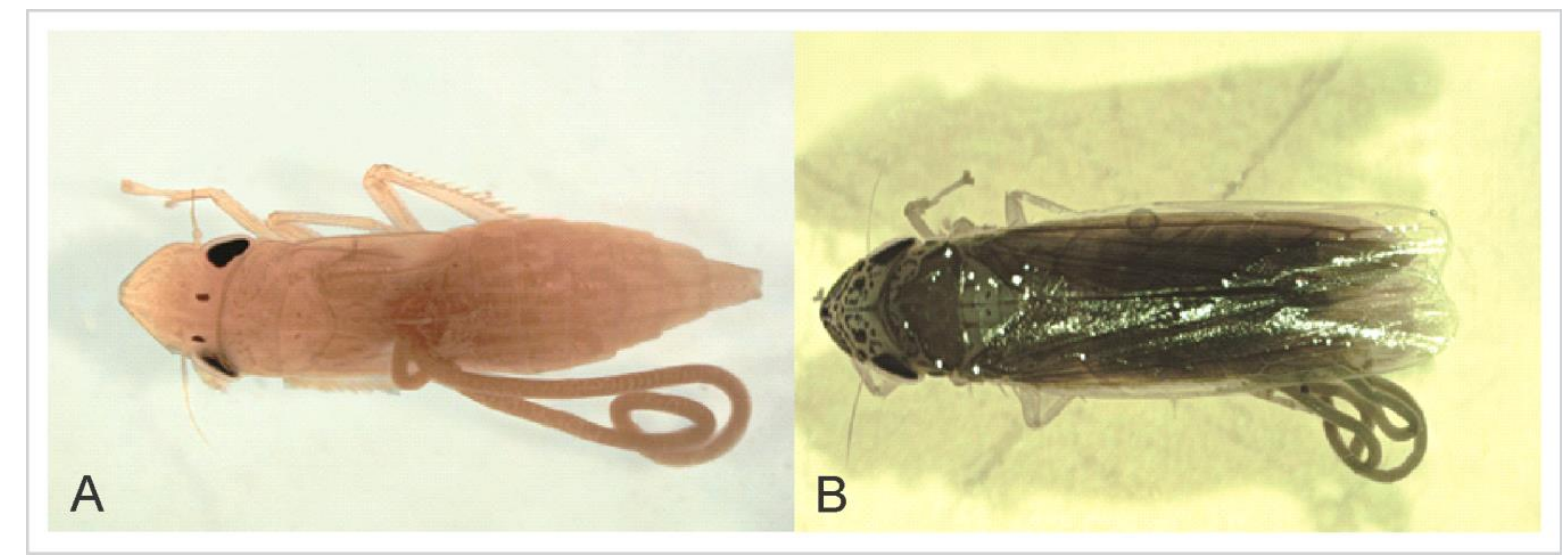

Figura 82. Ejemplares del cicadelino Hortensia similis parasitados por mermítidos. Larva del quinto estadio (A), adulto (B).

La mayoría de los mermítidos parasitan insectos, pero también se encuentran en arañas, crustáceos, moluscos y otros nematodes. Algunos géneros han sido ampliamente estudiados en plagas de la agricultura y registrados en cicadélidos plaga en Asia. Poinar (1975) sugiere que la mayoría de las asociaciones con hemípteros son probablemente infecciones accidentales sin embargo existen registros de niveles de 
mortalidad altos a causa de infecciones por mermítidos en delfácidos asiáticos (Waloff \& Jervis 1987).

En las observaciones a campo de las plantas cítricas se visualizaron numerosas posturas cubiertas por brocosomas lo que determina que pertenecen a ejemplares de la tribu Proconiini. En este estudio el proconino Molomea lineiceps fue predominante sobre los cítricos (Figura 83). Se conoce que esta especie produce brocosomas de huevos los cuales fueron descriptos por Azevedo-Filho \& Carvalho (2004).

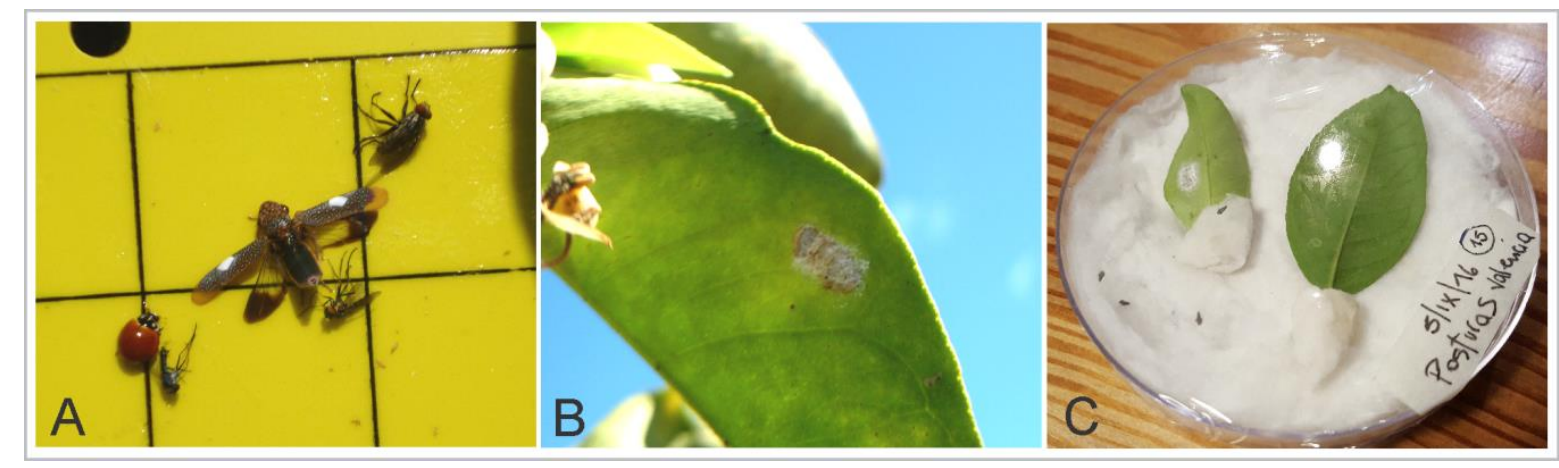

Figura 83. Ejemplar de Molomea lineiceps con brocosomas de huevo sobre trampa adhesiva amarilla (A), posturas de M. lineiceps sobre naranja Valencia en Bella Vista, Corrientes (B), larvas de M. lineiceps eclosionadas de posturas sobre hojas de naranja Valencia conservadas en cápsulas de Petri (C).

Los huevos de esta especie fueron atacados por tres especies de parasitoides: de varias posturas emergieron larvas de $M$. lineiceps y parasitoides de la especie Cosmocomoidea annulicornis (Ogloblin) (Mymaridae) (Figura 84A). Esta asociación fue previamente registrada por Paradell et al. (2012) y Dellapé (2013) en Entre Ríos. De una de las posturas recolectadas emergieron larvas de $M$. lineiceps y ejemplares del mimárido C. metanotalis (Ogloblin) (Figura 84B), la cual constituye una nueva asociación. El género Cosmocomoidea Howard incluye varias especies de parasitoides oófilos de Proconiini, varias de las cuales son utilizadas en el control biológico de Homalodisca vitripennis Germar, uno de los principales vectores del fitopatógeno Xf en California, USA (Triapitsyn 2013, Virla et al. 2005). Por último, de varias posturas eclosionaron larvas y parasitoides de una especie aún no identificada del género Burksiella sp. (Trichogrammatidae) (Figura 84C). Ejemplares de este parasitoide gregario han sido encontrados en huevos de fulgóridos y cicadélidos, particularmente 
atacando huevos de Oncometopia sp. y Homalodisca liturata Ball (Ávila Rodriguez et al. 2010). En la Argentina, la especie B. platensis (De Santis) parasitoidiza huevos de Tapajosa rubromarginata (Triapitsyn 2003); se registra por primera vez atacando huevos de M. lineiceps.

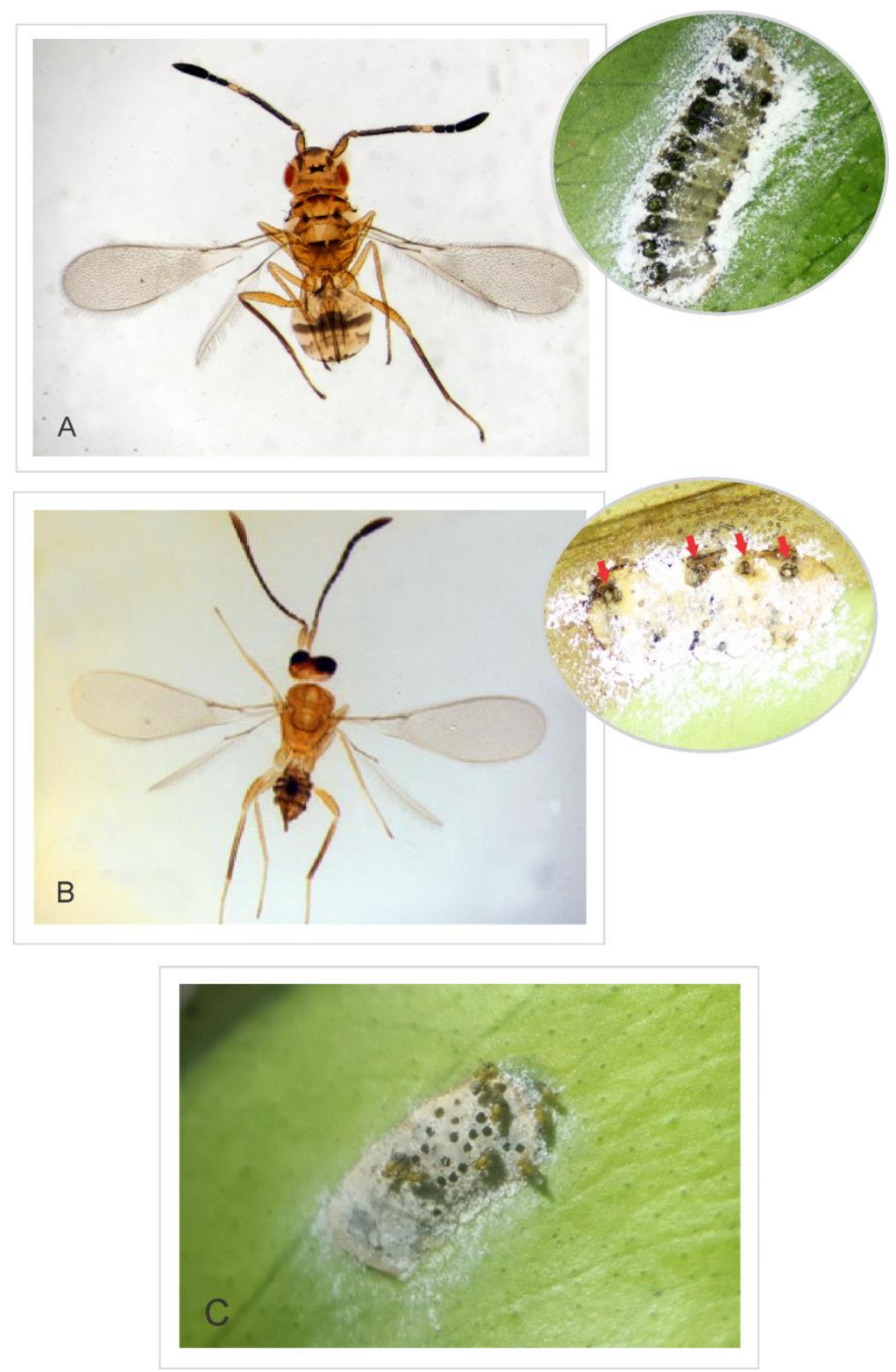

Figura 84. Parasitoides oófilos del proconino Molomea lineiceps registrados en cítricos de la EEA INTA Bella Vista, Corrientes. Cosmocomoidea annulicornis, en detalle posturas eclosionadas (A), C. metanotalis, en detalle posturas eclosionadas (B), ejemplares Burksiella sp. recién eclosionados (C). (Fotografías A y C cedidas por la Dra. Érica Luft Albarracín). 
Los estrepsípteros parasitoidizan (o "estilopizan" según algunos autores) a diversos grupos de insectos, entre los que se encuentran los auquenorrincos (Kathirithamby 1987). Es un grupo que exhibe un marcado dimorfismo sexual en el cual el macho adulto es de vida libre y la hembra neoténica es endoparásita permanente de su hospedador. En la Argentina estrepsípteros de las familias Halictophagidae y Elenchidae fueron registrados afectando a diversas especies de auquenorrincos (Dellapé 2013, Remes Lenicov 1970, Remes Lenicov \& Tesón 1975, Remes Lenicov et al. 1991). En los cicadelinos recolectadas en agroecosistemas citrícolas de Bella Vista se detectaron, con una incidencia muy baja, estrepsípteros de la familia Halictophagidae en la especie $H$. similis. Remes Lenicov \& Tesón (1985) registraron halictofágidos en $H$. similis en cultivos de arroz, y Remes Lenicov et al. (1999) y Dellapé (2013) citan a estos parasitoides en varias especies de cicadélidos asociados a cultivos citrícolas en las provincias de Misiones y Entre Ríos, respectivamente. En mayo de 2014, se colectaron 14 ejemplares de H. similis (8우, $6 \widehat{\jmath}$ ) con red entomológica de arrastre que se encontraban parasitoidizados mayormente por individuos hembra $(n=15)$. Las formas emergentes del parasitoide se localizaron en las partes dorso- y ventrolaterales del abdomen (Figura 85A, B), las hembras mayormente en posición pleuro-lateral tanto izquierda como derecha y los machos en posición tergo-lateral mayormente en el lateral derecho.

Las arañas son el segundo grupo de artrópodos más importante en los sistemas agrícolas y, como depredadores, cumplen un rol importante en el control biológico de especies plaga (Green 1996, Vangsgaard 1996). Los Cicadellidae figuran entre las presas potenciales de las arañas en los agroecosistemas (Medina 1994). Durante la observación directa realizada en las plantas cítricas un juvenil de la familia Salticidae (Araneae) fue observado alimentándose activamente de un ejemplar adulto de la especie Macugonalia cavifrons (Figura 85C). 


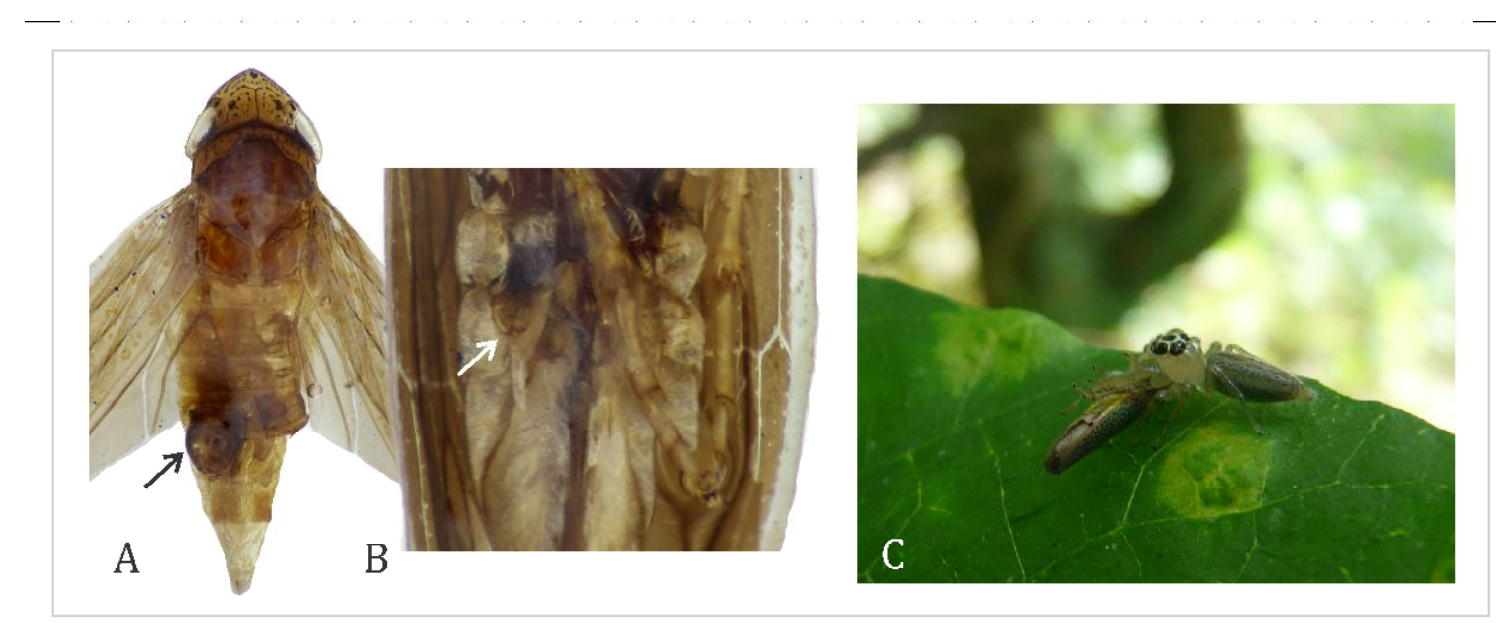

Figura 85. Ejemplar de Hortensia similis, en vista dorsal, parasitoidizado por un individuo (macho) del orden Strepsiptera (A), detalle en vista ventral de un estrepsíptero (hembra) en el abdomen de un ejemplar de $H$. similis (B), juvenil de la familia Salticidae (Araneae) alimentándose activamente de un ejemplar de Macugonalia cavifrons (Stål) (C). 


\section{Apéndice}

\section{Cicadellinae presentes en agroecosistemas citrícolas del NOA}

En el marco del proyecto “Bases para el manejo racional de la Clorosis Variegada de los Cítricos: relevamiento de potenciales vectores (Hemiptera: Cicadellidae) en agroecosistemas citrícolas deI NOA y NEA, y selección de parasitoides oófilos para su control biológico" (Código: PICT 2014-0607-E1) se realizaron muestreos estacionales desde el año 2015 hasta el 2017 con el fin de conocer las especies de chicharritas que se alimentan del xilema (Hemiptera: Cicadellidae: Proconiini, Cicadellini), e identificar los potenciales vectores de la CVC en agroecosistemas citrícolas del NOA y NEA. En el NOA los muestreos se realizaron en plantaciones de naranja Valencia (Citrus sinensis var. Late (L.) Osb. ubicadas en dos localidades diferentes: Yatasto (Salta) y Lules (Tucumán). Las capturas se realizaron al menos en cuatro momentos del año, con mayor intensidad durante la primavera y el verano cuando las poblaciones son más abundantes. Para la captura de los cicadelinos se utilizaron trampas adhesivas amarillas sobre los cítricos y red entomológica de arrastre en la vegetación espontanea asociada al cultivo. En cada sitio de muestreo se colocaron 6 trampas pegajosas en los árboles cítricos que fueron retiradas cada 15 días en el verano y la primavera, y una vez al mes durante el otoño e invierno. En la vegetación asociada se tomaron al menos diez muestras de 40 redadas cada una. Los insectos capturados fueron removidos de las trampas adhesivas con bencina y conservados en etanol $70 \%$ en frascos debidamente rotulados como los capturados con red entomológica. Todo el material recolectado fue transportado a la División Entomología de la Facultad de Ciencias Naturales y Museo (UNLP). La metodología empleada para la identificación de los ejemplares se detalla en el punto (III) de la sección Materiales y Métodos de este capítulo. 
Se colectaron un total de 733 ejemplares de Cicadellinae, siendo mayormente recolectados sobre las trampas cítricas (435 ejemplares). Del total de individuos capturados se identificaron 16 especies de Cicadellinae y dos aún no identificadas de los géneros Borogonalia Young y Oragua Melichar. La tribu Cicadellini estuvo representada por 12 especies mientras que Proconiini por cuatro.

De las especies identificadas, se menciona una cita nueva para la Argentina, ocho citas nuevas para la provincia de Salta y seis para Tucumán y cinco asociaciones nuevas con agroecosistemas citrícolas (Tabla 5).

En los muestreos realizados con trampas adhesivas amarillas, 11 especies fueron recolectadas de las cuales seis estuvieron presentes tanto en Salta como en Tucumán. En la vegetación circundante a los cítricos, un total de 13 especies fueron identificadas, cinco estuvieron en ambas provincias. En los dos sitios estudiados, las especies más abundantes recolectadas sobre los cítricos fueron Macugonalia cavifrons (Stål) y Scopogonalia subolivacea (Stål), seguidas por el proconino M. lineiceps Young y S. osteiphera Leal \& Creão-Duarte. En la vegetación asociada al cultivo, H. similis fue la especie más abundante en Tucumán, seguida por Draeculacephala tucumanensis Dietrich y Ciminius yana Young. En Salta, los individuos estuvieron más equitativamente distribuidos y no hubo especies que sobresalieran en número (Tabla $5)$.

En estudios previos realizados en Misiones (Remes Lenicov et al. 1999) y en Bella Vista, M. cavifrons fue registrada mayormente sobre las plantas cítricas pero no fue una especie predominante como en los agroecosistemas estudiados en el NOA. En ambos trabajos su presencia en la vegetación espontanea asociada al cultivo fue ocasional. En plantaciones de naranja Valencia de Entre Ríos no fue hallada. Resultados similares a los obtenidos en el NEA fueron observados por Molina et al. (2006, 2010) y Menegatti et al. (2008) en Brasil, en donde es considerada un vector potencial (Yamamoto \& Gravena 2000).

En coincidencia con lo observado en el NOA, en Misiones, S. subolivacea fue la especie más abundante sobre los cítricos, y también fue registrada en la vegetación espontánea aunque en menor número (Remes Lenicov et al. 1999). Resultados similiares fueron observados por Molina et al. (2006) en plantaciones citrícolas del estado de Santa Catarina, Brasil. En los estudios realizados en Entre Ríos no fue 
hallada y en Corrientes su abundancia sobre los cítricos fue rara y no se registró en la vegetación asociada al cultivo.

El proconino M. lineiceps fue registrado en cultivos de naranja Valencia en Brasil (Azevedo-Filho \& Carvalho 2004, 2006). En la Argentina, en los estudios realizados en Misiones no fue hallada (Remes Lenicov et al. 1999), mientras que en la provincia de Corrientes su comportamiento fue variable ya que en los estudios realizados por Beltrán et al. (2004) fue recolectada en bajo número sobre los cítricos; sin embargo en este estudio fue una de las dos especies predominantes recolectadas con las trampas adhesivas, siendo nulo su registro en la vegetación asociada al cultivo. En Entre Ríos, fue registrada en dos variedades de naranja dulce (Valencia Late y Criolla) y se comportó como una especie predominante sobre mandarina Nova. En la vegetación circundante al cultivo sólo se observó un ejemplar.

El Cicadellini S. osteiphera es asociado por primera vez a plantas de $C$. sinensis. Esta especie fue descripta recientemente por Leal et al. (2016) y está presente en Brasil y Argentina.

En Tucumán, el comportamiento observado de la especie $H$. similis es coincidente con los resultados obtenidos en los estudios realizados en el NEA y en diversos estudios brasileros (Molina et al. 2006, 2010, Nunes et al. 2007, Yamamoto et al. 2002) donde resultó ser una especie predominante sobre la vegetación espontánea siendo ocasional su ocurrencia sobre los cítricos.

El cicadelino D. tucumanensis es por primera vez registrado en agroecosistemas citrícolas y está únicamente citada para nuestro país. Otra especie del mismo género, D. minerva (Ball), es vector de $X f$ en almendros y vid en Estados Unidos (Purcell 1979, Severin 1949).

La especie C. yana es por primera vez asociada a agroecosistemas citrícolas. En la provincia de Misiones, Remes Lenicov et al. (1999) registraron a C. platensis en cítricos y la vegetación asociada al cultivo. Esta especie junto con $C$. albolineatus (Taschenberg) son frecuentes en la vegetación herbácea asociada a plantaciones citrícolas de Sudamérica (Redak et al. 2004).

Es para destacar, el registro de la especie D. costalimai en los agroecosistemas citrícolas estudiados ya que es considerado un vector clave de $X f$ subsp. pauca, cepa causal de la CVC en Brasil y en el NEA. 
Considerando por separado a las especies recolectadas con las trampas adhesivas y las recolectadas con red entomológica se podría agrupar a las especies que eligen a los cítricos como hospedador preferencial, aquellas que se encuentran preferentemente en la vegetación asociada al cultivo y otras que se encontraron en ambos hospedadores. Del total de las especies, cuatro fueron recolectadas únicamente sobre los cítricos: S. osteiphera, Macugonalia cavifrons, $M$. sobrina y $B$. xanthophis; y siete fueron asociadas únicamente a la vegetación espontánea: $D$. tucumanensis, P. mollicella, M. leucomelas, C. yana, Oragua sp. y el proconino Tapajosa similis (Melichar) (Tabla 5). El resto de las especies estuvieron presentes tanto en los cítricos como en la vegetación asociada aunque algunas fueron de ocurrencia ocasional en unos de los dos hospedadores.

En el NEA, 10 de las 13 especies vectoras de $X f$ en Sudamérica fueron registradas en agroecosistemas citrícolas de las provincias de Misiones, Corrientes y Entre Ríos. Debido a la relevancia fitosanitaria de esta subfamilia como principales transmisores de esta bacteria es importante destacar que en los agroecosistemas del NOA estudiados se hallaron tres especies vectoras: $B$. xanthophis, D. costalimai y el proconino O. facialis, los dos primeros, considerados vectores clave para la diseminación y transmisión de $X f$ en Brasil (Marucci et al. 2008), y seis de las especies confirmadas como portadoras de la bacteria en Misiones (de Coll et al. 2000a) y/o Entre Ríos (Dellapé et al. 2016), entre las que se destacaron por su abundancia $S$. subolivacea y $H$. similis (Tabla 5). Estas especies junto con el proconino M. lineiceps podrían considerarse vectores potenciales de la CVC en las áreas estudiadas.

Este primer acercamiento al conocimiento de la taxocenosis de las especies de Cicadellinae en agroecositemas citrícolas del NOA servirá de base para encarar futuros estudios ecológicos y moleculares. Toda la información recabada hasta el momento así como la proveniente de futuros estudios será una herramienta fundamental a la hora de implementar estrategias de manejo de estos insectos que representan un problema fitosanitario potencial para esta región de gran importancia en la producción de cítricos. 
Tabla 5. Especies de Cicadellinae asociadas a agroecosistemas citrícolas del NOA. Las especies más abundantes se indican sombreadas. En negrita se indican las nuevas asociaciones a Citrus sinensis.

\begin{tabular}{|c|c|c|c|c|c|}
\hline \multirow{2}{*}{ Tribu } & \multirow{2}{*}{ Especies } & \multicolumn{2}{|c|}{ Salta } & \multicolumn{2}{|c|}{ Tucumán } \\
\hline & & TA & VA & TA & VA \\
\hline \multirow{14}{*}{ 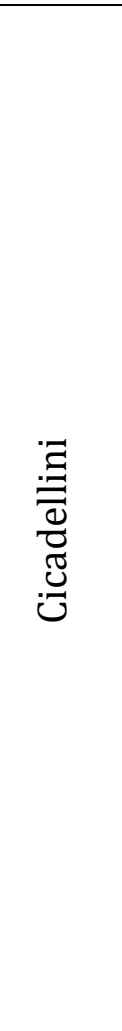 } & Borogonalia sp. & 4 & 2 & & \\
\hline & Bucephalogonia xanthophis (Berg) $\bullet_{+}^{+}$ & 4 & & & \\
\hline & Ciminius yana Young & & & & 34 \\
\hline & Diedrocephala bimaculata (Fabricius) & 1 & 1 & 1 & \\
\hline & Dilobopterus costalimai Young $\bullet^{\bullet}$ & 2 & 1 & & \\
\hline & Draeculacephala tucumanensis Dietrich & & 9 & & 37 \\
\hline & ${\text { Hortensia similis (Walker) }{ }^{+}}^{+}$ & & 2 & & 204 \\
\hline & Macugonalia cavifrons (Stål) & 94 & & 63 & \\
\hline & M. leucomelas (Walker) ${ }^{\bullet+}$ & & 1 & & 3 \\
\hline & M. sobrina (Stål) & 5 & & 13 & \\
\hline & Oragua sp. & & & & 2 \\
\hline & Plesiommata mollicella (Fowler) ${ }^{+}$ & & 2 & & 15 \\
\hline & Scopogonalia osteiphera Leal \& Creão-Duarte & 23 & & 15 & \\
\hline & S. subolivacea (Stål) ${ }^{+}$ & 90 & 9 & 36 & 3 \\
\hline \multirow{4}{*}{ 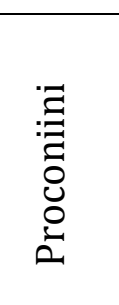 } & Molomea lineiceps (Stål) ${ }^{+}$ & 41 & 4 & 38 & \\
\hline & Oncometopia facialis (Signoret) ${ }^{\bullet}$ & & 4 & 13 & \\
\hline & Tapajosa rubromarginata (Signoret) ${ }^{+}$ & & & 1 & 2 \\
\hline & T. similis (Melichar) & & & & 2 \\
\hline
\end{tabular}

(• especies vectoras de $X f$ en Brasil, ${ }^{+}$especies positivas para $X f$ en el NEA). Referencias: TA, trampa amarilla; VA, vegetación asociada. 


\section{Clave para el reconocimiento de las especies de Cicadellinae asociadas a agroecosistemas citrícolas de la Argentina.}

1. Articulación fémoro-tibial del tercer par de patas, en reposo, alcanzando el margen posterior del proepímero; pigóforo y placas subgenitales del macho con macrosetas o con microsetas agrupadas; puente antenal, en vista dorsal, no protuberante. ..Cicadellini (9)

- Articulación fémoro-tibial no alcanzando el proepímero; pigóforo y placas subgenitales del macho con numerosas microsetas dispersas, ocasionalmente con algunas macrosetas; puente antenal protuberante Proconiini (2)

2. Coloración general pardo-grisácea. Alas anteriores en reposo ocultando el meron de las patas posteriores. Placas subgenitales de los machos con tres procesos; edeago corto con un par de procesos basales, finamente pubescentes en la mitad apical Dechachona missionum (Young 1968: 256).

- Coloración variable. Meron expuesto. Placas subgenitales de los machos sin procesos; edeago de forma variable

3. Superficie del cuerpo pubescente................................................................................. 5

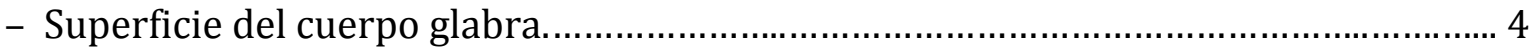

4. Margen anterior de la cabeza carenado y levemente elevado, sin protuberancia en forma de $\mathrm{M}$ sobre el margen posterior de la cabeza, pigóforo del macho fuertemente proyectado posteriormente, visible cuando las alas anteriores se encuentran en posición de reposo.

\section{Acrogonia Stål}

A. Cabeza, pronoto y escutelo de color negro con manchas amarillas. Pigóforo del macho con un lóbulo bien definido sobre el margen dorsal; conectivo de forma lineal; ápice del edeago bífido

A. flaveoloides (Young 1968: 269).

- Cabeza, pronoto y escutelo sin manchas amarillas; coloración dorsal variable, con una mancha en forma de $\mathrm{U}$ en el ápice de la cabeza. Pigóforo del macho sin lóbulo dorsal; conectivo en forma de Y; ápice del edeago terminado en punta

A. virescens (Young 1968: 267). 
- Margen anterior de la cabeza redondeado, no elevado; con una protuberancia en forma de M sobre el margen posterior de la cabeza. Pigóforo del macho oculto bajo las alas en posición de reposo. Edeago asimétrico, con un par de procesos ventrales divergentes, uno de ellos con una pequeña espina interna Phera centrolineata (Young 1968: 187).

5. Pronoto y alas anteriores con fóveas profundas; pronoto fuertemente convexo, alcanzando o sobrepasando el surco transverso del escutelo. Pigóforo de los machos, en vista ventral, con procesos puntiagudos curvados, entrecruzados en la línea media del cuerpo; estilos redondeados apicalmente; edeago con un par de procesos basales alargados.....................Tretogonia notatifrons (Young 1968: 171).

- Sin la combinación de caracteres anteriores 6

6. Metaepímero con una proyección en forma de repisa, donde se apoyan las alas anteriores en posición de reposo. Placas subgenitales del macho separadas a lo largo de toda su longitud Oncometopia Stål A. Corona, pronoto y escutelo violáceos, disco de la corona con una mancha oscura triangular que se extiende hacia atrás de los ocelos; alas anteriores opacas con venas amarillentas. Edeago con procesos ventrales: un par de procesos basales puntiagudos que se extienden lateralmente, un proceso impar medio alargado y curvado, y un par de procesos apicales divergentes unidos en su base

Oncometopia facialis (Dellapé 2013: 80).

- Metaepímero sin proyección o con una muy débil. Placas subgenitales del macho fusionadas basalmente.

8. Clípeo fuertemente protuberante, con impresiones musculares marcadas; machos con placas subgenitales muy cortas, las cuales no sobrepasan la longitud media del pigóforo

..Molomea China

A. Eje aedeagal con un proceso impar de posición media sobre el margen posteroventral cerca de la base. M. lineiceps (Young 1968:247).

- Eje aedeagal con procesos apicales. M. consolida (Young 1968: 248).

- Clípeo protuberante, con impresiones obscurecidas; machos con placas subgenitales alargadas que sobrepasan la longitud media del pigóforo. Tapajosa Melichar 
A. Edeago, en vista lateral,con un par de procesos basales apicalmente recurvados en dirección anteroventral. T. similis (Young 1968: 237).

- Edeago con los procesos basales rectos

T. rubromarginata (Young 1968: 238)

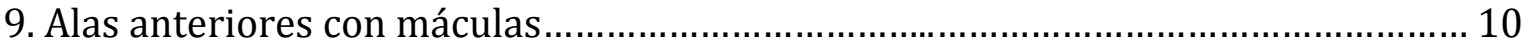

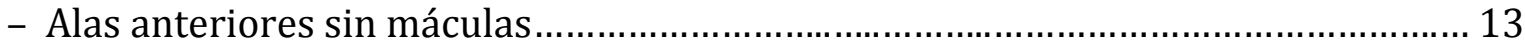

10. Coloración castaña oscura; tegmen con pequeñas máculas pálidas en casi toda su extensión

Oragua triplehorni (Cap II: 127).

- Coloración variable; tegmen con área maculada delimitada por una porción membranosa.

11. Margen anterior del pronoto con numerosas máculas pequeñas de color pálido en toda su extensión ...Macugonalia Young

A. Margen posterodorsal del pigóforo del macho con un pliegue interno

- Margen posterodorsal del pigóforo sin pliegue interno M. leucomelas (Young 1977: 948).

B. Margen posterodorsal del pigóforo del macho con un pliegue interno liso, no denticulado. Esternito abdominal VII de la hembra con una proyección posterior espiniforme de posición media que se extiende más allá de la mitad basal del pigóforo, ápice redondeado

M. cavifrons (Young 1977: 956; Cap. II: 116).

- Margen posterodorsal del pigóforo con el pliegue interno denticulado. Esternito abdominal VII de la hembra con una proyección posterior aguda que se extiende hasta la mitad basal del pigóforo, ápice terminado en punta. M. sobrina (Young 1977:955; Cap. II:116).

- Margen anterior del pronoto sin máculas, o con una mácula negra de posición media

12. Margen anterior del pronoto sin máculas. Tegmen con numerosas máculas pequeñas amarillentas en serie, y con una mácula grande, de forma redondeada cercana al ápice claval

Parathona gratiosa (Cap. II: 131).

- Margen anterior del pronoto con mácula negra de posición media. Tegmen con numerosas máculas circulares de color anaranjado. Edeago del macho simétrico, 
con un par de procesos estrechos que se originan en la mitad del eje y se proyectan posterodorsalmente. Ovipositor de la hembra, con los dientes de la valva II subtriangul Pawiloma victima (Young 1977: 736; Cap. II: 138, 140).

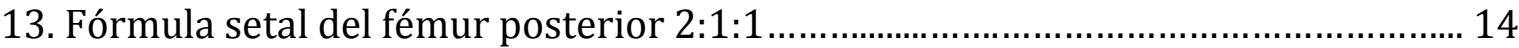

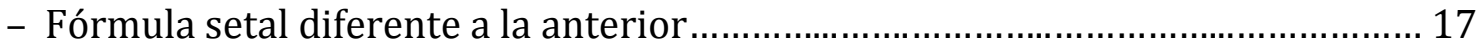

14. Alas anteriores mayormente hialinas con venas marcadas. 15

- Alas anteriores opacas con venas marcadas o del mismo color del tegumento .16

15. Alas posteriores con emarginación profunda entre el jugum y el resto del ala determinando un conspicuo lóbulo jugal

Dilobopterus costalimai (Young 1977: 146).

- Alas posteriores con área jugal pequeña 16

16. Eje aedeagal, en vista lateral, con una expansión dorsal de posición media. Margen dorsal de la valva II del ovipositor con dientes discontinuos y protuberantes, cada diente con el margen posterior en declive llevando diminutos dentículos Plesiommata mollicella (Young 1977:596; Cap. II: 149).

- Eje aedeagal, en vista lateral, abruptamente expandido en el ápice, sin expansión mediana. Margen dorsal de la valva II con dientes continuos, no protuberantes, cada diente con el margen posterior cóncavo llevando dentículos de mayor tamaño P. corniculata (Young 1977: 598; Cap. II: 147).

17. Alas anteriores con el tercio apical membranoso, incluyendo parcialmente las celdas anteapicales. Coloración general verde-amarillenta con o sin marcas negras en la corona.

Bucephalogonia xanthophis (Cap. II: 43).

- Alas anteriores con el cuarto apical membranoso, incluyendo sólo las celdas apicales. Coloración variable 18

18. Alas anteriores con el margen apical ligeramente cóncavo; con tres celdas anteapicales de las cuales la más externa es lenticular y no alcanza las celdas apicales; con tres celdas apicales. Patrón de coloración dorsal con una banda longitudinal continua o interrumpida, blanquecina y de posición media que no 
alcanza el ápice claval del tegmen

Diedrocephala bimaculata (Young 1977: 324; Cap. II: 66).

- Alas anteriores con ápice convexo; con cuatro celdas anteapicales y cuatro apicales.

Coloración diferente a la anterior

19. Patrón de coloración de las alas anteriores con bandas longitudinales paralelas.

- Patrón de coloración de las alas anteriores uniforme

20. Tegmen con bandas longitudinales paralelas de color negro y verde; cabeza con dos bandas longitudinales que convergen anteriormente y se proyectan posteriormente hasta el ápice claval. Estilos del macho con lóbulo preapical. Sibovia sagata (Cap. II: 176).

- Tegmen con bandas longitudinales paralelas de color anaranjado y verde; cabeza con una banda anaranjada paralela al margen anterior. Estilos del macho sin lóbulo preapical Ferrariana trivittata (Young 1977: 1030; Cap II.: 86).

21. Tegumento de color castaño oscuro a castaño ferruginoso 22

- Tegumento de color verde brillante a verde-amarillento 24

22. Especímenes pequeños menores a $6 \mathrm{~mm}$. Alas anteriores con dos celdas apicales. Conectivo del macho compuesto por dos escleritos Ciminius Young

A. Eje aedeagal, en vista lateral, con un proceso lobado postero-dorsal. Pigóforo de la hembra alargado con macrosetas en la proyección posterior y a lo largo del margen ventral C. yana (Young 1977: 590; Cap II.: 60).

- Eje aedeagal, en vista lateral, simple, sin el proceso postero-dorsal, con una constricción preapical y el margen ventral usualmente dentado. Pigóforo de la hembra ovalado con macrosetas en la mitad posterior C. platensis (Young 1977: 592; Cap II.: 60).

- Especímenes medianos a grandes, mayores a $6 \mathrm{~mm}$. Alas anteriores con cuatro o cinco celdas apicales. Conectivo de los machos conformado por un esclerito

23. Tegumento castaño oscuro a negro, con cuatro bandas pálidas transversales, una en el pronoto y el resto sobre el tegmen. Alas anteriores coriáceas con venas usualmente no distintivas; con cinco celdas apicales. Eje aedeagal, en 
vista lateral, estrecho y curvado $180^{\circ}$ desde la base, con dos procesos apicales Balacha melanocephala (Young 1977: 726; Cap II.: 35).

- Tegumento amarillento a castaño claro; cabeza, pronoto y escutelo con dos bandas negras longitudinales de posición sublateral. Alas anteriores coriáceas de color ferruginoso con venas marcadas, amarillentas; con cuatro celdas apicales. Eje aedeagal, en vista lateral, con un par de procesos ventrales originándose cerca de la base.....

Sonesimia grossa (Young 1977: 1085; Cap II.: 190).

24. Márgenes anterolaterales de la corona, en vista dorsal, convexos. Alas anteriores con plexo anteapical de venas.

Draeculacephala tucumanensis (Cap. II: 82).

- Márgenes de la corona rectos. Alas anteriores sin plexo anteapical de venas 26

26. Área basal de las alas anteriores punteada. Fórmula setal del fémur posterior usualmente 2:1:0 Syncharina argentina (Cap. II: 204).

- Alas anteriores sin puntos. Fórmula setal del fémur posterior usualmente $2: 1: 1$ 27

27. Cabeza y margen anterior del pronoto, con una mancha negra en forma de T. Alas anteriores con las dos celdas anteapicales más internas abiertas basalmente. Pigóforo del macho con procesos. Machos con paráfisis Scopogonalia Young

A. Alas anteriores de color verde brillante, con algunas celdas negras. Edeago con una estructura dorsoapical a modo de "capucha" S. osteiphera (Leal et al. 2016: 12).

- Alas anteriores de color uniforme, verde oliváceo. Edeago sin la estructura dorsoapical. S. subolivacea (Young 1977: 530; Cap II.: 172).

- Cabeza y margen anterior del pronoto con manchas negras. Alas anteriores con las tres celdas anteapicales cerradas basalmente. Pigóforo del macho sin procesos. Machos sin paráfisis Hortensia similis ((Young 1977:810; Cap II.: 92). 


\section{CONCLUSIONES}

En el presente capítulo se estudió la composición faunística de las especies de auquenorrincos, particularmente de la subfamilia Cicadellinae, en agroecosistemas citrícolas del norte de la Argentina; en el NEA (Bella Vista, Corrientes) y en el NOA (Yatasto, Salta y Lules, Tucumán) se realizaron las siguientes contribuciones:

En el NEA,

-Se identificaron 50 especies de auquenorrincos pertenecientes mayormente a la familia Cicadellidae (33), distribuídas en las subfamilias Cicadellinae, Coelidiinae, Deltocephalinae, Iassinae, Ledrinae, Megophthalminae, Typhlocybynae y Xestocephalinae; y a Membracidae, con 12 especies pertenecientes a las subfamilias Darninae, Membracinae y Smilinae.

-Se identificó una especie nueva del género Webaskola (Iassinae).

-Se registró por primera vez para la Argentina al vector de Xf, Plesiommata corniculata asociada a agroecosistemas citrícolas en la provincia de Corrientes.

-Se registraron 12 nuevas citas para la provincia de Corrientes, reunidas en siete especies: Adippe alliacea, Ceresa vitulus, Copididonus vittulatus, Cyphonia braccata, Frequenamia spiniventris, Plesiommata corniculata y Scaphytopius bolivianus, y cinco géneros: Aconophora, Microtalus, Notocera, Portanus y Stictopelta.

-Se registraron 15 nuevas asociaciones con agroecosistemas citrícolas: Adippe alliacea, Bergallia sp., Ceresa vitulus, Chlorotettix oglobini, Cyphonia braccata, Curtara compacta, C. mellella, Deois (Deois) knoblauchii, D. (Deois) mourei, Graminella puncticeps, Micrutalis sp., Notocera sp., Notozulia entreriana, Stictopelta sp. y Webaskola sp.

-Particularmente de la subfamilia Cicadellinae se colectaron un total de 5245 especímenes. La tribu Cicadellini presentó el mayor número de especies $(S=12)$ tanto en los cítricos (9) como en la vegetación espontánea (10) mientras que los Proconiini estuvieron representados por cuatro especies de las cuales sólo una fue recolectada en la vegetación circundante al cultivo.

-En los muestreos realizados con trampas adhesivas amarillas, dos especies de Cicadellinae fueron predominantes: Dilobopterus costalimai y Molomea lineiceps, mientras que en la vegetación circundante a los cítricos, predominó sólo la especie Hortensia similis. 
-El riego no influyó sobre la abundancia de la especie Molomea lineiceps, mientras que Dilobopterus costalimai resultó significativamente más abundante en la parcelas regadas.

-Del total de las especies de Cicadellinae identificadas, sólo cuatro fueron recolectadas con trampas adhesivas amarillas: Acrogonia virescens, Dilobopterus costalimai, Molomea lineiceps y Tetrogonia notatifrons y tres fueron únicamente asociadas a la vegetación espontánea: Hortensia similis, Plesiommata corniculata y Plesiommata mollicella.

-Se registró por primera vez a las especies Plesiommata corniculata y Acrogonia virescens en agroecosistemas citrícolas del NEA, lo que eleva a 10 el número de especies vectoras de $X f$ asociadas a este agroecosistema.

-Durante el período de muestreo, se observaron dos aumentos poblacionales de la especie Dilobopterus costalimai, uno en los meses de verano y otro durante el otoño, coincidentes con épocas de precipitaciones elevadas y temperatura promedio de 23$28^{\circ} \mathrm{C}$; el mayor, coincidente con la brotación más intensa. Molomea lineiceps presentó dos incrementos de su población, uno en el invierno y otro en la primavera, y en concordancia con la segunda y primera brotación, respectivamente. En la vegetación circundante a los cítricos, se observó un fuerte incremento de la población de Hortensia similis durante el invierno, cuando la temperatura y las precipitaciones descienden marcadamente.

-Por primera vez, se describió e ilustró mediante fotografías, el quinto estadio larval de las especies Hortensia similis, Sonesimia grossa y Tapajosa rubromarginata.

-Se confeccionó una clave para la identificación del 5ํo estadio larval de cinco especies de cicadelinos presentes en agroecosistemas citrícolas estableciéndose como caracteres diagnósticos la coloración general del cuerpo, forma del ápice de la cabeza y longitud de los esbozos alares respecto de los segmentos abdominales.

-Respecto de los enemigos naturales de los cicadelinos presentes en el área estudiada:

-Se registraron nematodes de la familia Mermithidae parasitando seis larvas del quinto estadio y un adulto de Hortensia similis.

-Se identificaron tres especies de parasitoides oófilos atacando posturas de Molomea lineiceps sobre los cítricos: Cosmocomoidea annulicornis, C. metanotalis (nueva asociación) (Hymenoptera: Mymaridae) y Burksiella sp. (Hymenoptera: Trichogrammatidae) (nueva asociación). 
-Se registraron estrepsípteros de la familia Halictophagidae en adultos de Hortensia similis.

-Por primera vez se registra un juvenil de la familia Salticidae (Araneae) alimentándose activamente de un ejemplar adulto de Macugonalia cavifrons.

Los resultados obtenidos en esta tesis junto con los datos registrados previamente para las provincias de Misiones y Entre Ríos permiten establecer la situación actual de los cicadelinos en las principales áreas citrícolas productoras de la región Litoral.

\section{En el NOA,}

-Se colectaron un total de 733 ejemplares de Cicadellinae (435 sobre cítricos y 298 sobre la vegetación circundante).

-Se identificaron 16 especies y dos aún no identificadas de los géneros Borogonalia y Oragua. La tribu Cicadellini fue la mejor representada (12 especies).

-Se registró un nuevo género para la Argentina (Borogonalia).

-Se registraron ocho nuevas especies para la provincia de Salta (Bucephalogonia xanthophis, Ciminius yana, Diedrocephala bimaculata, Dilobopterus costalimai, Macugonalia cavifrons, M. leucomelas, M. sobrina, Scopogonalia subolivacea) y seis para Tucumán (B. xanthophis, Hortensia similis, M. cavifrons, M. leucomelas, M. sobrina, S. subolivacea).

-Se registraron cinco nuevas asociaciones con agroecosistemas citrícolas (Borogonalia sp., C. yana, Draeculacephala tucumanensis, Scopogonalia osteiphera, Tapajosa similis).

-En los agroecosistemas estudiados, las especies más abundantes recolectadas sobre los cítricos fueron Macugonalia cavifrons y Scopogonalia subolivacea, seguidas por el proconino Molomea lineiceps y Scopogonalia osteiphera. En la vegetación circundante al cultivo, $H$. similis fue la especie más abundante en Tucumán mientras que en la provincia de Salta los individuos se distribuyeron de manera equitativa.

-Del total de las especies identificadas en el NOA, cuatro fueron recolectadas únicamente sobre los cítricos: S. osteiphera, M. cavifrons, M. sobrina y B. xanthophis; y siete fueron asociadas únicamente a la vegetación espontánea: $D$. tucumanensis, $P$. mollicella, M. leucomelas, C. yana, Oragua sp. y el proconino T. similis. 
-En los agroecosistemas citrícolas del noroeste se hallaron tres especies vectoras de Xf: B. xanthophis, Dilobopterus costalimai y el proconino Oncometopia facialis, y seis de las especies confirmadas como portadoras de la bacteria en Misiones y/o Entre Ríos: B. xanthophis, H. similis, M. leucomelas, P. mollicella, M. lineiceps y T. rubromarginata.

-Se confeccionó una clave taxonómica para la identificación de las especies de Cicadellinae presentes en agroecosistemas citrícolas de la Argentina utilizando como caracteres diagnósticos rasgos del tegumento (coloración general, pubescencia, esculturación), caracteres de la cabeza (forma del margen anterior), tórax (forma del pronoto, nerviación del primer par de alas, fórmula setal del fémur posterior), rasgos de la genitalia de los machos (morfología y quetotaxia de las placas subgenitales, pigóforo y estilos, morfología del conectivo y del edeago) y de las hembras (margen posterior del esternito abdominal VII, pigóforo y rasgos de la valva II del ovipositor).

\section{PERSPECTIVAS}

Los futuros trabajos deberían estar enfocados en:

-Avanzar en la prospección de áreas zoogeográficas poco estudiadas, principalmente en el NOA, con la intención de conocer en mayor profundidad las especies de Cicadellinae allí presentes.

-Estudiar desde el punto de vista taxonómico todas las especies de Cicadellini presentes en la Argentina, no sólo las asociadas a agroecosistemas citrícolas, ya que todas poseen potencialidad vectora.

-Encarar estudios filogenéticos entre los distintos taxa incluyendo caracteres morfológicos y moleculares.

-Considerando la escasez de datos biológicos para la mayoría de los cicadelinos es fundamental profundizar el estudio de la biología y la relación con sus plantas hospedadoras, sobre todo de aquellas especies que resulten predominantes en los cultivos.

-Avanzar en los ensayos de detección y transmisión de $X f$ en aquellas especies que resultaron predominantes o que poseen antecedentes como portadoras y/o vectoras, en países limítrofes, para avanzar en el conocimiento de las especies vectoras de cada región. 


\section{BIBLIOGRAFÍA CITADA}

AGOSTINI J. P. 1993. Clorosis Variegada de los cítricos (CVC). XVI Jornada Citrícola Nacional. INTA Concordia: 9-10.

AGUILAR E., VILLALOBOS W., MOREIRA L., RODRIGUEZ C.M., KITAJIMA E.W. \& RIVERA C. 2005. First report of Xylella fastidiosa infecting citrus in Costa Rica. Plant Disease 89(6): 687.

ALMEIDA R. P. P. \& LOPES J. S. 1999. Desenvolvimento de Imaturos de Dilobopterus costalimai Young e Oncometopia facilais (Signoret) e Homalodisca ignorata Melichar (Hemiptera: Cicadellidae) em citros. Anais da Sociedade Entomológica do Brasil 28: 179182.

ALMEIDA R. P. P. \& NUNNEY L. 2015. How do plant disease caused by Xylella fastidiosa emerge? Plant Disease 99: 1457-1467.

ALVES E., LEITE B., MARUCCI R. C., PASCHOLATI S. F., LOPES J. R. S., ANDERSON P. C. 2008. Retention sites for Xylella fastidiosa in four sharpshooter vectors (Hemiptera: Cicadellidae) analyzed by scanning electron microscopy. Current Microbiology 56: 531538.

ALMEIDA R.P.P. \& LOPES J.S. 1999. Desenvolvimento de imaturos de Dilobopterus costalimai Young, Oncometopia facialis (Signoret) e Homalodisca ignorata Melichar (Hemiptera: Cicadellidae) em citros. Anais da Sociedade Entomológica do Brasil 28: 179182.

ALVES E., LEITE B., MARUCCI R. C., PASCHOLATI S. F., LOPES J. R. S. \& ANDERSEN P. C. 2008. Retention sites for Xylella fastidiosa in four sharpshooter vectors (Hemiptera: Cicadellidae) analyzed by scanning electron microscopy. Current Microbiology 56: 531538.

ANDERSEN P.C., BRODBECK B.V. \& MIZELL III R.F. 1989. Metabolism of amino acids, organic acids and sugars extracted from the xylem fluid of four host plants by Homalodisca coagulata. Entomologia Experimentalis et Applicata 50: 149-159. 
ANDERSEN P. C., BRODBECK B. V. \& MIZELL III R. F. 1992. Feeding by the leafhopper, Homalodisca coagulata, in relation to xylem fluid chemistry and tension. Journal of Insect Physiology. 38 (8): 611-622.

ANUFRIEV G.A. \& EMELJANOV A.F. 1988. The Suborder Cicadinea (Auchenorrhyncha). Opredelitel'nasekomykh Dal'nego Vostoka SSSR (A key to insects of the Far East of the USSR, Vol. 2. Nauka, Leningrad. 495 pp.

ÁVILA-RODRÍGUEZ V., MYARTSEVA S. N. \& GONZÁLEZ-HERNÁNDEZ A. 2011. Una nueva especie de Burksiella de México (Hymenoptera: Trichogrammatidae). Acta Zoológica Mexicana 27(1): 77-85.

AZEVEDO-FILHO W. S. \& CARVALHO G. S. 2004. Guia para coleta e identificação de cigarrinhas em pomares de citros no Rio Grande do Sul. Edipucrs, Porto Alegre. 87 pp.

AZEVEDO-FILHO W.S. \& CARVALHO G.S. 2005. Brochocomes-for-eggs of the Proconiini (Hemiptera: Cicadellidae, Cicadellinae) species associated with orchards of Citrus sinensis (L) Osbeck in Rio Grande do Sul, Brazil. Neotropical Entomology 34(3): 387-394.

AZEVEDO-FILHO W. S. \& CARVALHO G. S. 2006. Cigarrinhas de citros no Rio grande do Sul: Taxonomia. Edipucrs, Porto Alegre. 141 pp.

BASSET Y. \& CHARLES E. 2000. An annotated list of insect herbivores foraging on the seedlings of five forest trees in Guyana. Anais da Sociedade Entomologica do Brasil 29: 433-452.

BAUTISTA L. G, CARDONA J. A., SOTO A, VELEZ E. 2014. Actividad entomopatógena de tres hongos sobre Hortensia similis (Hemiptera: Cicadellidae) y Collaria scenica (Hemiptera: Miridae) en sistemas silvopastoriles. Boletín Científico Centro de Museos Museo de Historia Natural 18 (1): 188-196.

BELTRÁN V. M., CÁCERES S., ZUBRZYCKI H., PLOPER D., WILLINK E. \& JALDO H. 2004. CVC Associated vectors in Valencia Orange of Corrientes, Argentina. Proceedings of the International Society of Citriculture: 10th International Citrus Congress 75-83.

BENREY B. \& LAMP W. 1994. Biological Control in the Management of Planthopper Populations. En: Denno R. F. \& Perfect T. J. (eds). Planthoppers: Their Ecology and Management, Part Five Ecological Approaches to Planthopper Management: 519-550. Chapman \& Hall, New York. 
BLANCHARD E. 1840. Histoire Naturelle des Insectes Orthoptheres, Neuropteres, Hemipteres, Hymenopteres, Lepidopteres, et Dipteres. P. Dumenil, Paris, 3: 672 pp.

BOUDREAUX H. 1979. Arthropod phylogeny with special reference to insects. J Wiley and Sons, New York. 320 pp.

BRLANSKY R. H., DAVIS C. L., TIMMER T. W., HOWD D. S. \& CONTRERAS J. 1991. Xylem- limited bacteria in citrus from Argentina with symptoms of citrus. Phytopathology 81: 1210 .

BRODBECK B., MIZELL III R.F. \& ANDERSEN P. 1993. Physiological and behavioral adaptations of three species of leafhoppers in response to the dilute nutrient content of xylem fluid. Journal of Insect Physiology 39(1): 73-81.

BRODBECK B. V., ANDERSEN P. C., MIZELL R. F. 1995. Differential utilization of nutrients during development by the xylophagous leafhopper, Homalodisca coagulata. Entomologia Experimentalis et Applicata 75:279-89.

BRODBECK B. V., ANDERSEN P. C. \& MIZELL R. F. 1996. Utilization of primary nutrients by the polyphagous xylophage, Homalodisca coagulata, reared on single host species. Archives of Insect Biochemistry and Physiology 32(1): 65-83.

BRODBECK B. V., ANDERSEN P. C., MIZELL R. F. 1999. The effects of total dietary nitrogen and amino acid balance on the development of xylophagous leafhoppers. Archives of Insect Biochemistry and Physiology 42:37-50.

CAMISÃO B. M., CAVICHIOLI R. R. \& TAKIYA D. M. 2014. Eight new species of Oragua Melichar, 1926 (Insecta: Hemiptera: Cicadellidae) from Amazonas State, Brazil, with description of the female terminalia of Oragua jurua Young, 1977, and new records for the genus. Zootaxa 3841 (4): 501-527.

CAMPBELL B., STEFFEN-CAMPBELL J., SORENSEN J. \& GILL R. 1995. Paraphyly of Homoptera and Auchenorrhyncha inferred from 18S rDNA nucleotide sequences. Systematic Entomology 20: 175-194.

CARVALHO R.A. \& MEJDALANI G. 2007. Taxonomic notes on Macugonalia geographica (Signoret) with descriptions of the male and female genitalia (Insecta: Hemiptera: Cicadellidae: Cicadellini). Studies on Neotropical Fauna and Environment 40(2): 143-148. 
CARVALHO R.A. \& MEJDALANI G. 2006. Two new species of the sharpshooter genus Desamera from northern Brazil (Insecta: Hemiptera: Cicadellidae). Zootaxa 1109: 15-26.

CARVALHO R. A. \& MEJDALANI G. 2014. Remarkable morphological features of taxonomic interest in the female genitalia of five Erythrogonia species (Hemiptera: Cicadomorpha: Cicadellidae). Zootaxa 3872: 275-290.

CARVALHO R.A., LOPES M.M \& RODRIGUES L.G.N. 2015. Espécies de cigarrinhas em cultivo de café no município de Santa Teresa, Espírito Eanto, Brasil (Hemiptera, Cicadellidae, Cicadellinae). Papéis Avulsos de Zoologia 55(13): 205-210.

CARVER M., GROSS G. \& WOODWARD T. 1991. Hemiptera. En Csiro. The insects of Australia. A text book for students and research workers. Vol 1., Melbourne University Press, Carlton. 429-509 pp.

CAVICHIOLI R. R. 1992. Análise cladística do grupo Paromenia Young, 1977, revisao e análise cladística de Parathona Melichar, 1926 (Homoptera, Cicadellidae, Cicadellinae). Ph.D. thesis, Universidade Federal do Paraná.

CAVICHIOLI R. R. 1996. Albiniana gen. n. e revalidacao de Alocha Melichar (Homoptera, Cicadellidae, Cicadellinae). Revista Brasilera de Zoologia 13: 677-683.

CAVICHIOLI R.R. 1997. Análise cladística e revisao de Parathona Melichar (Homoptera, Cicadellidae, Cicadellinae). Revista Brasilera de Zoologia 14: 523-537.

CAVICHIOLI R. R. \& WYLER M. R. 1992. Descrição da fêmea de Onega bracteata Young (Homoptera, Cicadellidae, Cicadellinae). Revista Brasilera de Zoologia 9: 127-129.

CHU H. \&. TENG K. F. 1950. Life history of the leafhopper, Cicadella viridis L. Homoptera: Cicadellidae. Acta Entomologica Sinica 1(1): 14-40.

COELHO J. H. C., XIMENES N. L., FELIPPE M. R., MONTESINO L. H., GARBIM L. F., SANCHES A. L., DALLA PRIA W. J. \& YAMAMOTO P. T. 2008. Faunistic Analysis of Sharpshooters (Hemiptera: Auchenorrhyncha, Cicadellidae) in a 'Westin' Sweet Orange Orchard. Neotropical Entomology 37(4): 449-456.

COLETTA F. H. D. \& MACHADO M. A. 2003. Geographical genetic structure of Xylella fastidiosa from citrus in São Paulo state, Brazil. Phytopathology (93): 28-34.

CONTRERAS J.V. 1990. Pecosita o falsa mancha grasienta: nueva enfermedad en naranjos en la provincia de Misiones. Citrusmisiones: 1-7. 
COSTA N., PLATA M.I., GARRÁN S.M. \& MIKA R. 2009. Detección de Clorosis Variegada de los Cítricos (CVC) en el Departamento de Concordia, provincia de Entre Ríos. XIII Jornadas Fitosanitarias Argentinas. Santiago del Estero. Resumen publicado en actas E021.

COSTA LIMA A. M. 1942. Insetos do Brasil, Homópteros. Escola Nacional de Agronomia 3 (23): 65.

CRONIN J. T. \& STRONG D. 1994. Parasitoid interactions and their contribution to the stabilization of Auchenorrhyncha populations, En: liz R. F. Denno and T. J. Perfect [eds.], Planthoppers: their ecology and management: 400-428. Chapman and Hall, New York.

CRYAN J.R. 2005. Molecular phylogeny of Cicadomorpha (Insecta: Hemiptera: Cicadoidea, Cercopoidea and Membracoidea): adding evidence to the controversy. Systematic Entomology 30(4): 563-574.

CRYAN J.R. \& URBAN J.M. 2012. Higher-level phylogeny of the insect order Hemiptera: is Auchenorrhyncha really paraphyletic?. Systematic Entomology 37: 7-21.

DAMSTEEGT V. D., BRLANSKY R. H., PHILLIPS P. A. \& ROY A. 2006. Transmission of Xylella fastidiosa, causal agent of Citrus Variegated Chlorosis, by the glassywinged sharpshooter, Homalodisca coagulata. Plant Disease 90: 567-570.

DE COLL O.R. 1996. Estudio sistemático y bioecológico de Homópteros Cicadelidos, potenciales vectores de la "Clorosis Variegada de los Cítricos". Tesis de Maestría en Protección Vegetal. UNLP. Buenos Aires, 268 pp.

DE COLL O.R., REMES LENICOV A.M.M., AGOSTINI J. \& PARADELL S. 2000a. Detection of Xylella fastidiosa in weeds and sharpshooters in orange groves affected with Citrus Variegated Chlorosis in Misiones, Argentina. Proceeding of the 14th Internacional Organization of Citrus Virologists Conference. InsectTransmitted Procaryotes: 216-222.

DE COLL O.R., REMES LENICOV A.M.M., AGOSTINI J. \& PARADELL S. 2000b. Some factors in a Pest Management Program for Valencia Sweet Orange Groves with Citrus Variegated Chlorosis (CVC). Proceeding of the 14th Internacional Organization of Citrus Virologists Conference. Insect-Transmitted Procaryotes: 238-242.

DECOURSEY R. M. \& ESSELBAUGH C. O. 1962. Descriptions of the nymphal stages of some North American Pentatomidae (Hemiptera: Heteroptera). Annals of the Entomological Society of America. 55: 323-341. 
DEFEA B. \& PARADELL S. 2016. Comparative morphology of female genitalia of the sharpshooter genus Syncharina (Hemiptera: Cicadellidae), with notes on the generic group Cicadella. Zoologischer Anzeiger 266: 148-157.

DEFEA B., PARADELL S., REMES LENICOV A. M. M. de. 2016. The genus Plesiommata Provancher (Hemiptera: Cicadellidae) in Argentina. First detailed description of the female genitalia and comparisons with its Neotropical congeners. Austral Entomology. 55:1-6.

DE LIMA J., MIRANDA V. S., HARTUNG J. S., BRLANSKY R. H., COUTINHO A. 1998. Coffee leaf scorch bacterium: axenic culture, pathogenicity, and comparison with Xylella fastidiosa of citrus. Plant Diseases. 82: 94-97.

DENNO R. E \& RODERICK G. K. 1990. Population biology of planthoppers. Annual Review of Entomology 35: 489-520.

DELLAPÉ G. 2013. Cicadelinos potenciales vectores de patógenos en cultivos citrícolas del NE argentino. Estudios taxonómicos y moleculares (Insecta: Hemiptera: Cicadellidae) Tesis Doctoral. Facultad de Ciencias Naturales y Museo. Universidad Nacional de La Plata. $227 \mathrm{pp}$.

DELLAPE G. 2015. Description of the female terminalia of twenty species of Proconiini (Hemiptera Cicadellidae) from Argentina. Zootaxa 3915: 521-539.

DELLAPÉ G. \& PARADELL S. 2011. First record of the genus Homalodisca (Hemiptera: Cicadellidae) from Argentina and redescription of the female of H. ignorata. Revista de la Sociedad Entomológica Argentina 70(3-4): 363-367.

DELLAPE G., BOUVET J.P. \& PARADELL S. 2016. Diversity of Cicadomorpha (Hemiptera: Auchenorrhyncha) in Citrus Orchards in Northeastern Argentina. Florida Entomologist 96: 1125-1134.

DIAMANTE A., ZUBRZYCKI H.M., DOCAMPO D. \& HAELTERMAN R. 1999.- Clorosis Variegada de los Cítrus. Una nueva enfermedad que afecta la citricultura comercial. Serie Mejoramiento Cítrico. Informe Técnico $\mathrm{N}^{\circ} 2$.

DIETRICH C. H. 1994. Systematics of the Leafhopper Genus Draeculacephala Ball (Homoptera:Cicadellidae). Transactions of the American Entomological Society 120 (2): 87-112. 
DIETRICH C. H. 1999. The role of grasslands in the diversification of leafhoppers (Homoptera: Cicadellidae): A phylogenetic perspective. Proceedings of the $15^{\text {th }}$ North American Prairie Conference: 44-49.

DIETRICH C.H. 2005. Keys to the families of Cicadomorpha and subfamilies and tribes of Cicadellidae (Hemiptera: Auchenorrhyncha). Florida Entomologist 88: 502-517.

DIETRICH C.H. 2013. Overview of the phylogeny, Taxonomy and Diversity of the Leafhopper (Hemiptera: Auchenorrhyncha: Cicadomorpha: Membracoidea: Cicadellidae) Vectors of Plant Pathogens. Proceedings of the 2013 International Symposium on the Insect Vectors and Insect-Borne Diseses. 47-70 pp.

DIETRICH C. \& DEITZ L. 1993. Superfamily Membracoidea (Homoptera: Auchenorrhyncha). II. Cladistic analysis and conclusions. Systematic Entomology 18: 297311.

DIETRICH C. H. \& POOLEY C. D. 1994. Automated identification of Leafhoppers (Homoptera: Cicadellidae: Draeculacephala Ball). Annals of the Entomological Society of America 87(4): 412-423.

DIETRICH C. H., MCKAMEY S. H. \& DEITZ L. L. 2001a. Morphology-based phylogeny of the treehopper family Membracidae (Hemiptera: Cicadomorpha: Membracoidea). Systematic Entomology 26: 213-239.

DIETRICH C.H., RAKITOV R.; HOLMES J. \& BLACK W. 2001b. Phylogeny of the major lineages of Membracoidea (Insecta: Hemiptera: Cicadomorpha) based on 28S rDNA sequences. Molecular Phylogenetics and Evolution 18(2): 293-305.

DI RIENZO J. A., CASANOVES F., BALZARINI M. G., GONZALEZ L., TABLADA M. \& ROBLEDO C. W. InfoStat versión 2012. Grupo InfoStat, FCA, Universidad Nacional de Córdoba, Argentina. http://www.infostat.com.ar

DMITRIEV D. 2010. Homologies of the head of Membracoidea based on nymphal morphology with notes on other groups of Auchenorrhyncha (Hemiptera). European Journal of Entomology. 107: 597-613.

DOBEL H. G. \& DENNO R. F. 1994. Predator planthopper interactions. En: R. E Denno \& T. J. Perfect [eds.]. Planthoppers: their ecology and management: 325-399. Chapman and Hall, NY. 
DOS SANTOS D., LOPES DE SIQUEIRA D. \& COUTINHO PICANÇO M. 2005. Flutuação populacional de espécies de cigarrinhas transmissoras da Clorose Variegada Dos Citros (CVC) em Viçosa - MG. Revista Brasileira de Fruticultura 27(2): 211-214.

DWORAKOWSKA I. 1988. Main veins of the wings of Auchenorrhyncha (Insecta, Rhynchota: Hemelytrata). Entomologische Abhandlungen Staatliches Museum für Tierkunde Dresden 52(1-3): 63-108.

EVANS J. 1947. A natural classification of leafhoppers (Jassoidea, Homoptera), Part 3, Jassidae. Transactions of the Entomological Society of London 98: 105-271.

FABIANI A., MIKA R., LAROCCA L. \& ANDERSON C. 1996. Manual para productores de naranja y mandarina de la región del Rio Uruguay. PRODIP - Proyecto de Diversificación Productiva INTA - Estación Experimental Agropecuaria Concordia Manual Serie A № 2, $215 \mathrm{pp}$.

FABRICIUS J.C. 1775. Ryngota. Systema entomologiae, sistens insectorum classes, ordines, genera, species, adiectis, synonymis, locis, descriptionibus, observationibus. 1816.

FABRICIUS J. C. 1794. Ryngota. Entomologia systematica emendata et aucta. Secundum classes, ordines, genera, species adjectis synonimis, locis, observationibus, descriptionibus 4: 1-472.

FAZOLIN M. 1991. Análise faunística de insetos coletados com armadilha luminosa em seringueira no acre. Tese (Doutorado na área de entomología) - Escola Superior de agricultura "Luis Queiroz", Universidade de Sao Paulo, Piracicaba. 236 pp.

FOWLER W. 1900. Insecta Rhynchota. Hemiptera-Homoptera. Biologia CentraliAmericana Vol I, 2: 257-264.

FREYTAG P. H. \& SHARKEY M. J. 2002. A preliminary list of the leafhoppers (Homoptera: Cicadellidae) of Colombia. Biota Colombiana 3(2): 235-283.

FUNDECITRUS 1999. Descobertos mais seis vetores de CVC. Revista Fundecitrus 94:8-9.

GALLEGO F.L. \& VELEZ A.R. 1992. Lista de insectos que atacan los principales cultivos, plantas forestales, animales domésticos y al hombre en Colombia. Medellín: Centro de publicaciones. Universidad Nacional de Colombia. 150p. 
GARITA-CAMBRONERO J., VILLALOBOS W., GODOY C. \& RIVERA C. 2008. Diversidad de cicadélidos y clastoptéridos (Hemiptera) en tres zonas productoras de café afectadas por Xylella fastidiosa Wells et al. en Costa Rica. Neotropical Entomology. 37(4): 436-448.

GERMAR E.F. 1821. Bermerkungen über einige Gattungen der Cicadarien. Magazin der Entomologie 4: 1-106.

GIUSTOLIN T. A., LOPES J. R. S., QUERINO R. B., CAVICHIOLI R. R., ZANOL K., AZEVEDOFILHO W. S. \& MENDES M. A. 2009. Diversidade de Hemiptera Auchenorrhyncha em Citros, Café e Fragmento de Floresta Nativa do Estado de São Paulo. Neotropical Entomology 38(6): 834-841.

GODOY C. \& WEBB M.D. 1994. Recognition of a new subfamily of Cicadellidae from Costa Rica based on a phenetic analysis with similar taxa (Hemiptera: Homoptera: Auchenorrhyncha). Tropical Zoology 7: 131-144.

GRAVENA S., LOPES J. R. S., PAIVA P. E. B., YAMAMOTO P. T. \& ROBERTO S. R. 1998. Os vetores da Xylella fastidiosa. En: Donadio L.C. \& Moreira C.S. (eds). Clorose variegada dos citros: 37-53. Bebedouro.

GREEN J. 1996. Spiders in biological control- Na Australian perspective. Revue Suisse de Zoologie, Geneva, vol. hors série, p. 245-253.

GRIMALDI D. \& ENGEL M.S. 2004. Evolution of the Insects. Cambridge University Press, New York, USA. 755 pp.

GULLAN P. 1999. Why the taxon Homoptera does not exist? Entomologica 33: 101104.

HACKMAN L.M. 1922. Studies on Cicadella hieroglyphica Say (Homoptera: Cicadellidae). The Kansas University Science Bulletin 14: 189-209.

HAELTERMAN R. M., NOME C. F., DOCAMPO D. M. \& NOME S. F. 1996. Hospedantes de Xyllela fastidiosa, bacteria causal de la escaldadura del borde de la hoja del almendro (Prunus amygdalus). Revista de Investigaciones Agropecuarias INTA 26(2): 65-72.

HAELTERMAN R. M., TOLOCKA P. A., ROCA M. E., GUZMÁN F. A., FERNÁNDEZ F. D. \& OTERO M. L. 2015. First presumptive diagnosis of Xylella fastidiosa causing olive scorch in Argentina. Journal of Plant Pathology (97): 393. 
HARTUNG J. S., BERETTA J., BRLANSKY R. H., SPISSO J. \& LEE R. 1994. Citrus variegated chlorosis bacterium: axenic culture, pathogenicity, and serological relationships with other strains of Xylella fastidiosa. Phytopathology 84: 591-597.

HAMILTON K. 1981. Morphology and evolution of the Rhynchotan head (Insecta: Hemiptera: Homoptera). The Canadian Entomologist 113: 953-974.

HAMILTON K. 1983. Classification, morphology and phylogeny of the family Cicadellidae (Rhynchota: Homoptera). En: Knight W.J.; Pant N.C., Robertson T.S. \& Wilson M.R. (eds). Proceedings of the 1st International Workshop on Biotaxonomy, Classification and Biology of Leafhoppers and Planthoppers (Auchenorrhyncha) of Economic Importance, London 15-37pp.

HAMILTON K. G. A. 1985. Review of Draeculacephala Ball (Homoptera, Auchenorrhyncha, Cicadellidae). Zoologische Abhandlungen 49(5): 83-103.

HARRIS K. F. \& MARAMOROSCH K. eds. 2013. Vectors of Plant Pathogens. Nueva York, Academic press.

HENNIG W. 1981. Insect phylogeny. J Wiley and Sons, New York. 510 pp.

HERNANDEZ-MARTINEZ R., PINCKARD T. R., COSTA H. S., COOKSEY D. A. \& WONG F. P. 2006. Discovery and characterization of Xylella fastidiosa strains in southern California causing mulberry leaf scorch. Plant Disease 90: 1143-1149.

HICKEL E.R., JEAN-PIERRE H.J., DUCROQUET H.J., LEITE-JUNIOR R.P., LEITE R.M.V.B.C. 2001. Fauna de Homoptera: Auchenorrhyncha em pomares de ameixeira em Santa Catarina. Neotropical Entomology 30: 725-729.

HILL B. G. 1970. Comparative morphological study of selected higher categories of leafhoppers (Homoptera: Cicadellidae). PhD thesis in entomology, North Carolina State University, Raleigh, 186 pp.

HIX R. L. 2001. Egg laying and brochosome production observed in glassy winged sharpshooter. California Agriculture 55(4): 19-22.

HOPKINS D.L. 1989. Xylella fastidiosa: Xylem-limited bacterial pathogen of plants. Annual Review of Phytopathology 27: 271-290.

HOPKINS D.L. \& PURCELL A.H. 2002. Xylella fastidiosa: Cause of Pierce's disease of grapevine and others emergent diseases. Plant Disease 86: 1056-1066. 
http://picssr.com/

https://www.flickr.com/

https://www.projectnoah.org/

https://www.colinmcraephotography.com/

HUMMEL N.A., ZALOM F.G. \& PENG C.Y.S. 2006. Structure of female genitalia of glassywinged sharpshooter, Homalodisca coagulata (Say) (Hemiptera: Cicadellidae). Arthropod Structure \& Development 35: 111-125.

INFORME DEL SECTOR CITRÍCOLA EN LA ARGENTINA. 2014/2015. CFI. biblioteca.cfi.org.ar/wp-content/uploads/sites/2/2015/.../informe-sector-citricola.pdf

JANSE J. D. \& OBRADOVIC A. 2010. Xylella fastidiosa: its biology, diagnosis, control and risks. Journal of Plant Pathology 92 (1, Suppl.) S1.35-48.

KATHIRITHAMBY J. 1987. The twisted-winged parasitoid of Auchenorrhyncha. Proceedings 6th Auchenorrhyncha Meeting. Turín, Italia: 631-639.

KRAMER S. 1950. The morphology and phylogeny of auchenorhynchous Homoptera (Insecta). Illinois Biological Monographs 20: 1-111.

KRISTENSEN N. 1973. The phylogeny of hexapod "orders." A critical review of recent accounts. Zeitschrift fur Zoologische Systematik und Evolutions Forschung 13: 1-

KRISTENSEN, N.P. 1991. Phylogeny of extant Hexapods. En Csiro. The insects of Australia. A text book for students and research workers. Vol 2. Pp: 125-140. Cornell University Press, Ithaca, USA.

KRÜGNER R., LOPES M. T. V., SANTOS J. S., BERETTA M. J. G. \& LOPES J. R. S. 2000. Transmission efficiency of Xylella fastidiosa to citrus by sharpshooters and identification of two new vector species. Proceedings of 14th International Organization of Citrus Virologists Conference: 423.

KUKALOVÁ-PECK J. 1983. Origin of the insect wing and wing articulation from the arthropodan leg. Canadian Journal of Zoology 61: 1618-1669.

LAUZIÈRE I. \& SÉTAMOU M. 2010. Life history studies of Homalodisca vitripennis Hemiptera: Cicadellidae, a vector of Pierce's disease of grapevine. Annals of the Entomological Society of America. 103 (1): 57-65. 
LEAL A.H., MEJDALANI G., CAVICHIOLI R.R. \& CARVALHO R.A. 2009. Taxonomy and phylogeny of the leafhopper genus Scoposcartula (Insecta: Hemiptera: Cicadellidae). Systematics and Biodiversity, 7:215-233.

LEAL A. H., CREÃO-DUARTE A. J. \& MEJDALANI G. 2016. Taxonomic review of Scopogonalia Young, 1977(Insecta: Hemiptera: Cicadellidae: Cicadellini) with description of six new species. Journal of Natural History. http://dx.doi.org/10.1080/00222933.2016.1166530.

LEE R.F., BERETTA M.J.G., HARTUNG J.H., HOOKER M.E. \& DERRICK K.S. 1993. Citrus variegated chlorosis: confirmation of Xylella fastidiosa as the causal agent. Summa Phytopathologica 19(2): 123-125.

LEITE R.P. \& NUNES L. M. 2003. Avanços nas pesquisas sobre Xylella fastidiosa do café no Brasil. p. 87-101. En L. Zambolim (ed.), Produção integrada de café. Viçosa, DFP 709p.

LINNAVUORI R. 1979. Revision of African Cicadellidae (Homoptera: Auchenorrhyncha), Part I. Revue de Zoologie Africaine 93: 647-747.

LINNAEUS C. 1758. Hemiptera. Systema Naturae, per regna tria naturae, secundum classes, ordines, genera, species cum characteribus, differentilis synonymis, locis Ed 10. Rev 1: 1-824.

LINSKII V. G. 1980. Cicadella viridis. Zashchita Rastenii (7). 62pp.

LOGARZO G. A., VIRLA E. G., TRAPITSYN S. V. \& JONES W. A. 2004. Biology of Zagella delicada (Hymenoptera: Trichogrammatidae), an egg parasitoid of the sharpshooter Tapajosa rubromarginata (Hempitera: Clypeorrhyncha: Cicadellidae) in Argentina. Florida Entomologist 87(4): 511-516.

LOPES J.R.S. 1996. Mecanismo de transmissão de Xylella fastidiosa por cigarrinhas. Laranja 17: 79-92.

LOPES J.S. 1999. Estudos com vectores de Xylella fastidiosa e implicações no manejo da clorose variegada dos citros. Laranja 20(2): 329-344.

LOPES J.R.S. 2008. Non-hosts of Xylella fastidiosa that sharpshooters would die for. A management strategy based on trap plants. Pierce's Disease conference. Disponible en: https://docslide.com.br/documents/nonhosts-of-xylella-fastidiosa-that-sharpshooterswould-die-for-a-management-strategy-based-on-trap-plants-jrs-lopes-pierces-diseaseconference-2008.html. 
LOPES J.R.S. \& KRUGNER R. 2016. Vector-Mediated Transmission of Plant Pathogens. En: Lopes J. R. S. \& Krugner R., (eds.). Chapter 14: Transmission ecology and epidemiology of the citrus variegated chlorosis strain of Xylella fastidiosa: 195-208. The American Phytopathological Society.

LOPES J.R.S. 2017. Diversity of xylem feeders and their role in epidemiology of diseases caused by Xylella fastidiosa. European Conference on Xylella fastidiosa 2017: finding answers to a global problem. Disponible en: https://www.efsa.europa.eu/sites/default/.../171113-5.1_Lopes.pdf

LOZADA ROBLES P. W. \& ARELLANO CRUZ G. A. 2008. Lista preliminar comentada de las "cigarritas" (Insecta: Hemiptera: Cicadellidae) de Chanchamayo y Satipo, Perú. Ecología Aplicada 7(1-2): 117-122.

LUFT ALBARRACIN E., TRIAPITSYN S.V. \& VIRLA E.G. 2009. Annotated key to the genera of Mymaridae (Hymenoptera: Chalcidoidea) in Argentina. Zootaxa 2129: 1-28.

MAES, J.M \& GODOY C. 1993. Catálogo de los Cicadellidae (Homoptera) de Nicaragua. Revista Nicaragüense de Entomología 24: 5:34.

McCABE D. \& SOPER R. S. 1985. Preparation of and entomopathogenic fungal insect control agent. U.S. Patent 4530834.

MAMOUDOU S. \& WALKER A.A. 2005. Biology and biometry of sharpshooter Homalodisca coagulata (Homoptera: Cicadellidae) reared on cowpea. Annals of the entomological Society of America 98(3): 322-328.

MARCO-NOALES E., LANDA B. B. \& LÓPEZ M. M. 2017. Xylella fastidiosa y las enfermedades que causa. Un problema global. Cap. 1. En: Cajamar Caja Rural (eds). Enfermedades causadas por la bacteria Xylella fastidiosa: 19-37.

MARUCCI R.C., CAVICHIOLI R.R. \& ZUCCHI R.A. 2000. Descrição dos estádios imaturos de Acrogonia sp., Dilobopterus costalimai Young e Oncometopia facialis (Signoret) (Hemiptera: Cicadellidae: Cicadellinae). Anais da Sociedade Entomológica do Brasil 29: 667-681.

MARUCCI R.C., GIUSTOLIN T.A., MIRANDA M.P., FERRAZ P.C. \& LOPES J.R.S. 2001. Sharpshooter transmission of a coffee strain of Xylella fastidiosa to coffee seedlings. Fitopatologia Brasileira. 26:277. 
MARUCCI R.C., CAVICHIOLI R.R. \& ZUCCHI R.A. 2002. Espécies de cigarrinhas (Hemiptera, Cicadellidae, Cicadellinae) em pomares de citros da região de Bebedouro, SP, com descrição de uma espécie nova de Acrogonia Stål. Revista Brasileira de Entomologia 46: $149-164$.

MARUCCI R.C., GIUSTOLIN T.A., MIRANDA M.P., MIQUELOTE H., ALMEIDA R.P.P. \& LOPES J.RS. 2003. Identification of a non-host plant of Xylella fastidiosa to rear healthy sharpshooter vectors. Scientia Agricola. 60: 669-675.

MARUCCI R.C., LOPES J.R.S., VENDRAMIM J.D. \& CORRENTE J.E. 2004. Feeding site preference of Dilobopterus costalimai Young and Oncometopia facialis (Signoret) (Hemiptera: Cicadellidae) on citrus plants. Neotropical Entomology 33: 759-768.

MARUCCI R.C., LOPES J.R.S., CAVICHIOLI R.R. 2008. Transmission Efficiency of Xylella fastidiosa by Sharpshooters (Hemiptera: Cicadellidae) in Coffee and Citrus. Journal of Economic Entomology 101(4): 1114-1121.

McKAMEY S.H. 1998. Taxonomic catalogue of the Membracoidea (exclusive of leafhoppers): second supplement to fascicle 1 Membracidae of the general catalogue of the Hemiptera. Memories of the American Entomological Institute 60:1-377.

McKAMEY S.H. 2007. Taxonomic catalogue of the leafhoppers (Membracoidea). Part 1. Cicadellinae. Memoirs of the American Entomological Institute 78: 1-394.

MEDINA A.C. 1994. Las arañas: controladores naturales de insectos fitófagos en el cultivo de arroz en norte de Santander. Revista Colombiana de Entomologia 20(3): 179186.

MEJDALANI G. 1995. Scopogonalia paula Young, 1977: morphology of the female genitalia and comparative notes on the Juliaca Generic Group (Homoptera, Cicadellidae). Revista Brasileira de Entomologia 39(1): 193-202.

MEJDALANI G. 1998. Morfologia externa dos Cicadellinae (Homoptera, Cicadellidae): comparacao entre Versigonalia ruficauda (Walker) (Cicadellini) e Tretogonia cribrata Melichar (Proconiini), com notas sobre outras especies e analise da terminologia. Revista Brasileira de Zoologia 15: 451-544.

MELICHAR L. 1924. Monographie der Cicadellinen I. - Annales Historico-Naturales Musei Nationalis Hungarici 21: 195-243. 
MELICHAR L. 1925. Monographie der Cicadellinen II. - Annales Historico-Naturales Musei Nationalis Hungarici 22: 329-410.

MELICHAR L. 1926. Monographie der Cicadellinen III. - Annales Historico-Naturales Musei Nationalis Hungarici 23: 273-394.

MENEGATTI A.C.O., GARCIA F. R. M. \& SAVARIS M. 2008. Análise faunística e flutuação populacional de cigarrinhas (Hemiptera, Cicadellidae) em pomar cítrico no município de Chapecó, Santa Catarina. Biotemas 21(1): 53-58.

MENG Z. H., YANG M.F. 2012. Female genitalia of Seasogonia Young from China, with a new synonym and a new record (Hemiptera, Cicadellidae, Cicadellini). ZooKeys 164: 2540.

METCALF Z.P. 1965. General catalog of the Homoptera. Fasc. VI. Cicadelloidea. Part 1 Tettigellidae. Agriculture Research Services. United States Department of Agriculture. 730 pp.

MILANEZ J.M., PARRA J.R.P. \& MAGRI D.C. 2001. Alternation of host plants as a survival mechanism of leafhoppers Dilobopterus costalimai and Oncometopia facialis (Hemiptera: Cicadellidae), vectors of the citrus variegated chlorosis (CVC). Scientia Agricola 58(4): 699-702.

MIRANDA M. P., LOPES J. R. S., DO NASCIMENTO A. S., DOS SANTOS J. L. \& CAVICHIOLI R. R. 2009. Levantamento Populacional de Cigarrinhas (Hemiptera:Cicadellidae) Associadas à Transmissão de Xylella fastidiosa em Pomares Cítricos do Litoral Norte da Bahia. Neotropical Entomology 38(6): 827-833.

MITTLER T.E. 1967. Water tension in plants. An entomological approach. Annals of the entomological Society of America 60 (5): 1074-1076.

MIZELL R. \& ANDERSEN P. 2001. Keys to management of glassy-winged sharpshooter: interactions between host plants, malnutrition and natural enemies. pp. 81-84 In Proceedings of the Pierce's Disease Research Symposium. 2001. Coronado Island Marriot Resort, San Diego, California. Department of Food and Agriculture, Digital Logistix, Sacramento, California. 141 pp.

MOLINA R.O., NUNES W. M. C., GONÇALVES A.M.O., CORAZZA-NUNES M.J., ZANUTTO C. A., YAMAMOTO A.Y. \& VARGAS R.G. 2006. Ocorrência de cigarrinhas vetoras de Xylella 
fasidiosa em pomares cítricos do município de Loanda, no noroeste do Paraná. Laranja 27: $243-250$.

MOLINA R.O., GONÇALVES A.M.O, ZANUTTO C.A. \& NUNES W.M.C. 2010. Populational Fluctuation of Vectors of Xylella fastidiosa Wells in Sweet Orange [Citrus sinensis (L.) Osbeck] Varieties of Northwest Paraná State, Brazil. Brazilian Archives of Biology and Technology 53: 549-554.

MORAN N.A., MUNSON M.A., BAUMANN P., ISHIKAWA H. 1993. A molecular clock in endosymbiotic bacteria is calibrated using the insect hosts. Proceedings of the Royal Society of London. Series B, Biological Sciences, 253: 167-171.

NIELSON M.W. 1965. A revision of the genus Cuerna (Homoptera, Cicadellidae). Technical Bulletin of the United States Department of Agriculture 1318: 1-48.

NIELSON M.W. 1968. The leafhopper vectors of phytopatogenic virus (Homop.: Cicadellidae). Technical Bulletin of the United States Department of Agriculture 1382 pp.

NIELSON M.W. 1985. Leafhopper systematic. En: Nault L. \& Rodriguez J. (eds.). The Leafhoppers and Planthoppers: 11-39. John Wiley \& Sons, New York.

NIELSON M.W. \& GODOY C. 1995. Studies on the Leafhoppers of Central America (Homoptera:Cicadellidae). Contributions Entomology, International. 2: 210-217 .

NIELSON M. \& KNIGHT W. 2000. Distributional patterns and possible origin of leafhoppers (Homoptera, Cicadellidae). Revista Brasileira de Zoologia 17(1): 81-156.

NOME S.F., HAELTERMAN R., DOCAMPO D., PRATAVIERA A. y DI FEO L. 1992. Escaldadura de las hojas del almendro en Argentina. Fitopatologia Brasileira 17(1): 57-60.

NOVOTNY V. \& WILSON M. R. 1997. Why are there no small species among xylem sucking insects?. Evolutionary Ecology 11: 419-437.

NUNES W.M.C., MOLINA R.O., ALBUQUERQUE F.A., CORAZZA-NUNES M.J., ZANUTTO C. A. \& MACHADO M. 2007. Flutuação populacional de cigarrinhas vetoras de Xylella fastidiosa em pomares comerciais de citros no noroeste do Paraná. Neotropical Entomology 36: 254-260.

OLMI M. \& VIRLA E.G. 2014. Dryinidae of the Neotropical region (Hymenoptera: Chrysidoidea). Zootaxa 3792 (1): 1-534. 
OMAN P. 1949. The Nearctic leafhoppers (Homoptera: Cicadellidae). A generic classification and check list. Memoirs of the Entomological Society of Washington 3: 1-253.

OMAN P., KNIGHT W. \& NIELSON M. 1990. Leafhoppers (Cicadellidae): a bibliography, generic check-list and index to the world literature 1956-1985. CAB International Institute of Entomology, Wallingford, U.K. 368 pp.

OSBORN H. 1926. Neotropical Homoptera of the Carnegie Museum. Part 5. Report upon the collections in the subfamily Cicadellinae, with descriptions of new species. Annals of the Carnegie Museum 16: 155-248.

OTT A.P., AZEVEDO-FILHO W.S., FERRARI A. \& CARVALHO G.S. Abundância e sazonalidade de cigarrinhas (Hemiptera, Cicadellidae, Cicadellinae) em vegetação herbácea de pomar de laranja doce, no município de Montenegro, Estado do Rio Grande do Sul, Brasil. Iheringia Série Zoologica 96(4): 425-429.

PAIVA BRANCO P. E., DA SILVA J. L., GRAVENA S. \& TAKAO Y. 1996. Cigarrinhas de xilema em pomares de laranja do estado de São Paulo. Laranja 17(1): 41-54.

PAIVA P.E.B., BENVENGA S.R. \& GRAVENA S. 2001. Aspectos biológicos das cigarrinhas Acrogonia gracilis (Osborn), Dilobopterus costalimai Young e Oncometopia facialis (Signoret) (Hemiptera: Cicadellidae) em Citrus sinensis L. Osbeck. Neotropical Entomology 30: 25-28.

PANFILIO K.A. \& ANGELINI D.R. 2017. By land, air and sea: hemipteran diversity through the genomic lens. Current Opinion in Insect Science 25: 106-115.

PARADELL S. 1995. Especies argentinas de homópteros cicadélidos asociados al cultivo de maíz (Zea mays L.). Revista de la Facultad de Agronomia de La Plata 71(2): 213234.

PARADELL S.; REMES LENICOV A.M.M.; DE COLL O. \& AGOSTINI J. 2000. Cicadélidos asociados a citrus afectados por la Clorosis Variegada de los citrus (CVC) en Montecarlo, Misiones, República Argentina (Insecta: Hemiptera: Auchenorryncha). Revista de la Sociedad Entomológica Argentina 59(1-4): 103-118.

PARADELL S., VIRLA E. \& TOLEDO A. 2001. Leafhoppers species richness and abundance on corn crops in Argentina (Insecta-Hemiptera-Cicadellidae). Boletín Sanidad Vegetal - Plagas 27: 465-474. 
PARADELL S., VIRLA E., REMES LENICOV DE A. M. M., GIMÉNEZ PECCI M. P., CATALANO M. I., LAGUNA I. G., \& MURÚA L. 2005. Cicadélidos sobre cultivos de maíz y la maleza asociada en áreas afectadas por Corn Stunt Spiroplasma (CSS) de las provincias de la zona centro de Argentina (Hemiptera-Auchenorryncha). VIII Congreso Nacional de Maíz, Rosario, Santa Fe: 296-299.

PARADELL S., REMES LENICOV M. A. M. DE, CATALANO M. I., VARELA G., DELLAPÉ G., ROSSI BATIZ M. F., BONNOT G., 2006. Cicadélidos sobre arroz y la maleza asociada en áreas productoras de la provincia de Entre Ríos, Argentina (Insecta-HemipteraAuquenorrhyncha). En: Acenolaza P., Vittar F. (Eds.), Proc IX Jornadas de Ciencias Naturales del Litoral. Argentina: 22-24.

PARADELL S.L., ROCCA M. \& DEFEA B.S. 2011. Primer registro de Syncharina lineiceps (Hemiptera: Cicadellidae) en la Argentina. Clave para el reconocimiento de las especies del género. Revista de la Sociedad Entomológica Argentina 70(1-2): 141-145.

PARADELL S. L., VIRLA E. G., LOGARZO G. A. \& DELLAPÉ G. 2012. Proconiini Sharpshooters of Argentina, with notes on its distribution, host plants, and natural enemies. Journal of Insect Science 12(116): 1-17.

PARADELL S., DEFEA B., DUGHETTI A., ZÁRATE A., \& REMES LENICOV ANA M. M. DE. 2014a. Diversity of Auchenorrhyncha (Hemiptera: Cicadellidae: Delphacidae) Associated with Vicia villosa in Southern Buenos Aires Province, Argentina. Florida Entomologist. 97(2): $674-684$.

PARADELL S., MACIÁ A., ASBORNO M., CATALANO M. I., BRENTASSI M. E., VARELA G., DELLAPÉ G., DEFEA B.S., FOIERI A. \& MARINO DE REMES LENICOV A. M. 2014b. Diversity of leafhoppers (Hemiptera: Cicadellidae) in experimental rice lots and associated weeds in Buenos Aires province, Argentina". Studies on Neotropical Fauna and Environment 49(3): 213-221.

PARIS P., TOLOTTI S., PERUZZO L. \& AZEVEDO FILHO W. S. 2012. Cigarrinhas (Cicadellidae: Cicadellinae) na cultura da canola no município de Vacaria, Rio Grande do Sul, Brasil. Caderno de Pesquisa, Série Biologia 24 (3).

PARRA J.R.P., OLIVEIRA H.N. \& PINTO A.S. 2003. Pragas e insetos benéficos com Citros. FEALQ, Piracicaba, Brasil, 73 pp.

POINAR G.O. 1975. Entomogenous nematodes. A manual and host list of insectnematode associations. E. J. Brill, Leiden. 317 pp. 
POSADA O.L. 1989. Lista de insectos dañinos y otras plagas en Colombia. Bogotá: Instituto Colombiano Agropecuario. Boletín Técnico No. 43. 662 pp.

PURCELL A.H. 1989. Homopteran transmission of xylem-inhabiting bacteria. En: Harrys F. K., (eds.). Advances in disease vector research. Springer, New York, 243-266pp.

PURCELL A.H. \& FINLAY A.H. 1979. Evidence for noncirculative transmission of Pierce's disease bacterium by sharpshooter leafhoppers. Phytopathology 69: 393-395.

RAKITOV R.A. 1996. Post-moulting behaviour associated with Malpighian tubule secretions in leafhoppers and treehoppers (Auchenorrhyncha: Membracoidea). European Journal of Entomology 93: 167-184.

RAKITOV R.A. 1998. On differentiation of cicadellid leg chaetotaxy (Homoptera, Auchenorrhyncha, Membracoidea). Russian Entomological Journal 6: 7-27.

RAKITOV R.A. 2004. Powdering of egg nests with brochosomes and related sexual dimorphism in leafhoppers (Hemiptera: Cicadellidae). Zoological Journal of the Linnean Society 140: 353-381.

REDAK R., PURCELL A., LOPES J.R.S., BLUA M., MIZELL R.F. \& ANDERSEN P.C. 2004. The biology of Xylem Fluid-Feeding Insect Vectors of Xylella fastidiosa and their relation to disease epidemiology. Annual Review of Entomology 49: 243-270.

REMES LENICOV A.M.M. 1970 Un nuevo Estrepsiptero de Argentina, parásito de Membracidos (Insecta, Strepsiptera). Revista de la Sociedad Entomológica Argentina 32(1-4): 35-41.

REMES LENICOV A.M.M. 1982. Aportes al conocimiento de los Agalliinae argentinos. (Homoptera-Cicadellidae). Neotropica 28(80): 125-138.

REMES LENICOV A.M.M. \& TESÓN A. 1985. Cicadélidos que habitan los cultivos de arroz (Homoptera- Cicadellidae). Revista de Investigaciones Agropecuarias INTA 20(1): 131-141.

REMES LENICOV A.M.M. \& VIRLA E.G. 1993. Homópteros Auquenorrincos asociados

al cultivo de trigo en la República Argentina. I. Análisis preliminar de la importancia relativa de las especies. Studies on Neotropical Fauna and Environment (Ecol. Syst.) 28: 211-222. 
REMES LENICOV A. M. M., TESÓN A., DAGOBERTO E. \& PARADELL S. 1991. Acción del parasitoide Elenchus tenuicornis (Kirby) sobre la densidad poblacional de Delphacodes kuscheli Fennah (Insecta, Strepsiptera, Homóptera: Delphacidae). Revista de la Asociación de Ciencias Naturales del Litoral 22(1): 1-9.

REMES LENICOV A. M. M. DE, PARADELL S., VIRLA E., VARELA G., COSTAMAGNA A. C., MARIANI R. 1997. Cicadélidos y Delfácidos perjudiciales a cultivos de maíz en la República Argentina (Insecta-Homoptera). Proc. VI Congreso Nacional de Maíz I Sec. II, Pergamino, Buenos Aires: 58-69.

REMES LENICOV A. M. M., PARADELL S., DE COLL O. \& AGOSTINI J. 1999. Cicadelinos asociados a citrus afectados por la Clorosis Variegada (CVC) en la República Argentina (Insecta: Homoptera: Cicadellidae). Revista de la Sociedad Entomológica Argentina 58(34): 211-225.

REMES LENICOV A.M.M.; PARADELL S. \& CATALANO M. 2006. Hemípteros auquenorrincos perjudiciales al cultivo de sorgo en la Argentina (Insecta-Hemiptera). Revista de Investigaciones Agropecuarias INTA 35(2): 3-20.

RINGENBERG R. 2008. Análise faunística de cigarrinhas (Hemiptera: Cicadellidae) e flutuação populacional de potenciais vetores de Xylella fastidiosa em vinhedos nos estados do Rio Grande do Sul e Pernambuco, Brasil. Tesis doutorado. 200 pp.

ROSATO Y. B., RODRIGUES NETO J., MIRANDA V. S., CARLOS E. F. \& MANFIO G. P. 1998. Diversity of a Xylella fastidiosa population isolated from Citrus sinensis affected by citrus variegated chlorosis in Brazil. Systematic and Applied Microbiology. 21: 593-598.

SAKAGAMI SH. F. \& MATSUMURA T. 1967. Relative abundance, phenology and flower preference of andrenid bees in Sapporo, North Japan (Hymenoptera, Apoidea). Japan Journal of Ecology 16 (6): 237-250.

SISTERSON M., CHRISTOPHER M.W. \& DRAKE C. S. 2015. Effects of Glassy-Winged Sharpshooter (Hemiptera: Cicadellidae) Feeding, Size, and Lipid Content on Egg Maturation. Journal of Economic Entomology 1-11. DOI: 10.1093/jee/tov049

SISTERSON M.S., WALLIS C.M. \& STENGER D.C. 2017. Effects of Xylem-Sap Composition on Glassy-Winged Sharpshooter (Hemiptera: Cicadellidae) Egg Maturation on High- and Low-Quality Host Plants. Environmental Entomology 46(2): 299-310. DOI: $10.1093 / \mathrm{ee} / \mathrm{nvx} 042$ 
SONG N., LIANG A.P. \& BU C.P. 2012 A molecular phylogeny of Hemiptera inferred from mitochondrial genome sequences. PLOS ONE 7, e48778. DOI:10.1371/journal.pone.0048778.

SCHAAD N.W., POSTNIKOVA E., LACY G., FATMI M. \& CHANG C.J. 2004. Xylella fastidiosa subspecies: X. fastidiosa subsp piercei, subsp. nov., X. fastidiosa subsp. multiplex subsp. nov., and $X$. fastidiosa subsp. pauca subsp. nov. Systematic and Applied Microbiology 27: 290-300 \& 763.

SCHRÖDER H. 1959. Taxionomische und tiergeographische Studien an neotropischen Zikaden (Cicadellidae, Tettigellinae). Abhandlungen der Senckenbergischen Naturforschenden Gesellschaft 499: 1-93.

SCHUENZEL E.L., SCALLY M., STOUTHAMER R. \& NUNNEY L. 2005. The multigene phylogenetic study of clonal diversity and divergence in North American strains of the plant pathogen Xylella fastidiosa. Applied and Environmental Microbiology 71: 38323839.

SEVERIN H. H. P. 1949. Transmission of the virus of Pierce's disease of grapevines by leafhoppers. Hilgardia 19(6): 190-202.

SIGNORET V. 1853a. Revue iconographique des Tettigonides. Annales de la Société Entomologique de France 1(3): 13-40.

SIGNORET V. 1853b. Revue iconographique des Tettigonides. Annales de la Société Entomologique de France 1(3): 323-374.

SIGNORET V. 1853c. Revue iconographique des Tettigonides. Annales de la Société Entomologique de France 1(3): 661-688.

SIGNORET V. 1854a. Revue iconographique des Tettigonides. Annales de la Société Entomologique de France 2(3): 5-28.

SIGNORET V. 1854b. Revue iconographique des Tettigonides. Annales de la Société Entomologique de France 2(3): 341-366.

SIGNORET V. 1854c. Revue iconographique des Tettigonides. Annales de la Société Entomologique de France 2(3): 483-496.

SIGNORET V. 1854d. Revue iconographique des Tettigonides. Annales de la Société Entomologique de France 2(3): 717-732. 
SIGNORET V. 1855a. Revue iconographique des Tettigonides. Annales de la Société Entomologique de France 3(3): 49-60.

SIGNORET V. 1855b. Revue iconographique des Tettigonides. Annales de la Société Entomologique de France 3(3): 225-240.

SIGNORET V. 1855c. Revue iconographique des Tettigonides. Annales de la Société Entomologique de France 3(3): 507-528.

SIGNORET V. 1855d. Revue iconographique des Tettigonides. Annales de la Société Entomologique de France 3(3): 765-836.

SILVA M.R.L., MENEGUIM A.M., PAIÃO F.G., MENEGUIM L., CANTERI M.G. \& LEITE R.P. JR. 2007. Infectividade Natural por Xylella fastidiosa Wells et al. de Cicadelíneos (Hemiptera: Cicadellidae) de Lavouras Cafeeiras do Paraná. Neotropical Entomology 36(2): 274-281.

SILVEIRA NETO S., NAKANO O., BARBIN D. \& VILLA NOVA N.A. 1976. Manual de ecologia dos insetos. Piracicaba, Agronômica Ceres. 416 pp.

SILVEIRA NETO S., MONTEIRO R.C., ZUCCHI R.A. \& MORAES R.C.B. 1995. Uso da análise faunística de insetos na avaliação do impacto ambiental. Scientia Agricola 52: 9-15.

SORENSEN J., CAMPBELL B., GILL R. \& STEFFEN-CAMPBELL J. 1995. Nonmonophyly of Auchenorrhyncha ("Homoptera"), based upon 18S rDNA phylogeny: ecoevolutionary and cladistic implications within pre-heteropterodea Hemiptera (s.l.) and a proposal for new monophyletic suborders. Pan-Pacific Entomologist 71(1): 31-60.

STÅL C. 1869. Hemiptera Fabriciana. Fabricianska Hemipterarter, efter de IKöpenhamn och Kielförvarade typexemplaren granskade och beskrifne, 2. Kungliga Svenska vetenskapsakademiens handlingar 8: 1-130.

SWAIN R.B. 1937. Notes on the oviposition and life-history of the leafhopper Oncometopia undata Fabr. (Homoptera: Cicadellidae). Entomological News 47: 264-266.

TAKIYA D.M. 2007. Systematic Studies on the Leafhopper Subfamily Cicadellinae (Hemiptera: Cicadellidae). Tesis Doctoral. University of Illinois, UrbanaChampaign, USA.

TAKIYA D.M \& CAVICHIOLI R.R. 2004a. A Review of the Neotropical sharpshooter genus Onega Distant. Zootaxa, 718: 1-19. 
TAKIYA D. M. \& MEJDALANI G. 2004b. Taxonomic revision and phylogenetic analysis of the sharpshooter genus Balacha Melichar (Hemiptera: Cicadellidae: Cicadellini). Systematic Entomology 29: 69-99.

TAKIYA D. M., MEJDALANI G. \& FELIX M. 2001. A new genus and species of Cicadellini (Hemiptera Cicadellidae Cicadellinae) from Southeastern Brazil. Tropical Zoology 14: 175183.

THAO M. L. L., CLARK M. A., BURCKHARDT D. H., MORAN N. A., \& BAUMANN P. 2001. Phylogenetic analysis of vertically transmitted psyllid endosymbionts (Candidatus Carsonella ruddii) based on atpAGD and rpoC: comparisons with 16S-23S rDNA-derived phylogeny. Current Microbiology 42: 419-421.

THAO M. L. L., GULLAN P. J.,\& BAUMANN P. 2002. Secondary (gamma-Proteobacteria) endosymbionts infect the primary (beta-Proteobacteria) endosymbionts of mealybugs multiple times and coevolve with their hosts. Applied and Environmental Microbiology 68: 3190-3197.

TESÓN A., REMES LENICOV A. M. M. DE, DAGOBERTO E. L., PARADELL S. 1986. Estudio de las poblaciones de delfácidos sobre maíz, avena y maleza circundante (Homoptera-Fulgoroidea). Gaceta Agronómica 7: 507-517.

TIPPING C. \& MIZELL III R.F. 2004. Sharpshooters, Leafhoppers, Cicadellidae (Insecta: Hemiptera: Auchenorrhyncha: Cicadellidae). United States Department of Agriculture, Cooperative Extension Service, University of Florida: 1-8.

TOLEDO J. M., VERA R., LASCANO C. \& LENNÉ J. L. 1989. Andropogon gayanus Kunth. En: Un Pasto Para los Suelos Ácidos del Trópico (ed Centro Internacional de Agricultura Tropical), pp. 406. CIAT, Cali, Colombia.

TOLEDO A.V., VIRLA E., HUMBER R.H., PARADELL S. \& LÓPEZ LASTRA C.C. 2006. First record of Clonostachys rosea (Ascomycota: Hypocreales) as an entomopathogenic fungus of Oncometopia tucumana and Sonesimia grossa (Hemiptera: Cicadellidae) in Argentina. Journal of Invertebrate Pathology 92: 7-10.

TOLEDO A.V., REMES LENICOV A.M.M. \& LÓPEZ LASTRA C.C. 2008. Host range findings on Beauveria bassiana and Metarhizium anisopliae (Ascomycota: Hypocreales) in Argentina. Boletín de la Sociedad Argentina de Botánica 43 (3-4): 211-220. 
TRIAPITSYN S.V. 2003. Taxonomic notes on the genera and species of Trichogrammatidae (Hymenoptera) - egg parasitoids of the proconine sharpshooters (Hemiptera: Clypeorrhyncha: Cicadellidae: Proconiini) in southern USA. Transactions of American Entomological Society 129 (2): 245-265.

TRIAPITSYN S.V. 2013. Taxonomy and Biology of Egg Parasitoids of Auchenorrhyncha of Economic Importance in Taiwan and Adjacent Countries, and of Proconiine Sharshooters in the New World. Proceedings of the 2013 International Symposium on Insect Vectors and Insect-Borne Diseases: 123-144.

TRIAPITSYN S. V, MIZELL R. F. III, BOSSART J. L. \& CARLTON C. E. 1998. Egg parasitoids of Homalodisca coagulata (Homoptera: Cicadellidae). Florida Entomologist 81: 241-243.

TRIAPITSYN S. V., LOGARZO G. A., VIRLA E. G. \& DE LEÓN J. H. 2007. A new species of Gonatocerus (Hymenoptera: Mymaridae) from Argentina, an egg parasitoid of Tapajosa rubromarginata (Hemiptera: Cicadellidae). Zootaxa 1619: 61-68.

TURNER W.F. \& POLLARD H.N. 1959. Life histories and behaviour on five insect vectors of Phony Peach Disease. United States Department of Agriculture Technical Bulletin $\mathrm{N}^{\circ} 1188$ : 1-28.

VANGSGAARD C. 1986. Spatial distribution and dispersal of spiders in a Danish barley field. Revue Suisse de Zoologie, Geneva, vol. hors. Série: 671-682.

VELEMA H.P., HEMERIK L., HODDLE M. S. \& LUCK R.F. 2005. Brochosome influence on parasitisation efficiency of Homalodisca coagulata (Say) (Hemiptera: Cicadellidae) egg masses by Gonatocerus ashmeadi Girault (Hymenoptera: Mymaridae). Ecological Entomology 30: 485-496.

VILVASTE J. 1971. Eeste tirdid I. 284 p. Tallinn.

VILVASTE J. 1982. Preliminary key for the identification of the nymphs of North European Homoptera Cicadenea. II. Cicadelloidea. Annales Zoologici Fennici 19: 1-20.

VIRLA E. G. \& LUFT ALBARRACIN E. 2012. Potencialidad de especies antagonistas en el manejo racional de poblaciones de vectores de enfermedades del maíz causadas por virus en Argentina. En: Giménez Pecci M.P., Laguna I.M., Lenardón L. (eds). Enfermedades del maíz producidas por virus y mollicutes en Argentina: 151-168. INTA, Ministerio de Agricultura, Ganadería y Pesca, Buenos Aires. 
VIRLA E. G., LOGARZO G. A., JONES W. A. \& TRAPITSYN S. V. 2005. Biology of Gonatocerus tuberculifermur (Hymeoptera: Mymaridae), an egg parasitoid of the sharpshooter, Tapajosa rubromarginata (Hemiptera: Cicadellidae). Florida Entomologist 88(1): 67-71.

VIRLA E. G., LOGARZO G. A., PARADELL S. L. \& TRIAPITSYN S. V. 2008. Bionomics of Oncometopia tucumana (Hempitera: Cicadellidae), a sharpshooter from Argentina, with notes on its distribution, host plants and egg parasitoids. Florida Entomologist 91(1): 5562.

VIRLA E. G., LUFT ALBARRACIN E., TRAPITSYN S. V., VIGGIANI G. \& LOGARZO G. A. 2009. Description and biological traits of a new species of Paracentrobia (Hymenoptera: Trichogrammatidae), an egg parasitoid of the sharpshooter Tapajosa rubromarginata (Hemiptera: Cicadellidae) in Argentina. Studies on Neotropical Fauna and Environment 44(1): 47-53.

VON DOHLEN C. \& MORAN N. 1995. Molecular phylogeny of the Homoptera: a paraphyletic taxon. Journal of Molecular Evolution 41: 211-223.

WALKER F. 1851. List of the specimens of Homopterous insects in the collection of the British Museum. Parte III: 651-728.

WALOFF, N. \& M. A. JERVIS. 1987. Communities of parasitoids associated with leafhoppers and planthoppers in Europe. In: A. Macfayden and E. D. Ford (eds). Communities of parasitoids associated with leafhoppers and planthoppers in Europe: 281402. London: Academic Press inc. limited.

WELLS J. M., RAJU B. C., HUNG H. Y., WEISBURG W. G., MANDELCOPAUL L. \& BRENNER D. J. A. 1987. Xylella fastidiosa gen. nov., sp. nov: gram-negative, xylem-limited, fastidious plant bacteria related to Xanthomonas spp. Int. J. International Journal of Systematic and Bacteriology. 37(2): 136-143.

WHEELER W., SCHUH R. \& BANG R. 1993. Cladistic relationship among higher groups of Heteroptera: congruence between morphological and molecular data sets. Entomologica Scandinavica 24: 121-137.

WILSON M.R. \& CLARIDGE M.F. 1991. Handbook for the Identification of Leafhoppers of Rice. Wallingford, UK: CAB Intl. 142 pp. 
WILSON M.R., TURNER J.A. \& MCKAMEY S.H. 2009. Sharpshooter Leafhoppers of the World (Hemiptera: Cicadellidae subfamily Cicadellinae). Amgueddfa Cymru - National Museum Wales. http://naturalhistory.museumwales.ac.uk/Sharpshooters.

YAMAMOTO P.T. \& GRAVENA S. 2000. Espécies e abundância de cigarrinhas e psilídeos (Homoptera) em pomares cítricos. Anais da Sociedade Entomológica do Brasil 29: $169-176$.

YAMAMOTO P. T., ROBERTO S. R., DALLA PRIA W. J., FELIPPE R. M. \& FREITAS E. P. 2002. Espécies e flutuação populacional de cigarrinhas em viveiro de citros no município de Mogi-Guaçu-SP. Revista Brasileira de Fruticultura 24: 389-394.

YAMAMOTO P. T., FELIPPE R. M., CAETANO A. C., SANCHES A. L. \& LOPES J. R. S. 2007. First Report of Fingeriana dubia Cavichioli Transmitting Xylella fastidiosa to Citrus. Fitopatologia Brasileira 32(3): 266.

YOSHIZAWA K. \& SAIGUSA T. 2001. Phylogenetic analysis of paraneopteran orders (Insecta: Neoptera) based on forewing base structure, with comments on monophyly of Auchenorrhyncha (Hemiptera). Systematic Entomology 26: 1-13.

YOUNG D. A. 1968. Taxonomic study of the Cicadellinae (Homoptera: Cicadellidae), Part 1, Proconiini. Bulletin of the United States National Museum 261. 287 pp.

YOUNG D. A. 1977. Taxonomic study of the Cicadellinae (Homoptera: Cicadellidae), Part 2, New World Cicadellini and the genus Cicadella. Technical Bulletin of the North Carolina Agricultural Experiment Station 239. 1135 pp.

YOUNG D. A. 1986. Taxonomic study of the Cicadellinae (Homoptera: Cicadellidae), Part 3, Old World Cicadellini. Bulletin of the North Carolina agricultural Experimental Station 281: 639 pp.

YOUNG D. A. \& DAVIDSON R. H.1959. A review of leafhoppers of the genus Draeculacephala. U.S. Department of Agriculture. Technical Bulletin 1198:1-32.

ZHIXIAN K. Z. 1996. Study on the biological characters of Tettigella viridis. J. Jilin Agric. Univ. (3).

Zanol K.M. \& Menezes M. 1982. Lista preliminar dos Cicadellideos (Homoptera:Cicadellidae) do Brasil. Iheringia, Serie Zoologica 61: 9-65. 
ZAR H. 1984. Bioestatistical Analysis. Englewood Cliffs, New Jersey, Estados Unidos, Prentice Hall, 662 pp. 